\title{
Consumer Xenocentrism: Antecedents, consequences (and moderators) and related constructs
}

\author{
by \\ Dhanachitra Rettanai Kannan
}

A thesis submitted to the Faculty of Graduate and Postdoctoral Affairs in partial fulfillment of the requirements for the degree of

\author{
Doctor of Philosophy \\ in \\ Management \\ Carleton University, \\ Ottawa, Ontario
}

(C2020 Dhanachitra Rettanai Kannan 


\begin{abstract}
$\underline{\text { Abstract }}$

\section{Purpose:}

The purpose of this thesis is to identify and test the antecedents, related constructs and consequences and moderators of consumers xenocentrism.
\end{abstract}

\title{
Design/methodology/approach:
}

An extensive literature review was performed across different disciplines (international business, economics, sociology, psychology, political science, anthropology and consumer behavior) and interviews with five different experts from the five different fields were conducted to put together the initial model. A combined sample of 1306 respondents from four different countries namely Kenya, India, Ecuador and Romania in four different continents Africa, Asia, South America and Europe were collected through online questionnaires. The data was analyzed using structural equation modeling (SEM) to either confirm or disprove the hypotheses that had been set.

\section{Findings:}

International travel experience, status consumption and susceptibility to normative influence were the most significant antecedents that positively influenced consumer xenocentrism. Culture (power distance and collectivism) had an indirect positive influence on consumer xenocentrism through the consumption-specific constructs, status consumption and susceptibility to normative influence respectively. With respect to related constructs, consumer worldmindedness was positively significantly related to consumer xenocentrism and consumer ethnocentrism and national identity were negatively 
significantly related to consumer xenocentrism. With respect to the consequences' variables, consumer xenocentrism positively influenced ownership (actual purchase) of foreign products and purchase intention of foreign products. There was very little support for any moderator relationships that were proposed.

\section{Research limitation:}

The data was collected via online questionnaires, a method that has been criticized for being less interactive. Additionally, the results of this study cannot be generalized to all other countries. Although, the sample contains citizens from four countries, there might be other factors that may affect the preferences in other countries. Thus, generalizability of these results is only possible after replications across different cultures. Also, the sample was predominantly well-educated with most of them having at least a bachelor's degree and holding professional jobs. So, the results of this study are reflective of such a sample.

\section{Originality/value:}

This is the first study to examine the antecedents of consumers xenocentrism and to empirically test a wide range of related constructs for consumer xenocentrism. Additionally, this the first study to test ownership (actual purchase) of foreign products as a consequence. This thesis also proposed a new comprehensive model of consumer xenocentrism. The literature on consumer xenocentrism is still very limited in international marketing and this research gives a deeper understanding of the topic. As developing countries continue to increase in prominence on the world scene, this study brings to light the consumer preferences in those countries. 


\section{Acknowledgments}

Firstly, I would like to express my deepest gratitude to my thesis supervisor Dr. José Rojas-Méndez, who took a chance on me even before meeting me. He has been my continued advocate and for that I am greatly thankful. I'm extremely grateful for his valuable guidance and mentorship throughout my time in the program. He is a great teacher and the lessons I learned from him will help me throughout my career.

I would like to thank Dr. Nicolas Papadopoulos from whom I learned a lot —about International Business and beyond-during the brief time we worked together. I'm grateful for his faith in my abilities from day one and for encouraging me to push beyond my comfort zone.

I am thankful to my committee members Dr. Luciara Nardon and Dr. Michel Rod for their valuable contributions to my thesis which made my research much stronger. Dr. Nardon has been an incredible mentor to me and is a great role model for aspiring female academics.

I wanted to take this opportunity to thank Dr. Blair Rutherford, Dr. Cristina Rojas, Dr. George Pollard, Dr. Radovan Vadovič, Dr. Daniel Rosenblatt, Dr. Lorena Ruci, Dr. Isaac Otchere and Melissa Jennings for their valuable time and inputs during the initial stages of this thesis when I was trying to make sense of a nascent topic and figuring out ways to collect data, especially in Africa. I am thankful to Dr. Tudor Jijie for his assistance in collecting data in Romania. I want to express my sincere gratitude to Dr. Gerald Grant, Dr. Leighann Neilson and Dr. Greg Sears for their invaluable support and for going beyond their call of duty to help me out. 
I would like to thank Melissa Doric and Amanda Bradford-Janke for being extremely helpful and professional with everything within their area of control. I also appreciate the financial support from the Sprott School of Business scholarship and Ontario Graduate Scholarship (OGS).

My colleagues at the PhD program, Dr. Erin Oldford, Dr. Dan Gulanowski, Lucille Perreault, Nada Elnahla and Tasnuva Chaudhury, I thank you for your incredible support through this journey.

On the personal front, I would like to thank my parents, my biggest professional inspirations, for raising me to believe that everything is possible if I was willing to work hard for it. I would like to thank my friends, Pearl, Megha, Anne, Ranjeeta and Mahathi for being my relentless cheerleaders and supporters over the years.

Finally, most importantly, I would like to thank my husband Naveen. I'm deeply grateful for his unwavering support, patience and kindness throughout this process. This milestone would not have been possible without him, and this thesis is dedicated to him. 


\section{Table of Contents}

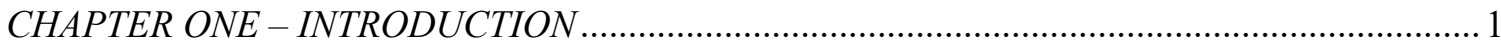

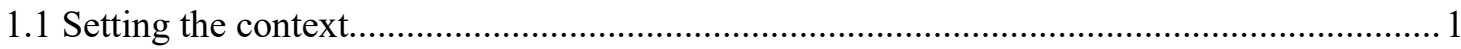

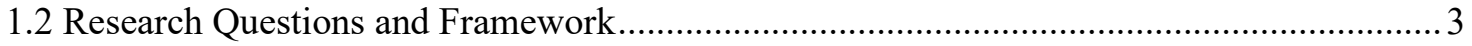

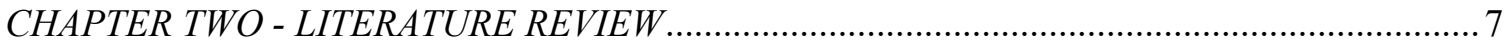

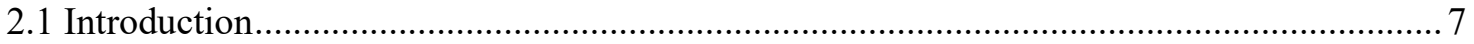

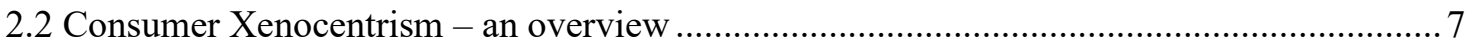

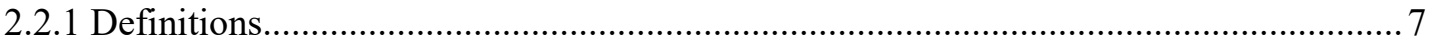

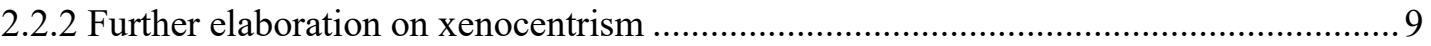

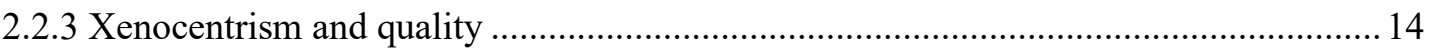

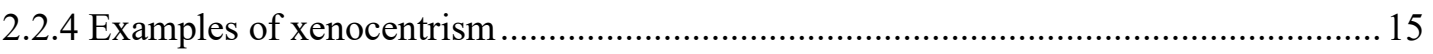

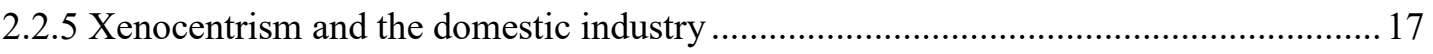

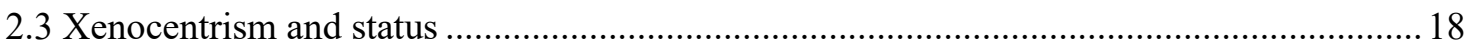

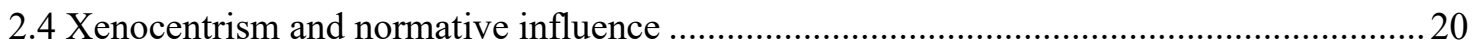

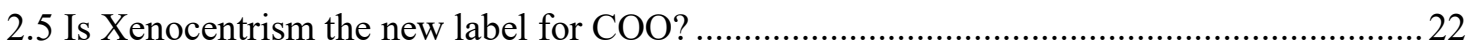

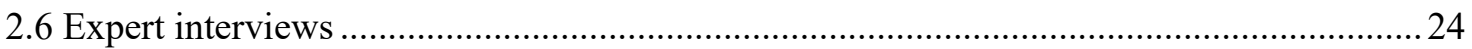

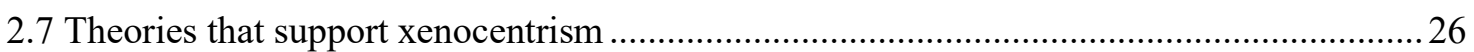

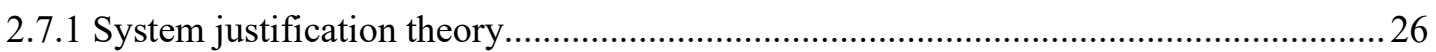

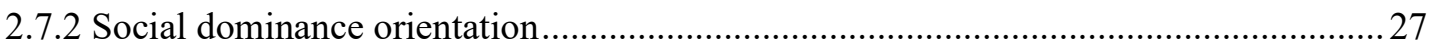

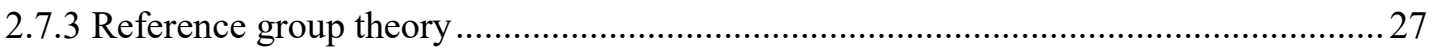

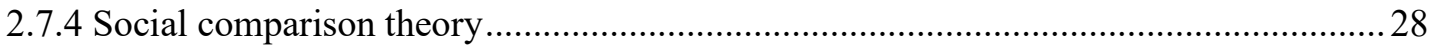

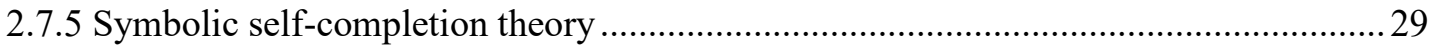

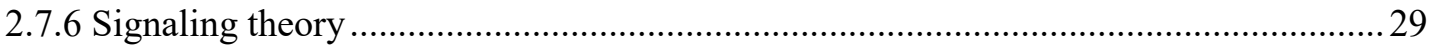

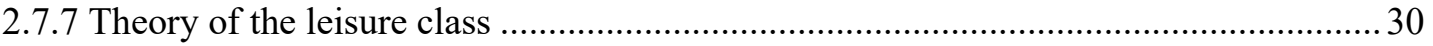

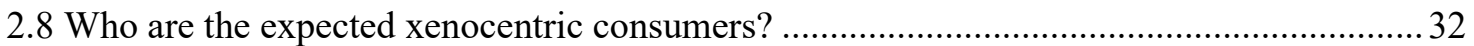

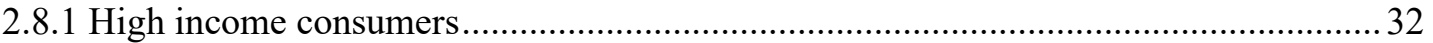

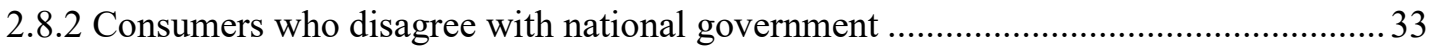

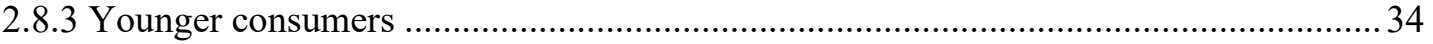

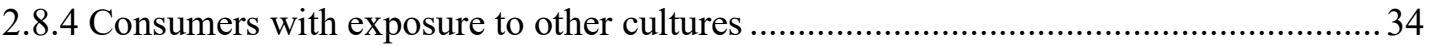

2.8.5 White-collar employees and higher education consumers............................................ 35

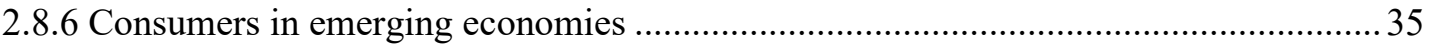

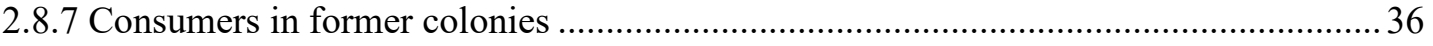

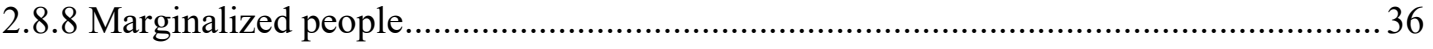

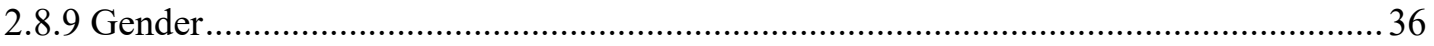

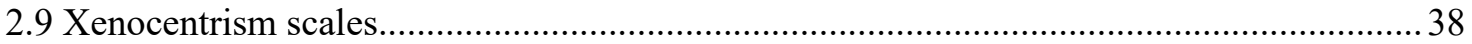




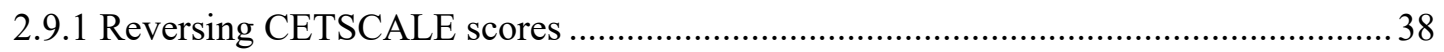

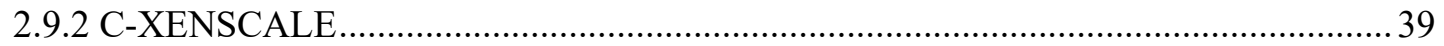

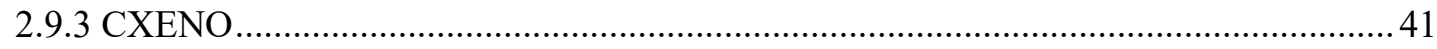

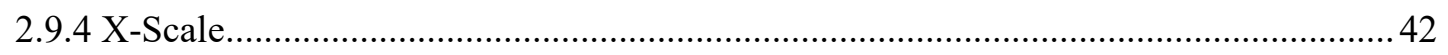

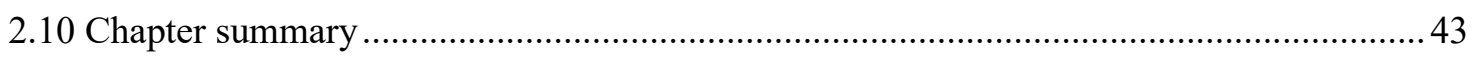

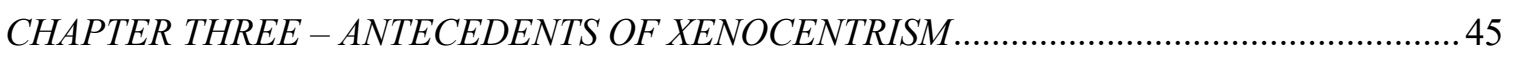

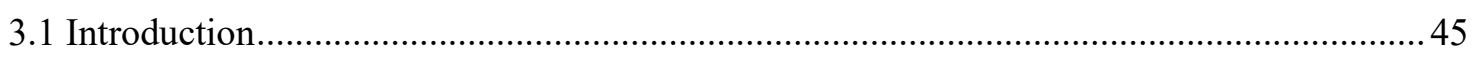

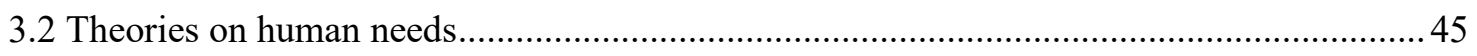

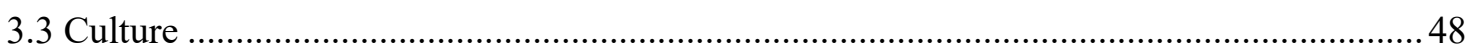

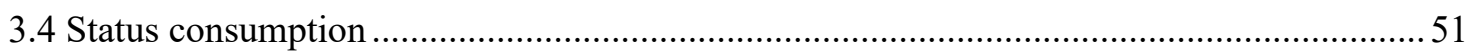

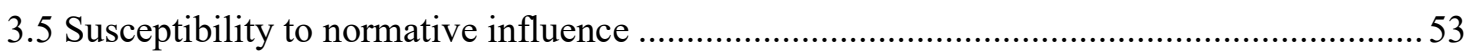

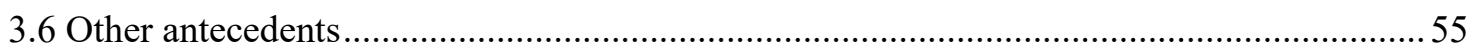

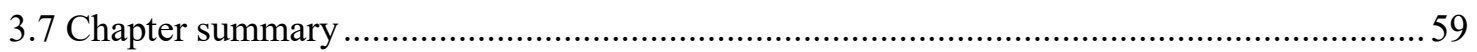

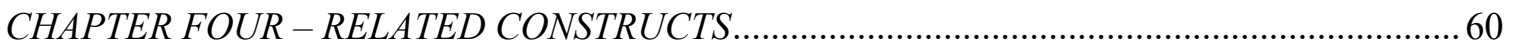

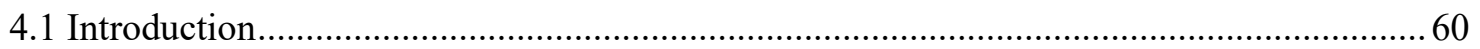

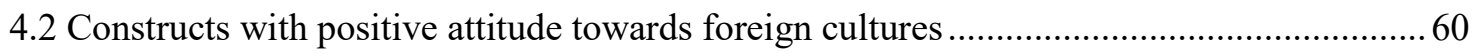

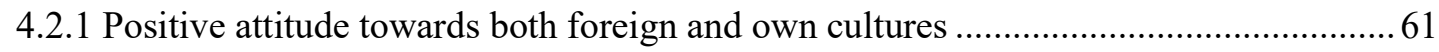

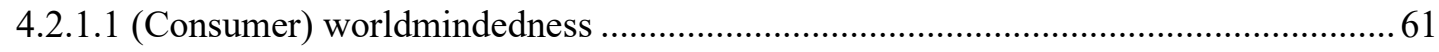

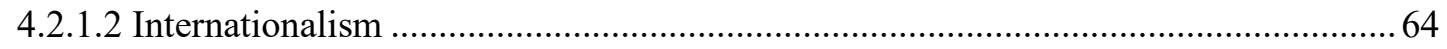

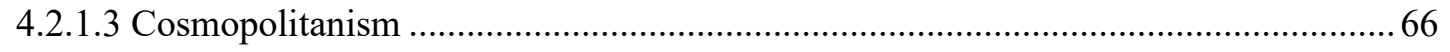

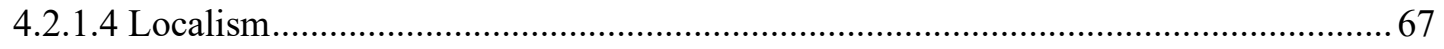

4.2.2 Positive attitude towards foreign cultures and neutral towards own culture..................68

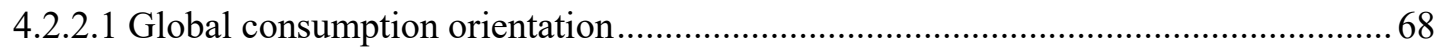

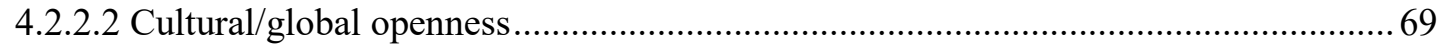

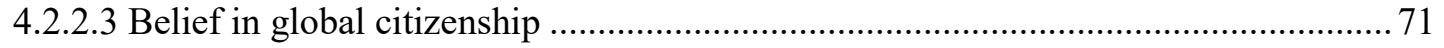

4.2.2.4 Susceptibility to Global consumer culture (SGCC) ................................................... 72

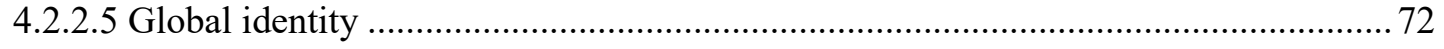

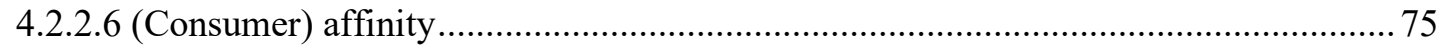

4.2.3 Positive attitude towards foreign cultures and negative towards own culture .............. 76

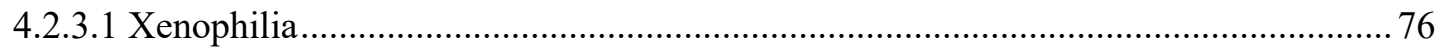

4.3 Constructs with neutral attitude towards foreign cultures............................................... 78

4.3.1 Neutral attitude towards foreign cultures and positive towards own culture ................ 78

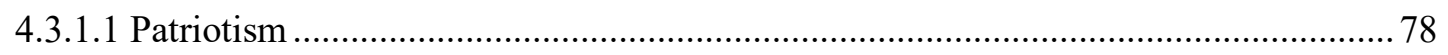

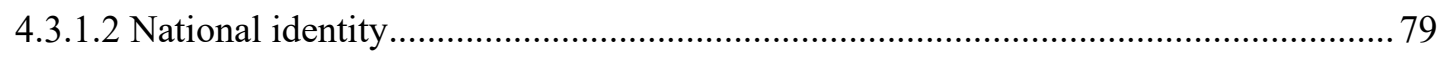

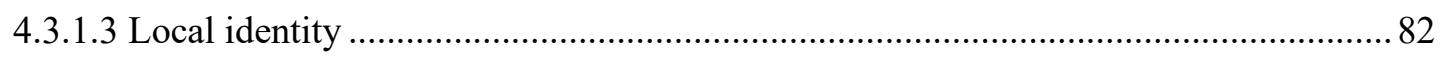




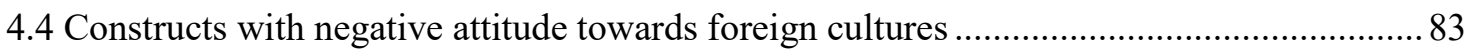

4.4.1 Negative attitude towards foreign cultures and positive towards own culture.............. 84

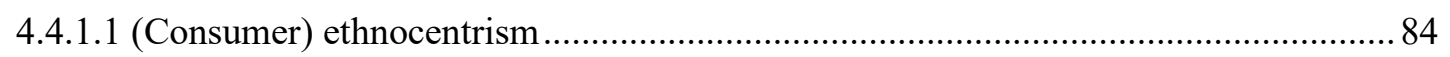

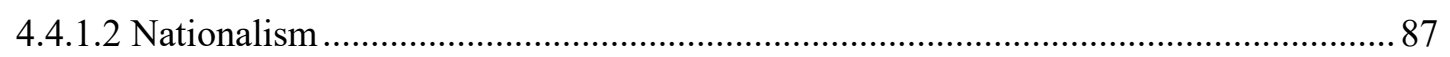

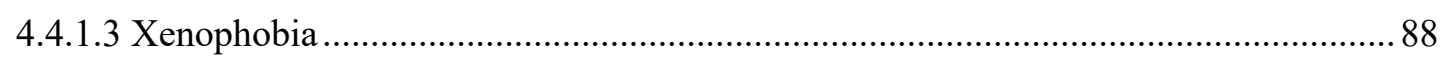

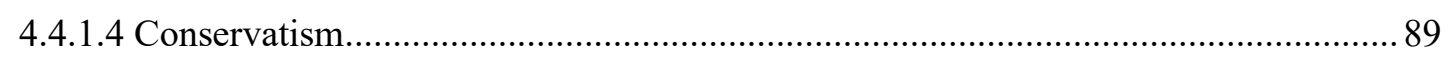

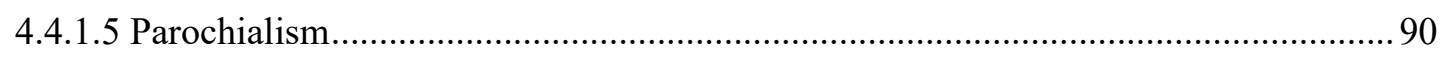

4.4.2 Negative attitude towards foreign cultures and neutral towards own culture ...............90

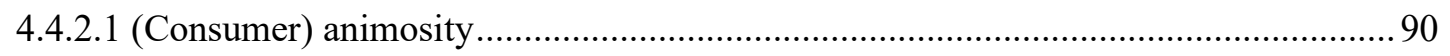

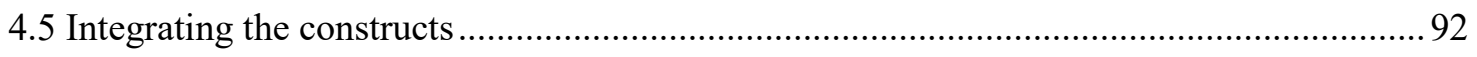

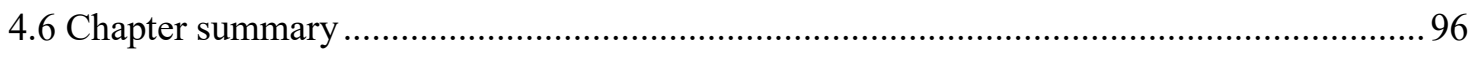

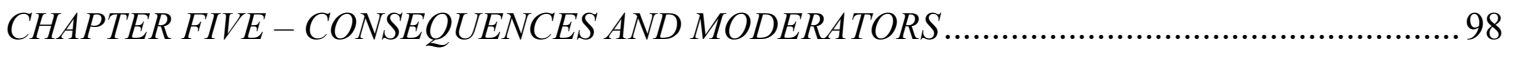

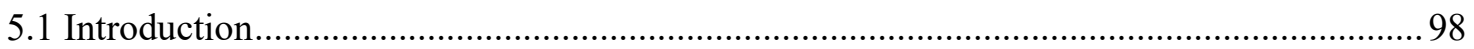

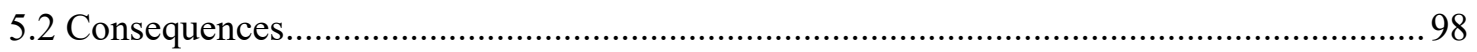

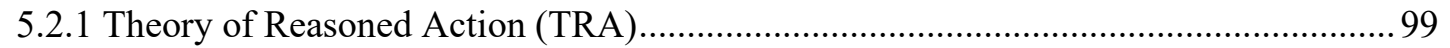

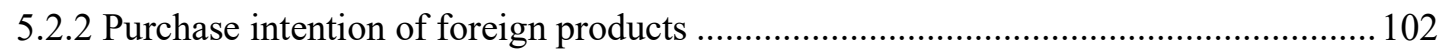

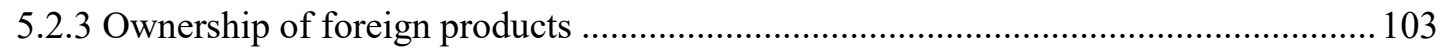

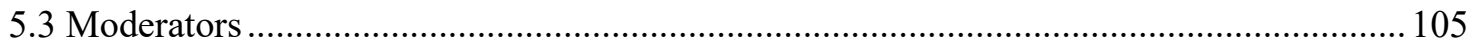

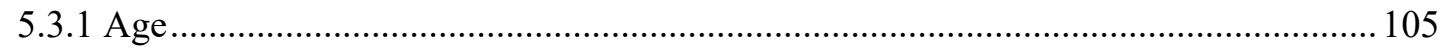

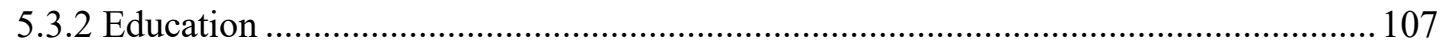

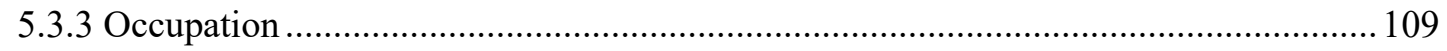

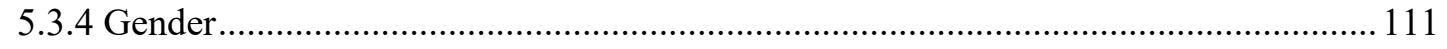

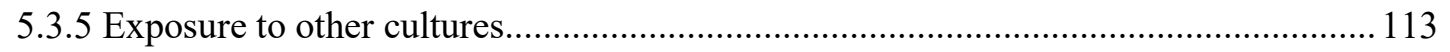

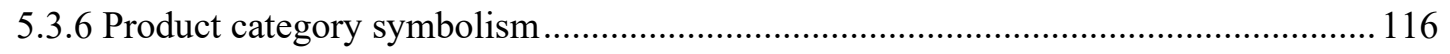

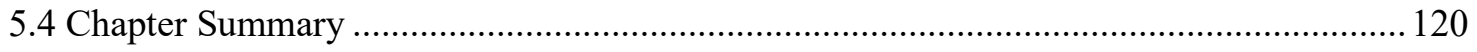

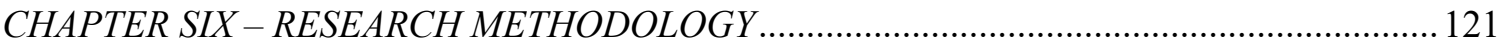

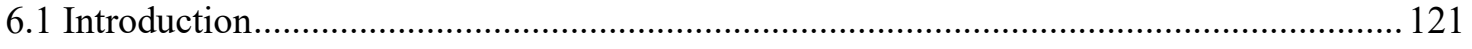

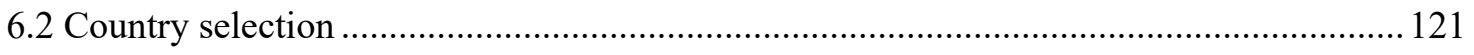

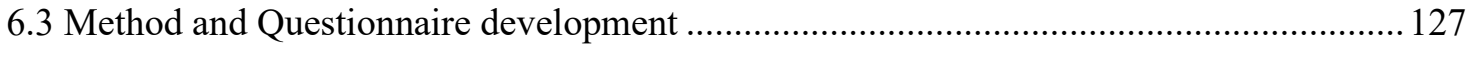

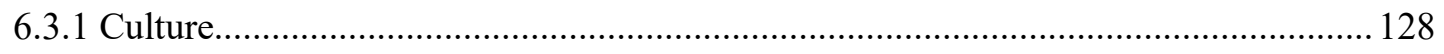

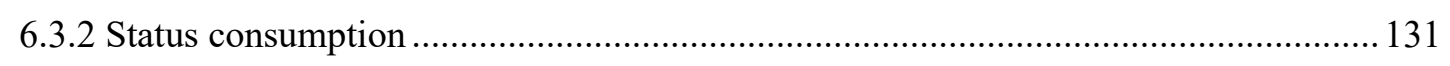

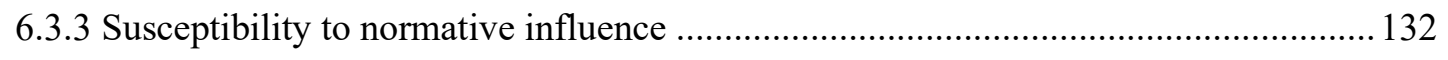

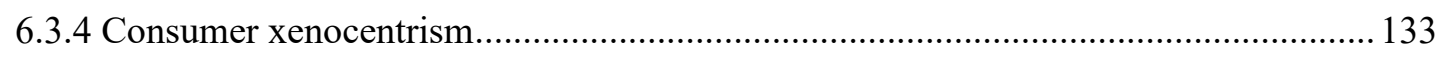

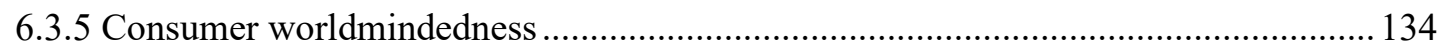

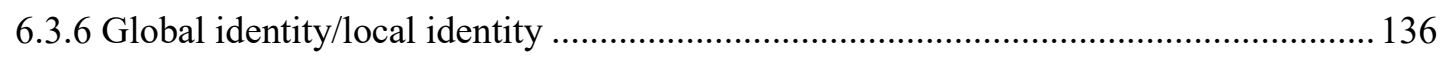




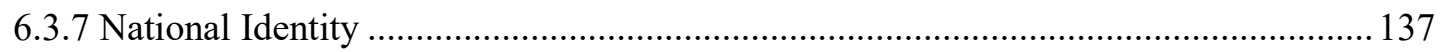

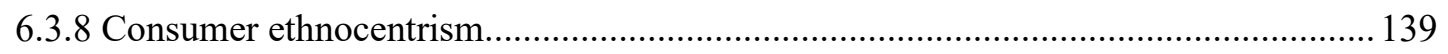

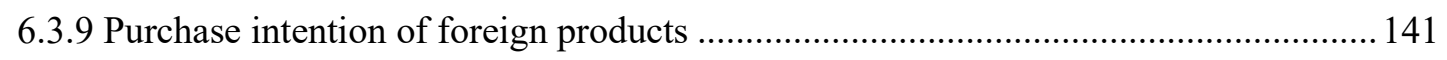

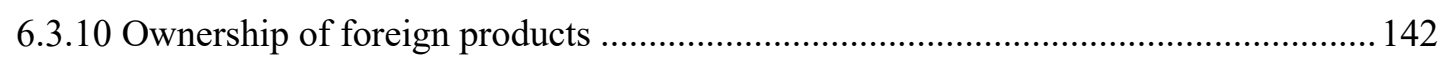

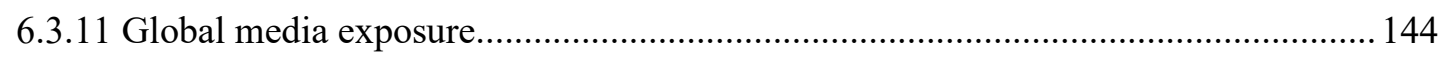

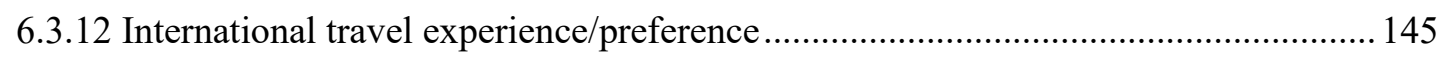

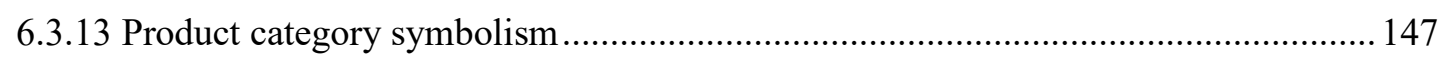

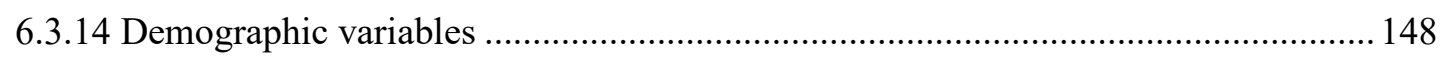

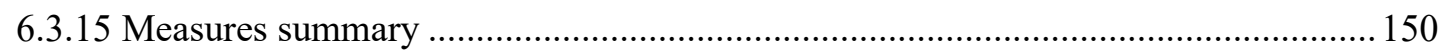

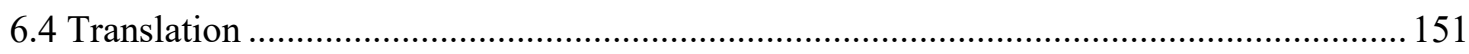

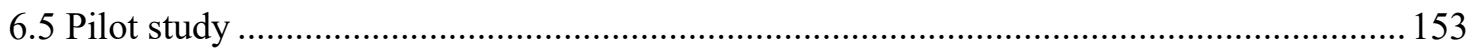

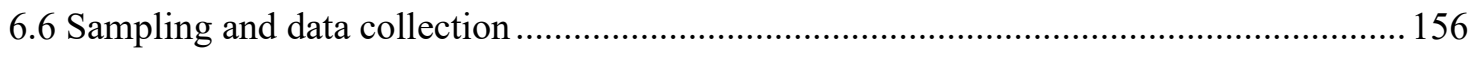

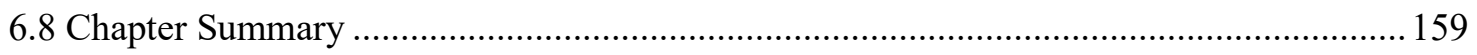

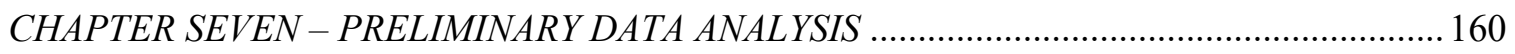

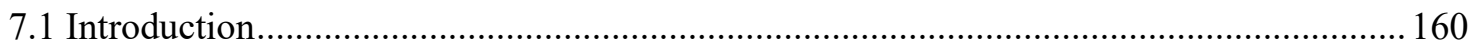

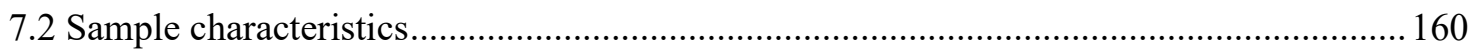

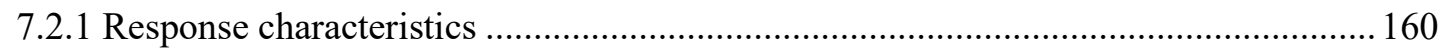

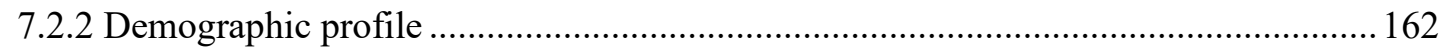

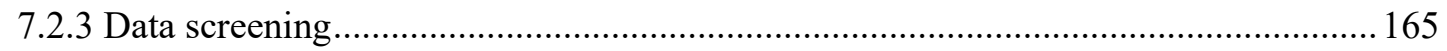

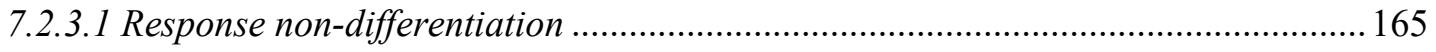

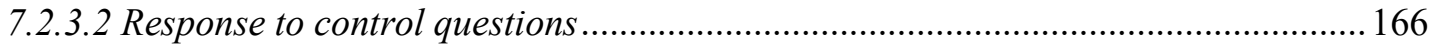

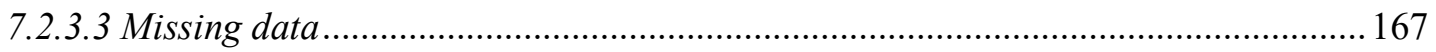

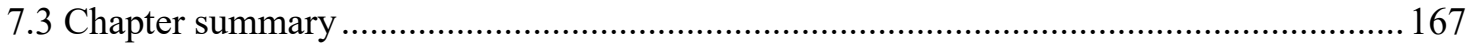

CHAPTER EIGHT - ANALYSIS OF XENOCENTRISM AND ANTECEDENTS ........................ 168

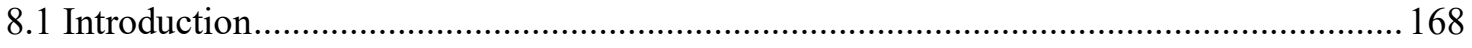

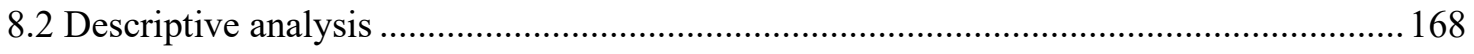

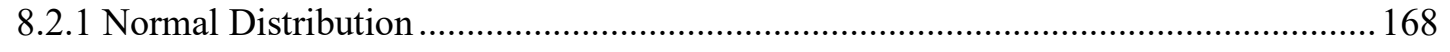

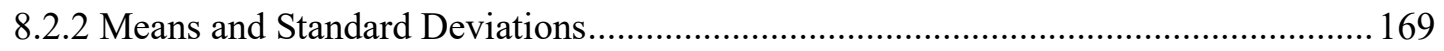

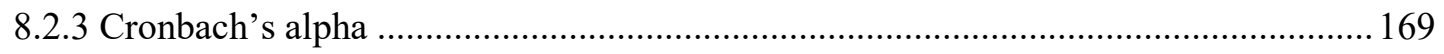

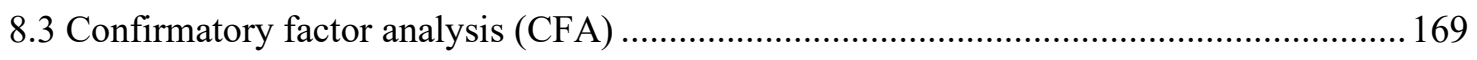

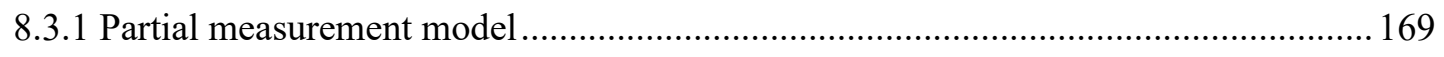

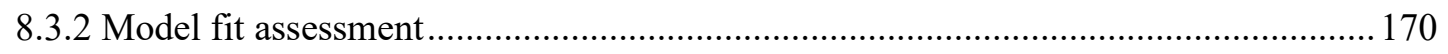

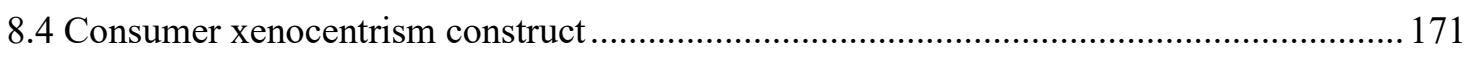

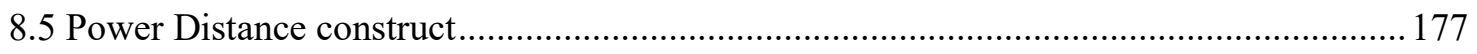

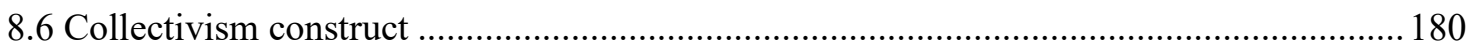




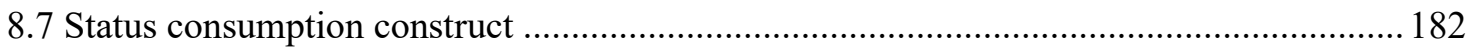

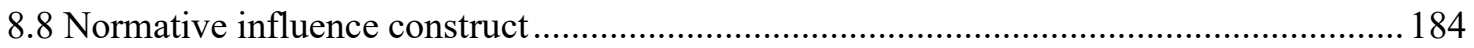

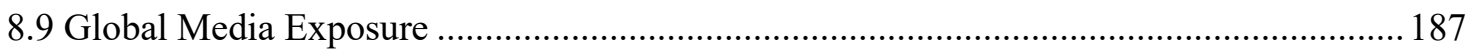

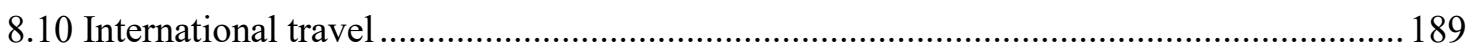

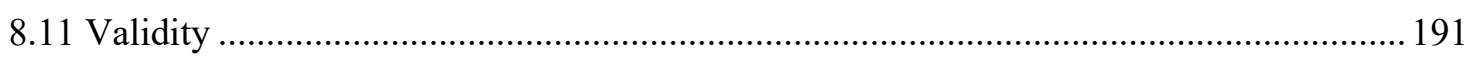

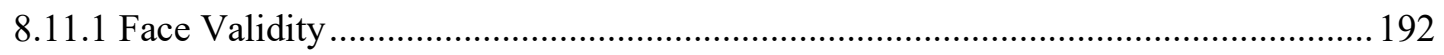

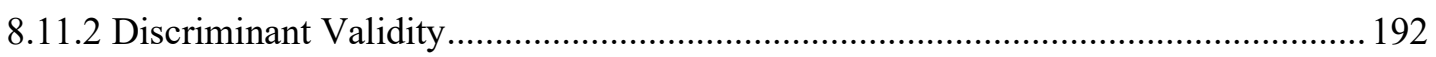

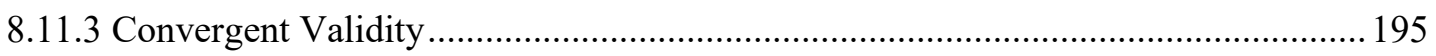

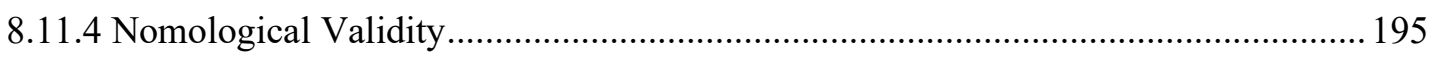

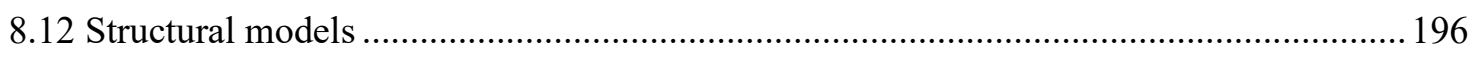

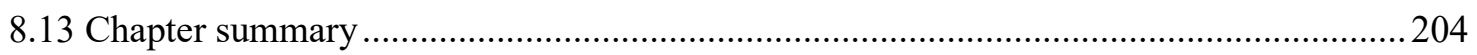

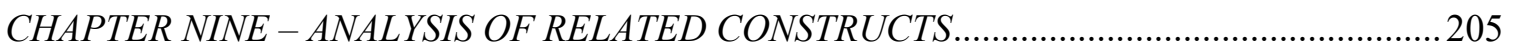

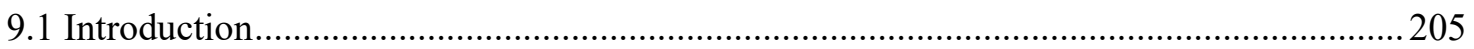

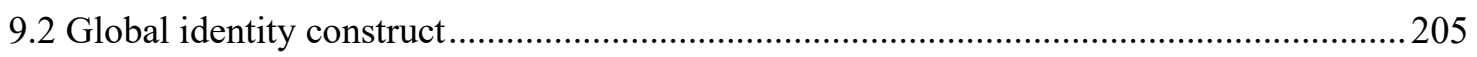

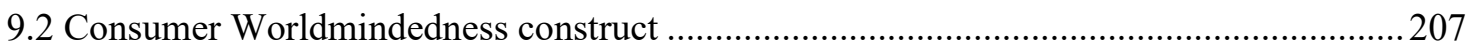

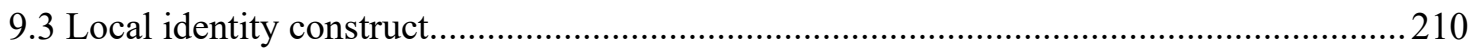

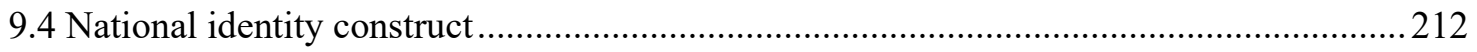

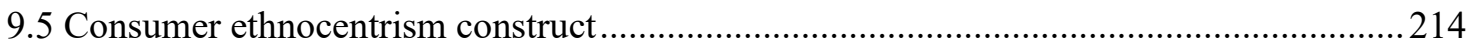

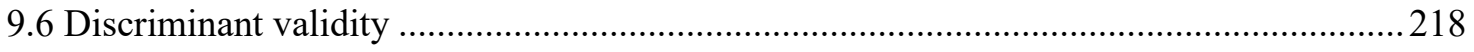

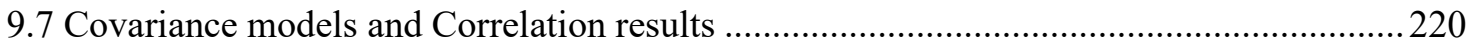

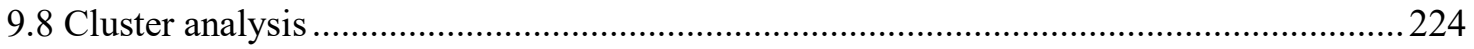

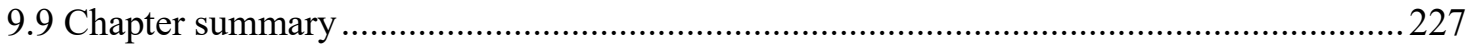

CHAPTER TEN - ANALYSIS OF CONSEQUENCES AND MODERATORS............................229

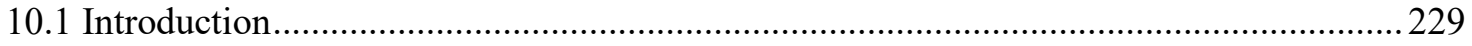

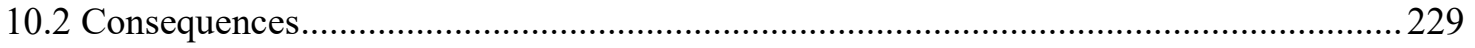

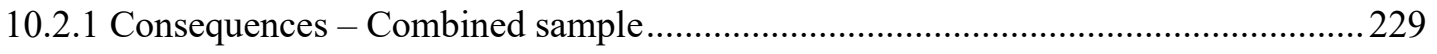

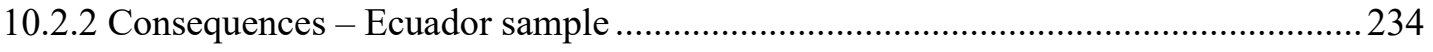

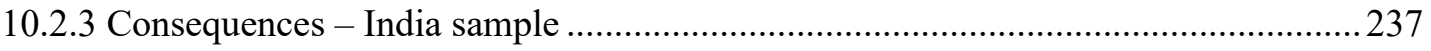

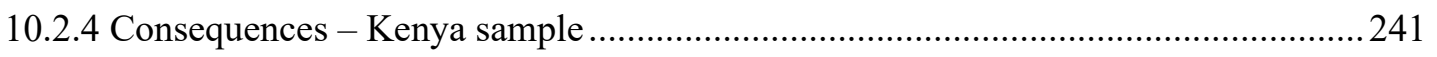

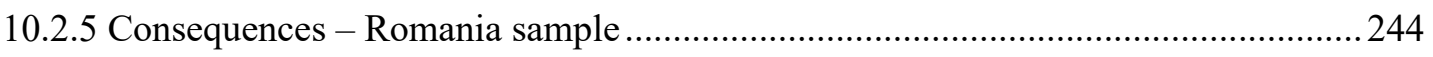

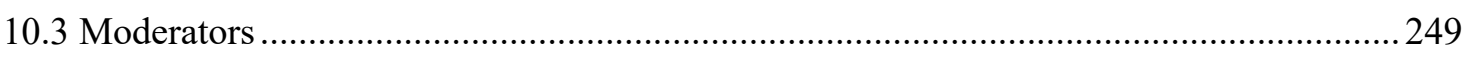

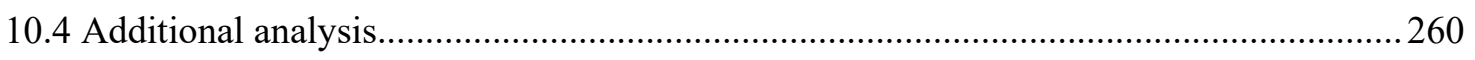

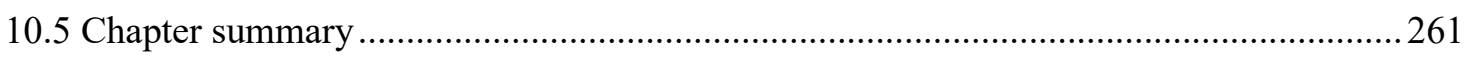

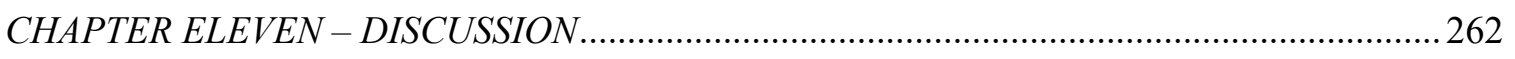

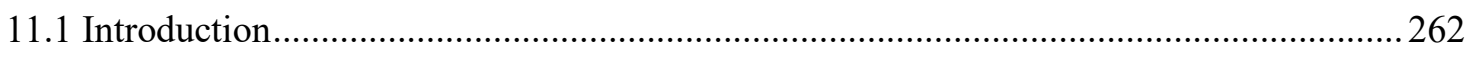




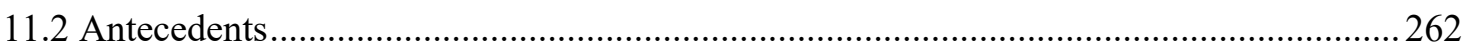

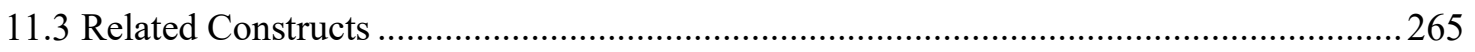

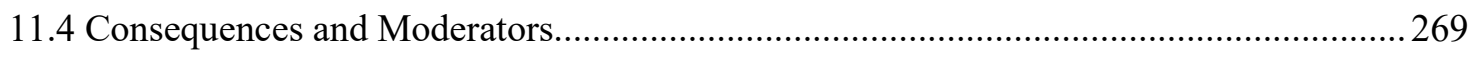

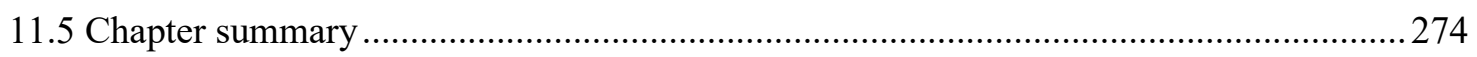

CHAPTER TWELVE - CONTRIBUTIONS AND LIMITATIONS ...........................................2 276

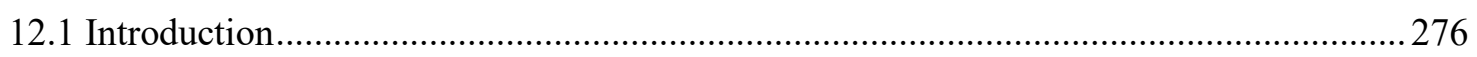

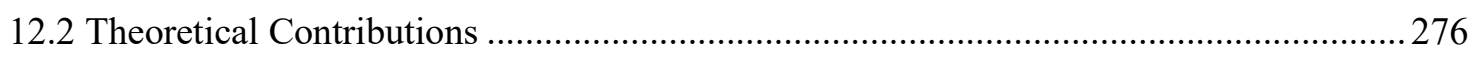

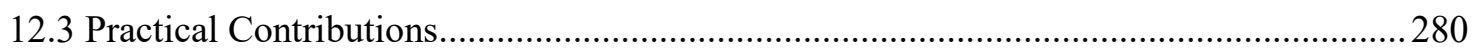

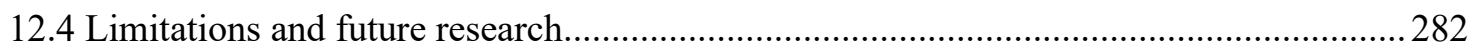

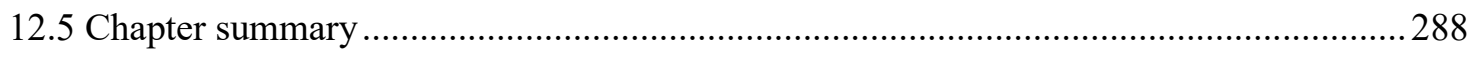

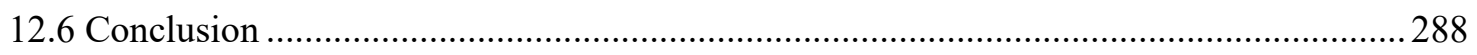

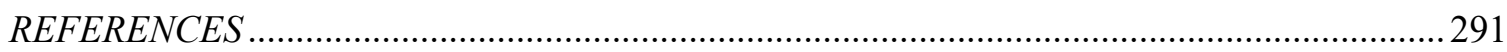

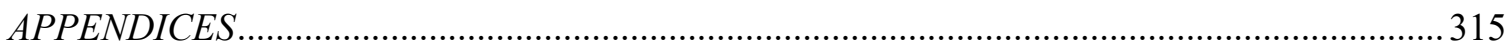

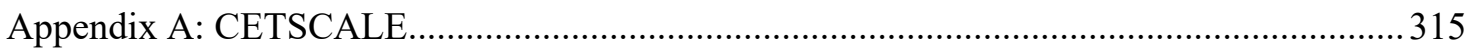

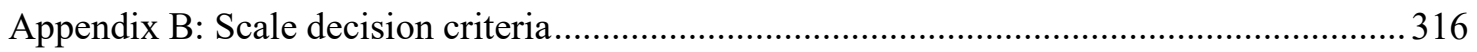

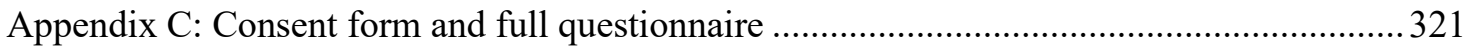

Appendix D: Diagram of complete proposed consumer xenocentrism model ........................339 


\section{List of Tables}

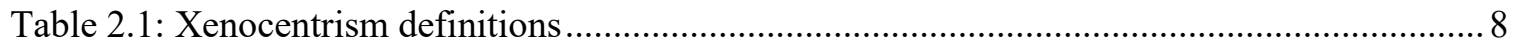

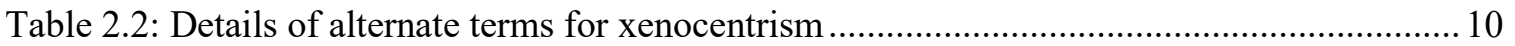

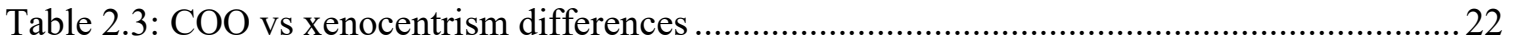

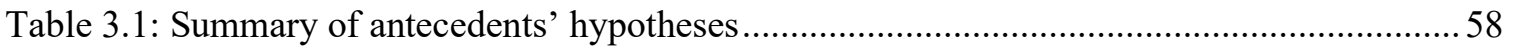

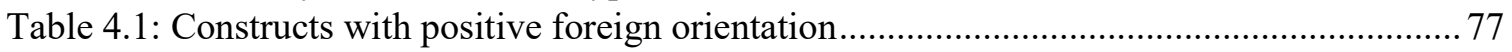

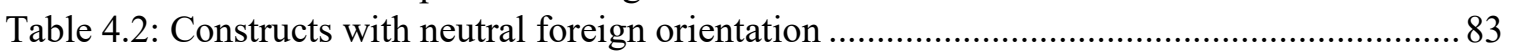

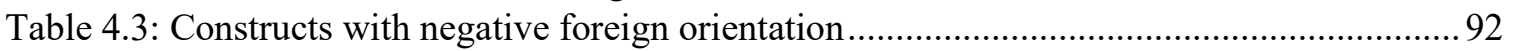

Table 4.4: Classification according to attitude towards domestic/foreign cultures ...................... 94

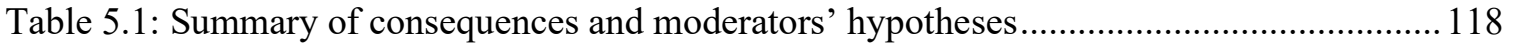

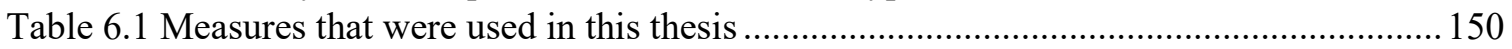

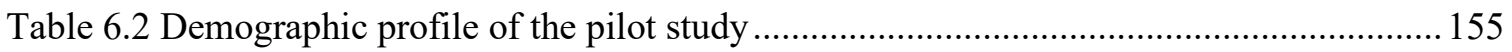

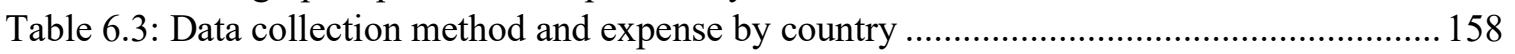

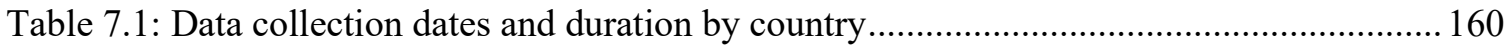

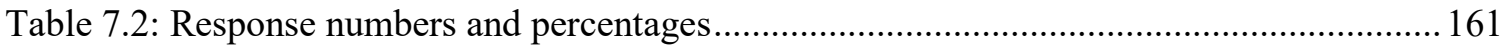

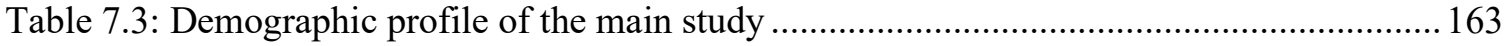

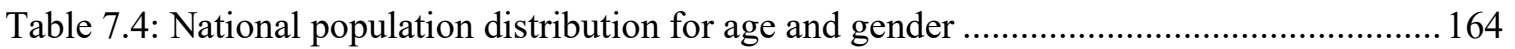

Table 8.1: Descriptive analysis for consumer xenocentrism construct for the combined sample 173

Table 8.2: Descriptive analysis for consumer xenocentrism construct for the Ecuador sample.. 173

Table 8.3: Descriptive analysis for consumer xenocentrism construct for the India sample....... 173

Table 8.4: Descriptive analysis for consumer xenocentrism construct for the Kenya sample..... 174

Table 8.5: Descriptive analysis for consumer xenocentrism construct for the Romania sample. 174

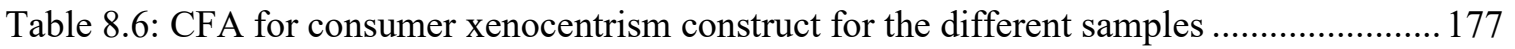

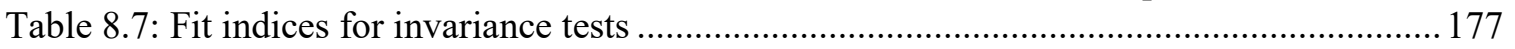

Table 8.8: Descriptive analysis for power distance construct for the combined sample ............. 179

Table 8.9: Descriptive analysis for power distance construct for the Ecuador sample................ 179

Table 8.10: Descriptive analysis for power distance construct for the India sample................... 179

Table 8.11: Descriptive analysis for power distance construct for the Kenya sample................. 179

Table 8.12: Descriptive analysis for power distance construct for the Romania sample............. 180

Table 8.13: CFA for power distance construct for the different samples ................................... 180

Table 8.14: Descriptive analysis for collectivism construct for the combined sample................. 181

Table 8.15: Descriptive analysis for collectivism construct for the Ecuador sample .................. 181

Table 8.16: Descriptive analysis for collectivism construct for the India sample ....................... 181

Table 8.17: Descriptive analysis for collectivism construct for the Kenya sample ..................... 181

Table 8.18: Descriptive analysis for collectivism construct for the Romania sample .................. 182

Table 8.19: Confirmatory factor analysis for collectivism construct for the different samples... 182

Table 8.20: Descriptive analysis for status consumption construct for the combined sample..... 183

Table 8.21: Descriptive analysis for status consumption construct for the Ecuador sample ....... 183

Table 8.22: Descriptive analysis for status consumption construct for the India sample ............ 183

Table 8.23: Descriptive analysis for status consumption construct for the Kenya sample .......... 184

Table 8.24: Descriptive analysis for status consumption construct for the Romania sample ...... 184

Table 8.25: CFA for status consumption construct for the different samples.............................. 184

Table 8.26: Descriptive analysis for normative influence construct for the combined sample ... 185

Table 8.27: Descriptive analysis for normative influence construct for the Ecuador sample...... 185

Table 8.28: Descriptive analysis for normative influence construct for the India sample ............ 186 
Table 8.29: Descriptive analysis for normative influence construct for the Kenya sample......... 186

Table 8.30: Descriptive analysis for normative influence construct for the Romania sample..... 186

Table 8.31: CFA for normative influence construct for the different samples ........................... 186

Table 8.32: Descriptive analysis for global media exposure construct for the combined sample 187

Table 8.33: Descriptive analysis for global media exposure construct for the Ecuador sample.. 188

Table 8.34: Descriptive analysis for global media exposure construct for the India sample....... 188

Table 8.35: Descriptive analysis for global media exposure construct for the Kenya sample..... 188

Table 8.36: Descriptive analysis for global media exposure construct for the Romania sample. 188

Table 8.37: CFA for global media exposure construct for the different samples ....................... 189

Table 8.38: Descriptive analysis for international travel construct for the combined ................. 190

Table 8.39: Descriptive analysis for international travel construct for the Ecuador .................... 190

Table 8.40: Descriptive analysis for international travel construct for the India......................... 190

Table 8.41: Descriptive analysis for international travel construct for the Kenya....................... 191

Table 8.42: Descriptive analysis for international travel construct for the Romania................... 191

Table 8.43: CFA for international travel construct for the different samples ............................ 191

Table 8.44: Discriminant validity for antecedent constructs for the combined sample ............... 193

Table 8.45: Discriminant validity for antecedent constructs for the Ecuador sample ................. 193

Table 8.46: Discriminant validity for antecedent constructs for the India sample ....................... 194

Table 8.47: Discriminant validity for antecedent constructs for the Kenya sample .................... 194

Table 8.48: Discriminant validity for antecedent constructs for the Romania sample ............... 195

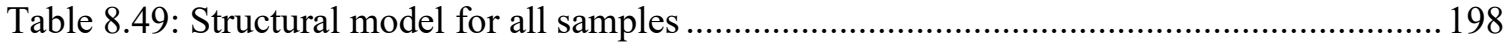

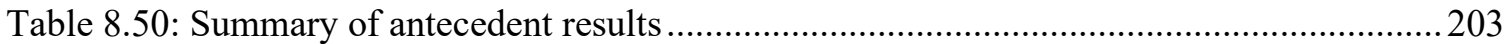

Table 9.1: Descriptive analysis for global identity construct for the combined sample ..............206

Table 9.2: Descriptive analysis for global identity construct for the Ecuador sample.................206

Table 9.3: Descriptive analysis for global identity construct for the India sample......................206

Table 9.4: Descriptive analysis for global identity construct for the Kenya sample ...................207

Table 9.5: Descriptive analysis for global identity construct for the Romania sample ...............207

Table 9.6: Confirmatory factor analysis for global identity construct for the different samples 207

Table 9.7: Descriptive analysis for worldmindedness construct for the combined sample .........208

Table 9.8: Descriptive analysis for worldmindedness construct for the Ecuador sample............209

Table 9.9: Descriptive analysis for worldmindedness construct for the India sample.................209

Table 9.10: Descriptive analysis for worldmindedness construct for the Kenya sample ............209

Table 9.11: Descriptive analysis for worldmindedness construct for the Romania sample ........210

Table 9.12: CFA for worldmindedness construct for the different samples ...............................210

Table 9.13: Descriptive analysis for local identity construct for the combined sample .............211

Table 9.14: Descriptive analysis for local identity construct for the Ecuador sample.................211

Table 9.15: Descriptive analysis for local identity construct for the India sample...................... 211

Table 9.16: Descriptive analysis for local identity construct for the Kenya sample....................212

Table 9.17: Descriptive analysis for local identity construct for the Romania sample................212

Table 9.18: Confirmatory factor analysis for local identity construct for the different samples .212

Table 9.19: Descriptive analysis for national identity construct for the combined sample .........213

Table 9.20: Descriptive analysis for national identity construct for the Ecuador sample............213

Table 9.21: Descriptive analysis for national identity construct for the India sample.................213

Table 9.22: Descriptive analysis for national identity construct for the Kenya sample...............214

Table 9.23 Descriptive analysis for national identity construct for the Romania sample............214

Table 9.24: CFA for national identity construct for the different samples .................................214

Table 9.25: Descriptive analysis for ethnocentrism construct for the combined sample.............216

Table 9.26: Descriptive analysis for ethnocentrism construct for the Ecuador sample ...............216 
Table 9.27: Descriptive analysis for ethnocentrism construct for the India sample 216

Table 9.28: Descriptive analysis for ethnocentrism construct for the Kenya sample

Table 9.29: Descriptive analysis for ethnocentrism construct for the Romania sample ..............217

Table 9.30: CFA for ethnocentrism construct for the different samples....................................217

Table 9.31: Discriminant validity for related constructs for the combined sample .....................218

Table 9.32: Discriminant validity for related constructs for the Ecuador sample........................219

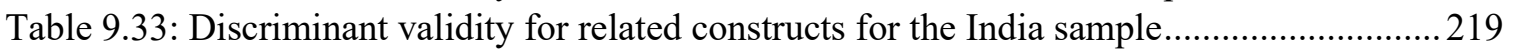

Table 9.34: Discriminant validity for related constructs for the Kenya sample ..........................219

Table 9.35: Discriminant validity for related constructs for the Romania sample .....................220

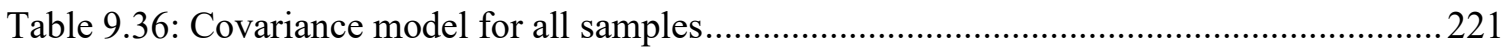

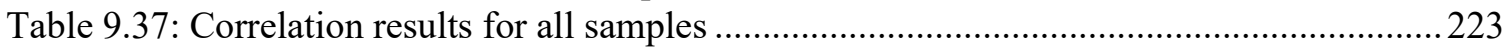

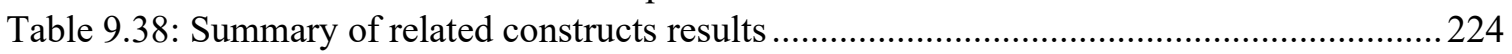

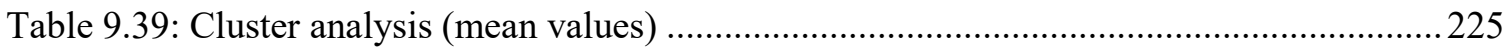

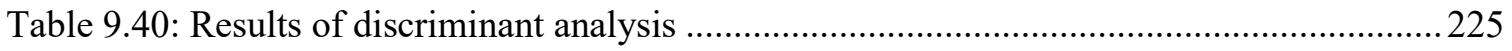

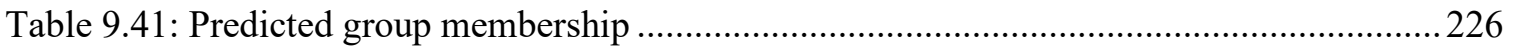

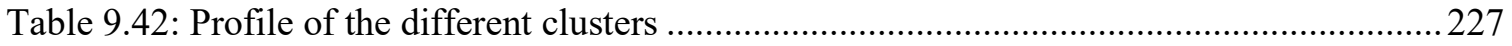

Table 10.1: Structural model for the consequences combined sample ......................................231

Table 10.2: Relationship between purchase intention to ownership for the combined sample ...232

Table 10.3: Purchase intention and product ownership means for the combined sample ...........233

Table 10.4: Structural model for the consequences Ecuador sample........................................235

Table 10.5: Relationship between purchase intention to ownership for the Ecuador sample......236

Table 10.6: Purchase intention and product ownership means for the Ecuador sample ..............237

Table 10.7: Structural model for the consequences India sample..............................................239

Table 10.8: Relationship between purchase intention to ownership for the India sample ...........240

Table 10.9: Purchase intention and product ownership means for the India sample ...................240

Table 10.10: Structural model for the consequences Kenya sample .........................................242

Table 10.11: Relationship between purchase intention to ownership for the Kenya sample.......243

Table 10.12: Purchase intention and product ownership means for the Kenya sample...............244

Table 10.13: Structural model for the consequences Romania sample ......................................246

Table 10.14: Relationship between purchase intention to ownership for the Romania sample... 247

Table 10.15: Purchase intention and product ownership means for the Romania sample ...........248

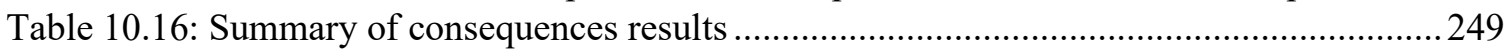

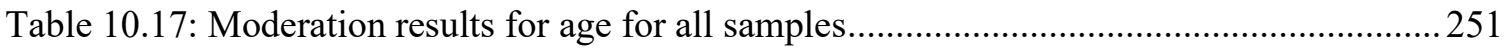

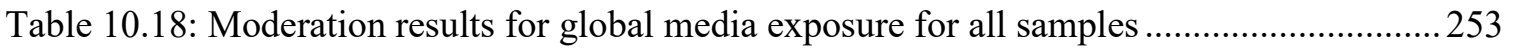

Table 10.19: Moderation results for product category symbolism for all samples .......................255

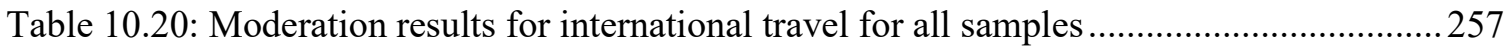

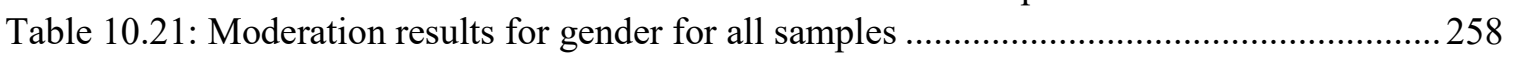

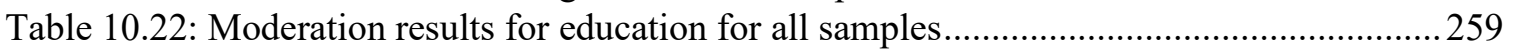

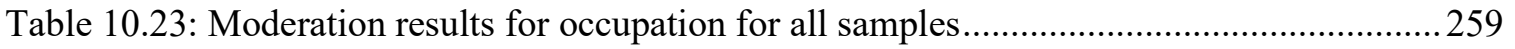

Table 10.24: Impact of xenocentrism and related constructs on consequences...........................260 


\section{List of Figures}

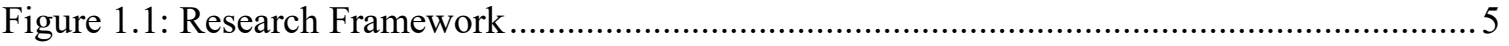

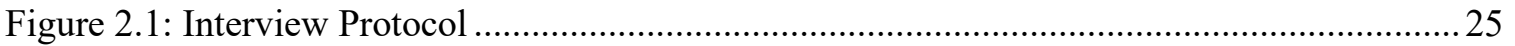

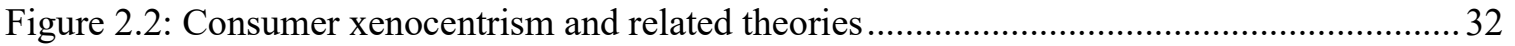

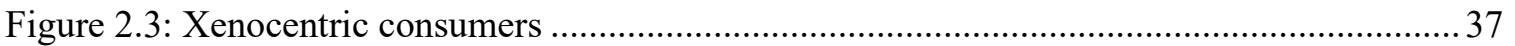

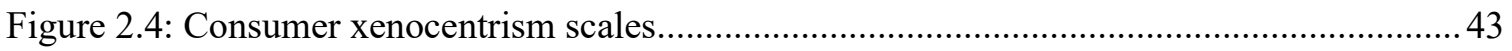

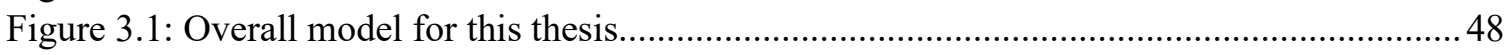

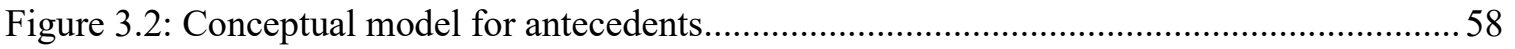

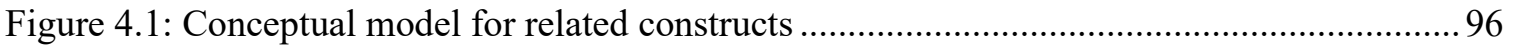

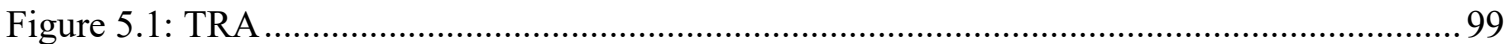

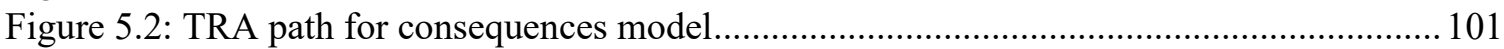

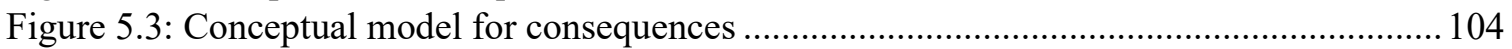

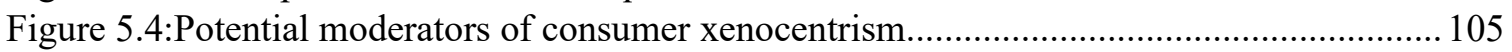

Figure 5.5: Conceptual model for consequences and moderators........................................... 118

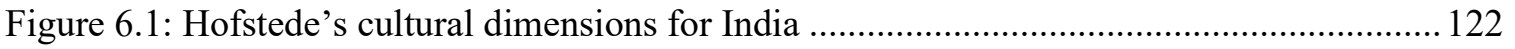

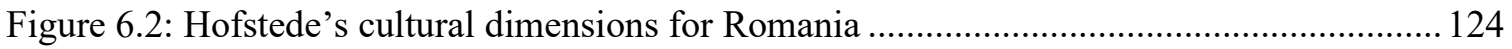

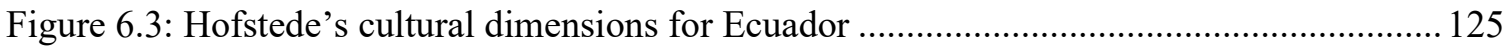

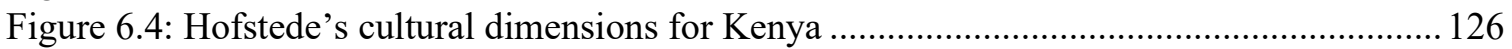

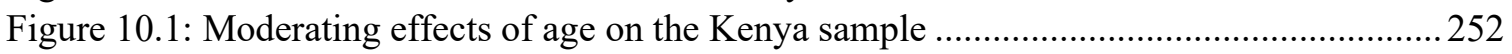

Figure 10.2: Moderating effects of global media exposure on the combined sample .................254

Figure 10.3: Moderating effects of product category symbolism on the combined sample ........256

Figure 10.4: Moderating effects of product category symbolism on the India sample................256 


\section{CHAPTER ONE - INTRODUCTION}

\subsection{Setting the context}

Xenocentrism involves considering the local culture inferior and giving a high preference or romanticizing foreign cultures (Prince, Davies, Cleveland and Palihawadana, 2016). To put it another way, xenocentrism emphasizes out-group love and in-group hate (Mueller, Wang, Liu and Cui, 2016). Ethnocentrism, which emphasizes in-group love and out-group hate, has received the bulk of the attention in international marketing over the years whereas xenocentrism has received scant attention despite the construct first being identified in the 1950s (Mueller, Wang, Liu and Cui, 2016; Rojas-Méndez and Chapa, 2019; Balabanis and Diamantopoulos, 2016; Mueller and Broderick, 2009; Prince, Davies, Cleveland and Palihawadana, 2016).

A third orientation in international marketing that has received lesser attention than ethnocentrism but a lot more attention than xenocentrism is cosmopolitanism (Holt, 1998; Thompson and Tambyah, 1999). Cosmopolitanism has its origins from the Greek word "cosmos" which means world and "politis" which means citizen (Riefler and Diamantopoulos, 2009). Rightly so as cosmopolitans see themselves as global citizens rather than citizens of a country (Merton, 1957a). Translating this behavior to consumption, cosmopolitans consume both the foreign and local products (Cannon and Yaprak, 2002; Figueiredo, 2012). They look for diversity and superiority in the products they consume (Holt, 1997) rather than whether it is a domestic or foreign product.

Constructs such as xenocentrism and cosmopolitanism have their origins in sociology (Bartsch et al., 2016). Kent and Burnight (1951) were probably the first scholars 
to address the concept of xenocentrism and to give the phenomenon its name. According to Rojas-Méndez and Chapa (2017) xenocentrism can be seen in the consumption (consumer xenocentrism) as well as in the social context (social xenocentrism). Social xenocentrism is the preference towards foreign people and rejection of domestic individuals. The authors also found that the higher the social xenocentrism, the greater the preference for foreign products. Consumer xenocentrism is the preference for foreign products and rejection of domestic ones (Rojas-Méndez and Chapa, 2019). This thesis will only focus on consumer xenocentrism. "Malinchismo" is a term used in Mexico that signifies xenocentrism (Rojas-Méndez and Chapa, 2019). In consumer behavior, it is manifested as the preference of products from the developed countries such as the United States, Germany and Japan over their domestic products (Soto, 2008).

There have been very few empirical studies on consumer xenocentrism in the international marketing literature (Rojas-Méndez and Chapa, 2019; Balabanis and Diamantopoulos, 2016; Prince et al., 2016; Lawrence 2012; Diamantopoulos, Davydova and Arslanagic-Kalajdzic, 2019). Some of the reasons for the limited research in this area could be because 1.) Xenocentrism is mostly experienced in the developing world and data collection in those regions can be difficult (some reasons are low internet penetration rates in the developing world as compared to the developed countries, necessity to translate surveys to local languages to name a few) 2.) Often the theories coming from developed countries are assumed to be applicable to the developing world as well (De Mooij, 2013; Rojas-Méndez and Chapa, 2019) - this may not always be the case. For example, we see that ethnocentrism is a predominant consumer orientation in developed countries such as 
the U.S. but this is not necessarily the case in the developing world where xenocentrism may be the dominant consumer orientation (Rojas-Méndez and Chapa, 2019).

A better understanding of the consumer xenocentrism has become imperative today because of multiple reasons. With globalization making availability and purchase of foreign goods in the developing markets easier than ever before it has now become crucial to study xenocentrism (Soto, 2008; Lawrence, 2012). Secondly, more and more people in developing countries such as China are moving into the middle-class with growing disposable incomes and this trend is expected to continue into the future (CNBC, 2016). This translates into increased consumer spending. In fact, by 2023, Asia-Pacific is expected to surpass North America with respect to the highest consumer spending (Euromonitor International, 2018). These consumers have more purchasing power now and been found to be xenocentric in an exploratory study (Mueller et al., 2016). Thus, more empirical studies on xenocentrism are needed to better understand this concept. Finally, from the developed countries' perspective it would be more beneficial to expand their consumer base beyond their respective countries and current trading countries as developing countries offer a huge consumer base given their population and preference for foreign goods.

\subsection{Research Questions and Framework}

This research attempts to answer four major questions:

1.) What are the antecedents to consumer xenocentrism?

2.) What is the relationship between consumer xenocentrism and other allied constructs? 
3.) What are the consequences of consumer xenocentrism?

4.) What are the moderators between consumer xenocentrism and its consequences?

In order to answer these questions a two-step process is followed. The first step is to review the extant literature and complement it with interviews from experts in five different academic disciplines. This step is exploratory and follows an inductive approach. This step will aid in creating the model and hypotheses. The resulting model is strongly theoretically grounded and draws on several disciplines such as international business, economics, sociology, psychology, political science, anthropology and consumer behavior. In particular, this step identifies the potential antecedents, related constructs and consequences (and moderators) of consumer xenocentrism.

The second step is creating and running a survey that answers the research questions. In other words, it involves formulating and administering a survey to test the hypotheses that have been proposed in the previous step. This survey is based on existing measures in the extant literature (although adaptations are made where necessary) and is run in four developing countries. This step is deductive, and it is the theory-testing stage. After the survey is run, data analysis is performed using SPSS and AMOS, the results are compared to the hypotheses that were initially set and the final conclusions are drawn.

The research framework as elaborated in the two steps above is illustrated in figure 1.1: 
Figure 1.1: Research Framework

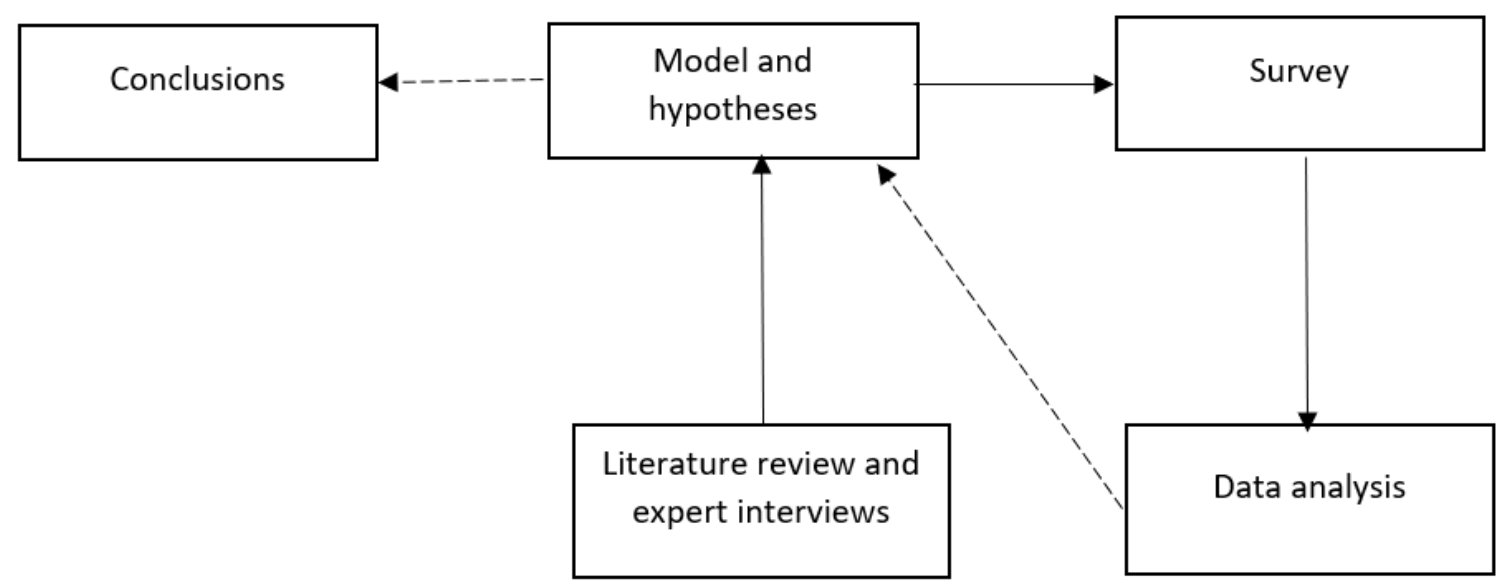

Overall, several authors have agreed on what consumer xenocentrism is (Mueller and Broderick, 2009; Mueller et al., 2016; Balabanis and Diamantopoulos, 2016; RojasMéndez and Chapa, 2019), there have been several attempts to establish a scale for the same (Balabanis and Diamantopoulos, 2016; Lawrence, 2012; Rojas-Méndez and Chapa, 2019) and related constructs such as ethnocentrism and cosmopolitanism and the willingness to buy foreign products consequence has been tested with the construct (RojasMéndez and Chapa, 2019). However, much more research is needed on what causes consumer xenocentrism (antecedents), what are the other constructs related to consumer xenocentrism (excluding ethnocentrism and cosmopolitanism) and what are the consequences and moderators of consumer xenocentrism (excluding willingness to buy foreign products). Thus, these topics will be the focus of this thesis. Knowledge of the antecedents, related constructs, consequences and moderators will make a theoretical contribution as to what constructs cause consumer xenocentrism (for example, does culture have an impact on consumer xenocentrism?), how other related constructs are related to consumer xenocentrism (for example, how is national identity related to consumer 
xenocentrism?), if there are any other consequences to consumer xenocentrism (for example, does xenocentrism translate to actual behavior?) and if there are any moderators to consumer xenocentrism. Additionally, this study will also be useful to practitioners because knowledge of what causes xenocentrism and the consequences can help international marketers effectively position and market their products and services (for example, should the focus on objective or social characteristics of the product?).

The remainder of this thesis is organized as follows. Chapter Two provides a review of the consumer xenocentrism and general xenocentrism literature and the associated theories from international business, economics, sociology, psychology, political science, anthropology and consumer behavior. Chapter Three describes the potential antecedent constructs, associated theories and sets the antecedents hypotheses. Chapter Four reviews the related constructs to consumer xenocentrism with the corresponding theories and outlines the related constructs hypotheses. Chapter Five examines the consequences and moderator constructs and sets the corresponding hypotheses. Chapter Six discusses the research methodology that has been used in this thesis. Chapter Seven elaborates on the preliminary data analysis carried out such as reviewing the characteristics of the sample collected. Chapters Eight, Nine and Ten summarize the analyses of antecedents, related constructs, and consequences and moderators respectively. These chapters check whether the hypotheses set in Chapters Three, Four and Five are proved or disproved. Chapter Eleven is the discussion section which elaborates on the main findings of this thesis. Finally, Chapter Twelve outlines the contributions of this thesis and its limitations. 


\section{CHAPTER TWO - LITERATURE REVIEW}

\subsection{Introduction}

In this chapter, first, an overview of consumer xenocentrism is given. Next, two very important, frequently appearing themes with respect to xenocentrism are reviewed. The issue of whether consumer xenocentrism is just another name for country-of-origin (COO) effect is discussed. Then, the expert interview process is discussed. Later, the theoretical foundations of consumer xenocentrism are explained. Next, which kind of consumers are expected to be more xenocentric are examined. Finally, the various scales used to measure consumer xenocentrism are reviewed.

\subsection{Consumer Xenocentrism - an overview}

This section will give an overview of xenocentrism. In particular, it will summarize all the definitions of xenocentrism from extant literature, elaborate on the concept, discuss the disassociation between consumer xenocentrism and quality, provide examples of xenocentrism from various regions around the world and finally discuss xenocentrism with respect to the domestic industry.

\subsubsection{Definitions}

Table 2.1 gives the various xenocentrism definitions in the literature. 
Table 2.1: Xenocentrism definitions

\begin{tabular}{|l|l|l|}
\hline S.no. & Author & Definition \\
\hline General xenocentrism & $\begin{array}{l}\text { Kent and Burnight } \\
\text { (1951, p. 256) }\end{array}$ & $\begin{array}{l}\text { A view of things in which a group other than one's } \\
\text { own is at the center of everything, and all other groups, } \\
\text { including one's own, are scaled and rated with } \\
\text { reference to it. }\end{array}$ \\
\hline 1 & $\begin{array}{l}\text { Soto (2008, p.1) } \\
\text { (2) }\end{array}$ & $\begin{array}{l}\text { Malinchismo effect: } \\
\text { To dislike one's own and preferring the other - giving } \\
\text { oneself to the foreigner and abandoning and betraying } \\
\text { one's own. }\end{array}$ \\
\hline 3 & $\begin{array}{l}\text { Merriam-Webster } \\
\text { dictionary (2016) }\end{array}$ & $\begin{array}{l}\text { Oriented toward or preferring a culture other than one's } \\
\text { own. }\end{array}$ \\
\hline Consumer xenocentrism /xenocentric \\
\hline 4 & $\begin{array}{l}\text { Mueller and } \\
\text { Broderick (2009, } \\
\text { p.6); Mueller et al., } \\
\text { (2016, p.74) }\end{array}$ & $\begin{array}{l}\text { The author(s) draw on Kent and Burnight (1951) } \\
\text { definition of xenocentrism and define consumer } \\
\text { xenocentrics as follows: } \\
\text { a person who prefers products from a country (or } \\
\text { region) other than their own and who rates products in } \\
\text { reference to the foreign country and not their own. }\end{array}$ \\
\hline 5 & $\begin{array}{l}\text { Lawrence (2012, } \\
\text { p.18) }\end{array}$ & $\begin{array}{l}\text { The author draws on Kent and Burnight (1951) } \\
\text { definition of xenocentrism and defines consumer } \\
\text { xenocentrism: } \\
\text { An individual's preference for the products or services } \\
\text { (2016, p. 61) } \\
\text { of a society other than their own. A propensity to rate } \\
\text { and scale all products and services in reference to this } \\
\text { foreign society. }\end{array}$ \\
\hline
\end{tabular}


From Table 2.1 it can be seen that most of the consumer xenocentrism definitions are based on Kent and Burnight's (1951) idea of xenocentrism. Their idea has been taken as the foundation for the different consumer xenocentrism definitions. A couple of things to note about the consumer xenocentrism definitions 1.) The definition of Lawrence (2012) makes it seem like consumer xenocentrism is preference of products from one particular foreign country. However, CXENO, the scale developed by Lawrence (2012) measures the preference for foreign products in general and not just preference from one specific foreign country. 2.) Balabanis and Diamantopoulos (2016) in addition to defining consumer xenocentrism also state what causes this phenomenon, social aggrandizement. A more elaborate discussion on this construct is provided in Section 2.9.2 when analyzing the consumer xenocentrism scale put forth by these authors.

\subsubsection{Further elaboration on xenocentrism}

Xenocentrism is simply not a preference for the foreign, it is also accompanied by the rejection of the local (Kent and Burnight, 1951; Balabanis and Diamantopoulos, 2016; Perlmutter, 1954; Kala and Chaubey, 2016). Kent and Burnight (1951) state that, "One who is ethnocentric sees virtues where none exist; one who is xenocentric sees faults where none exist." (Kent and Burnight, 1951, p. 257). Xenocentrics associate themselves with the foreign group and overestimate the out-group while looking down at their own group (Kent and Burnight, 1951; Traian-Alexandru, 2016; Bartsch et al., 2016). Rejection of in-group is a key characteristic of xenocentrism and one that differentiates xenocentrism from other positive foreign bias constructs. Xenocentrism is predominately found in developing and transitional countries (Kisawike, 2015; Rojas-Méndez and Chapa, 2019; Balabanis and Diamantopoulos, 2016). 
In xenocentrism research, "foreign products" only refers to products from developed countries such as the US, West European countries and Japan (Mueller et al., 2016) and not products from other developing countries. In fact, the term "Western products" is also used interchangeably with "foreign products" in extant literature, though objectively countries studied like Japan are not Western countries (Mueller and Broderick, 2009). In short, "foreign/Western products" signifies that the products are from the developed countries.

The alternate terms used to describe xenocentrism in the extant literature are malinchismo / malinchismo effect (Bailey and Pineres, 1997; Ueltschy and Ryans, 1997; Rojas-Méndez and Chapa, 2019; Soto, 2008), altercentrism (Montero, 1986), consumer geocentrism (Szromnik, 2014), negative ethnocentrism (Swartz, 1961) and colonial hangover (Bashkow, 2006). Table 2.2 shows the field that each term comes from and how the term is defined.

Table 2.2: Details of alternate terms for xenocentrism

\begin{tabular}{|c|l|l|}
\hline Term & \multicolumn{1}{|c|}{ Field } & \multicolumn{1}{|c|}{ Definition (s) } \\
\hline Malinchismo or & Consumer behavior & "Individuals who have a \\
Malinchismo effect & propensity for foreign made \\
(xenocentrism) $/$ & goods over Mexican made \\
Malinchista (individual & goods." (Bailey and Pineres, \\
who is xenocentric) & 1997; p.27). \\
& \\
\hline
\end{tabular}




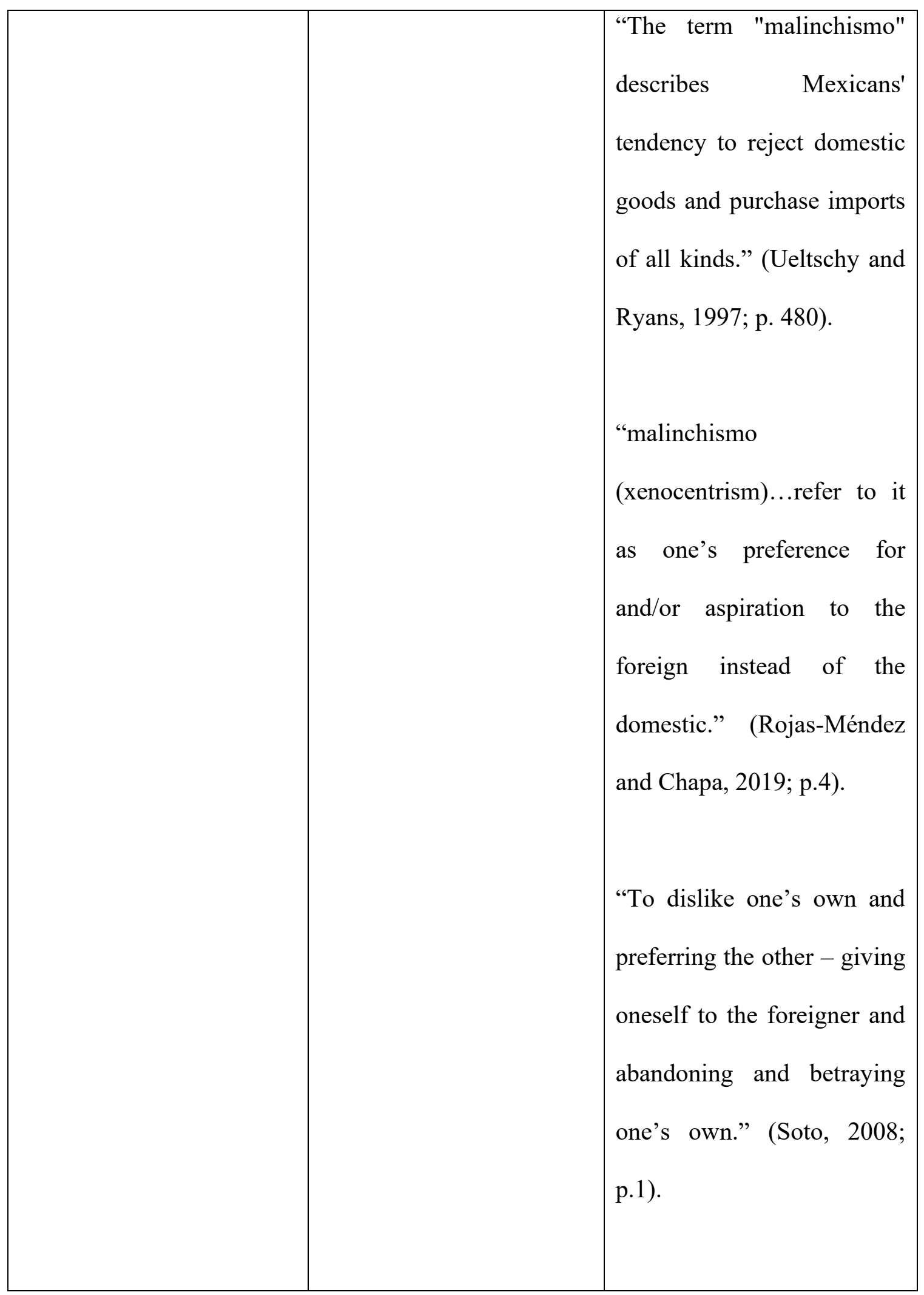




\begin{tabular}{|c|c|c|}
\hline Altercentrism & Political Psychology & $\begin{array}{l}\text { "Montero (1986) applied the } \\
\text { term 'altercentrism' to } \\
\text { describe the widespread and } \\
\text { consistent overevaluation of } \\
\text { the U.S. culture and under- } \\
\text { evaluation of Latin } \\
\text { Americans' own." (Mueller } \\
\text { and Broderick, 2009, p. 4). }\end{array}$ \\
\hline Consumer geocentrism & Business Economics & $\begin{array}{l}\text { "is connected to preferences } \\
\text { in doing shopping and } \\
\text { consumption of foreign } \\
\text { products, in this case, called } \\
\text { by the authors "consumer } \\
\text { geocentrism" } \\
\text { "xenocentrism"." } \\
\text { (Szromnik, 2014, p. 28) }\end{array}$ \\
\hline $\begin{array}{l}\text { Negative ethnocentrism } \\
\text { *Further discussion is } \\
\text { presented in section 2.9.1 } \\
\text { on the appropriateness of } \\
\text { calling xenocentrism, } \\
\text { negative ethnocentrism. }\end{array}$ & Conflict Resolution & $\begin{array}{l}\text { "people's frequent low } \\
\text { evaluation of themselves } \\
\text { and, at least verbal, high } \\
\text { regard for American ways." } \\
\text { (Swartz, 1961, p. 75). } \\
\text { Note: Though the above } \\
\text { quote states American ways }\end{array}$ \\
\hline
\end{tabular}




\begin{tabular}{|c|c|c|}
\hline & & $\begin{array}{l}\text { as an example, the paper } \\
\text { considers out-groups in } \\
\text { general. This is outlined in } \\
\text { Muller and Broderick's } \\
\text { (2009) quote below. } \\
\text { "Swartz (1961) similarly } \\
\text { describes the great esteem } \\
\text { for a foreign material culture } \\
\text { and the poor evaluation of } \\
\text { one's own as "negative } \\
\text { ethnocentrism"." (Mueller } \\
\text { and Broderick, 2009, p. 4) }\end{array}$ \\
\hline Colonial hangover & Anthropology & $\begin{array}{l}\text { "unconscious elevation of } \\
\text { whitemen" } \\
\text { "constantly measuring } \\
\text { them[selvesl against } \\
\text { outsiders, .. it leads them to } \\
\text { devalue their own moral } \\
\text { strengths, producing an } \\
\text { unfortunate and unwarranted }\end{array}$ \\
\hline
\end{tabular}




\begin{tabular}{|l|l|l|}
\hline & & $\begin{array}{l}\text { "inferiority complex"” } \\
\text { (Bashkow, 2006, p.233) }\end{array}$ \\
\hline
\end{tabular}

\subsubsection{Xenocentrism and quality}

One could argue that the preference of foreign goods could be due to the highquality of these products, but researchers have found that this is not always the case (Balabanis and Diamantopoulos, 2016; van Herk and Torelli, 2017). Some of the foreign product purchases can be linked to higher quality and thus to $\mathrm{COO}$ benefits but not all of it (Mueller et al., 2016). Consumers bought foreign products even when similar or even better quality and lower priced local products were available in the domestic market (Mueller and Broderick, 2009; van Herk and Torelli, 2017; Mueller et al., 2016) and this effect was found for a variety of products such as clothing, footwear, cosmetics and building materials (Mueller and Broderick, 2009). Kent and Burnight (1951, p.258) argue that this attitude is "not entirely objective and rational". Thus, foreign products are used not for objective purposes but for other social characteristics linked to using those products (Dong and Tian, 2009; Mueller et al., 2016). Consumer xenocentrism thus is associated more with hedonic consumption than with utilitarian consumption (Mueller et al., 2016; de Leff, 2002; Kent and Burnight, 1951). Hedonic consumption is based on emotions or affect (Hirschman and Holbrook,1982) as opposed to utilitarian consumption which is based on functionality (Batra and Ahtola, 1990). 


\subsubsection{Examples of xenocentrism}

This section consists of examples on how xenocentrism is manifested in different regions in the world. The following examples are from Asia, Africa and South America.

In China, domestic products are given foreign names - some examples are Chinese housing projects given names such as "California Garden" and "Vancouver Forest" (Mueller et al., 2016). A similar trend has been found in Pakistan where domestic products such as milk and bread have been given foreign names (Balabanis and Diamatopoulos, 2016). This practice can likely be carried out by domestic businesses to take advantage of xenocentrism (Mueller et al., 2016).

Additionally, some more examples from Asia include, in the Philippines a store called "Kultura Filipino" which translated to Filipino Culture but it exhibited Santa Claus and other Western items. The target shoppers were Filipinos who have embraced the Western culture and the author claims that Filipinos in general are xenocentric (Montemayor, 2015). In Indonesia, Western music (mostly British and American) was placed on top of the shelves and the Indonesian music was placed lower. This practice emphasized the status hierarchy in that Western music was considered superior to local music (Wallach, 2002). Indonesian music was looked down at and was even accused of copying Western music which enjoyed a superior position among Indonesians (Wallach, 2002). This again can be related to xenocentrism which is not just a positive foreign bias but also a local negative bias or rejection of the domestic market.

In Africa the practice of skin bleaching has also been related to xenocentrism - the practice is linked to self-hate / inferiority complex and a love for the foreign (Asakitikpi, 
2016). Fairer skin is seen superior to a darker one. Fairer skin has also been associated with the prosperity of the developed countries and there is a perception that dark skin prevents individuals in developing countries from attaining such kind of a development (Bashkow, 2006). Skin bleaching is not only popular in Africa but also among people of color in several parts of the world (Charles, 2003; Asakitikpi, 2016). For example, in India, skin lightening creams such as "Fair and Lovely" for women and "Fair and Handsome" for men are popular. In Africa the foreign admiration is said to have influenced not only the quest for fairer skin but also the clothing style and language (Asakitikpi, 2016).

Waithaka (2017) found the existence of xenocentrism in Kenyan preschools. Both parents and teachers preferred using English to their mother tongues. They believed that English was superior to their mother tongue. Though some part of this attitude was associated with learning of English leading to the child having global opportunities, the other part, the author claims, is associated with xenocentrism. One of the reasons parents preferred their children learn English was that they wanted their children to be as smart as the Europeans, a reference to their colonial past (Waithaka, 2017).

Xenocentrism has also been observed in South America. de Leff (2002) and Gerson (2004) argue that in Mexico, xenocentrism (referred to as malinchismo there) resulted in people giving their children American or foreign-sounding names instead of the traditional Spanish or Christian names. Also, people spoke Spanish interspersed with English to signal high status (de Leff, 2002; Gerson, 2004) and this practice is associated with xenocentrism.

From the above examples it can be seen that xenocentrism has been observed in several regions around the world - noteworthy is that each of these countries is a developing one. These examples are also from a wide range of disciplines such as 
international marketing, anthropology, sociology, education and psychology. This shows that the concept of xenocentrism has been observed from the perspectives of different fields although research in international marketing in itself has been scarce.

\subsubsection{Xenocentrism and the domestic industry}

The downsides of consumer xenocentrism and preference for foreign products in general can lead to a loss of the domestic companies (Okechuku and Onyemah, 1999), a reduction in product options to consumers and in extreme cases a dependency on foreign products (Mueller and Broderick, 2009; Mueller et al., 2016). Thus, consumer xenocentrism is perceived to harm the domestic industries. On the other hand, some researchers argue that consumer xenocentrism to a certain extent might actually be good for the domestic industry (Kisawike, 2015; Kent and Burnight, 1951). This is the case because domestic industries are challenged to produce better products, price products competitively and experiment with their promotions (Kisawike, 2015). Mueller and Broderick (2009) argue that the damaging effects might still outweigh these benefits because in spite of the domestic goods being objectively equal or even better in quality and priced cheaper, xenocentrics would still prefer foreign products thus causing damage to the domestic industries. This could be because of the status these goods confer. The association between xenocentrism and status is discussed in-depth in the next section 2.3.

Lost opportunities for domestic industries translate to gains for the foreign companies. It was found that Mexican consumers are loyal to US brands, an effect caused by malinchismo (Ueltschy and Ryans, 1997). 


\subsection{Xenocentrism and status}

Social aggrandizement is part of the xenocentrism scale of Balabanis and Diamantopoulos (2016) though this should potentially be an antecedent of xenocentrism, not part of the construct itself. Nonetheless it shows that status and xenocentrism are associated. Though the relationship has not been empirically tested, the association between xenocentrism and status is one of the most recurrent themes in the xenocentrism extant literature. As a case in point in China, several authors have noted that the consumption of foreign goods has been associated with the symbolic value of status and prestige that those goods offer (Dong and Tian, 2009; Mueller et al., 2016; Song, 2012). This behavior is prevalent despite foreign goods being expensive in China (Mueller et al., 2016) when taking into account the exchange rates. In the study by Mueller et al. (2016) in China, though some respondents did point out better quality was one of the reasons that they preferred foreign products, they also mentioned that using foreign products helped them show their status or signal that their status has improved. By displaying that they are able to afford expensive foreign products these individuals signal their status.

This is not the case only in China. Several authors have argued that in developing countries in general buying foreign products has been associated with the social status it bestows and in "showing" who is successful and who isn’t (Rojas-Méndez and Chapa, 2019; Balabanis and Diamantopoulos, 2016; Prince et al., 2016; Kala and Chaubey, 2016; Mueller and Broderick, 2009). Groups that are lower in status have a greater aspiration to elevate their status by purchasing high-status goods (Mazzocco et al., 2012). This can be translated to developing countries which have lower quality of life and less-sophisticated infrastructure (low-status group) compared to developed countries wanting to elevate their 
status by purchasing foreign products (high-status goods). Additionally, in cultures that are hierarchical (high power distance), the need to display status and one's place in the hierarchy is greater (Mueller et al., 2016; Song, 2012). Purchasing foreign goods (and thus signaling higher status) also helps individuals in those societies to move upward in the hierarchy (Batra et al., 2000).

Asakitikpi (2016) argues that skin bleaching in Africa has also been related to gaining social status. Thus, what is foreign (white skin) is associated with higher status. Wallach (2012) argues that Western songs are placed on top of the "gengsi" scale in Indonesia. Gengsi is a key concept in Indonesia which means "outward appearances" and this appearance is intended to showcase status (Hofstede, 2018a). Associating oneself to the successful group increases one's own status (van Herk and Torelli, 2017). The successful group in our context is the developed countries. Emulating them (as in the case of skin bleaching) or buying their products increases the status of individuals in the developing countries.

High price may not be a deterrent for owning foreign products to show status for even low-income consumers in developing countries as they are likely to use counterfeits (Mueller et al., 2016; Balabanis and Diamantopoulos. 2016; Mueller and Broderick, 2009). Using of counterfeits shows that consumers are not necessarily buying the foreign product for quality reasons (Mueller and Broderick, 2009). It was found that consumers in Thailand place domestic brand cigarettes in foreign Marlboro packets to show their status (Goldberg and Baumgartner, 2002). Even damaged foreign products are bought to display status (Mueller and Broderick, 2009). From the above examples we can see that signaling status is not just the habit of the rich and that foreign products are not necessarily bought for 
quality or objective reasons which is the case in COO stereotyping. In the case of xenocentrism we see that the foreign products are bought for hedonic purposes. In fact, one of the reasons people buy products that are associated with prestige is because of the perceived hedonic value (Vigneron and Johnson, 1999).

\subsection{Xenocentrism and normative influence}

This is the second most recurring theme in the xenocentrism literature, after xenocentrism and status. In general, normative influence is a very strong predictor of behavior even though individuals sometimes may not be aware of it (Nolan, Schultz, Cialdini, Goldstein and Griskevicius, 2008). Mueller et al. (2016) in their exploratory study found that peer pressure results in consumers having to display their status through owning foreign products or be xenocentric. They also found that in China the pressure to follow social conventions was very high - if buying foreign products was the norm, then it should be followed. This in part can be attributed to the collectivistic culture of China where the social conventions of the group are very important and one that has a powerful effect on the members of the group (Shi, Wen and Fan, 2012; Wei and Yu, 2012). This behavior again ties into the social meaning that the display of foreign goods carries and does not have much to do with the quality or the objective value of the foreign product itself as would be the case in $\mathrm{COO}$ stereotyping. To a certain extent, buying products due to normative influence is also seen in the West and is often referred to as "keeping up with the Joneses", but the pressure to conform to social conventions is comparatively much higher in collectivistic cultures (Wong and Ahuvia, 1998). For the most part, as Wong and Ahuvia (1998, p. 433) put it, "Whereas in Western culture there is a greater tendency for people to conspicuously consume luxuries because they want to (i.e., the products reflect 
private preferences), in the East Asian Confucian societies, there is a greater tendency for people to behave this way because they feel they have to (i.e., the products conform to social norms)."

The link between xenocentrism and susceptibility to normative influence has been acknowledged by several authors (Mueller et al., 2016; Rojas-Méndez and Chapa, 2019; Balabanis and Diamantopoulos, 2016). Susceptibility to interpersonal influence consists of both susceptibility to normative influence and susceptibility to informational influence. Bearden, Netemeyer, and Teel (1989) assert that susceptibility to normative influence is the conforming to the norms of the group when buying products and susceptibility to informational influence is gathering data from the group or monitoring the group for the products they generally buy. Some papers use both dimensions indicating multidimensionality (Balabanis and Diamantopoulos, 2016; Siamagka and Balabanis, 2015) while others use only the susceptibility to normative influence dimension (Alden, Steenkamp and Batra, 2006; Phau and Teah, 2009; Kastanakis and Balabanis, 2012). Balabanis and Diamantopoulos (2016) empirically tested the relationship between xenocentrism and susceptibility to interpersonal influence (of which normative influence is one dimension) and found the constructs to be positively related. Thus, peer pressure and views held by one's group are associated with xenocentrism.

Vigneron and Johnson (1999) argue that perceived social value is one of the most important aspects when making a decision to buy products that are attributed with prestige. Thus, it is no surprise that xenocentrism is associated with both status and normative influence from the extant literature. 
Some scholars may argue that xenocentrism is just another name for COO. However, I argue that xenocentrism and $\mathrm{COO}$ are two distinct constructs. The differences between the constructs are listed below in Table 2.3.

Table 2.3: COO vs xenocentrism differences

\begin{tabular}{|c|c|c|}
\hline S.no. & $\mathrm{COO}$ & Xenocentrism \\
\hline 1.) & $\begin{array}{l}\text { COO is based on perceived product } \\
\text { quality. Thus, COO is grounded in } \\
\text { utilitarian consumption (Verlegh } \\
\text { and Steenkamp, } \\
\text { Papadopoulos, 1999). }\end{array}$ & $\begin{array}{l}\text { Xenocentrism is based on emotion. Thus, } \\
\text { xenocentrism is grounded in hedonic } \\
\text { consumption (Mueller et al., 2016; de } \\
\text { Leff, 2002; Kent and Burnight, 1951). }\end{array}$ \\
\hline 2.) & $\begin{array}{l}\text { COO is an extrinsic cue. Some } \\
\text { examples are a country's name or } \\
\text { flag, a country's landmark or people } \\
\text { on a product's packaging } \\
\text { (Papadopoulos, 1999). }\end{array}$ & $\begin{array}{l}\text { Xenocentrism does not involve an } \\
\text { extrinsic cue. In fact, it is based on an } \\
\text { internal process of augmenting one's } \\
\text { status and keeping up with the social } \\
\text { norms by rejecting the local and } \\
\text { preferring foreign products (Mueller et } \\
\text { al., 2016; Rojas-Méndez and Chapa, } \\
\text { 2019; Balabanis and Diamantopoulos, } \\
\text { 2016; Prince et al., 2016; Kala and } \\
\text { Chaubey, 2016; }\end{array}$ \\
\hline
\end{tabular}




\begin{tabular}{|c|c|c|}
\hline & & $\begin{array}{l}\text { Mueller and Broderick, 2009; } \\
\text { Asakitikpi, 2016; Wallach, 2012). }\end{array}$ \\
\hline 3.) & $\begin{array}{l}\text { COO involves associating one } \\
\text { product or service to one country/ } \\
\text { regions of countries. Examples: } \\
\text { Scotch whiskey or German } \\
\text { engineering (Papadopoulos, 1999). }\end{array}$ & $\begin{array}{l}\text { Xenocentrism is a preference for } \\
\text { Western, developed countries in general } \\
\text { and not necessarily an association with a } \\
\text { specific country. Xenocentrism has also } \\
\text { been found with respect to a variety of } \\
\text { products such as mobile phones, } \\
\text { alcoholic beverages, home appliances, } \\
\text { cars and sportswear (Balabanis and } \\
\text { Diamantopoulos, 2016; Rojas-Méndez } \\
\text { and Chapa, 2019) to name a few. Thus, } \\
\text { xenocentrism involves many products } \\
\text { and many countries. Furthermore, } \\
\text { xenocentrism has also been found in } \\
\text { other aspects of life such as education } \\
\text { language choices and naming of children } \\
\text { de Leff, 2002; Gerson, 2004). }\end{array}$ \\
\hline
\end{tabular}

In sum, table 2.3 lists the three main differences between $\mathrm{COO}$ and xenocentrism. Unlike COO, xenocentrism is based on hedonic consumption, is an internal process and involves preference for foreign products in general. These differences provide support for the standpoint that xenocentrism and COO are separate constructs. 


\subsection{Expert interviews}

In addition to the extant literature review, expert interviews were conducted to better understand xenocentrism as it is an understudied concept in international business and marketing. Specifically, interviews were conducted with experts in five different disciplines in an attempt to understand how this phenomenon is explained from those disciplines. The fields in which interviews were conducted are sociology, economics, anthropology, political science and psychology. Following are some details of the different experts' profiles:

1.) Associate professor in economics at Carleton University with research interests in behavioral and experimental economics. The professor is an expert on how psychology and economics interact.

2.) Full professor in anthropology at Carleton University with research interests in Africa, globalization and colonization.

3.) Full professor in political science at Carleton University with research interests in Latin America and globalization.

4.) Associate professor in sociology at Carleton University with research interests in social relations and media.

5.) Instructor in psychology at Carleton University with research interest in social psychology.

The duration of each interview was approximately half an hour. The concept of xenocentrism was briefly explained to the interviewees. Then the interview protocol shown in figure 2.1 was used. 
Figure 2.1: Interview Protocol

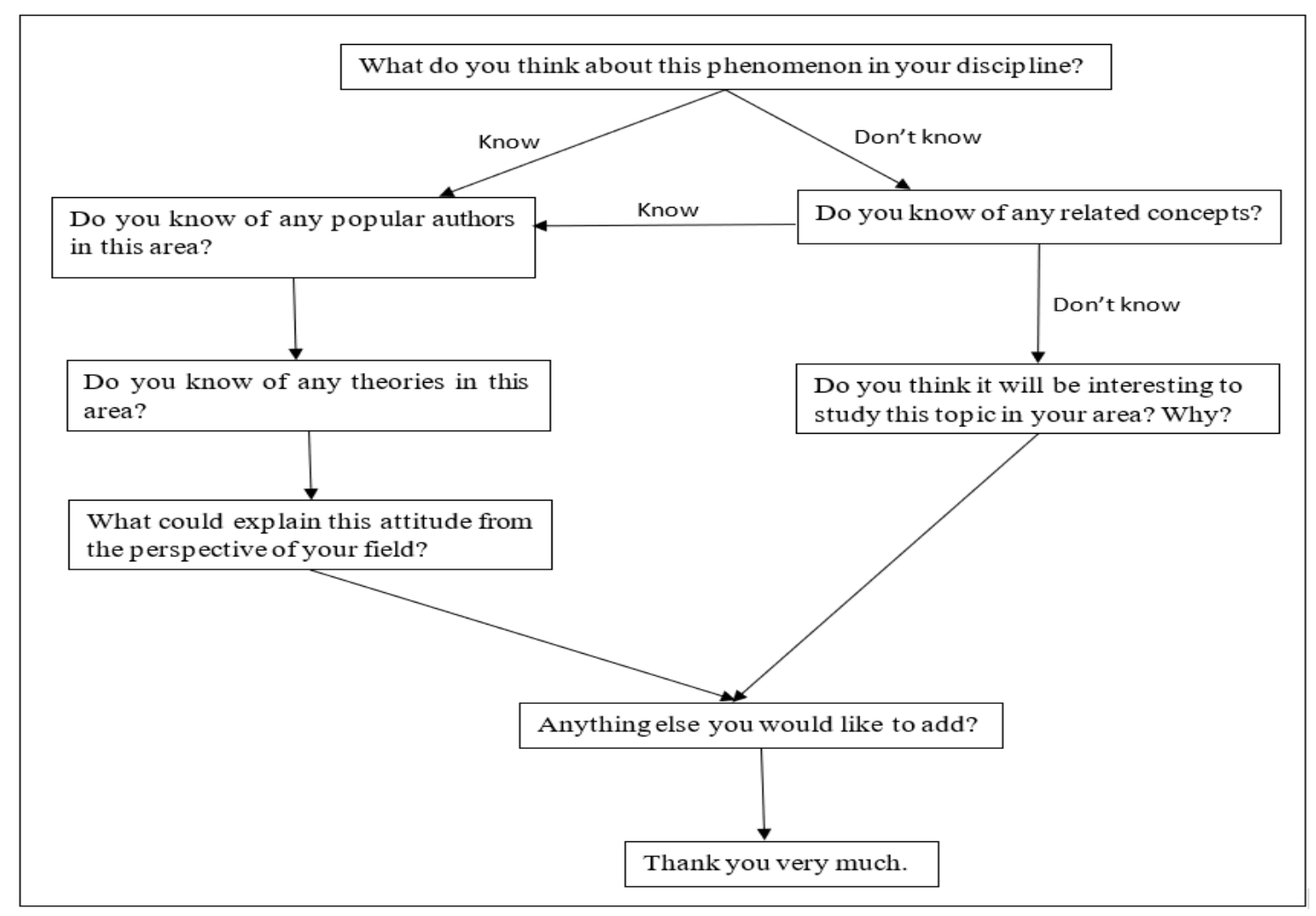

The outcome of these interviews was the identification of multiple theories and concepts from the various disciplines that have been incorporated throughout this thesis. The need for status came up in many discussions. Additionally, signaling theory from economics and reference group theory was suggested by the experts. The laissez-faire kind of economic system which is similar to worldmindedness was also proposed during an interview. The term "mediascapes", "colonial hangover" and the potential presence of consumer xenocentrism in former colonies (see more about these concepts in sections 5.3.5 and 2.8.7) was discussed. Consumer xenocentrism in the field of music and thus a preference of Western music in developing countries was also suggested. 


\subsection{Theories that support xenocentrism}

This section will review the theories on which consumer xenocentrism is based. It will also discuss how xenocentrism is related to each theory. The theories come from the fields of social psychology, sociology, psychology and economics.

\subsubsection{System justification theory}

This is the dominant theory from social psychology explaining xenocentrism (Rojas-Méndez and Chapa, 2019; Balabanis and Diamantopoulos, 2016). This theory explains the phenomena of inferiority of the in-group (one's country) and perceived superiority of the out-group (foreign country). Low-status groups (such as the ones in developing countries) accept their status and thus this leads to evaluating themselves in an inferior manner (Jost and Banaji, 1994; Rojas-Méndez and Chapa, 2019). Members of lowstatus groups (i.e. groups that are low in things such as resources, wealth and economic status), display rejection of their own group and favoritism towards the out-group to the degree that they perceive such differences to be reasonable (Jost and Burgess 2000). This kind of behavior also helps people in low-status groups deal with the inequalities in the world (Jost and Hunyady, 2005). Perceived inferiority of one's own group creates a yearning to increase one's own status and one of the ways this is achieved is by owning goods high in status (Sivanathan and Pettit 2010). Since foreign products are perceived to be high in status by individuals in the developing world, this situation gives rise to xenocentrism.

The social identity theory on which ethnocentrism is based is only able to explain in-group favoritism and out-group derogation (Tajfel and Turner, 1986) and not vice-versa. 
System justification theory explains the opposite effect. Thus, in social identity theory the in-group is viewed favorably and in system justification theory the out-group is viewed more favorably.

\subsubsection{Social dominance orientation}

Balabanis and Diamantopoulos (2016) found xenocentrism to be positively associated with social dominance orientation (SDO). SDO is a construct from social psychology. Individuals with high SDO prefer hierarchy between groups as opposed to equality (Pratto, Sidanius, Stallworth and Malle, 1994). SDO is similar to system justification and high power distance constructs in that all these constructs deal with inequalities in social groups. The difference between the constructs is that SDO is at an individual level as opposed to system justification theory and power distance which are at a group level. Also, in high SDO the individual prefers the inequality whereas in system justification and high power distance the groups accept the inequality.

\subsubsection{Reference group theory}

Reference group theory (Merton and Rossi, 1950; Merton, 1957a) is from sociology and this theory suggests that people evaluate themselves with their social group and their attitude and behavior is influenced by that group. This social group is called the reference group and an out-group can also serve as a reference group (Druckman, 1994). Thus, countries other than one's own can also serve as the reference group and the members of the group will try to espouse the values of that foreign country rejecting one's country's values (Druckman, 1994). In our case, this can translate to individuals from the developing 
countries buying foreign products to emulate their reference group (foreign countries) and rejecting their own products.

Balabanis and Diamantopoulos (2016) argue that individuals who are susceptible to interpersonal influence are more inclined to follow the reference group. Thus, this effect is likely to be higher in collectivistic cultures where the pressure to conform to social norms is high. Also, Vigneron and Johnson (1999) assert that reference group theory explains the primary reason why people consume products for prestige. As there is a potential link between xenocentrism and status, this theory is relevant for our context.

\subsubsection{Social comparison theory}

Xenocentrism has also been argued to be based on social comparison theory (RojasMéndez and Chapa, 2019). This theory comes from social psychology. Festinger's (1954) social comparison theory states that as human beings we have a need to judge our opinions with that of others. Not all groups are equal though. The opinions of more attractive groups will be more valuable than other groups. Developed countries are seen as high-status groups because of their better lifestyle and infrastructure to name a few. Thus, owning foreign products helps one identify with that attractive group. Another way this theory applies to xenocentrism is that within the country itself there can be a successful group that one finds attractive. In order to be associated with them one can compare their opinions and attitudes with those successful groups. And if possessing foreign products is the norm in that group, then the person in order to associate with that group will buy foreign products. Even if one initially has a different opinion to that of a successful group, the attraction to the successful group will aid in him changing his opinion to match that of the attractive group (Festinger, 1954). 


\subsubsection{Symbolic self-completion theory}

This theory comes from the field of psychology. Symbolic self-completion theory states that consumers use and exhibit symbols that are associated with their ideal self (Wicklund and Gollwitzer, 1982). This can be translated to owning foreign products which is associated with being successful or well-placed in a society (ideal self) in a low-status group such as a developing country. "Products can be viewed as symbols of completeness... When someone is low in a symbolic dimension, (s)he will try to substitute it with an alternative symbol of completeness" (Balabanis and Diamantopoulos, 2016, p. 61). For example, the Old Spice, "Smell like a man, man" campaign (Procter and Gamble, 2010) reached out to consumers for whom being masculine (symbolic dimension) was an aspect of the ideal self. This deodorant enabled them to increase their masculinity by using Old Spice. Thus, the deodorant acts as a "symbol of completeness" in this example. This type of behavior can be further extended to people who buy objects that denote status (such as foreign products in emerging markets) and those products can act as a symbol of completeness to help them reach their high-status ideal self.

\subsubsection{Signaling theory}

This theory comes from the field of economics. There is a belief that one party (seller) has greater information about a tangible or intangible object than the other party (buyer) and thus there is information asymmetry (Akdeniz and Talay, 2013). Spence's (1973) signaling theory was based on the interaction between the employer and the prospective employee or the job applicant. The job applicant's worth is not known to the employer, but it is known to the job applicant and thus there is an information asymmetry. 
The job applicant's educational degree acts as a signal in transmitting the applicant's worth to the employer and the employer in turn offers a higher salary to this job applicant. The signal is used to decrease the uncertainty for the employer and also consequently reduce the information asymmetry between the two parties (Magnusson et al., 2015; Schmid and Dauth, 2014). Therefore, signaling theory deals with transmitting some information about oneself reliably to another person or group.

Relating this theory to consumer xenocentrism, an individual might be successful but other individuals in the society may not know about his success and thus there is information asymmetry. Possessing and showing foreign goods reduces information asymmetry by serving as a signal in transmitting the individual's success to others. In turn, the people in the group award this successful individual with a higher status or rank in the society (Eastman et al., 1999).

\subsubsection{Theory of the leisure class}

Theory of the leisure class (Veblen, 1899) is a socio-economic theory. Leisure class refers to the high-income individuals in a society. Veblen (1899) argues that individuals give much importance to status and that status is displayed using possessions. Veblen (1899, p.36) states that, "In order to gain and to hold the esteem of men it is not sufficient merely to possess wealth or power. The wealth or power must be put in evidence, for esteem is awarded only on evidence". That is, the act of displaying expensive possessions to acquire status helps the individuals gain respect and envy from others (Gaur et al., 2015; Kastanakis and Balabanis, 2012; Braun and Wickund, 1989). 
In the traditional supply-demand curve in economics as price increases, the demand for the product decreases but with respect to Veblen's (1899) theory as price increases, the product is more appealing because of the status associated with an expensive product (Braun and Wickund, 1989). "Veblen effect" occurs when individuals are willing to pay a premium price for a product even when other functionally similar products exist in the market (Bagwell and Bernheim, 1996; Gaur et al., 2015). This can be equated to consumer xenocentrism where individuals often purchase foreign products even when cheaper and functionally equivalent domestic alternatives are available.

Veblen (1899) describes two kinds of status consumptions - Invidious comparison and Pecuniary emulation. He argues that invidious comparison happens when the higherincome individuals publicly consume expensive products to show their status and distinguish themselves from the lower-income individuals. With respect to consumer xenocentrism, this can relate to higher-income individuals in developing countries consuming foreign products to separate themselves from the lower-income individuals in their society. On the other hand, Veblen (1899) claims that pecuniary emulation happens when lower-income individuals publicly consume expensive goods so that they are presumed to be higher-income individuals. In terms of consumer xenocentrism, this can be seen in individuals of the developing countries trying to emulate the individuals from the developed countries to be seen at the same level. Another way to relate this to xenocentrism is that lower-income individuals in developing countries might consume counterfeits of foreign products to be considered as a higher-income individual in their group and thus gain some status. 
Figure 2.2 below illustrates consumer xenocentrism and all the relevant theories discussed above.

Figure 2.2: Consumer xenocentrism and related theories

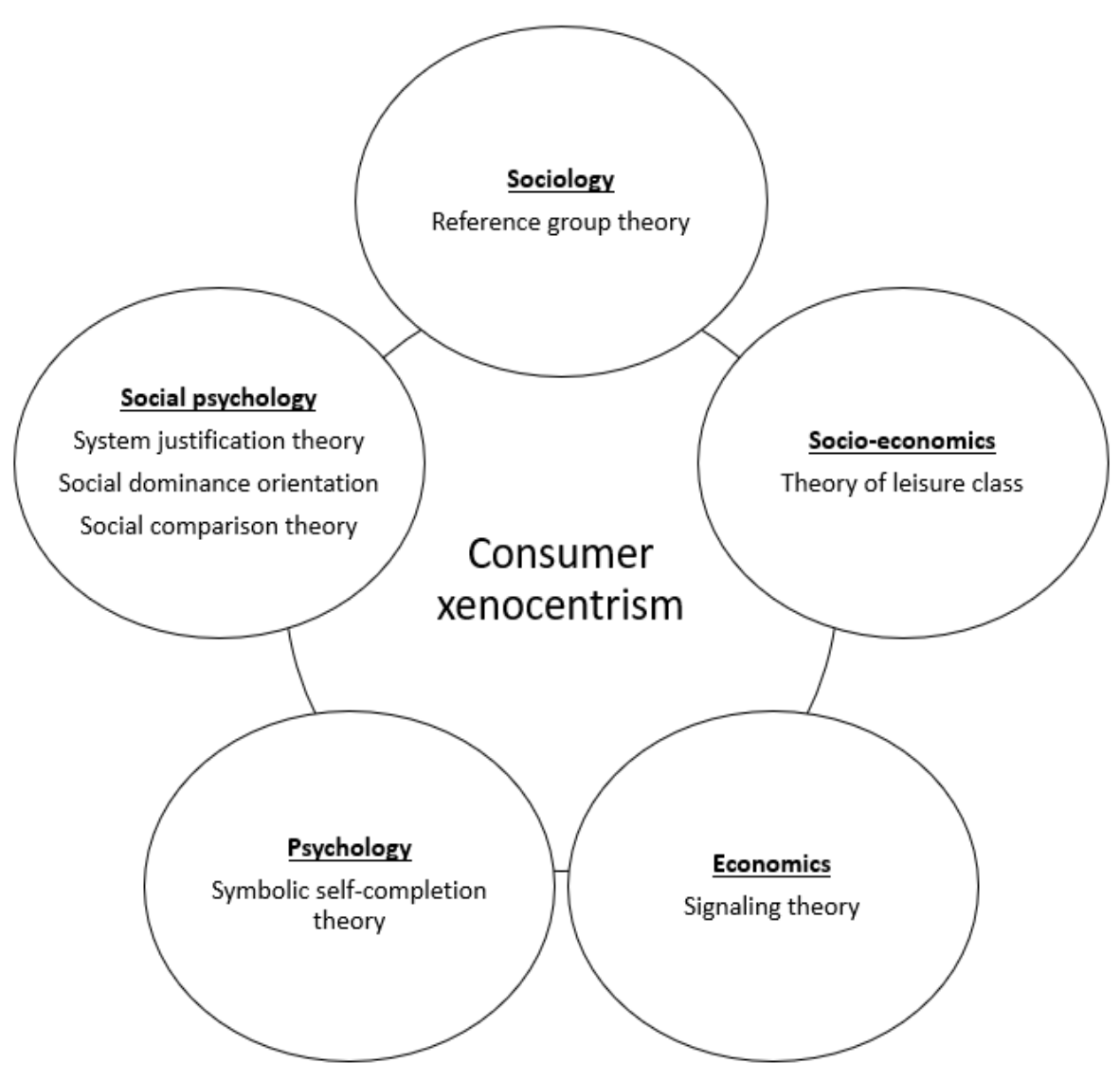

2.8 Who are the expected xenocentric consumers?

This section discusses the types of individuals who are most likely to be xenocentric according to the extant literature.

\subsubsection{High income consumers}

A number of studies spanning different continents across countries such as China, Tanzania and Mexico have found that consumers with higher income and those that belong 
to the higher socio-economic class are more xenocentric (Mueller et al., 2016; Bailey and de Pineres, 1997; Kisawike, 2015). One of the reasons that xenocentric consumers are usually consumers with higher income is because they can afford to buy expensive foreign products and brands (Mueller et al., 2016). Also, as owning foreign products are seen as a sign of success (Balabanis and Diamantopoulos, 2016), successful, high-income individuals would like to show their status by acquiring and displaying foreign products. Conversely, low-income consumers have also been found to be using lower-priced foreign products and counterfeits to display their status (Mueller and Broderick, 2009) but xenocentrism is likely to be higher for high-income consumers (Mueller et al., 2016; Bailey and de Pineres, 1997; Kisawike, 2015).

\subsubsection{Consumers who disagree with national government}

Xenocentrics are also people who rebel against the politics or economic policies of their home country (Kent and Burnight, 1951; Lawrence 2012; Mueller and Broderick, 2009). Those unhappy with their country's policies might idealize or be attracted to another country (Belk, 1982; Lawrence, 2012). As an example, Americans opposing the US Vietnam war largely boycotted US products preferring foreign products (Belk, 1982). This kind of buying is also called oppositional buying (Lawrence, 2012). Another example of oppositional buying was seen in former communist Eastern Europe where buying and using foreign products was seen as a way to rebel against the communist system and to idealize the political values of the Western world (Bar-Haim, 1987). Self-determination theory (Ryan and Deci, 2000) states that autonomy and relatedness are two human psychological needs. People who rebel against their country's policies and hence are independent thinkers (autonomy), look for relatedness or a sense of belonging with other countries and hence 
buy their products. This thesis will not be touching on the cause of rebellious nature on consumer xenocentrism. Rather the focus will only be primarily on the role of social causes of xenocentrism such as status and susceptibility to normative influence. Rebellious nature of individuals leading to xenocentrism can contribute to a future study.

\subsubsection{Younger consumers}

A number of studies have found younger consumers to be more xenocentric than older consumers (Bailey and de Pineres, 1997; Mueller et al., 2016; Kisawike, 2015; Prince et al., 2016). Younger consumers tend to be xenocentric because they consider it as a way to show their freedom (Kent and Burnight, 1951). As a case in point, in China it was found that younger consumers bought foreign goods as a means to rebel against authority (Mueller et al., 2016). Additionally, younger consumers can also be more xenocentric because they have more exposure to foreign cultures (Lawrence, 2012; Kent and Burnight, 1951). In this study, the exposure to foreign cultures will be focused on, but as mentioned in the previous sub-section the cause of rebellious nature on consumer xenocentrism will not be examined.

\subsubsection{Consumers with exposure to other cultures}

Consumers who are exposed to foreign cultures are expected to be more xenocentric than those who are not, and usually younger consumers are more exposed to foreign cultures (Kent and Burnight, 1951; Lawrence, 2012). Those who are educated abroad, work in a multinational company or have foreign connections are more likely to be xenocentric and thus buy foreign goods (Mueller et al., 2016). 


\subsubsection{White-collar employees and higher education consumers}

White-collar employees and those with higher education were also found to be more xenocentric (Mueller et al., 2016; Bailey and de Pineres, 1997). This is in sharp contrast to blue-collar employees and those with lower levels of education being more ethnocentric (Klein and Ettensoe, 1999; Lee et al., 2003; de Ruyter, van Birgelen and Wetzels, 1998).

\subsubsection{Consumers in emerging economies}

Xenocentrism is predominantly found in the developing world (Mueller et al., 2016; Balabanis and Diamantopoulos, 2016; Mueller and Broderick, 2009; Soto, 2008; RojasMéndez and Chapa, 2019). A superior view of the Western, more developed countries and a rejection towards their own local culture has been found in Africa, Latin America and parts of Asia (e.g. Mueller and Broderick, 2009; Batra et al., 2000; Bailey and de Pineres, 1997; Waithaka, 2017). Consumers in emerging economies preferred foreign products over local ones even when the local ones were better in quality and priced lower (Mueller and Broderick, 2009; van Herk and Torelli, 2017; Mueller et al., 2016).

Using foreign products is associated with signaling of status, prosperity and modernity in developing countries (Mueller et al., 2016). Also, people in general mimic successful groups (Mueller and Broderick, 2009). Thus, consumers in the emerging economies who look up to the Western, developed world try to emulate the consumption choices of the developed countries. Owning foreign products helps consumers in the developing countries to associate themselves with the affluent lifestyles of the developed countries (Rojas-Méndez and Chapa, 2017). Additionally, foreign product bias can be 
linked to the pursuit of making one's life better (Mueller and Broderick, 2009). For the consumer of the developing world, thus, the foreign products also signify an aspiration to be like the individuals in developed countries and to improve one's quality of life (Mueller and Broderick, 2009).

\subsubsection{Consumers in former colonies}

Xenocentrism is also found to be very prevalent in former colonies (Wallach, 2002; Mueller and Broderick, 2009). The perceived inferiority on one's culture and the superiority of the colonizers' way of life could be associated with the colonial influence. In other words, colonization has contributed to inferior self-image and overestimating the West (Mueller and Broderick, 2009). This is also termed as the "colonial hangover" (Bashkow, 2006). In turn, this attitude can be linked to the rejection of local goods and the preference for foreign ones (Balabanis and Diamantopoulos, 2016; Batra et al., 2000; Aleksic, 2002).

\subsubsection{Marginalized people}

Marginalized people in a society are also argued to be xenocentric. Such people feel that they do not belong to their national group or in extreme cases they might even feel ignored by their national group and in an attempt to rebel, associate themselves with an out-group (foreign countries) and thus are xenocentric (Prince et al., 2016; Kent and Burnight, 1951).

\subsubsection{Gender}

Rojas-Méndez and Kolotylo (2018) found that men are more xenocentric than women. This can due to gender equalities in developing countries where men usually 
occupy more influential positions and thus their social standing is more important to them.

On the other hand, Mueller and Broderick (2009) argue that women may be more xenocentric than men, but this is only a theoretical paper compared to Rojas-Méndez and Kolotylo (2018) which tested the relationship.

Figure 2.3 summarizes the types of consumers who are most likely to be xenocentric.

Figure 2.3: Xenocentric consumers

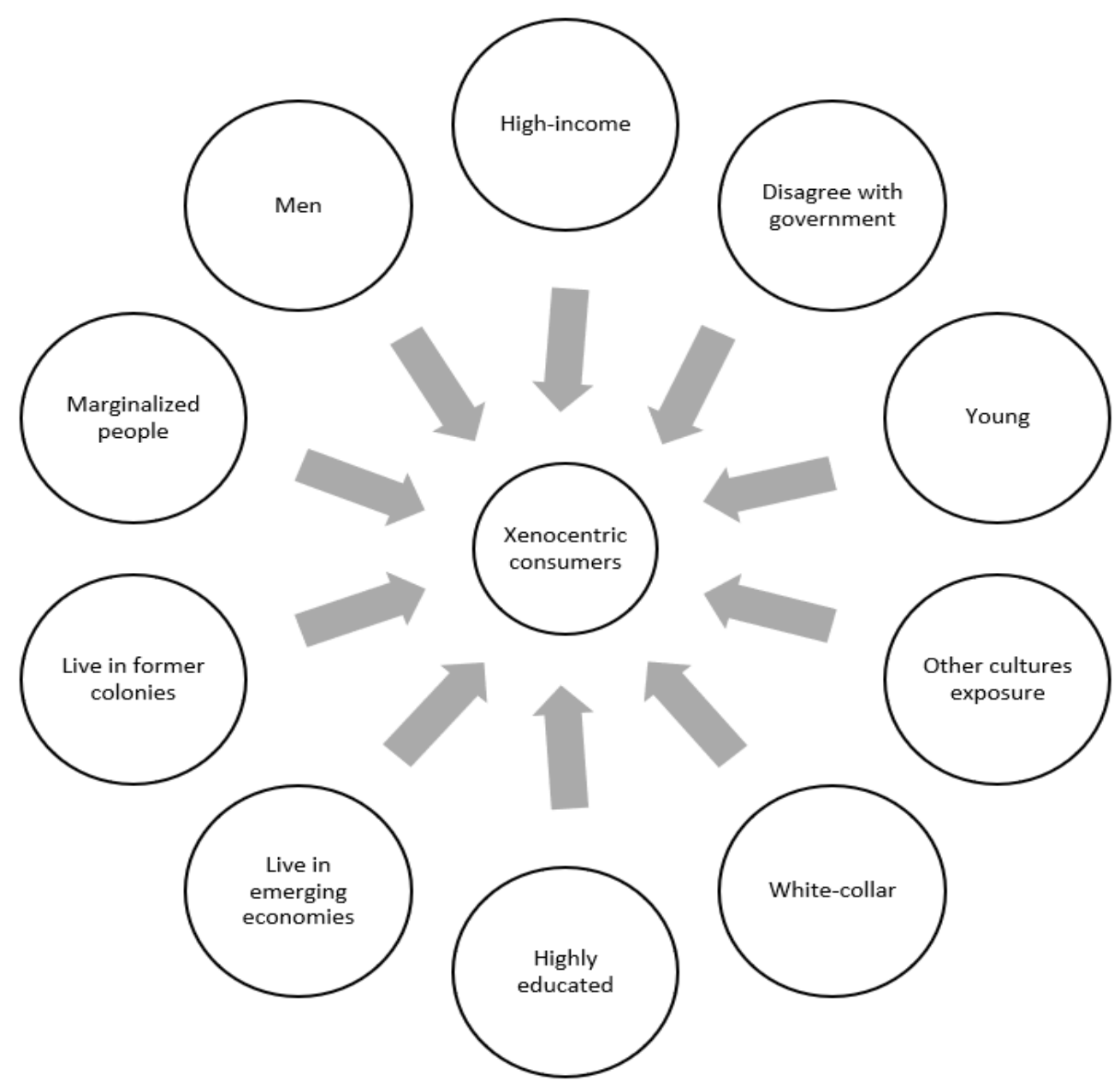




\subsection{Xenocentrism scales}

While on one hand there have been studies on consumer xenocentrism that are theoretical or qualitative (Mueller et al., 2016; Muller and Broderick, 2009; Kisawike, 2015), there have also been a few studies which have attempted to measure the construct. This section will analyze the different scales that have been developed / used to measure consumer xenocentrism in the extant literature. This section will also specify which scale is used in this thesis.

\subsubsection{Reversing CETSCALE scores}

CETSCALE, a unidimensional scale, is the most popular scale to measure consumer ethnocentrism (Shimp and Sharma, 1987) which is presented in Appendix A. A number of consumer xenocentrism papers have reverse interpreted the CETSCALE scores - i.e. a low score on the ethnocentrism scale means that the consumer is xenocentric, or reversing the CETSCALE items (Prince et al., 2016; Bailey and de Pineres, 1997; Soto, 2008). It might be incorrect to use the ethnocentrism scale scores in reverse to measure xenocentrism (Rojas-Méndez and Chapa, 2019) as someone who is not ethnocentric need not be xenocentric, they could be cosmopolitan or utilitarian or have any other consumer orientation. As an example, someone who does not agree to, "American products, first, last and foremost" (an item of the ethnocentric scale), can have any aforementioned consumer orientation and need not necessarily be xenocentric. Additionally, Rojas-Méndez and Chapa (2019) and Balabanis and Diamantopoulos (2016) both have developed xenocentrism scales that have two dimensions. Thus, xenocentrism is a multi-dimensional construct whereas ethnocentrism as per the CETSCALE is a unidimensional construct. Both Balabanis and Diamantopoulos (2016) and Rojas-Méndez and Chapa (2019) argue 
that ethnocentrism and xenocentrism are not two ends of the same continuum. Balabanis and Diamantopoulos (2016) emphasized three reasons for this argument 1.) Ethnocentrism and xenocentrism are both based on different theoretical backgrounds. While ethnocentrism is based on social identity theory, the dominant theory for xenocentrism is system justification theory. Social identity theory cannot explain xenocentrism because according to this theory low-status groups will also evaluate their group positively and outgroups negatively. Thus, xenocentrism is explained by system justification theory which argues that low status groups accept their alleged inferiority and favor high-status out-groups. 2.) The two constructs are driven by different motives (i.e. ethnocentrism is driven by moral responsibility to buy domestic products while xenocentrism is driven by the need for social aggrandizement) 3.) Ethnocentrism and xenocentrism can co-exist in the same country proving that theses constructs are not mutually exclusive. This view is also shared by Prince et al. (2016) who argue that ethnocentrism and xenocentrism can be present in the same society as one nation can feel superior to some countries and inferior to others. Thus, xenocentrism and ethnocentrism are not polar opposites. Hence, for all the above reasons, reversing the CETSCALE may not be the appropriate way to measure xenocentrism.

\subsubsection{C-XENSCALE}

Balabanis and Diamantopoulos (2016) have proposed the C-XENSCALE to measure consumer xenocentrism. The scale has two dimensions - perceived inferiority and social aggrandizement. Perceived inferiority is one of the main characteristics of consumer xenocentrism. The second dimension social aggrandizement, I would argue, does not constitute part of the consumer xenocentrism construct. Consumer xenocentrism is the 
rejection of domestic goods and the preference of foreign ones (Kent and Burnight, 1951; Balabanis and Diamantopoulos, 2016; Perlmutter, 1954; Kala and Chaubey, 2016). Social aggrandizement might be the cause/antecedent of xenocentrism, not part of the construct itself. For this reason, this consumer xenocentrism scale will not be used in this thesis.

C-XENSCALE scale is presented below:

(strongly agree $=7$, strongly disagree $=1$ )

\section{Perceived Inferiority}

1. There are very few domestic products that are of equal quality to foreign products.

2. I cannot think of any domestic brands that are as good as the foreign ones I purchase.

3. I trust more foreign than domestic companies, because they are more experienced and have more resources.

4. In most product categories, foreign brands outperform domestic ones.

5. I trust foreign products more than the domestic ones.

\section{Social Aggrandizement}

1. Using foreign products enhances my self-esteem.

2. People that buy domestic products are less regarded by others.

3. I prefer foreign to domestic brands as most of my acquaintances buy foreign brands.

4. Buying foreign products makes me trendier.

5. I purchase foreign brands to differentiate myself from others. 


\subsubsection{CXENO}

CXENO is the unidimensional consumer xenocentrism scale developed by Lawrence (2012). It has been used by Prince et al. (2016) to validate the consumer xenocentrism scale used in their study. CXENO was the first scale developed to measure the consumer xenocentrism construct. The scale focuses solely on foreign product bias and there is no item that measures domestic rejection which is a key consumer xenocentrism dimension. This is the dimension that differentiates it from the other positive foreign bias constructs. Furthermore, both the Rojas-Méndez and Chapa (2019) and the Balabanis and Diamantopoulos (2016) xenocentrism scales conceptualize consumer xenocentrism as a two-dimensional construct. Also, this scale was developed and validated only in one developed country (the US), however, consumer xenocentrism is more prevalent in emerging and transitional economies. For all the above reasons this consumer xenocentrism scale will not be used in this thesis.

CXENO scale is presented below:

$(1=$ Strongly Disagree to $5=$ Strongly Agree $)$

1. I prefer to buy foreign made products.

2. All other things being equal, I prefer to buy foreign products.

3. I find that I enjoy using foreign made products more so than products made in the U.S. 4. I get a better feeling from buying a foreign made-made product than from buying one that is made in the U.S.

5. Compared to the U.S. there are many other countries I prefer to buy from.

6. I feel better about buying most foreign products than American-made products. 


\subsubsection{X-Scale}

This scale proposed by Rojas-Méndez and Chapa (2019) is used to measure consumer xenocentrism. The two factors for consumer xenocentrism are domestic rejection and foreign admiration. This scale is apt to use for this thesis because xenocentrism is not just foreign admiration or purchase of foreign products. One of the main criterion that separates consumer xenocentrism from other positive foreign product bias constructs is the perceived inferiority of the domestic goods. This scale covers both the aspects of consumer xenocentrism and is essentially the best scale to measure the construct of all the scales currently available. It has very good reliability and validity and has been tested in several developing countries (China, Ecuador, Mexico, Peru and Colombia) where xenocentrism is predominant (Rojas-Méndez and Chapa, 2019).

$\mathrm{X}-\mathrm{Scale}$ is presented below:

$(1=$ strongly disagree and 5-strongly agree $)$

\section{Foreign Admiration}

1. I recommend foreign products to my friends and families.

2. I tend to prefer foreign products compared to national ones.

3. I admire foreign products.

4. I like buying products of foreign origin.

5. I value foreign products a lot.

\section{Domestic Rejection}

1. I tend to reject national products.

2. I think foreign products are superior to national products.

3. Generally, I don't value products made in my country. 
4. Sometimes I undervalue products made in my country.

5. Sometimes I feel embarrassed about products made in [COUNTRY NAME] when I compare them with similar products made in foreign countries.

Figure 2.4 displays all the consumer xenocentrism scales that have been discussed.

Figure 2.4: Consumer xenocentrism scales

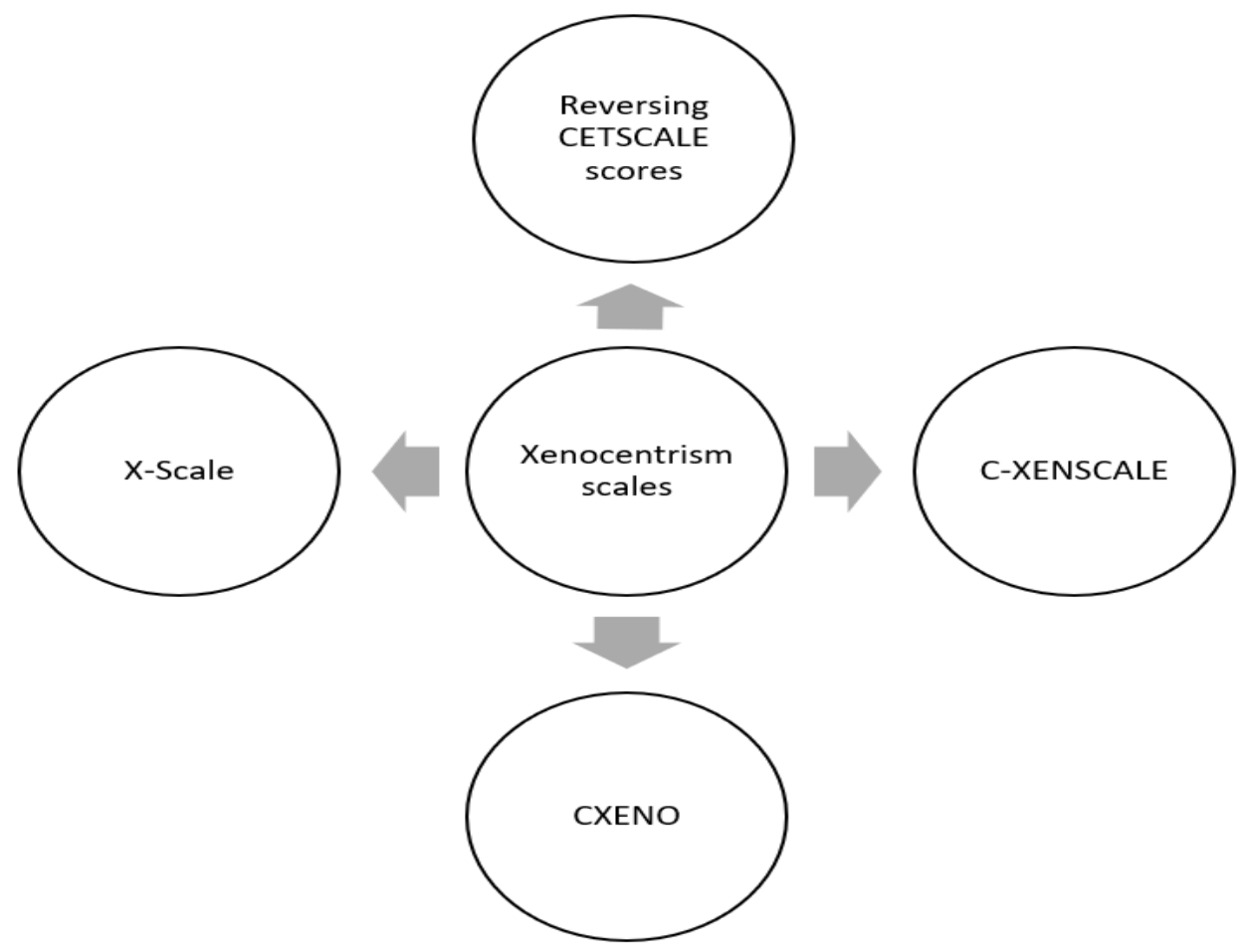

\subsection{Chapter summary}

This chapter included an overview of xenocentrism. Two recurrent themes in the xenocentrism extant literature, status and normative influence were discussed. Xenocentrism was differentiated from $\mathrm{COO}$ and the expert interview process was discussed. The various theories that support xenocentrism from different disciplines were explained. The types of individuals who are most likely to be xenocentric were reviewed. 
Finally, all the xenocentrism scales in the extant literature were assessed and the one that is used in this thesis was selected.

Overall, there has been consensus on what consumer xenocentrism is and it has been addressed in various fields by the same or a different name. It is also known that consumer xenocentrism is present in developing countries. However, although status and normative influence are the two main themes associated with consumer xenocentrism, these relationships are either yet to be empirically tested or only partially tested. Additionally, with respect to the types of individuals who are xenocentric (e.g. consumers with exposure to other cultures) much of the propositions are theoretical or exploratory study findings and have not been empirically tested. Thus, this thesis will empirically test these relationships (as antecedents and moderators) to further our understanding of the consumer xenocentrism construct. Currently, the few empirical studies that have been conducted on consumer xenocentrism have mostly been on establishing a scale for this construct. Thus, empirical research is needed on the antecedents, consequences, related constructs and moderators of consumer xenocentrism in order to get a deeper understating of the construct. These areas remain the focus of this thesis. To that end, the next chapter will discuss the potential antecedents of consumer xenocentrism. 


\section{CHAPTER THREE - ANTECEDENTS OF XENOCENTRISM}

\subsection{Introduction}

In this chapter the potential antecedents of consumer xenocentrism will be discussed. The theories associated with these antecedents will also be presented and the corresponding hypotheses will be set.

van Torelli and Herk (2017) and Balabanis and Diamantopoulos (2016) assert that antecedents to consumer xenocentrism should be researched. At the time of writing, there has been no study that examines the antecedents to consumer xenocentrism. However, Balabanis and Diamantopoulos (2016) test the correlation of consumer xenocentrism with the susceptibility to interpersonal influence construct to establish the validity of their scale and this construct could potentially be an antecedent to xenocentrism. Correlations only shows that the two constructs are related and not the dependencies between constructs. Thus, there is still a need to test this construct as an antecedent, if it is considered as such after reviewing its theoretical foundation.

\subsection{Theories on human needs}

This section will outline the important human needs theories from extant literature that is relevant to identifying the antecedents for this study.

McClelland's Human Motivation Theory or Three Needs Theory, from psychology (McClelland, 1961), suggests that humans have three motivating factors or needs namely the need for achievement, the need for affiliation and the need for power and that for each individual one of these factors is more dominant than others. This theory is also called the Acquired Needs theory because an individual's motivating factor is considered to be learnt 
based on his experiences and culture. The need for affiliation from McClelland's Three Needs Theory involves being accepted by one's group and conforming to the group norms. This aspect can be related to the proposed antecedents, collectivism and susceptibility to normative influence, which stress on the importance of belonging to the group and behaving according to the group norms. The need for power from McClelland's Three Needs Theory involves wanting to be influential and the need for status and recognition. This idea is in sync with the proposed antecedents high power distance and status consumption, which stress on power inequality and buying products to display status. McClelland's Three Needs Theory is the main theory that covers all the antecedents (other than demographics variables) that will be tested in this study.

Another motivation theory relevant to the proposed antecedents is the Sirota's three factor theory from organizational behavior (Sirota, Mischkind and Meltzer, 2005). According to this theory there are three motivating factors for employees in the workplace namely fairness, achievement and camaraderie. Camaraderie involves the importance given to interpersonal relationships and is similar to affiliation in the McClelland's Three Needs Theory. This aspect is in turn related to the proposed antecedents, collectivism and susceptibility to normative influence as discussed in the previous paragraph.

Still another motivation theory is Maslow's hierarchy of needs which is from the field of psychology (Maslow,1954). The theory puts forth five tiers of needs in a pyramid form ordered from the most essential to the least essential human need. The five needs are physiological (most essential), safety, belonging and love, esteem and self-actualization (least essential). Physiological needs such as food and water are the most basic needs for human beings. Next in the hierarchy are safety needs such as law and order. Further up in 
the hierarchy is belonging and love. This stage involves the importance of interpersonal relationships for a human being and the importance of acceptance in one's group. This idea is similar to affiliation in the McClelland's Three Needs Theory and camaraderie in the Sirota's three factor theory. Thus, this aspect is in-sync with the proposed antecedents, collectivism and susceptibility to normative influence as discussed in the two preceding paragraphs. Next in the hierarchy is esteem which corresponds to an individual's status or prestige. This factor is in-line with the need for power in McClelland's Three Needs Theory. This aspect is related with the proposed antecedents, high power distance and status consumption as mentioned previously. The highest need as described by Maslow is self-actualization which means realization of one's potential.

In sum, the four main antecedents proposed, culture (power distance, collectivism), status consumption and susceptibility to normative influence are strongly supported by the human needs theories. These antecedents were also finalized based on the themes from the consumer xenocentrism and foreign product preference extant literature. Additionally, the expert interviews in five disciplines also played a role in finalizing these antecedents.

Figure 3.1 succinctly illustrates the overall model for this thesis. The human needs theories, such as McClelland's Human Motivation Theory, are the driving factors for consumer xenocentrism. The constructs operationalized as antecedents are based on these theories as see in the second box in figure 3.1. Box 1 and 2 are the focus of this chapter. These constitute the antecedents of consumer xenocentrism and the underlying overall theory. The third box is the attitudinal consumer xenocentrism construct which is the positive evaluation towards buying foreign products/brands and negative evaluation towards buying domestic ones. Consumer xenocentrism and other constructs at the same 
level as it (called related constructs), will fall in box 3. This is analyzed in the related constructs chapter 4 . The intention and behavior are the consequences of consumer xenocentrism. They represent the probability of buying foreign products and the actual purchase. These last two boxes are elaborated in chapter 5 which is on the consequences of consumer xenocentrism. In short, this model suggests that human needs/motivations drive consumer xenocentrism (attitude) which in turn influences purchase intention of foreign products (intention) which has an effect on actual purchase of foreign products (behavior).

Figure 3.1: Overall model for this thesis

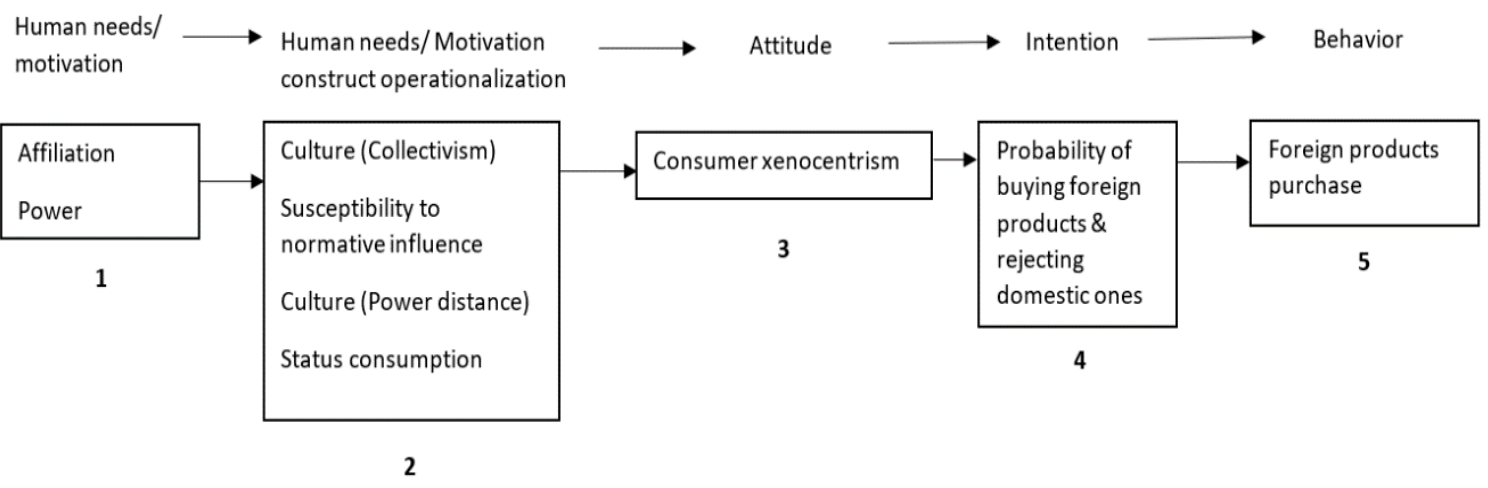

The following sections will discuss the potential antecedents to consumer xenocentrism (box 2 in figure 3.1) in greater depth.

\subsection{Culture}

This is the first antecedent that is proposed. Hofstede defines culture as the "collective mental programming of the human mind which distinguishes one group of people from another". (Hofstede, 2018b). It is the norms that are prevalent in a society 
(Furrer et al., 2000). Hofstede's cultural dimensions model quantifies the construct of culture. The model was developed from a world-wide large-scale survey. Hofstede and McCrae (2004) argue that Hofstede was one of the first researchers to show how a complex variable such as culture can be unloaded into simple and usable dimensions which is also versatile enough to be used across disciplines. They assert that culture is at the group (national) level and that it is seen in behavior of people in a society. Additionally, they argue that people get acquainted to the culture they live in as early as the initial ten years of their lives. Hofstede's cultural dimensions model has been extensively used in international marketing and management research (Sødergaard 1994; Furrer et al., 2000).

Hofstede and McCrae (2004) believe that Hofstede's cultural dimensions focused on the issues that every society face. The scores on the different dimensions only make sense on comparison between different cultures and cannot be used to predict or understand individual behavior (Hofstede, 2018b).

Each of the hypotheses with respect to the cultural dimensions discussed below are proposed after considering the level of development of the countries (i.e. only for developing countries as consumer xenocentrism is predominantly present there).

\section{Power distance}

This is one of Hofstede's cultural dimensions. Hofstede (2018c) defines this dimension as "the degree to which the less powerful members of a society accept and expect that power is distributed unequally". The dimension deals with the inequalities in a society (Minkov and Hofstede, 2011). Cultures that have a high power distance are hierarchical and those with low power distance are more equal societies. Individuals in 
high power distance societies expect and accept a hierarchical society and ones in low power distance societies attempt to minimize inequalities with respect to authority (Hofstede, 2018c). With respect to xenocentrism, high power distance societies are expected to be more xenocentric. This is because owning foreign goods/brands provides status and reinforces the hierarchy already present in these societies. Extant literature also shows that higher income, successful individuals (hence higher in the hierarchy) are more xenocentric (Mueller et al., 2016; Bailey and de Pineres, 1997; Kisawike, 2015). For members of high power distance societies, social status is considered utmost important (Rojas and Chapa, 2019) and Western brands are used for this purpose in those cultures (de Mooji, 2011). Additionally, Rojas-Méndez and Chapa (2019) and Balabanis and Diamantopoulos (2016) argue that hierarchical systems might influence xenocentrism. Taking together the above points, high power distance is expected to have a positive influence on consumer xenocentrism. Hence the following hypothesis is proposed:

H1: Power distance will have a positive effect on consumer xenocentrism.

\section{Collectivism/Individualism}

Collectivism is another one of Hofstede's cultural dimensions. "Collectivism, represents a preference for a tightly-knit framework in society in which individuals can expect their relatives or members of a particular ingroup to look after them in exchange for unquestioning loyalty." (Hofstede, 2018c). On the other hand, in individualistic cultures, members look after only themselves and their close family members (Hofstede, 2018c). Hofstede and McCrae (2004) argue that in collectivistic cultures the in-group bonds are stronger whereas in individualistic cultures the bonds are looser. 
According to Mueller et al. (2016) collectivistic cultures are more likely to be xenocentric. This is because in collectivistic cultures much importance is given to the social or symbolic significance of a product (Mueller and Broderick, 2009) and xenocentrism is related to symbolic consumption and not functionality of the product. Additionally, if the group norm is to be xenocentric, it is most likely to be followed in collectivistic cultures as tendency to follow group norms is greater in those cultures as they display stronger conformity (Bond and Smith, 1996). Since several developing countries seem to be both xenocentric and collectivistic, a relationship is expected between the two constructs. Thus, collectivism is expected to have a positive influence on consumer xenocentrism. Hence the following hypothesis is proposed:

H2: Collectivism will have a positive effect on consumer xenocentrism.

\subsection{Status consumption}

Eastman et al. (1999) describes status as the ranking of a person in a culture which is given by others. They argue that an individual spends immense effort in trying to earn status and that one of the ways to earn status is through consuming products that symbolize status. Eastman et al. (1999, p. 42) define status consumption as, "the motivational process by which individuals strive to improve their social standing through conspicuous consumption of consumer products that confer and symbolize status both for the individual and surrounding significant others". They argue that status consumption is not limited to the higher-income individuals and low-income consumers too consume for status. They assert that people consume this way to get acceptance from the group and be part of a group. This can be related to consumer xenocentrism with respect to people in developing countries consuming foreign products to emulate the individuals in the developed countries 
and be part of that group. It can also be related to people in developing countries consuming foreign products to be considered as part of the higher-income or successful group in their country. The association between status and consumer xenocentrism is one of the most frequently appearing themes in the extant literature (Rojas-Méndez and Chapa, 2019; Balabanis and Diamantopoulos, 2016; Prince et al., 2016; Kala and Chaubey, 2016; Mueller and Broderick, 2009), however this relationship is yet to be empirically tested.

Status consumption can be explained by the theory of leisure class which has already been covered briefly in section 2.7.7. Status consumption signifies consuming products for the purpose of displaying status. According to the theory of leisure class, individuals display status through their possessions and this act helps them gain respect from others.

Status consumption is associated with buying luxury products and counterfeits (Kastanakis and Balabanis, 2012; Phau and Teah, 2009). It is likely that high-income consumers can afford luxury products while lower-income consumers use counterfeits to show their status. In India, the cheapest car in the world, Tata Nano was rejected. A car is a status symbol in India and people did not want to be associated with a cheap car and were instead stretching their budgets to get a better car which provided them with higher status (BusinessInsider, 2011). Additionally, Gaur et al. (2015) argue that status consumption is displayed in Mexico where consumers preferred to indicate their status through consuming foreign brands. They add that several foreign brands only use English language in their advertising in Latin America to imply status. Therefore, consuming foreign products/brands has been associated with status. 
In sum, status consumption or consuming products to display status can be one of the prime motivations for consumer xenocentrism. Thus, it is expected that status consumption will have a positive influence on consumer xenocentrism. Hence the following hypothesis is proposed:

H3: Status consumption will have a positive effect on consumer xenocentrism.

\subsection{Susceptibility to normative influence}

Susceptibility to normative influence deals with conforming to the group's standards or expectations when purchasing products (Bearden, Netemeyer, and Teel, 1989). It involves being in line with the behavior and views of the group (Huang et al., 2010). Susceptibility to normative influence has been found to positively influence the animosity construct and also purchasing of luxury products (Huang et al., 2010; Kastanakis and Balabanis, 2012). Thus, this shows that susceptibility to normative influence can be an important predictor of both consumer attitudes and behavior.

Susceptibility to normative influence is based on the reference group theory from sociology which has already been covered briefly in section 2.7.3. According to the reference group theory an individual assesses himself with his group and the views and actions of that individual are significantly shaped by the group (Merton and Rossi, 1950; Merton, 1957a; Bearden and Etzel, 1982; Batra et al., 2000). The group has a large impact on the behavior of the individual (Batra et al., 2001). Hyman (1942) was the first scholar to use the term "reference group" and he argues that this is the group an individual compares himself to (Bearden and Etzel, 1982). 
Batra et al. (2000) argue that reference groups play a role in consumers buying foreign brands. They add that in developing countries, using foreign brands gives an individual status among his reference group and thus the individual is more likely to buy foreign products. The authors believe that buying foreign products augments the individual's self-image and helps him achieve acceptance within his group. An individual also sticks to the group norms to refrain from forming an undesirable image about himself (Wooten and Reed II, 2004). Thus, if xenocentrism is the reference group norm, then an individual is more likely to be xenocentric.

Susceptibility to normative influence has been proposed as an antecedent for constructs with a pro-foreign consumer orientation (Bartsch et al., 2016) and xenocentrism is a pro-foreign construct. Also, the association between xenocentrism and normative influence is the second most frequently appearing theme in the extant literature and is discussed in section 2.4. Several authors have mentioned this relationship (Mueller et al., 2016; Rojas-Méndez and Chapa, 2019; Balabanis and Diamantopoulos, 2016). Only Balabanis and Diamantopoulos (2016) have verified this relationship statistically and found that susceptibility to normative influence and xenocentrism are positively related. However, they only do a correlation and thus the dependencies between the two constructs has not been discussed deeply. Taking together the above points, there is a need to test the relationship between susceptibility to normative influence and xenocentrism.

It is expected that susceptibility to normative influence will positively influence consumer xenocentrism. This is because 1.) Several authors acknowledge the positive link between the two constructs 2.) Since xenocentrism is expected to be prevalent in developing and transitional countries, it is possible that an individual's reference group in 
those countries is xenocentric or believed to be higher in position and this is likely to make the individual xenocentric as well. Hence the following hypothesis is proposed:

H4: Susceptibility to normative influence will have a positive effect on consumer xenocentrism

In sum, the proposed antecedents to consumer xenocentrism, culture (power distance and collectivism), status consumption and susceptibility to normative influence are strongly supported by the human needs theories from the extant literature. In particular, with respect to the McClelland's human motivation theory, two of the three main human motivation factors namely affiliation and power are very much relevant with respect to why people are xenocentric (in other words the antecedents to consumer xenocentrism). Additionally, each antecedent is also backed by support from the consumer xenocentrism extant literature.

\subsection{Other antecedents}

Demographic variables such as age, education, gender and exposure to other cultures (through global media and international travel) will also serve as antecedents. In addition, antecedents can play the role of moderators. An antecedent causes a phenomenon (in this case consumer xenocentrism) while a moderator increases or decrease the effect of an independent variable on a dependent variable (in this case, the independent variable is xenocentrism and dependent variable is the consequence or outcome of xenocentrism). The testing of variables as both an antecedent and a moderator has been previously carried out in studies when theoretically supported (e.g. Josiassen et al., 2011). Since there is support from the extant literature that this could possibly be the case for consumer xenocentrism, 
almost all the demographic variables will serve as both antecedents and moderators. I will only briefly touch on the demographics antecedent relationships here because elaborate explanations for these relationships can be found in the consequences and moderators chapter 5 .

Younger people are expected to be more xenocentric. This is because they believe it is a way to display their freedom (Kent and Burnight, 1951; Mueller et al., 2016). Nowadays, younger people also have more exposure to foreign cultures (Lawrence, 2012). Hence the following hypothesis is proposed:

H5: As age increases, the impact of consumer xenocentrism will lessen.

Individuals with higher education level are expected to be more xenocentric (Bailey and Pineres, 1997; Kisawike, 2015). This is because such individuals have higher exposure to foreign cultures through work, travel or study. Hence the following hypothesis is proposed:

H6: As education level increases, the impact of consumer xenocentrism will increase.

With respect to gender, males are expected to be more xenocentric (Rojas-Méndez and Kolotylo, 2018). This is because due to inequalities in the society, men usually occupy more powerful positions and thus status is more important to them. Hence the following hypothesis is proposed:

H7: Gender (Males) will have a positive effect on consumer xenocentrism.

Individuals with more exposure to other cultures are expected to be more xenocentric (Kent and Burnight, 1951; Lawrence, 2012; Mueller et al., 2016). This is 
because exposure to other cultures creates images of consumption practices in foreign countries and the related superior lifestyle that comes with it and people in developing countries emulate those consumption practices which leads to consumer xenocentrism. Exposure to other cultures will be measured in two ways: global media exposure and international travel experience/preference. Global media exposure involves exposure to other cultures when staying at home whereas international travel experience/preference involves exposure to other cultures when traveling outside of the home country. The following hypotheses are proposed:

H8: Exposure to global media will have a positive effect on consumer xenocentrism.

H9: International travel experience/preference will have a positive effect on consumer xenocentrism.

Figure 3.2 gives a pictorial representation of all the hypotheses that have been proposed in this chapter. Table 3.1 consolidates all the hypotheses established in this chapter. 
Figure 3.2: Conceptual model for antecedents

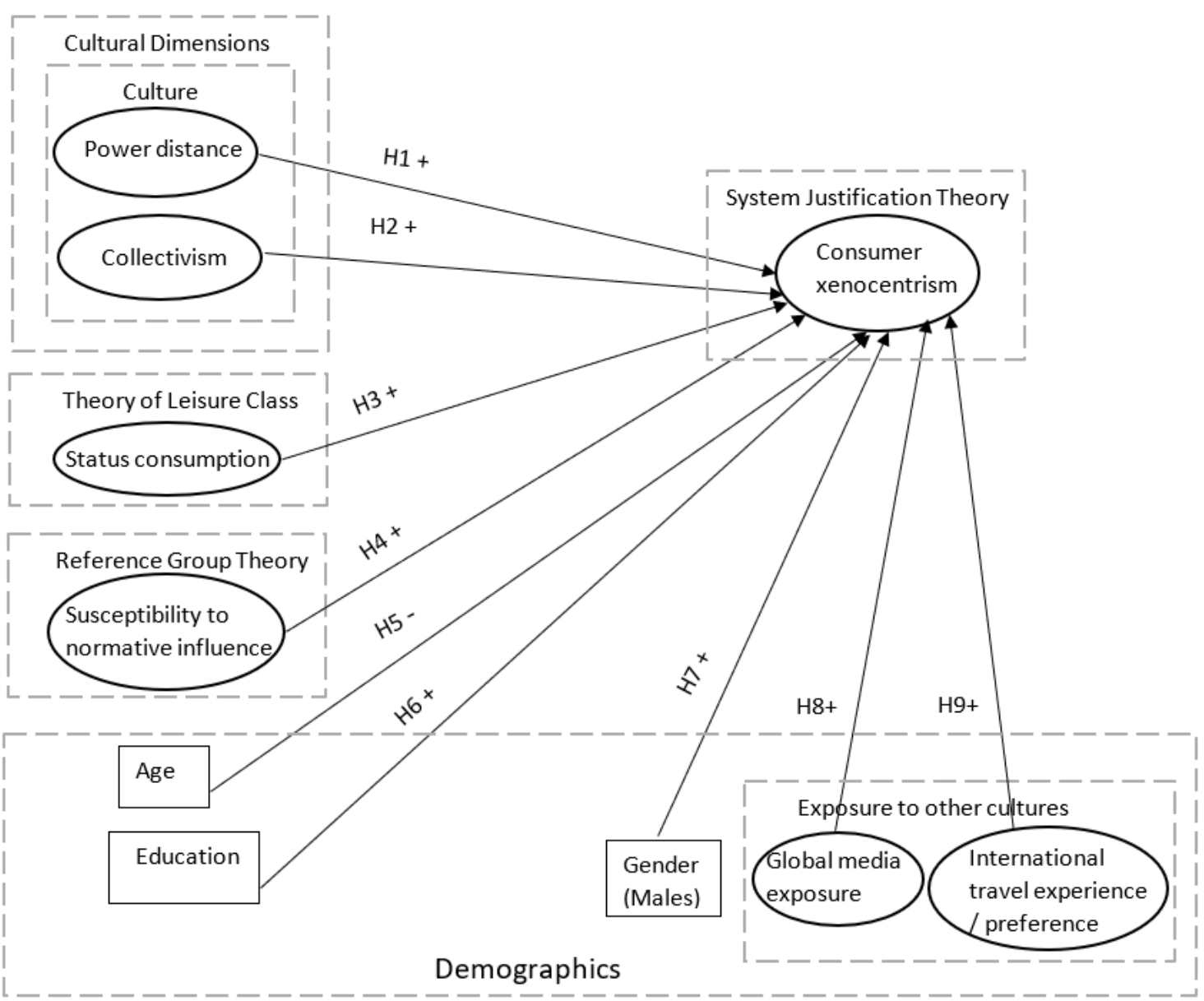

Table 3.1: Summary of antecedents' hypotheses

\begin{tabular}{l}
\hline H1: Power distance will have a positive effect on consumer xenocentrism. \\
\hline H2: Collectivism will have a positive effect on consumer xenocentrism. \\
\hline H3: Status consumption will have a positive effect on consumer xenocentrism. \\
\hline $\begin{array}{l}\text { H4: Susceptibility to normative influence will have a positive effect on consumer } \\
\text { xenocentrism. }\end{array}$ \\
\hline H5: As age increases, the impact of consumer xenocentrism will lessen. \\
\hline H6: As education level increases, the impact of consumer xenocentrism will increase. \\
\hline H7: Gender (Males) will have a positive effect on consumer xenocentrism. \\
\hline H8: Exposure to global media will have a positive effect on consumer xenocentrism. \\
\hline $\begin{array}{l}\text { H9: International travel experience/preference will have a positive effect on consumer } \\
\text { xenocentrism. }\end{array}$
\end{tabular}




\subsection{Chapter summary}

This chapter outlined the theories on human needs and highlighted two human needs, affiliation and power as it related to this thesis. Additionally, it discussed the proposed antecedents to consumer xenocentrism and the corresponding supporting theories for these potential antecedents. Relevant hypothesis for every potential antecedent was established and a conceptual model for the antecedents was presented. The demographics antecedents will be discussed in detail in Chapter 5 as these antecedents may also act as moderators.

In conclusion, this chapter addressed the first research question and based on literature review has thus proposed the potential antecedents to consumer xenocentrism. The upcoming chapter will address the second research question and will accordingly discuss the potential related attitudinal constructs to consumer xenocentrism. 


\section{CHAPTER FOUR - RELATED CONSTRUCTS}

\subsection{Introduction}

In this chapter the constructs that are potentially related to consumer xenocentrism are discussed. These constructs are not necessarily antecedents, consequences or moderators but are at the same attitudinal level as the consumer xenocentrism construct. The constructs are broadly divided into three main categories: constructs with positive attitude towards foreign cultures, constructs with neutral attitude towards foreign cultures, and constructs with negative attitude towards foreign cultures. These three groupings will be discussed in the following sections. Finally, the constructs that will be empirically tested in this thesis are identified and the hypotheses are set.

\subsection{Constructs with positive attitude towards foreign cultures}

Bartsch, Riefler and Diamantopoulos (2016) in their literature review of constructs with positive foreign orientations (i.e. constructs with positive attitude towards foreign cultures) argue that a number of positive foreign orientation constructs overlap. Wherever this might be the case, it will be discussed below in the respective construct.

The positive foreign orientation constructs discussed below all have different definitions, are based on different theories and are influenced by different motivational factors. What they do have in common with consumer xenocentrism is that each of these constructs also have a pro-foreign orientation. Therefore, it is likely that these constructs will be positively related to consumer xenocentrism. Although, till now only very few of these constructs have been empirically tested with consumer xenocentrism and have been 
found to be positively related, it is expected that all of the positive foreign orientation constructs will share a positive relationship with xenocentrism.

The constructs with positive foreign orientation or constructs with positive attitude towards foreign cultures are further divided into constructs with a.) Positive attitude towards both foreign and own cultures which is addressed in section 4.2.1 below b.) Positive attitude towards foreign cultures and neutral towards own culture which is discussed in section 4.2.2 and c.) Positive attitude towards foreign cultures and negative towards own culture which is elaborated in section 4.2.3.

\subsubsection{Positive attitude towards both foreign and own cultures}

Following are constructs that have positive attitudes towards both foreign cultures and their own culture. Four constructs from the extant literature fall into this category namely, consumer worldmindedness, internationalism, cosmopolitanism and localism.

\subsubsection{1 (Consumer) worldmindedness}

Worldmindedness construct is originally from the field of psychology (Barstch et al., 2016). Sampson and Smith (1957, p.99) define a highly worldminded individual as,

"The individual who favors a world-view of the problems of humanity, whose primary reference group is mankind, rather than American, English, Chinese, etc.". Rawwas, Rajendran and Wuehrer (1996) also refer to the Sampson and Smith's (1957) definition of worldmindedness. Rawwas et al. (1996) argue that for a worldminded person "world sharing" and being considerate towards other groups of people is of utmost importance. They add that a worldminded individual also believes there is no need for political governance at the national level. This is somewhat similar to the laissez-faire kind of 
economic system that proposes that there should be less government interferences in the nation's economy and promotes free trade between countries (Viner, 1927).

On the other hand, Nijssen and Douglas (2008) define the worldmindedness construct differently. They consider the worldmindedness construct synonymous to the cosmopolitanism construct. The authors define a person who is worldmindeded as someone who has "cultural openness" and "cultural adaptability" (Nijssen and Douglas 2008, p. 87). In other words, a person who is more accepting of other cultures and is able to adapt to the local aspects of other cultures is considered worldmindeded. For this thesis the worldmindedness definition put forth by Sampson and Smith (1957) and Rawwas, Rajendran and Wuehrer (1996) will be followed because Nijssen and Douglas' (2008) definition is too close to the definition of cosmopolitanism (Merton 1957b; Cleveland and Laroche 2007) which is generally a distinct construct. Although Westjohn et al. (2012) argue that to a certain extent openness to other cultures is required for being worldminded, I argue that in itself does not constitute to a person being worldminded. While openness to other cultures entails only accepting other cultures without any bias, worldmindedness goes one step further and stresses on seeing the whole world as a single entity (Sampson and Smith, 1957 and Rawwas, Rajendran and Wuehrer, 1996).

Foreign travel and having international contacts were empirically tested to be antecedents of worldmindedness (Nijssen and Douglas 2008; Kagitcibasi, 1978). Younger, more educated people and women were found to be more worldminded (Boatler, 1994; Bartsch et al., 2016; Hazeltine and Rezvanian, 1998; Deng and Boatler,1993). Also, those people who spoke foreign languages were more worldminded - the worldmindedness score 
was higher for people who spoke two or more foreign languages (Boatler, 1994; Hazeltine and Rezvanian, 1998).

Consumers who are highly worldminded perceived foreign products to be high in quality (Rawwas et al., 1996). Such consumers also had a more positive view on grocery stores that had a foreign brand section (Nijssen and Douglas, 2008). Highly worldminded consumers also favored products that played a role in global welfare such as being part of an international cause as saving rainforests (Rawwas et al., 1996). This action is in-line with the definition of worldminded consumers who care about the world and not just their country.

With respect to how worldmindedness is related to the other constructs, Balabanis et al. (2001) argue that worldmindedness is conceptually close to internationalism because some of the items of the worldmindedness scale was used for developing the internationalism scale by Kosterman and Feshbach's (1989). Also, though both consumer xenocentrism and worldmindedness are positive towards foreign product constructs, unlike the former, the latter is not associated with dislike for the home country's products. (Mueller et al., 2016).

Worldmindedness can be explained by the modernization theory from sociology. Bernstein (1971) argues that the issue of the need for development of non-Western countries gained significance after the Second World war and the decolonization of nation states. Modernization theory talks about the transformation of nations from traditional (economically backward) to modern (economically forward) societies and asserts that this can be achieved by using the same process that was used by the now-Western developed economies to get there (Bernstein, 1971). It is the course of transformation that will shift 
the non-Western world towards the types of institutions (political, social and economic) that have been developed in the West (Bernstein 1971). By the process of this change, the non-Western world will eventually catch up with the Western world and ultimately the whole world will be similar. In other words, the theory deals with integrating all societies in the world with help from the Western world (Bernstein 1971).

Modernization theory is one of the globalization theories. Globalization deals with seeing the whole world as a single market and endorses the view that nation-wide differences are artificial (Levitt, 1983). This is in-line with the concept of worldmindedness that does not see nationality as an important variable but rather for worldminded individuals "their reference group is mankind" (Sampson and Smith, 1957, p.99). Additionally, worldmindedness is associated with preference towards a single government world-wide, an individual being a citizen of the world and preference towards an international organization controlling immigration instead of the process being nation-wide (i.e. the construct endorses a world without borders just like the modernization theory). Also, in modernization theory the help of the Western world to bring other nations to the same level of development is equivalent to the world sharing and empathy characteristics of the worldmindedness construct.

\subsubsection{Internationalism}

Kosterman and Feshbach (1989, p. 271) argue that, "Internationalism focuses on international sharing and welfare, and reflects an empathy for the people of other countries." The construct is concerned with international harmony and an inclination to bring about equality even at the cost of lowering one's standards (Karasawa, 2002; 
Kosterman and Feshbach, 1989; Balabanis et al., 2001). This stance in turn creates a positive attitude towards people of other countries (Balabanis et al., 2001).

Balabanis et al. (2001) argue that internationalists are more likely to buy foreign products when the product supports global welfare. This aspect is comparable to worldminded consumers. Also, internationalism and worldmindedness constructs are very similar in the way that they are defined. Moreover, some of the items of the Sampson and Smith's (1957) worldmindedness scale were used to create the internationalism scale such as, "If necessary, we ought to be willing to lower our standard of living to cooperate with other countries in getting an equal standard for every person in the world" and "We should teach our children to uphold the welfare of all people everywhere even though it may be against the best interests of our own country.” (Balabanis et al., 2001; Kosterman and Feshbach, 1989). Taking together all the above points, both internationalism and worldmindedness are thus conceptually very close constructs (Balabanis et al., 2001). With respect to ethnocentrism, studies have found internationalism and ethnocentrism to be negatively correlated (Ishii, 2009; Lee et al., 2003) although Balabanis et al. (2001) did not find a significant correlation between the two constructs.

Internationalism was found to be associated with those who had a liberal political party affiliation, high media exposure and knowledge of international matters (Karasawa, 2002; Kosterman and Feshbach, 1989). Also, internationalism was associated with positive foreign product evaluations and willingness to buy (through mediators) foreign products (Shoham et al. 2006; Bartsch et al., 2016) thus making it a pro-foreign product construct. 


\subsubsection{Cosmopolitanism}

Cosmopolitanism originated from the field of sociology (Bartsch et al., 2016). Cosmopolitanism is conceptualized in several ways in the literature. Merton (1957b) and Cleveland and Laroche (2007) emphasize that cosmopolitans are those people who are open to foreign cultures and have an inclination to engage with those cultures. On the other hand, Saran and Kalliny (2012) stress more on the positive inclination of individuals towards products from different cultures. Alternatively, Riefler et al. (2012) argue that cosmopolitanism is a multi-dimensional construct with three-facets: open-mindedness towards other cultures, diversity of products from various cultures and positive inclination towards buying foreign goods. Thus, Merton (1957b) and Cleveland and Laroche (2007) focus on general cosmopolitanism, Saran and Kalliny (2012) on consumer cosmopolitanism and Riefler et al. (2012) on both of these aspects (Bartsch et al., 2016). Likewise, there are several scales to measure cosmopolitanism such as C-COSMO (Riefler et al., 2012), COS scale (Cleveland et al., 2014), CYMYC scale (Cannon et al. 1994), CCOS scale (Lawrence, 2012), COSMOSCALE (Saran and Kalliny, 2012) and CONCOS Scale (Altintas et al. 2013) to name the popular ones. Cleveland et al. (2014, p.268) state that for cosmopolitanism a "consensual definition is lacking". I add to that observation that as a result a consensual scale is lacking too.

Cosmopolitans choose their products based on the merit of the product and not based on where it is produced (Prince et al., 2016; Lawrence, 2012). They appreciate diversity among the products they consume (i.e. they consume foreign and local products) (Prince et al., 2016; Zeugner-Roth et al., 2015). However, since cosmopolitans are openminded and willing to explore products from different cultures and look beyond their local 
culture, this results most of the time in a positive foreign product bias (Lawrence, 2012). Additionally, it was also found that cosmopolitanism had a positive relationship with purchasing foreign products (Parts and Vida, 2013; Riefler and Diamantopoulos 2009). Thus, cosmopolitanism is a pro-foreign construct (Zeugner-Roth et al., 2015) and are also not biased against the local culture.

International media exposure, travel abroad and cross-cultural training are considered to be predictors of cosmopolitanism (Hannerz, 1990; Prince et al., 2012; Belk, 1998; Cannon and Yaprak, 2002; Craig and Douglas, 2006; Riefler and Diamantopoulos, 2009). Given the influence of global mass media it is possible to develop a cosmopolitan outlook even without leaving one's country (Cleveland et al., 2009). Empirically, individuals who were younger, more educated, had traveled outside their home country, had exposure to global media, were residing in main cities and women were found to be more cosmopolitan (Prince et al., 2016; Cleveland et al., 2009; Yoon et al., 1996).

With respect to other related constructs, while ethnocentrism is a more prodomestic construct, cosmopolitanism is a pro-foreign construct. Accordingly, cosmopolitanism was negatively related to ethnocentrism and positively related to xenocentrism (Cleveland et al., 2009; Cleveland and Balakrishnan, 2019; Parts and Vida, 2013; Prince et al., 2016). Cosmopolitanism has also been used to test the nomological validity of xenocentrism (Rojas-Méndez and Chapa, 2019).

\subsubsection{Localism}

"Localism describes people who exhibit a strong commitment to their local culture. This is not inconsistent with a cosmopolitan orientation. Locals may appreciate other 
cultures as well as their own." (Yoon et al. 1996, p. 217). In other words, the authors argue that localism pertains to individuals who are both pro-domestic and pro-foreign, though more pro-domestic. Yoon et al. (1996) argue that locals are more comfortable with tradition but are also pro-foreign. The authors also assert that being both pro-local and pro-foreign are not mutually exclusive.

Cannon and Yaprak (2001) believe that localism is not the opposite of cosmopolitanism as believed by Merton (1957b) and Gouldner (1957) - parochialism (discussed in section 4.4.1.5) is. Thus, Cannon and Yaprak (2001) and Cannon et al. (1994) argue that cosmopolitanism and localism are distinct dimensions and are not opposite to one another.

\subsubsection{Positive attitude towards foreign cultures and neutral towards own culture}

Following are constructs that have positive attitudes towards foreign cultures and are neutral towards their own culture. Six constructs from the existing literature fall into this category namely, global consumption orientation, cultural/global openness, belief in global citizenship, susceptibility to global consumer cultures, global identity and consumer affinity. These constructs are discussed below.

\subsubsection{Global consumption orientation}

Alden, Steenkamp, and Batra (2006, p. 227) define global consumption orientation (GCO) as the "Consumer preferences for globalized, localized or hybridized alternatives within a given consumption domain". They classify consumer preferences into four categories: preference for global products, preference for local products, preference for 
both types of products (global + local) termed as "hybrid" choice and a lack of interest with respect to product preferences (Guo, 2013).

A strong (or high) GCO signifies a preference for global products (Alden et al., 2006). With respect to other related constructs, a strong GCO was positively related to xenocentrism and cosmopolitanism and negatively to ethnocentrism (Prince et al., 2016; Alden et al., 2006). These relationships are intuitive given that xenocentrism and cosmopolitanism are pro-foreign constructs and ethnocentrism is a pro-domestic construct. Tu et al. (2012) found that high GCO was related to having a global identity.

High GCO was positively associated with materialism, higher income and exposure to other cultures through mass media exposure, travel abroad and expatriate experience (Prince et al., 2016; Alden et al., 2006). Additionally, younger individuals and males had a stronger GCO (Prince et al., 2016). However, as mentioned in section 4.2.1.3, women were found to be more cosmopolitan, another pro-foreign construct. Thus, in the extant literature there is mixed evidence when it comes to which gender is more pro-foreign. Also, higher GCO was associated positively towards willingness to consume foreign products and having positive attitudes towards foreign brands (Alden et al., 2006; Riefler et al., 2012).

\subsubsection{Cultural/global openness}

Sharma et al. (1995, p. 28) define cultural openness as, "experience with and openness toward the people, values, and artifacts of other cultures. The opportunity to interact with other cultures can have the effect of reducing cultural prejudice." Suh and Kwon (2002, p.667) define global openness as, "the impact of globalization and thus 
reflecting a self-conscious level of globalization as a process of deepening consciousness and increasing sensitivity to other people and cultures." In other words, both definitions stress on the exposure to other cultures which in turn leads to the acceptance of people/practices from other cultures. Cultural/global openness is an avid interest to learn about other cultures (Bartsch et al., 2016). Studies have acknowledged that both global and cultural openness might be identical constructs (Bartsch et al., 2016; Shankarmahesh, 2006) and thus this thesis will treat it as such.

Shankarmahesh (2006) argues that worldmindedness and cultural openness are different constructs. He asserts that while cultural openness is the interest to learn about other cultures and their way of life through exposure to various cultures, worldmindedness is about having empathy towards other cultures and involves seeing everyone not according to their nationality but as part of mankind. He argues that one can be worldminded without having any contact with individuals from other cultures (i.e. without being culturally open).

Except one study (Vida et al., 2008) which did not find an association, several studies have confirmed that cultural openness was negatively associated with ethnocentrism, a pro-domestic and anti-foreign construct (Javalgi et al., 2005; de Ruyter et al., 1998; Sharma et al., 1995). The negative association between ethnocentrism and cultural openness is in sync with the traditional understanding that interacting across cultures widens one's mind (Shankarmahesh, 2006). Cultural openness was positively associated with cosmopolitanism (Bartsch et al., 2016; Striznakova et al., 2008) - a proforeign construct. Additionally, cultural openness lead to individuals rating the quality of foreign products highly (Howard, 1989). 


\subsubsection{Belief in global citizenship}

This construct is described as, "The belief that global brands create an imagined global identity with like-minded people" (Strizhakova, Coulter, and Price 2008, p. 59). Cultural openness was found to influence belief in global citizenship. Belief in global citizenship had an influence on the foreign brands purchase intention and the percentage of foreign brands bought (through mediators, quality signals and partially through selfidentity signals) (Gammoh, Koh, and Okoroafo 2011; Strizhakova et al., 2011). It is worth noting that the effect of belief in global citizenship on percentage of foreign brands bought was significantly mediated through self-identity signals only for the developing country Russia and not the other two developed countries, the U.S. and the U.K. This reinforces the stance that consumers in developing countries may buy foreign products for status. There is not much research done on this construct in the field of marketing.

Though belief in global citizenship like worldmindedness has to do with creating a similar identity with people around the world, it is a slightly different construct. Worldmindedness emphasizes that the idea of identifying with people around the world (i.e. having a single identity) makes individuals pro-foreign. On the other hand, belief in global citizenship construct emphasizes something different. That is, buying global products (or being pro-foreign) makes one identify with people around the world. In sum, though both worldmindedness and belief in global citizenship are pro-foreign constructs, the manner in which they are defined is different and sets them apart. 


\subsubsection{Susceptibility to Global consumer culture (SGCC)}

"SGCC is simply defined as the consumer's desire or tendency for the acquisition and use of global brands. It is denoted as a general trait of consumers that varies across individuals and cultures" (Zhou, Teng, and Poon 2008, p. 337). The definition of this construct is only slightly different to that of high GCO (Alden et al., 2006). SGCC was found to have three facets: conformity to consumption trend, quality perception, and social prestige (Zhou et al., 2008) — social prestige is similar to status which is one of the proposed antecedents to consumer xenocentrism. SGCC has an influence on the willingness to buy foreign products (Zhou et al., 2008). There is very little research that has been done on this construct (Bartsch et al., 2016) in the field of marketing. There are a few antecedents proposed to this construct such as tourism, immigration, exposure to mass media, exposure to pop culture and global marketing (Zhou et al., 2008) but these are only conceptual propositions and have not been empirically tested.

\subsubsection{Global identity}

"A global identity consists of mental representations in which consumers believe in the positive effects of globalization, recognize the commonalities rather than dissimilarities among people around the world, and are interested in global events; broadly, being global means identifying with people around the world." (Zhang and Khare, 2009, p. 525). Just like in the cultural/global openness construct, globalization also has an effect on the global identity construct. Having a global identity means that individuals associate themselves to a global lifestyle, perceive people around the world to be their neighbors and consider themselves as belonging to the world rather than only their local culture (Tu et 
al., 2012; Westjohn et al., 2009). This construct touches on some aspects of cosmopolitanism and worldmindedness as they also believe that they are citizens of the world (Merton, 1957b; Rawwas et al., 1996). But unlike worldminded individuals, individuals who have a strong global identity do not have world sharing and common welfare as a priority (Rawwas et al., 1996) and unlike cosmopolitans, individuals who have a strong global identity do not have engaging with other cultures to learn about that local culture as a priority (Cleveland and Laroche, 2007; Merton 1957b) as they are more interested in the commonalities rather than the differences in world culture. Thus, there is some degree of overlap between the three constructs, but they are distinct constructs. Scales such as Zhang and Khare (2009) and Tu et al. (2012) measure both global and local identity while scales such as Bartikowski and Walsh (2015) and Westjohn et al. (2012) measure only global identity.

The personality trait openness to experiences is positively associated with global identity (Westjohn et al., 2012). This is intuitive as one must be reasonably open to new experiences to look beyond their immediate local surrounding to search for products and services (Westjohn et al., 2009) and to adopt a global lifestyle. Consumers high in global identity are positively inclined towards cultural diversity (Bartikowski and Walsh, 2015). They are also positively inclined towards having an unbiased disposition to understand the commonalities and differences between their culture and other ones (Bartikowski and Walsh, 2015).

A high global identity was positively related to high GCO (Tu et al., 2012). Accordingly, consumer high in global identity preferred foreign products (Zhang and Khare, 2009). They also had a positive attitude towards foreign brands (Magnusson et al., 
2015). Additionally, consumer who have a strong global identity evaluate positively and are willing to buy brands that are socially responsible (Magnusson et al., 2015) which is an aspect similar to worldminded consumers.

The global/local identity constructs are based on the regulatory focus theory from psychology. The regulatory focus theory argues that individuals have two motivational aspects called the promotion regulatory focus and prevention regulatory focus (Higgins, 1997). The promotion focus stresses on aims and achievements and the prevention focus stresses on safety and security (Westjohn et al., 2016). Promotion-focused individuals see the world as a safe place and are more risk-taking and as a result are more open to looking at global choices (Pham and Chang 2010; Westjohn et al., 2016). On the other hand, prevention-focused individuals look at the world with caution and are less willing to have negative experiences and thus stick to the tried-and-tested local choices that are available (Higgins 1997; Westjohn et al., 2016). The promotion-focused individual is more open to change and trying new things whereas the prevention-focused individual gives more importance to being orthodox, secure and is less open to trying out new things. An individual will either lean more towards a promotion focus or a prevention focus (Westjohn et al., 2016). Drawing parallels, individuals with a global identity can be associated with being promotion focused because they are attracted towards global events and are more open to connecting with the world. Alternatively, individuals with a local identity can be associated with being prevention focused as they are more attached to the local community and events and are less open to the outside world. They feel more secure in a well-known environment and therefore they do not look for new things. 


\subsubsection{6 (Consumer) affinity}

Oberecker et al. (2008, p.26) define consumer affinity as, "A feeling of liking, sympathy, and even attachment toward a specific foreign country that has become an ingroup as a result of the consumer's direct personal experience and/or normative exposure and that positively affects the consumer's decision making associated with products and services originating from the affinity country". Consumer affinity construct is different from the other positive foreign constructs because it is associated with a positive emotional attachment towards a specific country and it is not a general positive disposition towards foreign products (Bartsch et al., 2016; Lawrence, 2012; Oberecker et al. 2008). Consumer affinity towards a specific country can be influenced by a great relationship between the home country and that specific country and/or having family or friends or good travel experiences or mass media exposure to that country (Oberecker et al., 2008).

Oberecker et al. (2008) assert that internationalism might be positively associated with consumer affinity though this relationship has not been empirically verified. Oberecker and Diamantopoulos (2011) posit that consumers perceive purchasing products from the affinity country to be less risky. They also find that consumer affinity is positively related to product purchase intention from the affinity country. Furthermore, they also uncover that consumer affinity was a stronger predictor than consumer ethnocentrism with respect to perceived risk and purchase intention. Additionally, they find that consumer affinity is positively associated with the willingness to visit and invest in the affinity country. 
4.2.3 Positive attitude towards foreign cultures and negative towards own culture

The below subsection discusses a construct that has positive attitudes towards foreign cultures and a negative attitude towards its own culture. Consumer xenocentrism, the main construct that this thesis analyzes, also falls in this category. Since this chapter only discusses related constructs, the consumer xenocentrism construct is not elaborated here. This is an understudied area in the literature and has just one other construct, xenophilia which is discussed below.

\subsubsection{Xenophilia}

Xenophilia construct is from the field of psychology. Perlmutter (1954, p. 29) defines xenophilia as, "a love for strangers and foreigners... and an implicit or explicit disrespect for or hatred of one's own sociological reference group". In other words, xenophilia is love for the out-group and dislike for the in-group. This construct looks very similar to consumer xenocentrism, but it is slightly different. While xenophilia has more to do with foreigners and foreign society in general, consumer xenocentrism is specific to products/brands. Prince et al. (2016) assert that consumer xenocentrism arises because of xenophilia. Balabanis and Diamatopolous (2016) found xenophilia and consumer xenocentrism to be positively related. Additionally, they used the xenophilia construct to test the discriminant validity of the consumer xenocentrism scale. Taken together, this proves that xenophilia and consumer xenocentrism are positively related but distinct constructs.

Oberecker et al. (2008) proposed (though not empirically tested) that xenophilia will be positively related to consumer affinity. Similarly, some authors (Perlmutter, 1954; 
Bartsch et al., 2016) propose that foreigners are considered better than locals because foreigners are perceived to have higher education and a better personality. The above are conceptual propositions and there is not much empirical research available on xenophilia and how the construct is related to consumer behavior (Bartsch et al., 2016).

Table 4.1 shows all the constructs with positive foreign orientation that have been discussed. In other words, these are constructs that have a positive attitude towards foreign cultures. The boxes in table 4.1 consists of constructs that have a positive attitude towards foreign cultures and negative towards own culture, a positive attitude towards foreign cultures and neutral towards own culture and a positive attitude towards both foreign and own cultures.

Table 4.1: Constructs with positive foreign orientation

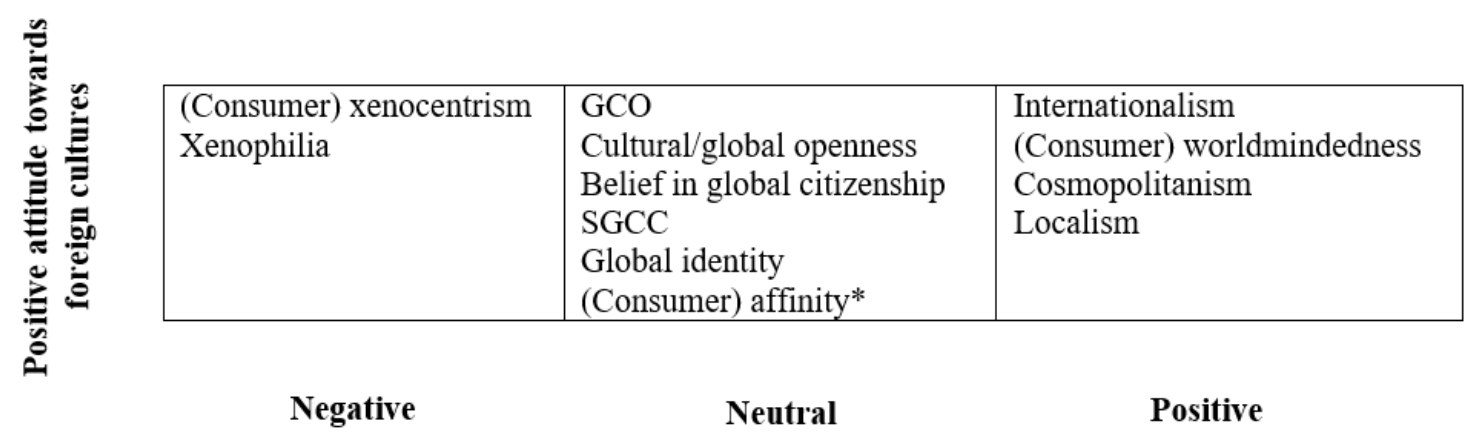

Attitudes towards own culture

* Specific to a foreign country 


\subsection{Constructs with neutral attitude towards foreign cultures}

This section elaborates on constructs that have a neutral foreign orientation. Unlike consumer xenocentrism which has a pro-foreign orientation, these constructs have a neutral foreign orientation (that is, they are neither positive nor negative about foreign cultures). The neutral foreign orientation or constructs with neutral attitude towards foreign cultures are further divided into constructs with a.) Neutral attitude towards foreign cultures and positive attitude towards their own culture b.) Neutral attitude towards both foreign and own cultures c.) Neutral attitude towards foreign cultures and negative towards own culture. Of these three sub-categories, to the best of my knowledge, only the first subcategory, neutral attitude towards foreign cultures and positive attitude towards their own culture, has been studied in the extant literature. Since constructs in this sub-category are positive towards their own culture, it is likely that there is a preference for local products. Thus, these constructs will be negatively related to consumer xenocentrism, which is a proforeign construct. This sub-category is discussed below.

\subsubsection{Neutral attitude towards foreign cultures and positive towards own culture}

Following are constructs that have neutral attitudes towards foreign cultures and positive attitudes towards their own culture. Three constructs from the existing literature fall into this category namely, patriotism, national identity and local identity.

\subsubsection{Patriotism}

Balabanis et al. (2001, p.162) defines patriotism as, "love of country." Kosterman and Feshbach (1989) states that patriotism is based on emotions and it is the attachment 
one has towards one's country. Patriotism is a pro-domestic construct but not explicitly anti-foreign - that is it only concerns the love and attachment for a country and not dislike for other countries. Thus, this construct is neutral towards foreign countries.

Patriotism has been found related to conservative political party support (Kosterman and Feshbach, 1989). With respect to other related constructs, several studies found patriotism to be positively related to consumer ethnocentrism (Ishii, 2009; Javalgi et al., 2005; Klein and Ettensoe, 1999; Balabanis et al., 2001; de Ruyter et al., 1998) while Lee et al. (2003) did not find support for this relationship. Patriotism was associated with domestic product purchase (Granzin and Olsen, 1998; Han 1988).

Schatz et al. (1999, p. 151) further divides patriotism into blind patriotism and constructive patriotism. "Blind patriotism is defined as an attachment to country characterized by unquestioning positive evaluation, staunch allegiance, and intolerance of criticism. Constructive patriotism is defined as an attachment to country characterized by support for questioning and criticism of current group practices that are intended to result in positive change." In other words, blind patriotism involves loving one's country and defending it at any cost. This can be characterized by for example, only consuming news that support the nation. On the other hand, constructive patriotism involves loving one's country but at the same time wanting to make the country better through for example political efficiency (Schatz et al., 1999).

\subsubsection{National identity}

National identity can be defined as, "the importance of national affiliation as well as the subjective significance of an inner bond with the nation" (Blank and Schmidt, 2003, 
p. 296). National identity is based on attachment towards one's country and this act helps achieve "a sense of identity and self-esteem" (Druckman, 1994, p.44). With respect to one's attachment towards his/her nation, one can have either a positive national identity or a negative national identity (Blank, 2003). National identity in most scenarios is positive but negative national identification does exist e.g. national disidentification in the case of immigrants who hold opposing views towards the country that they reside in (Josiassen 2011; Mackie and Smith 1998; Zeugner-Roth et al., 2015).

National identity is largely a pro-in-group construct and not necessarily an antioutgroup construct (Zeugner-Roth et al., 2015). Thus, it is similar to patriotism which is also a pro-in-group construct with no reference made to the out-group and dissimilar to ethnocentrism and nationalism (discussed in sections 4.4.1.1 and 4.4.1.2) which are both pro-in-group and anti-out-group constructs. Hence, national identity is neutral towards foreign countries. National identity is positively associated with ethnocentrism and patriotism (Vida et al., 2008; Cleveland et al., 2016; Verlegh, 2007; Blank and Schmidt, 2003). Also, Blank and Schmidt (2003) found that national identity and nationalism is positively related.

National identity is also positively related to agreeableness (Westjohn et al., 2012). Agreeableness is a trait that is important for group harmony and for maintaining relationships (Lun and Bond 2006; Westjohn et al., 2012) and the relationship is intuitive given that national identity is a pro-in-group construct and group harmony is highly prized in any group. Also, individuals high in national identity did not give much importance to cultural diversity and had a disinterest knowing about other cultures (Bartikowski and 
Walsh, 2015). They were also uncomfortable with establishing connections with individuals from other cultures (Bartikowski and Walsh, 2015).

Consumers who have a higher national identification perceive domestic goods to be of higher quality (Verlegh, 2007). National identity is also associated with the purchase intention of domestic goods (Zeugner-Roth et al., 2015; Verlegh, 2007) and the effect of national identity on purchase intention is stronger than that of consumer ethnocentrism (Zeugner-Roth et al., 2015). Furthermore, national identity is associated with actual purchase of domestic goods (Cleveland et al., 2016).

National identity is based on the self-categorization theory from psychology. The self-categorization theory describes the situation under which individuals see themselves as a group and the functioning of the grouping process (Turner and Reynolds, 2011). Individuals see themselves as a group when the intragroup differences are less than the intergroup differences (Turner and Reynolds, 2011). In other words, individuals see themselves in a group when the perceived differences within the group is less than the perceived differences between one's own group and the out-group. Once individuals see themselves in a group, they learn the suitable behaviors and emotions of the group and these aspects become second-nature (internalization) to them and as a result depersonalization happens (Hornsey, 2008; Turner and Reynolds, 2011). Depersonalization involves individuals in a group acting as "prototypes" of the group (i.e. each group member behaves identical to the other group members) (Hornsey, 2008).

Drawing parallels with national identity, self-categorization is needed for recognizing the in-group (one's own country) and the out-group (other countries) - here an individual perceives that the differences within his group (his country) are less than the 
differences between his group (his country) and the out-group (other countries). This in turn results in the affiliation towards one's country. The appropriate emotions associated with the one's own nation (in-group) are learnt and in this case, it is the strong emotional connection with one's country. Individuals with strong national identity internalize this connection and each individual with a strong national identity has a strong bond with the country (depersonalization).

\subsubsection{Local identity}

Local identity can be defined as, "mental representations in which consumers have faith in and respect for local traditions and customs, are interested in local events, and recognize the uniqueness of local communities; broadly, being local means identifying with people in one's local community." (Zhang and Khare, 2009, p. 525). In other words, having a local identity means having a sense of belonging to the local group and connecting with the local ways of life and the local tradition (Tu et al., 2012). Local identity is the opposite of global identity. Local identity is positively related to ethnocentrism and nationalism, other pro-domestic constructs but is found to be distinct from them (Tu et al., 2012). Individuals who have a local identity prefer domestic products (Zhang and Khare, 2009). They are not necessarily anti-foreign and can be neutral towards foreign countries and products. Local identity can be explained by the regulatory focus theory which has already been discussed in section 4.2.2.5.

Table 4.2 shows all the constructs with neutral foreign orientation that have been discussed. These are also known as constructs that have a neutral attitude towards foreign cultures. As can be seen in table 4.2, the boxes that represent neutral attitude towards 
foreign cultures and negative towards own culture, and neutral attitude towards foreign cultures and neutral towards own culture are empty, signifying that there has been no research in these areas to the best of my knowledge. The box representing neutral attitude towards foreign cultures and positive attitude towards own cultures was discussed in this section.

Table 4.2: Constructs with neutral foreign orientation

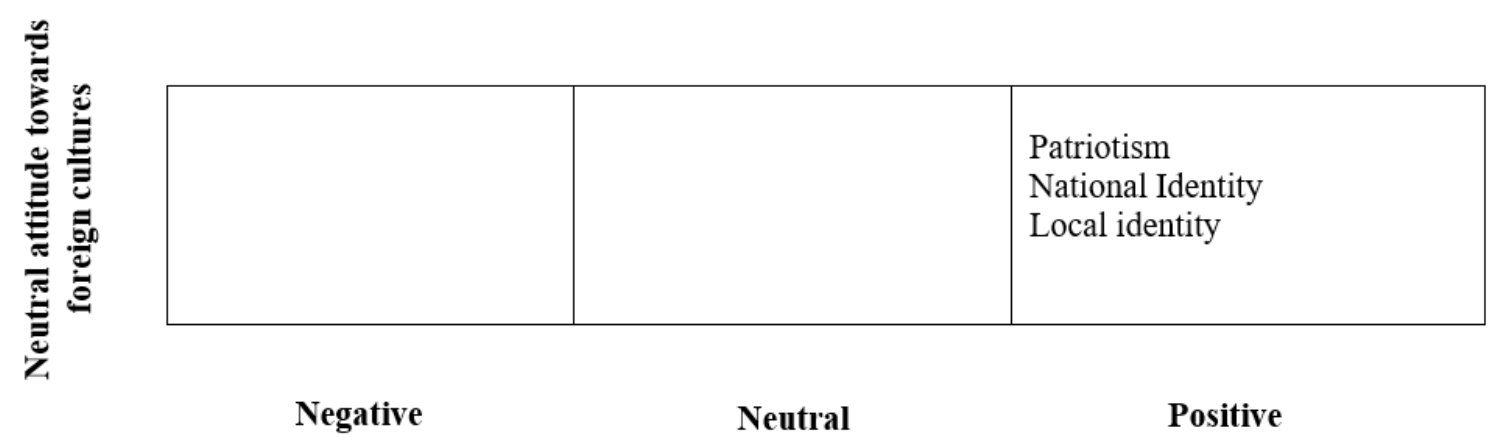

Attitudes towards own culture

\subsection{Constructs with negative attitude towards foreign cultures}

This section will cover constructs that have a negative foreign orientation. The negative foreign orientation constructs discussed below all have different definitions, are based on different theories and are influenced by different motivational factors. Additionally, they also have an anti-foreign orientation unlike consumer xenocentrism which has a pro-foreign orientation. Therefore, it is likely that these constructs will be negatively related to consumer xenocentrism. So far, only ethnocentrism has been empirically tested with consumer xenocentrism and has been found to be negatively 
related. It is expected that all of the negative foreign orientation constructs will also share a negative relationship with xenocentrism.

The negative foreign orientation or constructs with negative attitude towards foreign cultures are further divided into constructs with a.) Negative attitude towards foreign cultures and positive attitude towards own culture which is addressed in section 4.4.1 below b.) Negative attitude towards foreign cultures and neutral towards own culture which is discussed in section 4.4.2 and c.) Negative attitude towards both foreign and own cultures which is not discussed here because to the best of my knowledge there are no constructs that address this category in the existing literature.

\subsubsection{Negative attitude towards foreign cultures and positive towards own culture}

Following are constructs that have negative attitudes towards foreign cultures and positive attitudes towards their own culture. Five constructs from the existing literature are in this category namely, consumer ethnocentrism, nationalism, xenophobia, conservatism and parochialism.

\subsubsection{1 (Consumer) ethnocentrism}

This is one of the most studied constructs in the extant literature (Lawrence, 2012). Shimp and Sharma (1987) introduced the term, "consumer ethnocentrism". They defined and adapted the construct for consumer behavior from the concept of general ethnocentrism proposed by Sumner (1906). They defined consumer ethnocentrism as, “... the beliefs held by American consumers about the appropriateness, indeed morality, of purchasing foreignmade products." (Shimp and Sharma, 1987, p.280). For the ethnocentric consumer 
consuming foreign goods is immoral because it would damage the local economy and also because it is disloyal to the country (Shimp and Sharma, 1987). Ethnocentric consumers see foreign goods as "objects of contempt" (Shimp and Sharma, 1987, p.280). Thus, consumer ethnocentrism is not only pro-domestic but also an anti-foreign construct. When certain products do not exist in their home country, ethnocentric consumers buy products from rather culturally similar countries than culturally dissimilar countries (Watson and Wright, 2000; Lee et al., 2014).

With respect to the other related constructs, ethnocentrism has been used to test the nomological and discriminant validity of xenocentrism scale (Rojas-Méndez and Chapa, 2019; Balabanis and Diamantopoulos, 2016). Also, ethnocentrism is negatively associated with cosmopolitanism, xenocentrism, internationalism, worldmindedness and cultural openness (Cleveland et al., 2009; Prince et al., 2016; Rojas-Méndez and Chapa, 2019; Ishii, 2009; Lee et al., 2003; Sharma et al., 1995; Shankarmahesh, 2006) - all pro-foreign constructs. Additionally, ethnocentrism is positively associated with patriotism, conservatism and nationalism (Sharma et al., 1995; Shankarmahesh, 2006; Baughn and Yaprak, 1996) - all pro-domestic constructs. Looking beyond related constructs, older individuals, women, individuals with lower education and individuals with lower income levels were found to be more ethnocentric (Cleveland et al., 2009; Sharma et al., 1995).

Consumer ethnocentrism influences preference for and willingness to buy local products (Balabanis and Diamantopoulos, 2004; Cleveland et al., 2009). Local products signify the local culture to ethnocentric consumers, and they believe that their local culture is superior to all others (Lee et al., 2014). Consumer ethnocentrism is also negatively 
related with attitude towards foreign products, foreign brand preference and willingness to buy foreign products (He and Wang, 2015; Kwak et al., 2006; Shankarmahesh, 2006).

Consumer ethnocentrism is based on the social identity theory (Zeugner-Roth et al., 2015; Balabanis and Diamantopoulos, 2016) from psychology. Social identity theory describes intergroup behavior (Brown, 2000). It deals with favoring of one's group and derogating the out-group (Tajfel and Turner, 1979). Tajfel and Turner (1979) argue that this is the case because individuals aspire to have a positive self-concept (a high selfesteem). They add that this positive self -concept is derived from seeing the groups that the individuals are associated with in very positive light (Hornsey, 2008; Brown, 2000). According to the social comparison theory (Festinger, 1954) as human beings we have a need to judge ourselves against others and this translates to one judging their own group with another group (Hornsey, 2008). In the quest to maintain a positive self-concept thus one favors one's group and devalues the outgroup (Tajfel and Turner, 1979; Hornsey, 2008).

Drawing parallels with social identity theory, consumer ethnocentrism is a construct that favors in-group and devalues out-groups. To put in more specifically, ethnocentric consumers perceive their culture to be superior and have a strong preference for domestic goods (Lee et al., 2014). On the other hand, they despise foreign goods which leads to the rejection of those goods (Shimp and Sharma, 1987). These actions in turn gives the ethnocentric consumers a more positive self- concept. Social identity theory is also mainly applicable in high status groups and this explains why ethnocentrism is a predominant construct in the developed countries such as the U.S and New Zealand (Shimp and Sharma, 1987; Watson and Wright, 2000). Additionally, one of the ways that 
individuals in low status groups cope with their situation is by disassociating themselves from their in-group and this might be the reason why xenocentrism which involves rejection of in-group is popular in the developing world.

\subsubsection{Nationalism}

Kosterman and Feshbach, 1989 (p. 261) define nationalism as, "The view that America is superior and should be dominant." Though the authors mention America in this context, with respect to a general definition this could mean any country. Nationalism and patriotism are often constructs that are spoken about interchangeably, but they are different and separate constructs (Prince et al., 2016). While patriotism is love and attachment towards one's country, nationalism is love and attachment for one's country along with hostility towards foreign countries (Balabanis et al., 2001; Kosterman and Feshbach, 1989; Prince et al., 2016). Nationalism is the view that the home country is superior and dominant to all others and it is a "downward comparison of other nations" (Kosterman and Feshbach, 1989, p. 271). Thus, while patriotism is only pro-in-group, nationalism is both pro-in-group and anti-out-group. Nationalism is also a distinct concept from economic nationalism, where the focus is only on defending the economic interest of the home country and protecting it against foreign companies (Ahkter, 2007).

Nationalism and consumer ethnocentrism are positively related constructs (Lee et al., 2003; Vida et al., 2008; Balabanis et al., 2001). Also, both nationalism and general ethnocentrism are pro-in-group and anti-out-group constructs. Additionally, nationalism focuses on the ingroup being superior and dominant and ethnocentrism focuses on the ingroup being at the "center of the universe" (Kosterman and Feshbach, 1989; Shimp and 
Sharma, 1987, p.280), that is, both constructs indicate that the perceived superiority of the in-group. Taking together all the above points, both these constructs are very similar to each other.

Internationalism and nationalism are not two ends of the same continuum - they are distinct constructs (Balabanis et al., 2001; Lee et al., 2003; Kosterman and Feshbach, 1989). Kosterman and Feshbach (1989) argue that nationalism is based on love for one's country and hostility for other nations but internationalism though it is based on support for other nations, there is no mention of any feelings towards the home country. In other words, Kosterman and Feshbach (1989) assert that nationalism is pro-in-group and antioutgroup and internationalism is only pro-outgroup and not necessarily anti-in-group. Furthermore, in their study the individuals who had a high internationalism score did not have a low score on nationalism (Lee et al., 2003). Thus, Kosterman and Feshbach (1989) argue that internationalism and nationalism are not opposite sides of the same dimension and are distinct constructs.

Nationalism, like patriotism, is related to conservative political party support in the US (Kosterman and Feshbach, 1989). Also, consumers who are highly nationalistic had positive quality perceptions of domestic products (Rawwas et al., 1996).

\subsubsection{Xenophobia}

Hjerm (1998 p. 341) define xenophobia as, "a negative attitude toward, or fear of, individuals or groups of individuals that are in some sense different (real or imagined) from oneself or the group(s) to which one belongs." In other words, it is the extreme dislike for the outgroup or people of other cultures (Rojas-Méndez and Chapa, 2019) which also 
makes xenophobia a pro-in-group construct. Individuals with conservative values were found to be more xenophobic (Altintas and Tokol, 2007). Additionally, xenophobia was also positively related to ethnocentrism (Altintas and Tokol, 2007). These relationships are relatable as both conservatism and ethnocentrism are pro-in-group constructs and additionally ethnocentrism is also an anti-out-group construct. Xenophobia was negatively associated with attitude towards foreign tourists and foreign investments (Altintas and Tokol, 2007). There has been very little research on this construct in the field of marketing.

\subsubsection{Conservatism}

Sharma et al. (1995, p.28) define conservatism as, "tendency to cherish traditions and social institutions that have survived the test of time, and to introduce changes only occasionally, reluctantly, and gradually." In other words, conservatism is valuing one's tradition highly and only slowly changing with the times. The opposite of conservative values are liberal values (Ray, 1983).

Conservatism was positively related to consumer ethnocentrism (Sharma et al., 1995; Balabanis et al., 2002; Altintas and Tokol, 2007; Javalgi et al., 2005; de Ruyter et al., 1998) and nationalism (Baughn and Yaprak, 1996) - both pro-domestic constructs. Conservatism was negatively related to cosmopolitanism (Cleveland et al. 2011) - a proforeign construct. Conservatism was also negatively associated with attitude towards foreign products and preference of foreign products (Anderson and Cunningham 1972; Sharma et al., 1995). 


\subsubsection{Parochialism}

Yoon et al. (1996, p.217) posit that "parochialism describes people whose local commitment comes at the expense of cosmopolitan values". In other words, it is seen as the opposite of cosmopolitanism (Cannon and Yaprak, 2002). Parochialism is also referred to as narrow-mindedness (Yoon et al.,1996). Individuals who are parochial are greatly influenced by the local culture and the norms of their society (Cannon and Yaprak, 2002). Thus, these individuals are more likely to buy local products. There is not much research on this construct in the field of international marketing.

\subsubsection{Negative attitude towards foreign cultures and neutral towards own culture}

The below subsection discusses a construct that has negative attitudes towards foreign cultures and a neutral attitude towards its own culture. This is an understudied area in the literature and has just one construct, consumer animosity which is discussed below.

\subsubsection{1 (Consumer) animosity}

Klein et al. (1998, p. 90) define consumer animosity as, "The remnants of antipathy related to previous or ongoing military, political, or economic events." This construct much like consumer affinity is specific to a country and does not apply to all foreign countries in general (Klein et al. 1998; Lawrence, 2012). While ethnocentrism is pro-domestic and a general anti-foreign construct, animosity is only anti-foreign towards a particular country (Klein and Ettensoe, 1999). Also, unlike the cause for ethnocentrism which is the intent of protecting the local economy, the cause for consumer animosity is conflicts with a particular foreign country (Prince et al., 2016). Some of the possible reasons for consumer 
animosity are political, military tensions between the two countries and/ or perceived unfair trade practices conducted by a country (Klein et al., 1998; Lawrence, 2012). The political conflict between Saudi Arabia and Canada (Globe and Mail, 2018), trade war between U.S. and China (Financial Times, 2018) and past and ongoing military and political conflicts between the China and Japan (Time, 2013) are some examples of animosity between two countries.

Normative influence was found to have a positive influence on consumer animosity (Huang et al., 2010). That is, the reference group of an individual influences the individual in not buying products from the country which is the object of animosity. With respect to quality perception of the products from the animosity country there are mixed results while some studies have found that this perception was not affected (Klein et al. 1998; Ettensoe and Klein 2005), others found that this was not the case (Huang et al., 2010). However, in either instance, consumer animosity negatively impacts product purchase intention from the animosity country (Klein et al. 1998; Ettensoe and Klein 2005; Huang et al., 2010). Additionally, in some cases the animosity was found to be so high that customers were unwilling to buy even hybrid products (such as home country products made in the animosity country) (Cheah et al., 2016). Moreover, it was also found that consumer animosity led to rejection of products from the animosity country even a year after a conflict had ended (Ettensoe and Klein, 2005).

Table 4.3 shows all the constructs with negative foreign orientation or negative attitude towards foreign cultures that have been discussed. As can be seen in table 4.3, the boxes that represent negative attitude towards foreign cultures and negative towards own culture is empty, and negative attitude towards foreign cultures and neutral towards own 
culture has only one construct. This indicates that these are under-researched areas. On the other hand, the box representing negative attitude towards foreign cultures and positive attitude towards own cultures is a well-researched area.

Table 4.3: Constructs with negative foreign orientation

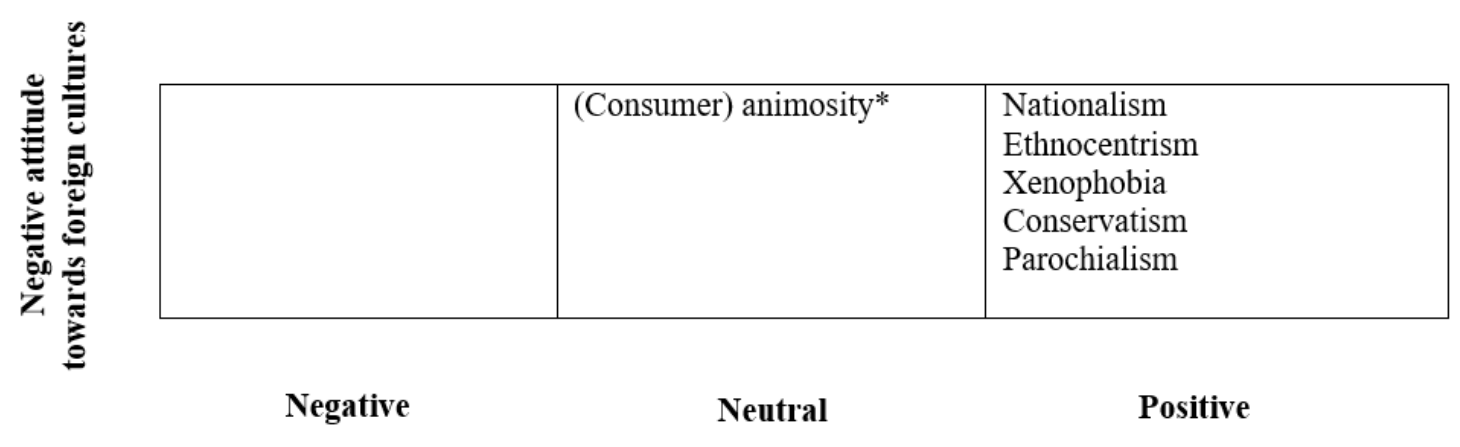

Attitudes towards own culture

* Specific to a foreign country

\subsection{Integrating the constructs}

In this chapter, 20 related constructs to xenocentrism have been reviewed. The constructs either have a positive foreign orientation, a neutral foreign orientation or a negative foreign orientation. This paragraph summarizes some key observations. 1.) Not all of the constructs are based on theory. In fact, a majority of the constructs have no theoretical underpinnings (e.g: GCO, belief in global citizenship, parochialism and localism to name a few). 2.) A few constructs are very similar to each other (e.g. GCO and SGCC; cultural openness and global openness; internationalism and worldmindedness). 3.) There has been very less research on constructs such as xenophilia, belief in global 
citizenship, SGCC, xenophobia and parochialism. On the other hand, there has been a lot of research done on the ethnocentrism and cosmopolitanism constructs. Yet there is no consensus on the cosmopolitanism definition or the scale. 4.) Except consumer animosity and affinity which are associated with a specific country, all other constructs are related to multiple foreign countries. 5.) Some of the constructs are associated with preference for local/foreign products (e.g. consumer ethnocentrism) and others are related to preference for other aspects such as local/foreign people and culture to name a few (e.g. xenophilia). 6.) Very few of the related constructs have been empirically tested with consumer xenocentrism.

Table 4.4 below classifies all the 20 related constructs and consumer xenocentrism according to the attitude towards foreign cultures and attitude towards own culture. This table is a combination of tables 4.1, 4.2 and 4.3. It can be seen, to the best of my knowledge, there is no research done when the attitude towards own culture and foreign cultures are both neutral or both negative or a combination of both. Also, it can be seen that some boxes are more researched than others. Of specific interest with respect to this thesis is the positive attitude towards foreign cultures and negative attitude towards our culture box. Both constructs in this box, consumer xenocentrism and xenophilia are under-researched constructs in International Business and Marketing. With respect to international marketing, consumer xenocentrism is more relevant and this construct is the focus of this thesis. Thus, this thesis concentrates on an understudied construct in an under-researched area i.e. positive attitude towards foreign products and negative attitude towards domestic products. 
Table 4.4: Classification according to attitude towards domestic/foreign cultures

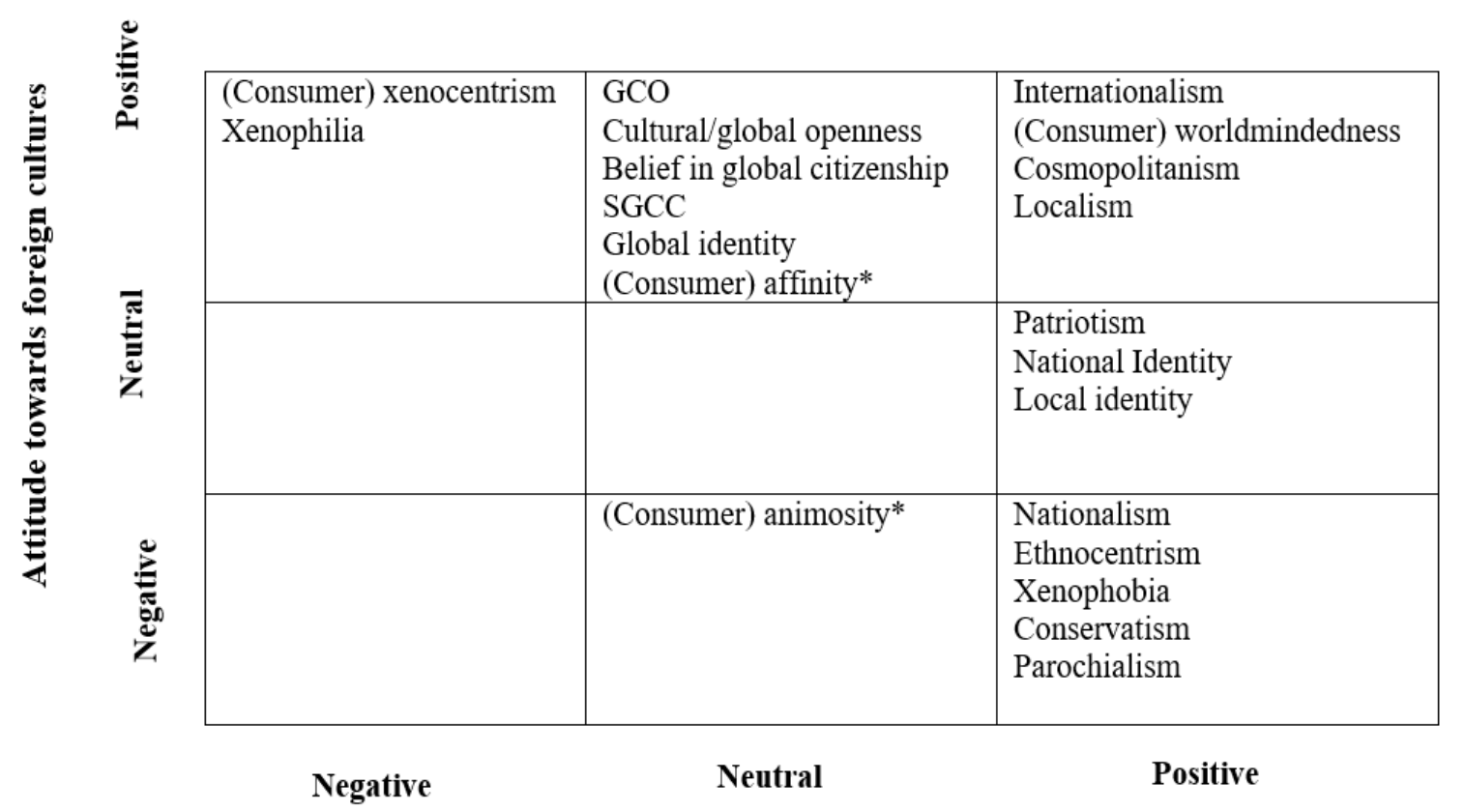

Attitudes towards own culture

* Specific to a foreign country

For this thesis, several aspects were considered when choosing which related constructs would be tested in relationship to consumer xenocentrism. The selection criteria are as follows: 1.) The related construct should be theoretically grounded 2.) The related construct is a general and not specific foreign construct like consumer animosity and consumer affinity 3.) The scales for the related construct should have good psychometric properties, be in-line with how the construct is defined and be parsimonious. In short, the related construct should have a strong scale. 4.) After fulfilling all the above criteria, one related construct from each box in table 4.4 was selected to empirically test its relationship with consumer xenocentrism. Thus, global identity, consumer worldmindedness, national identity, local identity and ethnocentrism were selected. Though, local identity is the 
second construct to be chosen from the same box this is because local identity is the opposite of global identity and testing both constructs will give a fuller picture.

As mentioned earlier, the positive foreign constructs are expected to be positively associated with xenocentrism, neutral foreign constructs (because of them being positive to their own culture) are expected to have a negative relationship with xenocentrism and the negative foreign constructs are expected to be negatively associated with xenocentrism. Thus, five hypotheses are proposed below:

H10: Consumer xenocentrism will be positively related to consumer worldmindedness.

H11: Consumer xenocentrism will be positively related to global identity.

H12: Consumer xenocentrism will be negatively related to local identity.

H13: Consumer xenocentrism will be negatively related to national identity.

H14: Consumer xenocentrism will be negatively related to consumer ethnocentrism.

Figure 4.1 gives a pictorial representation of all the hypotheses that have been proposed in this chapter. Each related construct has been shown along with its supporting theory. Specifically, the related construct consumer worldmindedness is supported by the modernization theory, global and local identities are backed by the regulatory focus theory, national identity is based on the self-categorization theory and consumer ethnocentrism is supported by the social identity theory. The main construct of interest in this thesis, consumer xenocentrism, is associated with the system justification theory. 
Figure 4.1: Conceptual model for related constructs

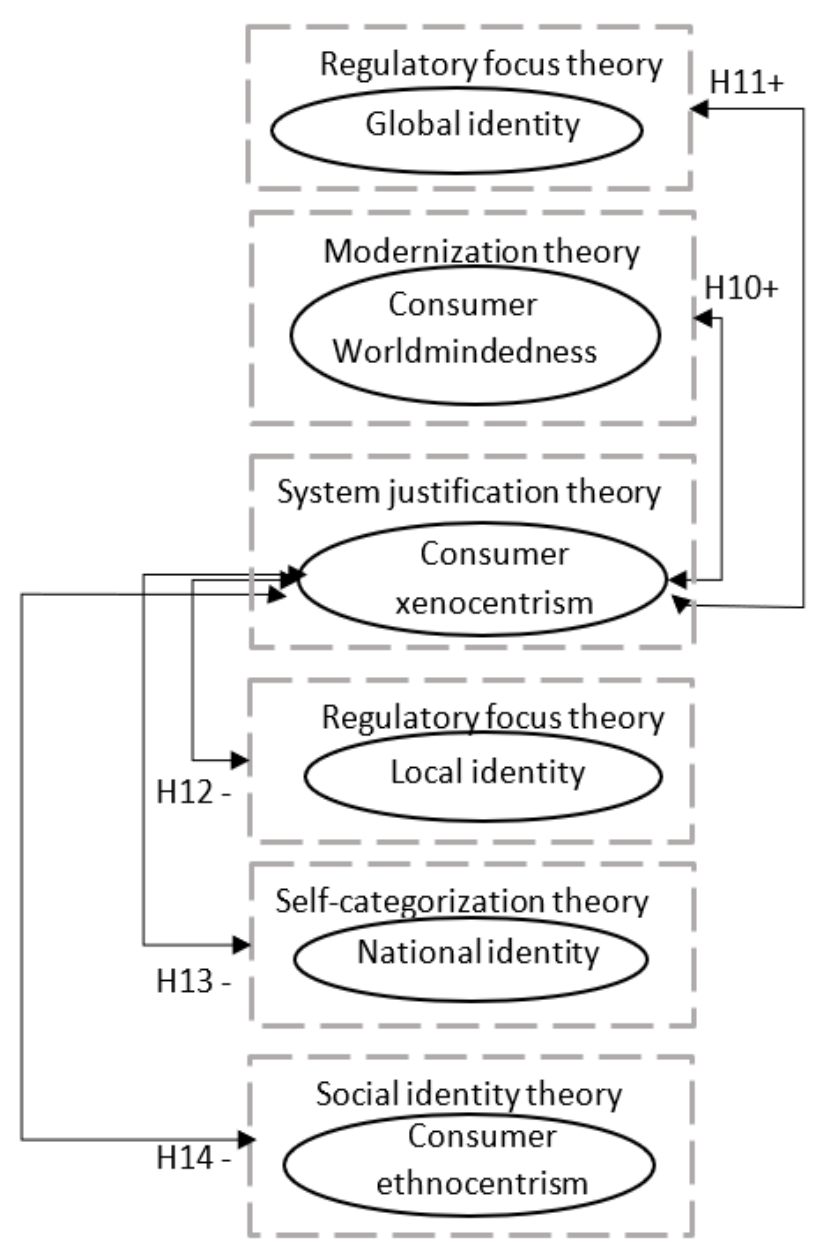

\subsection{Chapter summary}

This chapter first individually reviewed the constructs related to consumer xenocentrism. The constructs were mainly divided into constructs with positive attitude towards foreign cultures, constructs with neutral attitude towards foreign cultures, and constructs with negative attitude towards foreign cultures and were examined. It was found that some areas were more researched than others. This comprehensive review threw light on the under-researched area of positive attitude towards foreign cultures and negative attitude towards own culture which will be studied in this thesis via the construct, consumer 
xenocentrism. All 20 constructs reviewed and consumer xenocentrism were then integrated. Five related constructs (consumer worldmindedness, global identity, local identity, national identity and consumer ethnocentrism) were then selected using a few decision criteria and relevant hypotheses were proposed. Finally, a conceptual diagram for the selected related constructs along with the corresponding theory for each of those related constructs was presented.

It is important to know how consumer xenocentrism is associated with the other existing related constructs in the literature. Currently, consumer xenocentrism has been tested only with very few of the related constructs. Testing it with more related constructs from the literature will give a wider sense of how the consumer xenocentrism construct relates to these constructs while also checking the validity of the consumer xenocentrism scale itself (which is new).

So far, in this thesis, the antecedents and related constructs of consumer xenocentrism have been covered. The upcoming chapter will address the third and fourth research questions and will thus discuss the potential consequences and moderators of consumer xenocentrism. 


\section{CHAPTER FIVE - CONSEQUENCES AND MODERATORS}

\subsection{Introduction}

In this chapter, first the potential consequences of consumer xenocentrism will be discussed. Next, the potential moderators to the relationship between consumer xenocentrism and the various consequences variables will be examined. Simultaneously, the theories relevant to the consequences and moderators will also be reviewed and the hypotheses will be set.

\subsection{Consequences}

There is scant research done on the consequences of consumer xenocentrism (Bartsch et al., 2016). Few studies have used potential consequences constructs such as preference for foreign goods and willingness to buy foreign goods to test the predictive validity of their respective consumer xenocentrism scales (Rojas-Méndez and Chapa, 2019; Balabanis and Diamantopoulos, 2016). Other than these studies, there is not much empirical knowledge about the consequences of consumer xenocentrism. Also, these studies have each used a different consumer xenocentrism scale to test a different xenocentrism consequence. That is, Rojas-Méndez and Chapa (2019) test for relationship between consumer xenocentrism and preference for foreign goods using X-Scale and Balabanis and Diamantopoulos (2016) test for relationship between consumer xenocentrism and willingness to buy foreign goods using C-XENSCALE. Thus, there is a need to study how consumer xenocentrism influences multiple consequences using the same scale to get a fuller picture. In sum, owing to very little research that has been conducted on the consequences of consumer xenocentrism and the fact that the tested 
consequences all use different consumer xenocentrism scales, there is a need to study the consequences of consumer xenocentrism in a more in-depth and structured manner.

The consequences constructs proposed in this chapter are based on and derived from the Theory of Reasoned Action (TRA). Thus, TRA is discussed first followed by the two proposed consequences constructs, purchase intention of foreign products and ownership of foreign products.

\subsubsection{Theory of Reasoned Action (TRA)}

TRA (Fishbein and Ajzen, 1975; Ajzen, 1991) is from the field of psychology. TRA has received a great deal of attention since it was introduced by Fishbein and Ajzen in 1975. The theory has been used in a variety of fields - ethics (Chang, 1998), consumer behavior (Shimp and Kavas, 1984), healthcare (Roberto et al., 2011) and information technology (Moore and Benbasat, 1996) to name a few. Figure 5.1 shows the diagrammatic representation of the theory.

Figure 5.1: TRA (Adapted from Dillard and Pfau, 2002)

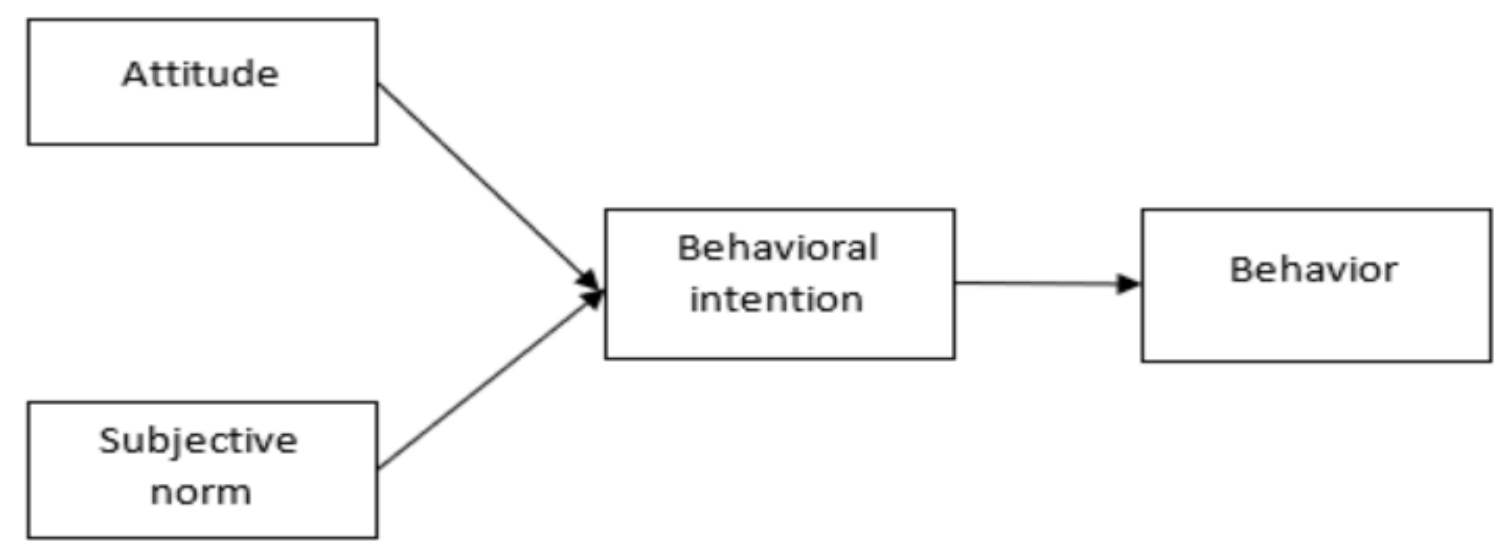


The main aim of TRA is to explain what influences behavior. Behavioral intention is the nearest, direct predictor of behavior. In other words, behavioral intention comes before real behavior. In turn, behavioral intention has two antecedents: attitude and subjective norm (Fishbein and Ajzen, 1975; Ajzen, 1991). The following paragraphs will explain the constructs of the model in more depth.

Attitude can be defined as "a learned predisposition to respond to an object in a consistently favorable or unfavorable manner" (Fishbein and Ajzen, 1975, p. 336). Fishbein and Ajzen (1975) and Ajzen (1991) argue that attitude towards the behavior is the extent to which an individual has positive or negative evaluations towards that behavior. Fishbein and Ajzen (1975) add that attitude is based on feelings.

Subjective norm is the perceived belief of whether one's group approves of or does not approve of a behavior. Put another way, it is an individual's perception of whether his social group wants him to perform or not perform that behavior (Fishbein and Ajzen, 1975; Ajzen, 1991; Dillard and Pfau, 2002). Subjective norm consists of normative beliefs and motivation to comply (Fishbein and Ajzen, 1975; Dillard and Pfau, 2002). Normative beliefs are the perceived standards of the group. An example of normative beliefs is that the social group believes that owning foreign goods is the standard. Motivation to comply is the pressure that the individual experiences to behave in a way that conforms the perceived group's standards (Fishbein and Ajzen, 1975; Dillard and Pfau, 2002).

Behavioral intention is the measurement of probability that a behavior will happen, and behavior is the actual response (Fishbein and Ajzen, 1975; Ajzen, 1991). The greater the attitude towards the behavior and the subjective norms, the greater is the behavioral 
intention. It follows that the greater the behavioral intention, the more probability that the actual behavior will take place (Fishbein and Ajzen, 1975; Ajzen, 1991).

In our case, the intended behavior is purchasing foreign products. The attitude towards purchasing foreign products and the subjective norms (perception of an individual's social group on purchasing foreign products) will play a crucial role on the behavioral intention (purchase intention of the foreign product) which in turn will influence the behavior (purchasing foreign products).

Earlier studies have found that attitudes and subjective norms are both highly correlated constructs (Ajzen, 1991). Furthermore, the susceptibility to normative influence construct (which can be used to measure subjective norm) will be used as an antecedent to consumer xenocentrism keeping in line with the extant literature findings that associate xenocentrism and normative influence (Mueller et al., 2016; Rojas-Méndez and Chapa, 2019; Balabanis and Diamantopoulos, 2016) as elaborated in section 2.4 and section 3.5. Additionally, several studies have tested / mentioned only the path from attitude to behavioral intention to behavior (Bartsch et al., 2016; Evanschitzky and Wunderlich, 2006; Yoo and Donthu, 2005). Since consumer xenocentrism is an attitude, taking together all the above points, only the path from behavioral intention to behavior shown in figure 5.1 will be used in the consequences model. This path is illustrated below in figure 5.2.

Figure 5.2: TRA path for consequences model

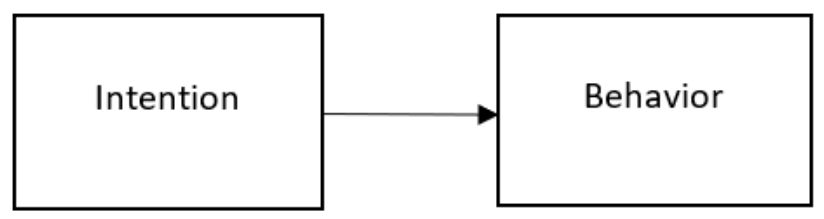


Next, the two consequences constructs to be tested in this thesis based on TRA will be reviewed.

\subsubsection{Purchase intention of foreign products}

Purchase intention has also been called willingness to buy in the extant literature. Purchase intention corresponds to the behavioral intention in TRA. Rojas and Chapa (2019) and Balabanis and Diamatopoulos (2016) find that consumer xenocentrism was negatively associated with purchase intention of domestic products. Rojas and Chapa (2019) also find that consumer xenocentrism is positively associated with purchase intention of foreign goods from developed countries. These relationships were tested as part of confirming the predictive validity of their respective scales.

High GCO and SGCC, both pro-foreign constructs, are positively associated with purchase intention of foreign products (Riefler et al., 2012; Zhou et al., 2008). On the other hand, consumer ethnocentrism, a pro-domestic construct, is negatively associated with purchase intention of foreign products (Yoo and Donthu, 2005; Shankarmahesh, 2006). In line with the above findings, it is expected that consumer xenocentrism will positively influence the purchase intention of foreign products. Thus, the following hypothesis is proposed:

H15: Consumer xenocentrism will have a positive effect on purchase intention of foreign products. 


\subsubsection{Ownership of foreign products}

This construct corresponds to the actual behavior in TRA. Behavior has been conceptualized as purchasing frequency (Cleveland et al., 2009; Shoham and Brencic, 2003; Riefler et al., 2012) or ownership in the extant literature (Klein et al., 1998; Yoo and Donthu, 2005; Yu and Albaum, 2002; Granzin and Olsen; 1998, He and Wang, 2015; Russell et al., 2011; Strizhakova and Coulter, 2015; Strizhakova et al., 2011). The link between consumer xenocentrism and actual behavior (purchasing frequency or ownership of foreign products) has not been tested yet.

Cosmopolitanism, a pro-foreign construct, positively influences purchase of foreign products (Parts and Vida, 2013; Riefler et al., 2012). Similarly, consumer xenocentrism, a pro-foreign construct, is also expected to positively influence the ownership of foreign products. Additionally, purchase intention of foreign products has been found to positively influence ownership of foreign products (Yoo and Donthu, 2005). In general, purchase intention has been found to positively influence ownership of products (Klein et al., 1998). Both the above statements are in line with TRA which posits that behavioral intentions influence behavior. Thus, with respect to consumer xenocentrism, positive purchase intention of foreign products is expected to positively influence ownership of foreign products.

Taking together the points from the previous paragraph the two expected relationships are 1.) consumer xenocentrism will positively influence ownership of foreign products 2.) positive purchase intention of foreign products will positively influence ownership of foreign products. Thus, the following hypotheses are proposed: 
H16: Consumer xenocentrism will have a positive effect on ownership of foreign products.

H17: Purchase intention of foreign products will have a positive effect on ownership of foreign products.

Figure 5.3 gives a pictorial representation of the consequences model with all the hypotheses that have been proposed so far in this chapter. It must be noted that an adapted model of TRA is being used. That is, not only is a link proposed between consumer xenocentrism (attitude), to purchase intention of foreign products (behavioral intention) to ownership of foreign products (behavior), there is a direct link proposed between consumer xenocentrism and ownership of foreign products as well because there is support for such an association from extant literature.

Figure 5.3: Conceptual model for consequences

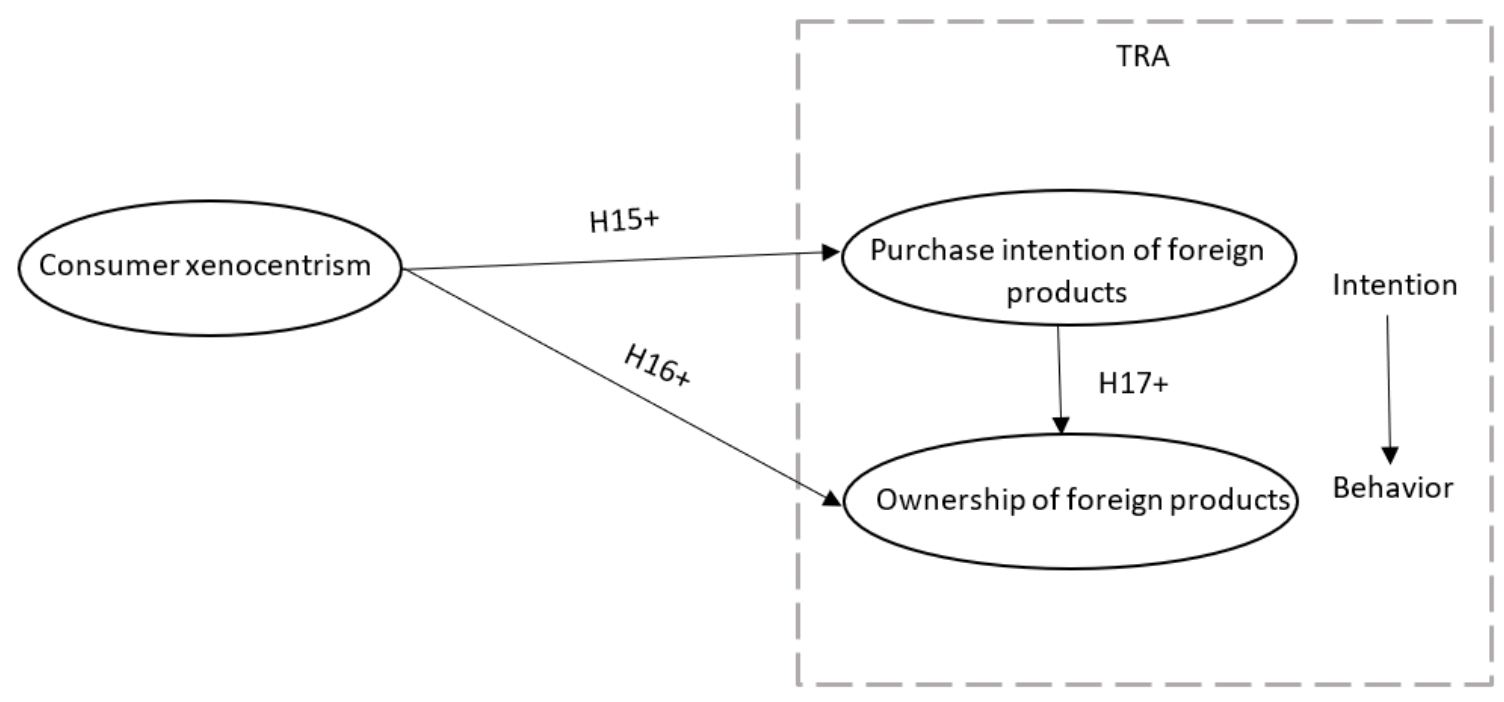




\subsection{Moderators}

This section will discuss potential moderators to the relationship between consumer xenocentrism and the different consequences variables. Figure 5.4 shows all the potential moderators that will be discussed in the upcoming sections.

Figure 5.4:Potential moderators of consumer xenocentrism

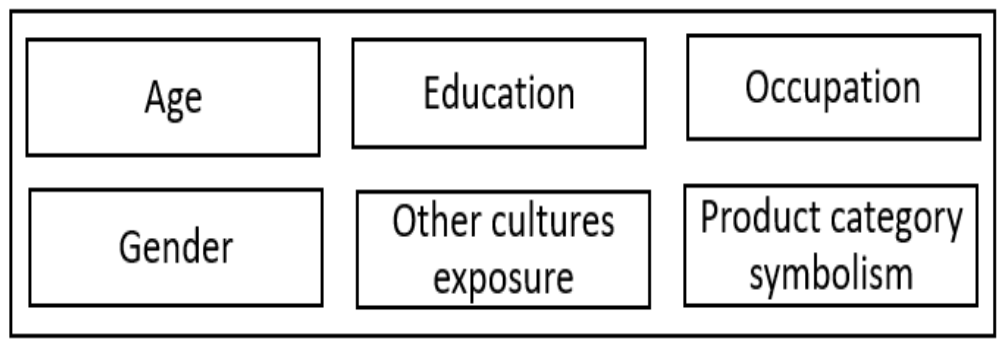

The proposed moderators were identified based on the themes from the consumer xenocentrism and other related constructs extant literature. These themes are elaborated under each moderator construct section below. Additionally, two of the moderators, exposure to other cultures and product category symbolism are theoretically grounded.

\subsubsection{Age}

The first moderator that is proposed is age. Bailey and Pineres (1997) found younger consumers to be more xenocentric. Their research however reverse interprets the CETSCALE scores to measure consumer xenocentrism i.e. a low score on the ethnocentrism scale means that the consumer is xenocentric. The disadvantages of this approach have been discussed in chapter 2, section 2.9.1. Mueller et al. (2016) and 
Kisawike (2015) argue that younger consumers are more xenocentric, but both studies are not empirical. Additionally, Mueller and Broderick (2009) argue that age might be a potential moderator to consumer xenocentrism. Thus, there is a need to empirically test age as a moderator.

From the extant literature, following are the reasons why younger people are expected to be more xenocentric 1.) Younger individuals view foreign goods as symbols of modernity and independence (Mueller et al., 2016; Batra et al., 2000) 2.) Younger individuals have more exposure to foreign cultures through for example living overseas or having social connections abroad or global media and this aspect influences xenocentrism (Prince et al., 2016; Lawrence, 2012; Kent and Burnight, 1951). The relationship between xenocentrism and younger consumers was also explained in section 2.8.3.

Studies have found a positive relationship between younger people and cosmopolitanism (Riefler et al., 2012; Riefler and Diamantopoulos, 2009) cosmopolitanism being a pro-foreign construct. On the other hand, studies have found a positive relationship between older consumers and consumer ethnocentrism, a prodomestic construct (Cleveland et al., 2009; Josiassen et al., 2011; Lee et al., 2003; de Ruyter et al., 1998). Taken together, there is additional support that younger consumers are expected to be more pro-foreign.

In sum, given all the points mentioned in this section, age seems to be an important variable to test with xenocentrism. Thus, age will be tested in two ways 1.) The relationship between age and consumer xenocentrism will be tested (antecedent) 2.) The effect of age on the relationship between consumer xenocentrism and the consequence variables will be tested (moderator). It is expected that younger consumers will be more xenocentric than 
older consumers and that the impact of consumer xenocentrism on consequences variables decreases with age. It is expected that age will also be a moderator because Mueller and Broderick (2009) suggest that relationship. Additionally, because it is expected that younger people will be more xenocentric, it can also expected that that attitude will translate into them having a higher willingness to buy and own foreign products than older people. Since younger individuals see foreign goods as a sign of modernity and freedom, they will want to want to own it more than the older individuals.

The testing of demographic variables as both an antecedent and a moderator has been previously done in studies (e.g. Josiassen et al., 2011) and will be carried out in this thesis as well. The antecedent hypothesis for age and xenocentrism has already been proposed in the antecedents chapter 3, section 3.6 (hypothesis H5). Thus, only the moderator hypotheses for age are proposed below:

H18: The impact of consumer xenocentrism on purchase intention of foreign products decreases with age.

H19: The impact of consumer xenocentrism on ownership of foreign products decreases with age.

\subsubsection{Education}

Education is the second moderator that is proposed for xenocentrism. Bailey and Pineres (1997) found that individuals with higher education were more xenocentric. The shortcoming of this study, as mentioned previously, is the use of ethnocentrism scale in a reverse manner to measure consumer xenocentrism. Kisawike (2015) also suggests that highly educated consumers to be more xenocentric but this was a qualitative study with 
few respondents. Thus, there is a need to empirically study the effects of education on consumer xenocentrism.

Highly educated consumers are likely to travel abroad more, have social contacts overseas and know a foreign language (Riefler et al., 2012). In other words, they have a greater probability of being exposed to other cultures in one way or the other and this aspect could contribute to them being xenocentric. Also, it has been found that there is a positive relationship between highly educated consumers and other pro-foreign constructs such as cosmopolitanism and worldmindedness (Riefler et al., 2012; Cleveland et al., 2009; Bartsch et al., 2016). Thus, there is additional support that highly educated consumers are more pro-foreign.

In sum, education seems to be a key variable to test with xenocentrism. Therefore, education will be tested in two ways 1.) The relationship between education and consumer xenocentrism will be tested (antecedent) 2.) The effect of education on the relationship between consumer xenocentrism and the consequences variables will be tested (moderator). It is expected that highly educated consumers will be more xenocentric than less educated consumers and that the impact of consumer xenocentrism on consequences variables increases with education. As there is some evidence in extant literature that highly educated consumers are more xenocentric, it is likely that this positive evaluation of foreign products will likely result in them willing to buy and own foreign products more than consumers with lower education. Also, since highly educated consumers are likely welltravelled and have contacts overseas, they are likely to own foreign products to emulate their contacts and elevate their own status more than lower educated consumers. 
The antecedent hypothesis for education and xenocentrism has already been proposed in the antecedents chapter 3, section 3.6 (hypothesis H6). Thus, only the moderator hypotheses for education are proposed below:

H20: The impact of consumer xenocentrism on purchase intention of foreign products increases with education.

H21: The impact of consumer xenocentrism on ownership of foreign products increases with education.

\subsubsection{Occupation}

In their study, Mueller et al. (2016) propose that white collar or professional employees were more xenocentric. However, Mueller et al. (2016) was an exploratory, qualitative research and a larger empirical study is needed to test the relationship between occupation and consumer xenocentrism. Additionally, blue collar or non-professional employees have been found to be more ethnocentric, ethnocentrism being a pro-domestic construct (Han 1988). Thus, it is likely that professional employees will be more proforeign.

In a number of studies, the income variable has been used instead of occupation. Higher income has been associated with foreign product consumption. For example, Mueller et al. (2016) argue that the wealthy are more xenocentric. They argue that this is the case because people with higher incomes are able to afford expensive foreign products. Additionally, several studies have established the relationship between higher income and owning foreign goods (Bailey and Pineres, 1997; Belk, 2000; Kisawike, 2015). Also, Mueller and Broderick (2009) assert that the wealthy might purchase foreign goods to 
display their status. The authors suggest that there might be a positive association between income and consumer xenocentrism. However, the problem with using income variable in a study is that often people are not very truthful about their income. Also, they might be uncomfortable sharing this information as it is sensitive and personal. Taking into account the above disadvantages, the occupation variable will be used in this study instead of the income variable. That is, occupation can serve as a substitute or proxy for income.

The effect of occupation on the relationship between consumer xenocentrism and the consequences variables will be tested (moderator). It is expected that the impact of consumer xenocentrism on consequences variables is moderated by occupation so that the relationship is stronger for professional employees than for non-professional employees. In other words, occupation is expected to be a moderator because there is evidence from Mueller et al. (2016) that professional employees are xenocentric and because usually they are in higher-paying jobs in developing countries, they might be able to afford foreign products and thus increase their status more than employees with non-professional jobs.

The hypotheses for occupation are proposed below:

H22: The impact of consumer xenocentrism on purchase intention of foreign products is moderated by occupation so that the relationship is stronger for professional employees than for non-professional employees.

H23: The impact of consumer xenocentrism on ownership of foreign products is moderated by occupation so that the relationship is stronger for professional employees than for nonprofessional employees. 


\subsubsection{Gender}

The next moderator that will be tested is gender. Mueller and Broderick (2009) assert that women may be more xenocentric than men and call for empirically testing the relationship. They argue that this might be the case because women who live in maledominated societies may buy foreign products as a way to rebel against their society. The Gender Gap report published by the World Economic forum shows that with respect to gender equality several top spots are dominated by the Western developed countries and many developing countries in Asia, Latin America and Africa rank much lower than the developed countries (United Nations Dispatch, 2018). With respect to the different regions, Western Europe and North America which are regions that have the majority of developed countries, are the most gender-equal places (World Economic Forum, 2017). Thus, women in the developing countries and transitional economies where gender equality is lower may purchase foreign products from the more gender-equal developed countries as a way of protest. Additionally, Schooler (1971) find that women have a foreign products bias. Women were also found to be more cosmopolitan, a pro-foreign construct (Cleveland et al., 2009). Therefore, it is possible that women are more xenocentric than men.

On the other hand, Rojas-Méndez and Kolotylo (2018) in a study conducted in Russia found that men are more xenocentric than women. Additionally, a number of studies have found women to be more ethnocentric (a pro-domestic construct) than men (Balabanis et al., 2001; Javalgi et al., 2005; Lee et al., 2003). Also, males had a stronger GCO, a proforeign construct (Prince et al., 2016). Therefore, it is possible that men are more xenocentric than women. 
In sum, taking all the above points together, there are mixed results from extant literature on which gender is more xenocentric. Although Mueller and Broderick (2009) assert that women are likely to be more xenocentric, it is only a proposition and has not been empirically tested. Only one study has previously empirically tested this relationship (Rojas-Méndez and Kolotylo, 2018) and found males to be more xenocentric. Additionally, because of gender inequality in societies, men are usually in positions of high power and hence status is important to them (Eagly, 1983). Thus, it is more likely that men are more xenocentric than women and this is the relationship that will be tested in this thesis.

Gender will be tested in two ways 1.) The relationship between gender and consumer xenocentrism will be tested (antecedent) 2.) The effect of gender on the relationship between consumer xenocentrism and the consequences variables will be tested (moderator). Gender is expected to also be a moderator because men in developing countries are xenocentric and thus they would be more willing to buy and own foreign products to reinforce their status than women in those countries.

The antecedent hypotheses have already been proposed in the antecedents chapter 3, section 3.6 (hypothesis H7). Thus, only the moderator hypotheses for gender are proposed below:

H24: The impact of consumer xenocentrism on purchase intention of foreign products is moderated by gender so that the relationship is stronger for men than for women. H25: The impact of consumer xenocentrism on ownership of foreign products is moderated by gender so that the relationship is stronger for men than for women. 


\subsubsection{Exposure to other cultures}

The fifth moderator to be tested will be exposure to other cultures. Several authors argue that individuals who have exposure to other cultures are more xenocentric (Kent and Burnight, 1951; Lawrence, 2012; Mueller et al., 2016). Mueller et al. (2016) posit that people who have exposure to other cultures through oversees contacts or from having studied or worked abroad are more xenocentric. However, Mueller et al. (2016) is an exploratory study and an empirical study is needed to test this relationship.

Mueller and Broderick (2009) assert that exposure to other cultures through mass media, tourists and travel enables individuals in developing countries to form stereotypes of consumption patterns in Western countries and the associated superior lifestyle that comes with it. The distribution of media throughout the world and how this action aids in different cultures forming opinions about each other is referred to as "mediascapes" in anthropology (Appadurai, 1996). Additionally, exposure to other cultures has been positively associated with different pro-foreign constructs such as internationalism, cosmopolitanism, worldmindedness and GCO (Bartsch et al., 2016; Riefler et al., 2012; Kagitcibasi 1978; Nijssen and Douglas 2008; Sampson and Smith 1957; Alden et al., 2006). Thus, there is support that consumers with exposure to other cultures have a positive foreign bias.

Having a preference for foreign products because of exposure to foreign cultures is based on the "mere exposure effect" theory. This theory is from the field of psychology. Mere exposure effect proposes that repeatedly exposing someone to an object will contribute to that person having positive feelings towards that object (Zajonc, 1968). 
Zajonc (2001) argues that it is not necessary for the person to engage with the object in anyway and the mere repeated exposure is enough for forming a favorable attitude towards that object. That is, he asserts that the mere exposure effect does not require a conscious effort. Mere exposure effect has been shown with several animate and inanimate objects including people (Zajonc, 1968; Zajonc, 2001). To elaborate, for example, the more an individual sees another person, the more positively the individual views that person. Thus, mere exposure to an object enhances preference towards that object (Tom et al., 2007). Relating this to xenocentrism, repeated exposure to other cultures and in turn their products results in individuals developing a positive attitude towards the products of other cultures.

Thus, exposure to other cultures will be tested in two ways 1.) The relationship between exposure to other cultures and consumer xenocentrism will be tested (antecedent) 2.) The effect of exposure to other cultures on the relationship between consumer xenocentrism and the consequences variables will be tested (moderator). It is expected that exposure to other cultures will be positively associated with xenocentrism and that the impact of consumer xenocentrism on consequences variables will be moderated by exposure to other cultures so that the relationship for individuals with higher exposure to other cultures is stronger than for those who have lower exposure to other cultures. This is because higher exposure to other cultures has made the individuals in the developing countries see the superior lifestyle lived by consumers in the developed countries and in order to elevate their own status, they emulate consumption practices of consumers in foreign countries. This in turn leads to them willing to buy foreign products and own those products more than developing country consumers with lower exposure to foreign cultures. 
Exposure to other cultures will be measured in two ways: global media exposure and international travel experience/preference. Global media exposure measures exposure to other cultures while an individual is still in his home country. It is possible that mere repeated exposure to other cultures through media can make an individual favor foreign products and make him xenocentric. On the other hand, international travel experience/preference measures exposure to other cultures based on an individual's experience abroad. It is possible that repeated exposure to other cultures through foreign travel can make a person like foreign products and in turn make him xenocentric.

The antecedent hypotheses for exposure to other cultures (both global media exposure and international travel experience/preference) and xenocentrism have already been proposed in the antecedents chapter 3, section 3.6 (hypotheses H8 and H9). Thus, only the moderator hypotheses for exposure to other cultures (both global media exposure and international travel experience/preference) are proposed below:

H26: The impact of consumer xenocentrism on purchase intention of foreign products is moderated by global media exposure so that the relationship is stronger for individuals with higher exposure to global media than for individuals with lower exposure to global media.

H27: The impact of consumer xenocentrism on ownership of foreign products is moderated by global media exposure so that the relationship is stronger for individuals with higher exposure to global media than for individuals with lower exposure to global media. 
H28: The impact of consumer xenocentrism on purchase intention of foreign products is moderated by international travel experience/preference so that the relationship is stronger for individuals with higher frequency and interest in international travel than for individuals with lower frequency and interest in international travel.

H29: The impact of consumer xenocentrism on ownership of foreign products is moderated by international travel experience/preference so that the relationship is stronger for individuals with higher frequency and interest in international travel than for individuals with lower frequency and interest in international travel.

\subsubsection{Product category symbolism}

The last moderator that will be tested is product category symbolism. Product category symbolism can be explained by the seminal work in consumer behavior called "Possessions and the extended self". Belk (1988) argues that the objects we own are a chief contributor of our identities. He asserts that this is because identity influences our selfesteem. Thus, individuals pursue experiences that augment one's identity (Sirgy, 1982). Belk (1988) uses the example of the brand of automobile that a man drives as an important contributor of his identity. In this example, Belk (1988) argues that the automobile is very much linked to that person's identity that it becomes part of the person's extended self.

People use products to communicate their intended identities to others (Strizhakova and Coulter, 2015). Berger and Heath (2007) argue that this expression of identity is greater with respect to some product categories than others. They assert that this is because some product categories are perceived as symbolic of one's identity and are used by others to 
conclude one's identity. They point out that some product categories that are symbolic of one's identity are car brands and music genres.

With respect to consumer xenocentrism this could be associated with individuals tending to buy more foreign products in product categories that are symbolic of their identity than other product categories. For example, it could be higher for product categories that are important contributors of one's identity such as cars, watches, phones than products such as toiletries. Thus, the effect of product category symbolism on the relationship between consumer xenocentrism and the consequences variables will be tested. The impact of consumer xenocentrism on consequences variables is expected to be moderated by product category symbolism so that the relationship for product categories that contribute to one's identity is stronger than for other product categories.

The moderator hypotheses for product category symbolism are proposed below:

H30: The impact of consumer xenocentrism on purchase intention of foreign products is moderated by product category symbolism so that the relationship is stronger for product categories that contribute to one's identity than for other product categories.

H31: The impact of consumer xenocentrism on ownership of foreign products is moderated by product category symbolism so that the relationship is stronger for product categories that contribute to one's identity than for other product categories.

The specific products categories will be discussed in section 6.3 .13 in the next chapter. Figure 5.5 includes the moderator hypotheses added to the consequences model in figure 5.3. This is the complete conceptual model for consequences and moderators. 
Figure 5.5: Conceptual model for consequences and moderators

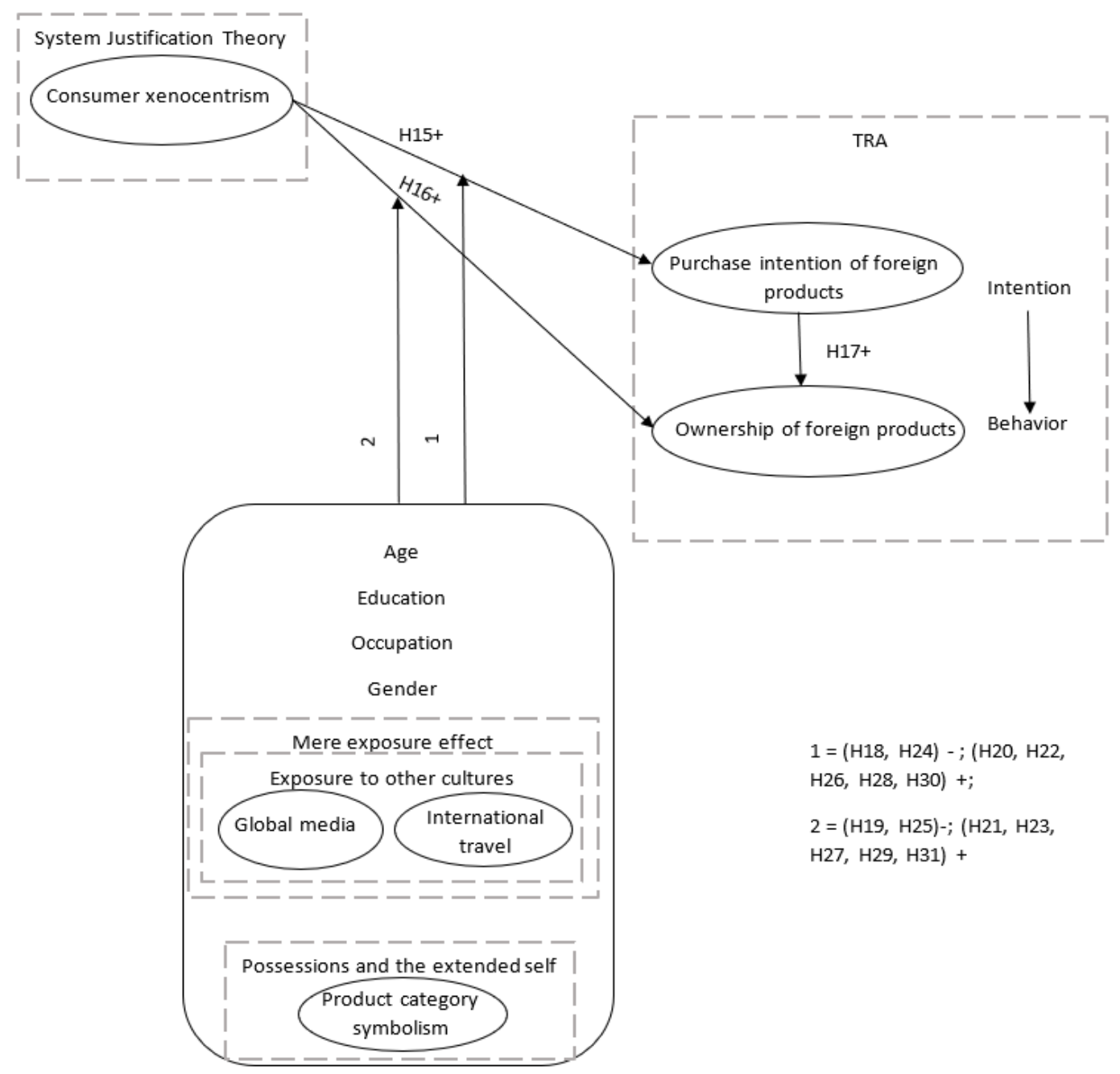

Table 5.1 consolidates all the hypotheses established in this chapter.

Table 5.1: Summary of consequences and moderators' hypotheses

H15: Consumer xenocentrism will have a positive effect on purchase intention of foreign products.

H16: Consumer xenocentrism will have a positive effect on ownership of foreign products.

H17: Positive purchase intention of foreign products will have a positive effect on ownership of foreign products. 
H18: The impact of consumer xenocentrism on purchase intention of foreign products decreases with age.

H19: The impact of consumer xenocentrism on ownership of foreign products decreases with age.

H20: The impact of consumer xenocentrism on purchase intention of foreign products increases with education.

H21: The impact of consumer xenocentrism on ownership of foreign products increases with education.

H22: The impact of consumer xenocentrism on purchase intention of foreign products is moderated by occupation so that the relationship is stronger for professional employees than for non-professional employees.

H23: The impact of consumer xenocentrism on ownership of foreign products is moderated by occupation so that the relationship is stronger for professional employees than for non-professional employees.

H24: The impact of consumer xenocentrism on purchase intention of foreign products is moderated by gender so that the relationship is stronger for men than for women.

H25: The impact of consumer xenocentrism on ownership of foreign products is moderated by gender so that the relationship is stronger for men than for women.

H26: The impact of consumer xenocentrism on purchase intention of foreign products is moderated by global media exposure so that the relationship is stronger for individuals with higher exposure to global media than for individuals with lower exposure to global media.

H27: The impact of consumer xenocentrism on ownership of foreign products is moderated by global media exposure so that the relationship is stronger for individuals with higher exposure to global media than for individuals with lower exposure to global media.

H28: The impact of consumer xenocentrism on purchase intention of foreign products is moderated by international travel experience/preference so that the relationship is stronger for individuals with higher frequency and interest in international travel than for individuals with lower frequency and interest in international travel.

H29: The impact of consumer xenocentrism on ownership of foreign products is moderated by international travel experience/preference so that the relationship is stronger for individuals with higher frequency and interest in international travel than for individuals with lower frequency and interest in international travel.

H30: The impact of consumer xenocentrism on purchase intention of foreign products is moderated by product category symbolism so that the relationship is stronger for product categories that contribute to one's identity than for other product categories.

H31: The impact of consumer xenocentrism on ownership of foreign products is moderated by product category symbolism so that the relationship is stronger for product categories that contribute to one's identity than for other product categories. 


\subsection{Chapter Summary}

This chapter discussed all the proposed consequences of xenocentrism and moderators to the relationship between consumer xenocentrism and the various consequences variables. The corresponding theories were also reviewed. Two consequences, purchase intention of foreign products and ownership of foreign products were proposed, and their relationship was explained by the theory of reasoned action. Seven moderator variables namely age, education, occupation, gender, global media, international travel and product category symbolism were proposed. Mere exposure effect and the theory of extended self explained the non-demographic moderators global media, international travel and product category symbolism. Relevant hypotheses were set for every consequence and moderator variable and a conceptual model for the consequences and moderators was presented. This chapter completed the setting of all the hypotheses for this thesis. The next chapter touches on the research methodology that was followed for this research. 


\section{CHAPTER SIX - RESEARCH METHODOLOGY}

\subsection{Introduction}

This chapter outlines the methodology used in this research. First, the countries where the study was carried out are discussed. Second, the method used and questionnaire development along with the measures employed is explained. Third, the translation practices of the survey instrument are elaborated. Fourth, the pilot study process is described, and the preliminary analysis is presented. Finally, the data collection procedure is explained.

\subsection{Country selection}

The hypotheses that were proposed in the previous chapters were tested in four countries. It is known that xenocentrism is a phenomenon primarily observed in developing countries and transitional economies. Thus, four developing countries, one each from Asia, Eastern Europe, South America and Africa were used as locations for this study. In this section, each of the countries is discussed.

In Asia, India is the location where the study was conducted. The World Bank classifies India as a lower middle-income country (The World Bank, 2018a). Xenocentrism has been observed in other Asian countries such as China, Pakistan, Philippines and Indonesia and has been briefly discussed in chapter 2, section 2.2.4. Xenocentrism in India has not been studied yet. India was historically under the British colonial rule and the presence of xenocentrism in former colonies have been previously discussed section 2.8.7. India is a developing country and has the sixth largest GDP as of 2017 (The World Bank, 2018b). Over the past decade, the rapid economic growth has resulted in an increase in 
income and in turn in increased consumer spending (KPMG, 2017). Thus, a number of global brands have now opened stores in India. Therefore, taking all the above points into account, India seems to have a conducive environment for xenocentrism making it a good market to study the phenomenon. Additionally, India being the second-most populous country translates into a huge consumer base further making it an important market to conduct this research.

India's scores on Hofstede's cultural dimensions are shown in figure 6.1.

Figure 6.1: Hofstede's cultural dimensions for India (Hofstede, 2018d)

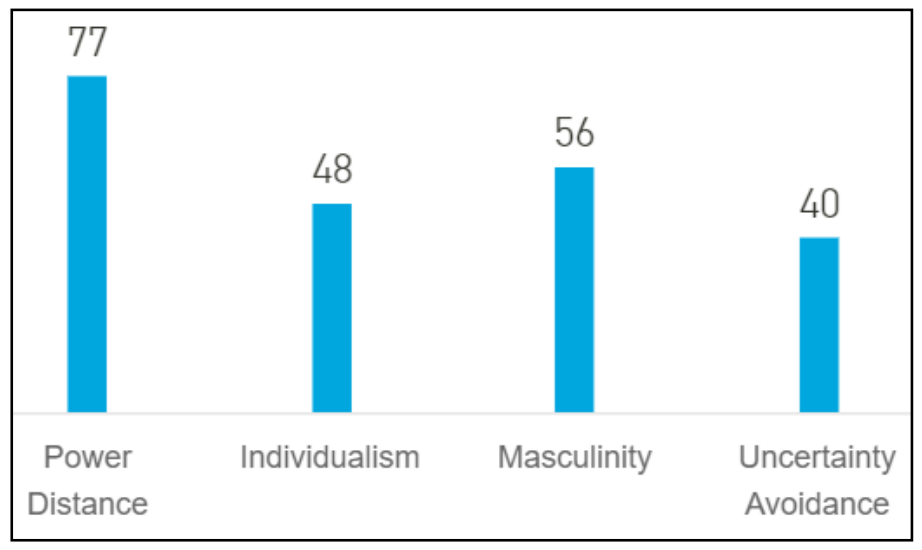

Hofstede's website also provides explanations for these cultural dimension scores which are discussed below. The power distance score of 77 signifies that India is a highly hierarchical society. Inequalities in the society are accepted by the individuals and individuals lower in the hierarchy take directions from ones higher in the order. Hierarchical societies are expected to be more xenocentric and this relationship has already been discussed in section 3.3. The individualism score of 48 for India signifies that the country is somewhere midway between individualism and collectivism, although slightly leaning towards collectivism. In collectivistic cultures there is a higher inclination to belong to large social structures and act according to the norms of the group. On the other 
hand, India's religious philosophies also have an emphasis on the role of an individual in living his life and thus there is focus on the individual as well. These aspects can explain the mid-way score of India in this dimension. Collectivistic societies are expected to be more xenocentric and this relationship has already been discussed in section 3.3. The masculinity score is 56 making India a masculine country where achievements and material rewards are a priority. Showing off one's success is very common although this is in moderation compared to countries with higher masculinity scores because humility is also valued in India. The uncertainty avoidance score of 40 signifies that India has medium to low inclination towards avoiding uncertainty. Rules and regulations are not hard and fast and are often circumvented.

In Eastern Europe, Romania is the location where the study was conducted. Romania is a member of the European Union. The World Bank classifies Romania as an upper middle-income country (The World Bank, 2018a). Thus, though Romania is better off in income than India, it is worse off than a Western developed country which fall under the high-income countries category. Till the late 1980s Romania was a communist country and adopted capitalism only in the 1990s. Much of Romania's rapid economic growth has been attributed to its membership in the European Union (EU) and it is seen as one of the fastest growing economies in the EU (Financial Observer, 2017). Romania joined the EU in 2007 and has since experienced phenomenal economic growth and this has in turn resulted in increased purchasing power (Romania Insider, 2017). This increase in purchasing power has led to a rise in consumer spending on Western products which is on par with the spending of the developed EU countries in some categories although the purchasing power of the developed EU countries are much higher (Passport, 2018; 
Romania Insider, 2017). Therefore, taking all the above points into account, Romania seems to have a conducive environment for xenocentrism making it a good market to study the phenomenon.

Romania's scores on Hofstede's cultural dimensions are shown in figure 6.2.

Figure 6.2: Hofstede's cultural dimensions for Romania (Hofstede, 2018e)

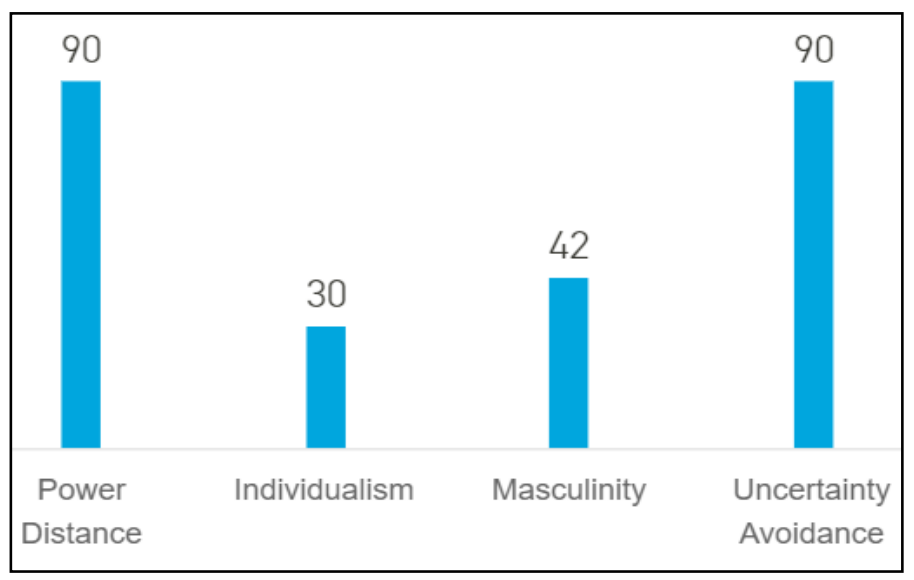

Romania's cultural dimension scores are elaborated below. These explanations are taken from Hofstede's website. The power distance score for Romania is 90 which shows that it is a highly hierarchical society. This score is even higher than that of India's making it a more hierarchical culture and thus Romania is likely to be xenocentric. Given that the individualism score is 30 , Romania is a collectivistic culture and is more collectivistic than India. Group norms and loyalty are given importance in collectivistic cultures. The score for masculinity is 42 making it a reasonably feminine society were values such as quality of life and harmony are highly prized. This is in contrast to India which is a bit more masculine society. The uncertainty avoidance score is 90 thus showing that the country has a high preference for avoiding uncertainty. This is in contrast to India which has a medium to low score on this dimension. 
In South America, Ecuador is the location where the study was conducted. Xenocentrism has been observed in Latin American countries such as Mexico, Colombia, Ecuador and Peru with Ecuador found to be the most xenocentric of the four (de Leff, 2002; Rojas-Méndez and Chapa, 2019; Bailey and de Pineres,1997). Ecuador has been under the colonial rule of Spain and the presence of xenocentrism in former colonies has been previously discussed in section 2.8.7. Ecuador is a developing country and like Romania is classified as an upper-middle income country (The World Bank, 2018a).

Ecuador's scores on Hofstede's cultural dimensions are shown in figure 6.3.

Figure 6.3: Hofstede's cultural dimensions for Ecuador (Hofstede, 2018f)

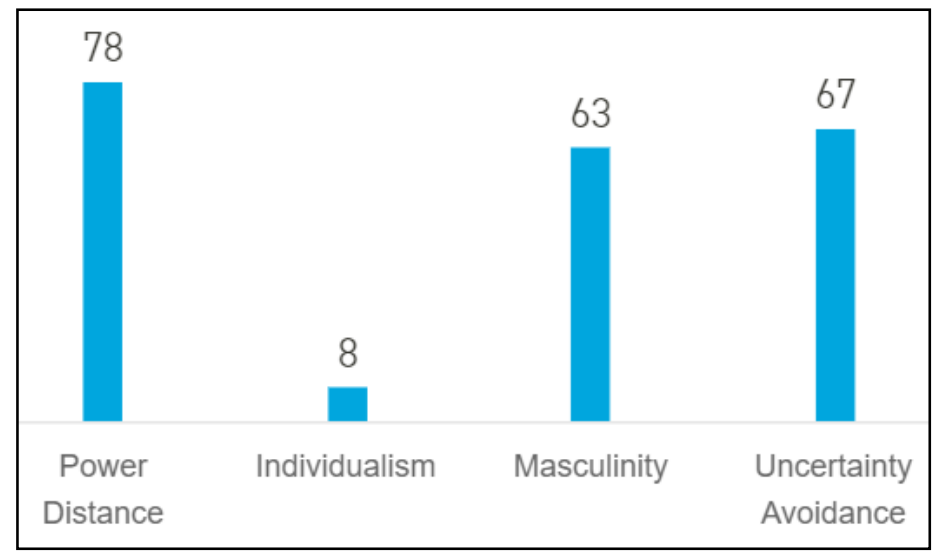

Ecuador's cultural dimension scores are reviewed in this paragraph (Hofstede, 2018f). The power distance score of 78 signifies that Ecuador is a highly hierarchical society. Here, the people of European descent are considered superior to others and this hierarchy is widely accepted by the individuals in the country. Ecuador is more or less as hierarchical as India and less hierarchical than Romania. In terms of individualism, Ecuador with a score of 8 is the second-most collectivistic country in the world and thus group norms are adhered to and group harmony is highly prized. Ecuador is more collectivistic than both India and Romania. The masculinity score of 63 makes Ecuador a 
masculine country like India and unlike Romania. Thus, in Ecuador, success and achievements are highly regarded. The uncertainty avoidance score of 67 signifies that Ecuador has a high inclination towards avoiding uncertainty. This score is less than that of Romania's (which has a higher inclination towards avoiding uncertainty) and higher than India (which has medium to low inclination towards avoiding uncertainty).

In Africa, Kenya is the location where the study was conducted. Xenocentrism has been previously observed in Kenya in the general xenocentrism and consumer xenocentrism contexts (Waithaka, 2017; Kiriri, 2019). The general xenocentrism context has been briefly discussed in chapter 2 , section 2.2.4. Additionally, the second-hand clothes market in Kenya comprising of Western clothing shipped from the Western charities or thrift shops are in heavy demand in the country (Reuters, 2014). Thus, it is likely that Kenya has a conducive environment for consumer xenocentrism. Kenya has also been under the colonial rule of Britain and the presence of xenocentrism in former colonies has been previously discussed in section 2.8.7. Kenya is a developing country and like India is classified as a lower middle-income country (The World Bank, 2018a).

Kenya's scores on Hofstede's cultural dimensions are shown in figure 6.4.

Figure 6.4: Hofstede's cultural dimensions for Kenya (Hofstede, 2018g)

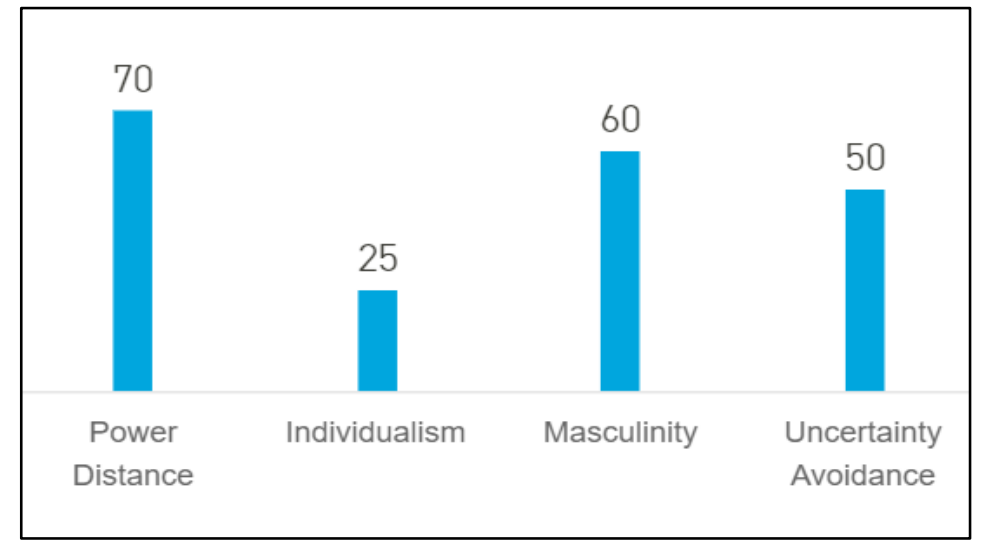


Kenya's cultural dimension scores are examined below (Hofstede, 2018g). The power distance score for Kenya is 70 which shows that it is a hierarchical society. In other words, hierarchies are very pronounced in these kinds of societies. Kenya is less hierarchical than all the other three countries discussed namely India, Romania and Ecuador. With respect to individualism, given the score of 25, Kenya is a collectivistic culture. Individuals in this kind of culture are highly loyal to their group. Kenya is less collectivistic than Ecuador but more collectivistic than Romania and India. The masculinity score of 60 makes Kenya a masculine country like India and Ecuador and unlike Romania. Thus, achievements and success are given high importance in Kenya. The uncertainty avoidance score is 50 which is at the halfway mark thus showing no particular preference as compared to Ecuador and Romania that score high on this dimension and India which scores lower.

\subsection{Method and Questionnaire development}

This study used a quantitative approach to test the hypotheses that were proposed. Specifically, the method used to collect data was an online survey. The survey consisted of the consent form and six sections. The consent form included some general information regarding the survey and assured anonymity of the participants. After that, the first section asked participants about the purchase intention and ownership of foreign products, the two dependent variables. To avoid priming effects the participants were first asked to answer the dependent variable questions. It has been found in previous $\mathrm{COO}$ research that there has been a bias in products evaluations (dependent variables) when participants were asked to evaluate the $\mathrm{COO}$ construct first and dependents variables after that (Hong and Wyer Jr, 1990). The second section of the survey asked the opinion of the participants on some 
general aspects of their life. This section consists of the power distance and collectivism questions. This section also consists of a control question which asked the respondents to click on "Somewhat Disagree" for that question. This is done to ensure that respondents are paying attention to the survey. The third section asked the participants general views regarding products. This section consisted of the status consumption, susceptibility to normative influence and product category symbolism questions. The fourth section asked the participants their local and foreign preferences. This section consists of the consumer xenocentrism, worldmindedness, global/local identity, national identity, consumer ethnocentrism and international travel experience/preference questions. Again, just like in section two, there is a control question in this section as well. The respondent is asked to click on "Agree" for that question to check if he/she is attentive. The fifth section asked the participants their media preferences and consisted of global media exposure questions. The sixth and last section asked the participant their demographic information namely age, gender, occupation and education.

\section{Measures}

Following are the measures or questions asked in the questionnaire.

\subsubsection{Culture}

This is one of the antecedents that was tested for consumer xenocentrism. Hofstede's cultural dimensions, power distance and individualism/collectivism were measured. Collectivism and individualism are the extent to which people are incorporated in a group (Hofstede and McCrae, 2004). Power distance is defined as "the degree to which the less powerful members of a society accept and expect that power is distributed 
unequally". (Hofstede, 2018). These constructs have already been elaborately discussed in section 3.3.

For finalizing the scale to measure each antecedent, five criteria were used: Whether the scale was 1) in-line with the definition of the antecedent 2.) had good psychometric properties 3.) has been cited by others 4.) was parsimonious and 5.) had a minimum of four items.

Several attempts have been made to measure Hofstede's cultural dimensions at the individual level as it is a widely used framework across different disciplines. Each scale has a different purpose. Of the several scales available, five were shortlisted for review. These are scales that could be used to measure collectivism and power distance in general, or specific scales that are relevant to the context of this thesis. These five scales were then assessed using the five-point decision criteria mentioned in the previous paragraph. The analysis of all the five scales using the decision criteria can be found in Appendix B.

Using the decision criteria, Yoo et al. (2011) scale was selected for measuring collectivism/individualism. This scale uses a five-point Likert format and has six items. The alphas are between 0.76 to 0.80 . The scale has been validated in three countries using a total sample size of 1530 respondents. The Farh et al. (2007) scale has been selected for measuring power distance. This scale uses a five-point Likert format and has six items. The alpha is 0.74 and the sample size is 338 respondents. The scales and their corresponding items are presented below. 
Collectivism/Individualism (Yoo et al., 2011)

\begin{tabular}{|c|c|c|c|c|c|c|c|c|}
\hline & Statement & 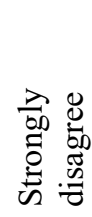 & 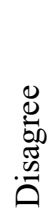 & 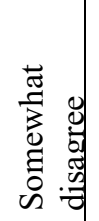 & 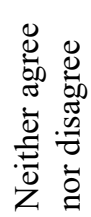 & 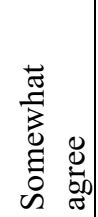 & 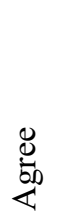 & 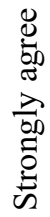 \\
\hline 1 & $\begin{array}{l}\text { Individuals should sacrifice self-interest for the } \\
\text { group. }\end{array}$ & & & & & & & \\
\hline 2 & $\begin{array}{l}\text { Individuals should stick with the group even } \\
\text { through difficulties. }\end{array}$ & & & & & & & \\
\hline 3 & $\begin{array}{l}\text { Group welfare is more important than individual } \\
\text { rewards. }\end{array}$ & & & & & & & \\
\hline 4 & $\begin{array}{l}\text { Group success is more important than individual } \\
\text { success. }\end{array}$ & & & & & & & \\
\hline 5 & $\begin{array}{l}\text { Individuals should only pursue their goals after } \\
\text { considering the welfare of the group. }\end{array}$ & & & & & & & \\
\hline 6 & $\begin{array}{l}\text { Group loyalty should be encouraged even if } \\
\text { individual goals suffer. }\end{array}$ & & & & & & & \\
\hline
\end{tabular}

Power distance (Farh et al., 2007)

\begin{tabular}{|c|c|c|c|c|c|c|c|c|}
\hline & Statement & 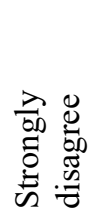 & 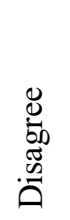 & 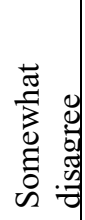 & 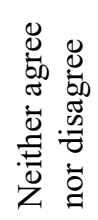 & 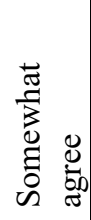 & $\underset{⿱ 亠 凶}{\mathbb{E}}$ & 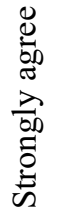 \\
\hline 1 & $\begin{array}{l}\text { Managers should make most decisions without } \\
\text { consulting subordinates. }\end{array}$ & & & & & & & \\
\hline 2 & $\begin{array}{l}\text { It is frequently necessary for a manager to use } \\
\text { authority and power when dealing with } \\
\text { subordinates. }\end{array}$ & & & & & & & \\
\hline 3 & $\begin{array}{l}\text { Managers should seldom ask for the opinions of } \\
\text { employees. }\end{array}$ & & & & & & & \\
\hline 4 & $\begin{array}{l}\text { Managers should avoid off-the-job social contacts } \\
\text { with employees. }\end{array}$ & & & & & & & \\
\hline 5 & $\begin{array}{l}\text { Employees should not disagree with management } \\
\text { decisions. }\end{array}$ & & & & & & & \\
\hline 6 & $\begin{array}{l}\text { Managers should not delegate important tasks to } \\
\text { employees. }\end{array}$ & & & & & & & \\
\hline
\end{tabular}


It can be argued that Hofstede's cultural dimensions are not applicable at the individual level and thus should not be measured at that level. However, both the power distance and collectivism scales although operationalized at the individual level, the data as such will be analyzed at a group level (i.e. they will be analyzed with respect to the whole sample and not just the individual data). In other words, it will be analyzed at the country sample level or combined sample level, whether the samples have a high or low power distance or high or low collectivistic nature. This is not the first study to use this approach. This method has been used in the extant literature (Gunkel, Schlagel and Engle, 2014; Farh et al., 2007; Kirkman et al., 2009; Winterich and Zhang, 2014).

\subsubsection{Status consumption}

This is the second antecedent that was tested for consumer xenocentrism. Status consumption is defined as, "the motivational process by which individuals strive to improve their social standing through conspicuous consumption of consumer products that confer and symbolize status both for the individual and surrounding significant others" (Eastman et al., 1999, p. 42). The construct has been discussed in section 3.4.

Status consumption was measured by the highly cited Eastman et al. (1999) scale. This is the only scale available to measure this construct. The scale was assessed using the five-point decision criteria which it fulfilled. The analysis of this scale using the decision criteria can be found in Appendix B.

The scale consists of five items measured in a seven-point Likert format. The authors reported that a total of six studies were conducted and the alphas ranged from 0.81 to 0.87 . The sample size ranged from 121 to 391 respondents for the different studies. The 
last item in this scale is, "A product is more valuable to me if it has some snob appeal.". Since "snob appeal" is a very colloquial term used in the US, it was changed to "status" to be better understood by respondents from different cultures. The scale is presented below.

Status consumption (Eastman et al., 1999)

\begin{tabular}{|c|c|c|c|c|c|c|c|c|}
\hline & Statement & 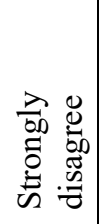 & 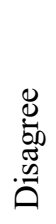 & 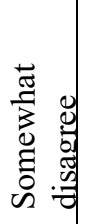 & 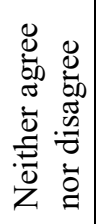 & 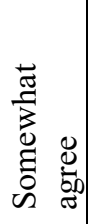 & 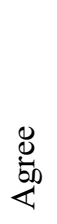 & 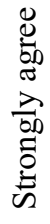 \\
\hline 1 & I would buy a product just because it has status. & & & & & & & \\
\hline 2 & I am interested in new products with status. & & & & & & & \\
\hline 3 & I would pay more for a product if it had status. & & & & & & & \\
\hline 4 & $\begin{array}{l}\text { The status of a product is irrelevant to me } \\
\text { (negatively worded). }\end{array}$ & & & & & & & \\
\hline 5 & $\begin{array}{l}\text { A product is more valuable to me if it has some } \\
\text { status. }\end{array}$ & & & & & & & \\
\hline
\end{tabular}

\subsubsection{Susceptibility to normative influence}

This is the third antecedent that was tested for consumer xenocentrism. Susceptibility to normative influence deals with conforming to the group's standards when purchasing products (Bearden et al., 1989). This construct has been discussed in section 3.5 .

Susceptibility to normative influence was measured by the shortened version of the widely used Bearden et al. (1989) scale. The original Bearden et al. (1989) scale is called the susceptibility to interpersonal influence and has two dimensions - normative and informational. In this thesis, only the normative dimension was used as it is the most relevant for this research. The original scale has eight items for measuring susceptibility to normative influence and it is measured using a seven-point Likert format. 
There are shortened versions of Bearden et al. (1989) scale used in studies such as by Alden et al. (2006), Batra et al. (2000) and Lee et al. (2014). This thesis used the fouritem scale by Lee et al. (2014) as both the other shortened scales have only three items and the psychometric properties are not good. The Lee et al. (2014) scale was assessed using the five-point decision criteria which it fulfilled. The analysis of all the susceptibility to normative influence scales using the decision criteria can be found in Appendix B.

Lee et al. (2014) scale used a seven-point Likert format. The alphas ranged from 0.75 to 0.76 for the two country samples and the total aggregated sample. The sample size was 515 for both countries together and 257 and 258 individually. The scale is presented below.

Susceptibility to normative influence (Lee et al., 2014)

\begin{tabular}{|c|c|c|c|c|c|c|c|c|}
\hline & Statement & 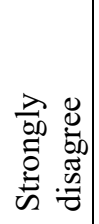 & 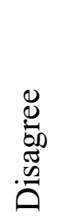 & 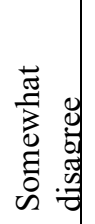 & 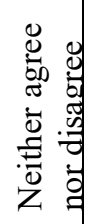 & 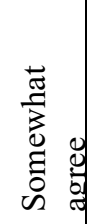 & 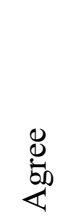 & 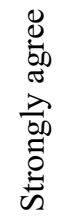 \\
\hline 1 & $\begin{array}{l}\text { It is important that others like the products and } \\
\text { brands I buy. }\end{array}$ & & & & & & & \\
\hline 2 & $\begin{array}{l}\text { I achieve a sense of belonging by purchasing the } \\
\text { same products and brands that others purchase. }\end{array}$ & & & & & & & \\
\hline 3 & $\begin{array}{l}\text { When buying products, I generally purchase those } \\
\text { brands that I think others will approve of. }\end{array}$ & & & & & & & \\
\hline 4 & $\begin{array}{l}\text { If I want to be like someone, I often try to buy the } \\
\text { same brands that they buy. }\end{array}$ & & & & & & & \\
\hline
\end{tabular}

\subsubsection{Consumer xenocentrism}

This is the main construct of interest in this thesis. Consumer xenocentrism is the rejection of domestic goods and the preference of foreign ones (Balabanis and Diamantopoulos, 2016; Rojas-Méndez and Chapa, 2019). The various consumer 
xenocentrism scales were reviewed in chapter 2 , section 2.9 and it was declared that the XScale developed by Rojas-Méndez and Chapa (2019) is the most appropriate be used in this thesis. This scale has two dimensions, foreign admiration and domestic rejection, with 5 items each and uses a five-point Likert format. Studies in five different countries were conducted to develop this scale. The alphas ranged from 0.87 to 0.88 for foreign admiration and from 0.84 to 0.88 for domestic rejection dimensions. The sample sizes were between 284 to 427 participants for the various studies. The scale is presented below. This scale was already presented in Chapter 2 but this time it includes the Likert format as well.

Consumer xenocentrism (Rojas-Méndez and Chapa, 2019)

\begin{tabular}{|c|c|c|c|c|c|c|}
\hline & Statement & 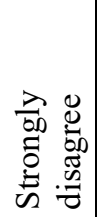 & 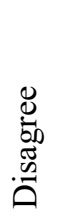 & 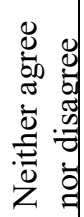 & $\underset{\mathscr{E}}{\stackrel{\Xi}{女}}$ & 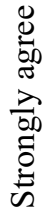 \\
\hline & Foreign admiration & & & & & \\
\hline 1 & I recommend foreign products to my friends and families. & & & & & \\
\hline 2 & $\begin{array}{l}\text { I tend to prefer foreign products compared to national } \\
\text { ones. }\end{array}$ & & & & & \\
\hline 3 & I admire foreign products. & & & & & \\
\hline 4 & I like buying products of foreign origin. & & & & & \\
\hline 5 & I value foreign products a lot. & & & & & \\
\hline & Domestic rejection & & & & & \\
\hline 1 & I tend to reject national products. & & & & & \\
\hline 2 & I think foreign products are superior to national products. & & & & & \\
\hline 3 & Generally, I don't value products made in my country. & & & & & \\
\hline 4 & Sometimes I undervalue products made in my country. & & & & & \\
\hline 5 & $\begin{array}{l}\text { Sometimes I feel embarrassed about products made in } \\
\text { [COUNTRY NAME] when I compare them with similar } \\
\text { products made in foreign countries. }\end{array}$ & & & & & \\
\hline
\end{tabular}

\subsubsection{Consumer worldmindedness}

This is the first related construct that was tested with consumer xenocentrism. Sampson and Smith (1957, p.99) define a highly worldminded individual as, "The 
individual who favors a world-view of the problems of humanity, whose primary reference group is mankind, rather than American, English, Chinese, etc.". This construct has been discussed in section 4.2.1.1.

Worldmindedness has three scales - Sampson and Smith (1957), Nijssen and Douglas (2008) and Rawwas et al. (1996). In chapter 4, it was decided to go with the Sampson and Smith (1957) definition of worldmindedness. However, that scale is very long with 32 items and hence it is not used in its original form. Instead, the worldmindedness scale by Rawwas et al. (1996) is used as this scale is adapted from Sampson and Smith (1957) and also modified for consumer worldmindedness which is relevant for the purpose of this thesis. The scale was assessed using the five-point decision criteria which it fulfilled. The analysis of all three worldmindedness scales using the decision criteria can be found in Appendix B.

The Rawwas et al. (1996) scale contains seven items measured on a five-point scale. The authors reported an alpha of 0.69 based on a sample of 593 respondents. The last item in the scale is, "Austria should permit foreigners to immigrate here even if it lowers our standard of living." Since this statement is country specific it was adapted to the name of the country that is being surveyed. The scale is presented below.

Consumer worldmindedness (Rawwas et al., 1996)

\begin{tabular}{|c|c|c|c|c|c|c|}
\hline & Statement & 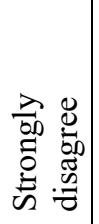 & 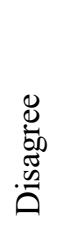 & 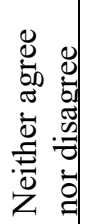 & 这 & 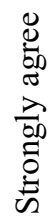 \\
\hline 1 & $\begin{array}{l}\text { I find imported goods more desirable than } \\
\text { domestically produced products. }\end{array}$ & & & & & \\
\hline
\end{tabular}




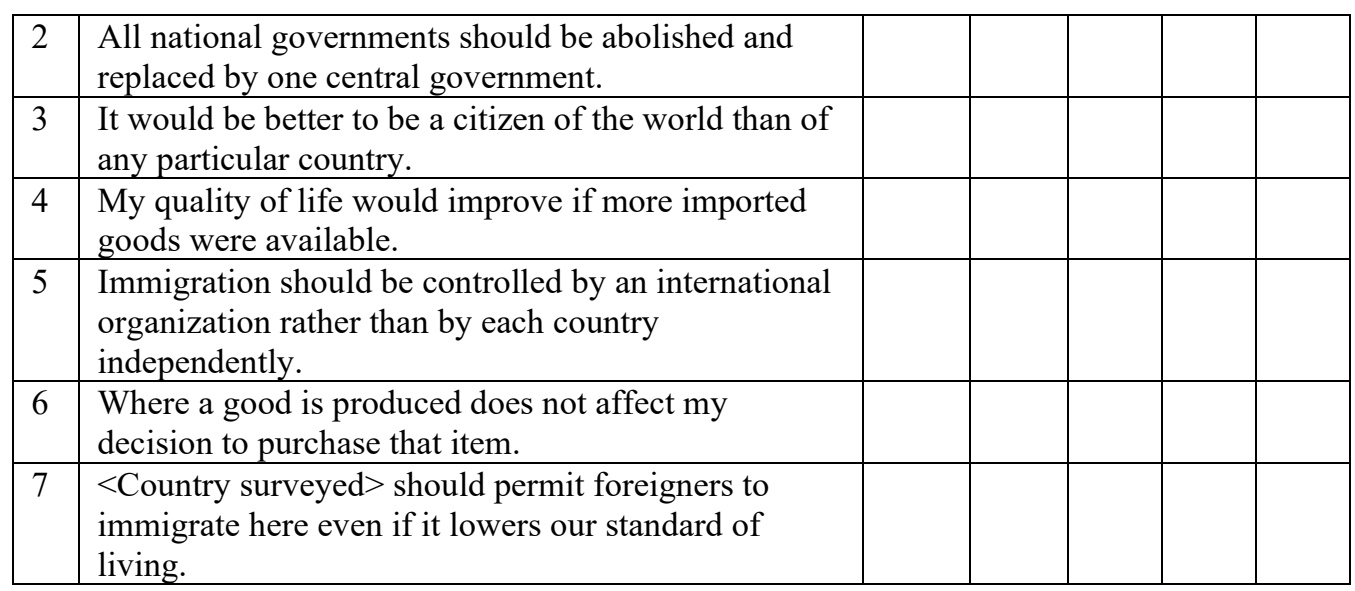

\subsubsection{Global identity/local identity}

These are the second and third related constructs that were tested with consumer xenocentrism. "A global identity consists of mental representations in which consumers believe in the positive effects of globalization, recognize the commonalities rather than dissimilarities among people around the world, and are interested in global events; broadly, being global means identifying with people around the world." (Zhang and Khare, 2009, p. 525). This construct has been discussed in section 4.2.2.5. "A local identity consists of mental representations in which consumers have faith in and respect for local traditions and customs, are interested in local events, and recognize the uniqueness of local communities; broadly, being local means identifying with people in one's local community." (Zhang and Khare, 2009, p. 525). This construct has been discussed in section 4.3.1.3.

There are few scales that measure both global and local identity and a few others measure only global identity. Four scales (Zhang and Khare, 2009; Bartikowski and Walsh, 2015; Westjohn et al., 2009; Tu et al., 2012) were assessed using the five-point decision 
criteria. The analysis of all the four scales using the decision criteria can be found in Appendix B.

Using the decision criteria, the Tu et al. (2012) scale was selected as it is succinct, measures both global and local identity and has the best psychometric properties of all scales. This scale is the shortened version of the Zhang and Khare (2009) scale. Tu et al. (2012) scale has four items each for global and local identity and is measured using a sevenpoint Likert scale. The alphas are 0.89 and 0.87 for local and global identity respectively. The authors also assert that these alphas are very close to that of the original Zhang and Khare (2009) scale. The sample size ranged from 45- 253 respondents in six studies. The scale is presented below.

Global and local identity (Tu et al., 2012)

\begin{tabular}{|c|c|c|c|c|c|c|c|c|}
\hline & Statement & 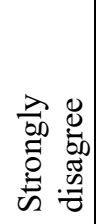 & 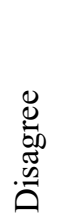 & 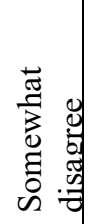 & 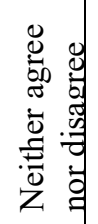 & 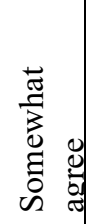 & 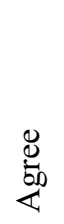 & 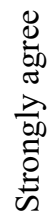 \\
\hline & Global identity & & & & & & & \\
\hline 1 & My heart mostly belongs to the whole world. & & & & & & & \\
\hline 2 & $\begin{array}{l}\text { I believe people should be made more aware of } \\
\text { how connected we are to the rest of the world. }\end{array}$ & & & & & & & \\
\hline 3 & I identify that I am a global citizen. & & & & & & & \\
\hline 4 & I care about knowing global events. & & & & & & & \\
\hline & Local identity & & & & & & & \\
\hline 1 & My heart mostly belongs to my local community. & & & & & & & \\
\hline 2 & I respect my local traditions. & & & & & & & \\
\hline 3 & I identify that I am a local citizen. & & & & & & & \\
\hline 4 & I care about knowing local events. & & & & & & & \\
\hline
\end{tabular}

\subsubsection{National Identity}

This is the fourth related construct that was tested with consumer xenocentrism. National identity is defined as, "the importance of national affiliation as well as the 
subjective significance of an inner bond with the nation" (Blank and Schmidt, 2003, p. 296). This construct has been discussed in section 4.3.1.2.

There are six scales available to measure national identity. These scales were assessed using the five-point decision criteria. The analysis of all the scales using the decision criteria can be found in Appendix B. Though three scales (Zeugner-Roth et al., 2015; Verlegh, 2007; Bartikowski and Walsh, 2015) fulfilled the decision criteria, Verlegh (2007) was selected because it had the best psychometric properties, was well-cited and was published in a better journal than the other scales.

The Verlegh (2007) scale has composite reliability (CR) of 0.83 and an Average Variance extracted (AVE) value of 0.56 (most of the scales for the other measures do not mention AVE values and primarily only discuss Cronbach's alpha). The Verlegh (2007) scale has four items in a seven-point Likert format. The sample size was 186 and 103 respondents in two studies (a total of 289 respondents). As the scale is very countryspecific, wherever "Dutch" is present in the scale it was changed to the nationality surveyed and wherever "The Netherlands" is present in the scale it was changed to the country surveyed. The last item in the scale is, "I don't feel any ties with $<$ country name>". "Ties with" was changed to "attachment towards" for it to be better understood in developing countries. The scale is presented below. 
National Identity (Verlegh, 2007)

\begin{tabular}{|c|c|c|c|c|c|c|c|c|}
\hline & Statement & 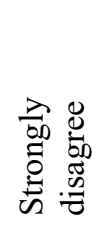 & 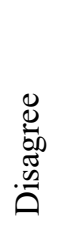 & 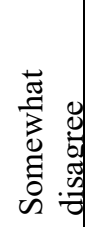 & 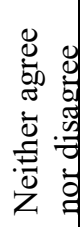 & 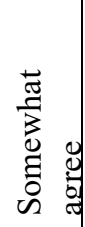 & $\begin{array}{l}\stackrel{D}{0} \\
\stackrel{0}{<}\end{array}$ & 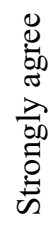 \\
\hline 1 & $\begin{array}{l}\text { Being [NATIONALITY SURVEYED] means a } \\
\text { lot to me. }\end{array}$ & & & & & & & \\
\hline 2 & I am proud to be [NATIONALITY SURVEYED]. & & & & & & & \\
\hline 3 & $\begin{array}{l}\text { When a foreign person praises [COUNTRY } \\
\text { NAME], it feels like a personal compliment. }\end{array}$ & & & & & & & \\
\hline 4 & $\begin{array}{l}\text { I don't feel any attachment towards [COUNTRY } \\
\text { NAME] (reversed). }\end{array}$ & & & & & & & \\
\hline
\end{tabular}

\subsubsection{Consumer ethnocentrism}

This is the fifth related construct that was tested with consumer xenocentrism. Consumer ethnocentrism is defined as, “... the beliefs held by American consumers about the appropriateness, indeed morality, of purchasing foreign-made products." (Shimp and Sharma, 1987, p.280). This construct has been discussed in section 4.4.1.1.

The consumer ethnocentrism scale by Shimp and Sharma (1987) is a widely used scale. Known as CETSCALE it originally consists of 17 items making it a fairly long scale. The authors also present a 10-item version. The other lesser known scale is the CES scale which has three dimensions and 18 items (Sharma, 2015) and has been introduced quite recently. The shortened form of CETSCALE (five-item) has also been used in the extant literature (Verlegh, 2007). Although the Verlegh (2007) scale fulfilled the five-point decision criteria and the 10-item Shimp and Sharma (1987) failed the parsimony criterion in the five-point decision criteria, the 10-item scale was used in the main study as five-item scale did not work in the pilot study (discussed in section 6.5). Previous studies have found CETSCALE to be multi-dimensional in developing countries suggesting the 
dimensionality of the scale might be culture-specific (Saffu and Walker 2005; Upadhyay and Singh, 2006) and thus the longer scale was more appropriate in those countries. The analysis of all scales using the decision criteria can be found in Appendix B.

The Shimp and Sharma (1987) scale consists of ten items measured using a sevenpoint Likert format. The alpha values are between $0.94-0.96$. The sample size is 2942 respondents. This scale is country-specific. For example, one item in the scale is, "Americans people should not buy foreign products, because this hurts American business and causes unemployment." In this statement and all other statements in the scale "American" was replaced by the nationality surveyed or country surveyed as appropriate.

The scale is presented below.

Consumer ethnocentrism (Shimp and Sharma, 1987)

\begin{tabular}{|c|c|c|c|c|c|c|c|c|}
\hline & Statement & 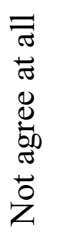 & & & & & & 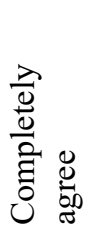 \\
\hline & & 1 & 2 & 3 & 4 & 5 & 6 & 7 \\
\hline 1 & $\begin{array}{l}\text { Only those products that are unavailable in } \\
<\text { country surveyed }>\text { should be imported. }\end{array}$ & & & & & & & \\
\hline 2 & $\begin{array}{l}<\text { Nationality surveyed }>\text { products, first, last, and } \\
\text { foremost. }\end{array}$ & & & & & & & \\
\hline 3 & $\begin{array}{l}\text { Purchasing foreign-made products is un- } \\
<\text { nationality surveyed }>\text {. }\end{array}$ & & & & & & & \\
\hline 4 & $\begin{array}{l}\text { It is not right to purchase foreign products, } \\
\text { because it puts }<\text { nationality surveyed }>\text { out of } \\
\text { jobs. }\end{array}$ & & & & & & & \\
\hline 5 & $\begin{array}{l}\text { A real }<\text { nationality surveyed }>\text { should always buy } \\
<\text { nationality surveyed }>\text {-made products. }\end{array}$ & & & & & & & \\
\hline 6 & $\begin{array}{l}\text { We should purchase products manufactured in } \\
<\text { country surveyed }>\text { instead of letting other } \\
\text { countries get rich off us. }\end{array}$ & & & & & & & \\
\hline 7 & $\begin{array}{l}<\text { Nationality surveyed }>\text { should not buy foreign } \\
\text { products, because this hurts }<\text { nationality } \\
\text { surveyed }>\text { business and causes unemployment. }\end{array}$ & & & & & & & \\
\hline 8 & $\begin{array}{l}\text { It may cost me in the long-run but I prefer to } \\
\text { support }<\text { nationality surveyed }>\text { products. }\end{array}$ & & & & & & & \\
\hline
\end{tabular}




\begin{tabular}{|l|l|l|l|l|l|l|l|}
\hline 9 & $\begin{array}{l}\text { We should buy from foreign countries only those } \\
\text { products that we cannot obtain within our own } \\
\text { country. }\end{array}$ & & & & & & \\
\hline 10 & $\begin{array}{l}<\text { Nationality surveyed }>\text { consumers who purchase } \\
\text { products made in other countries are responsible } \\
\text { for putting their fellow <nationality surveyed } \\
\text { out of work. }\end{array}$ & & & & & & \\
\hline
\end{tabular}

\subsubsection{Purchase intention of foreign products}

This is the first consequence that was tested for consumer xenocentrism. Purchase intention of foreign products is the probability that one would buy foreign products. The construct has been discussed in section 5.2.2.

The willingness to buy scale from Rojas-Méndez and Kolotylo (2018) was adapted for measuring this construct. This scale has been used in the consumer xenocentrism context in their study. The scale consists of ten items measured in a seven-point Likert format. The respondents were asked their overall willingness to buy products from ten countries. Out of the ten countries five are developed countries (Germany, U.S.A., Japan, France and South Korea) and five are developing or transitional economies including their own country (Thailand, Mexico, Russia, Brazil and India/Kenya/Ecuador/ Romania). The respondents were also be asked to assume that the products and services from the different countries have similar features and are sold at the same price in their country. This condition was adapted from Parts and Vida (2013). The modified scale is presented in below. 
Purchase intention of foreign products (Adapted from Rojas-Méndez and Kolotylo, 2018)

Please indicate your willingness to buy products and services from the countries listed below by choosing the alternative that best represents your opinion. Please assume that the products and services from the different countries have similar features and are sold at the same price in your country.

\begin{tabular}{|l|c|c|c|c|c|c|c|}
\hline Item & $\begin{array}{l}\text { Very } \\
\text { unlikely }\end{array}$ & Unlikely & $\begin{array}{l}\text { Somewhat } \\
\text { Unlikely }\end{array}$ & Neutral & $\begin{array}{l}\text { Somewhat } \\
\text { Likely }\end{array}$ & Likely & $\begin{array}{l}\text { Very } \\
\text { Likely }\end{array}$ \\
\hline $\begin{array}{l}\text { Willingness to buy products } \\
\text { from Germany }\end{array}$ & 1 & 2 & 3 & 4 & 5 & 6 & 7 \\
\hline $\begin{array}{l}\text { Willingness to buy products } \\
\text { from the U.S.A. }\end{array}$ & 1 & 2 & 3 & 4 & 5 & 6 & 7 \\
\hline $\begin{array}{l}\text { Willingness to buy products } \\
\text { from South Korea }\end{array}$ & 1 & 2 & 3 & 4 & 5 & 6 & 7 \\
\hline $\begin{array}{l}\text { Willingness to buy products } \\
\text { from Japan }\end{array}$ & 1 & 2 & 3 & 4 & 5 & 6 & 7 \\
\hline $\begin{array}{l}\text { Willingness to buy products } \\
\text { from France }\end{array}$ & 1 & 2 & 3 & 4 & 5 & 6 & 7 \\
\hline $\begin{array}{l}\text { Willingness to buy products } \\
\text { from Thailand }\end{array}$ & 1 & 2 & 3 & 4 & 5 & 6 & 7 \\
\hline $\begin{array}{l}\text { Willingness to buy products } \\
\text { from Russia }\end{array}$ & 1 & 2 & 3 & 4 & 5 & 6 & 7 \\
\hline $\begin{array}{l}\text { Willingness to buy products } \\
\text { from Mexico }\end{array}$ & 1 & 2 & 3 & 4 & 5 & 6 & 7 \\
\hline $\begin{array}{l}\text { Willingness to buy products } \\
\text { from Brazil }\end{array}$ & 1 & 2 & 3 & 4 & 5 & 6 & 7 \\
\hline $\begin{array}{l}\text { Willingness to buy products } \\
\text { from < country name> }\end{array}$ & 1 & 2 & 3 & 4 & 5 & 6 & 7 \\
\hline
\end{tabular}

\subsubsection{Ownership of foreign products}

This is the second consequence that was tested for consumer xenocentrism and the construct signifies the actual purchase and possession of foreign goods. The construct has been discussed in section 5.2.3. 
The ownership of foreign products scale was the only scale created for this study. The scale measured whether a respondent owns a domestic or foreign product in seven categories. Each of the product categories have both local and foreign products in each country surveyed. This eliminates the possibility that ownership of foreign products might be because of the unavailability of local goods. The product categories used are leather items, shoes, refrigerator, alcoholic drinks, clothing, soft drinks and food items. Later, the number of foreign products (from developed countries) owned by each respondent was added up. A value of 0 means that the respondent owns no foreign products and a value of seven means that a respondent owns foreign products in all seven categories (Yoo and Donthu, 2005). Thus, the scale could range from 0-7 and is presented in below.

Ownership of foreign products (Created for this study)

Please indicate if you currently own <nationality surveyed $>$ or foreign products in the following categories. If you have purchased multiple products for any category (e.g. alcoholic drinks), please answer based on whether you generally purchase a majority of $<$ nationality surveyed $>$ or foreign products in those categories.

\begin{tabular}{|l|c|c|c|c|}
\hline Category & Own <nationality & Own foreign & Own foreign & Don't \\
& surveyed & product from & product from & know/Not \\
& product & developed country & developing & applicable \\
& & & country & \\
\hline Leather items & & & & \\
\hline Shoes & & & & \\
\hline
\end{tabular}




\begin{tabular}{|l|l|l|l|l|}
\hline Refrigerator & & & & \\
\hline Alcoholic drinks & & & & \\
\hline Clothing & & & & \\
\hline Soft drinks & & & & \\
\hline Food items & & & & \\
\hline
\end{tabular}

\subsubsection{Global media exposure}

This construct was tested as an antecedent and moderator to consumer xenocentrism. Global media exposure involves exposure to other cultures through books, television programs and movies. The construct has been discussed in sections 3.6 and 5.3.5.

There are two main scales that measure this construct (Alden et al., 2006; Cleveland and Laroche, 2007). These two scales were assessed using the five-point decision criteria, which can be found in Appendix B.

Using the decision criteria, the Alden et al. (2006) scale was selected for measuring global media exposure. The scale consists of four items measured in a seven-point Likert format. The authors reported an alpha of 0.78 . The sample size was 419 respondents. A few adjustments were made to the scale. For example, the first item is, "How often do you watch fictional or non-fictional television programs (other than standard news programs) that are about people who live in other countries of the world?". In this item and all other items, the phrases "fictional or non-fictional" and "other than standard news programs" were removed. Another item reads, "How often do you see movies in a theater or rent one for home with fictional or non-fictional stories about people who live in other countries?". 
In this item in addition to removing "with fictional or non-fictional stories", "in a theater or rent one for home" was also be removed. All the above changes result in making the sentences brief while still conveying the appropriate idea. The adapted scale is presented below.

Global media exposure (adapted from Alden et al., 2006)

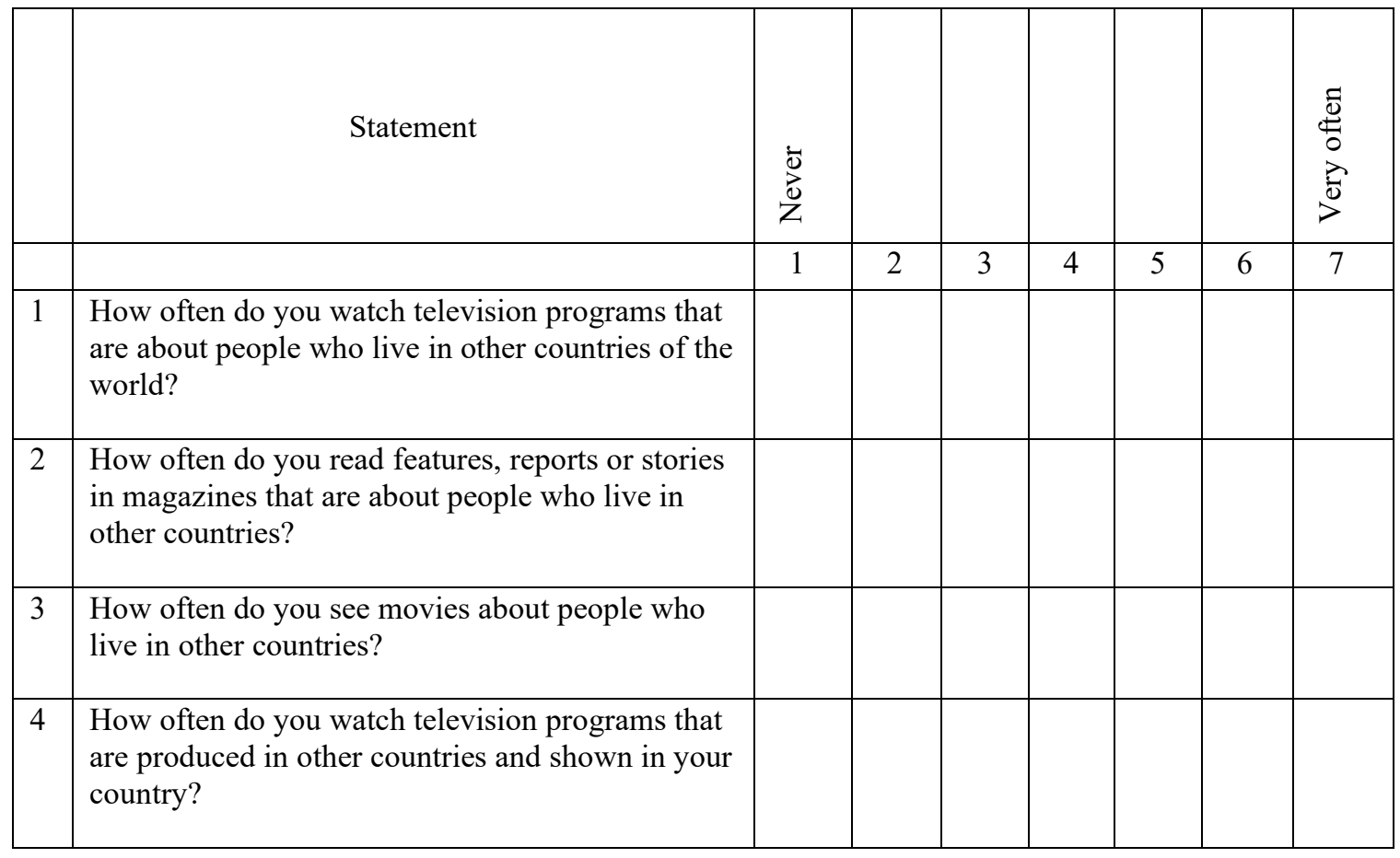

\subsubsection{International travel experience/preference}

This construct was tested as an antecedent and moderator to consumer xenocentrism. International travel experience/preference involves exposure to other cultures through an individual's prior travel abroad. The construct has been discussed in sections 3.6 and 5.3.5.

There are four scales that measure this construct (Douglas and Nijssen, 2003; Nijssen and Douglas, 2008; Cleveland and Laroche, 2007; Cleveland et al., 2014). These 
four scales were assessed using the five-point decision criteria. Cleveland and Laroche (2007) and Cleveland et al. (2014) both fulfilled the decision criteria but Cleveland et al. (2014) was chosen because it had better psychometrics properties, was more succinct and was a modified version of the authors' previous scale. The analysis of all the scales using the decision criteria can be found in Appendix B.

The Cleveland et al. (2014) scale consists of five items measured in a seven-point Likert format. The authors report an alpha of 0.81 . The sample size is 1538 respondents from four countries. The scale captures both international travel experience and preference and is presented below.

International travel experience/preference (Cleveland et al., 2014)

\begin{tabular}{|c|c|c|c|c|c|c|c|c|}
\hline & Statement & 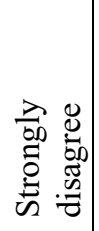 & 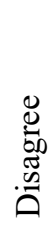 & 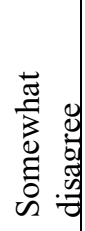 & 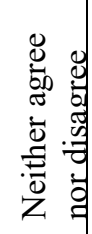 & 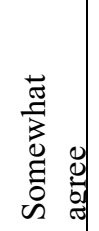 & 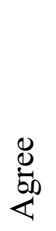 & 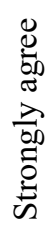 \\
\hline 1 & $\begin{array}{l}\text { I prefer spending my vacations outside of the } \\
\text { country that I live in. }\end{array}$ & & & & & & & \\
\hline 2 & $\begin{array}{l}\text { While vacationing, I would prefer to stay in my } \\
\text { home country, rather than visit another country } \\
\text { (reversed). }\end{array}$ & & & & & & & \\
\hline 3 & $\begin{array}{l}\text { I often think about going to different countries and } \\
\text { doing some traveling. }\end{array}$ & & & & & & & \\
\hline 4 & $\begin{array}{l}\text { I have traveled extensively outside of my home } \\
\text { country. }\end{array}$ & & & & & & & \\
\hline 5 & $\begin{array}{l}\text { Visiting foreign countries is one of my favorite } \\
\text { things. }\end{array}$ & & & & & & & \\
\hline
\end{tabular}




\subsubsection{Product category symbolism}

This construct was tested as a moderator to consumer xenocentrism. The expression of one's identity using products is greater for some product categories versus others and this is called product category symbolism (Berger and Heath, 2007). The construct has been discussed in section 5.3.6.

Product category symbolism is measured using the Strizhakova and Coulter (2015) scale. This is the only scale available to measure this construct. The scale was assessed using the five-point decision criteria which it fulfilled. The analysis of this scale using the decision criteria can be found in Appendix B.

The Strizhakova and Coulter (2015) scale has four items and uses a seven-point Likert format. The authors reported that the alpha ranged from 0.73 to 0.89 for the different product categories. The sample size was 300 . This scale was used for two product categories: one that is usually associated with one's identity (mobile phone) and one that isn't (bath soap brand). The scale is presented below.

Product category symbolism (Strizhakova and Coulter, 2015)

\begin{tabular}{|c|c|c|c|c|c|c|c|c|}
\hline & Statement & 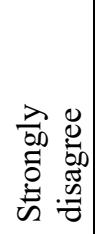 & 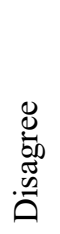 & 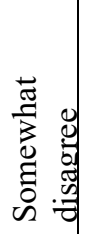 & 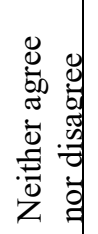 & 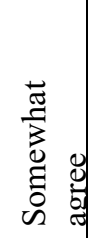 & 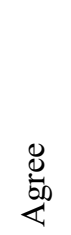 & 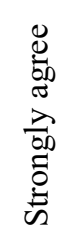 \\
\hline 1 & $\begin{array}{l}<\text { Product category }>\text { This product is part of my } \\
\text { self-image }\end{array}$ & & & & & & & \\
\hline 2 & $\begin{array}{l}<\text { Product category }>\text { People use this product to } \\
\text { communicate who they are to other people }\end{array}$ & & & & & & & \\
\hline 3 & $\begin{array}{l}<\text { Product category }>\text { This product portrays an } \\
\text { image of me to others }\end{array}$ & & & & & & & \\
\hline 4 & $\begin{array}{l}<\text { Product category }>\text { People use this product to } \\
\text { convey who they are to others }\end{array}$ & & & & & & & \\
\hline
\end{tabular}




\subsubsection{Demographic variables}

Age, education, occupation and gender are the demographic variables used in this thesis. All demographic variables except occupation serve as both antecedents and moderators. The scales for the same are presented below.

Demographic variables

Age (Rojas-Méndez and Kolotylo, 2018)

\begin{tabular}{|l|}
\hline $18-24$ years of age \\
\hline $25-34$ years of age \\
\hline $35-44$ years of age \\
\hline $45-54$ years of age \\
\hline $55-64$ years of age \\
\hline $64+$ years of age \\
\hline
\end{tabular}

\section{Education}

\begin{tabular}{|l|}
\hline $12^{\text {th }}$ grade/standard or less \\
\hline $\begin{array}{l}\text { Trade school/Polytechnic/Professional } \\
\text { school }\end{array}$ \\
\hline University Degree (Bachelors) \\
\hline Post graduate degree (Masters, Ph.D.) \\
\hline
\end{tabular}

The following education scale will be used for Kenya. It is a slightly modified version of the above scale.

\begin{tabular}{|l|}
\hline $\begin{array}{l}\text { Secondary/O-Level/high school graduate } \\
\text { or less }\end{array}$ \\
\hline Trade school/Polytechnic \\
\hline
\end{tabular}


University Degree (Bachelors)

Post graduate degree (Masters, Ph.D.)

The following education scale will be used for Ecuador. It is a slightly modified version of the above scale.

$12^{\text {th }}$ grade $/ 13^{\text {th }}$ year or less

Trade school/Polytechnic

University Degree (Bachelors)

Post graduate degree (Masters, Ph.D.)

Occupation (Adapted from Han, 1988)

Business

Salaried professional

Laborer/skilled labor

Student

Retired/others

Gender

Male

Female 


\subsubsection{Measures summary}

Table 6.1 below gives a summary of all the measures that have been discussed and was used in this study. A majority of the scales used a seven-point Likert scale, thus a decision was taken to convert the consumer xenocentrism and consumer worldmindedness scales that used a five-point scale into a seven-point scale to achieve consistency. There is evidence from the extant literature that both five-point and seven-point scales are easily transferable and produce similar results (Dawes, 2008; Colman, Norris, and Preston, 1997).

Table 6.1 Measures that were used in this thesis

\begin{tabular}{|l|l|l|l|}
\hline \multicolumn{1}{|c|}{ Construct } & \multicolumn{1}{|c|}{ Measure } & \multicolumn{1}{|c|}{ Items } & Answer type \\
\hline $\begin{array}{l}\text { Culture } \\
\text { Yoo et al. (2011) \& Farh } \\
\text { et al. (2007) }\end{array}$ & $\begin{array}{l}\text { Hofstede's cultural } \\
\text { dimensions (Power } \\
\text { distance and } \\
\text { Collectivism) }\end{array}$ & $6+6$ items & $\begin{array}{l}\text { 7-point Likert } \\
\text { scale }\end{array}$ \\
\hline $\begin{array}{l}\text { Status consumption } \\
\text { Eastman et al. (1999) }\end{array}$ & $\begin{array}{l}\text { Status consumption } \\
\text { scale }\end{array}$ & 5 items & $\begin{array}{l}\text { 7-point Likert } \\
\text { scale }\end{array}$ \\
\hline $\begin{array}{l}\text { Susceptibility to } \\
\text { normative influence } \\
\text { Lee et al. (2014) }\end{array}$ & $\begin{array}{l}\text { Susceptibility to } \\
\text { normative influence } \\
\text { scale (shortened } \\
\text { version) }\end{array}$ & 4 items & $\begin{array}{l}\text { 7-point Likert } \\
\text { scale }\end{array}$ \\
\hline $\begin{array}{l}\text { Consumer } \\
\text { xenocentrism } \\
\text { Rojas-Méndez and Chapa } \\
\text { (2019) }\end{array}$ & X-Scale & $5+5$ items & $\begin{array}{l}\text { 7-point Likert } \\
\text { scale }\end{array}$ \\
\hline $\begin{array}{l}\text { Consumer } \\
\text { worldmindedness } \\
\text { Rawwas et al. (1996) }\end{array}$ & $\begin{array}{l}\text { Worldmindedness } \\
\text { scale }\end{array}$ & 7 items & $\begin{array}{l}\text { 7-point Likert } \\
\text { scale }\end{array}$ \\
\hline $\begin{array}{l}\text { Global identity/local } \\
\text { identity } \\
\text { Tu et al. (2012) }\end{array}$ & $\begin{array}{l}\text { Global identity/local } \\
\text { identity scale } \\
\text { (shortened version) }\end{array}$ & $4+4$ items \\
\hline $\begin{array}{l}\text { National identity } \\
\text { Verlegh (2007) }\end{array}$ & scale & 5items \\
\hline
\end{tabular}




\begin{tabular}{|l|l|l|l|}
\hline $\begin{array}{l}\text { Consumer } \\
\text { ethnocentrism } \\
\text { Shimp and Sharma (1987) }\end{array}$ & $\begin{array}{l}\text { CETSCALE } \\
\text { (shortened version) }\end{array}$ & 10 items & $\begin{array}{l}\text { 7-point Likert } \\
\text { scale }\end{array}$ \\
\hline $\begin{array}{l}\text { Purchase intention of } \\
\text { foreign products } \\
\text { Rojas-Méndez and } \\
\text { Kolotylo (2018) }\end{array}$ & $\begin{array}{l}\text { Purchase intention } \\
\text { scale }\end{array}$ & 10 items & $\begin{array}{l}\text { 7-point Likert } \\
\text { scale }\end{array}$ \\
\hline $\begin{array}{l}\text { Ownership of foreign } \\
\text { products }\end{array}$ & Ownership scale & 7 items & Either/or option \\
\hline $\begin{array}{l}\text { Global media } \\
\text { exposure } \\
\text { Alden et al. (2006) }\end{array}$ & $\begin{array}{l}\text { Mass media } \\
\text { exposure scale }\end{array}$ & 4 items & $\begin{array}{l}\text { 7-point Likert } \\
\text { scale }\end{array}$ \\
\hline $\begin{array}{l}\text { International travel } \\
\text { experience/preference } \\
\text { Cleveland et al. (2014) }\end{array}$ & $\begin{array}{l}\text { International travel } \\
\text { scale }\end{array}$ & 5 items & $\begin{array}{l}\text { 7-point Likert } \\
\text { scale }\end{array}$ \\
\hline $\begin{array}{l}\text { Product category } \\
\text { symbolism } \\
\text { Strizhakova and Coulter } \\
\text { (2015) }\end{array}$ & $\begin{array}{l}\text { Product category } \\
\text { symbolism scale }\end{array}$ & 8 items & $\begin{array}{l}\text { 7-point Likert } \\
\text { scale }\end{array}$ \\
\hline $\begin{array}{l}\text { Demographics } \\
\text { occupation and } \\
\text { gender }\end{array}$ & 4 items & Either/or option \\
\hline
\end{tabular}

\subsection{Translation}

The initial survey was developed in English as almost all the measures are adopted from existing measures which are in English. However, the survey was translated into two other languages. Since Romanian and Spanish are widely spoken in Romania and Ecuador respectively, the survey was translated into these languages. India is a multilingual country with a large number of languages spoken but English and Hindi are the official languages. Though there are two official languages, English can be considered the "de facto national language of India" and is widely used (The New York Times, 2011). India has the second 
largest number of English speakers after the US, around 125 million people (BBC, 2012) but some authors argue that it might be very difficult to accurately arrive at a figure for the number of English-language users in India (The New York Times, 2011). From the extant literature, surveys in India have been run only in English (e.g. Cleveland et al., 2009). Thus, it was not necessary to translate the questionnaire for India. With respect to Kenya, there are two official languages, Swahili and English. Like India, due to Kenya previously being a British colony, English is spoken by several Kenyans. This is especially true for Kenyans who live in the urban areas (Brown, Asher and Simpson, 2006) which are likely where xenocentric consumers reside. There are an estimated 8 million English speakers in Kenya (Crystal, 2003). Since respondents were mostly recruited using a market research company which has a consumer panel of English-speaking Kenyan consumers, it was not necessary to translate the questionnaire for Kenya.

A five-step translation process was followed to convert the questionnaire from English to each of the foreign languages namely, Spanish and Romanian. This process consisted of translation, back-translation and validation (Sperber, Devellis, and Boehlecke 1994). The first step was translation of the English questionnaire to the foreign language by an individual fluent in both English and the foreign language. The next step involved another bilingual individual, who has a strong command over English and the foreign language, to back-translate the foreign language questionnaire to English. The third step involved the primary researcher comparing the original English version of the questionnaire to the back-translated version and marking the discrepancies between the two versions. The fourth step involved another bilingual individual going over the translated foreign language questionnaire and the discrepancies between the original and 
back-translated English version and making the final decision on those discrepancies. The final step involved a fourth bilingual person answering the survey once it has been uploaded to Qualtrics, suggesting any final changes to the foreign language questionnaire. Overall, a robust translation process was followed with as many as four bilingual individuals involved in each foreign language translation.

\subsection{Pilot study}

After finalizing the initial questionnaire, a pilot study was run on a small-scale to ensure that the questionnaire is working as intended. There is a strong case to run a pilot study as it is argued that pilot studies tend to increase the quality of data obtained (Bolton 1991; van Teijlingen and Hundley 2001). The pilot study was run to ensure that 1.) The questionnaire was accessible in both the web and mobile platforms. This is vital as the majority of internet users in Kenya access the internet through mobile phones (Standard Media, 2018). 2.) All the measures in the questionnaire were working as intended. 3.) The respondents were able to seamlessly answer the survey questions from start to finish without any problems.

The pilot study was conducted using an online questionnaire in two countries, India and Kenya. The data for India was collected using Amazon Mechanical Turk and for Kenya using the market research firm called Afrovas Research. A payment of USD \$2 was be given for each complete survey in Amazon Mechanical Turk. For Kenya, while I offered no direct incentives to the respondents to participate in the survey, the market research firms may or may not have provided such incentives. The sample size for the pilot study in Kenya was 31 and for India was 33. The total combined sample size was 64 respondents. For a pilot study, Hill (1998) recommends a sample size of 10 to 30 respondents while 
Julious (2005) recommends a sample size of minimum 12 respondents. The sample size used in the pilot study was in-line with these recommendations. Each respondent received a link to the online survey designed using the Qualtrics survey platform.

After the responses were received, a few preliminary analyses such as checking for frequencies, outliers, Cronbach's alphas and testing of hypothesized relationships were conducted. It was found that the shortened 5-item consumer ethnocentrism scale (CETSCALE) (Verlegh, 2007) was not working as intended, thus it was replaced with the 10-item CETSCALE (Shimp and Sharma, 1987) for the main study. Additionally, it was decided to add one more developed country (France) and one more developing country (Brazil) to the purchase intention question in the main study. This was done to check if there were likely to be any differences between the purchase intention from Western developed and non-Western developed countries and also to make the number of developing and developed countries the same (5 each). Additionally, Amazon Mechanical Turk had several data quality issues such as the same respondent answering multiple times and many unusable responses with extremely short response times, thus it was decided to collect data for India via Cint, an online market research platform, for the main study. Other than these changes, the other parts of the questionnaire remained the same.

Table 6.2 shows the demographic profiles of the pilot study. 
Table 6.2 Demographic profile of the pilot study

\begin{tabular}{|r|r|r|r|r|r|r|}
\hline \multicolumn{7}{|c|}{ Age } \\
\hline & \multicolumn{2}{|c|}{ Combined } & \multicolumn{2}{c|}{ India } & \multicolumn{2}{c|}{ Kenya } \\
\hline & Frequency & Percent & Frequency & Percent & Frequency & Percent \\
\hline $18-24$ & 19 & 29.69 & 7 & 21.21 & 12 & 38.71 \\
\hline $25-34$ & 31 & 48.44 & 19 & 57.58 & 12 & 38.71 \\
\hline $35-44$ & 12 & 18.75 & 7 & 21.21 & 5 & 16.13 \\
\hline $45-54$ & 1 & 1.56 & 0 & 0.00 & 1 & 3.23 \\
\hline $55-64$ & 1 & 1.56 & 0 & 0.00 & 1 & 3.23 \\
\hline $64+$ & 0 & 0.00 & 0 & 0.00 & 0 & 0.00 \\
\hline Total & 64 & 100 & 33 & 100 & 31 & 100 \\
\hline
\end{tabular}

\begin{tabular}{|r|r|r|r|r|r|r|}
\hline \multicolumn{7}{|c|}{ Gender } \\
\hline & \multicolumn{2}{|c|}{ Combined } & \multicolumn{2}{c|}{ India } & \multicolumn{2}{c|}{ Kenya } \\
\hline & Frequency & Percent & Frequency & Percent & Frequency & Percent \\
\hline Male & 36 & 56.25 & 21 & 63.64 & 15 & 48.39 \\
\hline Female & 28 & 43.75 & 12 & 36.36 & 16 & 51.61 \\
\hline Total & 64 & 100 & 33 & 100 & 31 & 100 \\
\hline
\end{tabular}

\begin{tabular}{|r|r|r|r|r|r|r|}
\hline \multicolumn{7}{|c|}{ Occupation } \\
\hline & \multicolumn{2}{|c|}{ Combined } & \multicolumn{2}{c|}{ India } & \multicolumn{2}{c|}{ Kenya } \\
\hline & Frequency & Percent & Frequency & Percent & Frequency & Percent \\
\hline Business & 16 & 25.00 & 9 & 27.27 & 7 & 22.58 \\
\hline Salaried Professional & 29 & 45.31 & 21 & 63.64 & 8 & 25.81 \\
\hline Laborer/ skilled labor & 6 & 9.38 & 2 & 6.06 & 4 & 12.90 \\
\hline Student & 11 & 17.19 & 1 & 3.03 & 10 & 32.26 \\
\hline Retired/others & 2 & 3.13 & 0 & 0.00 & 2 & 6.45 \\
\hline Total & 64 & 100 & 33 & 100 & 31 & 100 \\
\hline
\end{tabular}

\begin{tabular}{|r|r|r|r|r|r|r|}
\hline \multicolumn{7}{|c|}{ Education } \\
\hline & \multicolumn{2}{|c|}{ Combined } & \multicolumn{2}{c|}{ India } & \multicolumn{2}{c|}{ Kenya } \\
\hline & Frequency & Percent & Frequency & Percent & Frequency & Percent \\
\hline 12th grade or less & 7 & 10.94 & 1 & 3.03 & 6 & 19.35 \\
\hline Trade school/polytechnic & 5 & 7.81 & 0 & 0.00 & 5 & 16.13 \\
\hline University Degree (Bachelors) & 41 & 64.06 & 22 & 66.67 & 19 & 61.29 \\
\hline Postgraduate degree (Masters, PhD) & 11 & 17.19 & 10 & 30.30 & 1 & 3.23 \\
\hline Total & 64 & 100 & 33 & 100 & 31 & 100 \\
\hline
\end{tabular}




\subsection{Sampling and data collection}

Although consumer xenocentrism is a nascent field in international marketing and some scholars may argue that a qualitative study is required, there are several qualitative studies already available inside and outside of the international marketing field. This has led to a dearth of quantitative, empirical studies to better understand the phenomenon. Some examples of qualitative studies and theoretical papers on consumer xenocentrism in international marketing are Mueller et al. (2016) and Mueller and Broderick (2009). Additionally, some qualitative and theoretical papers on xenocentrism from other fields are: philosophy (Montemayor, 2015), anthropology (Bashkow, 2006; Wallach, 2002), sociology (Asakitikpi, 2016), education (Waithaka, 2017) and psychology (de Leff, 2002). Thus, there are several qualitative and theoretical papers on consumer xenocentrism and xenocentrism in general. In fact, some of these papers propose a number of theoretical propositions that are yet to be empirically tested. Taking all the above points into account, a quantitative study was conducted for this thesis, although a minor qualitative research was initially performed.

In all four countries an online questionnaire was used to conduct the study. An online questionnaire has the potential to reach respondents of different age groups, professions and to a certain extent, varying educational qualification. It is also easier to transform the data collected using online questionnaire into an analyzable form. Bryman et al. (2011) argue that there are several additional advantages to using an online questionnaire. Such kind of a questionnaire aids in accessing individuals from different parts of the country more than a face-to-face approach. From a practical standpoint, an online questionnaire approach is also less time-consuming and less expensive. Since 
questions can be made mandatory in an online survey, this practice results in better quality data than in paper surveys where a respondent can skip some key questions. Thus, missing data is less of an issue in this type of data collection. Using online surveys also avoids data coding errors which are common in paper surveys. Additionally, respondents answering online questionnaires also can take their time to reflect and answer the questions rather than in a hurried manner. They can also answer questions at their own convenience. Furthermore, in online questionnaires, questions placed ahead can be based on the answers of the current question (filter question) which means that respondents need to read lesser questions and answer only relevant questions. Furthermore, online survey tools can pinpoint issues regarding data quality (as will be discussed in section 7.2.3). Thus, there are several advantages of using online questionnaires for data collection. One may question the choice of using the online data collection in the continent of Africa. However, it should be noted that Kenya is the most technologically advanced country in Africa with as much as $83 \%$ of the population having internet access mostly through mobile phones (Standard Media, 2018). Overall, the decision to use an online questionnaire in all four countries was made keeping in mind the various practical and functional advantages that this method has to offer.

The online questionnaire was hosted in Qualtrics. The questionnaire length would require a maximum of $15-20$ minutes to complete which is the average attention span of an adult student (Middendorf and Kalish, 1996). All the questions were mandatory in order to avoid missing data. The survey was open to any Indian, Romanian, Kenyan and Ecuadorian aged 18 years or above living in their home country at the time of data collection. The study was cross-sectional. 
For data collection in Ecuador and India, the online market research platform Cint was used. Cint connects researchers and survey respondents worldwide. An advantage of this platform includes obtaining a sample that is close in demographics quotas to the entire target population. The Cint platform has several individuals from around the world who sign up to complete surveys that are suitable to them for a monetary or non-monetary compensation. While I do not provide any incentives to the respondents directly, Cint may offer some incentives to the individual respondents. The link to the online questionnaire was posted on Cint which was then assessed by Cint's consumer panel in India and Ecuador. Recruiting respondents for social science research using online platforms is an accepted practice and some of research that have used this technique have been published in top-rated marketing journals (e.g. Strizhakova and Coulter, 2015; Lawrence, 2012 and Bhattacharjee et al., 2014). In both Romania and Kenya, local market research firms were employed, and these firms used the online survey link to collect data from their online consumer panel. While I offered no direct incentives to the respondents to participate in the survey, the market research firms may or may not have provided such incentives.

Table 6.3 summarizes the data collection method and expense in each country. The data collection expense/complete survey is the amount I paid to the market research firm per complete survey.

Table 6.3: Data collection method and expense by country

\begin{tabular}{|c|c|c|}
\hline Countries & Data collection method & $\begin{array}{c}\text { Data collection } \\
\text { expense/complete survey (in } \\
\text { USD) }\end{array}$ \\
\hline Ecuador & Market research platform Cint & $\$ 3.06$ \\
\hline India & Market research platform Cint & $\$ 2.44$ \\
\hline
\end{tabular}




\begin{tabular}{|c|c|c|}
\hline Romania & $\begin{array}{c}\text { Market research firm, East } \\
\text { Marketing Romania }\end{array}$ & None \\
\hline Kenya & $\begin{array}{c}\text { Market research firm, Afrovas } \\
\text { Research }\end{array}$ & $\$ 5$ \\
\hline
\end{tabular}

Barrett (2007) argues that a sample size of minimum 200 respondents is recommended for data that undergoes structural equation modeling analysis and that guideline was followed. A minimum of 300 respondents were targeted in each country.

\subsection{Chapter Summary}

This chapter discussed the methodology that was used in this study. The countries where the study was conducted, and their cultures were discussed. The method of data collection was an online survey. The questionnaire development which consisted of what each section of the survey contained was explained. Each measure used in the survey was reviewed. For each measure, the scale selection criteria, the different available scales and how the one used in this study was selected has been explained. All the measures used in this thesis were then presented in a tabular format for a concise view. A detailed five-step translation process that was followed was discussed. Next, the pilot study process which was conducted to test the survey and its results were discussed. A few modifications were made to the survey for the main data collection after looking at the results of the pilot study. Finally, data collection process in each country was elaborated on. Specifically, the length of the survey, survey platform that the survey was available on, the criteria for the target sample, the market research firms used, and the number of respondents targeted for answering the survey were all mentioned. The upcoming chapter will discuss the preliminary data analysis of the data that was collected. 


\section{CHAPTER SEVEN - PRELIMINARY DATA ANALYSIS}

\subsection{Introduction}

In this chapter the preliminary data analysis will be discussed. Specifically, it will address the characteristics of the sample that was collected. First, in response characteristics, the data collection dates and duration for each country and the survey response numbers are discussed. Second, the demographic profile of data collected and its comparison to the national population demographics is discussed. Third, data screening procedure which includes the handling of response non-differentiation, response to control questions and missing data is explained.

\subsection{Sample characteristics}

\subsubsection{Response characteristics}

Table 7.1 gives the data collection dates and duration for each of the four countries where the data was collected. Data collection for Kenya and India started a month earlier than the other two countries as no survey translation was required for these countries. For Ecuador and Romania, data collection started in April after the translation of questionnaires into Spanish and Romanian were finalized.

Table 7.1: Data collection dates and duration by country

\begin{tabular}{|l|l|l|l|}
\hline Country & Data collection start date & Data collection end date & Total duration \\
\hline Kenya & March $10^{\text {th }}, 2019$ & March $13^{\text {th }}, 2019$ & 4 days \\
\hline India & March $10^{\text {th }}, 2019$ & March $20^{\text {th }}, 2019$ & 11 days \\
\hline Ecuador & April $10^{\text {th }}, 2019$ & April $15^{\text {th }}, 2019$ & 6 days \\
\hline Romania & April $22^{\text {nd }}, 2019$ & May $2^{\text {nd }}, 2019$ & 11 days \\
\hline
\end{tabular}


Table 7.2 gives the overall survey response numbers and percentages by country. Completed response counts are the final number of usable questionnaires. Screenout response counts are the total number of respondents who did not consent to participate in the survey and thus did not take part in it. Partial response counts are the number of respondents who started the survey but did not finish it. Finally, the disqualified response counts are the number of respondents who had completed the survey, but the quality of their responses was poor. A more elaborate account on the disqualification criteria can be found in the data screening section 7.2.3.1. Due to the nature of data collection (i.e. the survey link being hosted online, and the consumer panel asked to participate in the survey and the survey closed once there were 330 completed responses), it is not possible to calculate the response rates as the survey was not personally sent to a certain number of participants. However, for each country the percentage of usable (completed) responses out of all the data collected was calculated. This was between $54.52 \%$ to $97.98 \%$ for the different countries with the combined sample being $75.84 \%$.

Table 7.2: Response numbers and percentages

\begin{tabular}{|c|c|c|c|c|c|c|c|c|c|c|}
\hline \multirow{3}{*}{ Completed responses } & \multicolumn{2}{|c|}{ Overall } & \multirow{2}{*}{$\begin{array}{l}\text { Ecuador } \\
\text { Number }\end{array}$} & & \multicolumn{2}{|c|}{ India } & \multicolumn{2}{|c|}{ Kenya } & \multicolumn{2}{|c|}{ Romania } \\
\hline & Number & Percentage & & Percentage I & & Percentage | & nber & Percentage | & Number & Percentage \\
\hline & 1306 & \begin{tabular}{|l|l|}
$6 \quad 75,84 \%$ \\
\end{tabular} & 322 & $89.69 \%$ & 326 & $54.52 \%$ & 340 & $97.98 \%$ & 318 & $76.08 \%$ \\
\hline Screenout responses* & 48 & $2.79 \%$ & 14 & $3.90 \%$ & 22. & $3,68 \%$ & 5 & $1,44 \%$ & 7 & $1.67 \%$ \\
\hline Partial responses & 83 & $4.82 \%$ & 0 & $0.00 \%$ & 11 & $1.84 \%$ & 0 & $0,00 \%$ & 72 & $17.22 \%$ \\
\hline Disqualified responses & 285 & $5 \quad 16.55 \%$ & 23 & $6.41 \%$ & 239 & $39.97 \%$ & 2 & $0.58 \%$ & 21 & $5.02 \%$ \\
\hline Total responses & 1722 & \begin{tabular}{|l|l|}
2 & $100.00 \%$ \\
\end{tabular} & 359 & $100.00 \%$ & 598 & $100.00 \%$ & 347 & $100.00 \%$ & 418 & $100.00 \%$ \\
\hline
\end{tabular}

* did not consent to participate 


\subsubsection{Demographic profile}

Table 7.3 shows the demographic profile of the main study. In total, a combined sample of 1306 respondents, aged 18 years and above was obtained. In the overall sample, the split between the younger age group ( $<35$ years) and older sample $(>=35$ years), is approximately equal. For Ecuador, India and Kenya, the younger sample is slightly over the $50 \%$ mark and for Romania slightly below $50 \%$. With respect to gender, the male and female respondents are almost equally represented except in India where men are over-represented (64.42\%). With regards to occupation across countries and in the overall sample, the respondents predominately are those working in professional jobs (business and salaried professionals). Finally, with respect to education, the respondents are predominately well-educated with most of them having at least a bachelor's degree. 
Table 7.3: Demographic profile of the main study

\begin{tabular}{|c|c|c|c|c|c|c|c|c|c|c|c|}
\hline & & \multicolumn{2}{|c|}{ Overall } & \multicolumn{2}{|c|}{ Ecuador } & \multicolumn{2}{|c|}{ India } & \multicolumn{2}{|c|}{ Kenya } & \multicolumn{2}{|c|}{ Romania } \\
\hline & & Number & Percentage & Number & Percentage & Number & Percentage & Number & Percentage & Number & Percentage \\
\hline \multirow[b]{7}{*}{ Age } & $18-24$ & 268 & $20.52 \%$ & 93 & $28.88 \%$ & 57 & $17.48 \%$ & 62 & $18.24 \%$ & 56 & $17.61 \%$ \\
\hline & $25-34$ & 437 & $33.46 \%$ & 87 & $27.02 \%$ & 130 & $39.88 \%$ & 124 & $36.47 \%$ & 96 & $30.19 \%$ \\
\hline & $35-44$ & 384 & $29.40 \%$ & 98 & $30.43 \%$ & 84 & $25.77 \%$ & 96 & $28.24 \%$ & 106 & $33.33 \%$ \\
\hline & $45-54$ & 160 & $12.25 \%$ & 38 & $11.80 \%$ & 32 & $9.82 \%$ & 46 & $13.53 \%$ & 44 & $13.84 \%$ \\
\hline & $55-64$ & 50 & $3.83 \%$ & 6 & $1.86 \%$ & 17 & $5.21 \%$ & 11 & $3.24 \%$ & 16 & $5.03 \%$ \\
\hline & $64+$ & 7 & $0.54 \%$ & 0 & $0.00 \%$ & 6 & $1.84 \%$ & 1 & $0.29 \%$ & 0 & $0.00 \%$ \\
\hline & Total & 1306 & $100.00 \%$ & 322 & $100.00 \%$ & 326 & $100.00 \%$ & 340 & $100.00 \%$ & 318 & $100.00 \%$ \\
\hline \multirow[b]{3}{*}{ Gender } & Male & 675 & $51.68 \%$ & 161 & $50.00 \%$ & 210 & $64.42 \%$ & 157 & $46.18 \%$ & 147 & $46.23 \%$ \\
\hline & Female & 631 & $48.32 \%$ & 161 & $50.00 \%$ & 116 & $35.58 \%$ & 183 & $53.82 \%$ & 171 & $53.77 \%$ \\
\hline & Total & 1306 & $100.00 \%$ & 322 & $100.00 \%$ & 326 & $100.00 \%$ & 340 & $100.00 \%$ & 318 & $100.00 \%$ \\
\hline \multirow[b]{6}{*}{ Occupation } & Business & 283 & $21.67 \%$ & 61 & $18.94 \%$ & 39 & $11.96 \%$ & 110 & $32.35 \%$ & 73 & $22.96 \%$ \\
\hline & \begin{tabular}{|l} 
Salaried \\
professional
\end{tabular} & 682 & $52.22 \%$ & 144 & $44.72 \%$ & 216 & $66.26 \%$ & 158 & $46.47 \%$ & 164 & $51.57 \%$ \\
\hline & \begin{tabular}{|l} 
Laborer/ \\
skilled labor
\end{tabular} & 62 & $4.75 \%$ & 18 & $5.59 \%$ & 7 & $2.15 \%$ & 17 & $5.00 \%$ & 20 & $6.29 \%$ \\
\hline & Student & 199 & $15.24 \%$ & 68 & $21.12 \%$ & 36 & $11.04 \%$ & 44 & $12.94 \%$ & 51 & $16.04 \%$ \\
\hline & Retired/others & 80 & $6.13 \%$ & 31 & $9.63 \%$ & 28 & $8.59 \%$ & 11 & $3.24 \%$ & 10 & $3.14 \%$ \\
\hline & Total & 1306 & $100.00 \%$ & 322 & $100.00 \%$ & 326 & $100.00 \%$ & 340 & $100.00 \%$ & 318 & $100.00 \%$ \\
\hline \multirow[b]{5}{*}{ Education } & $\begin{array}{l}\text { 12th grade or } \\
\text { less }\end{array}$ & 178 & $13.63 \%$ & 69 & $21.43 \%$ & 23 & $7.06 \%$ & 28 & $8.24 \%$ & 58 & $18.24 \%$ \\
\hline & Trade school & 154 & $11.79 \%$ & 54 & $16.77 \%$ & 8 & $2.45 \%$ & 78 & $22.94 \%$ & 14 & $4.40 \%$ \\
\hline & \begin{tabular}{|l} 
University \\
degree \\
(Bachelors)
\end{tabular} & 626 & $47.93 \%$ & 166 & $51.55 \%$ & 157 & $48.16 \%$ & 208 & $61.18 \%$ & 95 & $29.87 \%$ \\
\hline & \begin{tabular}{|l|}
$\begin{array}{l}\text { Post graduate } \\
\text { degree }\end{array}$ \\
\end{tabular} & 348 & $26.65 \%$ & 33 & $10.25 \%$ & 138 & $42.33 \%$ & 26 & $7.65 \%$ & 151 & $47.48 \%$ \\
\hline & Total & 1306 & $100.00 \%$ & 322 & $100.00 \%$ & 326 & $100.00 \%$ & 340 & $100.00 \%$ & 318 & $100.00 \%$ \\
\hline
\end{tabular}


Table 7.4 below shows the national population distribution for age and gender for all the four countries. Since the national population distribution of a country has data from age 0 and above and this research was only open to consumers from age 18 years and above, the percentages available in the national population distribution data was converted so that the percentages for only ages $15+$ are taken into account. That is, the national population distribution data was converted such that the total percentage of the population distribution for ages 15 years and above is $100 \%$. This was achieved by first adding the original percentages for each age group from age $15+$ for each country. Then the percentage in every age group for every country was divided by that calculated total percentage described in the previous line.

Table 7.4: National population distribution for age and gender

\begin{tabular}{|c|c|c|c|c|c|}
\hline & & \multirow{3}{*}{\begin{tabular}{|l|} 
Ecuador \\
Percentage
\end{tabular}} & \multirow{3}{*}{\begin{tabular}{|l|} 
India \\
Percentage \\
\end{tabular}} & \multirow{3}{*}{\begin{tabular}{|l|} 
Kenya \\
Percentage \\
\end{tabular}} & \multirow{3}{*}{\begin{tabular}{|l|} 
Romania \\
Percentage
\end{tabular}} \\
\hline & & & & & \\
\hline & & & & & \\
\hline \multirow{4}{*}{ Age } & $15-24$ & $25.16 \%$ & $24.63 \%$ & $31.93 \%$ & $12.38 \%$ \\
\hline & 25-54 & $54.29 \%$ & $56.53 \%$ & $56.54 \%$ & $53.74 \%$ \\
\hline & $55-64$ & $10.33 \%$ & $10.25 \%$ & $6.54 \%$ & $14.72 \%$ \\
\hline & $65+$ & $10.22 \%$ & $8.59 \%$ & $5.00 \%$ & $19.16 \%$ \\
\hline \multirow[t]{3}{*}{ Gender } & Male & $49.60 \%$ & $51.80 \%$ & $49.70 \%$ & $48.50 \%$ \\
\hline & Female & $50.40 \%$ & $48.20 \%$ & $50.30 \%$ & $51.50 \%$ \\
\hline & Total & & & & \\
\hline
\end{tabular}

Sources: Adapted from Indexmundi, 2018a; Indexmundi, 2018b; Indexmundi, 2018c; Indexmundi, 2018d; StatisticsTimes, 2018; UN Women, 2018; TradingEconomics, 2018; Countrymeters, 2018.

In general, the survey attempted to collect a balanced sample with regards to age and gender. However, a perfect sample was difficult to achieve. The data collected for this thesis was compared with the demographic distribution of the population of the different countries. For age groups up to 24 years, in most cases, the national percentage is more or 
less in-line with the data collected. The 25-54 age group in the national population distribution data combines three age groups in the sample data collected. The combination of these three age groups is slightly over-represented in the sample (69.25\% to $78.24 \%)$ as compared to the national distribution $(53.74 \%$ to $56.54 \%)$. It must be noted that for all countries in both the sample and the national population this is the age group with the greatest number of individuals. For age group from 55-64 years, that demographic was slightly underrepresented in the data collected for this thesis. Finally, with respect to the $65+$ age group for Romania, the national distribution is $19.16 \%$ but in the thesis data it is $0 \%$. This is likely because of the online mode of data collection which might not be the most suitable method to access this age group. Regarding gender in the Indian sample, men are slightly overrepresented $(64.42 \%)$ as compared to the national distribution $(51.80 \%)$. However, for all other countries, the gender distribution in the sample is similar to the national population distribution.

\subsubsection{Data screening}

Data screening is necessary to ensure that an acceptable quality of data is being processed. To that end, first, response non-differentiation is discussed along with how this scenario is handled. Second, the management of incorrect responses to control questions is explained. Third, the handling of missing data is explained.

\subsubsection{Response non-differentiation}

The first data screening procedure is to check for non-differentiation responses or straightlining. This involves identifying respondents who respond to surveys by clicking on the same response every time or providing tree shaped responses. These respondents 
have not given necessary consideration to the survey and have provided repetitive forms of answers to survey questions (Qualtrics, 2018). Every row of data was inspected to check for non-differentiation responses. Additionally, a very short survey time duration might also raise suspicions on the respondent's level of attention. These participants are identified by checking how long they have spent on taking the survey which is a statistic provided by the online data collection tool, Qualtrics. Further visually inspecting the data, confirmed or refuted this suspicion. If non-differentiation response is confirmed, the respondent's data was removed. These response counts are recorded under the disqualified responses row in table 7.2.

\subsubsection{Response to control questions}

Two types of control scenarios were set-up. One involved two questions at different points in the survey which asked the respondents to click on "Agree" or "Somewhat Disagree" for those particular questions. Two, the answers to reverse-coded questions for status consumption, national identity, international travel experience/preference constructs were checked to see if they were in the opposite direction to that of the responses of nonreverse coded questions. If the responses failed these control scenarios, those responses were removed. These response counts are recorded under the disqualified responses row in table 7.2.

Thus, responses that showed non-differentiation and/or failed the control scenarios were recorded under the disqualified responses. A total of 285 responses were removed in this manner. The country-wise number of responses removed were 23 for Ecuador, 239 for India, 2 for Kenya and 21 for Romania. 


\subsubsection{Missing data}

The online questionnaire was designed such that answering all the questions were mandatory. Since the respondents were not allowed to skip any questions, the collected data was complete and there was no problem of missing data. It is possible that setting all questions to be mandatory might have caused some respondents to abort the questionnaire midway, but the nature of the study did not tolerate missing answers. The total number of respondents who have aborted the survey midway is 83 and the country-wise count for the same can be found in the "Partial responses" row in table 7.2.

\subsection{Chapter summary}

This chapter discussed the preliminary data analysis performed on the sample. The response characteristics i.e. the data collection dates and duration for each country and the survey response numbers are presented. The demographic profile of the sample is analyzed and its comparison to the national population demographics is completed. The sample has a good distribution of younger and older individuals, and male and female respondents. Additionally, a majority of respondents in the sample hold professional jobs and are university-educated - these are the respondents who are most likely to be xenocentric. Finally, data screening procedure which includes the handling of response nondifferentiation, response to control questions and missing data is explained. Overall, the quality of the data collected seems to be good. In the next chapter, the consumer xenocentrism and antecedent constructs are analyzed, and all the antecedent hypotheses are tested. 


\section{CHAPTER EIGHT-ANALYSIS OF XENOCENTRISM AND ANTECEDENTS}

\subsection{Introduction}

In this chapter, first, the theoretical explanation of descriptive analysis and confirmatory factor analysis (CFA) are discussed. Second, for the consumer xenocentrism and every antecedent construct, the results of the descriptive analysis and CFA are examined. Third, the various types of validities for the antecedent constructs are reviewed. And finally, the structural model results of the antecedent constructs are presented.

\subsection{Descriptive analysis}

The following analyses will be performed on the consumer xenocentrism variable and each antecedent variable.

\subsubsection{Normal Distribution}

First, the skewness and kurtosis of each variable will be checked to see if the data is normally distributed. Kline (2011) recommends that the absolute values of skewness and kurtosis should not exceed 3.0 and 10.0 respectively and these guidelines will be followed. Any variable exceeding these guideline values will be looked at for outliers and these outliers will be handled on a case-to-case basis. One of the three suggested ways of dealing with such outliers (deleting, leaving as-is, or modifying) (Kline, 2011) will be used. 


\subsubsection{Means and Standard Deviations}

Second, the mean and standard deviation will be analyzed for each variable. The standard deviation will help to check the variability in the data. The mean can aid in coming to some initial inferences regarding the sample.

\subsubsection{Cronbach's alpha}

Cronbach's alpha will be checked for each construct. This is a common way to assess the reliability of the factor and the recommended value for Cronbach's alpha is above 0.7 (Cortina, 1993; Nunnally and Bernstein, 1994). However, some scholars argue that constructs with lesser number of items can have lower Cronbach's alpha (Nunnally 1978; Cortina 1993). Additionally, Shay and Back (2004) argue that Cronbach's alpha of around 0.6 is acceptable but merit further investigation in future research as to make sure if they are weak constructs or if this is the case because of small number of items. Griethuijsen et al. (2014) also argue that Cronbach's alpha of around 0.6 is acceptable. In our case, it might also be that some measures that were developed and tested in Western countries might not work as expected or have low Cronbach's alpha in developing countries.

\subsection{Confirmatory factor analysis (CFA)}

\subsubsection{Partial measurement model}

The confirmatory factor analysis (CFA) is used to confirm the factor structure of the constructs in the database. According to Harrington (2008), CFA can be used to examine whether measures borrowed from other studies are applicable and appropriate to 
the new sample. CFA only focuses on the link between the items and the factor and this kind of model is called a measurement model (Byrne, 2010). For this study, CFA was conducted using the AMOS software.

Due to the large number of constructs in this study, it was decided to first test the measurement model of each construct separately before integrating and testing all the antecedent constructs together. This kind of approach is supported by Raykov, Tomer and Nesselroade (1991). Thus, for each antecedent, a partial measurement model was constructed. Items were deleted or errors were co-varied one at a time, where necessary, to improve the model fit. All modifications were made keeping in mind whether they made theoretical sense (Schreiber, Amaury, Stage, Barlow, and King, 2006). Once all the partial measurement models had an acceptable fit and made sense theoretically, the structural model was constructed and analyzed.

\subsubsection{Model fit assessment}

The measurement and structural model were assessed using the following indices: $\chi 2$ df, Goodness-of-fit (GFI), Adjusted-Goodness-of-fit (AGFI), Comparative-Fit-Index (CFI), Root Mean Square Error of Approximation (RMSEA), Standardized Root Mean Square Residual (SRMR) and Average Variance Extracted (AVE). The GFI, AGFI and CFI ranges between 0 and 1.0, with values close to 1.0 indicating a good fit (Byrne, 2010).

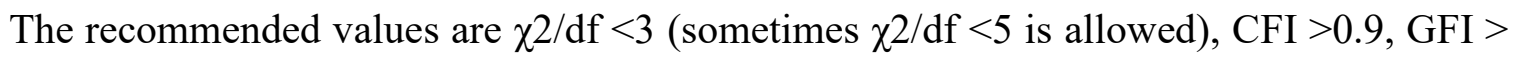
0.9 and AGFI >0.8 (Hu and Bentler, 1999; Bollen,1989; Doll et al., 1994). The recommended value for RMSEA is less than 0.08 (MacCallum, Browne, and Sugawara 1996) but Browne and Cudeck (1993) and Byrne (2010) argue that values till 0.10 are acceptable and anything above that constitutes poor fit. The recommended value for SRMR 
is $<0.9$ (Hu and Bentler, 1999). The acceptable value for Average Variance Extracted (AVE) is $>0.45$ (Netemeyer, Bearden, and Sharma 2003).

\subsection{Consumer xenocentrism construct}

Tables 8.1 to 8.5 show the descriptive analysis of the different samples for the consumer xenocentrism construct. Specifically, it shows, the mean, standard deviation, skewness and kurtosis for the construct and for each item within the construct. CXENO_foreign_admiration_1 to 5 represents the different items that make up the foreign admiration dimension of the consumer xenocentrism construct. Similarly, CXENO_domestic_reject_1 to 5 represents the different items that make up the domestic rejection dimension of the consumer xenocentrism construct. Average_FA and Average_DR are the final averages for foreign admiration and domestic rejection dimensions respectively.

The skewness and kurtosis are within acceptable ranges. Based on the standard deviation values, the sample exhibits an expected variability that does not raise any concerns. For most of the antecedent variables too this is the case, unless otherwise stated. On a scale of $1=$ Strongly disagree to $7=$ Strongly agree, the average foreign admiration factor mean is between 4.01 to 4.96 for the various samples, and the domestic rejection factor mean is between 2.84 to 3.53 for the different samples, indicates that the various samples are neutral about or agree that they admire foreign products and mostly disagree that they reject domestic products. The scores are low as it is likely to have social desirability bias which signifies that participants under-report socially undesirable behavior such as rejecting domestic products and preferring foreign products. Social desirability bias happens because of an individual's self-presentation concerns and the need 
for social approval (Krumpal, 2013). Participants choose answers that are more socially acceptable than what they truly believe (Grimm, 2010). This kind of behavior can be more prevalent in collectivistic cultures where individuals want to be accepted by the group. In fact, xenocentrism itself has negative connotations in certain cultures such as Mexico. The people who are xenocentric are called traitors (Soto, 2008). Additionally, it is known that individuals in many developing cultures avoid extreme answers and mostly select answers around the midpoint (Lee, Jones, Mineyama and Zhang, 2002). When the foreign admiration factor and domestic rejection factor means were divided into quartiles the means were between 3.75 and 5.25, and 2.21 and 3.41 respectively. That is, it shows that even the highest quartile has been conservative in its responses and this could be another reason for the low scores.

The country with the highest foreign admiration score (4.96) and highest domestic rejection score (3.53) is India while the country with the lowest score for both factors is Romania. Thus, India is the most xenocentric country and Romania is the least. An ANOVA was run to find out if the means were significantly different. For both the foreign admiration and domestic rejection, the difference between the means or average for all countries was significant $(\mathrm{p}<0.001)$. Figure 8.1 pictorially represents the foreign admiration and domestic rejection scores for each country. 
Table 8.1: Descriptive analysis for consumer xenocentrism construct for the combined sample

\begin{tabular}{|c|c|c|c|c|c|c|c|c|c|c|c|}
\hline & $\begin{array}{c}\text { CXENO_foreign_ } \\
\text { admiration_1 }\end{array}$ & $\begin{array}{c}\text { CXENO_foreign_ } \\
\text { admiration_3 }\end{array}$ & $\begin{array}{c}\text { CXENO_foreign } \\
\text { _admiration_4 }\end{array}$ & $\begin{array}{c}\text { CXENO_foreign } \\
\text { _admiration_5 }\end{array}$ & Average_FA & $\begin{array}{c}\text { CXENN_domestic } \\
\text { _reject_1 }\end{array}$ & $\begin{array}{c}\text { CXENO_domestic } \\
\text { reject_2 }\end{array}$ & $\begin{array}{c}\text { CXENO_domestic } \\
\text { reject_3 }\end{array}$ & $\begin{array}{c}\text { CXENO_domestic } \\
\text { _eject_4 }\end{array}$ & $\begin{array}{c}\text { CXENO_domestic } \\
\text { reject_5 }\end{array}$ & Average_DR \\
\hline Mean & 4.34 & 4.80 & 4.46 & 4.32 & 4.48 & 2.48 & 3.91 & 2.40 & 3.50 & 3.96 & 3.25 \\
\hline Std. Deviation & 1.57 & 1.40 & 1.50 & 1.54 & 1.50 & 1.40 & 1.68 & 1.43 & 1.83 & 1.79 & 1.63 \\
\hline Skewness & -0.27 & -0.63 & -0.40 & -0.30 & -0.40 & 1.09 & -0.07 & 1.18 & 0.22 & -0.16 & 0.45 \\
\hline Kurtosis & -0.66 & 0.09 & -0.41 & -0.62 & -0.40 & 0.67 & -0.95 & 0.78 & -1.18 & -1.18 & -0.37 \\
\hline
\end{tabular}

Table 8.2: Descriptive analysis for consumer xenocentrism construct for the Ecuador sample

\begin{tabular}{|c|c|c|c|c|c|c|c|c|c|c|c|}
\hline & $\begin{array}{c}\text { CXENO_foreign_- } \\
\text { admiration_1 }\end{array}$ & $\begin{array}{c}\text { CXENO_foreign_ } \\
\text { admiration_3 }\end{array}$ & $\begin{array}{c}\text { CXENO_foreign } \\
\text { _admiration_4 }\end{array}$ & $\begin{array}{l}\text { CXENO_foreign } \\
\text { _admiration_5 }\end{array}$ & Average_FA & $\begin{array}{c}\text { CXENO_domestic } \\
\text { reject_1 }\end{array}$ & $\begin{array}{c}\text { CXENO_domestic } \\
\text { reject_2 }\end{array}$ & $\begin{array}{c}\text { CXENO_domestic } \\
\text { reject_3 }\end{array}$ & $\begin{array}{c}\text { CXENO_domestic } \\
\text { reject_4 }\end{array}$ & $\begin{array}{c}\text { CXENO_domestic } \\
\text { reject_5 }\end{array}$ & Average_DR \\
\hline Mean & 4.37 & 4.86 & 4.66 & 4.62 & 4.63 & 2.61 & 3.93 & 2.53 & 2.92 & 3.89 & 3.18 \\
\hline Std. Deviation & 1.50 & 1.37 & 1.44 & 1.42 & 1.43 & 1.33 & 1.69 & 1.52 & 1.71 & 1.86 & 1.62 \\
\hline Skewness & -0.36 & -0.68 & -0.55 & -0.54 & -0.53 & 0.90 & -0.13 & 0.94 & 0.61 & -0.13 & 0.44 \\
\hline Kurtosis & -0.30 & 0.20 & -0.06 & -0.20 & -0.09 & 0.47 & -0.94 & -0.04 & -0.76 & -1.23 & -0.50 \\
\hline
\end{tabular}

Table 8.3: Descriptive analysis for consumer xenocentrism construct for the India sample

\begin{tabular}{|c|c|c|c|c|c|c|c|c|c|c|c|}
\hline & $\begin{array}{c}\text { CXEN0_foreign_ } \\
\text { admiration_1 }\end{array}$ & $\begin{array}{c}\text { CXENO_foreign_ } \\
\text { admiration_3 }\end{array}$ & $\begin{array}{c}\text { CXENO_foreign } \\
\text { admiration_4 }\end{array}$ & $\begin{array}{l}\text { CXEN0_foreign } \\
\text { _admiration_5 }\end{array}$ & Average_FA & $\begin{array}{c}\text { CXENO_domestic } \\
\text { _reject_1 }\end{array}$ & $\begin{array}{c}\text { CXENO_domestic } \\
\text { _eject_2 }\end{array}$ & $\begin{array}{c}\text { CXENO_domestic } \\
\text { _reject_3 }\end{array}$ & $\begin{array}{c}\text { CXENO_domestic } \\
\text { _eject_4 }\end{array}$ & $\begin{array}{c}\text { CXENO_domestic } \\
\text { _reject_5 }\end{array}$ & Average_DR \\
\hline Mean & 4.83 & 5.21 & 5.00 & 4.81 & 4.96 & 2.78 & 4.37 & 2.49 & 4.08 & 3.94 & 3.53 \\
\hline Std. Deviation & 1.55 & 1.33 & 1.44 & 1.55 & 1.47 & 1.60 & 1.68 & 1.66 & 1.89 & 1.90 & 1.75 \\
\hline Skewness & -0.56 & -0.80 & -0.75 & -0.57 & -0.67 & 0.82 & -0.36 & 1.11 & -0.21 & -0.10 & 0.25 \\
\hline Kurtosis & -0.27 & 0.68 & 0.36 & -0.30 & 0.12 & -0.19 & -0.71 & 0.22 & -1.15 & -1.23 & -0.61 \\
\hline
\end{tabular}


Table 8.4: Descriptive analysis for consumer xenocentrism construct for the Kenya sample

\begin{tabular}{|c|c|c|c|c|c|c|c|c|c|c|c|}
\hline & $\begin{array}{c}\text { CXENO_foreign_ } \\
\text { admiration_1 }\end{array}$ & $\begin{array}{c}\text { CXENO_foreign_ } \\
\text { admiration_3 }\end{array}$ & $\begin{array}{c}\text { CXENO_foreign } \\
\text { _admiration_4 }\end{array}$ & $\begin{array}{c}\text { CXEN0_foreign } \\
\text { _admiration_ } 5\end{array}$ & Average_FA & $\begin{array}{c}\text { CXENO_domestic } \\
\text { reject_1 }\end{array}$ & $\begin{array}{c}\text { CXENO_domestic } \\
\text { _reject_2 }\end{array}$ & $\begin{array}{c}\text { CXENO_domestic } \\
\text { _eject_3 }\end{array}$ & $\begin{array}{c}\text { CXENO_domestic } \\
\text { _eject_4 }\end{array}$ & $\begin{array}{c}\text { CXENO_domestic } \\
\text { _eject_5 }\end{array}$ & Average_DR \\
\hline Mean & 4.33 & 4.93 & 4.16 & 3.84 & 4.32 & 2.50 & 3.98 & 2.34 & 4.00 & 4.35 & 3.43 \\
\hline Std. Deviation & 1.60 & 1.38 & 1.53 & 1.64 & 1.54 & 1.40 & 1.77 & 1.27 & 1.81 & 1.69 & 1.59 \\
\hline Skewness & -0.31 & -0.88 & -0.24 & 0.05 & -0.35 & 1.21 & -0.13 & 1.28 & -0.16 & -0.52 & 0.34 \\
\hline Kurtosis & -0.85 & 0.64 & -0.75 & -0.96 & -0.48 & 1.00 & -1.13 & 1.44 & -1.22 & -0.86 & -0.16 \\
\hline
\end{tabular}

Table 8.5: Descriptive analysis for consumer xenocentrism construct for the Romania sample

\begin{tabular}{|c|c|c|c|c|c|c|c|c|c|c|c|}
\hline & $\begin{array}{c}\text { CXENO_foreign_- } \\
\text { admiration__ }\end{array}$ & $\begin{array}{c}\text { CXENO_foreign_ } \\
\text { admiration_3 }\end{array}$ & $\begin{array}{c}\text { CXENO_foreign } \\
\text { _admiration_4 }\end{array}$ & $\begin{array}{l}\text { CXENO_foreign } \\
\text { _admiration_5 }\end{array}$ & Average_FA & $\begin{array}{c}\text { CXENO_domestic } \\
\text { _eject_1 }\end{array}$ & $\begin{array}{c}\text { CXENO_domestic } \\
\text { _eject_2 }\end{array}$ & $\begin{array}{c}\text { CXENO_domestic } \\
\text { _reject_3 }\end{array}$ & $\begin{array}{c}\text { CXENO_domestic } \\
\text { _eject_4 }\end{array}$ & $\begin{array}{c}\text { CXENO_domestic } \\
\text { _eject_5 }\end{array}$ & Average_DR \\
\hline Mean & 3.81 & 4.19 & 4.00 & 4.03 & 4.01 & 2.02 & 3.36 & 2.23 & 2.97 & 3.63 & 2.84 \\
\hline Std. Deviation & 1.46 & 1.35 & 1.37 & 1.31 & 1.37 & 1.13 & 1.42 & 1.20 & 1.56 & 1.63 & 1.39 \\
\hline Skewness & 0.00 & -0.35 & -0.32 & -0.38 & -0.26 & 1.36 & 0.18 & 1.24 & 0.64 & 0.07 & 0.70 \\
\hline Kurtosis & -0.65 & -0.24 & -0.39 & -0.22 & -0.37 & 1.76 & -0.61 & 1.52 & -0.51 & $-1,12$ & 0.21 \\
\hline
\end{tabular}


Figure 8.1: Foreign admiration and domestic rejection scores for all samples

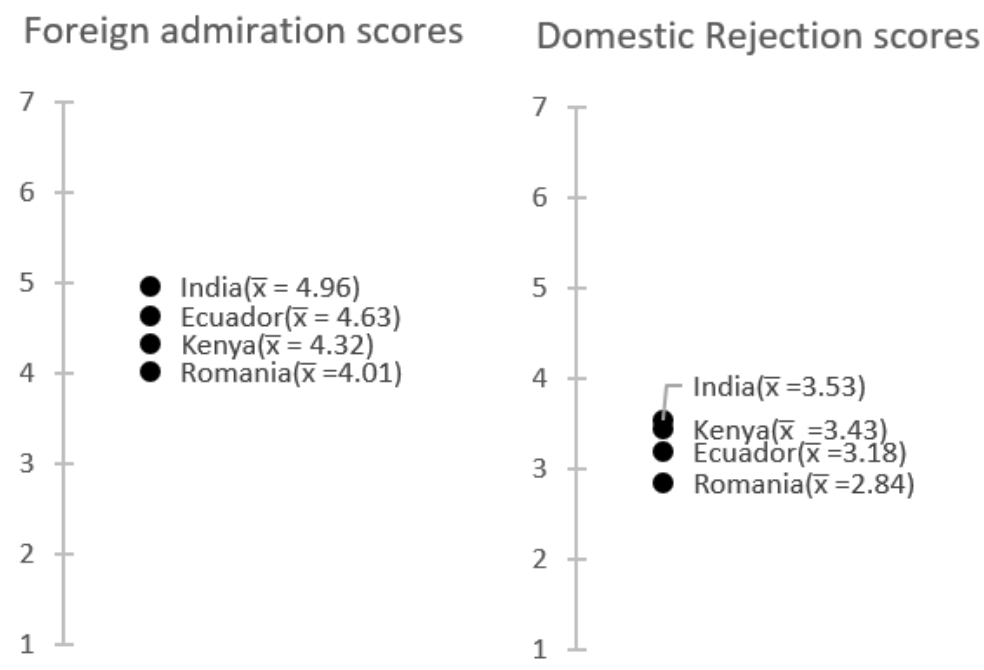

Table 8.6 shows the confirmatory factor analysis for the different samples. Except the $\chi^{2} / \mathrm{df}$ value for the combined sample and AVE values for the domestic rejection construct, all the model fit indices are in the recommended range. Hu and Bentler (1999) argue that $\chi^{2 / \mathrm{df}<5}$ is sometimes permissible and the value for the combined sample is borderline good considering this benchmark. All AVE values for the domestic rejection construct fell below the acceptable 0.45 mark. However, the Cronbach's alpha for foreign admiration and domestic rejection are both at acceptable levels. Ping (2004, p.132) argues that, "reliability and AVE are linked, but not always closely. While reliability is always larger than AVE, a highly reliable measure can have an unacceptable AVE”. Additionally, only the AVE value being low does not signify that the model has poor fit. SEM is based on a variety of fit indices and since most of the indices have a good fit, the overall CFA 
model can be considered to have a good fit. This is also the case for few other antecedent constructs as well. That is, the AVE value is low but overall the CFA model has a good fit. Item 2 ("I tend to prefer foreign products compared to local ones") in the foreign admiration factor was deleted in order to get a good fit for the CFA model. When item 2 is present, RMSEA and SRMR values are not in the acceptable range. Additionally, when testing for invariance, $\chi 2 / \mathrm{df}$ values are above recommended range and the structural invariance was not fulfilled when item 2 was present.

On removing item 2, the CFA has good fit indices and all three invariances (configural, structural and measurement) are supported. Table 8.7 shows the fit indices for the invariance tests. Configural invariance checks whether the CFA has good fit when the four groups (i.e. four countries) are tested together and freely without any constraints. This is done using the multi-group analysis feature in AMOS. Model 1 in table 8.7 indicates that the configural invariance has been fulfilled and provides support that the pattern of fixed and non-fixed parameters in the model is comparable for all four country samples. Next, measurement invariance was tested. For this type of invariance, all the factor coefficients were constrained to be equal in all four samples (model 2 in table 8.7). A chi-square difference test is performed, and results indicate that the difference is not statistically significant, and therefore measurement invariance is supported. Lastly, structural invariance tests whether the relationships among the latent variables are properly drawn the same way for each of the four groups in the analysis. Using the method discussed for measurement invariance, structural invariance is also confirmed (model 3 in table 8.7). In sum, the model is cross-validated for all four country samples. 
Table 8.6: Confirmatory factor analysis for consumer xenocentrism construct for the different samples

\begin{tabular}{|l|r|l|l|l|l|l|l|l|r|}
\hline Sample & X2/df & GFI & AGFI & CFI & RMSEA & SRMR & $\begin{array}{l}\text { Cronbach's } \\
\text { alpha }\end{array}$ & AVE values & $\begin{array}{l}\text { No. of } \\
\text { items }\end{array}$ \\
\hline Combined & 5.33 & 0.98 & 0.96 & 0.98 & 0.06 & 0.04 & $\begin{array}{l}\text { FA }=0.85 ; \\
\text { DR }=0.77\end{array}$ & $\begin{array}{l}\text { FA }=0.58 ; \\
\text { DR }=0.36\end{array}$ & 9 \\
\hline Ecuador & 2.93 & 0.95 & 0.91 & 0.95 & 0.08 & 0.06 & $\begin{array}{l}\text { FA }=0.82 ; \\
\text { DR }=0.79\end{array}$ & $\begin{array}{l}\text { FA }=0.54 ; \\
\text { DR }=0.40\end{array}$ & 9 \\
\hline India & 2.81 & 0.96 & 0.92 & 0.96 & 0.08 & 0.06 & $\begin{array}{l}\text { FA }=0.87 ; \\
\text { DR }=0.76\end{array}$ & $\begin{array}{l}\text { FA }=0.63 ; \\
\text { DR }=0.34\end{array}$ & 9 \\
\hline Kenya & 1.80 & 0.97 & 0.95 & 0.98 & 0.05 & 0.03 & $\begin{array}{l}\text { FA }=0.81 ; \\
\text { DR }=0.74\end{array}$ & $\begin{array}{l}\text { FA }=0.53 ; \\
\text { DR }=0.34\end{array}$ & 9 \\
\hline Romania & 1.70 & 0.97 & 0.95 & 0.98 & 0.05 & 0.04 & $\begin{array}{l}\text { FA }=0.86 ; \\
\text { DR }=0.77\end{array}$ & $\begin{array}{l}\text { FA }=0.60 ; \\
\text { DR }=0.38\end{array}$ & 9 \\
\hline
\end{tabular}

Table 8.7: Fit indices for invariance tests

\begin{tabular}{|c|c|c|c|c|c|c|c|c|c|}
\hline Test & CMIN & $d f$ & $\mathrm{x} 2 / \mathrm{df}$ & p-value & CFI & GFI & AGFI & RMSEA & Notes \\
\hline $\begin{array}{l}\text { Configural } \\
\text { invariance } \\
\text { (baseline model } \\
\text {-Model 1) } \\
\end{array}$ & 221.81 & 96 & 2.31 & $<0.001$ & 0.97 & 0.96 & 0.93 & 0.03 & $\begin{array}{l}\text { Configural invariance } \\
\text { is supported }\end{array}$ \\
\hline $\begin{array}{l}\text { Full } \\
\text { measurement } \\
\text { invariance } \\
\text { (Model 2) } \\
\end{array}$ & 255.31 & 123 & 2.08 & $<0.001$ & 0.97 & 0.96 & 0.94 & 0.03 & $\begin{array}{l}\text { Chi-square difference between model } 2 \text { and } \\
\text { model } 1 \text { shows that the difference betweeen the } \\
2 \text { models is not statistically significant. Thus } \\
\text { measurement invariance is supported. }\end{array}$ \\
\hline $\begin{array}{l}\text { Full } \\
\text { structural } \\
\text { invariance } \\
\text { (Model 3) }\end{array}$ & 263.22 & 126 & 2.09 & $<0.001$ & 0.97 & 0.96 & 0.94 & 0.03 & $\begin{array}{l}\text { Chi-square difference between model } 3 \text { and } \\
\text { model } 1 \text { shows that the difference betweeen the } \\
2 \text { models is not statistically significant. Thus, } \\
\text { structural invariance is supported. }\end{array}$ \\
\hline
\end{tabular}

\subsection{Power Distance construct}

Tables 8.8 to 8.12 show the descriptive analysis of the different samples for the power distance construct. Power_distance_1 to 6 represents the different items that make up the power distance construct.

On a scale of $1=$ Strongly disagree to $7=$ Strongly agree, the average power distance mean is between 2.86 (Romania) to 4.04 (India) for the various samples. This signifies that 
the various samples are neutral or disagree that hierarchical structures are better. Again, just like consumer xenocentrism these scores may suffer from social desirability bias. It might be more politically correct to accept that one wants a more equal society than a hierarchical one. Also, just like consumer xenocentrism, the power distance construct was divided into quartiles and the means were between 2.50 and 4.00 . Thus, it can be seen that overall the samples have selected midpoint answers for the power distance questions as is the case usually in developing countries.

Table 8.13 shows the confirmatory factor analysis for the power distance construct for the different samples. All the model fit indices are in the recommended range except the AVE values. All AVE values fell below acceptable levels. Also, the Cronbach's alphas for the combined sample, Ecuador and Romania fell below the acceptable 0.7 mark and are all in the 0.6 range. Some scholars (Shay and Back, 2004; Griethuijsen et al., 2014) argue that 0.6 is still an acceptable range for Cronbach alphas. Additionally, the Cronbach's alpha for Kenya was the weakest at 0.53 . Overall, this power distance scale doesn't look fully reliable for our context. It seems to have good reliability for India, Romania and the combined sample but seems weaker for the other two countries. Since the overall fit and reliability for India, Romania and the combined sample are good, this construct will still be included in the structural model. 
Table 8.8: Descriptive analysis for power distance construct for the combined sample

\begin{tabular}{|c|c|c|c|c|c|c|c|}
\hline & \begin{tabular}{|c|} 
Power_distance \\
1
\end{tabular} & \begin{tabular}{|c|} 
Power_distance \\
2
\end{tabular} & \begin{tabular}{|c|} 
Power_distance \\
3
\end{tabular} & $\begin{array}{c}\text { Power_distance } \\
4\end{array}$ & $\begin{array}{c}\text { Power_distance } \\
5\end{array}$ & \begin{tabular}{|c} 
Power_distance \\
6
\end{tabular} & Average \\
\hline Mean & 2.86 & 4.08 & 3.40 & 3.27 & 3.48 & 2.83 & 3.32 \\
\hline Std. Deviation & 1.67 & 1.73 & 2.11 & 1.77 & 1.74 & 1.63 & 1.77 \\
\hline Skewness & 0.83 & -0.16 & 0.46 & 0.53 & 0.35 & 0.93 & 0.49 \\
\hline Kurtosis & -0.22 & -1.10 & -1.29 & -0.80 & -0.92 & -0.05 & -0.73 \\
\hline
\end{tabular}

Table 8.9: Descriptive analysis for power distance construct for the Ecuador sample

\begin{tabular}{|c|c|c|c|c|c|c|c|}
\hline & \begin{tabular}{|c|} 
Power_distance \\
1
\end{tabular} & \begin{tabular}{|c} 
Power_distance \\
2
\end{tabular} & $\begin{array}{c}\text { Power_distance } \\
3\end{array}$ & $\begin{array}{c}\text { Power_distance } \\
4\end{array}$ & $\begin{array}{c}\text { Power_distance } \\
5\end{array}$ & $\begin{array}{c}\text { Power_distance } \\
6\end{array}$ & Average \\
\hline Mean & 3.32 & 4.11 & 2.73 & 2.95 & 3.58 & 2.90 & 3.27 \\
\hline Std. Deviation & 1.65 & 1.65 & 1.58 & 1.63 & 1.68 & 1.63 & 1.64 \\
\hline Skewness & 0.41 & -0.24 & 1.13 & 0.73 & 0.28 & 0.98 & 0.55 \\
\hline Kurtosis & -0.86 & -0.97 & 0.52 & -0.38 & -0.95 & 0.09 & -0.42 \\
\hline
\end{tabular}

Table 8.10: Descriptive analysis for power distance construct for the India sample

\begin{tabular}{|c|c|c|c|c|c|c|c|}
\hline & \begin{tabular}{|c|} 
Power_distance \\
$\ldots$
\end{tabular} & \begin{tabular}{|c} 
Power_distance \\
_2
\end{tabular} & \begin{tabular}{|c|} 
Power_distance \\
3
\end{tabular} & $\begin{array}{c}\text { Power_distance } \\
\ldots\end{array}$ & $\begin{array}{c}\text { Power_distance } \\
\text { - }\end{array}$ & \begin{tabular}{|c|} 
Power_distance \\
6
\end{tabular} & Average \\
\hline Mean & 3.36 & 4.72 & 4.94 & 3.64 & 4.24 & 3.37 & 4.04 \\
\hline Std. Deviation & 1.94 & 1.64 & 2.00 & 1.88 & 1.78 & 1.72 & 1.83 \\
\hline Skewness & 0.50 & -0.47 & -0.79 & 0.32 & -0.12 & 0.46 & -0.02 \\
\hline Kurtosis & -1.01 & -0.73 & -0.76 & -1.08 & -1.04 & -0.85 & -0.91 \\
\hline
\end{tabular}

Table 8.11: Descriptive analysis for power distance construct for the Kenya sample

\begin{tabular}{|c|c|c|c|c|c|c|c|}
\hline & \begin{tabular}{|c|} 
Power_distance \\
1 \\
\end{tabular} & \begin{tabular}{|c|} 
Power_distance \\
2 \\
\end{tabular} & \begin{tabular}{|c|} 
Power_distance \\
3 \\
\end{tabular} & $\begin{array}{c}\text { Power_distance } \\
4 \\
\end{array}$ & \begin{tabular}{|c|} 
Power_distance \\
5
\end{tabular} & \begin{tabular}{|c|} 
Power_distance \\
6 \\
\end{tabular} & Average \\
\hline Mean & 2.29 & 3.79 & 3.56 & 3.53 & 3.07 & 2.40 & 3.10 \\
\hline Std. Deviation & 1.42 & 1.83 & 2.30 & 1.88 & 1.65 & 1.48 & 1.76 \\
\hline Skewness & 1.38 & 0.03 & 0.29 & 0.33 & 0.69 & 1.38 & 0.68 \\
\hline Kurtosis & 1.62 & -1.28 & -1.57 & -1.15 & -0.42 & 1.28 & -0.25 \\
\hline
\end{tabular}


Table 8.12: Descriptive analysis for power distance construct for the Romania sample

\begin{tabular}{|c|c|c|c|c|c|c|c|}
\hline & Power_distance & \begin{tabular}{|c} 
Power_distance \\
2
\end{tabular} & $\begin{array}{c}\text { Power_distance } \\
\ldots 3\end{array}$ & $\begin{array}{c}\text { Power_distance } \\
\ldots\end{array}$ & $\begin{array}{c}\text { Power_distance } \\
\ldots\end{array}$ & $\begin{array}{c}\text { Power_distance } \\
6\end{array}$ & Average \\
\hline Mean & 2.49 & 3.72 & 2.35 & 2.92 & 3.03 & 2.67 & 2.86 \\
\hline Std. Deviation & 1.31 & 1.62 & 1.42 & 1.55 & 1.55 & 1.51 & 1.49 \\
\hline Skewness & 0.95 & -0.01 & 1.35 & 0.68 & 0.50 & 1.08 & 0.76 \\
\hline Kurtosis & 0.54 & -1.11 & 1.30 & -0.30 & -0.67 & 0.40 & 0.03 \\
\hline
\end{tabular}

Table 8.13: Confirmatory factor analysis for power distance construct for the different samples

\begin{tabular}{|l|r|r|r|r|r|r|r|r|r|}
\hline Sample & X2/df & GFI & \multicolumn{1}{l|}{ AGFI } & \multicolumn{1}{l|}{ CFI } & RMSEA & SRMR & $\begin{array}{l}\text { Cronbach's } \\
\text { alpha }\end{array}$ & AVE values & $\begin{array}{l}\text { No. of } \\
\text { items }\end{array}$ \\
\hline Combined & 4.48 & 0.99 & 0.98 & 0.97 & 0.05 & 0.03 & 0.69 & 0.28 & 6 \\
\hline Ecuador & 0.33 & 0.99 & 0.99 & 1.00 & 0.00 & 0.02 & 0.61 & 0.22 & 6 \\
\hline India & 1.97 & 0.98 & 0.96 & 0.98 & 0.06 & 0.03 & 0.76 & 0.36 & 6 \\
\hline Kenya & 3.02 & 0.98 & 0.94 & 0.89 & 0.08 & 0.05 & 0.53 & 0.20 & 6 \\
\hline Romania & 1.40 & 0.99 & 0.97 & 0.99 & 0.04 & 0.03 & 0.68 & 0.28 & 6 \\
\hline
\end{tabular}

\subsection{Collectivism construct}

Tables 8.14 to 8.18 show the descriptive analysis of the different samples for the collectivism construct. Collectivism_1 to 6 represents the different items that make up the collectivism construct.

On a scale of $1=$ Strongly disagree to $7=$ Strongly agree, the average collectivism mean is between 4.53 (Kenya) to 5.27 (India) for the various samples. This signifies that the various samples mostly favor the collectivistic nature of cultures. All these countries are collectivistic according to Hofstede's cultural dimensions as well.

Table 8.19 shows the confirmatory factor analysis for the different samples. All the model fit indices are in the recommended range except the AVE values for the combined, 
Ecuadorian, Indian and Kenyan samples which fell below recommended levels. Additionally, all the Cronbach's alphas are at acceptable levels. Overall, since most of the fit indices are good, the CFA model is considered to have a good fit.

Table 8.14: Descriptive analysis for collectivism construct for the combined sample

\begin{tabular}{|l|r|r|r|r|r|r|r|}
\hline & Collectivism_1 & Collectivism_2 & Collectivism_3 & Collectivism_4 & Collectivism_5 & Collectivism_6 & Average \\
\hline Mean & 4.31 & 5.27 & 4.96 & 4.61 & 4.47 & 5.12 & 4.79 \\
\hline Std. Deviation & 1.70 & 1.52 & 1.60 & 1.67 & 1.74 & 1.66 & $\mathbf{1 . 6 5}$ \\
\hline Skewness & -0.22 & -0.96 & -0.64 & -0.37 & -0.37 & -0.67 & $-\mathbf{0 . 5 4}$ \\
\hline Kurtosis & -0.98 & 0.33 & -0.41 & -0.83 & -0.94 & -0.50 & $-\mathbf{0 . 5 6}$ \\
\hline
\end{tabular}

Table 8.15: Descriptive analysis for collectivism construct for the Ecuador sample

\begin{tabular}{|l|r|r|r|r|r|r|r|}
\hline & Collectivism_1 & Collectivism_2 & Collectivism_3 & Collectivism_4 & Collectivism_5 & Collectivism_6 & Average \\
\hline Mean & 4.23 & 5.31 & 4.97 & 5.04 & 4.23 & 5.14 & 4.82 \\
\hline Std. Deviation & 1.69 & 1.49 & 1.64 & 1.55 & 1.80 & 1.66 & $\mathbf{1 . 6 4}$ \\
\hline Skewness & -0.22 & -1.01 & -0.66 & -0.67 & -0.16 & -0.67 & $-\mathbf{0 . 5 7}$ \\
\hline Kurtosis & -0.95 & 0.59 & -0.50 & -0.31 & -1.13 & -0.51 & $-\mathbf{0 . 4 7}$ \\
\hline
\end{tabular}

Table 8.16: Descriptive analysis for collectivism construct for the India sample

\begin{tabular}{|l|r|r|r|r|r|r|r|}
\hline & Collectivism_1 & Collectivism_2 & Collectivism_3 & Collectivism_4 & Collectivism_5 & Collectivism_6 & Average \\
\hline Mean & 4.80 & 5.32 & 5.58 & 5.04 & 5.11 & 5.79 & $\mathbf{5 . 2 7}$ \\
\hline Std. Deviation & 1.72 & 1.51 & 1.34 & 1.54 & 1.54 & 1.39 & $\mathbf{1 . 5 1}$ \\
\hline Skewness & -0.57 & -0.96 & -1.13 & -0.57 & -0.79 & -1.24 & $-\mathbf{0 . 8 8}$ \\
\hline Kurtosis & -0.71 & 0.33 & 1.26 & -0.40 & -0.04 & 1.04 & $\mathbf{0 . 2 5}$ \\
\hline
\end{tabular}

Table 8.17: Descriptive analysis for collectivism construct for the Kenya sample

\begin{tabular}{|l|r|r|r|r|r|r|r|}
\hline & Collectivism_1 & Collectivism_2 & Collectivism_3 & Collectivism_4 & Collectivism_5 & Collectivism_6 & Average \\
\hline Mean & 4.44 & 5.14 & 4.74 & 3.91 & 4.08 & 4.84 & 4.53 \\
\hline Std. Deviation & 1.75 & 1.71 & 1.71 & 1.85 & 1.87 & 1.82 & $\mathbf{1 . 7 9}$ \\
\hline Skewness & -0.33 & -0.90 & -0.53 & 0.14 & -0.12 & -0.54 & $-\mathbf{0 . 3 8}$ \\
\hline Kurtosis & -1.05 & -0.15 & -0.72 & -1.20 & -1.26 & -0.82 & $-\mathbf{0 . 8 7}$ \\
\hline
\end{tabular}


Table 8.18: Descriptive analysis for collectivism construct for the Romania sample

\begin{tabular}{|l|r|r|r|r|r|r|r|}
\hline & Collectivism_1 & Collectivism_2 & Collectivism_3 & Collectivism_4 & Collectivism_5 & Collectivism_6 & Average \\
\hline Mean & 3.75 & 5.30 & 4.57 & 4.48 & 4.47 & 4.72 & 4.55 \\
\hline Std. Deviation & 1.45 & 1.31 & 1.49 & 1.43 & 1.53 & 1.52 & $\mathbf{1 . 4 5}$ \\
\hline Skewness & 0.02 & -0.85 & -0.31 & -0.34 & -0.40 & -0.36 & $-\mathbf{0 . 3 7}$ \\
\hline Kurtosis & -0.75 & 0.34 & -0.58 & -0.61 & -0.70 & -0.74 & $-\mathbf{0 . 5 1}$ \\
\hline
\end{tabular}

Table 8.19: Confirmatory factor analysis for collectivism construct for the different samples

\begin{tabular}{|l|r|r|r|r|r|r|r|r|r|}
\hline Sample & \multicolumn{1}{|l|}{ X2/df } & GFI & \multicolumn{1}{l|}{ AGFI } & CFI & RMSEA & SRMR & $\begin{array}{l}\text { Cronbach's } \\
\text { alpha }\end{array}$ & AVE values & $\begin{array}{l}\text { No. of } \\
\text { items }\end{array}$ \\
\hline Combined & 3.15 & 0.99 & 0.97 & 0.98 & 0.05 & 0.03 & 0.79 & 0.39 & 6 \\
\hline Ecuador & 0.94 & 0.99 & 0.98 & 1.00 & 0.00 & 0.02 & 0.77 & 0.37 & 6 \\
\hline India & 2.31 & 0.98 & 0.95 & 0.98 & 0.06 & 0.03 & 0.80 & 0.40 & 6 \\
\hline Kenya & 1.96 & 0.98 & 0.96 & 0.98 & 0.05 & 0.03 & 0.75 & 0.34 & 6 \\
\hline Romania & 1.52 & 0.99 & 0.97 & 0.99 & 0.04 & 0.02 & 0.83 & 0.46 & 6 \\
\hline
\end{tabular}

\subsection{Status consumption construct}

Tables 8.20 to 8.24 show the descriptive analysis of the different samples for the status consumption construct. Status_1 to 5 represents the different items that make up the status consumption construct.

On a scale of $1=$ Strongly disagree to $7=$ Strongly agree, the average status consumption mean is between 3.63 (Ecuador) to 4.67 (India) for the various samples. On first glance, this signifies that the various samples disagree or are neutral towards consuming products for status. However, when splitting the construct into quartiles the means were $3.20\left(25^{\text {th }}\right.$ quartile $), 4.20\left(50^{\text {th }}\right.$ quartile $)$ and $5.20\left(75^{\text {th }}\right.$ quartile $)$. This shows that most respondents are neutral or agree towards consuming products for status and also that most respondents have chosen midpoint answers resulting in lower mean scores. 
Table 8.25 shows the confirmatory factor analysis for the different samples. All the model fit indices are in the recommended range. Both the AVE values and Cronbach's alphas are at acceptable levels. Overall, the CFA model has a good fit.

Table 8.20: Descriptive analysis for status consumption construct for the combined sample

\begin{tabular}{|l|r|r|r|r|r|r|}
\hline & Status_1 & Status_2 & Status_3 & Status_4_1 & \multicolumn{1}{l|}{ Status_5 } & \multicolumn{1}{l|}{ Average } \\
\hline Mean & 3.56 & 4.60 & 4.17 & 3.94 & 4.25 & $\mathbf{4 . 1 0}$ \\
\hline Std. Deviation & 1.80 & 1.68 & 1.80 & 1.79 & 1.79 & $\mathbf{1 . 7 7}$ \\
\hline Skewness & 0.20 & -0.54 & -0.23 & -0.03 & -0.34 & $\mathbf{- 0 . 1 9}$ \\
\hline Kurtosis & -1.16 & -0.61 & -1.13 & -1.12 & -1.01 & $\mathbf{- 1 . 0 1}$ \\
\hline
\end{tabular}

Table 8.21: Descriptive analysis for status consumption construct for the Ecuador sample

\begin{tabular}{|l|r|r|r|r|r|r|}
\hline & \multicolumn{1}{|c|}{ Status_1 } & \multicolumn{1}{c|}{ Status_2 } & Status_3 & Status_4_1 & \multicolumn{1}{c|}{ Status_5 } & \multicolumn{1}{l|}{ Average } \\
\hline Mean & 3.35 & 4.18 & 3.68 & 3.31 & 3.62 & $\mathbf{3 . 6 3}$ \\
\hline Std. Deviation & 1.74 & 1.62 & 1.73 & 1.68 & 1.73 & $\mathbf{1 . 7 0}$ \\
\hline Skewness & 0.24 & -0.23 & 0.09 & 0.37 & 0.02 & $\mathbf{0 . 1 0}$ \\
\hline Kurtosis & -1.10 & -0.77 & -1.17 & -0.80 & -1.12 & $\mathbf{- 0 . 9 9}$ \\
\hline
\end{tabular}

Table 8.22: Descriptive analysis for status consumption construct for the India sample

\begin{tabular}{|l|r|r|r|r|r|r|}
\hline & Status_1 & Status_2 & Status_3 & Status_4_1 & \multicolumn{1}{c|}{ Status_5 } & \multicolumn{1}{l|}{ Average } \\
\hline Mean & 4.13 & 5.33 & 4.81 & 3.96 & 5.12 & $\mathbf{4 . 6 7}$ \\
\hline Std. Deviation & 1.88 & 1.56 & 1.71 & 1.77 & 1.59 & $\mathbf{1 . 7 0}$ \\
\hline Skewness & -0.11 & -1.05 & -0.54 & 0.01 & -0.89 & $\mathbf{- 0 . 5 2}$ \\
\hline Kurtosis & -1.17 & 0.59 & -0.67 & -1.05 & 0.16 & $\mathbf{- 0 . 4 3}$ \\
\hline
\end{tabular}


Table 8.23: Descriptive analysis for status consumption construct for the Kenya sample

\begin{tabular}{|l|r|r|r|r|r|r|}
\hline & Status_1 & Status_2 & Status_3 & Status_4_1 & \multicolumn{1}{l|}{ Status_5 } & \multicolumn{1}{l|}{ Average } \\
\hline Mean & 3.54 & 4.48 & 4.26 & 4.15 & 4.26 & $\mathbf{4 . 1 4}$ \\
\hline Std. Deviation & 1.84 & 1.72 & 1.86 & 1.93 & 1.85 & $\mathbf{1 . 8 4}$ \\
\hline Skewness & 0.26 & -0.50 & -0.33 & -0.17 & -0.39 & $\mathbf{- 0 . 2 3}$ \\
\hline Kurtosis & -1.23 & -0.89 & -1.20 & -1.31 & -1.17 & $\mathbf{- 1 . 1 6}$ \\
\hline
\end{tabular}

Table 8.24: Descriptive analysis for status consumption construct for the Romania sample

\begin{tabular}{|l|r|r|r|r|r|r|}
\hline & Status_1 & Status_2 & Status_3 & Status_4_1 & Status_5 & \multicolumn{1}{l|}{ Average } \\
\hline Mean & 3.22 & 4.40 & 3.91 & 4.32 & 3.98 & $\mathbf{3 . 9 7}$ \\
\hline Std. Deviation & 1.62 & 1.57 & 1.67 & 1.57 & 1.63 & $\mathbf{1 . 6 1}$ \\
\hline Skewness & 0.29 & -0.64 & -0.25 & -0.31 & -0.29 & $\mathbf{- 0 . 2 4}$ \\
\hline Kurtosis & -1.15 & -0.37 & -1.15 & -0.78 & -0.94 & $\mathbf{- 0 . 8 8}$ \\
\hline
\end{tabular}

Table 8.25: Confirmatory factor analysis for status consumption construct for the different samples

\begin{tabular}{|l|r|r|r|r|r|r|r|r|r|}
\hline Sample & \multicolumn{1}{|l|}{ X2/df } & \multicolumn{1}{l|}{ GFI } & \multicolumn{1}{l|}{ AGFI } & \multicolumn{1}{l|}{ CFI } & RMSEA & SRMR & $\begin{array}{l}\text { Cronbach's } \\
\text { alpha }\end{array}$ & $\begin{array}{l}\text { No. of } \\
\text { AVE values } \\
\text { items }\end{array}$ \\
\hline Combined & 4.28 & 0.99 & 0.98 & 0.99 & 0.05 & 0.02 & 0.81 & 0.50 & 5 \\
\hline Ecuador & 2.40 & 0.98 & 0.95 & 0.99 & 0.07 & 0.03 & 0.79 & 0.48 & 5 \\
\hline India & 3.33 & 0.98 & 0.94 & 0.98 & 0.09 & 0.04 & 0.76 & 0.48 & 5 \\
\hline Kenya & 1.40 & 0.99 & 0.98 & 0.99 & 0.03 & 0.02 & 0.85 & 0.54 & 5 \\
\hline Romania & 0.86 & 0.99 & 0.98 & 1.00 & 0.00 & 0.02 & 0.80 & 0.46 & 5 \\
\hline
\end{tabular}

\subsection{Normative influence construct}

Tables 8.26 to 8.30 show the descriptive analysis of the different samples for the normative influence construct. Norm_influence_1 to 4 represents the different items that make up the normative influence construct.

On a scale of $1=$ Strongly disagree to $7=$ Strongly agree, the average normative influence mean is between 2.96 (Romania) to 4.41 (India) for the various samples. This indicates that the various samples are neutral about or disagree that they are influenced by 
the group when making product decisions. When the normative influence construct was divided into quartiles the means were between 2.25 and 4.50 . It can be seen that even the highest quartile has answered around the midpoint range and not given extreme answers, and this could be a reason for the low mean scores.

Table 8.31 shows the confirmatory factor analysis for the different samples. Most of the model fit indices are in the recommended range except the RMSEA values for the India sample which is slightly above the recommended maximum of 0.10 and the $\chi 2 / \mathrm{df}$ of the combined sample which is above the acceptable mark. The Cronbach's alpha and AVE values for the construct are at acceptable levels for all samples. Since most of the indices are good, the CFA model is considered to have an overall good fit.

Table 8.26: Descriptive analysis for normative influence construct for the combined sample

\begin{tabular}{|l|r|r|r|r|r|}
\hline & Norm_influence_1 & Norm_influence_2 & Norm_influence_3 & Norm_influence_4 & Average \\
\hline Mean & 3.70 & 3.50 & 3.68 & 3.11 & $\mathbf{3 . 5 0}$ \\
\hline Std. Deviation & 1.89 & 1.76 & 1.80 & 1.77 & $\mathbf{1 . 8 0}$ \\
\hline Skewness & 0.17 & 0.23 & 0.12 & 0.51 & $\mathbf{0 . 2 6}$ \\
\hline Kurtosis & -1.20 & -1.09 & -1.17 & -0.89 & $\mathbf{- 1 . 0 9}$ \\
\hline
\end{tabular}

Table 8.27: Descriptive analysis for normative influence construct for the Ecuador sample

\begin{tabular}{|l|r|r|r|r|r|}
\hline & Norm_influence_1 & Norm_influence_2 & Norm_influence_3 & Norm_influence_4 & Average \\
\hline Mean & 3.45 & 3.08 & 3.38 & 2.76 & $\mathbf{3 . 1 7}$ \\
\hline Std. Deviation & 1.80 & 1.63 & 1.77 & 1.61 & $\mathbf{1 . 7 0}$ \\
\hline Skewness & 0.29 & 0.51 & 0.30 & 0.70 & $\mathbf{0 . 4 5}$ \\
\hline Kurtosis & -1.12 & -0.69 & -1.14 & -0.62 & $-\mathbf{0 . 8 9}$ \\
\hline
\end{tabular}


Table 8.28: Descriptive analysis for normative influence construct for the India sample

\begin{tabular}{|l|r|r|r|r|r|}
\hline & Norm_influence_1 & Norm_influence_2 & Norm_influence_3 & Norm_influence_4 & Average \\
\hline Mean & 4.78 & 4.41 & 4.48 & 3.99 & $\mathbf{4 . 4 1}$ \\
\hline Std. Deviation & 1.80 & 1.70 & 1.69 & 1.88 & $\mathbf{1 . 7 7}$ \\
\hline Skewness & -0.51 & -0.35 & -0.33 & -0.11 & $-\mathbf{0 . 3 3}$ \\
\hline Kurtosis & -0.74 & -0.90 & -0.84 & -1.13 & $-\mathbf{0 . 9 0}$ \\
\hline
\end{tabular}

Table 8.29: Descriptive analysis for normative influence construct for the Kenya sample

\begin{tabular}{|l|r|r|r|r|r|}
\hline & Norm_influence_1 & Norm_influence_2 & Norm_influence_3 & Norm_influence_4 & Average \\
\hline Mean & 3.67 & 3.40 & 3.54 & 3.15 & $\mathbf{3 . 4 4}$ \\
\hline Std. Deviation & 1.85 & 1.81 & 1.85 & 1.79 & $\mathbf{1 . 8 3}$ \\
\hline Skewness & 0.16 & 0.31 & 0.27 & 0.50 & $\mathbf{0 . 3 1}$ \\
\hline Kurtosis & -1.28 & -1.16 & -1.23 & -1.00 & $\mathbf{- 1 . 1 7}$ \\
\hline
\end{tabular}

Table 8.30: Descriptive analysis for normative influence construct for the Romania sample

\begin{tabular}{|l|r|r|r|r|r|}
\hline & Norm_influence_1 & Norm_influence_2 & Norm_influence_3 & Norm_influence_4 & Average \\
\hline Mean & 2.87 & 3.11 & 3.31 & 2.54 & $\mathbf{2 . 9 6}$ \\
\hline Std. Deviation & 1.57 & 1.54 & 1.62 & 1.41 & $\mathbf{1 . 5 4}$ \\
\hline Skewness & 0.64 & 0.36 & 0.20 & 0.83 & $\mathbf{0 . 5 1}$ \\
\hline Kurtosis & -0.44 & -0.85 & -1.06 & -0.01 & $-\mathbf{0 . 5 9}$ \\
\hline
\end{tabular}

Table 8.31: Confirmatory factor analysis for normative influence construct for the different samples

\begin{tabular}{|l|r|r|r|r|r|r|r|r|r|}
\hline Sample & \multicolumn{1}{|c|}{ X2/df } & \multicolumn{1}{c|}{ GFI } & \multicolumn{1}{c|}{ AGFI } & \multicolumn{1}{l|}{ CFI } & RMSEA & SRMR & $\begin{array}{l}\text { lronbach's } \\
\text { alpha }\end{array}$ & AVE values & $\begin{array}{l}\text { No. of } \\
\text { items }\end{array}$ \\
\hline Combined & 10.75 & 0.99 & 0.96 & 0.99 & 0.09 & 0.02 & 0.83 & 0.55 & 4 \\
\hline Ecuador & 3.14 & 0.99 & 0.95 & 0.99 & 0.08 & 0.02 & 0.81 & 0.52 & 4 \\
\hline India & 4.94 & 0.98 & 0.92 & 0.98 & 0.11 & 0.03 & 0.83 & 0.55 & 4 \\
\hline Kenya & 3.70 & 0.99 & 0.95 & 0.98 & 0.09 & 0.03 & 0.78 & 0.47 & 4 \\
\hline Romania & 0.63 & 0.99 & 0.99 & 1.00 & 0.00 & 0.01 & 0.78 & 0.48 & 4 \\
\hline
\end{tabular}




\subsection{Global Media Exposure}

Tables 8.32 to 8.36 show the descriptive analysis of the different samples for the global media exposure construct. Media exposure_1 to 4 represents the different items that make up the global media exposure construct.

On a scale of $1=$ Strongly disagree to $7=$ Strongly agree, the average global media exposure mean is between 4.29 (Romania) to 5.29 (Kenya) for the various samples. This shows that various samples are neutral about or agree that they have a good amount of exposure to global media.

Table 8.37 shows the confirmatory factor analysis for the different samples. Most of the model fit indices are in the recommended range except the RMSEA values for the combined, India and Kenya samples which are above the recommended maximum of 0.10 and the $\chi^{2} / \mathrm{df}$ of the combined, India and Kenya sample which is above the acceptable mark. Since SEM is assessed using a number of fit indices and since most of the fit indices in this case are in the recommended range, it is acceptable to assume that the overall CFA models have a moderately good fit. All AVE values are in the recommended range. The Cronbach's alphas for the global media exposure construct are at acceptable levels.

Table 8.32: Descriptive analysis for global media exposure construct for the combined sample

\begin{tabular}{|l|r|r|r|r|r|}
\hline & Media exposure_1 & Media exposure_2 & Media exposure_3 & Media exposure_4 & Average \\
\hline Mean & 4.71 & 4.36 & 5.24 & 5.08 & $\mathbf{4 . 8 5}$ \\
\hline Std. Deviation & 1.84 & 1.81 & 1.69 & 1.76 & $\mathbf{1 . 7 7}$ \\
\hline Skewness & -0.35 & -0.11 & -0.72 & -0.63 & $-\mathbf{0 . 4 5}$ \\
\hline Kurtosis & -0.92 & -1.03 & -0.42 & -0.61 & $-\mathbf{0 . 7 4}$ \\
\hline
\end{tabular}


Table 8.33: Descriptive analysis for global media exposure construct for the Ecuador sample

\begin{tabular}{|l|r|r|r|r|r|}
\hline & Media exposure_1 & Media exposure_2 & Media exposure_3 & Media exposure_4 & Average \\
\hline Mean & 4.38 & 4.05 & 5.13 & 5.08 & $\mathbf{4 . 6 6}$ \\
\hline Std. Deviation & 1.95 & 1.89 & 1.82 & 1.85 & $\mathbf{1 . 8 8}$ \\
\hline Skewness & -0.20 & 0.11 & -0.69 & -0.68 & $-\mathbf{0 . 3 6}$ \\
\hline Kurtosis & -1.09 & -1.12 & -0.64 & -0.63 & $-\mathbf{0 . 8 7}$ \\
\hline
\end{tabular}

Table 8.34: Descriptive analysis for global media exposure construct for the India sample

\begin{tabular}{|l|r|r|r|r|r|}
\hline & Media exposure_1 & Media exposure_2 & Media exposure_3 & Media exposure_4 & Average \\
\hline Mean & 5.10 & 4.94 & 5.27 & 5.16 & $\mathbf{5 . 1 2}$ \\
\hline Std. Deviation & 1.61 & 1.56 & 1.55 & 1.56 & $\mathbf{1 . 5 7}$ \\
\hline Skewness & -0.63 & -0.60 & -0.74 & -0.69 & $-\mathbf{0 . 6 7}$ \\
\hline Kurtosis & -0.25 & -0.19 & -0.17 & -0.24 & $-\mathbf{0 . 2 1}$ \\
\hline
\end{tabular}

Table 8.35: Descriptive analysis for global media exposure construct for the Kenya sample

\begin{tabular}{|l|r|r|r|r|r|}
\hline & Media exposure_1 & Media exposure_2 & Media exposure_3 & Media exposure_4 & Average \\
\hline Mean & 5.25 & 4.71 & 5.74 & 5.46 & $\mathbf{5 . 2 9}$ \\
\hline Std. Deviation & 1.71 & 1.77 & 1.51 & 1.65 & $\mathbf{1 . 6 6}$ \\
\hline Skewness & -0.55 & -0.23 & -1.08 & -0.85 & $-\mathbf{0 . 6 8}$ \\
\hline Kurtosis & -0.82 & -1.06 & 0.37 & -0.24 & $-\mathbf{0 . 4 4}$ \\
\hline
\end{tabular}

Table 8.36: Descriptive analysis for global media exposure construct for the Romania sample

\begin{tabular}{|l|r|r|r|r|r|}
\hline & Media exposure_1 & Media exposure_2 & Media exposure_3 & Media exposure_4 & Average \\
\hline Mean & 4.07 & 3.71 & 4.80 & 4.57 & $\mathbf{4 . 2 9}$ \\
\hline Std. Deviation & 1.83 & 1.75 & 1.72 & 1.85 & $\mathbf{1 . 7 9}$ \\
\hline Skewness & 0.06 & 0.33 & -0.40 & -0.27 & $-\mathbf{0 . 0 7}$ \\
\hline Kurtosis & -0.99 & -0.75 & -0.76 & -0.99 & $-\mathbf{0 . 8 7}$ \\
\hline
\end{tabular}


Table 8.37: Confirmatory factor analysis for global media exposure construct for the different samples

\begin{tabular}{|l|r|l|r|r|r|r|r|r|r|}
\hline Sample & \multicolumn{1}{|l|}{ X2/df } & \multicolumn{1}{l|}{ GFI } & \multicolumn{1}{l|}{ AGFI } & \multicolumn{1}{l|}{ CFI } & RMSEA & SRMR & $\begin{array}{l}\text { Cronbach's } \\
\text { alpha }\end{array}$ & $\begin{array}{l}\text { No. of } \\
\text { AVE values } \\
\text { items }\end{array}$ \\
\hline Combined & 17.76 & 0.99 & 0.93 & 0.98 & 0.11 & 0.03 & 0.84 & 0.57 & 4 \\
\hline Ecuador & 1.33 & 0.99 & 0.98 & 0.99 & 0.03 & 0.02 & 0.80 & 0.52 & 4 \\
\hline India & 5.89 & 0.98 & 0.91 & 0.98 & 0.12 & 0.02 & 0.87 & 0.62 & 4 \\
\hline Kenya & 12.08 & 0.96 & 0.82 & 0.95 & 0.18 & 0.04 & 0.82 & 0.53 & 4 \\
\hline Romania & 2.27 & 0.99 & 0.97 & 0.99 & 0.06 & 0.02 & 0.83 & 0.57 & 4 \\
\hline
\end{tabular}

\subsection{International travel}

Tables 8.38 to 8.42 show the descriptive analysis of the different samples for the international travel construct. International_1, 3 and 5 represent the different items that make up the international travel construct.

On a scale of $1=$ Strongly disagree to $7=$ Strongly agree, the average international travel construct mean is between 4.88 (Ecuador) to 5.57 (India) for the various samples. This signifies that the various samples agree that they prefer international travel and have traveled internationally.

Table 8.43 shows the confirmatory factor analysis for the different samples. All the model fit indices are in the recommended range except the $\chi^{2} / \mathrm{df}$ for the combined sample. The Cronbach's alpha for Ecuador and Kenya fell below the acceptable 0.7 mark but they are above 0.6. Some scholars (Shay and Back, 2004; Griethuijsen et al., 2014) argue that 0.6 is an acceptable range for Cronbach alphas. The AVE values for all countries expect Kenya are near or above the recommended range. Item 2 ("While vacationing, I would prefer to stay in my home country, rather than visit another country") and item 4 ("I have 
traveled extensively outside of my home country.") were deleted in order to get a good fit for the CFA model. Overall, the fit for the CFA model is moderately good.

Table 8.38: Descriptive analysis for international travel construct for the combined sample

\begin{tabular}{|c|c|c|c|c|}
\hline & $\begin{array}{c}\text { International_travel } \\
\_1\end{array}$ & $\begin{array}{c}\text { International_travel } \\
{ }_{3}\end{array}$ & $\begin{array}{c}\text { International_travel } \\
{ }_{-} 5\end{array}$ & Average \\
\hline Mean & 4.44 & 5.76 & 5.29 & 5.17 \\
\hline Std. Deviation & 1.60 & 1.21 & 1.39 & 1.40 \\
\hline Skewness & -0.21 & -1.32 & -0.74 & -0.76 \\
\hline Kurtosis & -0.76 & 2.01 & 0.15 & 0.47 \\
\hline
\end{tabular}

Table 8.39: Descriptive analysis for international travel construct for the Ecuador sample

\begin{tabular}{|c|c|c|c|c|}
\hline & \begin{tabular}{|c|} 
International_travel \\
$\_1$
\end{tabular} & $\begin{array}{c}\text { International_travel } \\
{ }_{3}\end{array}$ & $\begin{array}{c}\text { International_travel } \\
{ }_{5}\end{array}$ & Average \\
\hline Mean & 4.02 & 5.50 & 5.12 & 4.88 \\
\hline Std. Deviation & 1.65 & 1.36 & 1.44 & 1.48 \\
\hline Skewness & -0.01 & -1.09 & -0.65 & -0.58 \\
\hline Kurtosis & -0.73 & 1.08 & -0.03 & 0.11 \\
\hline
\end{tabular}

Table 8.40: Descriptive analysis for international travel construct for the India sample

\begin{tabular}{|c|c|c|c|c|}
\hline & $\begin{array}{c}\text { International_travel } \\
\_1\end{array}$ & $\begin{array}{c}\text { International_travel } \\
-3\end{array}$ & $\begin{array}{c}\text { International_travel } \\
{ }_{5}\end{array}$ & Average \\
\hline Mean & 5.06 & 5.89 & 5.76 & 5.57 \\
\hline Std. Deviation & 1.50 & 1.10 & 1.17 & 1.26 \\
\hline Skewness & -0.55 & -1.05 & -0.95 & -0.85 \\
\hline Kurtosis & -0.40 & 1.09 & 0.86 & 0.52 \\
\hline
\end{tabular}


Table 8.41: Descriptive analysis for international travel construct for the Kenya sample

\begin{tabular}{|c|c|c|c|c|}
\hline & $\begin{array}{c}\text { International_travel } \\
\_1\end{array}$ & $\begin{array}{c}\text { International_travel } \\
{ }_{3} 3\end{array}$ & \begin{tabular}{|} 
International_travel \\
-5
\end{tabular} & Average \\
\hline Mean & 4.34 & 5.95 & 5.25 & 5.18 \\
\hline Std. Deviation & 1.65 & 1.10 & 1.38 & 1.38 \\
\hline Skewness & -0.23 & -1.71 & -0.78 & -0.91 \\
\hline Kurtosis & -0.98 & 3.85 & 0.11 & 0.99 \\
\hline
\end{tabular}

Table 8.42: Descriptive analysis for international travel construct for the Romania sample

\begin{tabular}{|c|c|c|c|c|}
\hline & $\begin{array}{c}\text { International_travel } \\
-1 \\
\end{array}$ & $\begin{array}{c}\mid \text { International_travel } \\
{ }_{3} 3\end{array}$ & $\begin{array}{c}\text { International_travel } \\
\ldots 5\end{array}$ & Average \\
\hline Mean & 4.34 & 5.70 & 5.03 & 5.02 \\
\hline Std. Deviation & 1.43 & 1.23 & 1.45 & 1.37 \\
\hline Skewness & 0.03 & -1.34 & -0.54 & -0.62 \\
\hline Kurtosis & -0.47 & 2.10 & -0.12 & 0.50 \\
\hline
\end{tabular}

Table 8.43: Confirmatory factor analysis for international travel construct for the different samples

\begin{tabular}{|l|r|r|r|r|r|r|r|r|r|}
\hline Sample & \multicolumn{1}{|l|}{ X2/df } & \multicolumn{1}{l|}{ GFI } & \multicolumn{1}{l|}{ AGFI } & \multicolumn{1}{l|}{ CFI } & RMSEA & SRMR & $\begin{array}{l}\text { Cronbach's } \\
\text { alpha }\end{array}$ & AVE values & $\begin{array}{l}\text { No. of } \\
\text { items }\end{array}$ \\
\hline Combined & 8.71 & 0.99 & 0.98 & 0.98 & 0.08 & 0.03 & 0.71 & 0.44 & 3 \\
\hline Ecuador & 4.31 & 0.98 & 0.95 & 0.96 & 0.10 & 0.04 & 0.68 & 0.46 & 3 \\
\hline India & 0.93 & 0.99 & 0.99 & 1.00 & 0.00 & 0.02 & 0.71 & 0.50 & 3 \\
\hline Kenya & 4.55 & 0.98 & 0.95 & 0.95 & 0.10 & 0.04 & 0.63 & 0.39 & 3 \\
\hline Romania & 3.25 & 0.99 & 0.96 & 0.98 & 0.08 & 0.03 & 0.77 & 0.50 & 3 \\
\hline
\end{tabular}

\subsection{Validity}

Validity is the extent to which a measure corresponds accurately to the concept that it is supposed to measure (Bryman et al., 2011). Several types of validities such as face 
validity, discriminant validity, convergent validity and nomological validity are used in this thesis.

\subsubsection{Face Validity}

Face validity is a subjective measure of validity. By visually inspecting each measure and the construct, it was confirmed by the researcher that the measures are measuring the concept that it is supposed to measure (Holden, 2010). For this thesis, all constructs except the ownership of foreign products construct are borrowed from existing constructs in peer-reviewed studies and thus it was easy to compare the measures to the respective constructs and visually validate them.

\subsubsection{Discriminant Validity}

Discriminant validity tests the extent to which a construct differs from the other constructs. One of the ways to test this kind of validity is to check if the correlation between two constructs is not as high as the construct's Cronbach's alpha (Rojas-Méndez, et al., 2013; Andaleeb, 1995). Tables 8.44 to 8.48 shows that this is the case for all the constructs. That is, in every case the correlation between constructs was less than the Cronbach's alpha of the construct. 
Table 8.44: Discriminant validity for antecedent constructs for the combined sample

\begin{tabular}{|l|r|r|r|r|l|l|}
\hline & & & & & & $\begin{array}{l}\text { Normative } \\
\text { Global } \\
\text { media } \\
\text { sample }\end{array}$ \\
\hline exposure & Power Distance & Collectivism & Status & $\begin{array}{l}\text { International } \\
\text { travel }\end{array}$ \\
\hline Collectivism & 0.69 & & & & & \\
\hline Status & 0.36 & 0.79 & & & & \\
\hline $\begin{array}{l}\text { Normative } \\
\text { influence }\end{array}$ & 0.28 & 0.23 & 0.81 & & & \\
\hline $\begin{array}{l}\text { Global } \\
\text { media exposure }\end{array}$ & 0.46 & 0.32 & 0.64 & 0.83 & & \\
\hline $\begin{array}{l}\text { International } \\
\text { travel }\end{array}$ & 0.05 & 0.07 & 0.20 & 0.16 & 0.84 & \\
\hline
\end{tabular}

Note: Diagonal entries are Cronbach's alpha coefficients; all others are correlation coefficients.

Table 8.45: Discriminant validity for antecedent constructs for the Ecuador sample

\begin{tabular}{|c|c|c|c|c|c|c|}
\hline Ecuador & Power Distance & Collectivism & Status & \begin{tabular}{|l|} 
Normative \\
influence
\end{tabular} & \begin{tabular}{|l|} 
Global \\
media \\
exposure
\end{tabular} & $\begin{array}{l}\text { International } \\
\text { travel }\end{array}$ \\
\hline Power Distance & 0.61 & & & & & \\
\hline Collectivism & 0.26 & 0.77 & & & & \\
\hline Status & 0.18 & 0.23 & 0.79 & & & \\
\hline $\begin{array}{l}\text { Normative } \\
\text { influence }\end{array}$ & 0.30 & 0.28 & 0.66 & 0.81 & & \\
\hline $\begin{array}{l}\text { Global } \\
\text { media exposure }\end{array}$ & -0.06 & 0.03 & 0.11 & -0.05 & 0.80 & \\
\hline \begin{tabular}{|l} 
International \\
travel
\end{tabular} & 0.03 & -0.03 & 0.17 & 0.10 & 0.31 & 0.68 \\
\hline
\end{tabular}

Note: Diagonal entries are Cronbach's alpha coefficients; all others are correlation coefficients. 
Table 8.46: Discriminant validity for antecedent constructs for the India sample

\begin{tabular}{|c|c|c|c|c|c|c|}
\hline India & Power Distance & Collectivism & Status & $\begin{array}{l}\text { Normative } \\
\text { influence }\end{array}$ & $\begin{array}{l}\text { Global } \\
\text { media } \\
\text { exposure }\end{array}$ & $\begin{array}{l}\text { International } \\
\text { travel }\end{array}$ \\
\hline Power Distance & 0.76 & & & & & \\
\hline Collectivism & 0.39 & 0.80 & & & & \\
\hline Status & 0.38 & 0.30 & 0.76 & & & \\
\hline $\begin{array}{l}\text { Normative } \\
\text { influence }\end{array}$ & 0.54 & 0.38 & 0.63 & 0.83 & & \\
\hline $\begin{array}{l}\text { Global } \\
\text { media exposure }\end{array}$ & 0.10 & 0.25 & 0.31 & 0.32 & 0.87 & \\
\hline $\begin{array}{l}\text { International } \\
\text { travel }\end{array}$ & 0.18 & 0.28 & 0.39 & 0.32 & 0.43 & 0.71 \\
\hline
\end{tabular}

Note: Diagonal entries are Cronbach's alpha coefficients; all others are correlation coefficients.

Table 8.47: Discriminant validity for antecedent constructs for the Kenya sample

\begin{tabular}{|c|c|c|c|c|c|c|}
\hline Kenya & Power Distance & Collectivism & Status & $\begin{array}{l}\text { Normative } \\
\text { influence }\end{array}$ & $\begin{array}{l}\text { Global } \\
\text { media } \\
\text { exposure }\end{array}$ & $\begin{array}{l}\text { International } \\
\text { travel }\end{array}$ \\
\hline Power Distance & 0.53 & & & & & \\
\hline Collectivism & 0.32 & 0.75 & & & & \\
\hline Status & 0.19 & 0.20 & 0.85 & & & \\
\hline $\begin{array}{l}\text { Normative } \\
\text { influence }\end{array}$ & 0.28 & 0.26 & 0.63 & 0.78 & & \\
\hline $\begin{array}{l}\text { Global } \\
\text { media exposure }\end{array}$ & -0.07 & -0.04 & 0.15 & 0.07 & 0.82 & \\
\hline $\begin{array}{l}\text { International } \\
\text { travel }\end{array}$ & 0.04 & 0.18 & 0.27 & 0.23 & 0.23 & 0.63 \\
\hline
\end{tabular}

Note: Diagonal entries are Cronbach's alpha coefficients; all others are correlation coefficients. 
Table 8.48: Discriminant validity for antecedent constructs for the Romania sample

\begin{tabular}{|l|r|r|r|r|r|r|}
\hline Romania & Power Distance & Collectivism & Status & $\begin{array}{l}\text { Normative } \\
\text { influence }\end{array}$ & $\begin{array}{l}\text { Global } \\
\text { media } \\
\text { exposure }\end{array}$ & $\begin{array}{l}\text { International } \\
\text { travel }\end{array}$ \\
\hline Power Distance & 0.68 & & & & & \\
\hline Collectivism & 0.15 & 0.83 & & & & \\
\hline Status & 0.13 & 0.05 & 0.80 & & & \\
\hline $\begin{array}{l}\text { Normative } \\
\text { influence }\end{array}$ & 0.30 & 0.11 & 0.55 & 0.78 & & \\
\hline $\begin{array}{l}\text { Global } \\
\text { media exposure }\end{array}$ & -0.02 & -0.00 & 0.12 & 0.08 & 0.83 & \\
\hline $\begin{array}{l}\text { International } \\
\text { travel }\end{array}$ & -0.16 & -0.16 & 0.17 & 0.02 & 0.16 & \\
\hline
\end{tabular}

Note: Diagonal entries are Cronbach's alpha coefficients; all others are correlation coefficients.

\subsubsection{Convergent Validity}

Convergent validity is a type of validity that shows that the measures of a construct are related (Campbell and Fiske, 1959). In other words, it shows that the measures within a construct are highly correlated. One way to verify convergent validity is to check if the factor loadings of each measure within each construct is greater than 0.5 (Hair, Black, Babin and Anderson, 2009). The consumer xenocentrism construct and all antecedent variables have all factor loadings greater than 0.5 and thus convergent validity is confirmed.

\subsubsection{Nomological Validity}

Nomological validity is a form of validity that requires that at least two constructs are correlated. This kind of validity tests the validity of a construct by checking if the constructs that are theoretically expected to be related are associated in the accepted direction (Lastovicka and Bonfield, 1980). The constructs used to determine nomological 
validity are usually a similar set of related constructs. For example, for establishing the nomological validity of consumer xenocentrism, the constructs, ethnocentrism and cosmopolitanism have been used in the extant literature (Rojas-Méndez and Chapa, 2019). All the constructs used as antecedents in this study are established constructs that, during the development phase, were subject to comparisons to similar constructs.

\subsection{Structural models}

The final step with the antecedents is to run structural models using structural equation modeling (SEM) in AMOS. A structural model establishes relationships between different factors (Byrne, 2010). SEM helps in analyzing many multiple regression paths at once and thus is more powerful than traditional multiple regression in this aspect. This step tests the hypothesized relationships. That is, the relationship between the antecedents (independent variable) and consumer xenocentrism (dependent variable) will be tested using structural models.

Sometimes, even if the measurement model has a good fit, the structural model may have unacceptable fit indices. Table 8.49 shows the details for the structural models for all samples, for 1.) consumer xenocentrism and 2.) when consumer xenocentrism is split into two factors, foreign admiration and domestic rejection. For these models, independent variables international travel and media exposure, power distance and collectivism, power distance and normative influence, and status and normative influence had to be covaried to get a better fit. International travel and global media exposure are both constructs that signify exposure to other cultures and thus they are expected to be correlated constructs. Power distance and collectivism are also expected to be correlated as both are Hofstede's 
cultural dimensions and all the four samples are from countries which are expected to have high power distance and are collectivistic. Normative influence is conforming with the group's expectations and for each individual that could mean a particular reference group in the hierarchy. Since high power distance cultures are hierarchical, normative influence and power distance are expected to be correlated. Status consumption is based on buying products that are likely to increase one's social standing in the one's group and susceptibility to normative influence involves being in-line with the group's expectation when buying products. Since both these concepts are related, they are expected to be correlated. 
Table 8.49: Structural model for all samples

\begin{tabular}{|c|c|c|c|c|c|c|c|c|c|c|c|c|c|c|c|}
\hline Sample & Combined & Ecuador & India & Kenya & Romania & Combined & Ecuador & India & Kenya & Romania & Combined & Ecuador & India & Kenya & Romania \\
\hline Variance explained & 0.44 & 0.46 & 0.59 & 0.45 & 0.33 & 0.39 & 0.46 & 0.45 & 0.44 & 0.28 & 0.29 & 0.25 & 0.55 & 0.25 & 0.20 \\
\hline Fit indices & & & & & & & & & & & & & & & \\
\hline $\mathrm{X} 2 / \mathrm{df}$ & 3.37 & 1.60 & 2.16 & 1.64 & 1.78 & 3.64 & 1.60 & 2.12 & 1.63 & 1.83 & 3.60 & 1.60 & 2.12 & 1.63 & 1.83 \\
\hline RMSEA & 0.04 & 0.04 & 0.06 & 0.04 & 0.05 & 0.05 & 0.04 & 0.05 & 0.04 & 0.05 & 0.05 & 0.04 & 0.05 & 0.04 & 0.05 \\
\hline GFI & 0.91 & 0.85 & 0.81 & 0.85 & 0.83 & 0.90 & 0.84 & 0.79 & 0.85 & 0.82 & 0.90 & 0.84 & 0.79 & 0.85 & 0.82 \\
\hline AGFI & 0.90 & 0.83 & 0.78 & 0.83 & 0.81 & 0.88 & 0.82 & 0.77 & 0.83 & 0.79 & 0.88 & 0.82 & 0.77 & 0.83 & 0.79 \\
\hline IFI & 0.90 & 0.89 & 0.85 & 0.88 & 0.87 & 0.89 & 0.89 & 0.83 & 0.88 & 0.85 & 0.89 & 0.89 & 0.83 & 0.88 & 0.85 \\
\hline $\mathrm{CFI}$ & 0.90 & 0.89 & 0.85 & 0.88 & 0.86 & 0.89 & 0.88 & 0.83 & 0.88 & 0.85 & 0.89 & 0.88 & 0.83 & 0.88 & 0.85 \\
\hline Independent variables & \multicolumn{5}{|c|}{ Consumer xenocentrism } & \multicolumn{5}{|c|}{ Consumer xenocentrism- Foreign admiration } & \multicolumn{5}{|c|}{ Consumer xenocentrism- Domestic rejection } \\
\hline \multicolumn{16}{|l|}{ Standardized coefficients } \\
\hline Power distance & $0.12^{*}$ & 0.04 (NS) & $0.23^{*}$ & 0.10 (NS) & $0.02(\mathrm{NS})$ & $0.09^{*}$ & $0.00(\mathrm{NS})$ & 0.06 (NS) & $0.08(\mathrm{NS})$ & 0.03 (NS) & $0.20^{* *}$ & -0.01 (NS) & $0.48^{* *}$ & 0.18 (NS) & 0.05 (NS) \\
\hline Collectivism & $-0.01(\mathrm{NS})$ & 0.08 (NS) & $-0.21^{* *}$ & $-0.07(\mathrm{NS})$ & -0.05 (NS) & $0.01(\mathrm{NS})$ & 0.10 (NS) & -0.12 (NS) & -0.04 (NS) & $-0.04(\mathrm{NS})$ & $-0.11^{* *}$ & 0.05 (NS) & $-0.31^{* *}$ & $-0.11(\mathrm{NS})$ & -0.10 (NS) \\
\hline Status consumption & $0.23^{* *}$ & $0.42^{* *}$ & 0.19 (NS) & $0.33^{* *}$ & $0.11(\mathrm{NS})$ & $0.24^{* *}$ & $0.43^{* *}$ & $0.31^{* *}$ & $0.33^{* *}$ & 0.11 (NS) & $0.02(\mathrm{NS})$ & 0.04 (NS) & -0.02 (NS) & $0.27^{*}$ & 0.07 (NS) \\
\hline $\begin{array}{l}\text { Suspectibility to Normative } \\
\text { influence }\end{array}$ & $0.22^{* *}$ & -0.09 (NS) & $0.34^{*}$ & 0.15 (NS) & $0.29^{*}$ & $0.16^{* *}$ & $-0.14(\mathrm{NS})$ & 0.13 (NS) & $0.17(\mathrm{NS})$ & $0.25^{*}$ & $0.43^{* *}$ & $0.39^{*}$ & $0.70^{* *}$ & 0.20 (NS) & $0.32^{* *}$ \\
\hline Global media exposure & $0.12^{* *}$ & $0.16^{*}$ & $0.04(\mathrm{NS})$ & 0.07 (NS) & $0.12(\mathrm{NS})$ & $0.13^{* *}$ & $0.17^{*}$ & 0.09 (NS) & $0.12^{*}$ & 0.10 (NS) & $0.10^{* *}$ & $0.17^{*}$ & -0.11 (NS) & $0.03(\mathrm{NS})$ & 0.11 (NS) \\
\hline $\begin{array}{l}\text { International travel } \\
\text { experience/ preference }\end{array}$ & $0.40^{* *}$ & $0.49^{* *}$ & $0.44^{* *}$ & $0.36^{* *}$ & $0.32^{* *}$ & $0.40^{* *}$ & $0.50^{* *}$ & $0.44^{* *}$ & $0.33^{* *}$ & $0.30^{* *}$ & $0.14^{* *}$ & $0.13^{*}$ & $0.27^{* *}$ & 0.11 (NS) & 0.06 (NS) \\
\hline Age & $-0.11^{* *}$ & -0.06 (NS) & -0.05 (NS) & -0.09 (NS) & $-0.20 * *$ & $-0.10^{* *}$ & -0.07 (NS) & -0.01 (NS) & -0.10 (NS) & $-0.19^{* *}$ & $-0.12^{* *}$ & -0.08 (NS) & -0.11 (NS) & -0.07 (NS) & $-0.15^{*}$ \\
\hline Education & $-0.08^{* *}$ & -0.04 (NS) & 0.08 (NS) & -0.09 (NS) & -0.08 (NS) & $-0.07^{*}$ & -0.05 (NS) & 0.08 (NS) & -0.09 (NS) & -0.08 (NS) & $-0.08^{*}$ & -0.04 (NS) & 0.04 (NS) & -0.08 (NS) & -0.08 (NS) \\
\hline Gender (Males) & 0.00 (NS) & -0.03 (NS) & $-0.11^{*}$ & 0.03 (NS) & $0.06(\mathrm{NS})$ & $0.03(\mathrm{NS})$ & -0.04 (NS) & -0.07 (NS) & $0.07(\mathrm{NS})$ & $0.10(\mathrm{NS})$ & $-0.07^{*}$ & -0.01 (NS) & $-0.14^{*}$ & -0.08 (NS) & -0.07 (NS) \\
\hline
\end{tabular}

* Significant at $p<=0.05$

** Significant at $p<=0.01$. 
For the combined sample, all model fit indices have values that indicate a good fit. The models explain $29 \%$ to $44 \%$ of the total variance in consumer xenocentrism. Power distance is a significant predictor of consumer xenocentrism (although not all coefficients were supported at the country level) and thus hypothesis H1 is supported. This relationship is also significant for the two factors of xenocentrism, foreign admiration and domestic rejection. On the other hand, there was no support for collectivism as a direct predictor of consumer xenocentrism. With respect to this relationship for only the domestic rejection factor, the relationship is significant in the direction opposite to the prediction in hypothesis $\mathrm{H} 2$. That is, individualistic individuals are more xenocentric. Thus, hypothesis $\mathrm{H} 2$ is not supported. Status consumption (except with the domestic rejection factor), susceptibility to normative influence, global media exposure and international travel are all highly significant predictors of consumer xenocentrism. In fact, they are all significant at the $\mathrm{p}<=0.01$ level. That is, these constructs have a positive effect on consumer xenocentrism. Thus, hypotheses H3, H4, H8 and H9 are supported. With respect to demographics, age is a significant predictor of consumer xenocentrism $(\mathrm{p}<=0.01)$. That is, age has a negative effect on xenocentrism signifying that younger individuals are more xenocentric. Thus, H5 is supported. With respect to education, the variable is significant in the direction opposite to our prediction in hypothesis H6. That is, individuals with lower education levels are more xenocentric. This could be the case because younger individuals are more xenocentric and younger individuals can be students who have lower levels of education. Thus, hypotheses H6 is not supported. Gender (males) was a significant predictor for only the domestic rejection factor so there is partial support for $\mathrm{H} 7$. 
For the Ecuador sample, all model fit indices have values that indicate a moderately good fit. The models explain $25 \%$ to $46 \%$ of the total variance in consumer xenocentrism. There was no support for power distance and collectivism as direct predictors of consumer xenocentrism disproving $\mathrm{H} 1$ and $\mathrm{H} 2$. Status consumption (except with the domestic rejection factor) and international travel had a significant positive effect on xenocentrism, thus supporting $\mathrm{H} 3$ and $\mathrm{H} 9$. Susceptibility to normative influence was significant in the positive direction for only the domestic rejection factor, so there is partial support for $\mathrm{H} 4$. Global media exposure was a significant predictor of consumer xenocentrism (in the positive direction) and thus hypothesis $\mathrm{H} 8$ is supported. All demographics variables were not significant. Thus, there is no support for hypotheses H5, H6 and H7.

For the India sample, all model fit indices have values that indicate a moderately good fit. The models explain $45 \%$ to $59 \%$ of the total variance in consumer xenocentrism. Power distance is a significant predictor (in the positive direction) of consumer xenocentrism (except with the foreign admiration factor), thus supporting H1. With respect to collectivism, the variable is significant in the direction opposite to our prediction in hypothesis $\mathrm{H} 2$ (except with the foreign admiration factor where it is not significant). That is, individualistic individuals are more xenocentric. Thus, H2 is not supported. Susceptibility to normative influence (except with the foreign admiration factor) and international travel are significant predictors in the positive direction thus supporting $\mathrm{H} 4$ and H9. Status consumption was significant in the positive direction for only the foreign admiration factor, so there is partial support for H3. Global media exposure is not significant disproving H8. With respect to demographics, age and education are not significant while gender is a significant predictor of consumer xenocentrism (except with 
the foreign admiration factor). In other words, males are more xenocentric. Thus, H5 and H6 are not supported while $\mathrm{H} 7$ is.

For the Kenya sample, all model fit indices have values that indicate a moderately good fit. The models explain $25 \%$ to $45 \%$ of the total variance in consumer xenocentrism. Power distance and collectivism are not significant predictors of consumer xenocentrism. Thus, $\mathrm{H} 1$ and $\mathrm{H} 2$ are disproved. Status consumption and international travel (except with domestic rejection factor) are significant (in the positive direction) predictors while susceptibility to normative influence is not significant thus supporting $\mathrm{H} 3$ and $\mathrm{H} 9$ while disproving H4. Global media exposure was significant in the positive direction for only the foreign admiration factor, so there is partial support for H8. All demographics variables were not significant. Thus, there is no support for hypotheses H5, H6 and H7.

Finally, for the Romania sample, all model fit indices have values that indicate a moderately good fit. The models explain $20 \%$ to $33 \%$ of the total variance in consumer xenocentrism. Power distance and collectivism are not significant predictors of consumer xenocentrism. Thus, $\mathrm{H} 1$ and $\mathrm{H} 2$ are disproved. Susceptibility to normative influence and international travel (except with domestic rejection factor) are significant predictors in the positive direction while status consumption and global media exposure are not significant thus supporting $\mathrm{H} 4$ and $\mathrm{H} 9$ while disproving $\mathrm{H} 3$ and $\mathrm{H} 8$. Age was a significant predictor of consumer xenocentrism. That is, younger consumers are more xenocentric. On the other hand, demographic variables, gender and education were not significant predictors, Thus, hypotheses $\mathrm{H} 5$ is supported while $\mathrm{H} 6$ and $\mathrm{H} 7$ are not.

Table 8.50 provides the summary of all the antecedent hypotheses results for all the samples. It displays the results for 1.) consumer xenocentrism 2.) foreign admiration factor 
and 3.) domestic rejection factor. International travel is the most significant predictor (13 times). Next, susceptibility to normative influence ( 9 times) and status consumption (8 times) are most significant. Global media exposure ( 7 times), age (6 times), power distance (5 times) and gender (3 times) are next most significant. Collectivism and education are not significant in any sample.

When only taking the results for consumer xenocentrism (the hypotheses was proposed at that level), international travel is the only significant predictor in all samples. Next, status consumption and susceptibility to normative influence are significant in two samples (not considering the combined sample). Power distance, age, gender and global media are significant in one sample and education and collectivism in no sample. Thorough discussion of these results will be done in chapter 11 . 
Table 8.50: Summary of antecedent results

\begin{tabular}{|c|c|c|c|c|c|c|c|c|c|c|c|c|c|c|c|c|c|}
\hline Hypotheses & Combined & Ecuador & India & Kenya & Romania & Hypotheses & Combined & Ecuador & India & Kenya & Romania & Hypotheses & Combined & Ecuador & India & Kenya & Romania \\
\hline $\begin{array}{l}\text { H1: Power distance will } \\
\text { have a positive effect on } \\
\text { consumer xenocentrism. }\end{array}$ & $\checkmark$ & $x$ & $\checkmark$ & $\mathrm{x}$ & $\mathrm{x}$ & $\begin{array}{l}\text { H1a: Power distance will } \\
\text { have a positive effect on } \\
\text { foreign admiration. }\end{array}$ & $\checkmark$ & $\mathrm{x}$ & $\mathrm{x}$ & $\mathrm{x}$ & $\mathrm{x}$ & $\begin{array}{l}\text { H1b: Power distance will } \\
\text { have a positive effect on } \\
\text { domestic rejection. }\end{array}$ & $\checkmark$ & $\mathrm{x}$ & $\checkmark$ & $x$ & $\mathrm{x}$ \\
\hline $\begin{array}{l}\mathrm{H} 2 \text { : Collectivism will } \\
\text { have a positive } \\
\text { effect on consumer } \\
\text { xenocentrism. } \\
\end{array}$ & $\mathrm{x}$ & $\mathrm{x}$ & $x$ & $\mathrm{x}$ & $\mathrm{x}$ & $\begin{array}{l}\text { H2a: Collectivism will } \\
\text { have a positive effect on } \\
\text { foreign admiration. }\end{array}$ & $\mathrm{x}$ & $x$ & $\mathrm{x}$ & $\mathrm{x}$ & $\mathrm{x}$ & $\begin{array}{l}\text { H2b: Collectivism will } \\
\text { have a positive effect on } \\
\text { domestic rejection. }\end{array}$ & $x$ & $\mathrm{x}$ & $\mathrm{x}$ & $x$ & $\mathrm{x}$ \\
\hline $\begin{array}{l}\text { H3: Status consumption } \\
\text { will have a } \\
\text { positive effect on } \\
\text { consumer xenocentrism. }\end{array}$ & $\checkmark$ & $\checkmark$ & $\mathrm{x}$ & $\checkmark$ & $\mathrm{x}$ & $\begin{array}{l}\text { H3a: Status consumption } \\
\text { will have a positive } \\
\text { effect on foreign } \\
\text { admiration. }\end{array}$ & 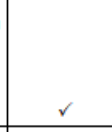 & $\begin{array}{c}\mathrm{c} \\
\mathrm{s}\end{array}$ & $\checkmark$ & $\checkmark$ & $x$ & $\begin{array}{l}\text { H3b: Status consumption } \\
\text { will have a positive } \\
\text { effect on domestic } \\
\text { rejection. }\end{array}$ & $\mathrm{x}$ & $\mathrm{x}$ & $\mathrm{x}$ & $\checkmark$ & $\mathrm{x}$ \\
\hline $\begin{array}{l}\text { H4: SNI will have a } \\
\text { positive effect on } \\
\text { consumer xenocentrism. }\end{array}$ & $\checkmark$ & $x$ & $\checkmark$ & $x$ & $\checkmark$ & $\begin{array}{l}\text { H4a: SNI will have a } \\
\text { positive effect on foreign } \\
\text { admiration. }\end{array}$ & $\checkmark$ & $x$ & $x$ & $x$ & $\checkmark$ & $\begin{array}{l}\text { H4b: SNI will have a } \\
\text { positive effect on } \\
\text { domestic rejection. }\end{array}$ & $\checkmark$ & $\checkmark$ & $\checkmark$ & $x$ & $\checkmark$ \\
\hline $\begin{array}{l}\text { H5: Age will have a } \\
\text { negative effect on } \\
\text { consumer xenocentrism. }\end{array}$ & $\checkmark$ & $\mathrm{x}$ & $x$ & $\mathrm{x}$ & 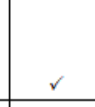 & $\begin{array}{l}\text { H5a: Age will have a } \\
\text { negative effect on } \\
\text { foreign admiration. }\end{array}$ & $r$ & $x$ & $\mathrm{x}$ & $x$ & 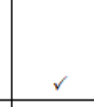 & $\begin{array}{l}\text { H5b: Age will have a } \\
\text { negative effect on } \\
\text { domestic rejection. }\end{array}$ & $\checkmark$ & $\mathrm{x}$ & $\mathrm{x}$ & $x$ & $r$ \\
\hline $\begin{array}{l}\text { H6: Education level will } \\
\text { have a positive } \\
\text { effect on consumer } \\
\text { xenocentrism. } \\
\end{array}$ & $\mathrm{x}$ & $\mathrm{x}$ & $\mathrm{x}$ & $\mathrm{x}$ & $\mathrm{x}$ & $\begin{array}{l}\text { H6a: Education level will } \\
\text { have a positive } \\
\text { effect on foreign } \\
\text { admiration. }\end{array}$ & $\mathrm{x}$ & $x$ & $x$ & $x$ & $x$ & $\begin{array}{l}\text { H6b: Education level will } \\
\text { have a positive } \\
\text { effect on domestic } \\
\text { rejection. }\end{array}$ & $x$ & $x$ & $x$ & $\mathrm{x}$ & $\mathrm{x}$ \\
\hline $\begin{array}{l}\text { H7: Gender (Males) will } \\
\text { have a positive } \\
\text { effect on consumer } \\
\text { xenocentrism. }\end{array}$ & $\mathrm{x}$ & $\mathrm{x}$ & $\checkmark$ & $x$ & $\mathrm{x}$ & $\begin{array}{l}\text { H7a: Gender (Males) will } \\
\text { have a positive } \\
\text { effect on foreign } \\
\text { admiration. }\end{array}$ & $\mathrm{x}$ & $x$ & $\mathrm{x}$ & $\mathrm{x}$ & $\mathrm{x}$ & $\begin{array}{l}\text { H7b: Gender (Males) will } \\
\text { have a positive } \\
\text { effect on domestic } \\
\text { rejection. }\end{array}$ & $\checkmark$ & $\mathrm{x}$ & $\checkmark$ & $x$ & $\mathrm{x}$ \\
\hline $\begin{array}{l}\text { H8: Exposure to global } \\
\text { media will have } \\
\text { a positive effect on } \\
\text { consumer xenocentrism. }\end{array}$ & $\checkmark$ & $\checkmark$ & $\mathrm{x}$ & $\mathrm{x}$ & $x$ & $\begin{array}{l}\text { H8a: Exposure to global } \\
\text { media will have } \\
\text { a positive effect on } \\
\text { foreign admiration. }\end{array}$ & 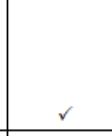 & $\begin{array}{c}\mathrm{c} \\
\mathrm{s}\end{array}$ & $\mathrm{x}$ & $\mathrm{s}$ & $x$ & $\begin{array}{l}\text { H8b: Exposure to global } \\
\text { media will have } \\
\text { a positive effect on } \\
\text { domestic rejection. }\end{array}$ & $\checkmark$ & $\begin{array}{c}\mathrm{c} \\
\mathrm{s}\end{array}$ & $\mathrm{x}$ & $x$ & $\mathrm{x}$ \\
\hline $\begin{array}{l}\text { H9: International travel } \\
\text { experience/ } \\
\text { preference will have a } \\
\text { positive effect on } \\
\text { consumer xenocentrism. }\end{array}$ & $\checkmark$ & $\checkmark$ & $\checkmark$ & $\checkmark$ & $\checkmark$ & $\begin{array}{l}\text { H9a: International travel } \\
\text { experience/ } \\
\text { preference will have a } \\
\text { positive effect on foreign } \\
\text { admiration. }\end{array}$ & $\begin{array}{r}r \\
\end{array}$ & $\checkmark$ & $\checkmark$ & $\checkmark$ & $\checkmark$ & $\begin{array}{l}\text { H9b: International travel } \\
\text { experience/ } \\
\text { preference will have a } \\
\text { positive effect on } \\
\text { domestic rejection. }\end{array}$ & 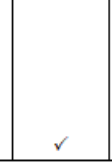 & $\checkmark$ & $\checkmark$ & $x$ & $x$ \\
\hline
\end{tabular}




\subsection{Chapter summary}

This chapter discussed the descriptive analysis and the CFA results for the consumer xenocentrism and every antecedent construct. The results of each partial measurement model were elaborated. The validities of the constructs were examined. Lastly, the structural model results of the antecedent constructs were examined. International travel followed by status consumption and susceptibility to normative influence seems to be the strongest antecedents to consumer xenocentrism in most samples. Power distance, age, gender and global media exposure were each significant predictors of consumer xenocentrism in only one sample whereas collectivism and education were significant in none of the samples. The analysis of the related constructs of consumer xenocentrism will be discussed in the next chapter. 


\section{CHAPTER NINE - ANALYSIS OF RELATED CONSTRUCTS}

\subsection{Introduction}

In this chapter, the analysis of the constructs that are expected to be related to consumer xenocentrism are discussed. For all five related constructs, the descriptive analysis and the CFA results are examined. Next, the discriminant validity analysis between the related constructs are reviewed. And finally, the covariance model and correlation results of the constructs are presented.

\subsection{Global identity construct}

Tables 9.1 to 9.5 show the descriptive analysis of the different samples for the global identity construct. For each sample, the table shows the mean, standard deviation, skewness and kurtosis for the construct and for each item within it. Global_identity_1 to 4 represent the different items that make up the global identity construct.

Skewness and kurtosis for the different samples are within acceptable limits. Based on the standard deviation values, the samples exhibit reasonable variability and do not raise any concerns. The mean of the global identity construct is between 4.69 (Romania) to 5.72 (India). This means that most people in all samples somewhat agree that they have a global identity i.e. they identify with cultures around the world.

Table 9.6 shows the confirmatory factor analysis for the different samples. The model fit indices are within acceptable range except the AVE values. However, the Cronbach's alpha for all the samples fell also below the acceptable 0.7 mark (Nunnally and Bernstein, 1994). While the combined, India and Kenya samples were in the 0.60 range, the other two samples were in the 0.5 range. Some scholars (Shay and Back, 2004; 
Griethuijsen et al., 2014) argue that 0.6 is an acceptable range for Cronbach alphas. One of the reasons for the poor Cronbach's alphas could be that this scale has been created and tested in developed countries. It has been tested in developing countries less frequently and mostly on student samples. Since this scale looks unstable in our context, the global identity construct will be dropped from further analysis.

Table 9.1: Descriptive analysis for global identity construct for the combined sample

\begin{tabular}{|l|r|r|r|r|r|}
\hline & $\begin{array}{c}\text { Global_ide } \\
\text { ntity_1 }\end{array}$ & $\begin{array}{c}\text { Global_ide } \\
\text { ntity_2 }\end{array}$ & $\begin{array}{c}\text { Global_ide } \\
\text { ntity_3 }\end{array}$ & $\begin{array}{c}\text { Global_ide } \\
\text { ntity_4 }\end{array}$ & \multicolumn{1}{c|}{ Average } \\
\hline Mean & 4.50 & 5.67 & 4.82 & 5.76 & $\mathbf{5 . 1 9}$ \\
\hline Std. Deviation & 1.80 & 1.22 & 1.65 & 1.10 & $\mathbf{1 . 4 4}$ \\
\hline Skewness & -0.35 & -1.29 & -0.62 & -1.24 & $\mathbf{- 0 . 8 7}$ \\
\hline Kurtosis & -0.94 & 2.14 & -0.39 & 2.32 & $\mathbf{0 . 7 8}$ \\
\hline
\end{tabular}

Table 9.2: Descriptive analysis for global identity construct for the Ecuador sample

\begin{tabular}{|l|r|r|r|r|r|}
\hline & $\begin{array}{c}\text { Global_ide } \\
\text { ntity_1 }\end{array}$ & $\begin{array}{c}\text { Global_ide } \\
\text { ntity_2 }\end{array}$ & $\begin{array}{c}\text { Global_ide } \\
\text { ntity_3 }\end{array}$ & $\begin{array}{c}\text { Global_ide } \\
\text { ntity_4 }\end{array}$ & \multicolumn{1}{c|}{ Average } \\
\hline Mean & 3.91 & 5.56 & 4.64 & 5.55 & $\mathbf{4 . 9 1}$ \\
\hline Std. Deviation & 1.97 & 1.26 & 1.67 & 1.21 & $\mathbf{1 . 5 2}$ \\
\hline Skewness & 0.06 & -1.09 & -0.42 & -1.08 & $-\mathbf{0 . 6 3}$ \\
\hline Kurtosis & -1.21 & 1.33 & -0.52 & 1.86 & $\mathbf{0 . 3 6}$ \\
\hline
\end{tabular}

Table 9.3: Descriptive analysis for global identity construct for the India sample

\begin{tabular}{|l|r|r|r|r|r|}
\hline & $\begin{array}{c}\text { Global_ide } \\
\text { ntity_1 }\end{array}$ & $\begin{array}{c}\text { Global_ide } \\
\text { ntity_2 }\end{array}$ & $\begin{array}{c}\text { Global_ide } \\
\text { ntity_3 }\end{array}$ & $\begin{array}{c}\text { Global_ide } \\
\text { ntity_4 }\end{array}$ & \multicolumn{1}{c|}{ Average } \\
\hline Mean & 5.61 & 5.82 & 5.48 & 5.99 & $\mathbf{5 . 7 2}$ \\
\hline Std. Deviation & 1.23 & 1.09 & 1.42 & 0.98 & $\mathbf{1 . 1 8}$ \\
\hline Skewness & -1.00 & -1.49 & -1.06 & -1.19 & $\mathbf{- 1 . 1 8}$ \\
\hline Kurtosis & 1.31 & 3.99 & 0.90 & 2.46 & $\mathbf{2 . 1 7}$ \\
\hline
\end{tabular}


Table 9.4: Descriptive analysis for global identity construct for the Kenya sample

\begin{tabular}{|l|r|r|r|r|r|}
\hline & $\begin{array}{c}\text { Global_ide } \\
\text { ntity_1 }\end{array}$ & $\begin{array}{c}\text { Global_ide } \\
\text { ntity_2 }\end{array}$ & $\begin{array}{c}\text { Global_ide } \\
\text { ntity_3 }\end{array}$ & $\begin{array}{c}\text { Global_ide } \\
\text { ntity_4 }\end{array}$ & \multicolumn{1}{c|}{ Average } \\
\hline Mean & 4.79 & 5.96 & 4.97 & 5.84 & $\mathbf{5 . 3 9}$ \\
\hline Std. Deviation & 1.70 & 1.05 & 1.57 & 1.10 & $\mathbf{1 . 3 5}$ \\
\hline Skewness & -0.56 & -1.51 & -0.74 & -1.50 & $\mathbf{- 1 . 0 8}$ \\
\hline Kurtosis & -0.74 & 3.27 & -0.20 & 2.83 & $\mathbf{1 . 2 9}$ \\
\hline
\end{tabular}

Table 9.5: Descriptive analysis for global identity construct for the Romania sample

\begin{tabular}{|l|r|r|r|r|r|}
\hline & $\begin{array}{c}\text { Global_ide } \\
\text { ntity_1 }\end{array}$ & $\begin{array}{c}\text { Global_ide } \\
\text { ntity_2 }\end{array}$ & $\begin{array}{r}\text { Global_ide } \\
\text { ntity_3 }\end{array}$ & $\begin{array}{c}\text { Global_ide } \\
\text { ntity_4 }\end{array}$ & \multicolumn{1}{c|}{ Average } \\
\hline Mean & 3.64 & 5.31 & 4.17 & 5.66 & $\mathbf{4 . 6 9}$ \\
\hline Std. Deviation & 1.53 & 1.36 & 1.68 & 1.03 & $\mathbf{1 . 4 0}$ \\
\hline Std. Error of & 0.14 & 0.14 & 0.14 & 0.14 & $\mathbf{0 . 1 4}$ \\
\hline Kurtosis & -0.75 & 1.09 & -0.81 & 2.13 & $\mathbf{0 . 4 2}$ \\
\hline
\end{tabular}

Table 9.6: Confirmatory factor analysis for global identity construct for the different samples

\begin{tabular}{|c|c|c|c|c|c|c|c|c|c|}
\hline Sample & $x 2 / d f$ & GFI & AGFI & CFI & RMSEA & SRMR & $\begin{array}{l}\text { Cronbach's } \\
\text { alpha }\end{array}$ & AVE value & No. of items \\
\hline Combined & 2.95 & 0.99 & 0.99 & 0.99 & 0.04 & 0.01 & 0.64 & 0.29 & 4 \\
\hline Ecuador & 4.88 & 0.99 & 0.93 & 0.97 & 0.11 & 0.03 & 0.57 & 0.28 & 4 \\
\hline India & 1.02 & 0.99 & 0.98 & 1.00 & 0.01 & 0.01 & 0.66 & 0.33 & 4 \\
\hline Kenya & 4.95 & 0.99 & 0.93 & 0.97 & 0.11 & 0.03 & 0.60 & 0.30 & 4 \\
\hline Romania & 0.04 & 1.00 & 0.99 & 1.00 & 0.00 & 0.00 & 0.59 & 0.28 & 4 \\
\hline
\end{tabular}

\subsection{Consumer Worldmindedness construct}

Tables 9.7 to 9.11 show the descriptive analysis of the different samples for the consumer worldmindedness construct. Worldminded_1 to 7 represent the different items that make up the consumer worldmindedness construct.

The skewness and kurtosis are within acceptable ranges. There is quite a bit of variability in the sample as evidenced from the standard deviation values. The average 
consumer worldmindedness mean is between 3.19 (Romania) and 4.47 (India). This signifies that except in India (where people are neutral about being worldminded), in all the other samples people tend to disagree about being worldminded. That is, in general, although the samples have a global identity and thus identify with people around the world, they do not go one step further and have a reference group as mankind rather than a particular nationality as would have been the case in worldminded individuals. Also, they disagree to favor foreign products.

Table 9.12 show the confirmatory factor analysis for the different samples. All the models fit indices except the AVE values are within the recommended range. Item six ("Where a good is produced does not affect my decision to purchase that item.") has been deleted to get a better model fit. There are three samples in which the Cronbach's alpha are in the 0.6 range, which some authors argue is an acceptable range. Other than those samples, the Cronbach's alpha of the other samples are above 0.70 .

Table 9.7: Descriptive analysis for consumer worldmindedness construct for the combined sample

\begin{tabular}{|c|c|c|c|c|c|c|c|}
\hline & $\begin{array}{c}\text { Worldminded_ } \\
1\end{array}$ & $\begin{array}{c}\text { Worldminded } \\
{ }_{2}\end{array}$ & $\begin{array}{c}\text { Worldminded } \\
-3\end{array}$ & $\begin{array}{c}\text { Worldminded } \\
4\end{array}$ & $\begin{array}{c}\text { Worldminded } \\
\ldots 5\end{array}$ & $\begin{array}{c}\text { Worldminded } \\
-7\end{array}$ & Average \\
\hline Mean & 4.16 & 3.08 & 4.21 & 3.86 & 3.53 & 3.12 & 3.66 \\
\hline Std. Deviation & 1.65 & 1.90 & 1.98 & 1.78 & 1.92 & 1.76 & 1.83 \\
\hline Skewness & -0.17 & 0.62 & -0.16 & 0.03 & 0.26 & 0.56 & 0.19 \\
\hline Kurtosis & -0.86 & -0.79 & -1.26 & -1.10 & -1.20 & -0.67 & -0.98 \\
\hline
\end{tabular}


Table 9.8: Descriptive analysis for consumer worldmindedness construct for the Ecuador sample

\begin{tabular}{|c|c|c|c|c|c|c|c|}
\hline & $\begin{array}{c}\text { Worldminded_ } \\
1\end{array}$ & $\begin{array}{c}\text { Worldminded } \\
\ldots \\
\end{array}$ & $\begin{array}{c}\text { Worldminded } \\
-3 \\
\end{array}$ & $\begin{array}{c}\text { Worldminded } \\
-4 \\
\end{array}$ & \begin{tabular}{|c} 
Worldminded \\
-5
\end{tabular} & \begin{tabular}{|c|} 
Worldminded \\
$\ldots$ \\
\end{tabular} & Average \\
\hline Mean & 4.62 & 2.89 & 4.16 & 3.90 & 3.52 & 3.02 & 3.69 \\
\hline Std. Deviation & 1.57 & 1.86 & 1.98 & 1.75 & 1.84 & 1.66 & 1.78 \\
\hline Skewness & -0.48 & 0.82 & -0.09 & 0.02 & 0.29 & 0.64 & 0.20 \\
\hline Kurtosis & -0.41 & -0.40 & -1.25 & -1.09 & -1.12 & -0.43 & -0.78 \\
\hline
\end{tabular}

Table 9.9: Descriptive analysis for consumer worldmindedness construct for the India sample

\begin{tabular}{|c|c|c|c|c|c|c|c|}
\hline & $\begin{array}{c}\text { Worldminded_ } \\
1\end{array}$ & \begin{tabular}{|c|} 
Worldminded \\
2 \\
\end{tabular} & $\begin{array}{c}\text { Worldminded } \\
-3 \\
\end{array}$ & \begin{tabular}{|c} 
Worldminded \\
4 \\
\end{tabular} & $\begin{array}{c}\text { Worldminded } \\
-5 \\
\end{array}$ & $\begin{array}{c}\text { Worldminded } \\
\ldots \\
\end{array}$ & Average \\
\hline Mean & 4.47 & 4.13 & 5.15 & 4.67 & 4.51 & 3.90 & 4.47 \\
\hline Std. Deviation & 1.63 & 1.91 & 1.67 & 1.70 & 1.87 & 1.91 & 1.78 \\
\hline Skewness & -0.39 & -0.12 & -0.82 & -0.55 & -0.42 & 0.09 & -0.37 \\
\hline Kurtosis & -0.60 & -1.08 & -0.11 & -0.47 & -0.94 & -1.15 & -0.73 \\
\hline
\end{tabular}

Table 9.10: Descriptive analysis for consumer worldmindedness construct for the Kenya sample

\begin{tabular}{|c|c|c|c|c|c|c|c|}
\hline & $\begin{array}{c}\text { Worldminded_ } \\
1\end{array}$ & $\begin{array}{c}\text { Worldminded } \\
{ }_{2}\end{array}$ & $\begin{array}{c}\text { Worldminded } \\
3\end{array}$ & $\begin{array}{c}\text { Worldminded } \\
-4\end{array}$ & $\begin{array}{c}\text { Worldminded } \\
-5\end{array}$ & $\begin{array}{c}\text { Worldminded } \\
-7\end{array}$ & Average \\
\hline Mean & 4.04 & 2.67 & 4.07 & 3.55 & 3.13 & 2.29 & 3.29 \\
\hline Std. Deviation & 1.69 & 1.77 & 2.07 & 1.76 & 2.02 & 1.53 & 1.81 \\
\hline Skewness & -0.13 & 1.06 & -0.05 & 0.25 & 0.62 & 1.37 & 0.52 \\
\hline Kurtosis & -1.01 & 0.09 & -1.48 & -1.08 & \begin{tabular}{|c|}
-1.08 \\
\end{tabular} & 1.21 & -0.56 \\
\hline
\end{tabular}


Table 9.11: Descriptive analysis for consumer worldmindedness construct for the Romania sample

\begin{tabular}{|c|c|c|c|c|c|c|c|}
\hline & $\begin{array}{c}\text { Worldminded_ } \\
1\end{array}$ & $\begin{array}{c}\text { Worldminded } \\
2\end{array}$ & $\begin{array}{c}\text { Worldminded } \\
-3\end{array}$ & $\begin{array}{c}\text { Worldminded } \\
\ldots\end{array}$ & $\begin{array}{c}\text { Worldminded } \\
-5\end{array}$ & $\begin{array}{c}\text { Worldminded } \\
-7\end{array}$ & Average \\
\hline Mean & 3.48 & 2.61 & 3.46 & 3.33 & 2.99 & 3.30 & 3.19 \\
\hline Std. Deviation & 1.45 & 1.65 & 1.81 & 1.62 & 1.54 & 1.51 & 1.60 \\
\hline Skewness & 0.16 & 0.82 & 0.22 & 0.33 & 0.38 & 0.25 & 0.36 \\
\hline Kurtosis & -0.70 & -0.28 & -1.06 & -0.85 & -0.76 & -0.58 & -0.71 \\
\hline
\end{tabular}

Table 9.12: Confirmatory factor analysis for consumer worldmindedness construct for the different samples

\begin{tabular}{|c|c|c|c|c|c|c|c|c|c|}
\hline Sample & $\mathrm{x} 2 / \mathrm{df}$ & GFI & AGFI & CFI & RMSEA $S$ & SRMR & \begin{tabular}{l|} 
Cronbach's \\
alpha
\end{tabular} & AVE value $\Lambda$ & No. of items \\
\hline Combined & 2.50 & 0.99 & 0.99 & 0.99 & 0.03 & 0.02 & 0.74 & 0.32 & 6 \\
\hline Ecuador & 2.09 & 0.98 & 0.95 & 0.96 & 0.06 & 0.04 & 0.65 & 0.24 & 6 \\
\hline India & 2.60 & 0.98 & 0.95 & 0.97 & 0.07 & 0.04 & 0.76 & 0.34 & 6 \\
\hline Kenya & 1.85 & 0.99 & 0.96 & 0.98 & 0.05 & 0.03 & 0.69 & 0.26 & 6 \\
\hline Romania & 1.29 & 0.99 & 0.97 & 0.99 & 0.03 & 0.03 & 0.67 & 0.29 & 6 \\
\hline
\end{tabular}

\subsection{Local identity construct}

Tables 9.13 to 9.17 show the descriptive analysis of the different samples for the local identity contract. Local identity_1 to 4 are the various items that makeup the local identity construct.

The skewness is within the acceptable range. The kurtosis is higher than most of the other constructs, but it is still within the recommended range. The standard deviation has some variability but not a lot. The mean of local identity construct is between 5.38 (Romania) to 5.87 (India). This is in-line with the mean in most constructs where Romania has the lowest score and India has the highest. Overall, all samples agree that they have high local identity (i.e. they have a sense of belonging to the local group). It is interesting to note that the consumers have both a high local and high global identity. 
Table 9.18 shows the confirmatory factor analysis for the different samples. Most of the indices are within the acceptable range except the AVE values for all samples and $\chi^{2 / \mathrm{df}}$ and RMSEA values for Ecuador. The Cronbach's alpha is mostly within the acceptable range. For the combined and Ecuador sample, the Cronbach's alpha is closer to the recommended 0.70 range. However, for Kenya the alpha is only 0.58 .

Table 9.13: Descriptive analysis for local identity construct for the combined sample

\begin{tabular}{|c|c|c|c|c|c|}
\hline & $\begin{array}{c}\text { Local_identity } \\
\ldots 1 \\
\end{array}$ & $\begin{array}{c}\text { Local_identity } \\
-2 \\
\end{array}$ & $\begin{array}{c}\text { Local_identity } \\
\text {-3 } \\
\end{array}$ & $\begin{array}{c}\text { Local_identity } \\
\ldots 4 \\
\end{array}$ & Average \\
\hline Mean & 5.25 & 6.02 & 5.61 & 5.83 & 5.68 \\
\hline Std. Deviation & 1.47 & 1.10 & 1.43 & 1.12 & 1.28 \\
\hline Skewness & -0.83 & -1.57 & -1.21 & -1.51 & -1.28 \\
\hline Kurtosis & 0.11 & 3.18 & 0.94 & 3.14 & 1.84 \\
\hline
\end{tabular}

Table 9.14: Descriptive analysis for local identity construct for the Ecuador sample

\begin{tabular}{|c|c|c|c|c|c|}
\hline & $\begin{array}{c}\text { Local_identity } \\
\ldots 1\end{array}$ & \begin{tabular}{|c|} 
Local_identity \\
$\ldots 2$
\end{tabular} & $\begin{array}{c}\text { Local_identity } \\
\ldots 3\end{array}$ & $\begin{array}{c}\text { Local_identity } \\
\ldots 4\end{array}$ & Average \\
\hline Mean & 5.29 & 5.94 & 5.67 & 5.64 & 5.64 \\
\hline Std. Deviation & 1.41 & 1.17 & 1.34 & 1.15 & 1.27 \\
\hline Skewness & -0.84 & -1.63 & -1.28 & -1.09 & -1.21 \\
\hline Kurtosis & 0.42 & 3.70 & 1.45 & 1.66 & 1.81 \\
\hline
\end{tabular}

Table 9.15: Descriptive analysis for local identity construct for the India sample

\begin{tabular}{|c|c|c|c|c|c|}
\hline & $\begin{array}{c}\text { Local_identity } \\
\text { 1 }\end{array}$ & $\begin{array}{c}\text { Local_identity } \\
\text { 2 }\end{array}$ & Local_identity & $\begin{array}{c}\text { Local_identity } \\
\text { 4 }\end{array}$ & Average \\
\hline Mean & 5.57 & 6.29 & 5.66 & 5.96 & 5.87 \\
\hline Std. Deviation & 1.32 & 0.96 & 1.43 & 1.02 & 1.18 \\
\hline Skewness & -1.12 & -1.78 & -1.23 & -1.50 & -1.41 \\
\hline Kurtosis & 1.07 & 4.07 & 1.06 & 3.24 & 2.36 \\
\hline
\end{tabular}


Table 9.16: Descriptive analysis for local identity construct for the Kenya sample

\begin{tabular}{|c|c|c|c|c|c|}
\hline & $\begin{array}{c}\text { Local_identity } \\
\_1\end{array}$ & \begin{tabular}{|c|} 
Local_identity \\
$\ldots 2$ \\
\end{tabular} & $\begin{array}{c}\text { Local_identity } \\
\text { _3 }\end{array}$ & $\begin{array}{c}\text { Local_identity } \\
\ldots 4 \\
\end{array}$ & Average \\
\hline Mean & 5.17 & 6.14 & 6.08 & 5.84 & 5.81 \\
\hline Std. Deviation & 1.60 & 1.05 & 1.18 & 1.27 & 1.27 \\
\hline Skewness & -0.76 & -1.88 & -2.00 & -1.73 & -1.59 \\
\hline Kurtosis & -0.27 & 4.82 & 4.39 & 3.26 & 3.05 \\
\hline
\end{tabular}

Table 9.17: Descriptive analysis for local identity construct for the Romania sample

\begin{tabular}{|c|c|c|c|c|c|}
\hline & $\begin{array}{c}\text { Local_identity } \\
\ldots 1\end{array}$ & \begin{tabular}{|c|} 
Local_identity \\
$\ldots 2$ \\
\end{tabular} & $\begin{array}{c}\text { Local_identity } \\
\ldots 3\end{array}$ & $\begin{array}{c}\text { Local_identity } \\
\ldots 4\end{array}$ & Average \\
\hline Mean & 4.96 & 5.70 & 4.98 & 5.89 & 5.38 \\
\hline Std. Deviation & 1.46 & 1.15 & 1.55 & 1.01 & 1.29 \\
\hline Skewness & -0.65 & -1.13 & -0.69 & -1.57 & -1.01 \\
\hline Kurtosis & -0.27 & 1.39 & -0.32 & 4.66 & 1.37 \\
\hline
\end{tabular}

Table 9.18: Confirmatory factor analysis for local identity construct for the different samples

\begin{tabular}{|l|r|r|r|r|r|r|r|r|r|}
\hline Sample & \multicolumn{1}{|l|}{} & X2/df & GFI & & AGFI & CFI & RMSEA & SRMR & \multicolumn{2}{l|}{$\begin{array}{l}\text { Cronbach's } \\
\text { alpha }\end{array}$} & AVE value & No. of items \\
\hline Combined & 5.14 & 0.99 & 0.98 & 0.99 & 0.06 & 0.01 & 0.69 & 0.40 & 4 \\
\hline Ecuador & 8.21 & 0.99 & 0.88 & 0.96 & 0.15 & 0.03 & 0.67 & 0.34 & 4 \\
\hline India & 0.45 & 0.99 & 0.99 & 1.00 & 0.00 & 0.01 & 0.77 & 0.44 & 4 \\
\hline Kenya & 3.26 & 0.99 & 0.95 & 0.98 & 0.08 & 0.02 & 0.58 & 0.28 & 4 \\
\hline Romania & 1.00 & 0.99 & 0.98 & 1.00 & 0.00 & 0.01 & 0.73 & 0.41 & 4 \\
\hline
\end{tabular}

\subsection{National identity construct}

Tables 9.19 to 9.23 show the descriptive analysis of the different samples for the national identity construct. National_identity_1 to 4 represents the different items that make up the national identity construct.

The skewness and kurtosis are higher compared to most other constructs that were reviewed so far but both the indices are within recommended limits. The standard deviation indicates a bit of variability. The average for the national identity mean is between 5.72 
(Romania) and 6.31 (Kenya). These values signify that all the samples highly agree that they have a strong attachment towards their country.

Table 9.24 show us the confirmatory factor analysis for the different samples. All the fit indices except the AVE values of Kenya are in the recommended range. Except the Cronbach's alpha for Kenya which is 0.58 , all other Cronbach's alphas are within accepted limits.

Table 9.19: Descriptive analysis for national identity construct for the combined sample

\begin{tabular}{|c|c|c|c|c|c|}
\hline & $\begin{array}{c}\text { National_identity } \\
\ldots\end{array}$ & $\begin{array}{c}\text { National_identity } \\
\_2\end{array}$ & $\begin{array}{c}\text { National_identity } \\
-\end{array}$ & $\begin{array}{c}\text { National_identity } \\
4 \_1\end{array}$ & Average \\
\hline Mean & 6.09 & 6.34 & 5.85 & 6.15 & 6.11 \\
\hline Std. Deviation & 1.21 & 1.13 & 1.28 & 1.32 & 1.24 \\
\hline Skewness & -1.70 & -2.23 & -1.42 & -2.08 & -1.86 \\
\hline Kurtosis & 2.97 & 5.28 & 2.20 & 4.28 & 3.68 \\
\hline
\end{tabular}

Table 9.20: Descriptive analysis for national identity construct for the Ecuador sample

\begin{tabular}{|c|c|c|c|c|c|}
\hline & $\begin{array}{c}\text { National_identity } \\
\ldots 1 \\
\end{array}$ & $\begin{array}{c}\text { National_identity } \\
\ldots 2\end{array}$ & $\begin{array}{c}\text { National_identity } \\
\ldots 3\end{array}$ & 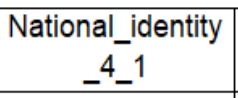 & Average \\
\hline Mean & 6.11 & 6.30 & 5.91 & 6.00 & 6.08 \\
\hline Std. Deviation & 1.28 & 1.14 & 1.28 & 1.42 & 1.28 \\
\hline Skewness & -1.74 & -2.10 & -1.32 & -1.84 & -1.75 \\
\hline Kurtosis & 2.89 & 4.92 & 1.58 & 3.12 & 3.13 \\
\hline
\end{tabular}

Table 9.21: Descriptive analysis for national identity construct for the India sample

\begin{tabular}{|c|c|c|c|c|c|}
\hline & $\begin{array}{c}\text { National_identity } \\
\_\end{array}$ & National_identity & $\begin{array}{c}\text { National_identity } \\
\ldots\end{array}$ & $\begin{array}{c}\text { National_identity } \\
4 \_1\end{array}$ & Average \\
\hline Mean & 6.36 & 6.63 & 6.11 & 6.09 & 6.30 \\
\hline Std. Deviation & 0.99 & 0.90 & 1.06 & 1.50 & 1.11 \\
\hline Skewness & -2.03 & -3.00 & -1.41 & -1.83 & -2.07 \\
\hline Kurtosis & 4.75 & 9.25 & 2.51 & 2.57 & 4.77 \\
\hline
\end{tabular}


Table 9.22: Descriptive analysis for national identity construct for the Kenya sample

\begin{tabular}{|c|c|c|c|c|c|}
\hline & National_identity & $\begin{array}{c}\text { National_identity } \\
\_\end{array}$ & $\begin{array}{c}\text { National_identity } \\
\ldots\end{array}$ & $\begin{array}{c}\text { National_identity } \\
{ }_{4} \_1\end{array}$ & Average \\
\hline Mean & 6.34 & 6.63 & 5.96 & 6.32 & 6.31 \\
\hline Std. Deviation & 0.99 & 0.79 & 1.35 & 1.15 & 1.07 \\
\hline Skewness & -2.33 & -3.35 & -1.98 & -2.71 & -2.59 \\
\hline Kurtosis & 6.89 & 14.83 & 4.18 & 8.50 & 8.60 \\
\hline
\end{tabular}

Table 9.23 Descriptive analysis for national identity construct for the Romania sample

\begin{tabular}{|c|c|c|c|c|c|}
\hline & $\begin{array}{c}\text { National_identity } \\
\_ \\
\end{array}$ & $\begin{array}{c}\text { National_identity } \\
\_\end{array}$ & $\begin{array}{c}\text { National_identity } \\
\ldots\end{array}$ & $\begin{array}{c}\text { National_identity } \\
{ }_{4}{ }_{-} 1\end{array}$ & Average \\
\hline Mean & 5.53 & 5.78 & 5.37 & 6.20 & 5.72 \\
\hline Std. Deviation & 1.37 & 1.41 & 1.29 & 1.17 & 1.31 \\
\hline Skewness & -1.08 & -1.40 & -0.98 & -2.03 & -1.37 \\
\hline Kurtosis & 0.91 & 1.64 & 0.97 & 4.90 & 2.11 \\
\hline
\end{tabular}

Table 9.24: Confirmatory factor analysis for national identity construct for the different samples

\begin{tabular}{|c|c|c|c|c|c|c|c|c|c|}
\hline Sample & $x 2 / d f$ & GFI & AGFI & CFI & RMSEA & SRMR & $\begin{array}{l}\text { Cronbach's } \\
\text { alpha }\end{array}$ & AVE value & No. of items \\
\hline Combined & 0.25 & 1.00 & 0.99 & 1.00 & 0.00 & 0.00 & 0.76 & 0.50 & 4 \\
\hline Ecuador & 0.03 & 1.00 & 1.00 & 1.00 & 0.00 & 0.00 & 0.82 & 0.57 & 4 \\
\hline India & 1.28 & 0.99 & 0.98 & 0.99 & 0.03 & 0.02 & 0.69 & 0.46 & 4 \\
\hline Kenya & 1.75 & 0.99 & 0.98 & 0.99 & 0.05 & 0.02 & 0.58 & 0.34 & 4 \\
\hline Romania & 0.29 & 0.99 & 0.99 & 1.00 & 0.00 & 0.00 & 0.82 & 0.54 & 4 \\
\hline
\end{tabular}

\subsection{Consumer ethnocentrism construct}

Tables 9.25 to 9.29 show the descriptive analysis of the various samples for the consumer ethnocentrism construct. CEthno_1 through 10 signifies the different items that comprise of the consumer ethnocentrism construct.

The skewness and kurtosis are within acceptable limits and the standard deviation has some variability. The average consumer ethnocentrism mean is between 3.87 (Romania) and 4.37 (India). Again, like with a lot of constructs reviewed earlier, Romania has the lowest mean and India the highest. Predominantly, the samples either disagree or 
are neutral about being ethnocentric. It is interesting that though the consumers predominantly have a high local and national identity, they are not very inclined towards buying their own products as evidenced by the low consumer ethnocentrism scores. It could be likely that these consumers are xenocentric and would like to buy foreign products and reject their own country's products (this will be covered in the next chapter which analyzes the consequences of consumer xenocentrism).

Table 9.30 shows the confirmatory factor analysis for all the five samples. All the fit indices (except the AVE values for Kenya and India and $\chi 2 / \mathrm{df}$ for the combined sample) are within the recommended range. The Cronbach's alphas for all the models are within acceptable limits. 
Table 9.25: Descriptive analysis for consumer ethnocentrism construct for the combined sample

\begin{tabular}{|c|c|c|c|c|c|c|c|c|c|c|c|}
\hline & CEthno_1 & CEthno_2 & CEthno_3 & CEthno_4 & CEthno_5 & CEthno_6 & CEthno_7 & CEthno_8 & CEthno_9 & CEthno_10 & Average \\
\hline Mean & 4.55 & 4.66 & 2.76 & 3.67 & 4.04 & 4.45 & 3.71 & 4.91 & 4.80 & 3.44 & 4.10 \\
\hline Std. Deviation & 1.82 & 1.53 & 1.53 & 1.67 & 1.78 & 1.74 & 1.70 & 1.47 & 1.70 & 1.72 & 1.67 \\
\hline \begin{tabular}{|l|} 
Skewness \\
\end{tabular} & -0.29 & -0.35 & 0.84 & 0.19 & -0.02 & -0.26 & 0.24 & -0.52 & -0.46 & 0.41 & -0.02 \\
\hline Kurtosis & -1.07 & -0.48 & 0.02 & -0.85 & -1.04 & -0.89 & -0.83 & -0.27 & -0.77 & -0.78 & -0.70 \\
\hline
\end{tabular}

Table 9.26: Descriptive analysis for consumer ethnocentrism construct for the Ecuador sample

\begin{tabular}{|c|c|c|c|c|c|c|c|c|c|c|c|}
\hline & CEthno_1 & CEthno_2 & CEthno_3 & CEthno_4 & CEthno_5 & CEthno_6 & CEthno_7 & CEthno_8 & CEthno_9 & CEthno_10 & Average \\
\hline Mean & 4.11 & 4.54 & 2.47 & 3.73 & 4.00 & 4.16 & 3.64 & 4.80 & 4.61 & 3.19 & 3.93 \\
\hline Std. Deviation & 1.85 & 1.51 & 1.36 & 1.66 & 1.78 & 1.70 & 1.69 & 1.39 & 1.74 & 1.65 & 1.63 \\
\hline Skewness & 0.03 & -0.20 & 1.00 & 0.19 & 0.10 & -0.06 & 0.35 & -0.33 & -0.24 & 0.62 & 0.15 \\
\hline Kurtosis & -1.18 & -0.60 & 0.54 & -0.84 & -1.05 & -0.87 & -0.66 & -0.49 & -1.05 & -0.40 & -0.66 \\
\hline
\end{tabular}

Table 9.27: Descriptive analysis for consumer ethnocentrism construct for the India sample

\begin{tabular}{|c|c|c|c|c|c|c|c|c|c|c|c|}
\hline & CEthno_1 & CEthno_2 & CEthno_3 & CEthno_4 & CEthno_5 & CEthno_6 & CEthno_7 & CEthno_8 & CEthno_9 & CEthno_10 & Average \\
\hline Mean & 4.94 & 5.07 & 3.02 & 3.61 & 4.35 & 4.71 & 3.80 & 5.11 & 5.06 & 4.04 & 4.37 \\
\hline Std. Deviation & 1.65 & 1.47 & 1.72 & 1.73 & 1.81 & 1.64 & 1.76 & 1.51 & 1.55 & 1.74 & 1.66 \\
\hline Skewness & -0.56 & -0.52 & 0.64 & 0.20 & -0.21 & -0.46 & 0.11 & -0.70 & -0.65 & 0.02 & -0.21 \\
\hline Kurtosis & -0.57 & -0.20 & -0.59 & -0.87 & -0.98 & -0.54 & -0.97 & -0.10 & -0.14 & -0.97 & -0.59 \\
\hline
\end{tabular}


Table 9.28: Descriptive analysis for consumer ethnocentrism construct for the Kenya sample

\begin{tabular}{|c|c|c|c|c|c|c|c|c|c|c|c|}
\hline & CEthno_1 & CEthno_2 & CEthno_3 & CEthno_4 & CEthno_5 & CEthno_6 & CEthno_7 & CEthno_8 & CEthno_9 & CEthno_10 & Average \\
\hline Mean & 4.99 & 4.58 & 2.68 & 3.75 & 4.01 & 4.70 & 3.77 & 5.04 & 5.09 & 3.54 & 4.21 \\
\hline Std. Deviation & 1.84 & 1.60 & 1.52 & 1.69 & 1.86 & 1.81 & 1.71 & 1.47 & 1.72 & 1.78 & 1.70 \\
\hline Skewness & -0.60 & -0.40 & 1.01 & 0.16 & -0.01 & -0.42 & 0.30 & -0.62 & -0.68 & 0.36 & -0.09 \\
\hline Kurtosis & -0.88 & -0.67 & 0.43 & -0.90 & -1.16 & -0.95 & -0.86 & -0.16 & -0.66 & -0.93 & -0.67 \\
\hline
\end{tabular}

Table 9.29: Descriptive analysis for consumer ethnocentrism construct for the Romania sample

\begin{tabular}{|c|c|c|c|c|c|c|c|c|c|c|c|}
\hline & CEthno_1 & CEthno_2 & CEthno_3 & CEthno_4 & CEthno_5 & CEthno_6 & CEthno_7 & CEthno_8 & CEthno_9 & CEthno_10 & Average \\
\hline Mean & 4.10 & 4.46 & 2.88 & 3.60 & 3.77 & 4.22 & 3.64 & 4.67 & 4.40 & 2.98 & 3.87 \\
\hline Std. Deviation & 1.74 & 1.47 & 1.43 & 1.60 & 1.63 & 1.73 & 1.63 & 1.46 & 1.71 & 1.49 & 1.59 \\
\hline Skewness & -0.09 & -0.31 & 0.63 & 0.21 & -0.07 & -0.14 & 0.17 & -0.48 & -0.28 & 0.59 & 0.02 \\
\hline Kurtosis & -1.02 & -0.24 & -0.18 & -0.76 & -0.96 & -0.88 & -0.81 & -0.16 & -0.83 & -0.29 & -0.61 \\
\hline
\end{tabular}

Table 9.30: Confirmatory factor analysis for consumer ethnocentrism construct for the different samples

\begin{tabular}{|c|c|c|c|c|c|c|c|c|c|}
\hline Sample & $x 2 / d f$ & GFI & AGFI & CFI & RMSEA & SRMR & \begin{tabular}{|l|} 
Cronbach's \\
alpha
\end{tabular} & AVE value & No. of items \\
\hline Combined & 12.00 & 0.94 & 0.89 & 0.94 & 0.09 & 0.04 & 0.89 & 0.45 & 10 \\
\hline Ecuador & 3.67 & 0.92 & 0.87 & 0.94 & 0.09 & 0.05 & 0.89 & 0.44 & 10 \\
\hline India & 4.39 & 0.91 & 0.85 & 0.91 & 0.10 & 0.05 & 0.88 & 0.39 & 10 \\
\hline Kenya & 3.61 & 0.93 & 0.88 & 0.94 & 0.09 & 0.05 & 0.89 & 0.41 & 10 \\
\hline Romania & 4.22 & 0.92 & 0.86 & 0.94 & 0.10 & 0.05 & 0.91 & 0.47 & 10 \\
\hline
\end{tabular}




\subsection{Discriminant validity}

Discriminant validity for the related constructs will be tested the same way as the discriminant validity for antecedents in the previous chapter. Tables 9.31 to 9.35 show the results of the discriminant validity for the related constructs. In almost every case, the local identity and national identity are highly correlated, and the correlation is very close to the Cronbach's alpha of the local identity construct. In one case, the local and national identity correlation is higher than the local identity Cronbach's alpha. These two constructs are highly correlated and thus only one of the two constructs (national identity) will be used for further analysis. Other than these two constructs, discriminant validity is satisfied for the other constructs.

Table 9.31: Discriminant validity for related constructs for the combined sample

\begin{tabular}{|l|r|r|l|l|}
\hline $\begin{array}{l}\text { Combined } \\
\text { sample }\end{array}$ & $\begin{array}{l}\text { Consumer } \\
\text { Worldmindedness }\end{array}$ & $\begin{array}{l}\text { Local } \\
\text { identity }\end{array}$ & $\begin{array}{l}\text { National } \\
\text { identity }\end{array}$ & $\begin{array}{l}\text { Consumer } \\
\text { ethnocentrism }\end{array}$ \\
\hline $\begin{array}{l}\text { Consumer } \\
\text { Worldmindedness }\end{array}$ & 0.74 & & & \\
\hline Local identity & -0.10 & 0.69 & & \\
\hline National identity & -0.19 & 0.63 & 0.76 & \\
\hline $\begin{array}{l}\text { Consumer } \\
\text { ethnocentrism }\end{array}$ & 0.00 & 0.41 & 0.26 & \\
\hline
\end{tabular}

Note: Diagonal entries are Cronbach's alpha coefficients; all others are correlation coefficients. 
Table 9.32: Discriminant validity for related constructs for the Ecuador sample

\begin{tabular}{|l|r|r|l|l|}
\hline $\begin{array}{l}\text { Ecuador } \\
\text { sample }\end{array}$ & $\begin{array}{l}\text { Consumer } \\
\text { Worldmindedness }\end{array}$ & $\begin{array}{l}\text { Local } \\
\text { identity }\end{array}$ & $\begin{array}{l}\text { National } \\
\text { identity }\end{array}$ & $\begin{array}{l}\text { Consumer } \\
\text { ethnocentrism }\end{array}$ \\
\hline $\begin{array}{l}\text { Consumer } \\
\text { Worldmindedness }\end{array}$ & 0.65 & & & \\
\hline Local identity & -0.27 & 0.67 & & \\
\hline National identity & -0.34 & 0.68 & 0.82 & \\
\hline $\begin{array}{l}\text { Consumer } \\
\text { ethnocentrism }\end{array}$ & -0.16 & 0.37 & 0.22 & 0.89 \\
\hline
\end{tabular}

Note: Diagonal entries are Cronbach's alpha coefficients; all others are correlation coefficients.

Table 9.33: Discriminant validity for related constructs for the India sample

\begin{tabular}{|l|r|r|l|l|}
\hline $\begin{array}{l}\text { India } \\
\text { sample }\end{array}$ & $\begin{array}{l}\text { Consumer } \\
\text { Worldmindedness }\end{array}$ & $\begin{array}{l}\text { Local } \\
\text { identity }\end{array}$ & $\begin{array}{l}\text { National } \\
\text { identity }\end{array}$ & $\begin{array}{l}\text { Consumer } \\
\text { ethnocentrism }\end{array}$ \\
\hline $\begin{array}{l}\text { Consumer } \\
\text { Worldmindedness }\end{array}$ & 0.76 & & & \\
\hline Local identity & -0.02 & 0.77 & & \\
\hline National identity & -0.25 & 0.55 & 0.69 & \\
\hline $\begin{array}{l}\text { Consumer } \\
\text { ethnocentrism }\end{array}$ & 0.18 & 0.38 & 0.10 & 0.88 \\
\hline
\end{tabular}

Note: Diagonal entries are Cronbach's alpha coefficients; all others are correlation coefficients.

Table 9.34: Discriminant validity for related constructs for the Kenya sample

\begin{tabular}{|l|r|r|l|l|}
\hline $\begin{array}{l}\text { Kenya } \\
\text { sample }\end{array}$ & $\begin{array}{l}\text { Consumer } \\
\text { Worldmindedness }\end{array}$ & $\begin{array}{l}\text { Local } \\
\text { identity }\end{array}$ & $\begin{array}{l}\text { National } \\
\text { identity }\end{array}$ & $\begin{array}{l}\text { Consumer } \\
\text { ethnocentrism }\end{array}$ \\
\hline $\begin{array}{l}\text { Consumer } \\
\text { Worldmindedness }\end{array}$ & 0.69 & & & \\
\hline Local identity & -0.18 & 0.58 & & \\
\hline National identity & -0.31 & 0.51 & 0.58 & \\
\hline $\begin{array}{l}\text { Consumer } \\
\text { ethnocentrism }\end{array}$ & -0.13 & 0.39 & 0.23 & 0.89 \\
\hline
\end{tabular}

Note: Diagonal entries are Cronbach's alpha coefficients; all others are correlation coefficients. 
Table 9.35: Discriminant validity for related constructs for the Romania sample

\begin{tabular}{|l|r|r|l|l|}
\hline $\begin{array}{l}\text { Romania } \\
\text { sample }\end{array}$ & $\begin{array}{l}\text { Consumer } \\
\text { Worldmindedness }\end{array}$ & $\begin{array}{l}\text { Local } \\
\text { identity }\end{array}$ & $\begin{array}{l}\text { National } \\
\text { identity }\end{array}$ & $\begin{array}{l}\text { Consumer } \\
\text { ethnocentrism }\end{array}$ \\
\hline $\begin{array}{l}\text { Consumer } \\
\text { Worldmindedness }\end{array}$ & 0.67 & & & \\
\hline Local identity & -0.26 & 0.73 & & \\
\hline National identity & -0.26 & 0.68 & 0.82 & \\
\hline $\begin{array}{l}\text { Consumer } \\
\text { ethnocentrism }\end{array}$ & -0.13 & 0.43 & 0.37 & 0.91 \\
\hline
\end{tabular}

Note: Diagonal entries are Cronbach's alpha coefficients; all others are correlation coefficients.

\subsection{Covariance models and Correlation results}

The relationship between the different related constructs and consumer xenocentrism was tested using covariance models in AMOS (results in table 9.36) and correlation in SPSS (results in table 9.37). These steps tested the various hypothesized relationships of the related constructs.

Table 9.36 shows the results of the covariance models for the different samples. A covariance model was run for each sample plus combined sample and thus in total five covariance models were run. Overall, the model fit was moderately good for all the samples. 
Table 9.36: Covariance model for all samples

\begin{tabular}{|c|c|c|c|c|c|}
\hline & Combined & Ecuador & India & Kenya & Romania \\
\hline \multicolumn{6}{|c|}{ Covariances between } \\
\hline $\begin{array}{l}\text { Consumer xeno - } \\
\text { Consumer } \\
\text { worldmindedness }\end{array}$ & $0.98^{* *}$ & $0.92^{* *}$ & $0.98^{* *}$ & $0.99 * *$ & $0.92^{* *}$ \\
\hline $\begin{array}{l}\text { Consumer xeno - } \\
\text { National identity }\end{array}$ & -0.03 (NS) & $-0.17 * *$ & $-0.15^{* *}$ & -0.02 (NS) & -0.09 (NS) \\
\hline $\begin{array}{l}\text { Consumer xeno - } \\
\text { Consumer ethno }\end{array}$ & $-0.12 * *$ & $-0.19 * *$ & 0.00 (NS) & $-0.08^{*}$ & $-0.13 * *$ \\
\hline \multicolumn{6}{|l|}{ Fit indices } \\
\hline$\chi 2 / d f$ & 5.99 & 2.20 & 2.60 & 2.35 & 2.34 \\
\hline RMSEA & 0.06 & 0.06 & 0.07 & 0.06 & 0.07 \\
\hline GFI & 0.88 & 0.84 & 0.82 & 0.84 & 0.84 \\
\hline AGFI & 0.86 & 0.81 & 0.79 & 0.81 & 0.81 \\
\hline IFI & 0.88 & 0.88 & 0.85 & 0.86 & 0.88 \\
\hline CFI & 0.88 & 0.88 & 0.85 & 0.86 & 0.88 \\
\hline
\end{tabular}

* Significant at $\mathrm{p}<=0.05$.

** Significant at $\mathrm{p}<=0.01$.

The positive covariance between consumer xenocentrism and consumer worldmindedness was highly significant $(\mathrm{p}<=0.01$ ). This was the case in all the samples. Thus, H10 is supported in all the samples. In other words, consumer xenocentrism is positively related to consumer worldmindedness. Next, consumer xenocentrism and national identity is significantly negatively covaried in Ecuador and India and not in the other two country samples and combined sample. Thus, H13 is significant for two countries and not significant for three samples. Therefore, there is partial support that consumer xenocentrism is negatively related to national identity. It should also be noted that even when the covariance between national identity and consumer xenocentrism was not significant, the direction of relationship between these constructs is negative, as it was predicted. Finally, consumer xenocentrism and consumer ethnocentrism is significantly negatively covaried in all samples except India. Thus, H14 is supported in all samples 
except in India. This result is in-line with that of the extant literature where consumer xenocentrism has been significantly negatively correlated to consumer ethnocentrism.

Table 9.37 shows the correlation between the two factors of consumer xenocentrism and the different related constructs (this also tests the nomological validity for the xenocentrism scale). Except the correlation between the two factors of consumer xenocentrism and consumer ethnocentrism for India which are not significant, all other correlations are significant and in the right direction. All the national identity covariances which were not significant in the covariance model which was discussed previously (results shown in table 9.36), were significant in the correlation in SPSS (results shown in table 9.37). It is likely that the positive effect of foreign admiration and negative effect of domestic rejection factors in consumer xenocentrism were cancelled out in the covariance models. Additionally, the nomological validity for the xenocentrism scale is also confirmed as most of the correlations are significant and in the right direction. 
Table 9.37: Correlation results for all samples

\begin{tabular}{|c|c|c|}
\hline & $\begin{array}{l}\text { Consumer } \\
\text { xenocentris } \\
\text { m - Foreign } \\
\text { admiration }\end{array}$ & \begin{tabular}{|l} 
Consumer \\
xenocentrism \\
Domestic \\
rejection
\end{tabular} \\
\hline \multicolumn{3}{|l|}{$\begin{array}{l}\text { Combined } \\
\text { sample }\end{array}$} \\
\hline $\begin{array}{l}\text { Consumer } \\
\text { Worldmindedness }\end{array}$ & $0.57 * *$ & $0.61 * *$ \\
\hline National identity & $-0.10 * *$ & $-0.24 * *$ \\
\hline $\begin{array}{l}\text { Consumer } \\
\text { ethnocentrism }\end{array}$ & $-0.18 * *$ & $-0.10 * *$ \\
\hline \multicolumn{3}{|l|}{$\begin{array}{l}\text { Ecuador } \\
\text { sample }\end{array}$} \\
\hline $\begin{array}{l}\text { Consumer } \\
\text { Worldmindedness }\end{array}$ & $0.50 * *$ & $0.53^{* *}$ \\
\hline National identity & $-0.20 * *$ & $-0.43^{* *}$ \\
\hline \begin{tabular}{|l} 
Consumer \\
ethnocentrism
\end{tabular} & $-0.34 * *$ & $-0.23^{* *}$ \\
\hline \multicolumn{3}{|l|}{ India sample } \\
\hline $\begin{array}{l}\text { Consumer } \\
\text { Worldmindedness }\end{array}$ & $0.58^{* *}$ & $0.62 * *$ \\
\hline National identity & $-0.14^{*}$ & $-0.43^{* *}$ \\
\hline \begin{tabular}{|l} 
Consumer \\
ethnocentrism
\end{tabular} & -0.07 (NS) & 0.09 (NS) \\
\hline \multicolumn{3}{|l|}{ Kenya sample } \\
\hline \begin{tabular}{|l|} 
Consumer \\
Worldmindedness \\
\end{tabular} & $0.54 * *$ & $0.44 * *$ \\
\hline National identity & $-0.17 * *$ & $-0.17 * *$ \\
\hline $\begin{array}{l}\text { Consumer } \\
\text { ethnocentrism }\end{array}$ & $-0.29 * *$ & $-0.19 * *$ \\
\hline \multicolumn{3}{|l|}{$\begin{array}{l}\text { Romania } \\
\text { sample }\end{array}$} \\
\hline \begin{tabular}{|l|} 
Consumer \\
Worldmindedness
\end{tabular} & $0.48^{* *}$ & $0.55^{* *}$ \\
\hline National identity & $-0.14^{*}$ & $-0.28^{* *}$ \\
\hline $\begin{array}{l}\text { Consumer } \\
\text { ethnocentrism }\end{array}$ & $-0.21 * *$ & $-0.14 *$ \\
\hline
\end{tabular}

Table 9.38 provides a summary of all the related constructs hypotheses results for all of the samples. It can be seen that consumer xenocentrism is significantly and positively related to consumer worldmindedness in all the samples. With ethnocentrism, consumer xenocentrism is significantly, negatively covaried in four samples. And finally, for national identity, consumer xenocentrism is significantly, negatively covaried in just two samples. Thorough discussion of these results will be conducted in the discussion chapter 11 . 
Table 9.38: Summary of related constructs results

\begin{tabular}{|c|c|c|c|c|c|}
\hline Hypotheses & Combined & Ecuador & India & Kenya & Romania \\
\hline $\begin{array}{l}\text { H10: Consumer } \\
\text { xenocentrism will be } \\
\text { positively related to } \\
\text { consumer } \\
\text { worldmindedness. }\end{array}$ & $\checkmark$ & $\checkmark$ & $\checkmark$ & $\checkmark$ & $\checkmark$ \\
\hline $\begin{array}{l}\text { H11: Consumer } \\
\text { xenocentrism will be } \\
\text { positively related to } \\
\text { global identity. }\end{array}$ & Not test & global ide & ale was & table in & context. \\
\hline $\begin{array}{l}\text { H12: Consumer } \\
\text { xenocentrism will be } \\
\text { negatively related to } \\
\text { local identity. }\end{array}$ & \multicolumn{5}{|c|}{$\begin{array}{l}\text { Not tested as local identity and national identy were highly } \\
\text { correlated in our context. }\end{array}$} \\
\hline $\begin{array}{l}\text { H13: Consumer } \\
\text { xenocentrism will be } \\
\text { negatively related to } \\
\text { national identity. }\end{array}$ & $\mathrm{x}$ & $\checkmark$ & $\checkmark$ & $x$ & $\mathrm{x}$ \\
\hline $\begin{array}{l}\text { H14: Consumer } \\
\text { xenocentrism will be } \\
\text { negatively related to } \\
\text { consumer } \\
\text { ethnocentrism. }\end{array}$ & $\checkmark$ & $\checkmark$ & $x$ & $\checkmark$ & $\checkmark$ \\
\hline
\end{tabular}

\subsection{Cluster analysis}

Cluster analysis is a method which splits data into meaningful smaller groups or clusters. Data within a cluster have more commonalities with each other and have more differences with data in other clusters (Everitt, Landau, Leese and Stahl, 2011). Cluster analysis was run using K-means clustering technique. The analysis showed a 4-cluster solution. Table 9.39 shows the grouping of 1306 cases into four clusters. 
Table 9.39: Cluster analysis (mean values)

\begin{tabular}{|r|r|r|r|r|r|r|}
\hline Clusters & Frequency & Percentage & Xenocentrism & Ethnocentrism & National identity & Worldmindedness \\
\hline 1 & 404 & $30.93 \%$ & 3.70 & 3.07 & 6.25 & 3.36 \\
\hline 2 & 341 & $26.11 \%$ & 4.31 & 4.79 & 6.33 & 4.85 \\
\hline 3 & 171 & $13.09 \%$ & 4.23 & 3.26 & 4.35 & 4.38 \\
\hline 4 & 390 & $29.86 \%$ & 2.82 & 4.93 & 6.53 & 2.61 \\
\hline
\end{tabular}

Next, a discriminant analysis was performed to confirm the cluster structure. The cluster numbers were the dependent variable and xenocentrism, ethnocentrism, national identity and worldmindedness were independent variables. Three discriminant functions were produced which explained $57.8 \%, 29.4 \%$ and $12.8 \%$ of the variance. The full model is statistically significant with a Wilks' Lambda of 0.10 at $p<0.01$. Wilks' Lambda determines how satisfactorily the functions splits the cases into clusters (IBM, 2019). Table 9.40 shows the results.

Table 9.40: Results of discriminant analysis

\begin{tabular}{|c|c|c|c|c|}
\hline $\begin{array}{l}\text { Discriminant } \\
\text { function } \\
\end{array}$ & Eigenvalue & $\begin{array}{l}\text { Canonical } \\
\text { correlation }\end{array}$ & $\begin{array}{l}\text { Wilk's } \\
\text { Lambda }\end{array}$ & $\chi^{2}$ significance \\
\hline 1 & 2.13 & 0.83 & 0.10 & 0.00 \\
\hline 2 & 1.09 & 0.72 & 0.33 & 0.00 \\
\hline 3 & 0.47 & 0.57 & 0.68 & 0.00 \\
\hline \multicolumn{5}{|c|}{ Standardized canonical discriminant function coefficients } \\
\hline & & Function 1 & Function 2 & Function 3 \\
\hline \multicolumn{2}{|l|}{ Xenocentrism } & -0.37 & 0.13 & 0.28 \\
\hline \multicolumn{2}{|l|}{ Ethnocentrism } & 0.57 & 0.83 & -0.63 \\
\hline \multicolumn{2}{|c|}{ National Identity } & 1.05 & 0.16 & 1.14 \\
\hline \multicolumn{2}{|c|}{ Worldmindedness } & -0.55 & 0.80 & 0.32 \\
\hline
\end{tabular}

Note: $93.8 \%$ of original grouped cases correctly classified. $93.5 \%$ of cross-validated grouped cases correctly classified.

Table 9.41 shows the predicted group membership. The prediction accuracy for each cluster is shown in the diagonal of the table. Overall, $93.80 \%$ of the original cases 
have been grouped in the correct clusters. Therefore, this prediction level reinforces support for our cluster solution.

Table 9.41: Predicted group membership*

\begin{tabular}{|l|c|c|c|c|c|}
\hline Groups & Number of cases & Cluster 1 & Cluster 2 & Cluster 3 & Cluster 4 \\
\hline Cluster 1 & 404 & $390(96.50 \%)$ & $4(1.00 \%)$ & $5(1.20 \%)$ & $5(1.20 \%)$ \\
\hline Cluster 2 & 341 & $12(3.50 \%)$ & $318(93.30 \%)$ & $1(0.3 \%)$ & $10(2.90 \%)$ \\
\hline Cluster 3 & 171 & $18(10.50 \%)$ & $9(5.30 \%)$ & $144(84.20 \%)$ & $0(0.00 \%)$ \\
\hline Cluster 4 & 390 & $12(3.10 \%)$ & $4(1.00 \%)$ & $1(0.30 \%)$ & $373(95.60 \%)$ \\
\hline
\end{tabular}

* $93.80 \%$ of original grouped cases correctly classified

Finally, the profiling of the clusters was performed to find the commonalities in each group and the differences between the various groups or clusters.

Individuals in cluster 1 dislike both foreign and local products as evidenced by the xenocentrism ( $\overline{\mathrm{x}}: 3.70)$, worldmindedness $(\overline{\mathrm{x}}: 3.36)$ and ethnocentrism $(\overline{\mathrm{x}}: 3.07)$ means. This cluster can be called "Rejects both local and foreign products". This cluster has the greatest number of older respondents aged above 35 (36.77\%) than any other cluster. Individuals in cluster 2 are mostly neutral about being xenocentric $(\overline{\mathrm{x}}: 4.31)$, worldminded $(\overline{\mathrm{x}}: 4.85)$ and ethnocentric $(\overline{\mathrm{x}}: 4.79)$. This cluster gives support to the argument that one can be ethnocentric and xenocentric at the same time and that both these concepts are not polar opposites. This cluster can be called "Buys both local and foreign products". This cluster has the greatest number of males $(30.81 \%)$, younger consumers $(31.77 \%$ of all younger than 35 years old consumers in the sample) and non-professional job holders (27.57\%) than any other cluster. Individuals in cluster 3 are more xenocentric $(\overline{\mathrm{x}}: 4.23)$ and worldminded $(\overline{\mathrm{x}}: 4.38)$ than ethnocentric ( $\overline{\mathrm{x}}: 3.26)$. This cluster can be called "Buys foreign products". This cluster consists of the least number of respondents in every demographic category compared to other clusters and respondents in this cluster come from different demographic 
categories. Finally, individuals in cluster 4 are more ethnocentric $(\overline{\mathrm{x}}: 4.93)$ than xenocentric $(\overline{\mathrm{x}}: 2.82)$ and worldminded ( $\mathrm{x}: 2.61)$. This cluster can be called "Buys local products". These consumers have the greatest number of females $(34.23 \%$ of all females in the sample) and second-greatest number of older respondents (34.61\% of older than 35 years) than any other cluster. This is in-line with the findings in the extant literature with respect to ethnocentric consumers (Cleveland et al., 2009; Sharma et al., 1995). Table 9.42 presents the mean scores for xenocentrism, ethnocentrism, national identity, worldmindedness and the percentage distribution of the demographic variables in each cluster.

Table 9.42: Profile of the different clusters

\begin{tabular}{|l|r|r|r|r|}
\cline { 2 - 5 } \multicolumn{1}{c|}{} & \multicolumn{3}{c|}{ Clusters } \\
\hline Male & $\mathbf{1}$ & $\mathbf{2}$ & $\mathbf{3}$ & $\mathbf{4}$ \\
\hline Female & $28.59 \%$ & $30.81 \%$ & $14.81 \%$ & $25.78 \%$ \\
\hline Age (<35) & $33.44 \%$ & $21.08 \%$ & $11.25 \%$ & $34.23 \%$ \\
\hline Age (>=35) & $25.96 \%$ & $31.77 \%$ & $16.45 \%$ & $25.82 \%$ \\
\hline Occupation (Non-professional) & $36.77 \%$ & $19.47 \%$ & $9.15 \%$ & $34.61 \%$ \\
\hline Occupation (Professional) & $27.27 \%$ & $27.57 \%$ & $18.18 \%$ & $26.98 \%$ \\
\hline Education (Lower) & $32.23 \%$ & $25.60 \%$ & $11.30 \%$ & $30.88 \%$ \\
\hline Education (Higher) & $30.72 \%$ & $24.40 \%$ & $15.66 \%$ & $29.22 \%$ \\
\hline Xenocentrism (mean) & $31.01 \%$ & $26.69 \%$ & $12.22 \%$ & $30.08 \%$ \\
\hline Ethnocentrism (mean) & 3.70 & 4.31 & 4.23 & 2.82 \\
\hline National identity (mean) & 3.07 & 4.79 & 3.26 & 4.93 \\
\hline Worldmindedness (mean) & 6.25 & 6.33 & 4.35 & 6.53 \\
\hline
\end{tabular}

\subsection{Chapter summary}

This chapter presented the analyses of the related constructs to consumer xenocentrism. Specifically, the descriptive analysis and the CFA results for all five related constructs namely consumer worldmindedness, global identity, local identity, national identity and consumer ethnocentrism are reviewed. Furthermore, the discriminant analysis between the related constructs is reviewed. Next, the covariance model and correlation 
results of the related constructs and consumer xenocentrism (which also tests the nomological validity) are examined. As expected, all of the positive foreign orientation constructs share a positive relationship with xenocentrism and all of the negative foreign orientation constructs share a negative relationship with xenocentrism. Consumer worldmindedness is the related construct that is significantly covaried with consumer xenocentrism in all the five samples. Finally, the cluster analysis for the related constructs and consumer xenocentrism was performed and four clusters emerged. There is confirmation for the argument that one can be ethnocentric and xenocentric at the same time. The upcoming chapter will discuss the analysis of the consequences and moderators to consumer xenocentrism. 


\section{CHAPTER TEN - ANALYSIS OF CONSEQUENCES AND MODERATORS}

\subsection{Introduction}

In this chapter, first, the analysis of the structural models for the proposed consequences of consumer xenocentrism are discussed for each sample. Next, the analysis of each of the hypothesized moderator relationships is elaborated.

\subsection{Consequences}

This section tests the hypothesized relationships between consumers xenocentrism and the consequences variables, purchase intention of foreign products from developed countries and ownership of foreign products (or actual purchase) from developed countries. Also, the hypothesized relationship between purchase intention from developed countries to ownership of foreign products from developed countries is tested. In addition to the hypothesized relationships, the same relationships are also tested for the home country and for other developing countries for comparison purposes. The results for each sample are discussed below.

\subsubsection{Consequences - Combined sample}

Table 10.1 shows the results of the structural model for the combined sample. Consumer xenocentrism positively and significantly influences purchase intention from developed countries $(\beta=0.14 ; \mathrm{p}<=0.01)$ and product ownership from developed countries $(\beta=0.25 ; \mathrm{p}<=0.01)$. Thus, $\mathrm{H} 15$ and $\mathrm{H} 16$ are supported for the combined sample. The fit indices are all mostly in the accepted range. However, the variance explained is low for 
purchase intention from developed countries (0.02) but is good for actual purchase from developed countries (0.11).

From the same table, consumer xenocentrism negatively affects the purchase intention and ownership of products from home countries. This is in-line with the definition of consumer xenocentrism which states that consumer xenocentrism is a preference for products from foreign developed countries and rejection of products from the home country. With respect to other developing countries, consumer xenocentrism positively influences purchase intention and has no significance when it comes to ownership of products from those countries.

Consumer xenocentrism was also split into foreign admiration and domestic rejection and tested with the consequences variables (results in table 10.1). It can be seen that foreign admiration positively and significantly influences purchase intention from developed countries and domestic rejection positively and significantly influences product ownership from developed countries. These relationships are in the expected direction. However, domestic rejection negatively and significantly influences purchase intention from developed countries which is counter to the prediction in this thesis. Thus, it looks like the combined consumer xenocentrism model (without splitting into foreign admiration and domestic rejection) is the best model. Additionally, the hypotheses were set at this higher level (i.e. consumer xenocentrism) and not at the individual factors of consumer xenocentrism which are foreign admiration and domestic rejection. The relationships to purchase intention and product ownership from home country and other developing countries are in the correct direction when using the foreign admiration and domestic rejection factors. 
Table 10.1: Structural model for the consequences combined sample

\begin{tabular}{|c|c|c|c|c|c|c|c|c|c|c|c|c|c|}
\hline \begin{tabular}{|l} 
Independent \\
variables
\end{tabular} & $\begin{array}{l}\text { Purchase } \\
\text { intention } \\
\text { from } \\
\text { developed } \\
\text { countries }\end{array}$ & $\begin{array}{l}\text { Product } \\
\text { ownership } \\
\text { from } \\
\text { developed } \\
\text { countries } \\
\end{array}$ & $\begin{array}{l}\text { Purchase } \\
\text { intention } \\
\text { from } \\
\text { home } \\
\text { country } \\
\end{array}$ & $\begin{array}{l}\text { Product } \\
\text { ownership } \\
\text { from } \\
\text { home } \\
\text { country } \\
\end{array}$ & $\begin{array}{l}\text { Purchase } \\
\text { intention } \\
\text { from other } \\
\text { developing } \\
\text { countries }\end{array}$ & $\begin{array}{l}\text { Product } \\
\text { ownership } \\
\text { from other } \\
\text { developing } \\
\text { countries }\end{array}$ & $\begin{array}{l}\text { Independent } \\
\text { variables }\end{array}$ & $\begin{array}{l}\text { Purchase } \\
\text { intention } \\
\text { from } \\
\text { developed } \\
\text { countries }\end{array}$ & \begin{tabular}{|l} 
Product \\
ownership \\
from \\
developed \\
countries \\
\end{tabular} & $\begin{array}{l}\text { Purchase } \\
\text { intention } \\
\text { from } \\
\text { home } \\
\text { country }\end{array}$ & $\begin{array}{l}\text { Product } \\
\text { ownership } \\
\text { from home } \\
\text { country }\end{array}$ & $\begin{array}{l}\text { Purchase } \\
\text { intention } \\
\text { from other } \\
\text { developing } \\
\text { countries }\end{array}$ & $\begin{array}{l}\text { Product } \\
\text { ownership } \\
\text { from other } \\
\text { developing } \\
\text { countries }\end{array}$ \\
\hline $\begin{array}{l}\text { Standardized } \\
\text { coefficients }\end{array}$ & & & & & & & $\begin{array}{l}\text { Standardized } \\
\text { coefficients }\end{array}$ & & & & & & \\
\hline \begin{tabular}{|l} 
Consumer \\
xenocentrism
\end{tabular} & $0.14^{* *}$ & $0.25^{* *}$ & $-0.14^{* *}$ & $-0.23^{* *}$ & $0.10^{* *}$ & 0.03 (NS) & $\begin{array}{l}\text { Consumer } \\
\text { xenocentrism - } \\
\text { Foreign } \\
\text { admiration }\end{array}$ & $0.30^{* *}$ & 0.11 (NS) & 0.09 (NS) & -0.07 (NS) & $0.37^{* *}$ & -0.07 (NS) \\
\hline & & & & & & & $\begin{array}{l}\text { Consumer } \\
\text { xenocentrism - } \\
\text { Domestic } \\
\text { rejection }\end{array}$ & $-0.19 * *$ & $0.14^{*}$ & $-0.22^{* *}$ & $-0.17^{* *}$ & $-0.25^{* *}$ & 0.10 (NS) \\
\hline $\begin{array}{l}\text { Variance } \\
\text { explained }\end{array}$ & 0.02 & 0.11 & 0.02 & 0.06 & 0.01 & 0.00 & $\begin{array}{l}\text { Variance } \\
\text { explained }\end{array}$ & 0.04 & 0.10 & 0.03 & 0.02 & 0.06 & 0.01 \\
\hline Fit indices & & & & & & & Fit indices & & & & & & \\
\hline$\chi 2 / d f$ & \multicolumn{2}{|c|}{5.16} & \multicolumn{2}{|c|}{4.79} & \multicolumn{2}{|c|}{3.67} & $x 2 / d f$ & \multicolumn{2}{|c|}{5.42} & \multicolumn{2}{|c|}{4.92} & \multicolumn{2}{|c|}{3.24} \\
\hline RMSEA & \multicolumn{2}{|c|}{0.06} & \multicolumn{2}{|c|}{0.05} & \multicolumn{2}{|c|}{0.05} & RMSEA & \multicolumn{2}{|c|}{0.06} & \multicolumn{2}{|c|}{0.05} & \multicolumn{2}{|c|}{0.04} \\
\hline GFI & \multicolumn{2}{|c|}{0.94} & \multicolumn{2}{|c|}{0.97} & \multicolumn{2}{|c|}{0.97} & GFI & \multicolumn{2}{|c|}{0.94} & \multicolumn{2}{|c|}{0.98} & \multicolumn{2}{|c|}{0.98} \\
\hline AGFI & \multicolumn{2}{|c|}{0.92} & \multicolumn{2}{|c|}{0.96} & \multicolumn{2}{|c|}{0.96} & AGFI & \multicolumn{2}{|c|}{0.92} & & 0.96 & \multicolumn{2}{|c|}{0.96} \\
\hline IFI & \multicolumn{2}{|c|}{0.92} & \multicolumn{2}{|c|}{0.97} & \multicolumn{2}{|c|}{0.97} & IFI & \multicolumn{2}{|c|}{0.92} & & 0.97 & \multicolumn{2}{|c|}{0.97} \\
\hline $\mathrm{CFI}$ & \multicolumn{2}{|c|}{0.92} & \multicolumn{2}{|c|}{0.97} & \multicolumn{2}{|c|}{0.97} & CFI & \multicolumn{2}{|c|}{0.92} & & 0.97 & \multicolumn{2}{|c|}{0.97} \\
\hline
\end{tabular}

* Significant at $p<=0.05$.

** Significant at $\mathrm{p}<=0.01$. 
The relationship between purchase intention and the product ownership was also tested and the fit indices are mostly within acceptable limits (table 10.2 shows the results). As hypothesized, the purchase intention of developed countries products significantly and positively influences the product ownership from developed countries $(\beta=0.18 ; p<=0.01)$. Thus, H17 is supported. Overall all the three consequences hypotheses, that is, H15, H16 and $\mathrm{H} 17$ are fully supported in the combined sample.

Table 10.2: Relationship between purchase intention to product ownership for the combined sample

\begin{tabular}{|l|c|c|c|}
\hline $\begin{array}{l}\text { Independent } \\
\text { variables }\end{array}$ & \multicolumn{2}{|c|}{ Product ownership } \\
\hline & Developed countries & Home country & Other developing countries \\
\hline $\begin{array}{l}\text { Standardized } \\
\text { coefficients }\end{array}$ & & & \\
\hline $\begin{array}{l}\text { Purchase } \\
\text { intention }\end{array}$ & $0.18^{* *}$ & & \\
\hline Fit indices & & 0.01 (NS) & 0.05 (NS) \\
\hline X2/df & 5.16 & 4.79 & 3.67 \\
\hline RMSEA & 0.06 & 0.05 & 0.05 \\
\hline GFI & 0.94 & 0.97 & 0.97 \\
\hline AGFI & 0.92 & 0.96 & 0.96 \\
\hline IFI & 0.92 & 0.97 & 0.97 \\
\hline CFI & 0.92 & 0.97 & 0.97 \\
\hline
\end{tabular}

As seen in table 10.3, predominantly, the combined sample agrees that they are inclined to purchase products from developed countries as evidenced from the purchase intention mean of 5.30. The purchase intention of home products has a mean of 6.39 which is higher than that of purchase intention of products from developed countries. This could be because people might not necessarily agree openly that they are more inclined to preferring products from developed foreign countries. Furthermore, from the results in table 10.1, consumer xenocentrism positively influenced purchase intention from 
developed countries and negatively influenced purchase intention from the home country. Also, home country purchase intention is measured using only one survey question unlike purchase intention from developed countries which is measured using multiple survey questions. That is, the purchase intention from developed countries was a latent variable in Structural Equation Modeling and purchase intention from Germany, USA, South Korea, Japan and France were its indicators. The purchase intention of products from other developing countries was the lowest with the mean at 4.39.

From the same table, the mean of ownership of products from home country is 4.03 whereas of products from foreign countries is 2.11 . However, from the results in table 10.1, it can be seen that consumer xenocentrism positively influenced ownership of products from developed countries and negatively influenced ownership from the home country. The ownership of products from other developing countries was the lowest with the mean at 0.43 which means that consumers in the sample are reluctant to buy products from other developing countries.

Table 10.3: Purchase intention and product ownership means for the combined sample

\begin{tabular}{|l|r|l|l|}
\hline & $\begin{array}{l}\text { From } \\
\text { developed } \\
\text { countries }\end{array}$ & $\begin{array}{l}\text { From } \\
\text { home } \\
\text { country }\end{array}$ & $\begin{array}{l}\text { From other } \\
\text { developing } \\
\text { countries }\end{array}$ \\
\hline Purchase intention mean & 5.30 & 6.39 & 4.39 \\
\hline Ownership of products mean & 2.11 & 4.03 & 0.43 \\
\hline
\end{tabular}




\subsubsection{Consequences - Ecuador sample}

Table 10.4 shows the results of the structural model for the Ecuador sample. Consumer xenocentrism has no effect on the purchase intention from developed countries although the score is in the predicted direction. However, consumer xenocentrism positively and significantly influences product ownership from developed countries $(\beta=$ $0.27 ; \mathrm{p}<=0.01)$. Thus, $\mathrm{H} 15$ is disproved but H16 is supported for the Ecuador sample. The fit indices are in the recommended range. The variance explained for product ownership from developed countries is good at 0.16 .

From the same table, consumers xenocentrism negatively and significantly impacts the purchase intention and product ownership from the home country. With respect to other developing countries, xenocentrism has no effect on the purchase intention or product ownership from those countries.

Consumer xenocentrism was also split into foreign admiration and domestic rejection and tested with the consequences variables and the results are shown in table 10.4. It can be seen that foreign admiration positively and significantly influences purchase intention from developed countries, as expected. However, domestic rejection negatively and significantly influences purchase intention from developed countries which is counter to the prediction in this thesis. Thus, like in the combined sample, the combined consumer xenocentrism model (without splitting into foreign admiration and domestic rejection) is the best model. The hypotheses were set at this higher level (i.e. consumer xenocentrism) as well. The relationships to purchase intention and product ownership from home country and other developing countries are in the correct direction when using the foreign admiration and domestic rejection factors. 
Table 10.4: Structural model for the consequences Ecuador sample

\begin{tabular}{|c|c|c|c|c|c|c|c|c|c|c|c|c|c|}
\hline $\begin{array}{l}\text { Independent } \\
\text { variables }\end{array}$ & $\begin{array}{l}\text { Purchase } \\
\text { intention } \\
\text { from } \\
\text { developed } \\
\text { countries }\end{array}$ & $\begin{array}{l}\text { Product } \\
\text { ownership } \\
\text { from } \\
\text { developed } \\
\text { countries }\end{array}$ & $\begin{array}{l}\text { Purchase } \\
\text { intention } \\
\text { from } \\
\text { home } \\
\text { country }\end{array}$ & $\begin{array}{l}\text { Product } \\
\text { ownership } \\
\text { from } \\
\text { home } \\
\text { country }\end{array}$ & $\begin{array}{l}\text { Purchase } \\
\text { intention } \\
\text { from other } \\
\text { developing } \\
\text { countries }\end{array}$ & $\begin{array}{l}\text { Product } \\
\text { ownership } \\
\text { from other } \\
\text { developing } \\
\text { countries }\end{array}$ & $\begin{array}{l}\text { Independent } \\
\text { variables }\end{array}$ & $\begin{array}{l}\text { Purchase } \\
\text { intention } \\
\text { from } \\
\text { developed } \\
\text { countries }\end{array}$ & $\begin{array}{l}\text { Product } \\
\text { ownership } \\
\text { from } \\
\text { developed } \\
\text { countries }\end{array}$ & \begin{tabular}{|l} 
Purchase \\
intention \\
from \\
home \\
country
\end{tabular} & $\begin{array}{l}\text { Product } \\
\text { ownership } \\
\text { from home } \\
\text { country }\end{array}$ & $\begin{array}{l}\text { Purchase } \\
\text { intention } \\
\text { from other } \\
\text { developing } \\
\text { countries }\end{array}$ & $\begin{array}{l}\text { Product } \\
\text { ownership } \\
\text { from other } \\
\text { developing } \\
\text { countries }\end{array}$ \\
\hline $\begin{array}{l}\text { Standardized } \\
\text { coefficients }\end{array}$ & & & & & & & $\begin{array}{l}\text { Standardized } \\
\text { coefficients }\end{array}$ & & & & & & \\
\hline $\begin{array}{l}\text { Consumer } \\
\text { xenocentrism }\end{array}$ & 0.11 (NS) & $0.27^{* *}$ & $-0.18^{* *}$ & $-0.24^{* *}$ & -0.06 (NS) & -0.07 (NS) & $\begin{array}{l}\text { Consumer } \\
\text { xenocentrism - } \\
\text { Foreign } \\
\text { admiration }\end{array}$ & $0.28^{* *}$ & 0.14 (NS) & 0.06 (NS) & -0.17 (NS) & 0.17 (NS) & -0.14 (NS) \\
\hline & & & & & & & $\begin{array}{l}\text { Consumer } \\
\text { xenocentrism - } \\
\text { Domestic } \\
\text { rejection }\end{array}$ & $-0.22^{*}$ & 0.13 (NS) & $-0.23^{*}$ & -0.06 (NS) & $-0.22^{*}$ & 0.07 (NS) \\
\hline $\begin{array}{l}\text { Variance } \\
\text { explained }\end{array}$ & 0.01 & 0.16 & 0.03 & 0.06 & 0.00 & 0.00 & $\begin{array}{l}\text { Variance } \\
\text { explained }\end{array}$ & 0.04 & 0.15 & 0.04 & 0.05 & 0.03 & 0.01 \\
\hline Fit indices & & & & & & & Fit indices & & & & & & \\
\hline $\mathrm{x} 2 / \mathrm{df}$ & \multicolumn{2}{|c|}{1.97} & \multicolumn{2}{|c|}{2.35} & \multicolumn{2}{|c|}{2.04} & $x 2 / d f$ & \multicolumn{2}{|c|}{2.03} & \multicolumn{2}{|c|}{2.40} & \multicolumn{2}{|c|}{2.02} \\
\hline RMSEA & \multicolumn{2}{|c|}{0.06} & \multicolumn{2}{|c|}{0.07} & \multicolumn{2}{|c|}{0.06} & RMSEA & \multicolumn{2}{|c|}{0.06} & \multicolumn{2}{|c|}{0.06} & \multicolumn{2}{|c|}{0.05} \\
\hline GFI & \multicolumn{2}{|c|}{0.91} & \multicolumn{2}{|c|}{0.95} & \multicolumn{2}{|c|}{0.94} & GFI & \multicolumn{2}{|c|}{0.90} & \multicolumn{2}{|c|}{0.95} & \multicolumn{2}{|c|}{0.94} \\
\hline AGFI & \multicolumn{2}{|c|}{0.88} & \multicolumn{2}{|c|}{0.91} & \multicolumn{2}{|c|}{0.91} & AGFI & \multicolumn{2}{|c|}{0.88} & \multicolumn{2}{|c|}{0.91} & \multicolumn{2}{|c|}{0.91} \\
\hline IFI & \multicolumn{2}{|c|}{0.93} & \multicolumn{2}{|c|}{0.95} & \multicolumn{2}{|c|}{0.95} & IFI & \multicolumn{2}{|c|}{0.93} & & 0.95 & \multicolumn{2}{|c|}{0.95} \\
\hline $\mathrm{CFI}$ & \multicolumn{2}{|c|}{0.93} & \multicolumn{2}{|c|}{0.95} & \multicolumn{2}{|c|}{0.95} & $\mathrm{CFI}$ & \multicolumn{2}{|c|}{0.92} & & 0.95 & \multicolumn{2}{|c|}{0.95} \\
\hline
\end{tabular}

$*$ Significant at $\mathrm{p}<=0.05$.

$* *$ Significant at $\mathrm{p}<=0.01$. 
The relationship between purchase intention and the product ownership was also tested and the fit indices are in the recommended range (table 10.5 shows the results). The relationship between purchase intention from developed countries and product ownership from developed countries is significant $(\beta=0.27 ; \mathrm{p}<=0.01)$. This is in-line with the hypothesis that purchase intention from developed countries positively and significantly influences product ownership from developed countries. Thus, H17 is supported. Overall, of the three consequences hypotheses, H16 and H17 are fully supported, whereas H15 is not.

Table 10.5: Relationship between purchase intention to product ownership for the Ecuador sample

\begin{tabular}{|c|c|c|c|}
\hline $\begin{array}{l}\text { Independent } \\
\text { variables }\end{array}$ & \multicolumn{3}{|c|}{ Product ownership } \\
\hline & Developed countries & Home country & Other developing countries \\
\hline \multicolumn{4}{|l|}{$\begin{array}{l}\text { Standardized } \\
\text { coefficients }\end{array}$} \\
\hline $\begin{array}{l}\text { Purchase } \\
\text { intention }\end{array}$ & $0.27 * *$ & -0.09 (NS) & $-0.03(\mathrm{NS})$ \\
\hline \multicolumn{4}{|l|}{ Fit indices } \\
\hline $\mathrm{x} 2 / \mathrm{df}$ & 1.97 & 2.35 & 2.04 \\
\hline RMSEA & 0.06 & 0.07 & 0.06 \\
\hline GFI & 0.91 & 0.95 & 0.94 \\
\hline AGFI & 0.88 & 0.91 & 0.91 \\
\hline IFI & 0.93 & 0.95 & 0.95 \\
\hline CFI & 0.93 & 0.95 & 0.95 \\
\hline
\end{tabular}

As seen in table 10.6, for the Ecuador sample, the mean for the purchase intention and ownership of products is higher for the home country than it is for products from developed countries. The mean for purchase intention and ownership of products from other developing countries is the lowest. These results are similar to the results of the combined sample. Although the means for product ownership from developed countries is 
less than that of the home country, it can be seen in the structural model results in table 10.4 that consumer xenocentrism positively influenced ownership of products from developed countries and negatively influenced ownership from the home country.

Table 10.6: Purchase intention and product ownership means for the Ecuador sample

\begin{tabular}{|l|r|l|l|}
\hline & $\begin{array}{l}\text { From } \\
\text { developed } \\
\text { countries }\end{array}$ & $\begin{array}{l}\text { From } \\
\text { home } \\
\text { country }\end{array}$ & $\begin{array}{l}\text { From other } \\
\text { developing } \\
\text { countries }\end{array}$ \\
\hline Purchase intention mean & 4.74 & 6.02 & 4.17 \\
\hline Ownership of products mean & 1.94 & 4.38 & 0.30 \\
\hline
\end{tabular}

\subsubsection{Consequences - India sample}

Table 10.7 shows the results of the structural model for the India sample. Consumer xenocentrism positively and significantly influences purchase intention from developed countries and product ownership from developed countries $(\beta=0.39 ; \mathrm{p}<=0.01 ; \beta=0.31$; $\mathrm{p}<=0.01)$. Thus, $\mathrm{H} 15$ and H16 are supported for the India sample. The fit indices are all mostly in the recommended range. The variance explained is good at 0.15 and 0.13 for purchase intention and product ownership from developed countries, respectively. From the same table, it can be seen that the effect of consumer xenocentrism on purchase intention from the home country is in the expected direction but it is not significant. However, consumer xenocentrism negatively and significantly impacts product ownership from home country. Also, it can be seen that consumer xenocentrism positively impacts the purchase intention and product ownership from other developing countries. The relationship between purchase intention from developed countries to product ownership 
from developed countries is not significant as seen in table 10.8. Overall, the hypotheses $\mathrm{H} 15$ and $\mathrm{H} 16$ are supported while $\mathrm{H} 17$ is not.

Consumer xenocentrism was also split into foreign admiration and domestic rejection and tested with the consequences variables (results in table 10.7). It can be seen that foreign admiration positively and significantly influences purchase intention from developed countries and product ownership from developed countries. These relationships are in the expected direction. However, foreign admiration positively and significantly influences purchase intention from home countries which is opposite to the direction it should be. Thus, it looks like the combined consumer xenocentrism model (without splitting into foreign admiration and domestic rejection) is the best model just like in the combined and Ecuador samples. The relationships to purchase intention and product ownership from other developing countries are in the right direction when using the foreign admiration and domestic rejection factors. 
Table 10.7: Structural model for the consequences India sample

\begin{tabular}{|c|c|c|c|c|c|c|c|c|c|c|c|c|c|}
\hline $\begin{array}{l}\text { Independent } \\
\text { variables }\end{array}$ & $\begin{array}{l}\text { Purchase } \\
\text { intention } \\
\text { from } \\
\text { developed } \\
\text { countries }\end{array}$ & $\begin{array}{l}\text { Product } \\
\text { ownership } \\
\text { from } \\
\text { developed } \\
\text { countries }\end{array}$ & $\begin{array}{l}\text { Purchase } \\
\text { intention } \\
\text { from } \\
\text { home } \\
\text { country }\end{array}$ & \begin{tabular}{|l|} 
Product \\
ownership \\
from \\
home \\
country \\
\end{tabular} & $\begin{array}{l}\text { Purchase } \\
\text { intention } \\
\text { from other } \\
\text { developing } \\
\text { countries }\end{array}$ & $\begin{array}{l}\text { Product } \\
\text { ownership } \\
\text { from other } \\
\text { developing } \\
\text { countries }\end{array}$ & $\begin{array}{l}\text { Independent } \\
\text { variables }\end{array}$ & $\begin{array}{l}\text { Purchase } \\
\text { intention } \\
\text { from } \\
\text { developed } \\
\text { countries }\end{array}$ & $\begin{array}{l}\text { Product } \\
\text { ownership } \\
\text { from } \\
\text { developed } \\
\text { countries }\end{array}$ & $\begin{array}{l}\text { Purchase } \\
\text { intention } \\
\text { from } \\
\text { home } \\
\text { country }\end{array}$ & \begin{tabular}{|l} 
\\
Product \\
ownership \\
from home \\
country
\end{tabular} & $\begin{array}{l}\text { Purchase } \\
\text { intention } \\
\text { from other } \\
\text { developing } \\
\text { countries }\end{array}$ & $\begin{array}{l}\text { Product } \\
\text { ownership } \\
\text { from other } \\
\text { developing } \\
\text { countries }\end{array}$ \\
\hline \begin{tabular}{|l|} 
Standardized \\
coefficients
\end{tabular} & & & & & & & $\begin{array}{l}\text { Standardized } \\
\text { coefficients }\end{array}$ & & & & & & \\
\hline \begin{tabular}{|l|} 
Consumer \\
xenocentrism
\end{tabular} & $0.39 * *$ & $0.31^{* *}$ & -0.03 (NS) & $-0.32 * *$ & $0.41^{* *}$ & $0.16^{*}$ & \begin{tabular}{|l} 
Consumer \\
xenocentrism - \\
Foreign \\
admiration
\end{tabular} & $0.50^{* *}$ & $0.25^{*}$ & $0.24^{*}$ & $-0.28^{* *}$ & $0.45^{* *}$ & 0.06 (NS) \\
\hline & & & & & & & \begin{tabular}{|l} 
Consumer \\
xenocentrism - \\
Domestic \\
rejection
\end{tabular} & -0.17 (NS) & 0.05 (NS) & $-0.28^{*}$ & -0.04 (NS) & -0.07 (NS) & 0.09 (NS) \\
\hline \begin{tabular}{|l} 
Variance \\
explained
\end{tabular} & 0.15 & 0.13 & 0.00 & 0.11 & 0.17 & 0.02 & $\begin{array}{l}\text { Variance } \\
\text { explained }\end{array}$ & 0.15 & 0.12 & 0.04 & 0.10 & 0.17 & 0.02 \\
\hline Fit indices & & & & & & & Fit indices & & & & & & \\
\hline$x 2 / d f$ & \multicolumn{2}{|c|}{2.52} & \multicolumn{2}{|c|}{2.65} & \multicolumn{2}{|c|}{2.16} & $x 2 / d f$ & \multicolumn{2}{|c|}{2.70} & \multicolumn{2}{|r|}{2.55} & \multicolumn{2}{|c|}{2.11} \\
\hline RMSEA & \multicolumn{2}{|c|}{0.07} & \multicolumn{2}{|c|}{0.07} & \multicolumn{2}{|c|}{0.06} & RMSEA & \multicolumn{2}{|c|}{0.07} & \multicolumn{2}{|r|}{0.07} & \multicolumn{2}{|c|}{0.06} \\
\hline GFI & \multicolumn{2}{|c|}{0.88} & \multicolumn{2}{|c|}{0.95} & \multicolumn{2}{|c|}{0.94} & GFI & \multicolumn{2}{|c|}{0.88} & \multicolumn{2}{|r|}{0.95} & \multicolumn{2}{|c|}{0.94} \\
\hline AGFI & \multicolumn{2}{|c|}{0.85} & \multicolumn{2}{|c|}{0.91} & \multicolumn{2}{|c|}{0.91} & AGFI & \multicolumn{2}{|c|}{0.84} & \multicolumn{2}{|r|}{0.91} & \multicolumn{2}{|c|}{0.91} \\
\hline IFI & \multicolumn{2}{|c|}{0.91} & \multicolumn{2}{|c|}{0.94} & \multicolumn{2}{|c|}{0.95} & IFI & \multicolumn{2}{|c|}{0.90} & & 0.95 & \multicolumn{2}{|c|}{0.96} \\
\hline $\mathrm{CFI}$ & \multicolumn{2}{|c|}{0.91} & \multicolumn{2}{|c|}{0.94} & \multicolumn{2}{|c|}{0.95} & CFI & \multicolumn{2}{|c|}{0.90} & & 0.95 & \multicolumn{2}{|c|}{0.96} \\
\hline
\end{tabular}

* Significant at $\mathrm{p}<=0.05$.

** Significant at $\mathrm{p}<=0.01$. 
Table 10.8: Relationship between purchase intention to product ownership for the India sample

\begin{tabular}{|c|c|c|c|}
\hline \multirow[t]{2}{*}{\begin{tabular}{|l|} 
Independent \\
variables \\
\end{tabular}} & \multicolumn{3}{|c|}{ Product ownership } \\
\hline & Developed countries & Home country & Other developing countries \\
\hline \multicolumn{4}{|l|}{$\begin{array}{l}\text { Standardized } \\
\text { coefficients }\end{array}$} \\
\hline $\begin{array}{l}\text { Purchase } \\
\text { intention }\end{array}$ & $0.10(\mathrm{NS})$ & 0.06 (NS) & -0.05 (NS) \\
\hline \multicolumn{4}{|l|}{ Fit indices } \\
\hline$\chi 2 / d f$ & 2.52 & 2.65 & 2.16 \\
\hline RMSEA & 0.07 & 0.07 & 0.06 \\
\hline GFI & 0.88 & 0.95 & 0.94 \\
\hline AGFI & 0.85 & 0.91 & 0.91 \\
\hline $\mathrm{IFI}$ & 0.91 & 0.94 & 0.95 \\
\hline $\mathrm{CFI}$ & 0.91 & 0.94 & 0.95 \\
\hline
\end{tabular}

As seen in table 10.9, like in the previous two samples, the purchase intention mean and ownership of products mean are the highest for the home country and that of developed countries are second highest. However, the structural model results in table 10.7 shows that consumer xenocentrism positively and significantly influences purchase intention and product ownership from developed countries and negatively influences product ownership from home country.

Table 10.9: Purchase intention and product ownership means for the India sample

\begin{tabular}{|l|r|l|l|}
\hline & $\begin{array}{l}\text { From } \\
\text { developed } \\
\text { countries }\end{array}$ & $\begin{array}{l}\text { From } \\
\text { home } \\
\text { country }\end{array}$ & $\begin{array}{l}\text { From other } \\
\text { developing } \\
\text { countries }\end{array}$ \\
\hline Purchase intention mean & 5.54 & 6.60 & 4.88 \\
\hline Ownership of products mean & 2.12 & 3.98 & 0.47 \\
\hline
\end{tabular}




\subsubsection{Consequences - Kenya sample}

Table 10.10 shows the results of the structural model for the Kenya sample. Consumer xenocentrism has a positive and significant effect on purchase intention and product ownership from developed countries $(\beta=0.17 ; \mathrm{p}<=0.05 ; \beta=0.29 ; \mathrm{p}<=0.01)$. Thus, H15 and H16 is supported for the Kenyan sample. The fit indices are in the accepted range. The variance explained for both purchase intention and product ownership from developed countries is moderately low at 0.03 and 0.09 , respectively. From the same table, it can be seen that consumer xenocentrism negatively affects purchase intention and product ownership from the home country. With respect to other developing countries, consumer xenocentrism negatively influences purchase intention and has no effect on product ownership from those countries.

Consumer xenocentrism was also split into foreign admiration and domestic rejection and tested with the consequences variables (results in table 10.10). All significant relationships between foreign admiration and domestic rejection, and the consequences variables, purchase intention and product ownership are in the expected direction. However, some of the relationships (consumer xenocentrism to product ownership from developed countries and consumer xenocentrism to purchase intention from home country) that are significant in the combined consumer xenocentrism model become insignificant in the foreign admiration and domestic rejection model. Thus, the combined consumer xenocentrism model (without splitting into foreign admiration and domestic rejection) is the best model and was the level the hypotheses were set. 
Table 10.10: Structural model for the consequences Kenya sample

\begin{tabular}{|c|c|c|c|c|c|c|c|c|c|c|c|c|c|}
\hline $\begin{array}{l}\text { Independent } \\
\text { variables }\end{array}$ & \begin{tabular}{|l|} 
Purchase \\
intention \\
from \\
developed \\
countries \\
\end{tabular} & $\begin{array}{l}\text { Product } \\
\text { ownership } \\
\text { from } \\
\text { developed } \\
\text { countries } \\
\end{array}$ & \begin{tabular}{|l|} 
Purchase \\
intention \\
from \\
home \\
country \\
\end{tabular} & \begin{tabular}{|l|} 
Product \\
ownership \\
from \\
home \\
country \\
\end{tabular} & \begin{tabular}{|l|} 
Purchase \\
intention \\
from other \\
developing \\
countries \\
\end{tabular} & $\begin{array}{l}\text { Product } \\
\text { ownership } \\
\text { from other } \\
\text { developing } \\
\text { countries }\end{array}$ & $\begin{array}{l}\text { Independent } \\
\text { variables }\end{array}$ & $\begin{array}{l}\text { Purchase } \\
\text { intention } \\
\text { from } \\
\text { developed } \\
\text { countries }\end{array}$ & $\begin{array}{l}\text { Product } \\
\text { ownership } \\
\text { from } \\
\text { developed } \\
\text { countries }\end{array}$ & \begin{tabular}{|l} 
Purchase \\
intention \\
from \\
home \\
country
\end{tabular} & $\begin{array}{l}\text { Product } \\
\text { ownership } \\
\text { from home } \\
\text { country }\end{array}$ & $\begin{array}{l}\text { Purchase } \\
\text { intention } \\
\text { from other } \\
\text { developing } \\
\text { countries }\end{array}$ & $\begin{array}{l}\text { Product } \\
\text { ownership } \\
\text { from other } \\
\text { developing } \\
\text { countries }\end{array}$ \\
\hline \begin{tabular}{|l|} 
Standardized \\
coefficients
\end{tabular} & & & & & & & $\begin{array}{l}\text { Standardized } \\
\text { coefficients }\end{array}$ & & & & & & \\
\hline \begin{tabular}{|l} 
Consumer \\
xenocentrism
\end{tabular} & $0.17^{*}$ & $0.29 * *$ & $-0.24^{* *}$ & $-0.18^{* *}$ & $-0.14^{*}$ & -0.02 (NS) & $\begin{array}{l}\text { Consumer } \\
\text { xenocentrism - } \\
\text { Foreign } \\
\text { admiration } \\
\end{array}$ & $0.63^{* *}$ & 0.40 (NS) & -0.10 (NS) & $-0.31^{*}$ & $0.73^{* *}$ & 0.18 (NS) \\
\hline & & & & & & & $\begin{array}{l}\text { Consumer } \\
\text { xenocentrism - } \\
\text { Domestic } \\
\text { rejection }\end{array}$ & -0.49 (NS) & -0.13 (NS) & -0.15 (NS) & 0.10 (NS) & $-0.76 * *$ & -0.18 (NS) \\
\hline $\begin{array}{l}\text { Variance } \\
\text { explained }\end{array}$ & 0.03 & 0.09 & 0.06 & 0.06 & 0.02 & 0.00 & $\begin{array}{l}\text { Variance } \\
\text { explained }\end{array}$ & 0.10 & 0.09 & 0.06 & 0.09 & 0.19 & 0.01 \\
\hline Fit indices & & & & & & & Fit indices & & & & & & \\
\hline$\times 2 / \mathrm{df}$ & \multicolumn{2}{|c|}{2.05} & \multicolumn{2}{|c|}{1.77} & \multicolumn{2}{|c|}{1.76} & $x 2 / d f$ & \multicolumn{2}{|c|}{1.98} & \multicolumn{2}{|c|}{1.63} & \multicolumn{2}{|c|}{1.60} \\
\hline RMSEA & \multicolumn{2}{|c|}{0.06} & \multicolumn{2}{|c|}{0.05} & \multicolumn{2}{|c|}{0.05} & RMSEA & \multicolumn{2}{|c|}{0.05} & \multicolumn{2}{|c|}{0.04} & \multicolumn{2}{|c|}{0.04} \\
\hline GFI & \multicolumn{2}{|c|}{0.91} & \multicolumn{2}{|c|}{0.96} & \multicolumn{2}{|c|}{0.95} & GFI & \multicolumn{2}{|c|}{0.92} & \multicolumn{2}{|c|}{0.97} & \multicolumn{2}{|c|}{0.96} \\
\hline AGFI & \multicolumn{2}{|c|}{0.89} & \multicolumn{2}{|c|}{0.94} & \multicolumn{2}{|c|}{0.93} & AGFI & \multicolumn{2}{|c|}{0.89} & \multicolumn{2}{|c|}{0.94} & \multicolumn{2}{|c|}{0.93} \\
\hline IFI & \multicolumn{2}{|c|}{0.91} & \multicolumn{2}{|c|}{0.97} & \multicolumn{2}{|c|}{0.96} & IFI & \multicolumn{2}{|c|}{0.91} & \multicolumn{2}{|c|}{0.98} & \multicolumn{2}{|c|}{0.97} \\
\hline $\mathrm{CFI}$ & \multicolumn{2}{|c|}{0.90} & \multicolumn{2}{|c|}{0.97} & \multicolumn{2}{|c|}{0.96} & CFI & \multicolumn{2}{|c|}{0.91} & \multicolumn{2}{|c|}{0.98} & \multicolumn{2}{|c|}{0.97} \\
\hline
\end{tabular}

* Significant at $p<=0.05$.

** Significant at $\mathrm{p}<=0.01$. 
The relationship between purchase intention and the product ownership was also tested and the fit indices are in the recommended range as seen in table 10.11. The relationship between purchase intention of products from developed countries to product ownership was not significant. Thus, H17 is not supported. However, the relationship was significant for the home country. Overall, the consequences hypotheses H15 and H16 were supported while $\mathrm{H} 17$ was not supported for the Kenyan sample.

Table 10.11: Relationship between purchase intention to product ownership for the Kenya sample

\begin{tabular}{|c|c|c|c|}
\hline \multirow[t]{2}{*}{\begin{tabular}{|l|} 
Independent \\
variables \\
\end{tabular}} & \multicolumn{3}{|c|}{ Product ownership } \\
\hline & Developed countries & Home country & Other developing countries \\
\hline \multicolumn{4}{|l|}{$\begin{array}{l}\begin{array}{l}\text { Standardized } \\
\text { coefficients }\end{array} \\
\end{array}$} \\
\hline $\begin{array}{l}\text { Purchase } \\
\text { intention }\end{array}$ & 0.05 (NS) & $0.14^{* *}$ & $0.03(\mathrm{NS})$ \\
\hline \multicolumn{4}{|l|}{ Fit indices } \\
\hline$\chi 2 / d f$ & 2.05 & 1.77 & 1.76 \\
\hline RMSEA & 0.06 & 0.05 & 0.05 \\
\hline GFI & 0.91 & 0.96 & 0.95 \\
\hline AGFI & 0.89 & 0.94 & 0.93 \\
\hline IFI & 0.91 & 0.97 & 0.96 \\
\hline CFI & 0.90 & 0.97 & 0.96 \\
\hline
\end{tabular}

As seen in table 10.12, the purchase intention mean and the ownership of product mean is the highest for the home country whereas the means for developed foreign countries are the second highest and that of other developing countries is the lowest. However, as seen in the previous samples, in the Kenyan sample too, consumer xenocentrism has a positive effect on product purchase intention and product ownership 
from developed countries and a negative effect on purchase intention and product ownership from home countries.

Table 10.12: Purchase intention and product ownership means for the Kenya sample

\begin{tabular}{|l|r|l|l|}
\hline & $\begin{array}{l}\text { From } \\
\text { developed } \\
\text { countries }\end{array}$ & $\begin{array}{l}\text { From } \\
\text { home } \\
\text { country }\end{array}$ & $\begin{array}{l}\text { From other } \\
\text { developing } \\
\text { countries }\end{array}$ \\
\hline Purchase intention mean & 5.52 & 6.47 & 4.45 \\
\hline Ownership of products mean & 2.46 & 3.62 & 0.53 \\
\hline
\end{tabular}

\subsubsection{Consequences - Romania sample}

Table 10.13 shows the results of the structural model with a Romanian sample. Consumer xenocentrism has no effect on purchase intention from developed countries but has a significant positive effect on product ownership from developed countries $(\beta=0.19$; $\mathrm{p}<=0.01)$. Thus, H15 is not supported but H16 is supported for the Romanian sample. The model fit indices are good. The variance for product ownership from developed countries is moderately low at 0.06 . The reason for the moderately low value can be that other factors such as price of the product and income of the consumers may have an effect on product ownership from developed countries.

From the same table, consumer xenocentrism negatively affects the purchase intention and product ownership from the home country. With respect to other developing countries, consumer xenocentrism has no effect on both these constructs. The fit indices for both these models are also good.

Additionally, consumer xenocentrism was split into foreign admiration and domestic rejection and tested with the consequences variables (results in table 10.13). 
Foreign admiration positively and significantly influences purchase intention from developed countries and domestic rejection positively and significantly influences product ownership from developed countries, as expected. However, domestic rejection negatively and significantly influences purchase intention from developed countries which is counter to the prediction in this thesis. Thus, it looks like the combined consumer xenocentrism model (without splitting into foreign admiration and domestic rejection) is the best model. The relationships to purchase intention and product ownership from home country and other developing countries are in the expected direction when using the foreign admiration and domestic rejection factors. 
Table 10.13: Structural model for the consequences Romania sample

\begin{tabular}{|c|c|c|c|c|c|c|c|c|c|c|c|c|c|}
\hline $\begin{array}{l}\text { Independent } \\
\text { variables }\end{array}$ & \begin{tabular}{|l} 
Purchase \\
intention \\
from \\
developed \\
countries
\end{tabular} & \begin{tabular}{|l|} 
Product \\
ownership \\
from \\
developed \\
countries \\
\end{tabular} & \begin{tabular}{|l|} 
Purchase \\
intention \\
from \\
home \\
country
\end{tabular} & $\begin{array}{l}\text { Product } \\
\text { ownership } \\
\text { from } \\
\text { home } \\
\text { country }\end{array}$ & \begin{tabular}{|l|} 
Purchase \\
intention \\
from other \\
developing \\
countries
\end{tabular} & $\begin{array}{l}\text { Product } \\
\text { ownership } \\
\text { from other } \\
\text { developing } \\
\text { countries }\end{array}$ & $\begin{array}{l}\text { Independent } \\
\text { variables }\end{array}$ & $\begin{array}{l}\text { Purchase } \\
\text { intention } \\
\text { from } \\
\text { developed } \\
\text { countries }\end{array}$ & $\begin{array}{l}\text { Product } \\
\text { ownership } \\
\text { from } \\
\text { developed } \\
\text { countries }\end{array}$ & $\begin{array}{l}\text { Purchase } \\
\text { intention } \\
\text { from } \\
\text { home } \\
\text { country }\end{array}$ & $\begin{array}{l}\text { Product } \\
\text { ownership } \\
\text { from home } \\
\text { country }\end{array}$ & $\begin{array}{l}\text { Purchase } \\
\text { intention } \\
\text { from other } \\
\text { developing } \\
\text { countries }\end{array}$ & $\begin{array}{l}\text { Product } \\
\text { ownership } \\
\text { from other } \\
\text { developing } \\
\text { countries }\end{array}$ \\
\hline $\begin{array}{l}\text { Standardized } \\
\text { coefficients }\end{array}$ & & & & & & & $\begin{array}{l}\text { Standardized } \\
\text { coefficients }\end{array}$ & & & & & & \\
\hline $\begin{array}{l}\text { Consumer } \\
\text { xenocentrism }\end{array}$ & 0.02 (NS) & $0.19^{* *}$ & $-0.16^{* *}$ & $-0.21^{* *}$ & -0.06 (NS) & 0.00 (NS) & \begin{tabular}{|l|} 
Consumer \\
xenocentrism - \\
Foreign \\
admiration \\
\end{tabular} & $0.24^{*}$ & -0.05 (NS) & 0.18 (NS) & 0.10 (NS) & 0.14 (NS) & -0.17 (NS) \\
\hline & & & & & & & $\begin{array}{l}\text { Consumer } \\
\text { xenocentrism - } \\
\text { Domestic } \\
\text { rejection }\end{array}$ & $-0.25^{*}$ & $0.24^{*}$ & $-0.33^{*}$ & $-0.29 * *$ & -0.20 (NS) & 0.17 (NS) \\
\hline $\begin{array}{l}\text { Variance } \\
\text { explained }\end{array}$ & 0.00 & 0.06 & 0.03 & 0.06 & 0.00 & 0.03 & $\begin{array}{l}\text { Variance } \\
\text { explained }\end{array}$ & 0.04 & 0.07 & 0.06 & 0.07 & 0.02 & 0.05 \\
\hline Fit indices & & & & & & & Fit indices & & & & & & \\
\hline $\mathrm{x} 2 / \mathrm{df}$ & \multicolumn{2}{|c|}{2.16} & \multicolumn{2}{|c|}{2.26} & \multicolumn{2}{|c|}{1.38} & $\mathrm{x} 2 / \mathrm{df}$ & \multicolumn{2}{|c|}{2.21} & \multicolumn{2}{|r|}{2.17} & \multicolumn{2}{|c|}{1.34} \\
\hline RMSEA & \multicolumn{2}{|c|}{0.06} & \multicolumn{2}{|c|}{0.06} & \multicolumn{2}{|c|}{0.04} & RMSEA & \multicolumn{2}{|c|}{0.06} & & 0.06 & \multicolumn{2}{|c|}{0.03} \\
\hline GFI & \multicolumn{2}{|c|}{0.89} & \multicolumn{2}{|c|}{0.95} & \multicolumn{2}{|c|}{0.96} & GFI & \multicolumn{2}{|c|}{0.89} & & 0.96 & \multicolumn{2}{|c|}{0.96} \\
\hline AGFI & \multicolumn{2}{|c|}{0.86} & \multicolumn{2}{|c|}{0.92} & \multicolumn{2}{|c|}{0.94} & AGFI & \multicolumn{2}{|c|}{0.86} & & 0.92 & \multicolumn{2}{|c|}{0.94} \\
\hline$|F|$ & \multicolumn{2}{|c|}{0.91} & \multicolumn{2}{|c|}{0.96} & \multicolumn{2}{|c|}{0.98} & IFI & \multicolumn{2}{|c|}{0.91} & & 0.96 & \multicolumn{2}{|c|}{0.98} \\
\hline $\mathrm{CFI}$ & \multicolumn{2}{|c|}{0.91} & \multicolumn{2}{|c|}{0.95} & \multicolumn{2}{|c|}{0.98} & $\mathrm{CFI}$ & \multicolumn{2}{|c|}{0.91} & & 0.96 & \multicolumn{2}{|c|}{0.98} \\
\hline
\end{tabular}

* Significant at $p<=0.05$.

*** Significant at $\mathrm{p}<=0.01$. 
The relationship between purchase intention from developed countries to product ownership from developed countries is significant and positive $(\beta=0.15 ; \mathrm{p}<=0.05)$ as seen from table 10.14. Hypothesis H17 is thus supported. Overall, of the three consequences hypotheses, $\mathrm{H} 15$ is not supported but $\mathrm{H} 16$ and $\mathrm{H} 17$ are fully supported in the Romanian sample. The relationship between purchase intention to product ownership from other developing countries is also significant and positive. For home country, the relationship is not significant, but it is in the expected direction.

Table 10.14: Relationship between purchase intention to product ownership for the Romania sample

\begin{tabular}{|l|c|r|r|r|}
\hline $\begin{array}{l}\text { Independent } \\
\text { variables }\end{array}$ & \multicolumn{3}{|c|}{ Product ownership } \\
\hline & Developed countries & Home country & Other developing countries \\
\hline $\begin{array}{l}\text { Standardized } \\
\text { coefficients }\end{array}$ & & & & \\
\hline $\begin{array}{l}\text { Purchase } \\
\text { intention }\end{array}$ & $0.15^{*}$ & & & \\
\hline Fit indices & & 0.10 (NS) & $0.17^{* *}$ & 1.38 \\
\hline X2/df & 2.16 & 2.26 & 0.04 \\
\hline RMSEA & 0.06 & 0.06 & 0.96 \\
\hline GFI & 0.89 & 0.95 & 0.94 \\
\hline AGFI & 0.86 & 0.92 & 0.98 \\
\hline IFI & 0.91 & 0.96 & \\
\hline CFI & 0.91 & 0.95 & \\
\hline
\end{tabular}

As seen in table 10.15, the purchase intention mean and ownership of products mean is higher for the home country than they are for the developed countries. The means are least for the purchase intention and ownership from other developing countries. These results are similar in all the five samples ( 4 country samples +1 combined). However, also as seen earlier, consumer xenocentrism has a positive effect on product ownership from 
developed countries and a negative effect on purchase intention and product ownership from home countries.

Table 10.15: Purchase intention and product ownership means for the Romania sample

\begin{tabular}{|l|r|l|l|}
\hline & $\begin{array}{l}\text { From } \\
\text { developed } \\
\text { countries }\end{array}$ & $\begin{array}{l}\text { From } \\
\text { home } \\
\text { country }\end{array}$ & $\begin{array}{l}\text { From other } \\
\text { developing } \\
\text { countries }\end{array}$ \\
\hline Purchase intention mean & 5.37 & 6.45 & 4.04 \\
\hline Ownership of products mean & 1.90 & 4.15 & 0.42 \\
\hline
\end{tabular}

Summary of the consequences results

Table 10.16 provides the summary of all the consequences hypotheses results for all the samples. These results are for the combined consumer xenocentrism model (without splitting into foreign admiration and domestic rejection) as it was decided that that was the best model. Also, the initial hypotheses were set at that level.

H16 is the hypothesis which is supported in all the samples. That is, consumer xenocentrism significantly and positively influences ownership of products from developed countries in all samples. Except in Ecuador and Romania, consumer xenocentrism positively influences purchase intention of products from developed countries. Additionally, in all samples except India and Kenya, purchase intention of foreign products positively influences ownership of products from developed countries which is in-line with the theory of reasoned action which states that behavioral intention (purchase intention of foreign products, in this case) will influence the behavior (ownership of products from developed countries, in this case). In sum, ownership of foreign products was the most significant consequence of consumer xenocentrism. Also, since purchase intention of foreign products is only significant in two samples and the combined sample, 
it is likely that there is social desirability bias as consumers do not want to accept that they have purchase intention for foreign products but still own those products. Thorough discussion of these results will be conducted in the discussion chapter 11 .

Table 10.16: Summary of consequences results

\begin{tabular}{|l|c|c|c|c|c|}
\hline Hypotheses & Combined & Ecuador & India & Kenya & Romania \\
\hline $\begin{array}{l}\text { H15: Consumer xenocentrism will have } \\
\text { a positive effect on purchase intention } \\
\text { of foreign products. }\end{array}$ & $\checkmark$ & X & $\checkmark$ & $\checkmark$ & X \\
\hline $\begin{array}{l}\text { H16: Consumer xenocentrism will have } \\
\text { a positive effect on ownership of } \\
\text { foreign products. }\end{array}$ & $\checkmark$ & $\checkmark$ & $\checkmark$ & $\checkmark$ & $\checkmark$ \\
\hline $\begin{array}{l}\text { H17: Positive purchase intention of } \\
\text { foreign products will have a positive } \\
\text { effect on ownership of foreign } \\
\text { products. }\end{array}$ & & & & & \\
\hline
\end{tabular}

\subsection{Moderators}

This section tests the hypothesized moderator relationships. The two consequence path relationships along with seven moderator variables, age, education, occupation, gender, global media, international travel and product category symbolism are tested. Tables 10.17 to 10.23 show the results of each moderation path. Hayes PROCESS Macro (PROCESS-Model 1) in SPSS was used to test the moderation effects specified in hypotheses H18-H31. A total of 210 moderator analyses was run using this macro for the seven moderator variables (i.e. thirty analyses for each of the seven moderator variables). The thirty analyses consisted of consumer xenocentrism and the individual consumer xenocentrism factors, foreign admiration and domestic rejection with the consequences, purchase intention of foreign products and ownership of foreign products. 
Most of the hypothesized relationships were not significant. Only four hypothesized relationships were significant, and these relationships are shown in bold in tables 10.17 to 10.19 below.

a.) Age

When age was the moderator, the impact of consumer xenocentrism on ownership of foreign products increased with age for Kenyan sample, as evidenced by zero not lying between the lower and upper levels of confidence intervals in Table 10.17. This result although significant, ran counter to the hypothesized relationship that impact of consumer xenocentrism on ownership of foreign products decreased with age, and thus H19 was not supported. This result can be numerically seen in table 10.17 and illustrated in figure 10.1. When consumer xenocentrism was tested using the foreign admiration and domestic rejection factors, similar effect was found between the domestic rejection and ownership of foreign products for the combined and Kenyan sample (this can be seen in table 10.17. For the sake of parsimony this is not plotted in a graph). The reason for this effect could be because older consumers have more disposable income and thus are able to afford foreign products more than younger consumers. It could also be that younger consumers are more inclined to purchase counterfeits as they are more affordable which would make an interesting future study. 
Table 10.17: Moderation results for age for all samples

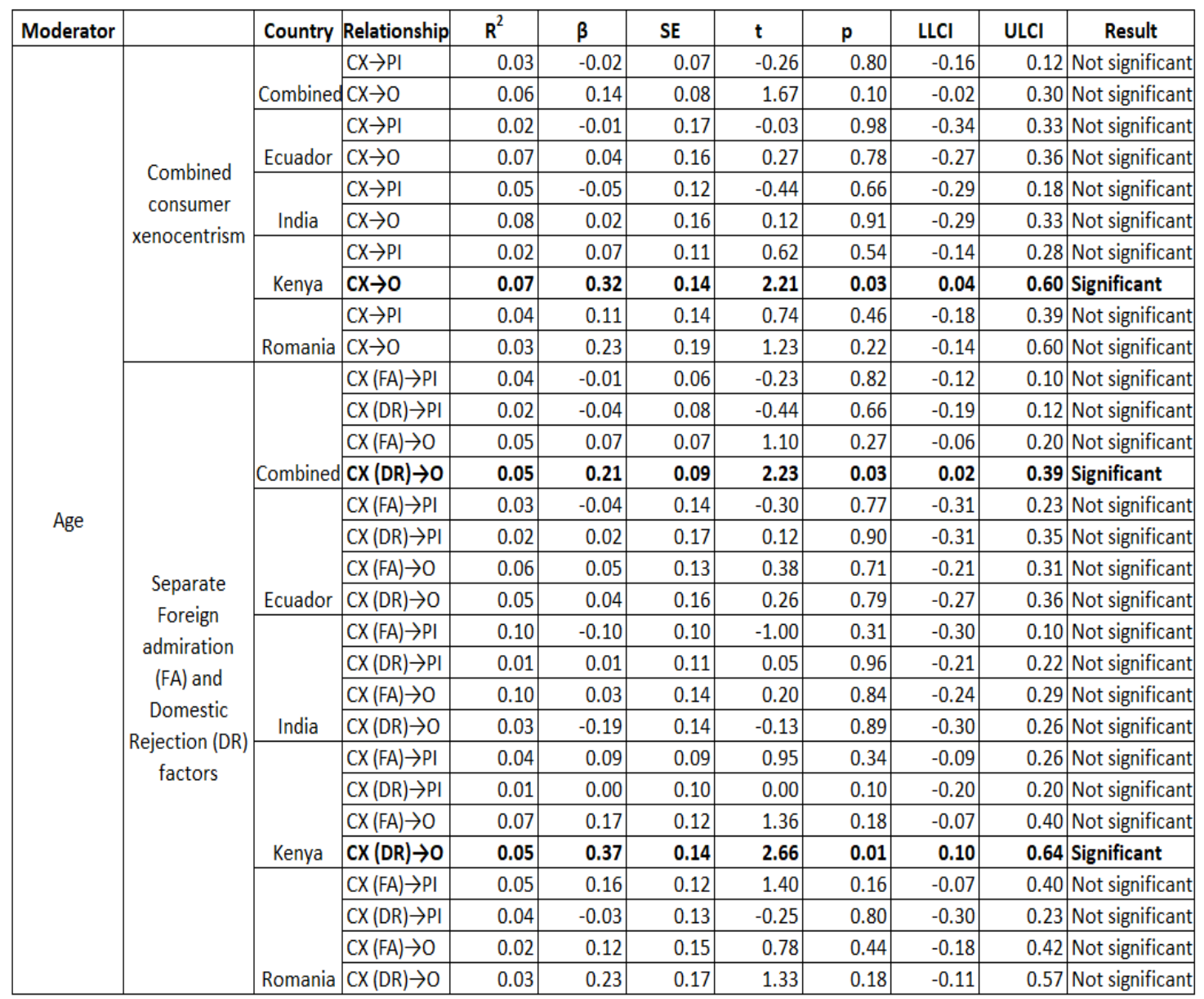

$\mathrm{CX}=$ Consumer xenocentrism; $\mathrm{PI}=$ Purchase intention if foreign products; $\mathrm{O}=$ Ownership of foreign products; $\mathrm{DR}=$ Domestic Rejection; $\mathrm{FA}=$ Foreign Admiration; $\mathrm{LLCl} / \mathrm{ULCl}=$ lower and upper confidence intervals; $\beta=$ Unstandardized coefficients; $S E=$ standard error 
Figure 10.1: Moderating effects of age on the Kenya sample $(\mathrm{CX} \rightarrow \mathrm{O})$

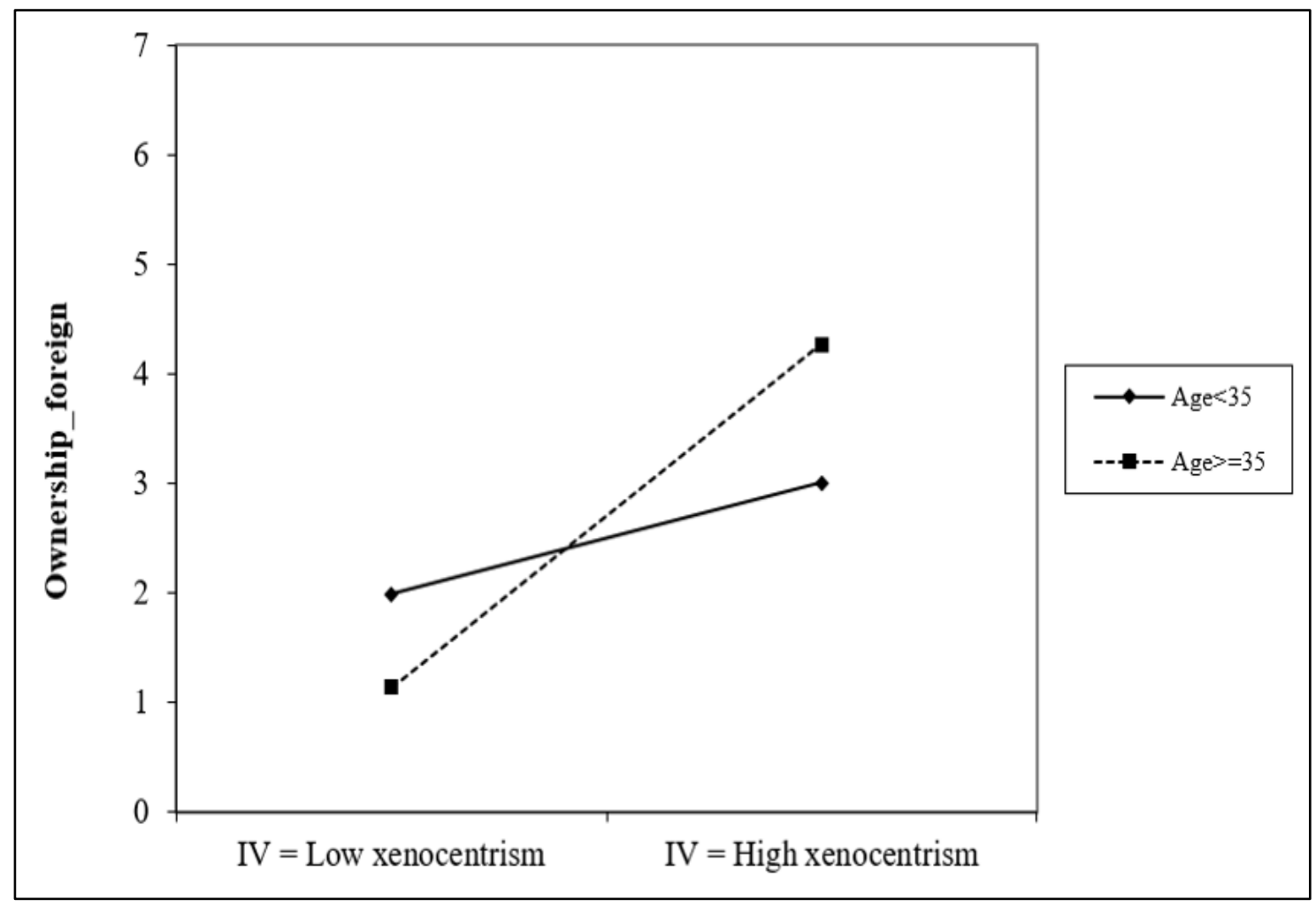

IV = Independent variable

b.) Global media exposure

When global media exposure was the moderator, the impact of consumer xenocentrism on purchase intention of foreign products increased with media exposure for the combined sample, as seen by zero not lying between the lower and upper confidence intervals. Therefore, H26 which states that the impact of consumer xenocentrism on purchase intention of foreign products is moderated by global media exposure so that the relationship is stronger for individuals with higher exposure to global media than for individuals with lower exposure to global media is supported for the combined sample. This result can be seen in table 10.18 and figure 10.2. In other words, those who were highly xenocentric and had high global media exposure, had a stronger foreign product 
purchase intent. When consumer xenocentrism was tested using the foreign admiration and domestic rejection factors, similar effect was found between the domestic rejection and purchase intent of foreign products for the combined sample (this can be seen in table 10.18). Only the significant effect from combined consumer xenocentrism variable (and not the domestic rejection sub-factor) has been plotted in graph 10.2 for simplicity.

Table 10.18: Moderation results for global media exposure for all samples

\begin{tabular}{|c|c|c|c|c|c|c|c|c|c|c|c|}
\hline Moderators & & Country & Relationship & $\mathbf{R}^{2}$ & $\beta$ & SE & $t$ & $p$ & LLCI & ULCI & Result \\
\hline \multirow{30}{*}{$\begin{array}{c}\text { Global } \\
\text { media } \\
\text { exposure }\end{array}$} & \multirow{10}{*}{$\begin{array}{c}\text { Combined } \\
\text { consumer } \\
\text { xenocentrism }\end{array}$} & \multirow[b]{2}{*}{ Combined } & $C X \rightarrow P I$ & 0.05 & 0.06 & 0.02 & 2.50 & 0.01 & 0.01 & 0.10 & Significant \\
\hline & & & $c x \rightarrow 0$ & 0.08 & 0.00 & 0.03 & -0.18 & 0.86 & -0.06 & 0.05 & Not significant \\
\hline & & \multirow[b]{2}{*}{ Ecuador } & $C X \rightarrow P I$ & 0.03 & 0.01 & 0.05 & 0.14 & 0.89 & -0.09 & 0.10 & Not significant \\
\hline & & & $c x \rightarrow 0$ & 0.09 & 0.02 & 0.05 & 0.54 & 0.59 & -0.07 & 0.12 & Not significant \\
\hline & & \multirow[b]{2}{*}{ India } & $C X \rightarrow P I$ & 0.15 & 0.05 & 0.04 & 1.16 & 0.25 & -0.03 & 0.13 & Not significant \\
\hline & & & $c x \rightarrow 0$ & 0.11 & -0.03 & 0.06 & -0.52 & 0.60 & -0.14 & 0.08 & Not significant \\
\hline & & \multirow[b]{2}{*}{ Kenya } & $C X \rightarrow P I$ & 0.02 & 0.02 & 0.04 & 0.43 & 0.67 & -0.06 & 0.10 & Not significant \\
\hline & & & $c x \rightarrow 0$ & 0.07 & -0.06 & 0.05 & -0.95 & 0.34 & -0.16 & 0.05 & Not significant \\
\hline & & \multirow[b]{2}{*}{ Romania } & $C X \rightarrow P I$ & 0.01 & 0.08 & 0.05 & 1.60 & 0.11 & -0.02 & 0.17 & Not significant \\
\hline & & & $c x \rightarrow 0$ & 0.03 & -0.01 & 0.06 & -0.21 & 0.84 & -0.13 & 0.11 & Not significant \\
\hline & \multirow{20}{*}{$\begin{array}{c}\text { Separate } \\
\text { Foreign } \\
\text { admiration } \\
\text { (FA) and } \\
\text { Domestic } \\
\text { Rejection (DR) } \\
\text { factors }\end{array}$} & \multirow[b]{4}{*}{ Combined } & $\mathrm{CX}(\mathrm{FA}) \rightarrow \mathrm{PI}$ & 0.05 & 0.03 & 0.18 & 1.74 & 0.08 & 0.00 & 0.07 & Not significant \\
\hline & & & $C X(D R) \rightarrow P I$ & 0.05 & 0.08 & 0.03 & 3.24 & 0.00 & 0.03 & 0.13 & Significant \\
\hline & & & $C X(F A) \rightarrow 0$ & 0.07 & -0.01 & 0.02 & -0.67 & 0.50 & -0.06 & 0.03 & Not significant \\
\hline & & & $C X(D R) \rightarrow 0$ & 0.08 & 0.02 & 0.03 & 0.65 & 0.51 & -0.04 & 0.08 & Not significant \\
\hline & & \multirow[b]{4}{*}{ Ecuador } & $C X(F A) \rightarrow P I$ & 0.04 & -0.01 & 0.04 & -0.20 & 0.84 & -0.88 & 0.07 & Not significant \\
\hline & & & $\mathrm{CX}(\mathrm{DR}) \rightarrow \mathrm{PI}$ & 0.04 & 0.03 & 0.05 & 0.66 & 0.51 & -0.07 & 0.13 & Not significant \\
\hline & & & $C X(F A) \rightarrow 0$ & 0.08 & -0.03 & 0.04 & -0.67 & 0.51 & -0.10 & 0.05 & Not significant \\
\hline & & & $C X(D R) \rightarrow 0$ & 0.09 & 0.09 & 0.05 & 1.95 & 0.05 & 0.00 & 0.18 & Not significant \\
\hline & & \multirow[b]{4}{*}{ India } & $C X(F A) \rightarrow P I$ & 0.16 & 0.00 & 0.03 & -0.13 & 0.90 & -0.07 & 0.06 & Not significant \\
\hline & & & $C X(D R) \rightarrow P I$ & 0.14 & 0.07 & 0.04 & 1.97 & 0.05 & 0.00 & 0.14 & Not significant \\
\hline & & & $C X(F A) \rightarrow 0$ & 0.12 & -0.03 & 0.05 & -0.65 & 0.51 & -0.13 & 0.06 & Not significant \\
\hline & & & $C X(D R) \rightarrow 0$ & 0.09 & -0.02 & 0.05 & -0.42 & 0.68 & -0.12 & 0.08 & Not significant \\
\hline & & \multirow[b]{4}{*}{ Kenya } & $C X(F A) \rightarrow P I$ & 0.03 & -0.01 & 0.03 & -0.27 & 0.79 & -0.08 & 0.06 & Not significant \\
\hline & & & $\mathrm{CX}(\mathrm{DR}) \rightarrow \mathrm{PI}$ & 0.01 & 0.04 & 0.04 & 1.12 & 0.26 & -0.03 & 0.11 & Not significant \\
\hline & & & $C X(F A) \rightarrow 0$ & 0.08 & -0.04 & 0.05 & -0.80 & 0.42 & -0.13 & 0.06 & Not significant \\
\hline & & & $C X(D R) \rightarrow 0$ & 0.04 & -0.04 & 0.05 & -0.86 & 0.39 & -0.14 & 0.06 & Not significant \\
\hline & & \multirow[b]{4}{*}{ Romania } & $C X(F A) \rightarrow P I$ & 0.01 & 0.06 & 0.04 & 1.49 & 0.14 & -0.02 & 0.13 & Not significant \\
\hline & & & $\mathrm{CX}(\mathrm{DR}) \rightarrow \mathrm{PI}$ & 0.02 & 0.06 & 0.04 & 1.43 & 0.15 & -0.02 & 0.15 & Not significant \\
\hline & & & $C X(F A) \rightarrow 0$ & 0.02 & -0.03 & 0.05 & -0.59 & 0.56 & -0.13 & 0.07 & Not significant \\
\hline & & & $C X(D R) \rightarrow 0$ & 0.03 & 0.02 & 0.06 & 0.39 & 0.70 & -0.89 & 0.13 & Not significant \\
\hline
\end{tabular}


Figure 10.2: Moderating effects of global media exposure on the combined sample (CX $\rightarrow \mathrm{PI})$

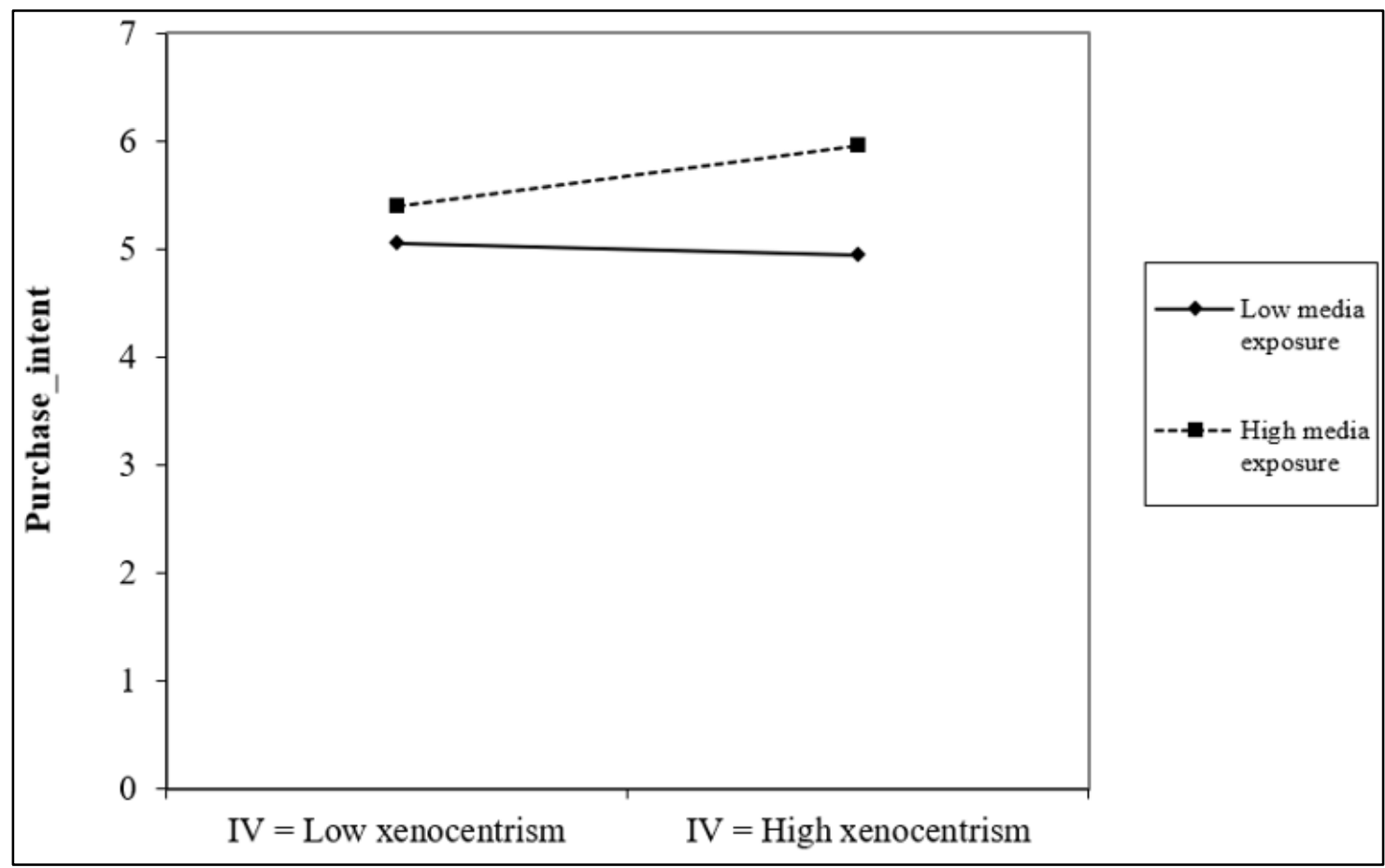

c.) Product category symbolism

For India and the combined sample, when product category symbolism was the moderator, the impact of consumer xenocentrism on purchase intention of foreign products is moderated by product category symbolism so that the relationship is stronger for product categories that contribute to one's identity (mobile phones) than for product categories that do not (bath soap). This is evidenced by zero not lying between the lower and upper levels of confidence intervals. Thus, H30 which states that the impact of consumer xenocentrism on purchase intention of foreign products is moderated by product category symbolism so that the relationship is stronger for product categories that contribute to one's identity than for other product categories, is supported for the combined and Indian samples. These results can be seen in table 10.19 and in figures 10.3 and 10.4. For the combined sample, 
these results can be seen for the separate xenocentrism factors, domestic rejection and foreign admiration as well (in table 10.19). It can also be seen from figure 10.3 for low product category symbolism, as xenocentrism increases, purchase intent decreases.

Table 10.19: Moderation results for product category symbolism for all samples

\begin{tabular}{|c|c|c|c|c|c|c|c|c|c|c|c|}
\hline Moderators & & Country & Relationship & $\mathbf{R}^{2}$ & $\beta$ & SE & $t$ & $p$ & LLCI & ULCI & Result \\
\hline \multirow{30}{*}{$\begin{array}{c}\text { Product } \\
\text { category } \\
\text { symbolism }\end{array}$} & \multirow{10}{*}{$\begin{array}{c}\text { Combined } \\
\text { consumer } \\
\text { xenocentrism }\end{array}$} & \multirow[b]{2}{*}{ Combined } & $\mathrm{CX} \rightarrow \mathrm{PI}$ & 0.03 & 0.07 & 0.02 & 3.24 & 0.00 & 0.03 & 0.12 & Significant \\
\hline & & & $C X \rightarrow 0$ & 0.06 & 0.00 & 0.03 & -0.06 & 0.95 & -0.05 & 0.05 & Not significant \\
\hline & & \multirow[b]{2}{*}{ Ecuador } & $C X \rightarrow P I$ & 0.01 & -0.14 & 0.13 & -1.12 & 0.26 & -0.40 & 0.11 & Not significant \\
\hline & & & $C X \rightarrow 0$ & 0.07 & -0.15 & 0.12 & -1.28 & 0.20 & -0.39 & 0.08 & Not significant \\
\hline & & \multirow[b]{2}{*}{ India } & $C X \rightarrow P I$ & 0.06 & 0.21 & 0.10 & 2.09 & 0.04 & 0.01 & 0.40 & Significant \\
\hline & & & $c x \rightarrow 0$ & 0.09 & 0.20 & 0.13 & 1.51 & 0.13 & -0.06 & 0.46 & Not significant \\
\hline & & \multirow[b]{2}{*}{ Kenya } & $C X \rightarrow P I$ & 0.02 & 0.04 & 0.09 & 0.51 & 0.61 & -0.13 & 0.22 & Not significant \\
\hline & & & $C X \rightarrow 0$ & 0.08 & -0.10 & 0.12 & -0.83 & 0.41 & -0.33 & 0.14 & Not significant \\
\hline & & \multirow[b]{2}{*}{ Romania } & $C X \rightarrow P I$ & 0.05 & -0.08 & 0.12 & -0.67 & 0.50 & -0.31 & 0.15 & Not significant \\
\hline & & & $c x \rightarrow 0$ & 0.03 & 0.17 & 0.15 & 1.13 & 0.26 & -0.13 & 0.48 & Not significant \\
\hline & \multirow{20}{*}{$\begin{array}{c}\text { Separate } \\
\text { Foreign } \\
\text { admiration } \\
\text { (FA) and } \\
\text { Domestic } \\
\text { Rejection (DR) } \\
\text { factors }\end{array}$} & \multirow[b]{4}{*}{ Combined } & $\mathrm{CX}(\mathrm{FA}) \rightarrow \mathrm{PI}$ & 0.04 & 0.06 & 0.02 & 3.42 & 0.00 & 0.03 & 0.10 & Significant \\
\hline & & & $C X(D R) \rightarrow P I$ & 0.03 & 0.08 & 0.03 & 2.96 & 0.00 & 0.03 & 0.13 & Significant \\
\hline & & & $\mathrm{CX}(\mathrm{FA}) \rightarrow 0$ & 0.05 & 0.01 & 0.02 & 0.26 & 0.80 & -0.04 & 0.05 & Not significant \\
\hline & & & $C X(D R) \rightarrow 0$ & 0.05 & -0.02 & 0.03 & -0.73 & 0.47 & -0.08 & 0.04 & Not significant \\
\hline & & \multirow[b]{4}{*}{ Ecuador } & $\mathrm{CX}(\mathrm{FA}) \rightarrow \mathrm{PI}$ & 0.02 & -0.15 & 0.11 & -1.39 & 0.16 & -0.36 & 0.06 & Not significant \\
\hline & & & $\mathrm{CX}(\mathrm{DR}) \rightarrow \mathrm{PI}$ & 0.01 & -0.08 & 0.13 & -0.61 & 0.54 & -0.33 & 0.18 & Not significant \\
\hline & & & $C X(F A) \rightarrow 0$ & 0.06 & -0.11 & 0.10 & -1.14 & 0.26 & -0.31 & 0.08 & Not significant \\
\hline & & & $C X(D R) \rightarrow 0$ & 0.05 & -0.11 & 0.12 & -0.91 & 0.37 & -0.35 & 0.13 & Not significant \\
\hline & & \multirow[b]{4}{*}{ India } & $\mathrm{CX}(\mathrm{FA}) \rightarrow \mathrm{PI}$ & 0.11 & 0.11 & 0.07 & 1.52 & 0.13 & -0.03 & 0.26 & Not significant \\
\hline & & & $\mathrm{CX}(\mathrm{DR}) \rightarrow \mathrm{PI}$ & 0.01 & 0.07 & 0.08 & 0.88 & 0.38 & -0.09 & 0.24 & Not significant \\
\hline & & & $\mathrm{CX}(\mathrm{FA}) \rightarrow 0$ & 0.10 & 0.02 & 0.10 & 0.18 & 0.85 & -0.18 & 0.21 & Not significant \\
\hline & & & $C X(D R) \rightarrow 0$ & 0.04 & 0.15 & 0.11 & 1.33 & 0.18 & -0.07 & 0.37 & Not significant \\
\hline & & \multirow[b]{4}{*}{ Kenya } & $C X(F A) \rightarrow P I$ & 0.04 & 0.06 & 0.07 & 0.74 & 0.46 & -0.09 & 0.20 & Not significant \\
\hline & & & $\mathrm{CX}(\mathrm{DR}) \rightarrow \mathrm{PI}$ & 0.01 & 0.02 & 0.08 & 0.23 & 0.82 & -0.14 & 0.18 & Not significant \\
\hline & & & $\mathrm{CX}(\mathrm{FA}) \rightarrow 0$ & 0.08 & -0.01 & 0.10 & -0.14 & 0.89 & -0.21 & 0.18 & Not significant \\
\hline & & & $C X(D R) \rightarrow 0$ & 0.05 & -0.13 & 0.11 & -1.19 & 0.23 & -0.35 & 0.09 & Not significant \\
\hline & & \multirow[b]{4}{*}{ Romania } & $\mathrm{CX}(\mathrm{FA}) \rightarrow \mathrm{PI}$ & 0.04 & -0.04 & 0.09 & -0.42 & 0.67 & -0.22 & 0.14 & Not significant \\
\hline & & & $\mathrm{CX}(\mathrm{DR}) \rightarrow \mathrm{PI}$ & 0.05 & -0.06 & 0.10 & -0.63 & 0.53 & -0.27 & 0.14 & Not significant \\
\hline & & & $\mathrm{CX}(\mathrm{FA}) \rightarrow 0$ & 0.02 & 0.14 & 0.12 & 1.16 & 0.25 & -0.10 & 0.38 & Not significant \\
\hline & & & $C X(D R) \rightarrow 0$ & 0.02 & 0.10 & 0.13 & 0.77 & 0.44 & -0.16 & 0.37 & Not significant \\
\hline
\end{tabular}


Figure 10.3: Moderating effects of product category symbolism on the combined sample $(\mathrm{CX} \rightarrow \mathrm{PI})$

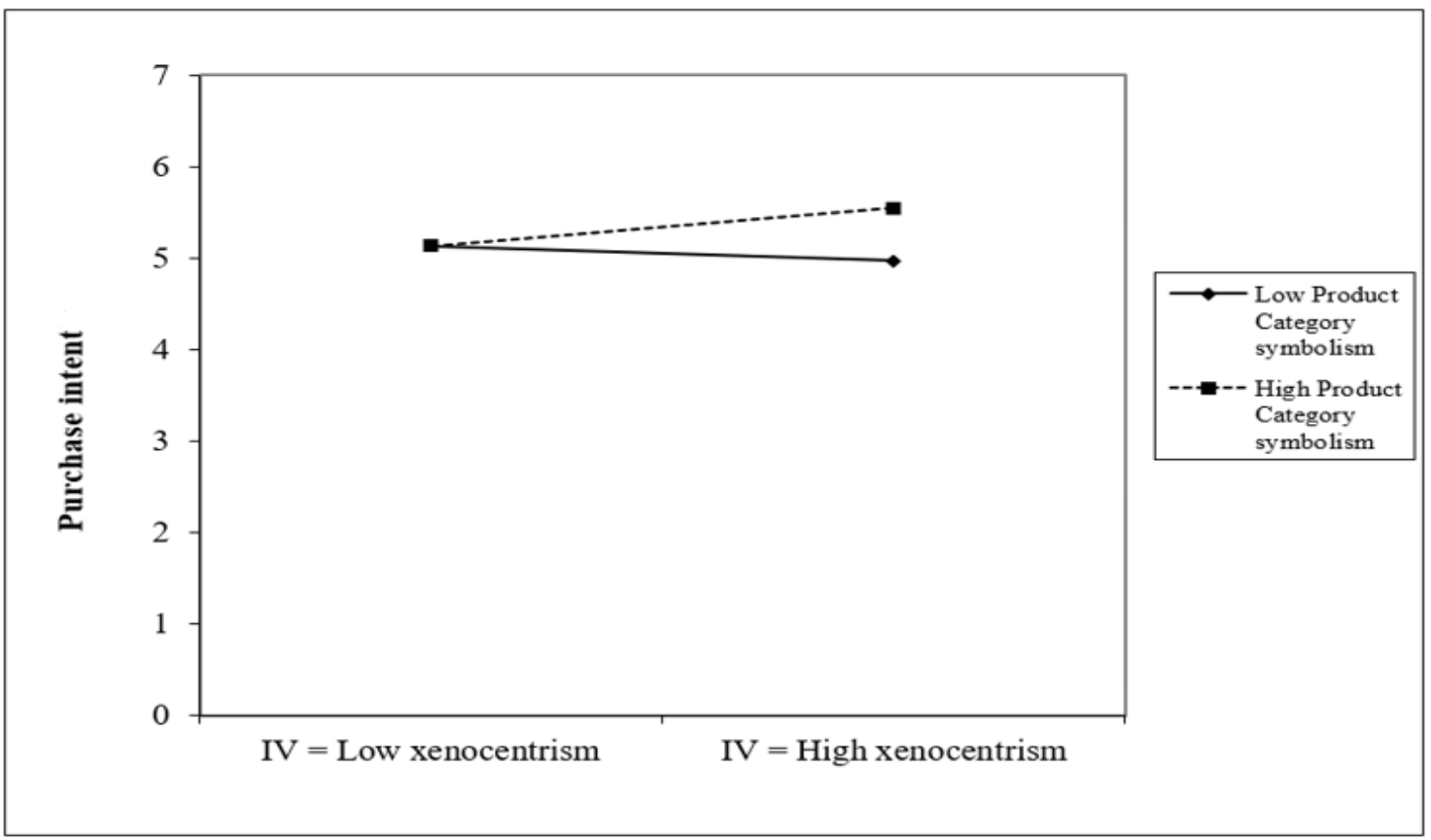

Figure 10.4: Moderating effects of product category symbolism on the India sample (CX $\rightarrow$ PI)

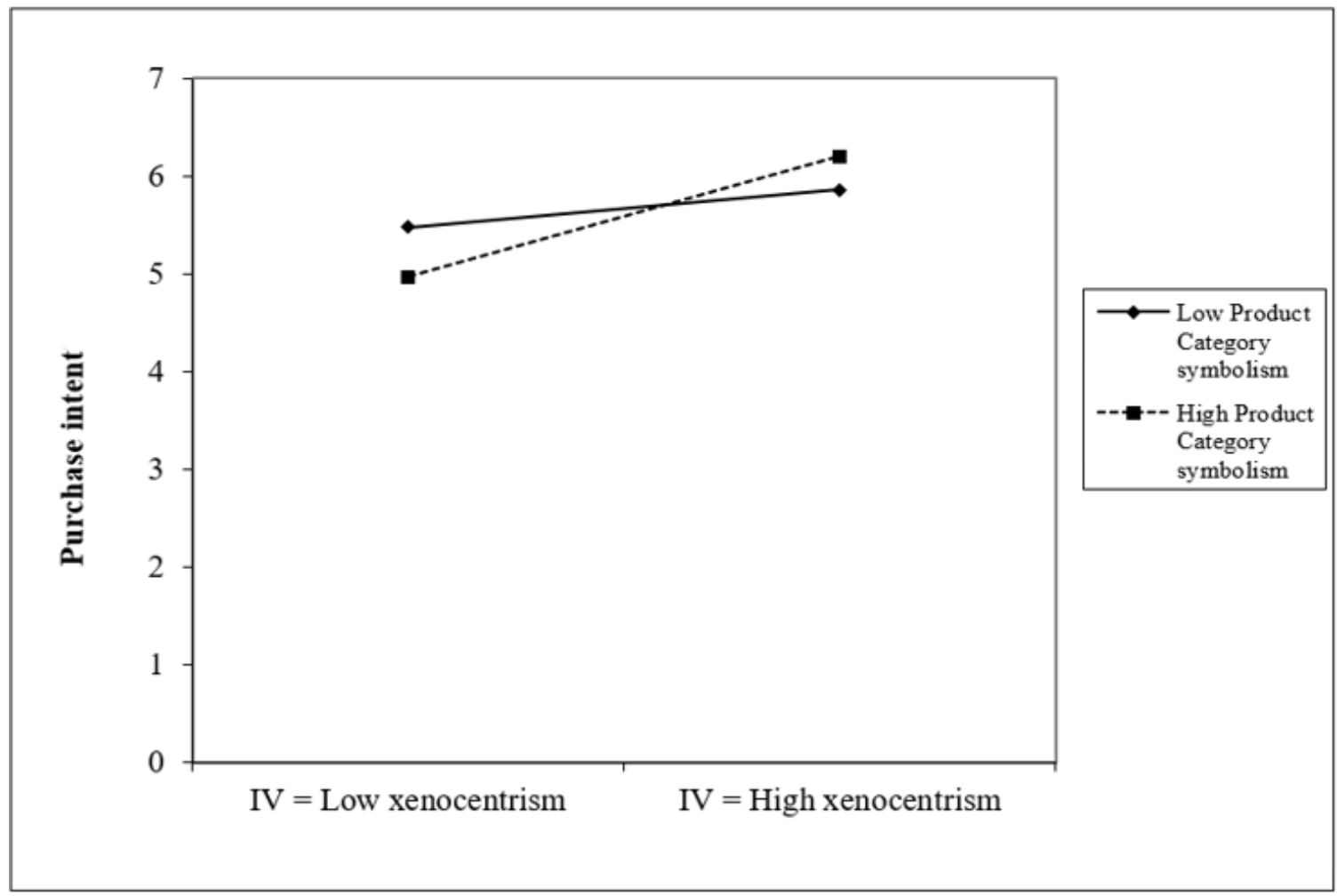


d.) Other hypothesized moderators

When international travel was the moderator, the impact of the domestic rejection factor on purchase intention of foreign products increased with international travel for the combined sample, as seen by zero not lying between the lower and upper confidence intervals. Therefore, $\mathrm{H} 28$ which states that the impact of consumer xenocentrism on purchase intention of foreign products is moderated by international travel experience/preference so that the relationship is stronger for individuals with higher frequency and interest in international travel than for individuals with lower frequency and interest in international travel is only partially supported. That is, it is supported only for the domestic rejection factor of consumer xenocentrism. This result can be seen in table 10.20 .

Table 10.20: Moderation results for international travel for all samples

\begin{tabular}{|c|c|c|c|c|c|c|c|c|c|c|c|}
\hline Moderators & & Country & Relationship & $\mathbf{R}^{2}$ & $\beta$ & SE & $\mathbf{t}$ & $\mathbf{p}$ & LLCI & ULCI & Result \\
\hline \multirow{30}{*}{$\begin{array}{c}\text { International } \\
\text { Travel }\end{array}$} & \multirow{10}{*}{$\begin{array}{c}\text { Combined } \\
\text { consumer } \\
\text { xenocentrism }\end{array}$} & \multirow[b]{2}{*}{ Combined } & $C X \rightarrow P I$ & 0.06 & 0.06 & 0.03 & 2.14 & 0.03 & 0.00 & 0.11 & Not significant \\
\hline & & & $c x \rightarrow O$ & 0.07 & -0.13 & 0.03 & -0.41 & 0.68 & -0.08 & 0.05 & Not significant \\
\hline & & \multirow[b]{2}{*}{ Ecuador } & $\mathrm{CX} \rightarrow \mathrm{PI}$ & 0.02 & 0.01 & 0.06 & 0.18 & 0.86 & -0.11 & 0.14 & Not significant \\
\hline & & & $c x \rightarrow O$ & 0.07 & 0.06 & 0.06 & 1.04 & 0.30 & -0.05 & 0.18 & Not significant \\
\hline & & \multirow[b]{2}{*}{ India } & $C X \rightarrow P I$ & 0.08 & 0.06 & 0.06 & 0.97 & 0.33 & -0.06 & 0.18 & Not significant \\
\hline & & & $c x \rightarrow 0$ & 0.10 & -0.15 & 0.08 & -1.84 & 0.06 & -0.32 & 0.01 & Not significant \\
\hline & & \multirow[b]{2}{*}{ Kenya } & $C X \rightarrow P I$ & 0.06 & -0.03 & 0.04 & -0.71 & 0.47 & -0.12 & 0.06 & Not significant \\
\hline & & & $c X \rightarrow 0$ & 0.06 & -0.06 & 0.06 & -1.01 & 0.31 & -0.18 & 0.06 & Not significant \\
\hline & & \multirow[b]{2}{*}{ Romania } & $C X \rightarrow P I$ & 0.06 & 0.10 & 0.05 & 1.81 & 0.07 & 0.00 & 0.21 & Not significant \\
\hline & & & $c x \rightarrow 0$ & 0.07 & 0.03 & 0.07 & 0.42 & 0.67 & -0.11 & 0.17 & Not significant \\
\hline & \multirow{20}{*}{\begin{tabular}{|c|} 
Separate \\
Foreign \\
admiration \\
(FA) and \\
Domestic \\
Rejection (DR) \\
factors
\end{tabular}} & \multirow[b]{4}{*}{ Combined } & $\mathrm{CX}(\mathrm{FA}) \rightarrow \mathrm{PI}$ & 0.06 & 0.04 & 0.02 & 1.66 & 0.10 & -0.01 & 0.08 & Not significant \\
\hline & & & $\mathrm{CX}(\mathrm{DR}) \rightarrow \mathrm{PI}$ & 0.06 & 0.09 & 0.03 & 2.74 & 0.01 & 0.03 & 0.15 & Significant \\
\hline & & & $\mathrm{CX}(\mathrm{FA}) \rightarrow \mathrm{O}$ & 0.06 & -0.01 & 0.03 & -0.42 & 0.68 & -0.06 & 0.04 & Not significant \\
\hline & & & $\mathrm{CX}(\mathrm{DR}) \rightarrow \mathrm{O}$ & 0.07 & -0.01 & 0.04 & -0.36 & 0.72 & -0.09 & 0.06 & Not significant \\
\hline & & \multirow[b]{4}{*}{ Ecuador } & $\mathrm{CX}(\mathrm{FA}) \rightarrow \mathrm{PI}$ & 0.02 & 0.00 & 0.05 & 0.13 & 0.89 & -0.10 & 0.11 & Not significant \\
\hline & & & $\mathrm{CX}(\mathrm{DR}) \rightarrow \mathrm{PI}$ & 0.03 & 0.06 & 0.07 & 0.79 & 0.43 & -0.08 & 0.20 & Not significant \\
\hline & & & $\mathrm{CX}(\mathrm{FA}) \rightarrow \mathrm{O}$ & 0.07 & 0.04 & 0.05 & 0.72 & 0.47 & -0.06 & 0.14 & Not significant \\
\hline & & & $\mathrm{CX}(\mathrm{DR}) \rightarrow \mathrm{O}$ & 0.07 & 0.03 & 0.07 & 0.42 & 0.68 & -0.10 & 0.16 & Not significant \\
\hline & & \multirow[b]{4}{*}{ India } & $\mathrm{CX}(\mathrm{FA}) \rightarrow \mathrm{PI}$ & 0.11 & 0.04 & 0.05 & 0.72 & 0.47 & -0.06 & 0.14 & Not significant \\
\hline & & & $\mathrm{CX}(\mathrm{DR}) \rightarrow \mathrm{PI}$ & 0.07 & 0.09 & 0.06 & 1.53 & 0.13 & -0.03 & 0.21 & Not significant \\
\hline & & & $C X(F A) \rightarrow O$ & 0.13 & -0.05 & 0.07 & -0.67 & 0.50 & -0.18 & 0.09 & Not significant \\
\hline & & & $\mathrm{CX}(\mathrm{DR}) \rightarrow \mathrm{O}$ & 0.11 & -0.03 & 0.08 & -0.31 & 0.75 & -0.18 & 0.13 & Not significant \\
\hline & & \multirow[b]{4}{*}{ Kenya } & $\mathrm{CX}(\mathrm{FA}) \rightarrow \mathrm{PI}$ & 0.09 & -0.03 & 0.04 & -0.67 & 0.50 & -0.11 & 0.05 & Not significant \\
\hline & & & $\mathrm{CX}(\mathrm{DR}) \rightarrow \mathrm{PI}$ & 0.09 & -0.05 & 0.05 & -0.93 & 0.35 & -0.15 & 0.05 & Not significant \\
\hline & & & $\mathrm{CX}(\mathrm{FA}) \rightarrow \mathrm{O}$ & 0.08 & 0.01 & 0.06 & 0.17 & 0.87 & -0.10 & 0.12 & Not significant \\
\hline & & & $\mathrm{CX}(\mathrm{DR}) \rightarrow \mathrm{O}$ & 0.05 & 0.05 & 0.07 & 0.64 & 0.52 & -0.10 & 0.19 & Not significant \\
\hline & & \multirow[b]{4}{*}{ Romania } & $C X(F A) \rightarrow P I$ & 0.08 & 0.08 & 0.05 & 1.79 & 0.07 & -0.01 & 0.17 & Not significant \\
\hline & & & $\mathrm{CX}(\mathrm{DR}) \rightarrow \mathrm{PI}$ & 0.09 & 0.11 & 0.06 & 2.07 & 0.04 & 0.01 & 0.22 & Not significant \\
\hline & & & $C X(F A) \rightarrow O$ & 0.09 & 0.05 & 0.06 & 0.88 & 0.38 & -0.06 & 0.17 & Not significant \\
\hline & & & $C X(D R) \rightarrow O$ & 0.10 & 0.07 & 0.07 & 0.93 & 0.35 & -0.07 & 0.20 & Not significant \\
\hline
\end{tabular}


Lastly, tables $10.21,10.22$ and 10.23 show the moderation results when gender, education and occupation are moderators. In these scenarios, none of the hypotheses are supported.

Table 10.21: Moderation results for gender for all samples

\begin{tabular}{|c|c|c|c|c|c|c|c|c|c|c|c|}
\hline Moderators & & Country & Relationship & $\mathbf{R}^{2}$ & $\beta$ & SE & $\mathbf{t}$ & $p$ & LLCI & ULCI & Result \\
\hline \multirow{30}{*}{ Gender } & \multirow{10}{*}{$\begin{array}{c}\text { Combined } \\
\text { consumer } \\
\text { xenocentrism }\end{array}$} & \multirow[b]{2}{*}{ Combined } & $C X \rightarrow P I$ & 0.01 & 0.00 & 0.07 & -0.03 & 0.98 & -0.14 & 0.14 & Not significant \\
\hline & & & $c x \rightarrow 0$ & 0.06 & -0.09 & 0.08 & -1.08 & 0.28 & -0.25 & 0.07 & Not significant \\
\hline & & \multirow[b]{2}{*}{ Ecuador } & $C X \rightarrow P I$ & 0.00 & -0.01 & 0.17 & -0.07 & 0.94 & -0.35 & 0.32 & Not significant \\
\hline & & & $c x \rightarrow 0$ & 0.06 & 0.05 & 0.16 & 0.34 & 0.73 & -0.26 & 0.36 & Not significant \\
\hline & & \multirow[b]{2}{*}{ India } & $C X \rightarrow P I$ & 0.05 & 0.03 & 0.12 & 0.21 & 0.83 & -0.22 & 0.27 & Not significant \\
\hline & & & $c x \rightarrow 0$ & 0.09 & -0.05 & 0.16 & -0.30 & 0.76 & -0.37 & 0.27 & Not significant \\
\hline & & \multirow[b]{2}{*}{ Kenya } & $C X \rightarrow P I$ & 0.04 & 0.04 & 0.10 & 0.40 & 0.69 & -0.16 & 0.25 & Not significant \\
\hline & & & $c x \rightarrow 0$ & 0.07 & -0.10 & 0.14 & -0.74 & 0.46 & -0.38 & 0.17 & Not significant \\
\hline & & \multirow[b]{2}{*}{ Romania } & $C X \rightarrow P I$ & 0.01 & 0.03 & 0.15 & 0.20 & 0.84 & -0.26 & 0.32 & Not significant \\
\hline & & & $c x \rightarrow 0$ & 0.03 & -0.26 & 0.19 & -1.40 & 0.16 & -0.62 & 0.11 & Not significant \\
\hline & \multirow{20}{*}{$\begin{array}{c}\text { Separate } \\
\text { Foreign } \\
\text { admiration } \\
\text { (FA) and } \\
\text { Domestic } \\
\text { Rejection (DR) } \\
\text { factors }\end{array}$} & \multirow[b]{4}{*}{ Combined } & $\mathrm{CX}(\mathrm{FA}) \rightarrow \mathrm{PI}$ & 0.02 & -0.02 & 0.06 & -0.40 & 0.69 & -0.13 & 0.09 & Not significant \\
\hline & & & $\mathrm{CX}(\mathrm{DR}) \rightarrow \mathrm{PI}$ & 0.01 & 0.04 & 0.08 & 0.47 & 0.64 & -0.12 & 0.19 & Not significant \\
\hline & & & $\mathrm{CX}(\mathrm{FA}) \rightarrow \mathrm{O}$ & 0.05 & -0.08 & 0.06 & -1.20 & 0.23 & -0.20 & 0.05 & Not significant \\
\hline & & & $C X(D R) \rightarrow O$ & 0.05 & -0.06 & 0.09 & -0.64 & 0.52 & -0.24 & 0.12 & Not significant \\
\hline & & \multirow[b]{4}{*}{ Ecuador } & $\mathrm{CX}(\mathrm{FA}) \rightarrow \mathrm{PI}$ & 0.01 & -0.06 & 0.14 & -0.45 & 0.66 & -0.34 & 0.22 & Not significant \\
\hline & & & $\mathrm{CX}(\mathrm{DR}) \rightarrow \mathrm{PI}$ & 0.00 & 0.02 & 0.17 & 0.14 & 0.89 & -0.31 & 0.35 & Not significant \\
\hline & & & $C X(F A) \rightarrow 0$ & 0.06 & 0.10 & 0.13 & 0.77 & 0.44 & -0.16 & 0.36 & Not significant \\
\hline & & & $C X(D R) \rightarrow O$ & 0.05 & -0.02 & 0.16 & -0.15 & 0.88 & -0.33 & 0.28 & Not significant \\
\hline & & \multirow[b]{4}{*}{ India } & $\mathrm{CX}(\mathrm{FA}) \rightarrow \mathrm{PI}$ & 0.10 & -0.07 & 0.10 & -0.66 & 0.51 & -0.27 & 0.13 & Not significant \\
\hline & & & $\mathrm{CX}(\mathrm{DR}) \rightarrow \mathrm{PI}$ & 0.01 & 0.15 & 0.11 & 1.39 & 0.17 & -0.06 & 0.37 & Not significant \\
\hline & & & $\mathrm{CX}(\mathrm{FA}) \rightarrow \mathrm{O}$ & 0.10 & -0.06 & 0.14 & -0.44 & 0.66 & -0.34 & 0.21 & Not significant \\
\hline & & & $C X(D R) \rightarrow O$ & 0.03 & 0.06 & 0.15 & 0.42 & 0.68 & -0.23 & 0.35 & Not significant \\
\hline & & \multirow[b]{4}{*}{ Kenya } & $\mathrm{CX}(\mathrm{FA}) \rightarrow \mathrm{PI}$ & 0.05 & 0.00 & 0.09 & -0.05 & 0.96 & -0.18 & 0.17 & Not significant \\
\hline & & & $\mathrm{CX}(\mathrm{DR}) \rightarrow \mathrm{PI}$ & 0.03 & 0.06 & 0.10 & 0.59 & 0.56 & -0.14 & 0.25 & Not significant \\
\hline & & & $\mathrm{CX}(\mathrm{FA}) \rightarrow \mathrm{O}$ & 0.07 & -0.08 & 0.12 & -0.66 & 0.51 & -0.32 & 0.16 & Not significant \\
\hline & & & $C X(D R) \rightarrow O$ & 0.04 & -0.13 & 0.14 & -0.96 & 0.34 & -0.40 & 0.14 & Not significant \\
\hline & & \multirow[b]{4}{*}{ Romania } & $\mathrm{CX}(\mathrm{FA}) \rightarrow \mathrm{PI}$ & 0.01 & 0.00 & 0.12 & -0.03 & 0.97 & -0.24 & 0.23 & Not significant \\
\hline & & & $C X(D R) \rightarrow P I$ & 0.02 & 0.05 & 0.13 & 0.34 & 0.73 & -0.22 & 0.31 & Not significant \\
\hline & & & $\mathrm{CX}(\mathrm{FA}) \rightarrow \mathrm{O}$ & 0.03 & -0.29 & 0.15 & -1.89 & 0.06 & -0.59 & 0.11 & Not significant \\
\hline & & & $C X(D R) \rightarrow O$ & 0.02 & -0.07 & 0.17 & -0.38 & 0.70 & -0.41 & 0.27 & Not significant \\
\hline
\end{tabular}


Table 10.22: Moderation results for education for all samples

\begin{tabular}{|c|c|c|c|c|c|c|c|c|c|c|c|}
\hline Moderators & & Country & Relationship & $\mathbf{R}^{2}$ & $\beta$ & SE & $\mathbf{t}$ & $\mathbf{p}$ & LLCI & ULCI & Result \\
\hline \multirow{30}{*}{ Education } & \multirow{10}{*}{$\begin{array}{c}\text { Combined } \\
\text { consumer } \\
\text { xenocentrism }\end{array}$} & \multirow[b]{2}{*}{ Combined } & $C X \rightarrow P I$ & 0.03 & 0.04 & 0.08 & 0.49 & 0.62 & -0.12 & 0.20 & Not significant \\
\hline & & & $c x \rightarrow 0$ & 0.07 & 0.00 & 0.09 & 0.03 & 0.98 & -0.18 & 0.19 & Not significant \\
\hline & & \multirow[b]{2}{*}{ Ecuador } & $C X \rightarrow P I$ & 0.01 & -0.08 & 0.18 & -0.43 & 0.67 & -0.43 & 0.27 & Not significant \\
\hline & & & $c x \rightarrow 0$ & 0.08 & -0.15 & 0.16 & -0.90 & 0.37 & -0.47 & 0.18 & Not significant \\
\hline & & \multirow[b]{2}{*}{ India } & $C X \rightarrow P I$ & 0.06 & 0.11 & 0.20 & 0.54 & 0.59 & -0.29 & 0.51 & Not significant \\
\hline & & & $C X \rightarrow O$ & 0.10 & -0.06 & 0.27 & -0.24 & 0.81 & -0.59 & 0.46 & Not significant \\
\hline & & \multirow[b]{2}{*}{ Kenya } & $C X \rightarrow P I$ & 0.02 & -0.06 & 0.11 & -0.57 & 0.57 & -0.28 & 0.16 & Not significant \\
\hline & & & $c x \rightarrow 0$ & 0.08 & -0.07 & 0.15 & -0.48 & 0.63 & -0.36 & 0.22 & Not significant \\
\hline & & \multirow[b]{2}{*}{ Romania } & $C X \rightarrow P I$ & 0.01 & 0.18 & 0.16 & 1.07 & 0.28 & -0.15 & 0.50 & Not significant \\
\hline & & & $c x \rightarrow O$ & 0.03 & 0.35 & 0.21 & 1.69 & 0.09 & -0.06 & 0.77 & Not significant \\
\hline & \multirow{20}{*}{$\begin{array}{c}\text { Separate } \\
\text { Foreign } \\
\text { admiration } \\
\text { (FA) and } \\
\text { Domestic } \\
\text { Rejection (DR) } \\
\text { factors }\end{array}$} & \multirow[b]{4}{*}{ Combined } & $\mathrm{CX}(\mathrm{FA}) \rightarrow \mathrm{PI}$ & 0.04 & 0.01 & 0.06 & 0.18 & 0.86 & -0.11 & 0.13 & Not significant \\
\hline & & & $\mathrm{CX}(\mathrm{DR}) \rightarrow \mathrm{PI}$ & 0.02 & 0.09 & 0.09 & 0.97 & 0.33 & -0.09 & 0.27 & Not significant \\
\hline & & & $\mathrm{CX}(\mathrm{FA}) \rightarrow \mathrm{O}$ & 0.06 & 0.00 & 0.07 & 0.05 & 0.96 & -0.14 & 0.15 & Not significant \\
\hline & & & $C X(D R) \rightarrow O$ & 0.06 & 0.02 & 0.11 & 0.18 & 0.86 & -0.19 & 0.23 & Not significant \\
\hline & & \multirow[b]{4}{*}{ Ecuador } & $\mathrm{CX}(\mathrm{FA}) \rightarrow \mathrm{PI}$ & 0.02 & -0.06 & 0.15 & -0.41 & 0.68 & -0.35 & 0.23 & Not significant \\
\hline & & & $\mathrm{CX}(\mathrm{DR}) \rightarrow \mathrm{PI}$ & 0.01 & -0.06 & 0.18 & -0.32 & 0.75 & -0.40 & 0.29 & Not significant \\
\hline & & & $\mathrm{CX}(\mathrm{FA}) \rightarrow \mathrm{O}$ & 0.07 & -0.10 & 0.14 & -0.72 & 0.47 & -0.37 & 0.17 & Not significant \\
\hline & & & $C X(D R) \rightarrow O$ & 0.06 & -0.13 & 0.16 & -0.81 & 0.42 & -0.45 & 0.19 & Not significant \\
\hline & & \multirow[b]{4}{*}{ India } & $\mathrm{CX}(\mathrm{FA}) \rightarrow \mathrm{PI}$ & 0.10 & -0.06 & 0.16 & -0.39 & 0.70 & -0.39 & 0.26 & Not significant \\
\hline & & & $\mathrm{CX}(\mathrm{DR}) \rightarrow \mathrm{PI}$ & 0.02 & 0.25 & 0.17 & 1.43 & 0.15 & -0.09 & 0.58 & Not significant \\
\hline & & & $\mathrm{CX}(\mathrm{FA}) \rightarrow \mathrm{O}$ & 0.11 & -0.03 & 0.22 & -0.12 & 0.91 & -0.46 & 0.41 & Not significant \\
\hline & & & $C X(D R) \rightarrow O$ & 0.05 & -0.01 & 0.23 & -0.63 & 0.95 & -0.47 & 0.44 & Not significant \\
\hline & & \multirow[b]{4}{*}{ Kenya } & $\mathrm{CX}(\mathrm{FA}) \rightarrow \mathrm{PI}$ & 0.04 & -0.12 & 0.09 & -1.24 & 0.21 & -0.30 & 0.07 & Not significant \\
\hline & & & $\mathrm{CX}(\mathrm{DR}) \rightarrow \mathrm{PI}$ & 0.01 & 0.05 & 0.11 & 0.47 & 0.64 & -0.16 & 0.26 & Not significant \\
\hline & & & $\mathrm{CX}(\mathrm{FA}) \rightarrow \mathrm{O}$ & 0.09 & -0.06 & 0.12 & -0.46 & 0.65 & -0.31 & 0.19 & Not significant \\
\hline & & & $C X(D R) \rightarrow O$ & 0.05 & -0.02 & 0.14 & -0.17 & 0.86 & -0.31 & 0.26 & Not significant \\
\hline & & \multirow[b]{4}{*}{ Romania } & $\mathrm{CX}(\mathrm{FA}) \rightarrow \mathrm{PI}$ & 0.02 & 0.14 & 0.13 & 1.08 & 0.28 & -0.12 & 0.40 & Not significant \\
\hline & & & $\mathrm{CX}(\mathrm{DR}) \rightarrow \mathrm{PI}$ & 0.02 & 0.12 & 0.15 & 0.78 & 0.44 & -0.18 & 0.42 & Not significant \\
\hline & & & $\mathrm{CX}(\mathrm{FA}) \rightarrow \mathrm{O}$ & 0.02 & 0.23 & 0.17 & 1.34 & 0.18 & -0.11 & 0.56 & Not significant \\
\hline & & & $C X(D R) \rightarrow O$ & 0.03 & 0.32 & 0.19 & 1.65 & 0.10 & -0.06 & 0.70 & Not significant \\
\hline
\end{tabular}

Table 10.23: Moderation results for occupation for all samples

\begin{tabular}{|c|c|c|c|c|c|c|c|c|c|c|c|}
\hline Moderators & & Country & Relationship & $\mathbf{R}^{2}$ & $\beta$ & SE & $\mathbf{t}$ & $\mathbf{p}$ & LLCI & ULCI & Result \\
\hline \multirow{30}{*}{ Occupation } & \multirow{10}{*}{$\begin{array}{c}\text { Combined } \\
\text { consumer } \\
\text { xenocentrism }\end{array}$} & \multirow[b]{2}{*}{ Combined } & $\mathrm{CX} \rightarrow \mathrm{PI}$ & 0.04 & -0.05 & 0.08 & -0.59 & 0.56 & -0.21 & 0.11 & Not significant \\
\hline & & & $C X \rightarrow O$ & 0.07 & -0.02 & 0.10 & -0.25 & 0.81 & -0.21 & 0.16 & Not significant \\
\hline & & \multirow[b]{2}{*}{ Ecuador } & $C X \rightarrow P I$ & 0.03 & 0.16 & 0.18 & 0.87 & 0.39 & -0.20 & 0.51 & Not significant \\
\hline & & & $C x \rightarrow O$ & 0.08 & 0.23 & 0.17 & 1.38 & 0.17 & -0.10 & 0.56 & Not significant \\
\hline & & \multirow[b]{2}{*}{ India } & $C X \rightarrow P I$ & 0.09 & 0.02 & 0.16 & 0.10 & 0.92 & -0.29 & 0.33 & Not significant \\
\hline & & & $C X \rightarrow O$ & 0.12 & 0.06 & 0.21 & 0.27 & 0.79 & -0.36 & 0.47 & Not significant \\
\hline & & \multirow{2}{*}{ Kenya } & $C X \rightarrow P I$ & 0.01 & -0.15 & 0.12 & -1.17 & 0.24 & -0.39 & 0.10 & Not significant \\
\hline & & & $C X \rightarrow O$ & 0.07 & -0.08 & 0.17 & -0.49 & 0.63 & -0.41 & 0.25 & Not significant \\
\hline & & \multirow[b]{2}{*}{ Romania } & $C X \rightarrow P I$ & 0.02 & 0.06 & 0.15 & 0.38 & 0.70 & -0.24 & 0.36 & Not significant \\
\hline & & & $C x \rightarrow O$ & 0.02 & -0.14 & 0.20 & -0.69 & 0.49 & -0.53 & 0.25 & Not significant \\
\hline & \multirow{20}{*}{$\begin{array}{c}\text { Separate } \\
\text { Foreign } \\
\text { admiration } \\
\text { (FA) and } \\
\text { Domestic } \\
\text { Rejection (DR) } \\
\text { factors }\end{array}$} & \multirow[b]{4}{*}{ Combined } & $\mathrm{CX}(\mathrm{FA}) \rightarrow \mathrm{PI}$ & 0.05 & -0.01 & 0.06 & -0.22 & 0.82 & -0.14 & 0.11 & Not significant \\
\hline & & & $C X(D R) \rightarrow P I$ & 0.03 & -0.09 & 0.09 & -1.05 & 0.29 & -0.27 & 0.08 & Not significant \\
\hline & & & $C X(F A) \rightarrow 0$ & 0.06 & 0.00 & 0.08 & -0.01 & 0.99 & -0.15 & 0.15 & Not significant \\
\hline & & & $C X(D R) \rightarrow O$ & 0.06 & -0.08 & 0.11 & -0.75 & 0.45 & -0.28 & 0.13 & Not significant \\
\hline & & \multirow[b]{4}{*}{ Ecuador } & $\mathrm{CX}(\mathrm{FA}) \rightarrow \mathrm{PI}$ & 0.03 & 0.17 & 0.15 & 1.17 & 0.24 & -0.12 & 0.47 & Not significant \\
\hline & & & $C X(D R) \rightarrow P I$ & 0.02 & 0.05 & 0.17 & 0.30 & 0.76 & -0.29 & 0.40 & Not significant \\
\hline & & & $\mathrm{CX}(\mathrm{FA}) \rightarrow \mathrm{O}$ & 0.07 & 0.15 & 0.14 & 1.11 & 0.27 & -0.12 & 0.43 & Not significant \\
\hline & & & $C X(D R) \rightarrow O$ & 0.07 & 0.18 & 0.16 & 1.09 & 0.28 & -0.14 & 0.50 & Not significant \\
\hline & & \multirow[b]{4}{*}{ India } & $\mathrm{CX}(\mathrm{FA}) \rightarrow \mathrm{PI}$ & 0.13 & 0.11 & 0.13 & 0.81 & 0.41 & -0.15 & 0.36 & Not significant \\
\hline & & & $\mathrm{CX}(\mathrm{DR}) \rightarrow \mathrm{PI}$ & 0.06 & -0.10 & 0.13 & -0.74 & 0.46 & -0.36 & 0.16 & Not significant \\
\hline & & & $\mathrm{CX}(\mathrm{FA}) \rightarrow \mathrm{O}$ & 0.13 & 0.09 & 0.17 & 0.50 & 0.62 & -0.26 & 0.44 & Not significant \\
\hline & & & $C X(D R) \rightarrow O$ & 0.08 & -0.04 & 0.18 & -0.23 & 0.82 & -0.40 & 0.31 & Not significant \\
\hline & & \multirow[b]{4}{*}{ Kenya } & $\mathrm{CX}(\mathrm{FA}) \rightarrow \mathrm{PI}$ & 0.03 & -0.12 & 0.11 & -1.18 & 0.24 & -0.33 & 0.08 & Not significant \\
\hline & & & $\mathrm{CX}(\mathrm{DR}) \rightarrow \mathrm{PI}$ & 0.01 & -0.10 & 0.12 & -0.90 & 0.37 & -0.34 & 0.13 & Not significant \\
\hline & & & $\mathrm{CX}(\mathrm{FA}) \rightarrow \mathrm{O}$ & 0.08 & -0.40 & 0.14 & -0.28 & 0.78 & -0.32 & 0.24 & Not significant \\
\hline & & & $C X(D R) \rightarrow O$ & 0.04 & -0.09 & 0.16 & -0.59 & 0.56 & -0.41 & 0.22 & Not significant \\
\hline & & \multirow[b]{4}{*}{ Romania } & $\mathrm{CX}(\mathrm{FA}) \rightarrow \mathrm{PI}$ & 0.02 & 0.02 & 0.13 & 0.17 & 0.86 & -0.23 & 0.27 & Not significant \\
\hline & & & $\mathrm{CX}(\mathrm{DR}) \rightarrow \mathrm{PI}$ & 0.02 & 0.08 & 0.14 & 0.53 & 0.60 & -0.21 & 0.36 & Not significant \\
\hline & & & $\mathrm{CX}(\mathrm{FA}) \rightarrow \mathrm{O}$ & 0.01 & -0.05 & 0.16 & -0.28 & 0.78 & -0.37 & 0.28 & Not significant \\
\hline & & & $C X(D R) \rightarrow O$ & 0.02 & -0.15 & 0.19 & -0.83 & 0.41 & -0.52 & 0.21 & Not significant \\
\hline
\end{tabular}


10.4 Additional analysis

An additional analysis was performed between consumer xenocentrism and its related constructs, consumer worldmindedness, consumer ethnocentrism and national identity and the two consequences, purchase intention and product ownership from developed countries. Table 10.24 shows the results of that analysis for the combined sample and it can be seen that of all the constructs, consumer xenocentrism is the strongest predictor of purchase intention and product ownership from developed countries $(\beta=0.12 ; \mathrm{p}<=0.01 ; \beta=0.29 ; \mathrm{p}<=0.01)$. It is also the only construct that significantly influences both the consequences variables.

Table 10.24: Impact of xenocentrism and related constructs on consequences

\begin{tabular}{|c|c|c|}
\hline $\begin{array}{l}\text { Independent } \\
\text { variables }\end{array}$ & \begin{tabular}{|l} 
Purchase \\
intention \\
from \\
developed \\
countries
\end{tabular} & \begin{tabular}{|l|} 
Product \\
ownership \\
from \\
developed \\
countries \\
\end{tabular} \\
\hline \multicolumn{3}{|l|}{$\begin{array}{l}\text { Standardized } \\
\text { coefficients }\end{array}$} \\
\hline $\begin{array}{l}\text { Consumer } \\
\text { xenocentrism }\end{array}$ & $0.12^{* * *}$ & $0.29^{* *}$ \\
\hline $\begin{array}{l}\text { Consumer } \\
\text { worldmindedness }\end{array}$ & 0.00 (NS) & $-0.10^{* *}$ \\
\hline $\begin{array}{l}\text { Consumer } \\
\text { ethnocentrism }\end{array}$ & -0.04 (NS) & $-0.10 * *$ \\
\hline National identity & $0.10^{* *}$ & 0.04 (NS) \\
\hline $\begin{array}{l}\text { Variance } \\
\text { explained }\end{array}$ & 0.02 & 0.07 \\
\hline \multicolumn{3}{|l|}{ Fit indices } \\
\hline $\mathrm{x} 2 / \mathrm{df}$ & & 4.82 \\
\hline RMSEA & & 0.05 \\
\hline GFI & & 0.98 \\
\hline AGFI & & 0.96 \\
\hline IFI & & 0.97 \\
\hline $\mathrm{CFI}$ & & 0.97 \\
\hline
\end{tabular}

* Significant at $\mathrm{p}<=0.05$.

** Significant at $\mathrm{p}<=0.01$. 


\subsection{Chapter summary}

This chapter discussed the results of the consequences and moderator relationships that were hypothesized. Most of the consequences' relationships were supported. That is, in most cases consumer xenocentrism had a positive effect on purchase intention and ownership of foreign products. Also, in many cases, consumer xenocentrism negatively impacted purchase intention and ownership of home country products. For the moderator relationships, however, very few of the hypotheses were supported. Product category symbolism had two moderator relationships significant, making it the construct with the highest number of moderator hypotheses that were supported. The upcoming chapter examines the main results of this thesis. 


\section{CHAPTER ELEVEN - DISCUSSION}

\subsection{Introduction}

This chapter discusses the main findings of the antecedents, related constructs and consequences and moderators to consumer xenocentrism.

\subsection{Antecedents}

There were a total of nine variables namely power distance, collectivism, status consumption, susceptibility to normative influence, age, educational level, gender, exposure to global media and international travel experience / preference that were proposed as antecedents to consumer xenocentrism. Out of these nine variables, international travel experience, status consumption and susceptibility to normative influence were the most significant predictors of consumer xenocentrism. International travel predicted consumer xenocentrism in all four samples and the combined sample whereas status and susceptibility to normative influence had a positive effect on consumer xenocentrism in two samples each plus the combined sample. These three variables and their effect on consumer xenocentrism will be discussed in-depth in this section.

International travel experience/ preference construct was the most significant predictor of consumer xenocentrism. It was found from the extant literature that individuals who are not culturally open were found to be more ethnocentric (Sharma et al., 1995). In other words, lack of openness toward the people, values, and artifacts of other cultures was found to be one of the reasons for favoring local products. Although consumer xenocentrism and ethnocentrism are not polar opposites, these constructs are pro-foreign and pro-domestic respectively and have a similar antecedent, albeit influencing the 
constructs in the opposite direction. Additionally, as discussed in section 4.2.2.2, cultural openness is an avid interest to learn about other cultures (Bartsch et al., 2016) and this aspect was positively related to other pro-foreign constructs such as cosmopolitanism. Thus, it extends that preference to international travel influences consumer xenocentrism.

Howard (1989) and Shimp and Sharma (1987) found that individuals in multicultural regions such as West Coast of the United States tend to prefer more imported products whereas the Midwest of the United States where the population was more homogeneous tend to prefer local products. That is, they found that people that had interaction with other cultures are less likely to be ethnocentric. International travel experience helps people learn about other cultures and become more accepting of other cultures. Although exposure to other cultures can happen through other forms such as global media exposure, the interaction with people of other cultures (which can be facilitated by international travel) might have resulted in people being more open towards products from other cultures and thus being xenocentric. Repeated exposure to other cultures through international travel could have also made people prefer foreign products (mere exposure effect) and thus more xenocentric. In their study, Mueller et al. (2016) found that people who have exposure to other cultures through oversees contacts or from having studied or worked abroad are more xenocentric. Mueller et al. (2016) is an exploratory study and results from this thesis provide large-scale empirical evidence for this relationship.

After international travel, status consumption and susceptibility to normative influence were the most significant predictors to consumers xenocentrism. It is interesting to note that status consumption was significant to in Ecuador and Kenya and susceptibility 
to normative influence was significant in the other two countries, India and Romania. Taken together, either status consumption or susceptibility to normative influence consumer xenocentrism in all four markets. That is, people consume products for the purpose of displaying status or to conform with the group's standards or expectations. These are the two most recurrent themes in the extant literature as well and this is the first research to empirically test the themes. In other words, this is the first study to test the association between xenocentrism and status and to test the susceptibility to normative influence as an antecedent. These two themes are also intertwined in that in developing countries using foreign brands gives an individual status among his reference group who in turn are more likely to influence purchase decisions (Batra et al., 2000). Additionally, in the Mueller et al. (2016) exploratory study, the consumers stated that peer pressure results in consumers having to display their status through owning foreign products.

With respect to the other antecedent variables, power distance, age, gender and global media exposure were each significant predictors of consumer xenocentrism in only one sample whereas collectivism and education were significant in none of the samples. Although extant literature had theoretical support for these antecedent variables, empirically there was little to no support. To test an additional hypothesis, two alternate models were run, one which goes from collectivism to susceptibility to normative influence to the two factors of consumer xenocentrism and second, which goes from power distance to status consumption to the two factors of consumer xenocentrism. This was done to test if collectivism and power distance were the general constructs and susceptibility to normative influence and status consumption were practical manifestations of these constructs which had an influence on consumer xenocentrism. As expected, these paths 
were significant for all samples. Thus, it looks like the reason the direct paths from collectivism and power distance to consumer xenocentrism had very little effect was because they were general constructs and they were maybe manifested practically as susceptibility to normative influence and status consumption which were strong predictors of consumer xenocentrism.

\subsection{Related Constructs}

There was a total of five variables namely global identity, consumer worldmindedness, local identity, national identity and consumer ethnocentrism that were proposed as related constructs to consumer xenocentrism. Out of these five variables, consumer worldmindedness $(+)$, national identity (-) and consumer ethnocentrism (-) were significantly related to consumer xenocentrism. Consumer worldmindedness was significantly related to consumer xenocentrism in all samples, consumer ethnocentrism in four samples and national identity in two samples. These three variables and their relationship with consumer xenocentrism will be discussed in-depth in this section. Additionally, the two constructs (global identity and local identity) that were not included in the analysis will also be briefly discussed.

Global identity and local identity although initially hypothesized, were excluded from the analysis because of different reasons. The global identity scale had a very poor Cronbach's alpha for all samples. Although this scale has been used in a few studies in the extant literature, the studies were mostly conducted in the developed countries and mostly on student samples (Zhang and Khare, 2009; Tu et al., 2012). All the countries tested in this thesis are developing countries and the sample is the general population. This could be some of the reasons that the scale didn't work. With respect to local identity, although 
almost all the fit and reliability indices were good, the construct is highly correlated to national identity and did not pass the discriminant validity test. In this thesis, internationalism and worldmindedness constructs were also found to be similar constructs during literature review as discussed in section 4.2.1.2. Additionally, global consumption orientation (GCO) and Susceptibility to Global consumer culture (SGCC), and cultural openness and global openness were also identified as similar constructs in section 4.5 and the extant literature (Alden et al., 2006; Bartsch et al., 2016; Shankarmahesh, 2006). There may be other such related constructs in the extant literature that have different names but measure more or less the same aspect and such constructs can be identified in future studies to eliminate redundancy.

Consumer worldmindedness was the most significant related construct to consumer xenocentrism in this study. The construct was significantly and positively associated with consumer xenocentrism in all samples. A person who is worldminded is someone who sees the whole world as a single entity instead of differentiating people or goods by nationality. This construct has a positive foreign orientation just like consumer xenocentrism. This is because for worldminded people the idea of identifying with people around the world (i.e. having a single identity) makes individuals pro-foreign. Foreign travel (Nijssen and Douglas 2008) was an antecedent to consumer worldmindedness and from this thesis this is a significant antecedent to consumer xenocentrism as well. Additionally, although worldminded people prefer foreign products this is mostly because they perceive it to be high quality unlike xenocentrism where it is for social characteristics. Since both of the constructs have a positive foreign orientation (albeit for different reasons), they are positively related. Although in our sample people mostly disagreed to being worldminded 
on an average, as worldmindedness increased, consumer xenocentrism also increased as evidenced by the positive relationship between the two constructs.

From extant literature, cosmopolitan was the only positive foreign orientation construct that was tested along with consumer xenocentrism, and was positively related (Prince et al., 2016; Rojas-Méndez and Chapa, 2019). This thesis tested another construct with positive orientation, consumer worldmindedness, thus advancing our knowledge of consumer xenocentrism and how it relates to other constructs in the literature.

Consumer ethnocentrism was the second-most significant related construct to consumer xenocentrism in this study. The negative relationship was significant in three country samples plus the combined sample. Consumer ethnocentrism has received a lot attention in the extant literature and is predominately seen in developed countries while xenocentrism has been so far predominately tested and observed in developing countries. A person who is ethnocentric favors products from one's country because he feels that it is his moral responsibility to buy local products. He also has a negative attitude toward buying foreign products. On the other hand, a person who is xenocentric prefers foreign products and rejects one's country's products. In other words, ethnocentric consumers have a negative foreign orientation and xenocentric consumers have a positive foreign orientation. Ethnocentric consumers believe that their culture is superior to other cultures (Lee et al., 2014) while xenocentric consumer believes that their culture is inferior to developed countries' culture. Thus, as hypothesized, consumer ethnocentrism was significantly and negatively associated with consumer xenocentrism. In other xenocentric studies too, consumer ethnocentrism was negatively related to consumer xenocentrism (Rojas-Méndez 
and Chapa, 2019; Balabanis and Diamantopoulos, 2016). Thus, the results from this study provide further confirmation for this relationship.

National identity was the third-most significant related construct to consumer xenocentrism in this study. The relationship was significant in two country samples. This construct has never been tested with consumer xenocentrism before and this is the first study to do so. National identity is one's attachment towards one's country. From the extant research, a person who has a high national identity perceives domestic goods to be of higher quality and prefers to buy domestic products (Verlegh, 2007). However, interestingly, in this thesis, the samples disagreed or were neutral about being ethnocentric (i.e. preference to buy domestic products) although they claimed to have a high national identity. That is, they were not very inclined towards buying their country's products even when they agreed to be very attached towards their country (correlation coefficients between national identity and ethnocentrism were low to moderate, specifically between 0.10 and 0.37 for the various country samples). From the extant literature, high national identity consumers have a neutral foreign orientation and xenocentric consumers have a positive foreign orientation, but since high national identity consumers have a pro-domestic orientation, the constructs were expected to be negatively related. As hypothesized, in two samples, national identity was significantly and negatively associated with consumer xenocentrism. This result further enhances our knowledge of consumer xenocentrism with respect to how it relates to other related constructs in the extant literature. There is some support (although, not entirely) that national identity and consumer xenocentrism are negatively related. 


\subsection{Consequences and Moderators}

There were two variables namely purchase intention of foreign products and ownership of foreign products that were proposed as consequences to consumer xenocentrism. Additionally, seven moderator variables, age, education, occupation, gender, global media, international travel and product category symbolism were tested on the path between consumer xenocentrism and the two consequences variables. With respect to the consequences' variables, consumer xenocentrism influenced ownership (actual purchase) of foreign products in all four samples and the combined sample. In two samples plus the combined sample, consumer xenocentrism influenced purchase intention of foreign products and purchase intention of foreign products influenced ownership of foreign products. The latter is in-line with the theory of reasoned action which states that behavioral intention will influence behavior (Ajzen, 1991). For the moderator relationships, however, very few of the proposed relationships were supported. Product category symbolism had two moderator relationships significant, while global media exposure had one significant relationship and the remaining moderator variables had no relationships significant. The significant consequences and moderator relationships will be discussed in this section.

Ownership of foreign products was the most significant consequence of consumer xenocentrism in this thesis. This relationship was significant in all the samples tested. From the extant literature, we do not have much empirical knowledge about the consequences of consumer xenocentrism in general. This is the first study to analyze the impact of consumer xenocentrism on ownership or actual purchase of foreign products. The influence of consumer xenocentrism on ownership of foreign products is an important finding because 
it shows that xenocentrism which is a preference for foreign products actually translates into behavior (i.e. buying foreign products). In previous studies, other positive foreign construct, cosmopolitanism has also been found to positively influence ownership of foreign products. From this thesis, it is proved that consumer xenocentrism, another proforeign construct, also does the same.

Purchase intention of foreign products was the other proposed consequence of consumer xenocentrism in this thesis and the relationship was significant in two samples and the combined sample. Purchase intention of foreign products has also been referred to as willingness to buy foreign goods in the extant literature and this construct has been used to test the predictive validity of the consumer xenocentrism scale (Rojas-Méndez and Chapa, 2019). From the previous literature, other positive foreign constructs such as high GCO and SGCC also positively influenced purchase intention of foreign products. From this thesis, there is some support (although, not entirely) that consumer xenocentrism positively influences purchase intention of foreign products. Overall, in most cases, consumer xenocentrism had a positive effect on purchase intention and ownership of foreign products in this thesis. Since the relationship between consumer xenocentrism and ownership of foreign products is significant in all samples but the relationship between consumer xenocentrism and purchase intention of foreign products is only significant in two samples and the combined sample, it is likely that there is social desirability bias (Grimm, 2010; Krumpal, 2013) as consumers do not want to accept that they have purchase intention for foreign products but still possess those products.

Purchase intention of foreign products is the precursor to buying foreign products or ownership of foreign products. In other words, purchase intention is the probability that 
the ownership of foreign products will happen. Purchase intention of foreign products positively influences ownership of products from developed countries in two samples and the combined sample. Taken together with the consumer xenocentrism construct, consumer xenocentrism (attitude or preference towards foreign products and rejection of domestic ones), has an effect on purchase intention of foreign products (behavioral intention) and this in turn has an effect on ownership of foreign products (behavior). From this thesis, there is partial support that the theory of reasoned action works with respect to consumer xenocentrism. The purchase intention of products has been found to positively influence ownership of products in the extant literature (Yoo and Donthu, 2005; Klein et al., 1998) and the results from this thesis adds partial support to these findings.

For the moderator relationships out of 70 hypothesized relationships only three were supported. Global media exposure and product category symbolism had moderator relationships significant as per the proposed hypotheses. With respect to global media exposure, for the combined sample, the impact of consumer xenocentrism on purchase intention of foreign products is moderated by global media exposure so that the relationship is stronger for individuals with higher exposure to global media than for individuals with lower exposure to global media. Mere exposure effect suggests that repeatedly exposing someone to an object will contribute to that person having positive feelings towards that object (Zajonc, 1968). Greater exposure to other cultures through global media exposure might have shown the consumption practices in foreign countries and the related perceived superior lifestyle that comes with it and people in developing countries might want to follow those consumption practices which might have led to higher purchase intent of 
foreign products. Thus, higher exposure to global media such as foreign television programs and movies could have caused a higher purchase intention of foreign products.

Next, product category symbolism was a significant moderator in two instances. For India and the combined sample, the impact of consumer xenocentrism on purchase intention of foreign products is moderated by product category symbolism so that the relationship is stronger for product categories that contribute to one's identity (mobile phones) than for product categories that do not (bath soap). Products such as mobile phones that enhances one's identity are likely to be seen as what Belk (1988) terms as our "extended self" and are important contributors of our identities. Thus, in such product categories there is higher purchase intention of foreign products. This type of consumption is also in-line with conspicuous consumption of products that give the user of the product higher status. In other words, mobile phones are products that are often conspicuously used and thus is likely to give the owner higher status within his group than bath soap which is used in a private setting.

The figure 11.1 below shows the final consumer xenocentrism model. The moderators are not shown as even the moderators that were significant (global media exposure and product category symbolism) were not significant in the majority of cases. As mentioned in section 11.2, the direct paths from collectivism and power distance to consumer xenocentrism had very little effect but the paths from power distance to status consumption to consumer xenocentrism and from collectivism to susceptibility to normative influence to consumer xenocentrism were significant. These paths are also illustrated in figure 11.1. 
Figure 11.1: Final consumer xenocentrism model

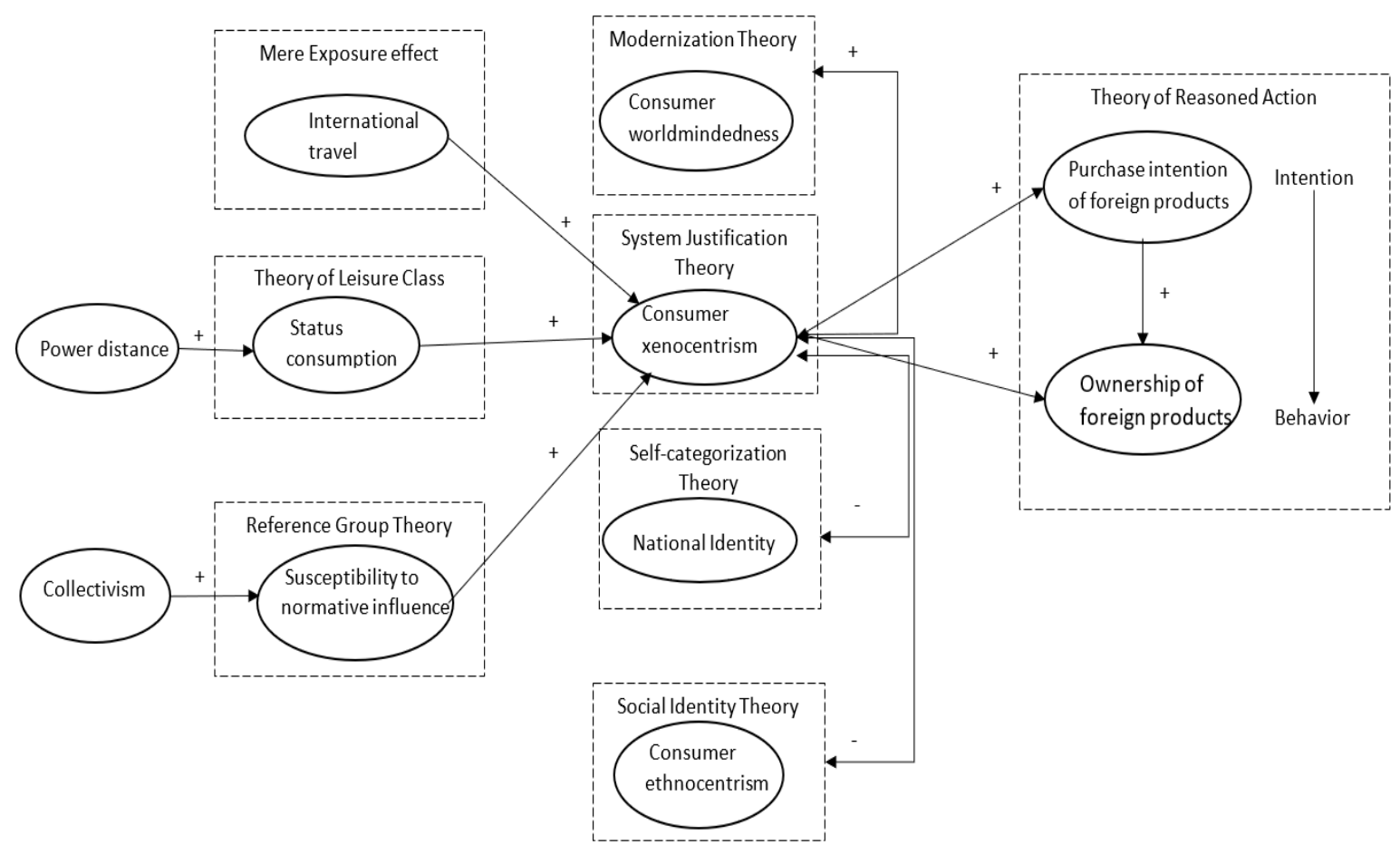

A few additional points of discussion:

1.) Experts interviewed during the initial phase of this research project and an expert on African consumer behavior were sent the research results and their opinions were sought out. Two of the six of them replied stating that the results made sense, providing additional support to the results of this thesis.

2.) The scale used to measure xenocentrism, X-Scale is fairly new. It has already been tested in five developing countries during its development and this thesis gave it additional opportunity to be tested in three new countries (it was already tested in Ecuador during scale development). There was excellent support with respect to the nomological validity of the X-scale when it was tested with other related constructs in the extant literature. 
3.) The model was assessed at both the level of the country samples and the combined sample for the antecedents, related constructs, consequences and moderators. This was done to check both the commonalities between all the samples (i.e. results from combined samples) and also the differences among all the samples (i.e. results from the four individual country samples). Inferences were made at both levels (i.e. combined sample and four individual country samples level). For example, status consumption and susceptibility to normative influence were significant at the combined sample level. Additionally, in individual country samples, status consumption was significant in Ecuador and Kenya and susceptibility to normative influence was significant in the other two countries, India and Romania. Taken together, either status consumption or susceptibility to normative influence had an effect on consumer xenocentrism in all four markets and overall with respect to all countries, both status consumption and susceptibility to normative influence influenced consumer xenocentrism. This kind of in-depth analysis was only possible because both the results of the country samples and the combined sample was taken into consideration. Additionally, this way of examining data (at both the country sample level and combined sample level) has been used previously in international marketing extant literature in multi-country studies (e.g. Cleveland et al., 2016).

\subsection{Chapter summary}

This chapter discussed the important findings of this thesis. International travel experience/ preference, status consumption and susceptibility to normative influence were found to be the main antecedents of consumer xenocentrism. Consumer worldmindedness, consumer ethnocentrism and national identity were the related constructs which were associated with consumer xenocentrism in the appropriate direction. Ownership of foreign 
products and purchase intention were the consequences to consumer xenocentrism. Finally, there was minor support for global media exposure and product category symbolism as moderators. The next chapter which is the final chapter of this thesis touches on the main contributions and limitations of this research. 


\section{CHAPTER TWELVE - CONTRIBUTIONS AND LIMITATIONS}

\subsection{Introduction}

This chapter outlines the theoretical and practical contributions of this thesis research. Next, the limitations and avenues for future research are discussed.

\subsection{Theoretical Contributions}

The main goal of this research was to identify the antecedents, consequences (and moderators) and related constructs for consumer xenocentrism. This dissertation and the proposed model made contributions at the theoretical level which are discussed below.

This thesis made contributions to the international marketing and consumer behavior literature. The literature on consumer xenocentrism is still very limited in international marketing and very much at the starting point of knowledge creation in this area. This research can inform future studies on this understudied topic and can be used by future research to build on. It answers the important questions such as what are some of the causes of xenocentrism and whether it translates into behavior. Also, the research showed how the existing related constructs were associated with consumer xenocentrism. The answers to these questions are imperative in getting a deeper understanding of the phenomenon.

Each of the constructs in this research are theoretically anchored making the model stronger. In other words, the model has a strong theoretical foundation. Theories and concepts from a variety of fields such as international business, economics, sociology, psychology, political science, anthropology and consumer behavior have been used in this research. Thus, the model draws on multiple fields and the resulting model in more holistic. 
This study also shows the relationship between consumer xenocentrism and both Hofstede's cultural dimensions and the Theory of reasoned action (TRA), two very widely used theories thus extending the application of those concepts as well. Consumer xenocentrism partially confirms TRA with respect to the consequences variables i.e. purchase intention of foreign product influences ownership in some cases. With respect to Hofstede's cultural dimensions, the dimensions did not have much influence on consumer xenocentrism as expected. It could be because of one of the two reasons. 1.) As mentioned in section 11.2, it looks like the reason the direct paths from collectivism and power distance to consumer xenocentrism did not have much influence but these constructs through susceptibility to normative influence and status consumption did, was because collectivism and power distance were general constructs and they maybe manifested practically as susceptibility to normative influence and status consumption which were strong predictors of consumer xenocentrism. (or) 2.) The reason Hofstede's cultural dimensions did not have much influence on consumer xenocentrism could be because of issues with the scales. That is, it could be because power distance scale was not entirely reliable for the different countries. Additionally, horizontal and vertical individualism/collectivism might be more appropriate than Hofstede's individualism/collectivism for this context (Singelis, Triandis, Bhawuk and Gelfand, 1995).

This is the first study to empirically test a number of theoretically proposed relationships in the extant literature such as xenocentrism and status and xenocentrism and demographics. Although status consumption and normative influence were the mostly frequently proposed antecedents to consumer xenocentrism from extant literature, the 
analysis showed that international travel was a more significant predictor. This is also the first study to empirically test a wide range of related constructs for consumer xenocentrism. Additionally, consumer preference in developed countries has received much attention and this study brings to light the preferences in developing countries. This study also focused on understudied countries such as Ecuador, Kenya, Romania and India.

Social aggrandizement is part of the consumer xenocentrism scale of Balabanis and Diamantopoulos (2016) but from this thesis it was seen that this construct is the antecedent of consumer xenocentrism and not part of the construct itself. Several studies from the extant literature have argued that consumer xenocentrism is associated with status (Mueller et al., 2016, Rojas-Méndez and Chapa, 2017; Prince et al., 2016; Kala and Chaubey, 2016; Mueller and Broderick, 2009) and this thesis confirms that proposition. The association with status occurs because developing countries' consumers aspire to elevate themselves to the level of the developed countries' consumers who tend to have a better lifestyle. Additionally, the developing countries' consumers also use foreign products to signal status within their own peer group in their country.

Demographics variables such as age, education, occupation and gender were tested with consumer xenocentrism and the relationships were not significant in most cases (although there was little support). Studies from extant literature (Mueller et al. 2016; Kisawike, 2015 and Bailey and Pineres, 1997) have found younger, more educated and consumers with professional jobs to be more xenocentric but these studies are either qualitative and based on low sample size or have used the reversed ethnocentrism scale to measure xenocentrism. With respect to gender and consumer xenocentrism there are mixed results from the extant literature (Mueller et al. 2016; Rojas-Méndez and Kolotylo, 2018), 
and this study did not find a significant effect in most cases. Overall, demographics did not play a major role with respect to xenocentrism, as expected.

Collectivism and power distance influenced susceptibility to normative influence and status consumption which in turn influenced consumer xenocentrism. The existing literature argues the influence of these four constructs on consumer xenocentrism but the order in which the influence takes place has been uncovered in this thesis. It looks like collectivism and power distance are broader concepts and susceptibility to normative influence and status consumption are practical manifestations of the same. Susceptibility to normative influence and status consumption have a significant effect on consumer xenocentrism which provides further support for the need for affiliation and power as basic human needs as mentioned in the various human needs theories such as McClelland's Human Motivation Theory.

The cluster analysis showed that consumer xenocentrism is not the direct opposite of consumer ethnocentrism as previously dealt with in a number of studies (Bailey and de Pineres, 1997; Soto, 2008) and that both xenocentrism and ethnocentrism can exist at the same time. This stance provides additional support to few other studies that have taken the same standpoint (Balabanis and Diamantopoulos, 2016; Rojas-Méndez and Chapa, 2017). The two constructs are based on different theories and different motives and it is possible that the same person can be both ethnocentric and xenocentric because he feels superior to one country and inferior to another.

This study also contained the most comprehensive review of consumer xenocentrism in the literature. The review touched on the concept from a variety of disciplines. The various terminologies used to refer to xenocentrism across the various 
disciplines was discussed. Examples of consumer xenocentrism from around the world were provided. This was the first study to differentiate xenocentrism and country-of-origin. Additionally, all the scales used to measure xenocentrism and theories that support xenocentrism were reviewed.

Finally, online survey was useful in collecting data in all four countries - India, Romania, Kenya and Ecuador. The postal mail system would have been unreliable and slow in some of these countries. Going door-to-door might be perceived as intrusive or even dangerous in some areas. Thus, online survey, though it has its own limitations, was the most suitable. Making the survey accessible via mobile phones was an important step as several individuals especially in India and Kenya access the internet via mobile phones. This may be true of other such developing countries which are "Mobile First" economies.

\subsection{Practical Contributions}

This dissertation has practical implications to marketers. Greater knowledge of what causes xenocentrism and the consequences can help international marketers effectively market products and services. For example, when marketing products in xenocentric markets the emphasis can be on social characteristics such as status and peer evaluations and not objective ones. Companies from developed countries can look beyond their own boundaries and serve consumers in xenocentric countries. The xenocentric consumer attitude in the developing countries can be used to the benefit of the companies from developed countries. On the other hand, companies from the developing countries can take advantage of xenocentrism by using foreign-sounding names and including English language in their marketing. 
Among xenocentric consumers, travel played an important role. International travel experience and preference was the most significant predictor of consumer xenocentrism in this study. Thus, foreign brands in the travel space such as airlines, hotels, luggage companies etc. can use this finding to their advantage and highlight the fact that they are foreign. Brands can also focus on how their products or services will enhance the status of the individual among their peers as status consumption is an important aspect of xenocentrism. Additionally, brands can market as to how their products or services appeal to one's family and friends, thus touching on the aspect of susceptibility to normative influence which was also one of the important factors influencing consumer xenocentrism.

There is some evidence that people might be more xenocentric in some product categories i.e. product categories that contribute to one's identity versus other product categories. Thus, this is a great marketing opportunity for foreign brands selling in these product categories. These brands might find xenocentric countries more lucrative. Companies that sell mobile phone, cars, TVs, clothes and fashion in general or any products that is used to show status in xenocentric cultures can greatly benefit. Foreign universities offering offshore programs in developing countries can take also take advantage of xenocentric countries as peer pressure influences the enrollment intention in the program (Li, Liu and Rojas-Mendez, 2013).

In the past in India even products sold to the poorer rural markets had English names and were written in English (The New York Times, 2011). Additionally, in Latin America, English is used in advertising by several brands to imply that the brand is associated with high status (Gaur et al., 2015). Thus, the language used in marketing can 
also be a factor to be considered for the brands. Maybe even local brands can use English to enhance the status of their brands in the eyes of the consumer.

Most people do not want to sound negative about their home country and in some cultures xenocentric individuals are referred to as traitors (Rojas-Méndez and Chapa, 2017; Soto, 2008). Thus, when companies conduct market research surveys in xenocentric countries, they should keep in mind that what people say is not necessarily what people prefer. Respondent answers might reflect their intention to fit in with the group and may not necessarily be a true reflection of their preference. In other words, their answers might be prone to social desirability bias or preference falsification (Grimm, 2010; Kuran, 1995). In this study, although people stated that they would purchase and own home country products, the analysis shows that xenocentrism negatively affected both purchase and ownership of home country products. It is possible that wording the survey items more on group preference rather than individual preferences might give more realistic results for the market research firms trying to analyze consumer behavior in these countries. Alternatively, to overcome bias, a method called nominative technique can be used where the survey asks for a close friend's choices instead of the respondent's choices. This method has been used when studying sensitive topics such as drug usage to get realistic results (Miller, 1985; Yeatman and Trinitapoli, 2011).

\subsection{Limitations and future research}

As with every research, this study too has its limitations. These limitations also double into avenues for future research. 
The data in India, Kenya, Romania and Ecuador was collected online. This method is less interactive. Although this research does not require high researcher-participant interaction, I do not disregard the fact that this interaction may have led to higher data quality. Additionally, owing to online data collection, the sample might not necessarily be representative of the country as only people with internet access would have responded to the survey (Bryman et al., 2011). But at the same time these individuals are the consumers who are likely to have more exposure to foreign products and brands. It is possible that a qualitative study could result in a wider range of antecedents or consequences than what was tested in this study - the researcher-participant interaction could enable that. Additionally, a qualitative study would also enable to reach participants who do not have access to the internet.

The collection of data online especially using online panels such as MTurk has received criticisms in the literature. Lowry, D'Arcy, Hammer and Moody (2016) note some of the criticisms and make a case for why it is still good to use such panels. Following are the criticisms and their rebuttals 1.) Online panels use convenience sampling. Lowry et al. (2016) argue that data collected through paper surveys and interviews are also convenience sampling and in fact pertain to one geographic location. Online panels expand the scope of who can be reached, and these panels can target based on specific characteristics such as demographics. 2.) Online panels may not result in good quality data because the respondents may not give the survey full attention. Lowry et al. (2016) argue that adding control questions and reverse-coded questions (both techniques have been used in this research) are useful ways around this problem. 3.) People who are part of online panels and take surveys for payment may not be "normal". Lowry et al. (2016) state that although this 
maybe an issue with other kinds of data collection as well, one of the approaches around this issue for online panels is to provide a payment around the US minimum wage rate (a fair compensation, in other words). This thesis research has used this rate as a guideline to pay the market research firms in Ecuador, India and Kenya.

This study reflects the current preference of the sample in four developing countries. Future research can collect longitudinal data to see if as the economy of a developing country flourishes, whether xenocentrism is reduced and if limited income is the only cause to create an appropriate environment for xenocentrism.

In this study, it was found that although xenocentrism positively affected purchase intention and ownership from foreign countries and negatively affected purchase intention and ownership from home countries, individuals in the survey stated that they would purchase and own home country products. There is a possibility of social desirability bias (Grimm, 2010; Krumpal, 2013), although the main objective of this study was not to test home country product preferences. Future research on xenocentrism can phrase questions in such a way that the questions do not point to the survey respondents' perspective but rather the general perspective. Similarly, the consumer xenocentrism scores indicated that the various samples are neutral about or agree that they admire foreign products and mostly disagree that they reject domestic products. These scores are low likely because of social desirability bias and future research can phrase questions that either point to the group preferences or a close friend's preferences to eliminate bias. Likewise, the relationship between consumer xenocentrism and ownership of foreign products is significant in all samples but the relationship between consumer xenocentrism and purchase intention of foreign products is only significant in two samples and the combined sample and it is likely 
that there is social desirability bias because consumers do not want to admit that they have the desire to purchase foreign products (purchase intention) but still possess those products. This bias can be minimized or eliminated by phrasing questions that ask for general preference rather than one's personal preference.

The results of this study cannot be generalized to all other countries. The sample contains citizens from only four developing countries. Although the four countries are in different parts of the world, there might be other factors such as the form of government (communism, monarchy etc.), economic and political stability and availability of foreign products that may affect the preferences in other developing countries. Future research on xenocentrism can be conducted in countries different from the ones that have been conducted in this study. For example, including countries from the Middle East which would have a completely different culture to the ones in this study would be interesting. Many countries in the Middle East such as Qatar are also high power distance and collectivistic cultures like the ones tested in this study. So, the same model used in this research can be tested there as well. However, since Qatar is much more developed (classified as high-income economy by the World Bank just like the Western developed countries) than the countries used in this study, it may be that people in Qatar may not be xenocentric. Testing this model in Middle Eastern countries would show whether level of economic development plays a major factor in being xenocentric. Additionally, research on consumer xenocentrism in developed countries might be another area to explore. For example, do Canadians think that products from the U.S. are superior to their own? It will be interesting to explore xenocentrism in Canada because although it is a low power distance and individualistic culture, as international travel is also a factor causing 
xenocentrism it will be interesting to see if Canadians who have traveled to the U.S. are more xenocentric and have greater intentions to buy foreign products from the U.S. Also, it can be tested whether susceptibility to normative influence or peer pressure has as much of an impact on xenocentrism in Canada as in developing countries. This effect maybe lesser in Canada than in collectivistic developing countries.

Although the scales were carefully chosen, power distance scale was not entirely reliable in the context of this study. Future research can perhaps use other power distance scales from the extant literature. Additionally, although the collectivism scale had good reliability metrics, the construct did not have an effect on consumer xenocentrism in most cases, although the extant literature suggests such a relationship exists. Thus, future research can test the effect of horizontal and vertical individualism/collectivism on consumer xenocentrism (Singelis, Triandis, Bhawuk and Gelfand, 1995). This maybe appropriate due to the nature of collectivism recognizing some hierarchy within a group. Similarly, the global identity scale was not fully reliable in this study. This could be because the scale was predominantly developed and tested in the developed countries and when it has been tested less frequently in developing countries, it was tested on student samples. Future research can develop a global identity scale in developing countries.

This research tests two consequences variables namely purchase intention of foreign products and ownership of foreign products. Future research can test the purchase intention and ownership of counterfeit products. It could be especially true that lowerincome and younger consumers such as the student population also want to show status and are unable to afford foreign products and therefore might buy counterfeits. The impact of consumer xenocentrism on counterfeits is an area that would be interesting to explore. 
Although Diamantopoulos, Davydova and Arslanagic-Kalajdzic (2019) slightly touch on this area, in-depth research is required to understand the full spectrum of the impact of consumer xenocentrism.

The sample across all four countries were predominantly well-educated with most of them having at least a bachelor's degree and holding professional jobs. So, the results of this study are reflective of such a sample and might not be entirely representative of the countries surveyed. That said, these kinds of individuals are the ones who are most likely to have exposure to other cultures and thus are likely to be xenocentric. Future research can focus on lower income consumers to see if xenocentrism has an impact.

A total of nine antecedents were tested in this thesis. However, there are likely to be other antecedents as well which the future studies can test. A few potential antecedents suggested are materialism, openness to foreign cultures and horizontal and vertical individualism/collectivism. Materialism is, "the importance of possessions in one's life" (Richins and Dawson 1992, p. 308). One must be materialistic and give importance to worldly possessions to be wanting to show status through products which is a main aspect of being xenocentric. Cultural openness might be another construct that could be an antecedent to consumer xenocentrism. One must be open towards foreign cultures in order to prefer products from those cultures. Someone who absolutely dislikes foreign cultures or is xenophobic is less likely to buy foreign products. Future research can also test if horizontal and vertical individualism/collectivism are antecedents to consumer xenocentrism (Singelis et al., 1995). Although collectivism had an indirect effect on consumer xenocentrism in this research, it maybe that horizontal and vertical 
individualism/collectivism is more suitable due to the nature of collectivism recognizing some hierarchy within a group.

There are two schools of thought on whether SEM and multiple regression implies causation or not. One school of thought argues that regression cannot imply causation and only shows correlation because random variables can be regressed and a significant relationship can be found while another school of thought argues that regression plus theory equals causation (Pearl, 2000). In the international marketing extant literature, SEM has been used to test causation when backed by relevant theory. Additionally, the hypotheses used in those studies have utilized the phrase "X will have a positive/negative effect on $\mathrm{Y}$ " instead of " $\mathrm{X}$ will be positively/negatively associated with $\mathrm{Y}^{\prime}$ to imply causation (Balabanis, Stathopoulou and Qiao, 2019; Rojas-Mendez, Kannan and Ruci, 2019). This thesis subscribes to the latter school of thought since all hypotheses have theoretical support from extant literature.

\subsection{Chapter summary}

This chapter discussed the theoretical and managerial contributions of this study. This was followed by elaborating on the limitations which were also areas of future research.

\subsection{Conclusion}

This research set out to answer four research questions: 1.) What are the antecedents to consumer xenocentrism? 2.) What is the relationship between consumer xenocentrism and its related constructs? 3.) What are the consequences of consumer xenocentrism? and 
4.) What are the moderators between consumer xenocentrism and its consequences? A minor qualitative research (interviews) was conducted along with extensive literature review to build the initial model along with its associated theories. For the related constructs, since there were several allied constructs to consumer xenocentrism in the literature (around 20 constructs), an objective criteria was used to pick a few of them to test in the model. The overall model was tested using a quantitative study (online surveys) that mostly contained scales from extant literature which were chosen using a decision criteria. A pilot study was run on a small-scale to ensure that the questionnaire was working properly, later necessary corrections were made and then the main study was run. Nine antecedents, five related constructs, two consequences and seven moderator variables were tested in this research. Data was collected in four developing countries, one each from Asia, Eastern Europe, South America and Africa namely India, Romania, Ecuador and Kenya respectively. For India and Kenya, the surveys were run in English and for Ecuador and Romania the surveys were run in Spanish and Romanian respectively. A total combined sample of 1306 respondents, aged 18 years and above was obtained. After collecting the data for the main study, the data quality was analyzed followed by testing of the hypotheses. The outcome of this study was a model of antecedents, consequences (and moderators) and related constructs to consumer xenocentrism. Specifically, international travel experience, status consumption and susceptibility to normative influence were the most significant antecedents to consumer xenocentrism. Consumer worldmindedness, consumer ethnocentrism and national identity were the related constructs associated with consumer xenocentrism in the expected direction. With respect to the consequences' variables, consumer xenocentrism positively influenced ownership of foreign products and 
purchase intention of foreign products. There was not much support for the moderator relationships. Overall, before this research, there was consensus on what was consumer xenocentrism, there were some scales for the construct and related constructs such as ethnocentrism and cosmopolitanism and the willingness to buy foreign products consequence had been tested with consumer xenocentrism. This research identified the antecedents, other constructs related to consumer xenocentrism, and the consequences of consumer xenocentrism. Knowledge of these aspects of consumer xenocentrism will make a theoretical contribution as to what constructs cause consumer xenocentrism (for example, culture has an impact on consumer xenocentrism), other related constructs related to consumer xenocentrism (consumer worldmindedness and national identity) and the consequence of consumer xenocentrism (xenocentrism translates into actual behavior because it influences ownership of foreign products). Additionally, this study will also be useful to practitioners because knowledge of antecedents and the consequences can help marketers in developing countries to successfully position and market their products and services (for example, the focus should be more on social characteristics than the objective features of the product). Overall, this research has enhanced our understanding of the consumer xenocentrism construct and will contribute to the existing, nascent literature on this construct. 


\section{REFERENCES}

Ajzen, I. (1991), "The theory of planned behavior", Organizational Behavior and Human Decision Processes, 50(2), 179-211.

Akdeniz, M. and Talay, M. (2013), "Cultural variations in the use of marketing signals: a multilevel analysis of the motion picture industry", Journal of the Academy of Marketing Science, 41 (5), 601-624.

Akhter, S.H. (2007) "Globalization, expectations model of economic nationalism, and consumer behavior", Journal of Consumer Marketing, 24 (3), 142-150.

Alden, D.L., Steenkamp, J-B. E.M. and Batra, R. (2006), "Consumer Attitudes Toward Marketplace Globalization: Structure, Antecedents and Consequences," International Journal of Research in Marketing, 23 (3), 227-239.

Aleksic, T. (2002), "Benevolent Racism: Can the Other Represent itself?", Linguistics and Literature, 2 (9): 349-357.

Altintas, M.H. and Tokol, T. (2007), "Cultural openness and consumer ethnocentrism: an empirical analysis of Turkish consumers", Marketing Intelligence and Planning, 25 (4), $308-325$.

Altintas, H. M., Kurtulmusoglu, F.B., Kaufmannc, H.R., Harcar, T. and Gundogan, N. (2013), "The Development and Validation of a Consumer Cosmopolitan ISM Scale: The Polar Opposite of Xenophobic Attitudes," Ekonomska Istrazivanja (Economic Research Journal), 26 (1), 137-154.

Andaleeb, S.S. (1995), "Dependence relations and the moderating role of trust: implications for behavioral intentions in marketing channels", International Journal of Research in Marketing, 12(2),157-172.

Anderson, W.T. and Cunningham, W.H. (1972), "Gauging Foreign Product Promotion", Journal of Advertising Research, 12 (1), 29-34.

Appadurai, A. (1996), "Modernity at large: cultural dimensions of globalization", Public Worlds, Minneapolis, MN.

Asakitikpi, A. (2016), "Skin bleaching as a metaphor for interrogating development crisis in Black Africa", IOSR Journal of Humanities and Social Science, 21 (12), 22-28.

Bagwell, L.S. and Bernheim, B.D. (1996), "Veblen Effects in a Theory of Conspicuous Consumption", The American Economic Review, 86 (3), 349-373. 
Bailey and de Pineres (1997), "Country of Origin Attitudes in Mexico", Journal of International Consumer Marketing, 9(3), 25-41.

Balabanis, G., Diamantopoulos, A., Mueller, R.D. and Melewar, T.C. (2001), "The Impact of Nationalism, Patriotism and Internationalism on Consumer Ethnocentric Tendencies", Journal of International Business Studies, 32 (1), 157-175.

Balabanis, G., Mueller, R. and Melewar, T.C. (2002), "The Relationship Between Consumer Ethnocentrism and Human Values", Journal of Global Marketing, 15 (3-4), 7 37.

Balabanis, G. and Diamantopoulos, A. (2004), "Domestic Country Bias, Country-ofOrigin Effects, and Consumer Ethnocentrism: A Multidimensional Unfolding Approach", Journal of the Academy of Marketing Science,32 (1), 80-95.

Balabanis, G. and Diamantopoulos, A. (2016), "Consumer xenocentrism as determinant of foreign product preference: A system justification perspective", Journal of International Marketing, 24 (3), 58-77.

Balabanis, G., Stathopoulou, A. and Qiao, J. (2019), "Favoritism Toward Foreign and Domestic Brands: A Comparison of Different Theoretical Explanations", Journal of International Marketing, 27 (2), 38-55.

Bar-Heim, G. (1987). "The Meaning of Western Commercial Artifacts for Eastern European Youth", Journal of Contemporary Ethnography, 16(2), 205-226.

Barrett, P. (2007), "Structural equation modeling: adjusting model fit", Personality and Individual Difference, 42, 815-824.

Bartikowski, B. and Walsh, G. (2015), "Attitude toward cultural diversity: A test of identity-related antecedents and purchasing consequences", Journal of business research, 68 (3), 526-533.

Bartsch, F., Riefler, P. and Diamantopoulos, A. (2016), "A Taxonomy and Review of Positive Consumer Dispositions Toward Foreign Countries and Globalization", Journal of International Marketing, 24 (1), 82-110.

Bashkow, I. (2006), "The meaning of Whitemen: Race and Modernity in the Orokaiva Cultural World", University of Chicago press, Chicago, IL.

Batra, R. and Ahtola, O.T. (1990), "Measuring the Hedonic and Utilitarian Sources of Consumer Attitudes", Marketing Letters, 2(2), 159-170.

Batra, R., Venkatraman, R., Alden, D.L., Steenkamp, J.-B.E.M. and Ramachander, S. (2000), "Effects of brand local/non-local origin on consumer attitudes", Journal of Consumer Psychology, 9 (2), 83-95. 
Batra, R., Homer, P.M. and Kahle, L.R. (2001), "Values, susceptibility to normative influence, and attribute importance weights: A nomological analysis", Journal of Consumer Psychology, 11 (2), 115-128.

Baughn, C.C. and Yaprak, A. (1996), "Economic Nationalism: Conceptual and Empirical Development", Political Psychology, 17 (4), 759-778.

Baumeister, R.F. and Vohs, K.D. (2007), "Encyclopedia of social psychology", Sage publications, Thousand Oaks, CA.

BBC (2012), "English or Hinglish - which will India choose?", available at https://www.bbc.com/news/magazine-20500312 (accessed 9 Sep 2018).

Bearden, W.O. and Etzel, M.J. (1982), "Reference Group Influence on Product and Brand Purchase Decisions”, Journal of Consumer Research, 9 (2), 183-194.

Bearden, W.O., Netemeyer, R.G. and Teel, J.E. (1989), "Measurement of Consumer Susceptibility to Interpersonal Influence", Journal of Consumer Research, 15 (4), 473-481.

Belk, R.W., Bahn, K.D. and Mayer, R.N. (1982), "Developmental Recognition of Consumption Symbolism”, Journal of Consumer Research, 9 (1), 4-17.

Belk, R.W. (1988), "Possessions and the Extended Self”, Journal of consumer research, 15 (2), 139-168.

Belk, R. (1998), "Been There, Done That, Bought the Souvenirs: Of Journeys and Boundary Crossing", in Consumer Research: Post cards from the Edge, Routledge, New York.

Belk, R.W. (2000), “Consumption Patterns of the New Elite in Zimbabwe”, working paper, University of Utah.

Berger, J. and Heath, C. (2007), "Where Consumers Diverge from Others: Identity Signaling and Product Domains", Journal of Consumer Research, 34 (2), 121-134.

Bernstein (1971), "Modernization theory and Sociological study of Development", Journal of Development Studies, 7 (2), 141-160.

Bhattacharjee, A., Berger, J. And Menon, G. (2014), "When Identity Marketing Backfires: Consumer Agency in Identity Expression", Journal of Consumer Research, 41(2), 294 309.

Blank, T. and Schmidt, P. (2003), "National Identity in a United Germany: Nationalism or Patriotism? An Empirical Test With Representative Data", Political Psychology, 24 (2), 289-312. 
Boatler, R.W. (1994), "Manager Worldmindedness and trade propensity", Journal of Global Marketing, 8 (1), 111-127.

Bollen, K. (1989), "Structural Equations with Latent Variables”, Wiley, New York, NY.

Bolton, R. N. (1991), “An exploratory investigation of questionnaire pretesting with verbal protocol analysis". Advances in Consumer Research, 18, 558-565.

Bond, R. and Smith, P.B. (1996), "Culture and Conformity: A Meta-Analysis of Studies Using Asch's (1952b, 1956) Line Judgment Task", Psychological Bulletin, 119 (1), 111 137.

Braun, O.L. and Wicklund, R.A. (1989), "Psychological antecedents of conspicuous consumption", Journal of Economic Psychology, 10 (2), 161-187.

Brown (2000), "Social Identity Theory: past achievements, current problems and future challenges", European Journal of Social Psychology, 30 (6), 634-667.

Brown, E.K., Asher, R.E. and Simpson, J.M.Y. (2006), "Encyclopedia of language \& linguistics", Volume 1, Edition 2. Elsevier.

Browne, M. W. and Cudeck, R. (1993), "Alternative ways of assessing model fit", In K. A. Bollen \& J. S. Long (Eds.), Testing structural equation models (pp. 136-162). Newbury Park, CA: Sage

Bryman, A., Bell, E., Mills, A.J. and Yue, A.R. (2011), "Business Research Methods", Oxford university Press, Don Mills, Ontario.

Burnell, P. J. (1986), "Economic nationalism in the third world”, Harvester Press, Brighton, Sussex, UK.

BusinessInsider (2011), "This is why the cheapest car in the world is a huge failure", available at https://www.businessinsider.com/tata-nano-failure-2011-12 (accessed 27 November 2019).

Byrne, B. (2010), "Structural Equation Modeling with AMOS: Basic Concepts, Applications and Programming (2nd edition)", Taylor and Francis group, New York, NY.

Campbell, D. T. and Fiske, D. W. (1959), "Convergent and discriminant validation by the multitrait-multimethod matrix", Psychological bulletin, 56(2), 81.

Cannon, H. M., Yoon, S.J., McGowan, L. and Yaprak, A. (1994). Toward a theory of crossnational segmentation. Paper presented at the Annual Meeting of the Academy of International Business, Maui. 
Cannon, H.M. and Yaprak, A. (2001), "Cosmopolitan-Based Cross National Segmentation in Global Marketing Simulations", Developments in Business Simulation and Experiential Learning, 28, 23-31.

Cannon, H.M. and Yaprak, A. (2002), "Will the real-world citizen please stand up! The many faces of cosmopolitan consumer behavior", Journal of International Marketing, $10(4), 30-52$.

Chang, M.K. (1998), "Predicting Unethical Behavior: A Comparison of the Theory of Reasoned Action and the Theory of Planned Behavior", Journal of Business Ethics, 17 (16), 1825-1834.

Charles, C.A.D. (2003), "Skin bleaching, self-hate, and Black identity in Jamaica", Journal of Black Studies, 33(6),711-718.

Cheah, I., Phau, I., Kea, G. and Huang, Y.A. (2016). "Modelling effects of consumer animosity: Consumers' willingness to buy foreign and hybrid products", Journal of Retailing and Consumer Services, 30, 184-192.

Cleveland, M. and Laroche, M. (2007), "Acculturation to the global consumer culture: Scale development and research paradigm", Journal of Business Research, 60 (3), 249259.

Cleveland, M., Laroche, M. and Papadopoulos, N. (2009), "Cosmopolitanism, Consumer Ethnocentrism, and Materialism: An Eight-Country Study of Antecedents and Outcomes," Journal of International Marketing, 17 (1), 116-146.

Cleveland, M., Erdogan, S., Arikan, G. and Poyraz, T. (2011), "Cosmopolitanism, individual-level values and cultural-level values: A cross-cultural study", Journal of Business Research, 64 (9), 934-943.

Cleveland, M., Laroche, M., Takahashi, I. and Erdogan, S. (2014), "Cross-linguistic validation of a unidimensional scale for cosmopolitanism", Journal of Business Research, 67 (3), 268-277.

Cleveland, M., Rojas-Méndez, J.I., Laroche, M. and Papadopoulos, N. (2016), "Identity, culture, dispositions and behavior: A cross-national examination of globalization and culture change", Journal of Business Research, 69 (3), 1090-1102.

Cleveland, M. and Balakrishnan, A. (2019) "Appreciating vs venerating cultural outgroups: The psychology of cosmopolitanism and xenocentrism", International Marketing Review, 36 (3), 416-444.

CNBC (2016), "China will be middle-income by 2030, with spending on cars, luxuries, health to rise", available at https://www.cnbc.com/2016/11/02/china-will-be-middle- 
income-by-2030with-spending-on-cars-luxuries-health-to-rise.html (accessed 26 May 2018).

Colman, A. M., Norris, C. E. and Preston, C. C. (1997), "Comparing rating scales of different lengths: Equivalence of scores from 5-point and 7- point scales", Psychological Reports, 80, 355-362.

Conner, M., Norman, P. and Bell, R. (2002), "The theory of planned behavior and healthy eating”, Health Psychology, 21 (2), 194-201.

Cortina, J. M. (1993), "What is coefficient alpha? An examination of theory and applications", Journal of applied psychology, 78(1), 98-104.

Countrymeters (2018), "Romanian Population 2018" available at https://countrymeters.info/en/Romania\#population_2018 (accessed 5 July 2019).

Craig, C. and Douglas, S. (2006), "Beyond national culture: Implications of cultural dynamics for consumer research", International Marketing Review, 23(3), 322-342.

Crystal, D. (2003), "English as a global language", Cambridge University Press, New York, NY.

Dawes, J. G. (2008), "Do data characteristics change according to the number of scale points used? An experiment using 5 point, 7 point and 10 point scales", International journal of market research, 51(1).

de Leff, J.F. (2002), "Racism in Mexico: Cultural Roots and Clinical Interventions", Family Process, 41(4), $619-623$.

de Mooij, M. (2011), "Consumer behavior and culture" $2^{\text {nd }}$ edition. Sage Publications, Thousand Oaks, CA.

de Mooij, M. (2013), "Global marketing and advertising: Understanding cultural paradoxes". Sage Publications, Thousand Oaks, CA.

Deng, S. and Boatler, R.W. (1993), "Worldmindedness among Canadian business students: Implications for curricula", Journal of Education for Business, 69 (2), 94-98.

de Ruyter, K., van Birgelen, M. and Wetzels, M. (1998), "Consumer ethnocentrism in international services marketing", International Business Review, 7 (2), 185-202.

Diamantopoulos, A., Davydova, O. and Arslanagic-Kalajdzic (2019), "Modeling the role of consumer xenocentrism in impacting preferences for domestic and foreign brands: A mediation analysis", Journal of Business Research, 104, 587-596.

Difallah, D. Filatova, E. and Ipeirotis, P. (2018), "Demographics and Dynamics of Mechanical Turk Workers", In Proceedings of WSDM 2018: The Eleventh ACM International Conference on Web Search and Data Mining, 135-143. 
Dillard, J.P. and Pfau, M.W. (2002), “The persuasion handbook: Developments in theory and practice", Sage Publications, London, UK.

Doll, W.J., Xia, W. and Torkzadeh, G. (1994), “A confirmatory factor analysis of the enduser computing satisfaction instrument”, MIS Quarterly 18(4), 357-369.

Dong, L. and Tian, K. (2009), "The use of Western brands in asserting Chinese national identity",

Journal of Consumer Research, 36(3), 504-523.

Douglas, S.P. and Nijssen, E.J. (2003), "On the use of "borrowed" scales in cross-national research: A cautionary note”, International Marketing Review, 20 (6), 621-642.

Druckman, D. (1994), "Nationalism, Patriotism and Group Loyalty: A Social Psychological Perspective", Mershon International Studies Review, 38 (1), 43-68.

Eagly, A.H. (1983), "Gender and social influence: A social psychological analysis", American Psychologist, 38(9), 971-981.

Earley and Erez (1997), “The Transplanted Executive: Why You Need to Understand How Workers in Other Countries See the World Differently 1st Edition", Oxford university press, New York.

Eastman, J.K., Goldsmith, R.E. and Flynn, L.R. (1999), "Status Consumption in Consumer Behavior: Scale Development and Validation", Journal of Marketing Theory and Practice, 7 (3), 41-52.

Ettenson, R. and Klein, J.G. (2005), "The fallout from French nuclear testing in the South Pacific: A longitudinal study of consumer boycotts", International Marketing Review, 22 (2), 199-224.

Euromonitor International (2018), "Income and Expenditure in Asia Pacific", Retrieved from https://blog.euromonitor.com/2018/05/income-expenditure-asia-pacific.html (accessed 11 Sep 2018).

Evanschitzky, H. and Wunderlich, M. (2006), “An examination of moderator effects in the four-stage loyalty model", Journal of Service Research, 8 (4), 330- 345.

Everitt, B.S., Landau, S., Leese, M. and Stahl, D. (2011), Cluster Analysis $5^{\text {th }}$ edition, John Wiley and Sons, Chichester, West Sussex.

Farh, J-L., Hackett, R.D. and Liang, J. (2007), "Individual-Level Cultural Values as Moderators of Perceived Organizational Support-Employee Outcome Relationships in China: Comparing the Effects of Power Distance and Traditionality", The Academy of Management Journal, 50(3), 715-729.

Festinger, L. (1954), “A theory of social comparison processes”, Human Relations, 7(2), $117-140$. 
Festinger, L. (1957). "A theory of cognitive dissonance". Stanford university press. California.

Figueiredo, B. (2012), "How Global Mobility Shapes Consumption Practices", doctoral dissertation, University of New South Wales.

Financial Observer (2017), "Romania shows fast economic growth after 10 years in EU", available at https://financialobserver.eu/cse-and-cis/romania/romania-shows-fasteconomic-growth-after-10-years-in-eu/ (accessed 9 Sep 2018).

Financial Times (2017), "Mexican affection for US endures despite Trump", available at https://www.ft.com/content/cc14b2d6-cf69-11e7-9dbb-291a884dd8c6 (accessed 26 May 2018).

Financial Times (2018), "What's at stake in US-China trade war", available at https://ig.ft.com/us-china-tariffs/ (accessed 5 November 2018).

Fishbein, M. and Ajzen, I. (1975), "Belief, Attitude, Intention, and Behavior: An Introduction to Theory and Research", Addison-Wesley, Reading, MA.

Fornell, C. and Larcker, D.F. (1981), "Evaluating structural equation models with unobservable variables and measurement error", Journal of Marketing Research, 18(1), $39-50$.

Furrer, O., Liu, B. S-C. and Sudharshan, D. (2000), "The relationships between culture and service quality perceptions: Basis for cross-cultural market segmentation and resource allocation", Journal of Service Research, 2 (4), 355-371.

Gammoh, B.S., Koh, A. C. and Okoroafo, S.C. (2011) "Consumer culture brand positioning strategies: an experimental investigation", Journal of Product and Brand Management, 20 (1), 48-57.

Gaur, S.S., Bathula, H. and Diaz, C.V. (2015), "Conceptualising the influence of the cultural orientation of Latin Americans on consumers' choice of US brands", European Business Review, 27 (5), 477-494.

Gerson, J. (2004), "Malinchismo: betraying one's own" in T. Singer and S.L. Kimbles (eds), The Cultural Complex: Contemporary Jungian Perspectives on Psyche and Society, Brunner- Routledge, New York, NY.

Globe and Mail (2018), "Canada- Saudi rift: The next steps forward for Ottawa", available at https://www.theglobeandmail.com/opinion/article-canada-saudi-rift-the-next-stepsforward-for-ottawa/ (accessed 17 Aug 2018).

Goldberg, M. E. and Baumgartner, H. (2002), "Cross-Country Attraction as a Motivation for Product Consumption," Journal of Business Research, 55 (11), 901-906. 
Gouldner, A. W. (1957). "Cosmopolitans and Locals: Toward an Analysis of Latent Social Roles," Administrative Science Quarterly, 2 (3), 281-306.

Gransin, K.L. and Olsen, J.E. (1998), “Americans' Choice of Domestic over Foreign Products: A Matter of Helping Behavior?”, Journal of Business Research, 43 (1), 39-54.

Griethuijsen, R. A. L. F., Eijck, M. W., Haste, H., Brok, P. J., Skinner, N. C., Mansour, N., Gencer, A.Y. and BouJaoude, S. (2014), "Global patterns in students' views of science and interest in science", Research in Science Education, 45(4), 581-603.

Grimm, P. (2010), "Social Desirability Bias" in Sheth J.N. and Malhotra N.K., eds., Wiley international encyclopedia of marketing, (New York, USA: John Wiley and Sons). http://onlinelibrary.wiley.com/doi/10.1002/9781444316568. wiem02057/abstract.

Gaur, S.S., Bathula, H. and Diaz, C.V. (2015), "Conceptualising the influence of the cultural orientation of Latin Americans on consumers' choice of US brands", European Business Review, 27 (5), 477-494.

Gunkel, M., Schlagel, C. and Engle, R.L. (2014), “Culture's Influence on Emotional Intelligence: An Empirical Study of Nine Countries ”, Journal of International Management, 20(2), 256-274.

Guo, X. (2013), "Living in a Global World: Influence of consumer global orientation on attitudes towards global brands from developed versus emerging countries", Journal of International Marketing, 21 (1), 1-22.

Hair, J. F., Jr., Black, W. C., Babin, B. J., and Anderson, R. E. (2009), Multivariate data analysis (7th ed.). Upper Saddle River, NJ: Pearson Prentice Hall.

Han, C.M. (1988), "The role of consumer patriotism in the choice of domestic versus foreign products", Journal of Advertising Research, 28, 25-32.

Hannerz, U. (1990), "Cosmopolitans and Locals in a World Culture," Theory, Culture and Society, 7, 237-51.

Harrington, D. (2008), “Confirmatory factor analysis”, Oxford University Press, USA.

Hazeltine, J.E. and Rezvanian, R. (1998), "World-Mindedness Among American and Russian Business Students: A Comparison”, Journal of Education for Business, 73 (6), 344-346.

He, J. and Wang, C.L. (2015), "Cultural identity and consumer ethnocentrism impacts on preference and purchase of domestic versus import brands: An empirical study in China", Journal of Business Research, 68 (6), 1225-1233.

Higgins, E.T. (1997), “Beyond pleasure and pain”, American Psychologist, 52 (12), 12801300 . 
Hill, R. (1998), "What sample size is "enough" in internet survey research?", Interpersonal Computing and Technology: An Electronic Journal for the 21st Century, 6(3-4)., 1-10.

Hirschman, E.C. and Holbrook, M.B. (1982), "Hedonic Consumption: Emerging Concepts, Methods and Propositions", Journal of Marketing, 46 (3), 92-101.

Hjerm, M. (1998), "National Identities, National Pride and Xenophobia: A comparison of four Western countries", Acta Sociologica, 41 (4), 335-347.

Hofstede, G. (1980), "Culture's Consequences: International Differences in Work-related Values", Beverly Hills: Sage.

Hofstede, G. (1991), "Cultures and Organizations: Software of the Mind", London: McGraw-Hill.

Hofstede (2018a), “Country comparison: What about Indonesia?", available at https://www.hofstede-insights.com/country-comparison/indonesia/ (accessed 26 May 2018).

Hofstede (2018b), “Compare countries", available at https:/www.hofstedeinsights.com/product/compare-countries/ (accessed 14 August 2018).

Hofstede (2018c), "The 6 dimensions of national culture", available at https://www.hofstede-insights.com/models/national-culture/ (accessed 26 May 2018).

Hofstede (2018d), "Country comparison - India", available at https://www.hofstedeinsights.com/country-comparison/india/ (accessed 9 Sep 2018).

Hofstede (2018e), "Country comparison - Romania", available at https://www.hofstedeinsights.com/country-comparison/romania/ (accessed 9 Sep 2018).

Hofstede (2018f), "Country comparison - Ecuador", available at https://www.hofstedeinsights.com/country-comparison/ecuador/ (accessed 9 Sep 2018).

Hofstede (2018g), "Country comparison - Kenya", available at https://www.hofstedeinsights.com/country/kenya/ (accessed 10 Nov 2018).

Hofstede, G., Hofstede, G.J. and Minkov, M. (2010), "Cultures and Organizations: Software of the Mind", 3rd ed., New York: McGraw-Hill.

Hofstede, G. and McCrae, R.R. (2004), "Personality and Culture Revisited: Linking Traits and Dimensions of Culture", Cross-Cultural Research, 38(1), 52-88.

Hofstede, G. and Minkov, M. (2010), "Long- versus short-term orientation: new perspectives", Asia Pacific Business Review, 16 (4), 493-504.

Holden, R. B. (2010). "Face validity". In Weiner, Irving B.; Craighead, W. Edward. The Corsini Encyclopedia of Psychology (4th ed.). Hoboken, New Jersey: Wiley. pp. 637-638. 
Holt, D. B. (1997), "Distinction in America? Recovering Bourdieu's theory of tastes from its critics", Poetics, 25(2/3), 93-120.

Holt, D.B. (1998), "Does Cultural Capital Structure American Consumption?”, Journal of Consumer Research, 25(1), 1-25.

Hong, S. T. and Wyer, R. S., Jr. (1990), "Determinants of product evaluation: Effects of the time interval between knowledge of a product's country of origin and information about its specific attributes", Journal of Consumer Research, 17(3), 277-288.

Hornsey, M.J. (2008), "Social Identity Theory and Self-categorization Theory: A Historical Review", Social and Personality Psychology Compass, 2 (1), 204-222.

Howard, D.G. (1989), "Understanding How American Consumers Formulate Their Attitudes about Foreign Products." Journal of International Consumer Marketing, 2 (2), 7 24.

Hu, L. and Bentler, P.M. (1999), "Cutoff criteria for fit indexes in covariance structure analysis: Conventional criteria versus new alternatives", Structural Equation Modeling: A Multidisciplinary Journal, 6(1), 1-55.

Huang, Y-A., Phau, I. and Lin, C. (2010), "Consumer animosity, economic hardship, and normative influence: How do they affect consumers' purchase intention?", European Journal of Marketing, 44 (7/8), 909-937.

Hui, H. (1988), "Measurement of individualism-collectivism", Journal of Research in Personality, 22(1), 17-36.

Hyman, H. H. (1942), "The Psychology of Status," Archives of Psychology, 269, 94-102.

IBM (2019), "Wilks' Lambda", available at http://www.ibm.com/support/knowledgecenter/SSLVMB_21.0.0/com.ibm.spss.statistics. cs/discrim_bankloan_wilks.htm (accessed on 20 Dec 2019).

Indexmundi (2018a), "Ecuador age structure", available at https://www.indexmundi.com/ecuador/age_structure.html (accessed 5 July 2019).

Indexmundi (2018b), "Romania age structure", available at https://www.indexmundi.com/romania/age_structure.html (accessed 5 July 2019).

Indexmundi (2018c), "Kenya age structure", available at https://www.indexmundi.com/kenya/age_structure.html (accessed 5 July 2019).

Indexmundi (2018d), "India demographics profile 2018", available at https://www.indexmundi.com/india/demographics_profile.html (accessed 5 July 2019). 
Ishii, K. (2009), "Nationalistic Sentiments of Chinese Consumers: The Effects and Determinants of Animosity and Consumer Ethnocentrism", Journal of International Consumer Marketing, 21 (4), 299-308.

Javalgi, R.G., Khare, V.P., Gross, A.C. and Scherer, R.F. (2005), “An application of the consumer ethnocentrism model to French consumers", International Business Review, 14 (3), 325-344.

Josiassen, A. (2011), "Consumer Disidentification and Its Effects on Domestic Product Purchases: An Empirical Investigation in the Netherlands", Journal of Marketing, 75 (2), 124-140.

Josiassen, A., Assaf, A.G. and Karpen, I.O. (2011), "Consumer ethnocentrism and willingness to buy: Analyzing the role of three demographic consumer characteristics", International Marketing Review, 28 (6), 627-646.

Jost, J. T. and Banaji, M. R. (1994), "The role of stereotyping in system-justification and the production of false consciousness". British Journal of Social Psychology, 33(1), 1-27.

Jost, J. T. and Burgess, D. (2000), "Attitudinal Ambivalence and the Conflict Between Group and System Justification Motives in Low Status Groups," Personality and Social Psychology Bulletin, 26 (3), 293-305.

Jost, J.T. and Hunyady, O. (2005). "Antecedents and Consequences of System-Justifying Ideologies," Current Directions in Psychological Science, 14 (5), 260-265.

Julious, S. A. (2005), "Sample size of 12 per group rule of thumb for a pilot study", Pharmaceutical Statistics, 4(4), 287-291.

Kagitcibasi, C. (1978), "Cross-National Encounters: Turkish Students in the United States,"

International Journal of Intercultural Relations, 2 (2), 141-160.

Kala, D. and Chaubey, D.S. (2016), "Country-of-origin effect and consumers' buying behavior: An evidence from Indian market", Management Convergence, 7 (1), 47-59.

Kalafatis, S.P., Pollard, M., East, R. and. Tsogas, M.H. (1999), "Green marketing and Ajzen's theory of planned behavior: a cross-market examination", Journal of Consumer Marketing, 16(5), 441-460.

Karasawa, M. (2002), "Patriotism, Nationalism, and Internationalism among Japanese Citizens: An Etic-Emic Approach," Political Psychology, 23 (4), 645-666. 
Kastanakis, M.N. and Balabanis, G. (2012), "Between the mass and the class: Antecedents of the "bandwagon" luxury consumption behavior", Journal of business research, 65, 1399-1407.

Keillor, B. D., Hult, T. M., Erffmeyer, R. C. and Babakus, E. (1996), "NATID: The Development and Application of a National Identity Measure for Use in International Marketing", Journal of International Marketing, 4(2), 57-73.

Kent, D.P. and Burnight, R.G. (1951), "Group Centrism in Complex Societies," American Journal of Sociology, 57 (3), 256-259.

Kim, C., Laroche, M. and Tomiuk, M.A. (2001), "Measure of Acculturation for ItalianCanadians: Scale Development and Construct Validation," International Journal of Intercultural Relations, 25 (6), 607 - 637.

Kiriri, P.N. (2019), "Consumer ethnocentrism and attitudes towards local products: A case of Kenyan consumers", The University Journal, 1(3), 1-18.

Kirkman, B.L., Chen, G., Farh, J-L., Chen, Z.X. and Lowe, K.B. (2009), "Individual Power Distance Orientation and Follower Reactions to Transformational Leaders: A Cross-Level, Cross-Cultural Examination", Academy of management Journal, 52(4), 744-764.

Kisawike, B. (2015), "How country of origin, consumer ethnocentrism and consumer xenocentrism impact upon risk and involvement in the malaria medication decision making process in Tanzania”, doctoral dissertation, University of Hull.

Klein, J.G., Ettenson, R. and Morris, M.D. (1998), "The Animosity Model of Foreign Product Purchase: An Empirical Test in the People's Republic of China", Journal of Marketing, 62 (1), 89-100.

Klein, J.G. and Ettensoe, R. (1999), "Consumer Animosity and Consumer Ethnocentrism", Journal of International Consumer Marketing, 11(4), 5-24.

Kline, R. B. (2011), "Principles and practice of structural equation modeling", Guilford press, New York, NY.

Kosterman, R. and Feshbach, S. (1989), "Toward a Measure of Patriotic and Nationalistic Attitudes”, Political Psychology, 10 (2), 257-274.

KPMG (2017), "India: the last great untapped opportunity", available at https:/home.kpmg.com/xx/en/home/insights/2017/01/india-the-last-great-untappedopportunity.html (accessed 9 Sep 2018).

Krumpal, I. (2013), "Determinants of social desirability bias in sensitive surveys: a literature review", Quality and Quantity, 47(4), 2025-2047. 
Kuran, T. (1995), "Private Truths, Public Lies: The Social Consequences of Preference Falsification", Harvard University Press, Cambridge, MA.

Kwak, H., Jaju, A. and Larsen, T. (2006), "Consumer Ethnocentrism Offline and Online: The Mediating Role of Marketing Efforts and Personality Traits in the United States, South Korea, and India", Journal of the Academy of Marketing Science, 34 (3), 367-385.

Lastovicka, J. L. and Bonfield, E. H. (1980), "Exploring the nomological validity of lifestyle types", Advances in Consumer Research, 7(1).

Lawrence, S. J. (2012), "Consumer Xenocentrism and Consumer Cosmopolitanism: The Development and Validation of Scales of Constructs Influencing Attitudes Towards Foreign Product Consumption," doctoral dissertation, Wayne State University.

Lee, J. W., Jones, P. S., Mineyama, Y. and Zhang, X. E. (2002), "Cultural Differences in Responses to a Likert Scale", Research in Nursing and Health, 25, 295-306.

Lee, W-N., Hong, J-Y. and Lee, S-J. (2003), "Communicating with American consumers in the post 9/11 climate: an empirical investigation of consumer ethnocentrism in the United States", International Journal of Advertising, 22(4), 487-510.

Lee, K.T., Lee, Y. Lee, R. (2014), "Economic nationalism and cosmopolitanism: A study of interpersonal antecedents and differential outcomes", European Journal of Marketing, $48(5 / 6), 1133-1158$.

Levitt, T. (1983), "The globalization of markets", Harvard Business Review (May-June), 92-102.

Li, J., Liu, F. and Rojas-Mendez, J.I. (2013), "How international students select offshore programs: The influence of image, attitude, subject norm, and perceived behavioral control", Asia Pacific Education Review, 14(3), 381-390.

Lowry, P.B., D’Arcy, J., Hammer, B. and Moody, G.D. (2016), ““'Cargo Cult” science in traditional organization and information systems survey research: A case for using nontraditional methods of data collection, including Mechanical Turk and online panels", Journal of Strategic Information Systems, 25, 232-240.

Lun, V. M.C. and Bond, M.H. (2006), "Achieving Relationship Harmony in Groups and Its Consequence for Group Performance," Asian Journal of Social Psychology, 9 (3), 195202.

Mackie, D. M. and Smith, E.R. (1998), "Intergroup Relations: Insights from a Theoretically Integrative Approach," Psychological Review, 105 (4), 499-529.

Magnusson, P. Westjohn, S.A. and Zdravkovic, S. (2015), "An examination of the interplay between corporate social responsibility, the brand's home country, and consumer global identification", International Marketing Review, 32 (6), 663-685. 
Maslow, A. (1954), "Motivation and personality”, Harper and Row Publishers, New York.

Mazzocco, P.J., Rucker, D. D., Galinsky A. D. and Anderson E. T. (2012), "Direct and Vicarious Conspicuous Consumption: Identification with Low-Status Groups Increases the Desire for High-Status Goods," Journal of Consumer Psychology, 22 (4), 520-528.

McClelland, D. (1961), “The Achieving Society”, Van Nostrand, New Jersey.

Merriam-Webster (2016), "Xenocentric", available at https://www.merriamwebster.com/dictionary/xenocentric (accessed 27 Oct 2018).

Merton, R.K. and Rossi, A.K. (1950) 'Contributions to the Theory of Reference Group Behavior' in R.K. Merton and P.F. Lazarsfeld (eds), Continuities in Social Research Free Press, New York.

Merton, R.K. (1957a), "Patterns of Influence: Local and Cosmopolitan Influentials" in Social Theory and Social Structure, The Free Press, New York.

Merton, R. K. (1957b), "Social Theory and Social Structure”, The Free Press, New York. Middendorf, J. and Kalish, A. (1996), "The "change-up" in lectures", The National Teaching and Learning Forum, 5(2), 1-5.

Miller, J.D. (1985). "The nominative technique: a new method of estimating heroin prevalence", NIDA Research Monograph, 57, 104-124.

Minkov, M., and Hofstede, G. (2011), "The evolution of Hofstede's doctrine", Cross Cultural Management: An International Journal, 18(1), 10-20.

Montemayor, J.I.N. (2015), "Legitimacy of Philippine Sovereignty (A library research paper)", working paper, University of Philippines.

Montero, M. (1986), "Political Psychology in Latin America?' In Political Psychology. Ed. Hermann G. Margaret, San Francisco: Jossey-Bass, 23-54.

Mueller, R.D. and Broderick, A.J. (2009), "Consumer Xenocentrism: An Alternative Explanation for Foreign Product Bias,” working paper, University of Charleston.

Mueller, R.D., Wang, G.X., Liu, G. and Cui, C.C. (2016), "Consumer xenocentrism in China: an exploratory study", Asia Pacific Journal of Marketing and Logistics, 28 (1), 7391.

Netemeyer, R.G., Bearden, W.O. and Sharma, S. (2003), Scaling Procedures: Issues and Applications. Thousand Oaks, CA: Sage Publications.

Nijssen, E.J. and Douglas, S.P. (2008), "Consumer World-Mindedness, SocialMindedness, and Store Image”, Journal of International Marketing, 16(3), 84-107. 
Nolan, J.M., Schultz, P.W., Cialdini, R.B., Goldstein, N.J. and Griskevicius, V. (2008), "Normative Social Influence is underdetected", Personality and Social psychology bulletin, 34 (7), 913-923.

Nunnally, J. C. (1978), "Psychometric theory (2nd ed.)", McGraw-Hill. New York, NY.Raykov, T., Tomer, A. and Nesselroade, J. R. (1991), "Reporting structural equation modeling results in Psychology and Aging: some proposed guidelines", Psychology and aging, 6(4), 499.

Nunnally, J. C., and Bernstein, I. H. (1994). Psychometric theory (3rd ed.). New York: McGraw-Hill.

Oberecker, E.M., Riefler, P. and Diamantopoulos, A. (2008), "The Consumer Affinity Construct: Conceptualization, Qualitative Investigation, and Research Agenda", Journal of International Marketing, 16 (3), 23-56.

Oberecker, E.M. and Diamantopoulos, A. (2011), "Consumers' Emotional Bonds with Foreign Countries: Does Consumer Affinity Affect Behavioral Intentions?”, Journal of International Marketing, 19 (2), 45-72.

Okechuku, C. and Onyemah, V. (1999), "Nigerian consumer attitude toward foreign and domestic products", Journal of International Business Studies, 30(3), 611-622.

Papadopoulos, N. (1999), "Product-country Images", in Michael J. Baker, ed., The Encyclopedia of Marketing, 2nd edition (London, UK: International Thomson Business Press), 719-731.

Parts, O. and Vida, I. (2013), "The effects of cosmopolitanism on consumer ethnocentrism, product quality, purchase intentions and foreign product purchase behavior", American International Journal of Contemporary Research, 3 (11), 144-155.

Passport (2018), "Apparel and Footwear in Romania", Retrieved from http://go.euromonitor.com/passport.html (accessed 9 Sep 2018).

Pearl, J. (2000), Causality: Models, Reasoning, and Inference (2 ${ }^{\text {nd }}$ ed.), New York, Cambridge University Press.

Perlmutter, H. (1954), "Some Characteristics of the Xenophilic Personality," The Journal of Psychology, 38 (2), 291-300.

Pham, M.T. and Chang, H.H. (2010), "Regulatory Focus, Regulatory Fit, and the Search and Consideration of Choice Alternatives", Journal of Consumer Research, 37 (4), 626640.

Phau, I. and Teah, M. (2009), "Devil wears (counterfeit) Prada: a study of antecedents and outcomes of attitudes towards counterfeits of luxury brands", Journal of Consumer Marketing, 26 (1), 15-27. 
Ping, R.A. (2004), “On assuring valid measures for theoretical models using survey data”, Journal of Business Research, 57(2), 125-141.

Pratto, F., Sidanius, J., Stallworth, L.M. and Malle, B.F. (1994), "Social Dominance Orientation: A Personality Variable Predicting Social and Political Attitudes," Journal of Personality and Social Psychology, 67 (4), 741-763.

Prince, M., Davies, M.A.P., Cleveland, M. and Palihawadana, D. (2016), "Here, there and everywhere: a study of consumer centrism", International Marketing Review, 33 (5), 715754.

Procter and Gamble (2010), "P\&G Old Spice Latest innovations", available at https://www.pg.com/en_US/downloads/innovation/factsheet_OldSpice.pdf (accessed 26 May 2018).

Qualtrics (2018), "Straightlining: What is it? How can it hurt you? And how to protect against it.", available at https:/www.qualtrics.com/blog/straightlining-what-is-it-how-canit-hurt-you-and-how-to-protect-against-it/ (accessed 9 Sep 2018).

Rawwas, M.Y.A., Rajendran, K.N. and Wuehrer, G.A. (1996), "The influence of worldmindedness and nationalism on consumer evaluation of domestic and foreign products", International Marketing Review, 13(2), 20-38.

Ray, J.J. (1983), “A scale to measure conservatism of American public opinion”, The Journal of Social Psychology, 119 (2), 293-294.

Reuters (2014), "The global business of secondhand clothes thrives in Kenya", available at https://www.reuters.com/article/us-kenya-textiles/the-global-business-of-secondhandclothes-thrives-in-kenya-idUSKCN0I41DS20141015 (accessed 11 Nov 2018).

Richins, M. L. and Dawson, S. (1992), "A Consumer Values Orientation for Materialism and Its Measurement: Scale Development and Validation," Journal of Consumer Research, 19 (3), 303-16.

Riefler, P. and Diamantopoulos, A. (2009), "Consumer cosmopolitanism: Review and replication of the CYMYC scale", Journal of Business Research, 62(4), 407-419.

Riefler, P., Diamantopoulos, A. and Siguaw, J.A. (2012), "Cosmopolitan consumers as a target group for segmentation", Journal of International Business Studies, 43 (3), 285-305.

Rojas-Méndez, J.I. and Chapa, S. (2017), "What is Xenocentrism? A Scale Proposal (Xscale) for Measuring its Consumer and Social Dimensions", The 2017 Academy of International Business Conference, Dubai, UAE.

Rojas-Méndez, J.I. and Chapa, S. (2019), "X-scale: a new scale to measure consumer xenocentrism", Market Intelligence and Planning, in print. 
Rojas-Méndez, J.I., Kannan, D. and Ruci, L. (2019), "The Japan brand personality in China: is it all negative among consumers?", Place Branding and Public Diplomacy, 15 (2), 109-123.

Rojas-Méndez, J.I. and Kolotylo, J. (2018), "Consumer Xenocentrism in Russia: Analysis of a Moderator and Consequences", 4th Academy of Business and Emerging Markets (ABEM) Conference, Manila, Philippines.

Rojas-Méndez, J., Murphy, S. and Papadopoulos, N. (2013), "The U.S. brand personality: A Sino perspective”, Journal of Business Research, 66, pp. 1028-1034.

Romania Insider (2017), "Purchasing power in Romania, a third of European average despite 12\% growth in 2016" available at https://www.romania-insider.com/purchasingpower-in-romania-a-third-of-european-average/ (accessed 9 Sep 2018).

Rosenberg, M. (1979), “Conceiving the Self”, Basic Books, New York.

Russell, C.A., Russell, D.W. and Neijens, P.C. (2011), "Consumption expressions of ideological resistance”, European Journal of Marketing, 45 (11/12), 1715-1724.

Ryan, R. M. and Deci, E. L. (2002), "Self-determination theory and the facilitation of intrinsic motivation, social development, and well-being”, American Psychologist, 55(1), $68-78$.

Saffu, K. and Walker, J. (2005), "An assessment of the consumer ethnocentric scale (CETSCALE) in an advanced and transitional country: the case of Canada and Russia", International Journal of Management, 22(4), 556-571.

Sampson, D.L. and Smith, H.P. (1957), "A scale to measure world-minded attitudes", The journal of social psychology, 45(1), 99-106.

Saran, A. and Kalliny, M. (2012), "Cosmopolitanism: Concept and Measurement," Journal of Global Marketing, 25 (5), 282-291.

Schatz, R.T., Staub, E. and Lavine, H. (1999), "On the Varieties of National Attachment: Blind Versus Constructive Patriotism”, Political Psychology, 20 (1), 151-174.

Schmid, S. and Dauth, T. (2014), "Does internationalization make a difference? Stock market reaction to announcements of international top executive appointments", Journal of World Business, 49 (1), 63-77.

Schooler, R. D. (1971), "Bias phenomena attendant to the marketing of foreign goods in the US", Journal of International Business Studies, 2 (1), 71-80.

Schreiber, J. B., Amaury, N., Stage, F. K., Barlow, E. A. and King, J. (2006), "Reporting structural equation modeling and confirmatory factor analysis results: A review", The Journal of Educational Research, 99(6), 323-337. 
Shankarmahesh, M.N. (2006) "Consumer ethnocentrism: an integrative review of its antecedents and consequences", International Marketing Review, 23 (2), 146-172.

Sharma, S., Shimp, T.A. and Shin, J. (1995), "Consumer ethnocentrism: A test of antecedents and moderators", Journal of the Academy of Marketing Science, 23 (1), 26-37.

Sharma, P. (2015), "Consumer ethnocentrism: Reconceptualization and cross-cultural validation”, Journal of International Business Studies, 46 (3), 381-389.

Shay, J. P. and Back, S. A. (2004), "Expatriate assignment, adjustment and effectiveness: An empirical examination of the big picture", Journal of International Business Studies, 35(3), 216-232.

Shi, Z., Wen, L. and Fan, L. (2012), "How Chinese face perception influences consumer's implicit and explicit attitudes towards brand country of origin", International Journal of Business and Management, 7(5), 123-139.

Shih, Y-Y. and Fang, K. (2004), "The use of a decomposed theory of planned behavior to study Internet banking in Taiwan", Internet Research, 14(3), 213-223.

Shimp, T.A. and Sharma, S. (1987), "Consumer-Ethnocentrism: Construction and Validation of the CETSCALE", Journal of Marketing Research, 24(3), 280-289.

Shoham, A. and Brenčič, M.M. (2003), "Consumer Ethnocentrism, Attitudes, and Purchase Behavior", Journal of International Consumer Marketing, 15 (4), 67-86.

Shoham, A. Davidow, M., Klein, J.G. and Ruvio, A. (2006), "Animosity on the Home Front: The Intifada in Israel and Its Impact on Consumer Behavior", Journal of International Marketing, 14 (3), 92-114.

Shoham, A., Segev, S. and Gavish, Y. (2017), "The effect of acculturation and ethnic identification on consumer disidentification and consumption: An investigation of U.S. Hispanics", Journal of Consumer Behaviour,16 (5), 403-412.

Siamagka, N-T. and Balabanis, G. (2015), "Revisiting Consumer Ethnocentrism: Review, Reconceptualization, and Empirical Testing”, Journal of International Marketing, 23(3), 66-86.

Singelis, T.M., Triandis, H.C., Bhawuk, D.P.S. and Gelfand, M.J. (1995), "Horizontal and Vertical Dimensions of Individualism and Collectivism: A Theoretical and Measurement Refinement", Cross-Cultural Research, 29(3), 240-275.

Sirgy, M. J. (1982), "Self-Concept in Consumer Behavior: A Critical Review", Journal of Consumer Research, 9(3), 287-300. 
Sirota, D., Mischkind, L.A. and Meltzer, M.I. (2005), "The Enthusiastic Employee: How Companies Profit by Giving Workers What They Want", Wharton school publishing, New Jersey.

Sivanathan, N. and Pettit, N.C. (2010), "Protecting the Self Through Consumption: Status Goods as Affirmational Commodities," Journal of Experimental Social Psychology, 46 (3), 564-570.

Sødergaard, M. (1994), "Hofstede's Consequences: A Study of Reviews, Citations and Replications," Organization Studies, 15 (3), 447-56.

Song, W. (2012), "Possible causes inhibiting the purchase of Chinese grocery own brands: a preliminary study", Journal of Business and Economics and Management, 13(2), 207-222.

Soto, M.H. (2008), "Does the malinchismo effect really exist in the Mexican consumer?" doctoral dissertation, Johannes Kepler University.

Spears, N. and Singh, S.N. (2004), "Measuring Attitude toward the Brand and Purchase Intentions", Journal of Current Issues and Research in Advertising, 26(2), 53-66.

Spence, M. (1973), “Job market signaling”, The Quarterly Journal of Economics, 87 (3), 355-374.

Sperber, A. D., Devellis, R. F. and Boehlecke, B. (1994), "Cross-cultural translation methodology and validation”, Journal of cross-cultural psychology, 25(4), 501-524.

Standard Media (2018), "Smartphone usage drives Kenya's Internet penetration", available at https://www.standardmedia.co.ke/business/article/2001273507/smartphone-adoptionputs-kenya-at-top-of-internet-penetration-in-africa (accessed 11 Nov 2018).

StatisticsTimes (2018), "Sex ratio in India", available at http://statisticstimes.com/demographics/sex-ratio-of-india.php (accessed 5 July 2019).

Strizhakova, Y., Coulter, R.A. and Price, L.L. (2008), "Branded Products as a Passport to Global Citizenship: Perspectives from Developed and Developing Countries", Journal of International Marketing, 16 (4), 57-85.

Strizhakova, Y., Coulter, R.A. and Price, L.L. (2011), "Branding in a global marketplace: The mediating effects of quality and self-identity brand signals", International Journal of research in marketing, 28 (4), 342-351.

Strizhakova, Y. and Coulter, R.A. (2015), "Drivers of local relative to global brand purchases: A contingency approach”, Journal of International Marketing, 23 (1), 1-22.

Suh, T. and Kwon, I.G. (2002), "Globalization and reluctant buyers", International Marketing Review, 19 (6), 663-680. 
Sumner, G.A. (1906), “Folkways”, Ginn Custom Publishing, New York.

Swartz, M.J. (1961), "Negative Ethnocentrism", The Journal of Conflict Resolution, $5(1), 75-81$.

Szromnik, A. (2014), "Consumer ethnocentrism vs consumer xenocentrism - An attempt to identify the anatomy of the phenomenon", Scientific journal, 6(1/2), 27-47.

Tabachnick, B. G. and Fidell, L. S. (2001), "Using multivariate Statistics”, Allyn and Bacon, Needham Heights, Massachusetts.

Tajfel, H. and Turner, J. C. (1979), "An integrative theory of intergroup conflict", in The Social Psychology of Intergroup Relations, Monterey, CA: Brooks/Cole, 33-47.

Tajfel, H. and Turner, J.C. (1986) "The Social Identity of Inter-group Behavior" in S.Worchel and W. Austin (eds), Psychology of Inter-group Relations, Nelson-Hall, Chicago, IL.

The Economic Times (2018), "India fastest growing economy at 7.4 per cent in 2018: IMF", available at https://economictimes.indiatimes.com/news/economy/indicators/indiafastest-growing-economy-at-7-4-per-cent-in-2018-imf/articleshow/64089078.cms (accessed 9 Sep 2018).

The New York Times (2011), "India Faces a Linguistic Truth: English Spoken Here", available at https://www.nytimes.com/2011/02/17/world/asia/17iht-letter17.html (accessed 9 Sep 2018).

The World Bank (2018a), "World Bank Country and Lending groups", available at https://datahelpdesk.worldbank.org/knowledgebase/articles/906519-world-bank-countryand-lending-groups (accessed 9 Sep 2018).

The World Bank (2018b), "GDP - All countries and economies", available at https://data.worldbank.org/indicator/NY.GDP.MKTP.CD?view=map\&year_high_desc=tr ue (accessed 9 Sep 2018).

Thompson, C.J. and Tambyah, S.K. (1999), "Trying to be cosmopolitan", Journal of Consumer Research, 26(3), 214-241.

Time (2013), "China and Japan may not like each other, but they need each other", available at http://world.time.com/2013/12/01/china-and-japan-may-not-like-each-otherbut-they-need-each-other/ (accessed 17 Aug 2018).

Tom, G., Nelson, C. Srzentic, T. and King, R. (2007), "Mere exposure and the endowment effect on consumer decision making", The journal of psychology, 141(2), 117-125.

TradingEconomics (2018), "Kenya-Population", available at https://tradingeconomics.com/kenya/population-female-percent-of-total-wb-data.html (accessed 5 July 2019). 
Traian-Alexandru (2016), "Ethnocentrism - the danger of cultures' collision", International Journal of Interdisciplinary Scientific Research, 2(4), 101- 105.

Tu, L., Khare, A. and Zhang, Y. (2012), “A short 8-item scale for measuring consumers' local-global identity", International journal of research in marketing, 29 (1), 35-42.

Turner, J.C. and Reynolds, K.J. (2011), "Self-categorization theory", in Handbook of Theories of Social Psychology, London: Sage publications, 399-417.

Ueltschy, L.C. and Ryans, J.K. (1997), "Employing Standardized promotion strategies in Mexico: The impact of language and cultural differences", The International Executive, 39 (4), 479-495.

United Nations Dispatch (2018), "Here's how every country in the world ranks on gender equality", available at https://www.undispatch.com/heres-every-country-world-ranksgender-equality/ (accessed 1 August 2018).

UN Women (2018), "UN Women - Asia and the Caribbean", available at http://lac.unwomen.org/en/donde-estamos/ecuador (accessed 5 July 2019).

Upadhyay, Y. and Singh, S. K. (2006), "Preference for domestic goods: A study of consumer ethnocentrism", Vision: The Journal of Business Perspective, 10(3), 59-68.

van Herk, H. and Torelli, C. J. (2017), "Cross cultural issues in consumer science and consumer psychology: Current perspectives and future directions", Springer, Cham, Switzerland.

van Teijlingen, E. and Hundley, V. (2001), "The importance of pilot studies", Social research update, (35), 1-4.

Veblen, T. (1899), "The theory of the leisure class: An economic study of institutions", Unwin Books, London.

Verkuyten, M. and Yildiz, A.A. (2007), "National (Dis)identification and Ethnic and Religious Identity: A Study Among Turkish-Dutch Muslims", Personality and Social Psychology Bulletin, 33 (10), 1448-1462.

Verlegh, P.W.V. and Steenkamp, J-B.E.M. (1999), "A review and meta-analysis of country-of-origin research”, Journal of Economic Psychology, 20(5), 521-546.

Verlegh, P.W.J. (2007), "Home Country Bias in Product Evaluation: The Complementary Roles of Economic and Socio-Psychological Motives", Journal of International Business Studies, 38 (3), 361-373.

Vida, I., Dmitrovic, T. and Obadia, C. (2008), "The role of ethnic affiliation in consumer ethnocentrism", European Journal of Marketing, 42 (3/4), 327-343. 
Vigneron, F. and Johnson, L.W. (1999), "A review and a conceptual framework of prestige-seeking consumer behavior", Academy of Marketing Science Review, 1, 1-14.

Viner, J. (1927), “Adam Smith and Laissez Faire”, Journal of Political Economy, 35 (2), 198-232.

Waithaka, E.N. (2017), "Choice of the Medium of Instruction in Kenyan Preschools: Averting Xenocentrism”, Journal of Education and Practice, 8 (9), 210 - 216.

Wallach, J. (2002), "Exploring Class, Nation, and Xenocentrism in Indonesian Cassette Retail Outlets", Indonesia,74, 79-102.

Watson, J.J. and Wright, K. (2000), "Consumer ethnocentrism and attitudes toward domestic and foreign products ”, European Journal of Marketing, 34 (9/10), 1149-1166.

Wei, Y. and Yu, C. (2012), "How do reference groups influence self-brand connections among Chinese consumers: implications for advertising", Journal of Advertising, 41(2), $39-53$.

Westjohn, S.A., Arnold, M.J., Magnusson, P., Zdravkovic, S. and Zhou, J.X. (2009), "Technology readiness and usage: a global-identity perspective", Journal of the Academy of Marketing Science, 37 (3), 250-265.

Westjohn, S.A., Singh, N. and Magnusson, P. (2012), "Responsiveness to Global and Local Consumer Culture Positioning: A Personality and Collective Identity Perspective", Journal of International Marketing, 20(1), 58-73.

Westjohn, S.A., Arnold, M.J., Magnusson, P. and Reynolds, K. (2016), "The influence of regulatory focus on global consumption orientation and preference for global versus local consumer culture positioning”, Journal of International Marketing, 24 (2), 22-39.

Wicklund, R. A. and Gollwitzer, P. M. (1982), “Symbolic self-completion”. L. Erlbaum Associates, Hillsdale, N.J.

Winterich, K.P. and Zhang, Y. (2014), “Accepting Inequality Deters Responsibility: How Power Distance Decreases Charitable Behavior", Journal of Consumer Research, 41(2), 274-293.

Wong, N.Y. and Ahuvia, A.C. (1998), "Personal Taste and Family Face: Luxury Consumption in Confucian and Western Societies", Psychology and Marketing, 15 (5), 423-441.

Wooten, D.B. and Reed II, A. (2004), "Playing It Safe: Susceptibility to Normative Influence and Protective Self-Presentation”, Journal of Consumer Research, 31 (3), 551556. 
World Economic Forum (2017), "The Global Gender Gap Report 2017", available at http://www3.weforum.org/docs/WEF_GGGR_2017.pdf (accessed 1 August 2018).

Yeatman, S. and Trinitapoli, J. (2011), "Best-Friend: A Tool for Measuring the Prevalence of Sensitive Behaviours", American Journal of Public Health, 101 (9): 1666-1667.

Yoo, B. and Donthu, N. (2005), "The Effect of Personal Cultural Orientation on Consumer Ethnocentrism”, Journal of International Consumer Marketing, 18 (1/2), 7-44.

Yoo, B., Donthu, N. and Lenartowicz, T. (2011), "Measuring Hofstede's Five Dimensions of Cultural Values at the Individual Level: Development and Validation of CVSCALE", Journal of International Consumer Marketing, 23(3/4), 193-210.

Yoon, S-J., Cannon, H.M. and Yaprak, A. (1996), "Evaluating the CYMYC cosmopolitanism scale on Korean consumers", Advances in International Marketing, 7, 211-232.

$\mathrm{Yu}$, J.H. and Albaum, G., "Sovereignty change influences on consumer ethnocentrism and product preferences: Hong Kong revisited one year later", Journal of business research, $55(11), 891-899$.

Zanjonc, R.B. (1968), "Attitudinal Effects of Mere Exposure", Journal of Personality and Social Psychology, 9 (2), 1-27.

Zanjonc, R.B. (2001), "Mere Exposure: A Gateway to the Subliminal”, Current Directions in Psychological Science, 10 (6), 224-228.

Zeugner-Roth, K.P., Zabkar, V. and Diamantopoulos, A. (2015), "Consumer ethnocentrism, national identity, and consumer cosmopolitanism as drivers of consumer behavior: A social identity theory perspective", Journal of International Marketing, 23 (2), $25-54$.

Zhang, Y. and Khare, A. (2009), "The Impact of Accessible Identities on the Evaluation of Global versus Local Products”, Journal of Consumer Research, 36 (3), 524-537.

Zhou, L., Teng, L. and Poon, P. (2008), "Susceptibility to global consumer culture: A threedimensional scale", Psychology and Marketing, 25 (4), 336-351. 
APPENDICES

Appendix A: CETSCALE (Shimp and Sharma, 1987)

(strongly agree $=7$, strongly disagree $=1$ )

1. American people should always buy American-made products instead of imports.

2. Only those products that are unavailable in the U.S. should be imported.

3. Buy American-made products. Keep America working.

4. American products, first, last, and foremost.

5. Purchasing foreign-made products is un-American.

6. It is not right to purchase foreign products, because it puts Americans out of jobs.

7. A real American should always buy American-made products.

8. We should purchase products manufactured in America instead of letting other countries get rich off us.

9. It is always best to purchase American products.

10. There should be very little trading or purchasing of goods from other countries unless out of necessity.

11. Americans should not buy foreign products, because this hurts American business and causes unemployment.

12. Curbs should be put on all imports.

13. It may cost me in the long-run but I prefer to support American products.

14. Foreigners should not be allowed to put their products on our markets.

15. Foreign products should be taxed heavily to reduce their entry into the U.S.

16. We should buy from foreign countries only those products that we cannot obtain within our own country.

17. American consumers who purchase products made in other countries are responsible for putting their fellow Americans out of work. 
Appendix B: Scale decision criteria

$\alpha=$ Cronbach's alpha

$\mathrm{AVE}=$ Average Variance extracted

$\mathrm{CR}=$ Composite reliability

Culture - Antecedent 1

\begin{tabular}{|c|c|c|c|c|c|c|c|}
\hline \multirow[b]{2}{*}{ Construct } & \multirow[b]{2}{*}{ Scale } & \multicolumn{5}{|c|}{ Decision Criteria } & \multirow[b]{2}{*}{$\begin{array}{l}\text { Scale } \\
\text { chosen? }\end{array}$} \\
\hline & & $\begin{array}{l}\text { In-line } \\
\text { with } \\
\text { definition }\end{array}$ & $\begin{array}{l}\text { Good } \\
\text { psychometric } \\
\text { properties }\end{array}$ & $\begin{array}{l}\text { Cited by } \\
\text { others }\end{array}$ & Parsimonious & $\begin{array}{l}\text { Has } \\
\text { minimum } \\
4 \text { items }\end{array}$ & \\
\hline Culture & $\begin{array}{l}\text { Furrer et } \\
\text { al. (2000) }\end{array}$ & $\checkmark$ & N/A & $\begin{array}{c}880 \\
\checkmark\end{array}$ & $\checkmark$ & $\begin{array}{r}4+4 \\
\checkmark\end{array}$ & $x$ \\
\hline Culture & Hui (1988) & $\checkmark$ & $\begin{array}{l}\text { Collectivism } \\
\begin{array}{c}\alpha=0.72 \\
\& 0.68 \\
\times\end{array}\end{array}$ & $\begin{array}{c}1090 \\
\checkmark\end{array}$ & $\begin{array}{l}8 \\
\times \\
\end{array}$ & $\checkmark$ & $x$ \\
\hline Culture & $\begin{array}{l}\text { Yoo et al. } \\
(2011)\end{array}$ & $\checkmark$ & $\begin{array}{c}\text { Collectivism } \\
\alpha=0.76 \text { to } \\
0.80 \\
\text { PD } \alpha=0.61 \\
\text { to } 0.69 \\
\quad\end{array}$ & $\begin{array}{c}342 \\
\checkmark\end{array}$ & $\checkmark$ & 6 & $\begin{array}{c}\text { Only } \\
\text { collectivism } \\
\checkmark\end{array}$ \\
\hline Culture & $\begin{array}{l}\text { Farh } \\
\text { et al. } \\
(2007)\end{array}$ & $\checkmark$ & $\mathrm{PD} \alpha \underset{\checkmark}{ }=0.74$ & 804 & $\checkmark$ & 6 & Only PD \\
\hline Culture & $\begin{array}{l}\text { Earley and } \\
\text { Erez } \\
(1997)\end{array}$ & $\checkmark$ & PD $\alpha=0.71$ & $\begin{array}{c}153 \\
\checkmark\end{array}$ & $\begin{array}{l}8 \\
\times\end{array}$ & $\checkmark$ & $x$ \\
\hline
\end{tabular}

Status consumption - Antecedent 2

\begin{tabular}{|l|l|l|l|l|l|l|l|}
\hline \multicolumn{2}{|l|}{} & \multicolumn{5}{|c|}{ Decision Criteria } & \\
\hline Construct & Scale & $\begin{array}{l}\text { In-line } \\
\text { with } \\
\text { definition }\end{array}$ & $\begin{array}{l}\text { Good } \\
\text { psychometric } \\
\text { properties }\end{array}$ & $\begin{array}{l}\text { Cited by } \\
\text { others }\end{array}$ & Parsimonious & $\begin{array}{l}\text { Has } \\
\text { minimum } \\
\text { items }\end{array}$ & $\begin{array}{l}\text { Scale } \\
\text { chosen? }\end{array}$ \\
\hline \multirow{2}{*}{$\begin{array}{l}\text { Status } \\
\text { consumption }\end{array}$} & $\begin{array}{l}\text { Eastman } \\
\text { et al. }\end{array}$ & & $\alpha=0.81$ to & & & & \\
(1999) & $\checkmark$ & 0.87 & 781 & & 5 & \\
\hline
\end{tabular}


Susceptibility to normative influence - Antecedent 3

\begin{tabular}{|c|c|c|c|c|c|c|c|}
\hline \multirow[b]{2}{*}{ Construct } & \multirow[b]{2}{*}{ Scale } & \multicolumn{5}{|c|}{ Decision Criteria } & \multirow[b]{2}{*}{$\begin{array}{l}\text { Scale } \\
\text { chosen? }\end{array}$} \\
\hline & & $\begin{array}{l}\text { In-line } \\
\text { with } \\
\text { definition }\end{array}$ & $\begin{array}{l}\text { Good } \\
\text { psychometric } \\
\text { properties }\end{array}$ & $\begin{array}{l}\text { Cited by } \\
\text { others }\end{array}$ & Parsimonious & $\begin{array}{l}\text { Has } \\
\text { minimum } \\
4 \text { items } \\
\end{array}$ & \\
\hline $\begin{array}{l}\text { Susceptibility } \\
\text { to normative } \\
\text { influence (SNI) }\end{array}$ & $\begin{array}{l}\text { Bearden } \\
\text { et al. } \\
(1989) \\
\end{array}$ & $\checkmark$ & $\begin{array}{c}\alpha=0.87 \text { to } \\
0.88 \\
\checkmark\end{array}$ & $\begin{array}{c}2527 \\
\checkmark \\
\end{array}$ & $\begin{array}{l}8 \\
\times \\
\end{array}$ & $\checkmark$ & $X$ \\
\hline SNI & $\begin{array}{l}\text { Alden et } \\
\text { al. (2006) }\end{array}$ & $\checkmark$ & $\begin{array}{c}\alpha=0.66 \\
x\end{array}$ & $\begin{array}{c}386 \\
\checkmark \\
\end{array}$ & $\checkmark$ & $\begin{array}{r}3 \\
\times \\
\end{array}$ & $\mathrm{X}$ \\
\hline $\mathrm{SNI}$ & $\begin{array}{l}\text { Batra et } \\
\text { al. (2000) }\end{array}$ & $\checkmark$ & $\begin{array}{c}\alpha=0.59 \\
x\end{array}$ & $\begin{array}{c}1210 \\
\checkmark \\
\end{array}$ & $\checkmark$ & $\begin{array}{r}3 \\
x \\
\end{array}$ & $X$ \\
\hline SNI & $\begin{array}{l}\text { Lee et al. } \\
(2014)\end{array}$ & $\checkmark$ & $\begin{array}{c}0.75 \text { to } 0.76 \\
\checkmark\end{array}$ & $\begin{array}{c}13 \\
\checkmark\end{array}$ & $\checkmark$ & $\begin{array}{l}4 \\
\checkmark\end{array}$ & $\checkmark$ \\
\hline
\end{tabular}

Consumer worldmindedness - Related construct 1

\begin{tabular}{|c|c|c|c|c|c|c|c|}
\hline \multirow[b]{2}{*}{ Construct } & \multirow[b]{2}{*}{ Scale } & \multicolumn{6}{|c|}{ Decision Criteria } \\
\hline & & $\begin{array}{l}\text { In-line } \\
\text { with } \\
\text { definition }\end{array}$ & \begin{tabular}{|l|} 
Good \\
psychometric \\
properties
\end{tabular} & $\begin{array}{l}\text { Cited by } \\
\text { others }\end{array}$ & Parsimonious & $\begin{array}{l}\text { Has } \\
\text { minimum } \\
4 \text { items }\end{array}$ & $\begin{array}{l}\text { Scale } \\
\text { chosen? }\end{array}$ \\
\hline $\begin{array}{l}\text { Consumer } \\
\text { worldmindedness }\end{array}$ & \begin{tabular}{|l|} 
Sampson \\
and \\
Smith \\
$(1957)$ \\
\end{tabular} & $\checkmark$ & $\begin{array}{c}\text { Odd-even } \\
\text { reliability = } \\
0.93 \\
\checkmark\end{array}$ & $\begin{array}{c}384 \\
\checkmark\end{array}$ & $\begin{array}{c}32 \\
\times\end{array}$ & $\checkmark$ & $X$ \\
\hline $\begin{array}{l}\text { Consumer } \\
\text { worldmindedness }\end{array}$ & $\begin{array}{l}\text { Nijssen } \\
\text { and } \\
\text { Douglas } \\
(2008) \\
\end{array}$ & $x$ & N/A & $\begin{array}{c}141 \\
\checkmark \\
\end{array}$ & $\begin{array}{l}8 \\
\times \\
\end{array}$ & $\mathrm{X}$ & $x$ \\
\hline $\begin{array}{l}\text { Consumer } \\
\text { worldmindedness }\end{array}$ & $\begin{array}{l}\text { Rawwas } \\
\text { et al. } \\
(1996)\end{array}$ & $\checkmark$ & $\begin{array}{c}\alpha=0.69 \\
\checkmark\end{array}$ & $\begin{array}{c}197 \\
\checkmark \\
\end{array}$ & $\begin{array}{l}7 \\
\checkmark \\
\end{array}$ & $\checkmark$ & $\checkmark$ \\
\hline
\end{tabular}


Global/local identity - Related construct 2 and 3

\begin{tabular}{|c|c|c|c|c|c|c|c|}
\hline \multirow[b]{2}{*}{ Construct } & \multirow[b]{2}{*}{ Scale } & \multicolumn{6}{|c|}{ Decision Criteria } \\
\hline & & $\begin{array}{l}\text { In-line } \\
\text { with } \\
\text { definition }\end{array}$ & $\begin{array}{l}\text { Good } \\
\text { psychometric } \\
\text { properties }\end{array}$ & $\begin{array}{l}\text { Cited by } \\
\text { others }\end{array}$ & Parsimonious & $\begin{array}{l}\text { Has } \\
\text { minimum } \\
4 \text { items } \\
\end{array}$ & $\begin{array}{l}\text { Scale } \\
\text { chosen? }\end{array}$ \\
\hline $\begin{array}{l}\text { Global identity/ } \\
\text { local identity }\end{array}$ & $\begin{array}{l}\text { Zhang and } \\
\text { Khare } \\
\text { (2009) }\end{array}$ & $\checkmark$ & $\begin{array}{c}\alpha=0.86 \& \\
0.83 \\
\checkmark\end{array}$ & $\begin{array}{c}179 \\
\checkmark\end{array}$ & $\begin{array}{c}19 \\
X\end{array}$ & $\checkmark$ & $\mathrm{x}$ \\
\hline $\begin{array}{l}\text { Global identity/ } \\
\text { local identity }\end{array}$ & $\begin{array}{l}\text { Bartikowski } \\
\text { and Walsh } \\
\text { (2015) }\end{array}$ & $\checkmark$ & $\alpha=0.80$ & $\begin{array}{c}14 \\
\checkmark\end{array}$ & $\checkmark$ & $\begin{array}{l}4 \\
\checkmark\end{array}$ & \begin{tabular}{|c|} 
Only \\
global \\
identity \\
scale \\
X
\end{tabular} \\
\hline $\begin{array}{l}\text { Global identity/ } \\
\text { local identity }\end{array}$ & $\begin{array}{l}\text { Westjohn et } \\
\text { al. (2009) }\end{array}$ & $\checkmark$ & $\begin{array}{c}\alpha=0.72 \\
\checkmark\end{array}$ & $\begin{array}{c}93 \\
\checkmark\end{array}$ & $\checkmark$ & $\begin{array}{l}5 \\
\checkmark\end{array}$ & \begin{tabular}{|c|} 
Only \\
global \\
identity \\
scale \\
X
\end{tabular} \\
\hline $\begin{array}{l}\text { Global identity/ } \\
\text { local identity }\end{array}$ & \begin{tabular}{|l} 
Tu et al. \\
(2012)
\end{tabular} & $\checkmark$ & $\begin{array}{c}\alpha=0.87 \& \\
0.89 \\
\checkmark\end{array}$ & $\begin{array}{l}58 \\
\checkmark\end{array}$ & $\checkmark$ & $\begin{array}{c}4+4 \\
\checkmark\end{array}$ & $\checkmark$ \\
\hline
\end{tabular}

National identity - Related construct 4

\begin{tabular}{|c|c|c|c|c|c|c|c|}
\hline \multirow[b]{2}{*}{ Construct } & \multirow[b]{2}{*}{ Scale } & \multicolumn{6}{|c|}{ Decision Criteria } \\
\hline & & \begin{tabular}{|l} 
In-line \\
with \\
definition
\end{tabular} & $\begin{array}{l}\text { Good } \\
\text { psychometric } \\
\text { properties }\end{array}$ & $\begin{array}{l}\text { Cited by } \\
\text { others }\end{array}$ & Parsimonious & $\begin{array}{l}\text { Has } \\
\text { minimum } \\
4 \text { items }\end{array}$ & $\begin{array}{l}\text { Scale } \\
\text { chosen? }\end{array}$ \\
\hline $\begin{array}{l}\text { National } \\
\text { identity }\end{array}$ & $\begin{array}{l}\text { NATID - } \\
\text { Keillor et al. } \\
(1996)\end{array}$ & $x$ & $\mathrm{~N} / \mathrm{A}$ & $\begin{array}{c}113 \\
\checkmark \\
\end{array}$ & $\begin{array}{r}17 \\
\times \\
\end{array}$ & $\checkmark$ & $x$ \\
\hline $\begin{array}{l}\text { National } \\
\text { identity }\end{array}$ & $\begin{array}{l}\text { Vida et al. } \\
(2007)\end{array}$ & $x$ & $\begin{array}{c}\mathrm{AVE}=0.48 \\
\mathrm{X}\end{array}$ & $\begin{array}{c}123 \\
\checkmark\end{array}$ & $\checkmark$ & $\begin{array}{l}3 \\
\times \\
\end{array}$ & $\mathrm{x}$ \\
\hline $\begin{array}{l}\text { National } \\
\text { identity }\end{array}$ & $\begin{array}{l}\text { Zeugner- } \\
\text { Roth } \\
\text { et al. (2015) }\end{array}$ & $\checkmark$ & $\begin{array}{c}\alpha=0.70 \\
\checkmark\end{array}$ & $\begin{array}{c}91 \\
\checkmark \\
\end{array}$ & $\checkmark$ & $\begin{array}{l}4 \\
\checkmark \\
\end{array}$ & $x$ \\
\hline $\begin{array}{l}\text { National } \\
\text { identity }\end{array}$ & $\begin{array}{l}\text { Verlegh } \\
(2007)\end{array}$ & $\checkmark$ & $\begin{array}{c}\mathrm{CR}=0.83 \& \\
\mathrm{AVE}=0.56 \\
\checkmark\end{array}$ & $\begin{array}{c}243 \\
\checkmark \\
\end{array}$ & $\checkmark$ & $\begin{array}{l}4 \\
\checkmark \\
\end{array}$ & $\begin{array}{c}\text { Best } \\
\text { psychometric; } \\
\text { Well-cited } \\
\checkmark\end{array}$ \\
\hline $\begin{array}{l}\text { National } \\
\text { identity }\end{array}$ & $\begin{array}{l}\text { Bartikowski } \\
\text { and Walsh } \\
(2015)\end{array}$ & $\checkmark$ & $\begin{array}{c}\alpha=0.82 \\
\checkmark\end{array}$ & $\begin{array}{c}14 \\
\checkmark \\
\end{array}$ & $\checkmark$ & $\begin{array}{l}4 \\
\checkmark \\
\end{array}$ & $x$ \\
\hline $\begin{array}{l}\text { National } \\
\text { identity }\end{array}$ & $\begin{array}{l}\text { Westjohn et } \\
\text { al. (2012) }\end{array}$ & $\checkmark$ & $\begin{array}{c}\text { AVE }=0.54 \text { to } \\
0.61 \\
\checkmark \\
\end{array}$ & $\begin{array}{l}87 \\
\checkmark \\
\end{array}$ & $\begin{array}{l}8 \\
x \\
\end{array}$ & $\checkmark$ & $x$ \\
\hline
\end{tabular}


Consumer ethnocentrism - Related construct 5

\begin{tabular}{|c|c|c|c|c|c|c|c|}
\hline \multirow[b]{2}{*}{ Construct } & \multirow[b]{2}{*}{ Scale } & \multicolumn{6}{|c|}{ Decision Criteria } \\
\hline & & \begin{tabular}{|l|} 
In-line \\
with \\
definition \\
\end{tabular} & $\begin{array}{l}\text { Good } \\
\text { psychometric } \\
\text { properties }\end{array}$ & $\begin{array}{l}\text { Cited by } \\
\text { others }\end{array}$ & Parsimonious & $\begin{array}{l}\text { Has } \\
\text { minimum } \\
4 \text { items } \\
\end{array}$ & $\begin{array}{l}\text { Scale } \\
\text { chosen? }\end{array}$ \\
\hline $\begin{array}{l}\text { Consumer } \\
\text { ethnocentrism }\end{array}$ & $\begin{array}{l}\text { CETSCALE- } \\
\text { Shimp and } \\
\text { Sharma } \\
(1987) \\
\end{array}$ & $\checkmark$ & $\begin{array}{c}\alpha=0.94- \\
0.96 \\
\checkmark\end{array}$ & $\begin{array}{c}2942 \\
\checkmark \\
\end{array}$ & $\begin{array}{r}17 \\
\times \\
\end{array}$ & $\checkmark$ & $\mathrm{x}$ \\
\hline $\begin{array}{l}\text { Consumer } \\
\text { ethnocentrism }\end{array}$ & $\begin{array}{l}\text { CETSCALE- } \\
\text { Shimp and } \\
\text { Sharma } \\
(1987) \\
\end{array}$ & $\checkmark$ & $\begin{array}{c}\alpha=0.94- \\
0.96 \\
\checkmark\end{array}$ & $\begin{array}{c}2942 \\
\checkmark\end{array}$ & $\begin{array}{r}10 \\
X \\
\end{array}$ & $\checkmark$ & $\checkmark$ \\
\hline $\begin{array}{l}\text { Consumer } \\
\text { ethnocentrism }\end{array}$ & $\begin{array}{l}\text { Sharma } \\
(2015)\end{array}$ & $x$ & $\begin{array}{c}\alpha=0.80- \\
0.86 \\
\checkmark\end{array}$ & $\begin{array}{c}56 \\
\checkmark \\
\end{array}$ & $\begin{array}{c}18 \\
\times\end{array}$ & $\checkmark$ & $x$ \\
\hline $\begin{array}{l}\text { Consumer } \\
\text { ethnocentrism }\end{array}$ & $\begin{array}{l}\text { Verlegh } \\
(2007)\end{array}$ & $\checkmark$ & $\begin{array}{c}\text { AVE }=0.57 \& \\
\text { CR }=0.87 \\
\checkmark\end{array}$ & $\begin{array}{c}243 \\
\checkmark\end{array}$ & $\checkmark$ & $\begin{array}{l}5 \\
\checkmark\end{array}$ & $\mathrm{x}$ \\
\hline
\end{tabular}

Global media exposure - Antecedent 4 and Moderator 1

\begin{tabular}{|c|c|c|c|c|c|c|c|}
\hline & & \multicolumn{6}{|c|}{ Decision Criteria } \\
\hline Construct & Scale & \begin{tabular}{|l} 
In-line \\
with \\
definition
\end{tabular} & $\begin{array}{l}\text { Good } \\
\text { psychometric } \\
\text { properties }\end{array}$ & $\begin{array}{l}\text { Cited by } \\
\text { others }\end{array}$ & Parsimonious & $\begin{array}{l}\text { Has } \\
\text { minimum } \\
4 \text { items }\end{array}$ & $\begin{array}{l}\text { Scale } \\
\text { chosen? }\end{array}$ \\
\hline $\begin{array}{l}\text { Global media } \\
\text { expsoure }\end{array}$ & $\begin{array}{l}\text { Alden et } \\
\text { al. (2006) }\end{array}$ & $\checkmark$ & $\begin{array}{c}\alpha=0.78 \\
\checkmark\end{array}$ & $\begin{array}{c}338 \\
\checkmark\end{array}$ & $\checkmark$ & $\begin{array}{l}4 \\
\checkmark\end{array}$ & $\checkmark$ \\
\hline $\begin{array}{l}\text { Global media } \\
\text { expsoure }\end{array}$ & $\begin{array}{l}\text { Cleveland } \\
\text { and } \\
\text { Laroche } \\
\text { (2007) }\end{array}$ & $x$ & $\begin{array}{c}\alpha=0.84 \\
\checkmark\end{array}$ & $\begin{array}{c}459 \\
\checkmark\end{array}$ & $\begin{array}{l}9 \\
X\end{array}$ & $\checkmark$ & $x$ \\
\hline
\end{tabular}


International travel experience/preference - Antecedent 5 and Moderator 2

\begin{tabular}{|c|c|c|c|c|c|c|c|}
\hline \multirow[b]{2}{*}{ Construct } & \multirow[b]{2}{*}{ Scale } & \multicolumn{6}{|c|}{ Decision Criteria } \\
\hline & & $\begin{array}{l}\text { In-line } \\
\text { with } \\
\text { definition }\end{array}$ & \begin{tabular}{|l|} 
Good \\
psychometric \\
properties
\end{tabular} & $\begin{array}{l}\text { Cited by } \\
\text { others }\end{array}$ & Parsimonious & \begin{tabular}{|l|} 
Has \\
minimum \\
4 items
\end{tabular} & $\begin{array}{l}\text { Scale } \\
\text { chosen? }\end{array}$ \\
\hline $\begin{array}{l}\text { International } \\
\text { travel }\end{array}$ & $\begin{array}{l}\text { Douglas } \\
\text { and } \\
\text { Nijssen } \\
(2003)\end{array}$ & $x$ & $\begin{array}{c}\alpha=0.84 \\
\checkmark\end{array}$ & $\begin{array}{c}172 \\
\checkmark\end{array}$ & $\checkmark$ & $\begin{array}{l}4 \\
\checkmark \\
\end{array}$ & $\begin{array}{l}\text { Last item does } \\
\text { not describe } \\
\text { construct well } \\
\text { X }\end{array}$ \\
\hline $\begin{array}{l}\text { International } \\
\text { travel }\end{array}$ & $\begin{array}{l}\text { Nijssen } \\
\text { and } \\
\text { Douglas } \\
(2008) \\
\end{array}$ & $x$ & N/A & $\begin{array}{c}141 \\
\checkmark \\
\end{array}$ & $\checkmark$ & $\begin{array}{l}3 \\
x \\
\end{array}$ & $x$ \\
\hline $\begin{array}{l}\text { International } \\
\text { travel }\end{array}$ & \begin{tabular}{|l|} 
Cleveland \\
and \\
Laroche \\
$(2007)$
\end{tabular} & $\checkmark$ & $\begin{array}{c}\alpha=0.74 \\
\checkmark\end{array}$ & $\begin{array}{c}459 \\
\checkmark \\
\end{array}$ & $\checkmark$ & $\begin{array}{l}6 \\
\checkmark \\
\end{array}$ & $x$ \\
\hline $\begin{array}{l}\text { International } \\
\text { travel }\end{array}$ & $\begin{array}{l}\text { Cleveland } \\
\text { et al. } \\
(2014)\end{array}$ & $\checkmark$ & $\begin{array}{c}\alpha=0.81 \\
\checkmark\end{array}$ & $\begin{array}{c}29 \\
\checkmark\end{array}$ & $\checkmark$ & $\begin{array}{l}5 \\
\checkmark \\
\end{array}$ & $\begin{array}{c}\text { Better } \\
\text { psychometrics } \\
\checkmark\end{array}$ \\
\hline
\end{tabular}

Product category symbolism - Moderator 3

\begin{tabular}{|c|c|c|c|c|c|c|c|}
\hline \multirow[b]{2}{*}{ Construct } & \multirow[b]{2}{*}{ Scale } & \multicolumn{6}{|c|}{ Decision Criteria } \\
\hline & & \begin{tabular}{|l|} 
In-line \\
with \\
definition
\end{tabular} & $\begin{array}{l}\text { Good } \\
\text { psychometric } \\
\text { properties }\end{array}$ & $\begin{array}{l}\text { Cited by } \\
\text { others }\end{array}$ & Parsimonious & $\begin{array}{l}\text { Has } \\
\text { minimum } \\
4 \text { items }\end{array}$ & $\begin{array}{l}\text { Scale } \\
\text { chosen? }\end{array}$ \\
\hline $\begin{array}{l}\text { Product } \\
\text { category } \\
\text { symbolism }\end{array}$ & $\begin{array}{l}\text { Strizhakova } \\
\text { and Coulter } \\
(2015)\end{array}$ & $\checkmark$ & $\begin{array}{c}\alpha=0.73 \text { to } \\
0.89 \\
\checkmark\end{array}$ & $\begin{array}{l}47 \\
\checkmark\end{array}$ & $\checkmark$ & $\begin{array}{l}4 \\
\checkmark\end{array}$ & $\checkmark$ \\
\hline
\end{tabular}




\title{
Appendix C: Consent form and full questionnaire
}

\author{
CONSENT FORM
}

Name and Contact Information of Researchers

Dhana Kannan

PhD student

Sprott school of business

Carleton university

Canada

Email: dhana.kannan@carleton.ca

Phone: 613-520-2600, ext. a014

Dr. José 1. Rojas-Méndez

Thesis supervisor and Professor of international business and marketing.

Sprott school of business

Carleton university

Canadia

Email: jose.rojas@carleton.ca

Phone: 613-520-2600, ext. 8014

Project Title

OPINIONS ON THE DAILY LIFE OF KENYAN CITIZENS AND CONSUMERS

Carleton University Project Clearance

Clearance \#: 110488

Date of Clearance: $06 / \mathrm{March} / 2019$

Invitation

We are asking you to complete this survey because you are Kenyan eitizen, living in Kenya and older than 18 years of age. This survey is being conducted by Dhana Kannan of the Carleton University. Sprott

school of business (dhana kannan@carleton.ca, 613-520-2600, ext. 8014) working under the supervision of Pror. Josẻ 1. Rojas-Mẻndez (jose,rojas@carleton.ca, 613-520-2600, ext. 8014).

Objectives and Summary

The aim of this study is to better understand consumers' opinions and preferences of local and foreign brands. We estimate that the survey will take about 15-20 minutes to complete. Your participation in this survey is woluntary, and you may choose not to take part. You can also withdraw at any step of this questionnaire until the submission of your answers. Participants cannot withdraw after submitting a questionnaire that is fully answered as the survey is anonymous.

Risks and Benefits:

We do not anticipate any risks from taking the survey.

Confidentiality and Data Storage

We will treat your personal information as confidential, although absolute privacy cannot be guaranteed. No information that discloses your identity will be released or published without your specific consent. Research records may be accessed by the Carleton University Research Ethics Board in order to ensure continuing ethics compliance.

The results of this study may be published, but the data will be presented so that it will not be possible to identify you, unless you give consent. All research data will be password-protected and any hard copies of data will be kept in a locked cabinet at Carleton University.

Your data will be stored and protected by Qualtrics, on servers located in the U.S., but may be disclosed via a court order or data breach. After the study is completed, we will retain your anonymized data for future research use.

REB Review and Contact Information

This project was reviewed and cleared by the Carleton University Research Ethics Board. If you have any ethical concerns with the study, please contact Dr. Bernadette Campbell, Chair by phone at 613-5202600 ext. 2517 or by email at ethics@carleton.ca. 


\section{SECTION I - YOUR PRODUCT PREFERENCES AS A CONSUMER}

Please indicate your willingness to buy products and services from the countries listed below by choosing the alternative that best represents your opinion. Please assume that the products and services from the different countries have similar features and are sold at the same price in your country.

\begin{tabular}{|c|c|c|c|c|c|c|c|}
\hline & $\begin{array}{l}\text { Very } \\
\text { unlikely }\end{array}$ & Unlikely & $\begin{array}{c}\text { Somewhat } \\
\text { unlikely }\end{array}$ & Neutral & $\begin{array}{l}\text { Somewhat } \\
\text { likely }\end{array}$ & Likely & $\begin{array}{l}\text { Very } \\
\text { likely }\end{array}$ \\
\hline Willingness to buy products from Thailand & $\bigcirc$ & $\bigcirc$ & $\bigcirc$ & $\bigcirc$ & $\bigcirc$ & $\bigcirc$ & $\bigcirc$ \\
\hline Willingness to buy products from South Korea & $\bigcirc$ & $\bigcirc$ & $\bigcirc$ & $\bigcirc$ & $\bigcirc$ & $\mathrm{O}$ & $\bigcirc$ \\
\hline Willingness to buy products from the U.S.A. & $\bigcirc$ & $\bigcirc$ & $\bigcirc$ & $\bigcirc$ & $\bigcirc$ & $\bigcirc$ & $\bigcirc$ \\
\hline Willingness to buy products from France & $\bigcirc$ & $\bigcirc$ & $\bigcirc$ & $\bigcirc$ & $\bigcirc$ & $\bigcirc$ & $\bigcirc$ \\
\hline Willingness to buy products from Brazil & $\bigcirc$ & $\bigcirc$ & $\bigcirc$ & $\bigcirc$ & $\bigcirc$ & $\bigcirc$ & $\bigcirc$ \\
\hline Willingness to buy products from Kenya & $\bigcirc$ & $\bigcirc$ & $\bigcirc$ & $\bigcirc$ & $\bigcirc$ & $\mathrm{O}$ & $\bigcirc$ \\
\hline Willingness to buy products from Mexico & $\bigcirc$ & $\bigcirc$ & $\bigcirc$ & $\bigcirc$ & $\bigcirc$ & $\bigcirc$ & $\bigcirc$ \\
\hline Willingness to buy products from Germany & $\bigcirc$ & $\bigcirc$ & $\bigcirc$ & $\bigcirc$ & $\mathrm{O}$ & $\bigcirc$ & $\bigcirc$ \\
\hline Willingness to buy products from Russia & $\bigcirc$ & $\bigcirc$ & $\bigcirc$ & $\bigcirc$ & $\bigcirc$ & $\bigcirc$ & $\bigcirc$ \\
\hline Willingness to buy products from Japan & $\bigcirc$ & $\bigcirc$ & $\bigcirc$ & $\bigcirc$ & $\bigcirc$ & $\mathrm{O}$ & $\bigcirc$ \\
\hline
\end{tabular}

Please indicate if you currently own Kenyan or foreign products in the following categories. If you have purchased multiple products for any category (e.g. alcoholic drinks), please answer based on whether you generally purchase a majority of Kenyan or foreign products in those categories.

\begin{tabular}{|c|c|c|c|c|}
\hline & $\begin{array}{l}\text { Own Kenyan } \\
\text { product }\end{array}$ & $\begin{array}{l}\text { Own foreign product } \\
\text { from developed } \\
\text { country }\end{array}$ & $\begin{array}{l}\text { Own foreign product } \\
\text { from developing } \\
\text { country }\end{array}$ & $\begin{array}{l}\text { Don't know/Not } \\
\text { applicable }\end{array}$ \\
\hline Leather items & $\bigcirc$ & $\bigcirc$ & $\mathrm{O}$ & $\bigcirc$ \\
\hline Shoes & 0 & $\bigcirc$ & $\mathrm{O}$ & $\mathrm{O}$ \\
\hline Refrigerator & 0 & $\bigcirc$ & $\mathrm{O}$ & $\bigcirc$ \\
\hline Alcoholic drinks & 0 & $\bigcirc$ & $\mathrm{O}$ & $\mathrm{O}$ \\
\hline Clothing & $\bigcirc$ & $\bigcirc$ & $\bigcirc$ & $\mathrm{O}$ \\
\hline Soft drinks & 0 & $\bigcirc$ & $\bigcirc$ & $\bigcirc$ \\
\hline Food items & $\mathrm{O}$ & $\bigcirc$ & $\bigcirc$ & $\bigcirc$ \\
\hline
\end{tabular}


SECTION II - YOUR OPINION ON GENERAL VIEWPOINTS

This section asks you about your opinion on some general viewpoints. For every statement, please choose the answer that best represents your opinion.

Group success is more important than individual success.

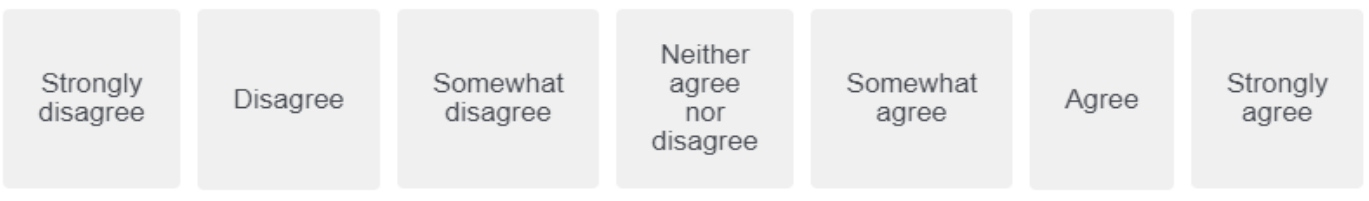

Managers should seldom ask for the opinions of employees.

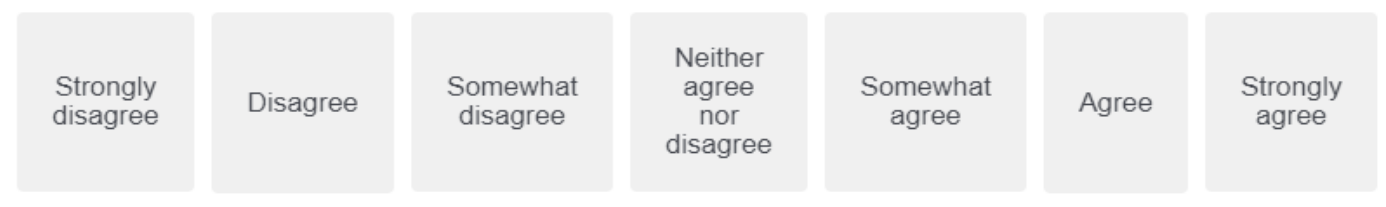

It is frequently necessary for a manager to use authority and power when dealing with subordinates.

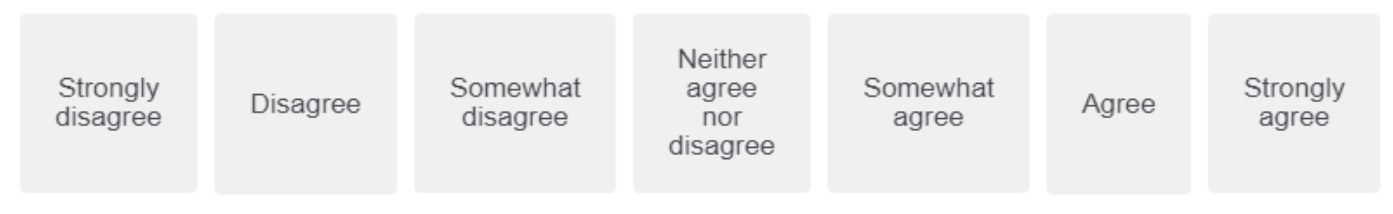

Individuals should stick with the group even through difficulties.

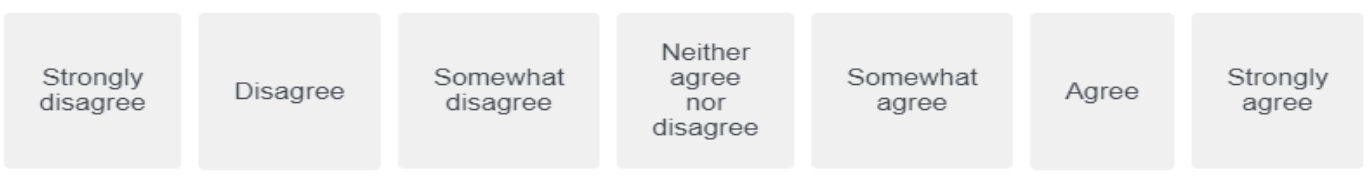

Employees should not disagree with management decisions.

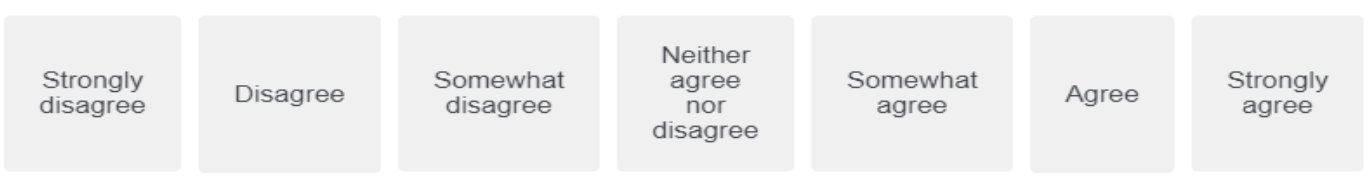

Managers should make most decisions without consulting subordinates.

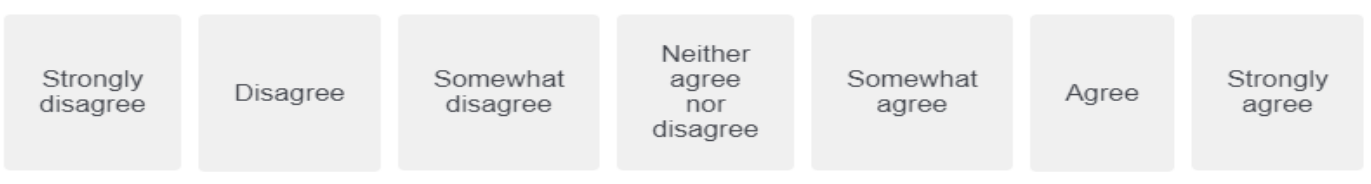


Group welfare is more important than individual rewards.

\begin{tabular}{|c|c|c|c|c|c|c|}
\hline $\begin{array}{l}\text { Strongly } \\
\text { disagree }\end{array}$ & Disagree & $\begin{array}{c}\text { Somewhat } \\
\text { disagree }\end{array}$ & $\begin{array}{l}\text { Neither } \\
\text { agree } \\
\text { nor } \\
\text { disagree }\end{array}$ & $\begin{array}{c}\text { Somewhat } \\
\text { agree }\end{array}$ & Agree & $\begin{array}{c}\text { Strongly } \\
\text { agree }\end{array}$ \\
\hline
\end{tabular}

Managers should avoid off-the-job social contacts with employees.

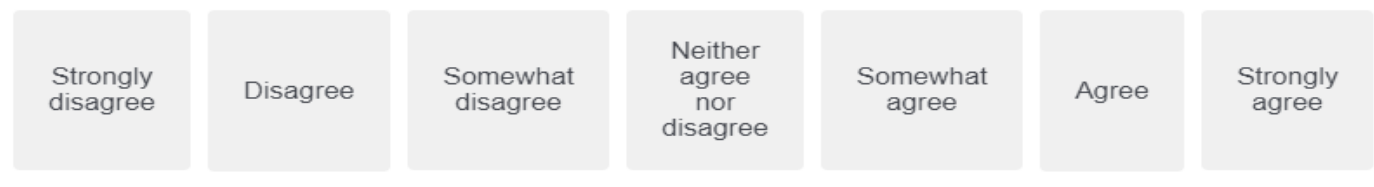

Managers should not delegate important tasks to employees.

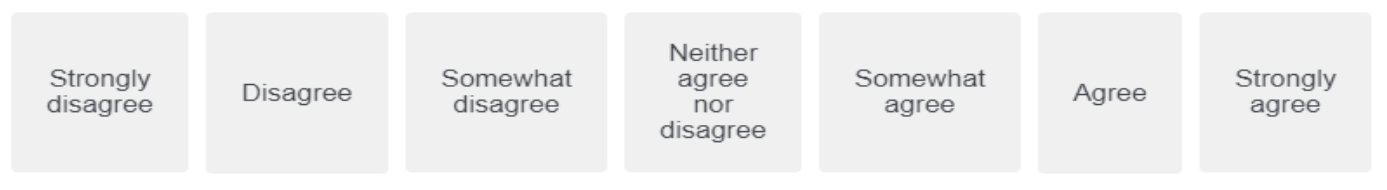

Group loyalty should be encouraged even if individual goals suffer.

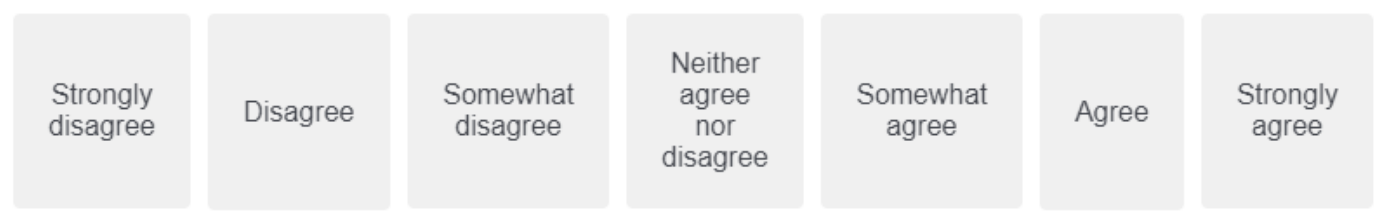

Individuals should only pursue their goals after considering the welfare of the group.

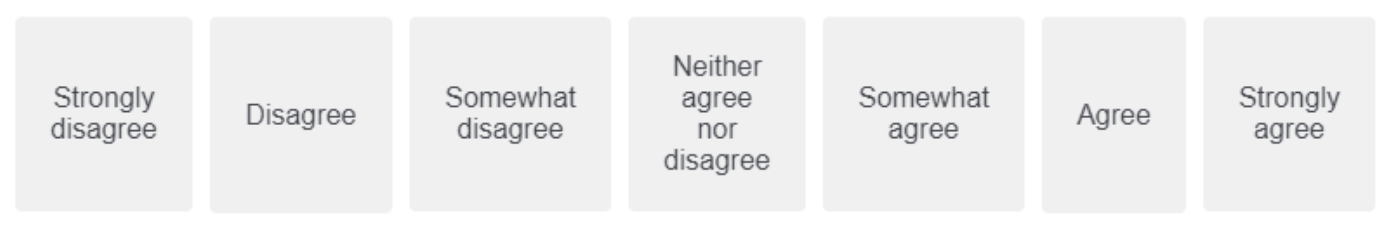

Individuals should sacrifice self-interest for the group.

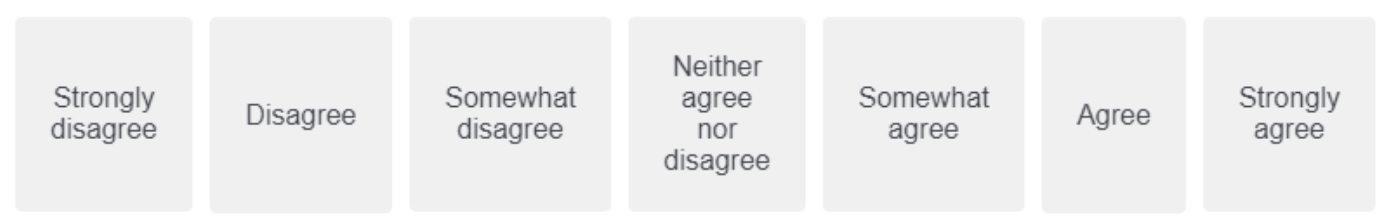


Please select "Somewhat disagree" below.

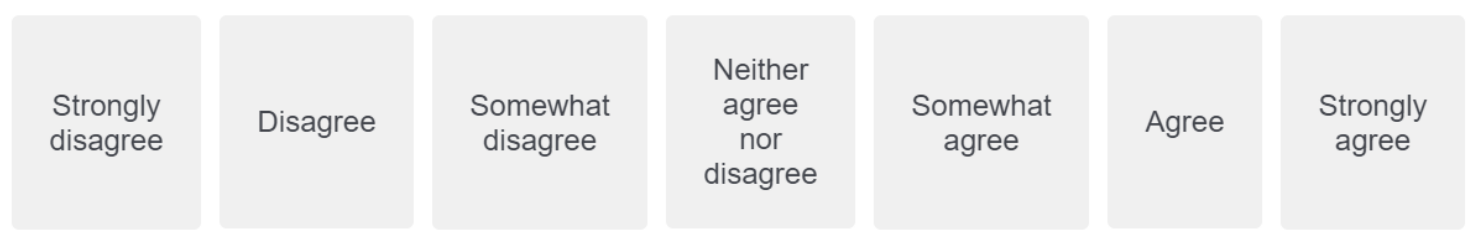

\section{SECTION III - GENERAL VIEWS REGARDING PRODUCTS}

This section asks you about your general views regarding products. For every statement, please choose the answer that best represents your opinion.

I achieve a sense of belonging by purchasing the same products and brands that others purchase.

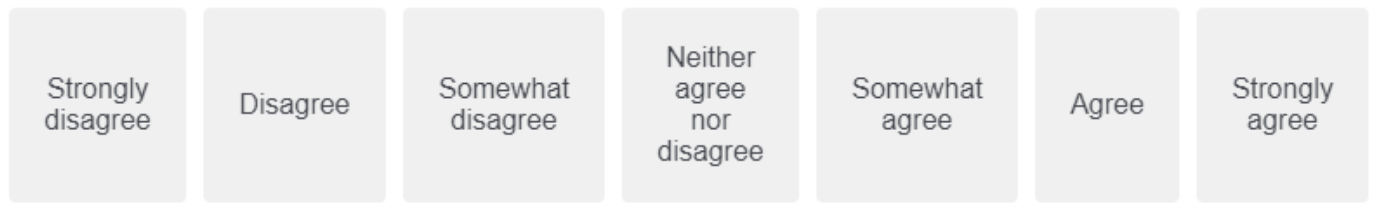

People use their mobile phone to convey who they are to others

\begin{tabular}{|c|c|c|c|c|c|c|}
\hline $\begin{array}{l}\text { Strongly } \\
\text { disagree }\end{array}$ & Disagree & $\begin{array}{c}\text { Somewhat } \\
\text { disagree }\end{array}$ & $\begin{array}{c}\text { Neither } \\
\text { agree } \\
\text { nor } \\
\text { disagree }\end{array}$ & $\begin{array}{c}\text { Somewhat } \\
\text { agree }\end{array}$ & Agree & $\begin{array}{c}\text { Strongly } \\
\text { agree }\end{array}$ \\
\hline
\end{tabular}


It is important that others like the products and brands I buy.

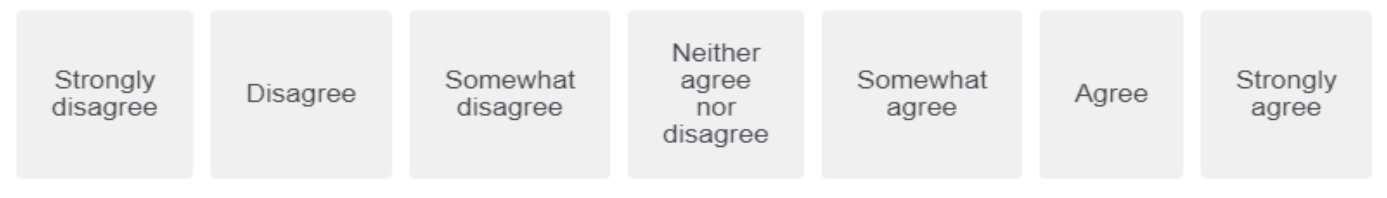

People use their mobile phone to communicate who they are to other people

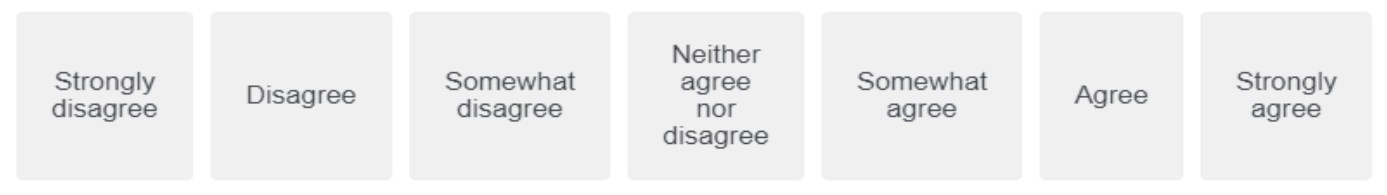

My bath soap brand portrays an image of me to others

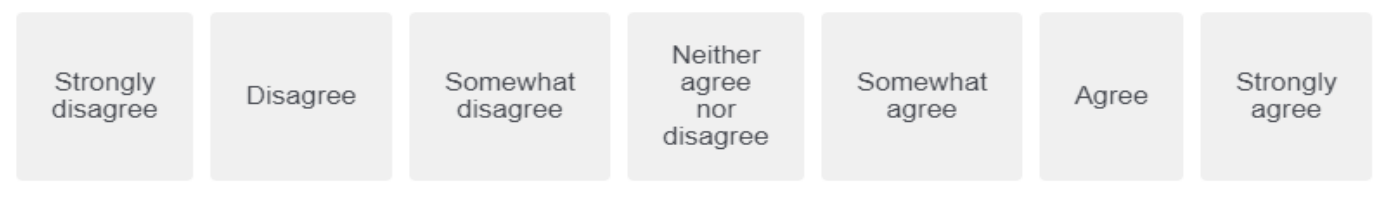

People use their bath soap brand to communicate who they are to other people

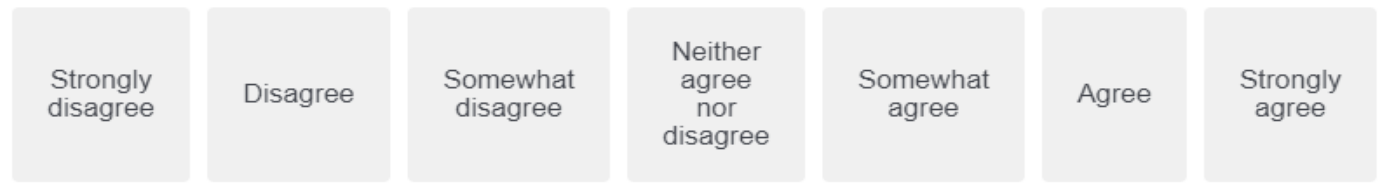

My bath soap brand is part of my self-image

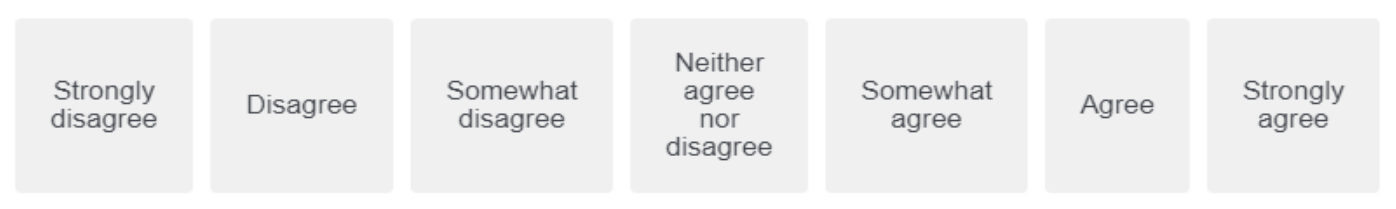

I would buy a product just because it has status.

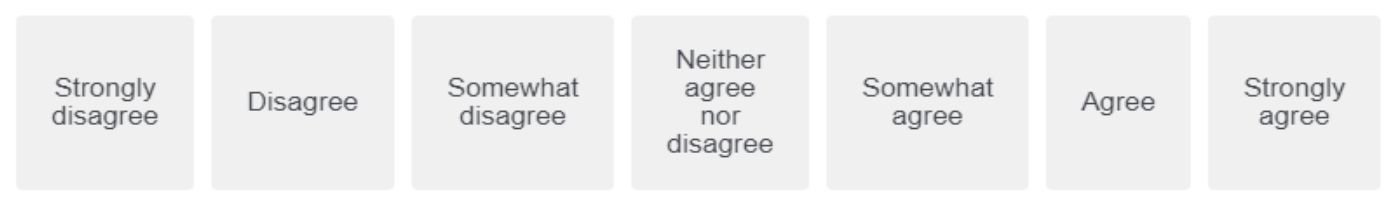


I would pay more for a product if it had status.

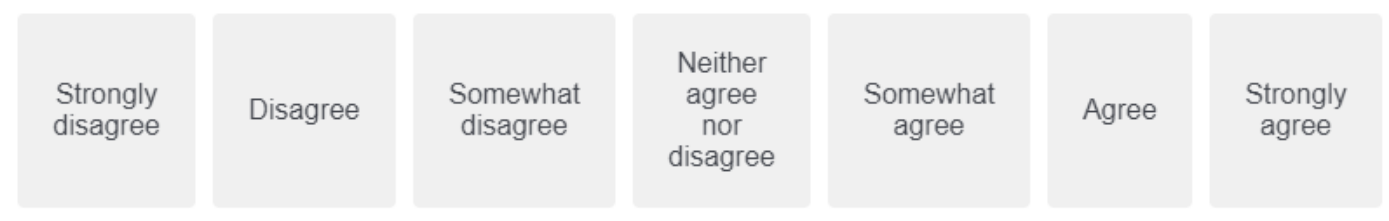

I am interested in new products with status.

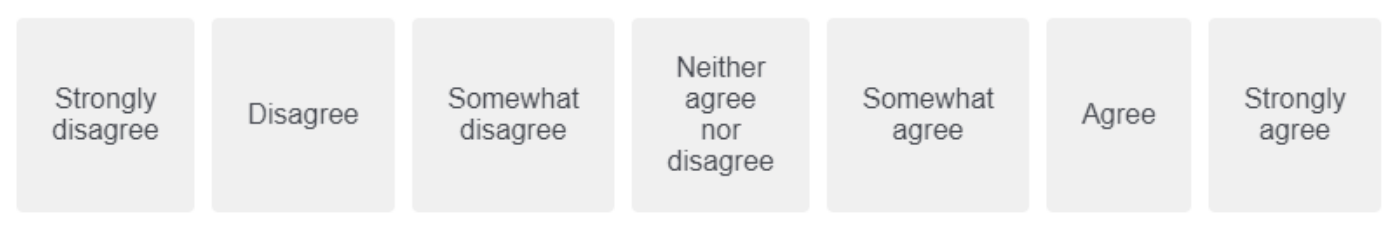

The status of a product is irrelevant to me.

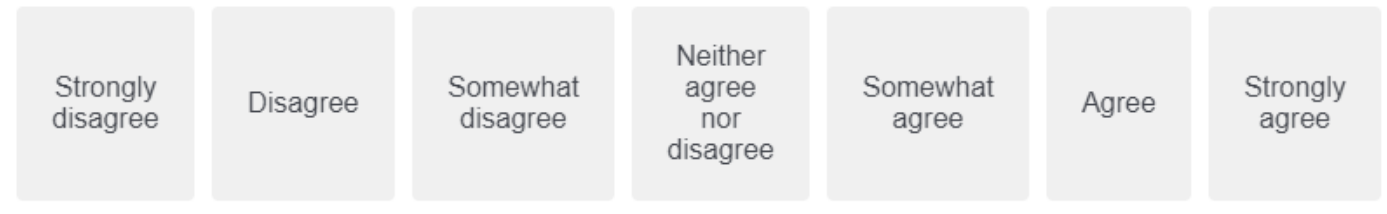

People use their bath soap brand to convey who they are to others

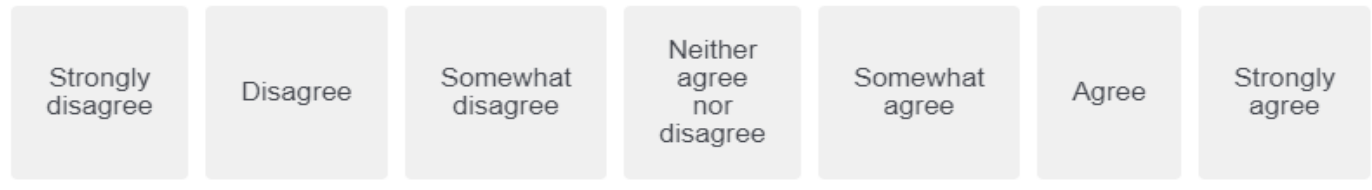

When buying products, I generally purchase those brands that I think others will approve of.

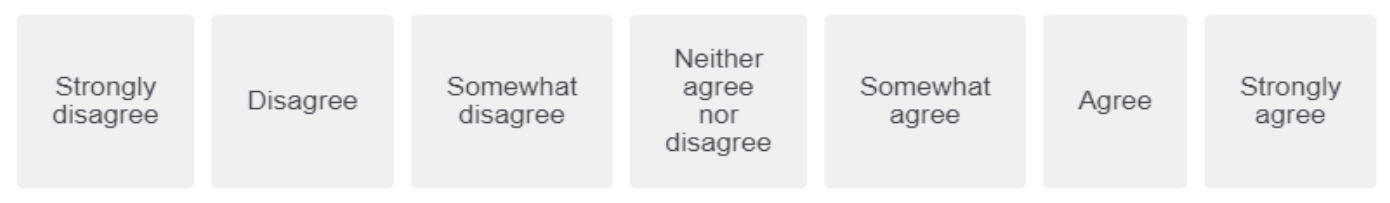

If I want to be like someone, I often try to buy the same brands that they buy.

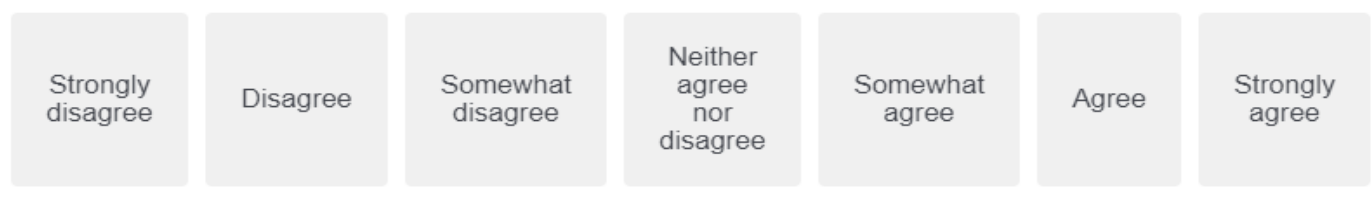


A product is more valuable to me if it has some status.

\begin{tabular}{|l|l|l|l|l|l|l||}
\hline \begin{tabular}{|l|l|l|}
$\mid$ \\
Strongly \\
disagree
\end{tabular} & Disagree & $\begin{array}{c}\text { Somewhat } \\
\text { disagree }\end{array}$ & $\begin{array}{c}\text { Neither } \\
\text { agree } \\
\text { nor } \\
\text { disagree }\end{array}$ & $\begin{array}{c}\text { Somewhat } \\
\text { agree }\end{array}$ & Agree & $\begin{array}{c}\text { Strongly } \\
\text { agree }\end{array}$ \\
\hline
\end{tabular}

My mobile phone is part of my self-image

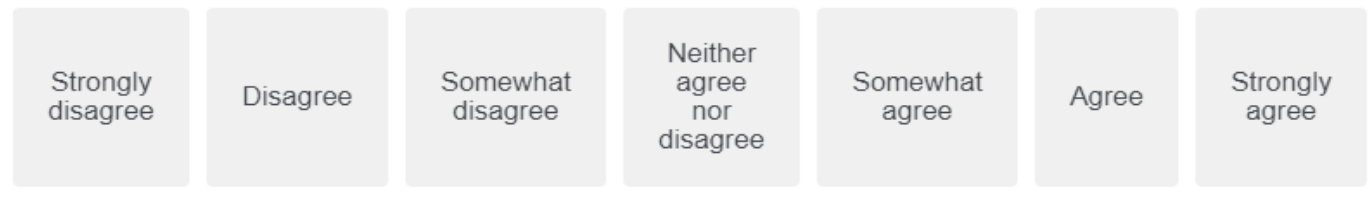

My mobile phone portrays an image of me to others

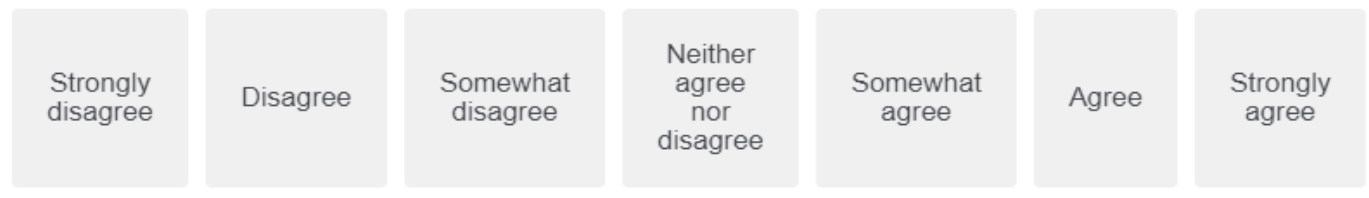

\section{SECTION IV - LOCAL AND FOREIGN PREFERENCES}

In this section, there are various statements on local and foreign preferences with respect to products and in general. For every statement, please choose the answer that best represents your opinion.

It would be better to be a citizen of the world than of any particular country.

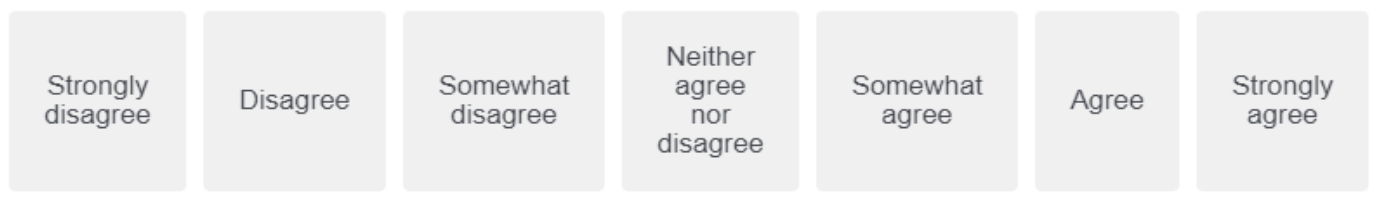

Sometimes I feel embarrassed about products made in Kenya when I compare them with similar products made in foreign countries.

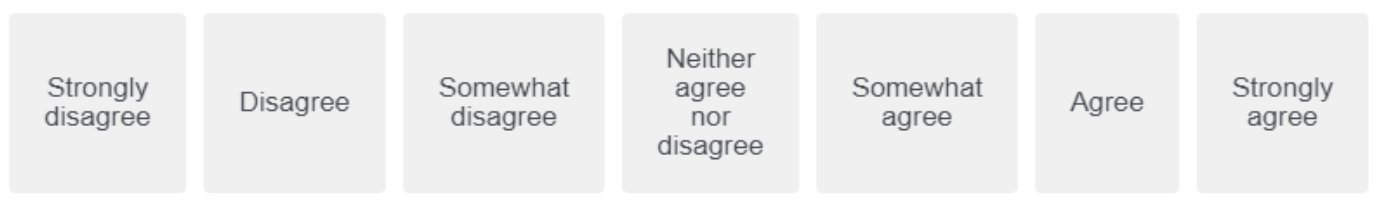


Kenya should permit foreigners to immigrate here even if it lowers our standard of living.

\begin{tabular}{|c|c|c|c|c|c|c|}
\hline $\begin{array}{l}\text { Strongly } \\
\text { disagree }\end{array}$ & Disagree & $\begin{array}{c}\text { Somewhat } \\
\text { disagree }\end{array}$ & $\begin{array}{c}\text { Neither } \\
\text { agree } \\
\text { nor } \\
\text { disagree }\end{array}$ & $\begin{array}{c}\text { Somewhat } \\
\text { agree }\end{array}$ & Agree & $\begin{array}{c}\text { Strongly } \\
\text { agree }\end{array}$ \\
\hline
\end{tabular}

I believe people should be made more aware of how connected we are to the rest of the world.

\begin{tabular}{|c|c|c|c|c|c|c|}
\hline $\begin{array}{l}\text { Strongly } \\
\text { disagree }\end{array}$ & Disagree & $\begin{array}{c}\text { Somewhat } \\
\text { disagree }\end{array}$ & $\begin{array}{c}\text { Neither } \\
\text { agree } \\
\text { nor } \\
\text { disagree }\end{array}$ & $\begin{array}{c}\text { Somewhat } \\
\text { agree }\end{array}$ & Agree & $\begin{array}{c}\text { Strongly } \\
\text { agree }\end{array}$ \\
\hline
\end{tabular}

My quality of life would improve if more imported goods were available.

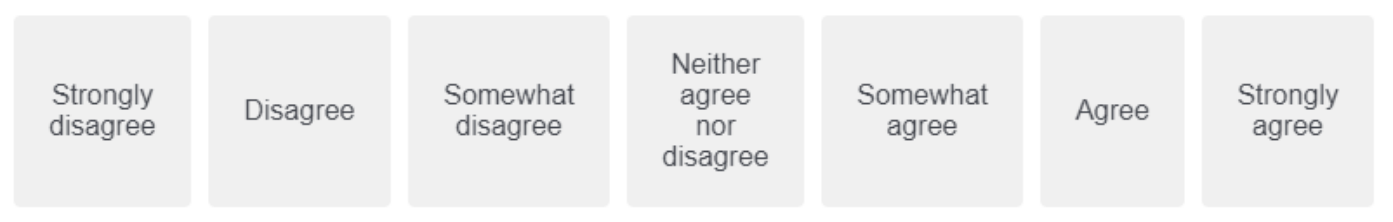

Sometimes I undervalue products made in my country.

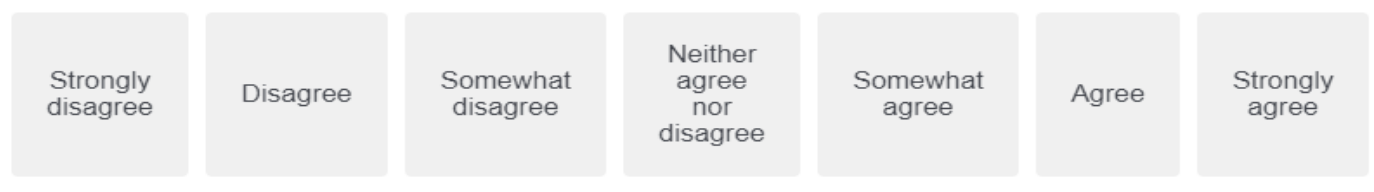

Generally, I don't value products made in my country.

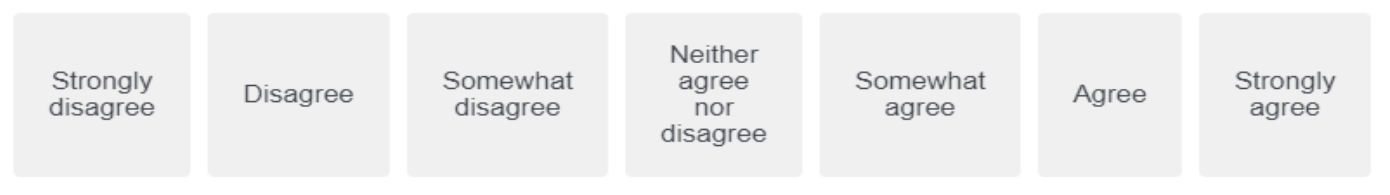

Immigration should be controlled by an international organization rather than by each country independently.

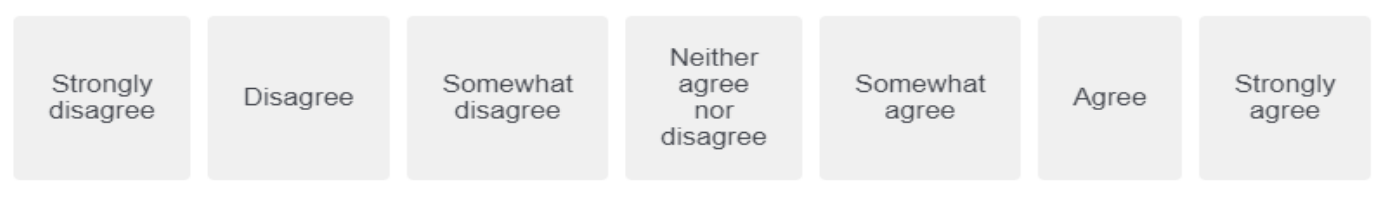


Please select "Agree" below.

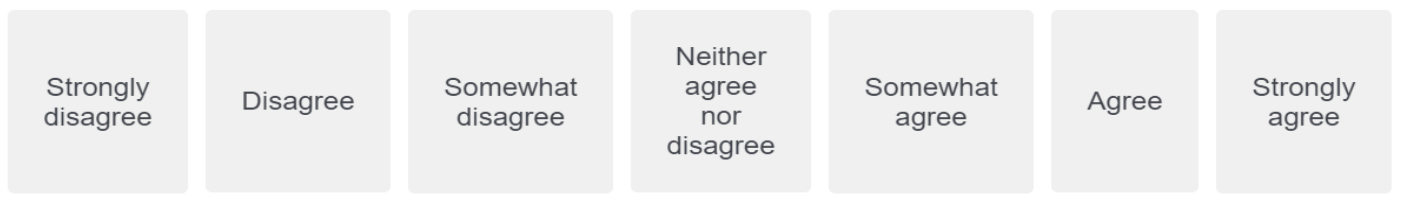

I tend to prefer foreign products compared to local ones.

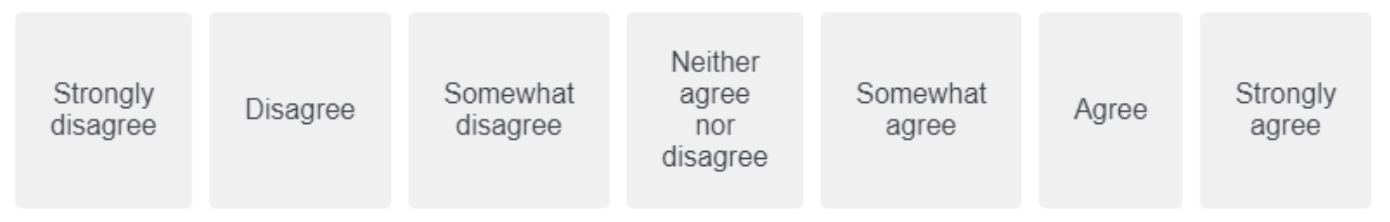

I value foreign products a lot.

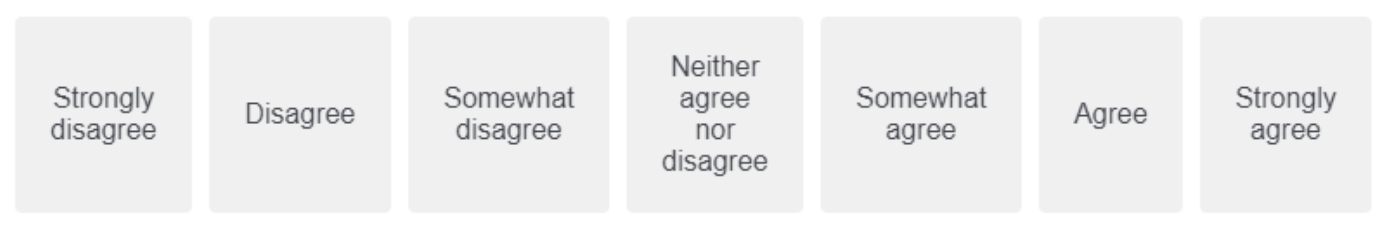

I like buying products of foreign origin.

\begin{tabular}{|c|c|c|c|c|c|c|}
\hline $\begin{array}{l}\text { Strongly } \\
\text { disagree }\end{array}$ & Disagree & $\begin{array}{c}\text { Somewhat } \\
\text { disagree }\end{array}$ & $\begin{array}{c}\text { Neither } \\
\text { agree } \\
\text { nor } \\
\text { disagree }\end{array}$ & $\begin{array}{c}\text { Somewhat } \\
\text { agree }\end{array}$ & Agree & $\begin{array}{c}\text { Strongly } \\
\text { agree }\end{array}$ \\
\hline
\end{tabular}


I tend to reject local products.

\begin{tabular}{|c|c|c|c|c|c|c|}
\hline $\begin{array}{l}\text { Strongly } \\
\text { disagree }\end{array}$ & Disagree & $\begin{array}{l}\text { Somewhat } \\
\text { disagree }\end{array}$ & $\begin{array}{l}\text { Neither } \\
\text { agree } \\
\text { nor } \\
\text { disagree }\end{array}$ & $\begin{array}{c}\text { Somewhat } \\
\text { agree }\end{array}$ & Agree & $\begin{array}{l}\text { Strongly } \\
\text { agree }\end{array}$ \\
\hline
\end{tabular}

My heart mostly belongs to the whole world.

\begin{tabular}{|c|c|c|c|c|c|c|}
\hline $\begin{array}{l}\text { Strongly } \\
\text { disagree }\end{array}$ & Disagree & $\begin{array}{c}\text { Somewhat } \\
\text { disagree }\end{array}$ & $\begin{array}{l}\text { Neither } \\
\text { agree } \\
\text { nor } \\
\text { disagree }\end{array}$ & $\begin{array}{c}\text { Somewhat } \\
\text { agree }\end{array}$ & Agree & $\begin{array}{c}\text { Strongly } \\
\text { agree }\end{array}$ \\
\hline
\end{tabular}

All national governments should be abolished and replaced by one central government.

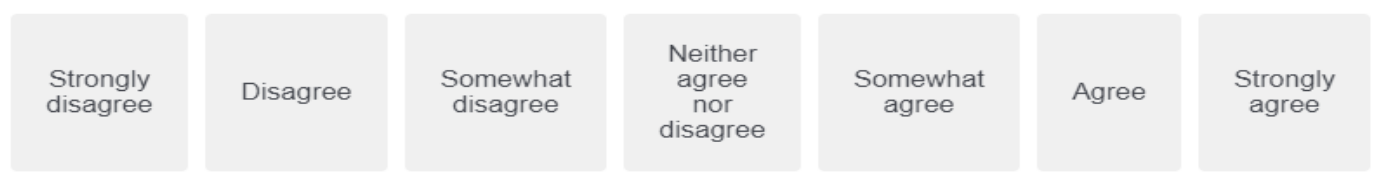

I find imported goods more desirable than domestically produced products.

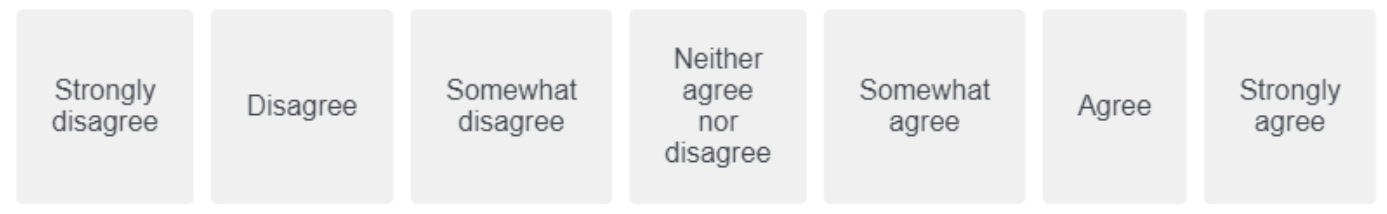

I recommend foreign products to my friends and families.

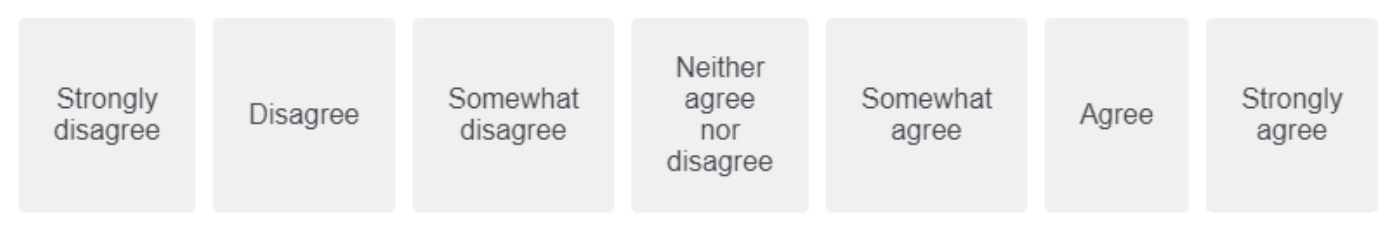

I admire foreign products.

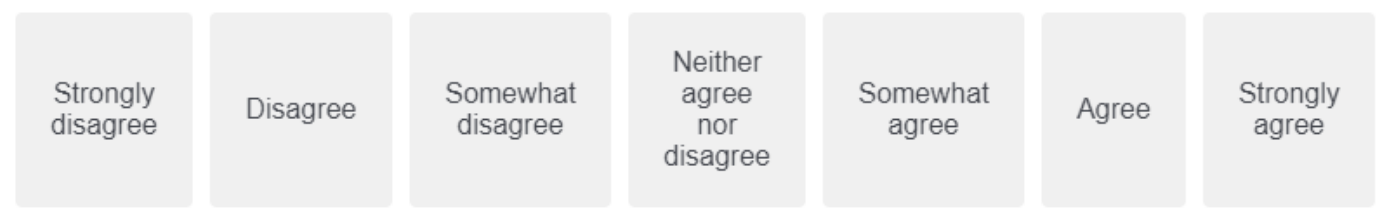


Where a good is produced does not affect my decision to purchase that item.

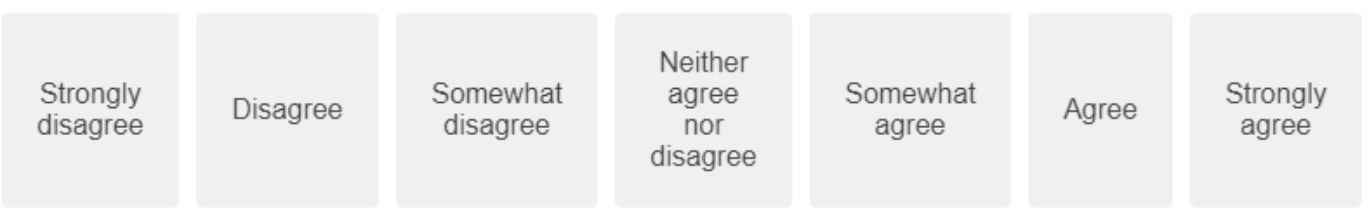

I think foreign products are superior to local products.

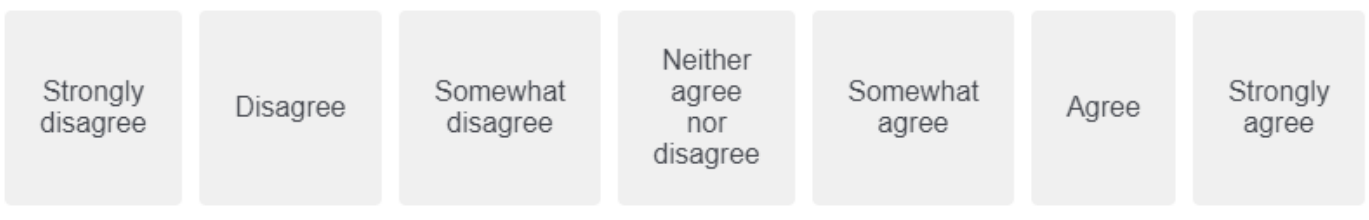

\section{SECTION IV - LOCAL AND FOREIGN PREFERENCES (continued)}

I identify that I am a global citizen.

\begin{tabular}{|c|c|c|c|c|c|c|}
\hline $\begin{array}{l}\text { Strongly } \\
\text { disagree }\end{array}$ & Disagree & $\begin{array}{c}\text { Somewhat } \\
\text { disagree }\end{array}$ & $\begin{array}{c}\text { Neither } \\
\text { agree } \\
\text { nor } \\
\text { disagree }\end{array}$ & $\begin{array}{c}\text { Somewhat } \\
\text { agree }\end{array}$ & Agree & $\begin{array}{c}\text { Strongly } \\
\text { agree }\end{array}$ \\
\hline
\end{tabular}

Visiting foreign countries is one of my favorite things.

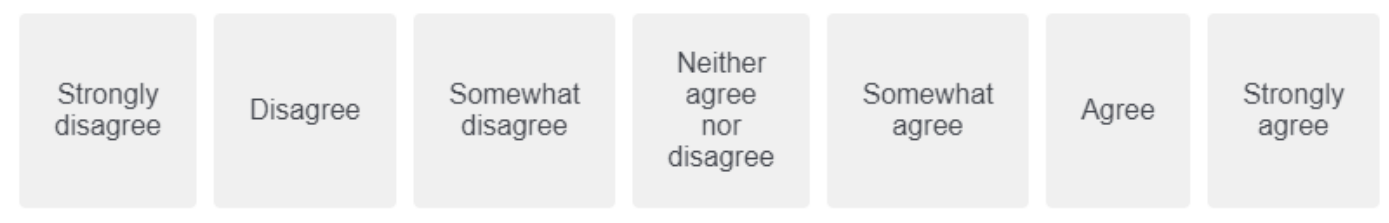

It is not right to purchase foreign products, because it puts Kenyans out of jobs.

\begin{tabular}{|c|c|c|c|c|c|c|}
\hline $\begin{array}{l}\text { Strongly } \\
\text { disagree }\end{array}$ & Disagree & $\begin{array}{c}\text { Somewhat } \\
\text { disagree }\end{array}$ & $\begin{array}{c}\text { Neither } \\
\text { agree } \\
\text { nor } \\
\text { disagree }\end{array}$ & $\begin{array}{c}\text { Somewhat } \\
\text { agree }\end{array}$ & Agree & $\begin{array}{c}\text { Strongly } \\
\text { agree }\end{array}$ \\
\hline
\end{tabular}


Being Kenyan means a lot to me.

\begin{tabular}{|c|c|c|c|c|c|c|}
\hline $\begin{array}{l}\text { Strongly } \\
\text { disagree }\end{array}$ & Disagree & $\begin{array}{l}\text { Somewhat } \\
\text { disagree }\end{array}$ & $\begin{array}{c}\text { Neither } \\
\text { agree } \\
\text { nor } \\
\text { disagree }\end{array}$ & $\begin{array}{c}\text { Somewhat } \\
\text { agree }\end{array}$ & Agree & $\begin{array}{c}\text { Strongly } \\
\text { agree }\end{array}$ \\
\hline
\end{tabular}

I identify that I am a local citizen.

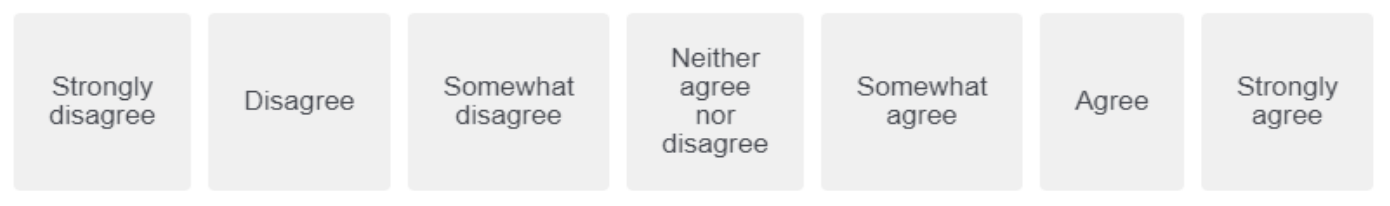

Kenyan products, first, last, and foremost.

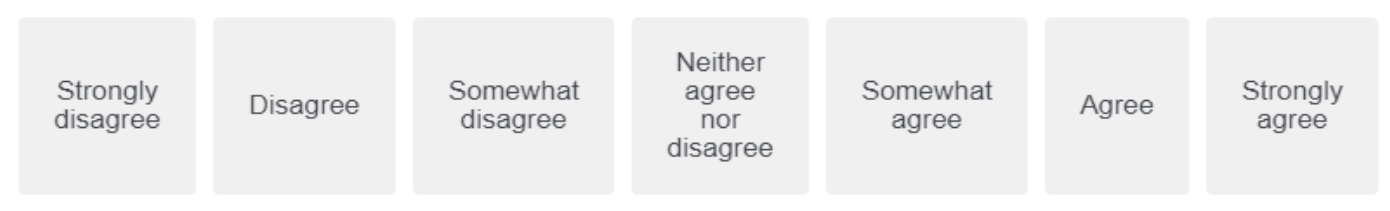

When a foreign person praises Kenya, it feels like a personal compliment.

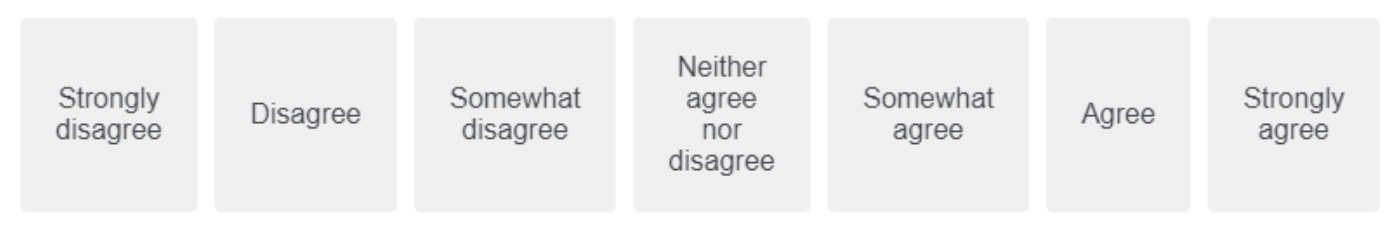

My heart mostly belongs to my local community.

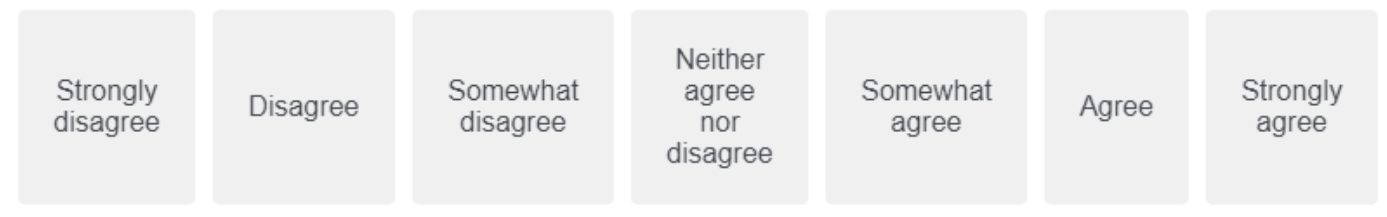

I have traveled extensively outside of my home country.

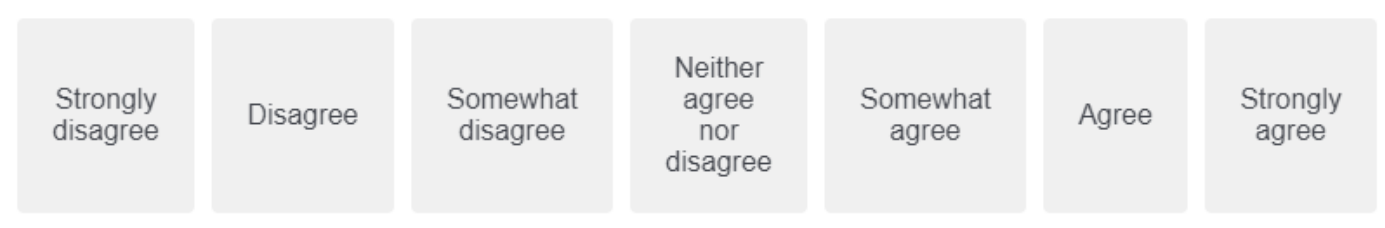


Purchasing foreign-made products is un-Kenyan.

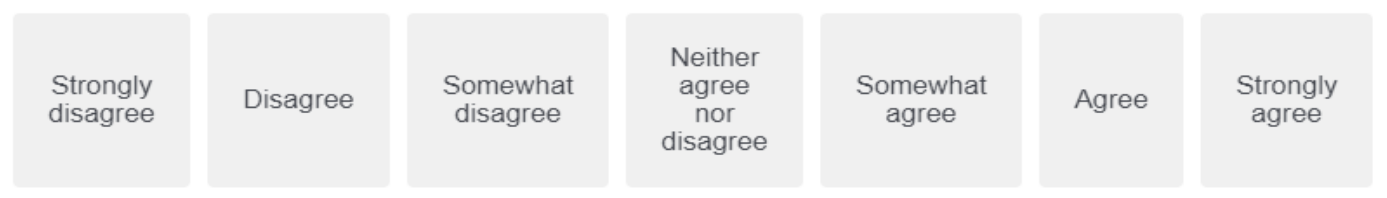

Only those products that are unavailable in Kenya should be imported.

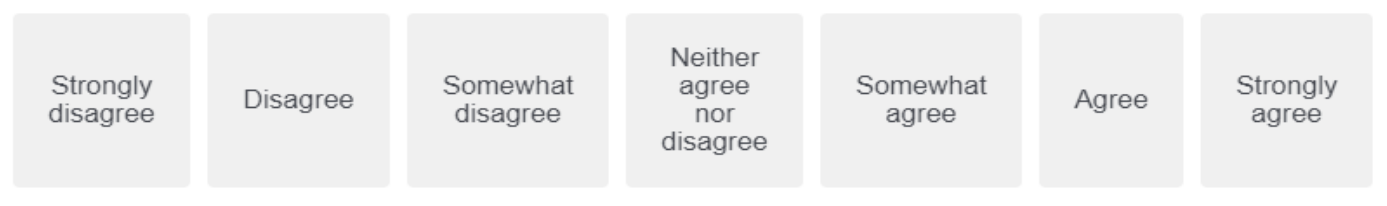

I often think about going to different countries and doing some traveling.

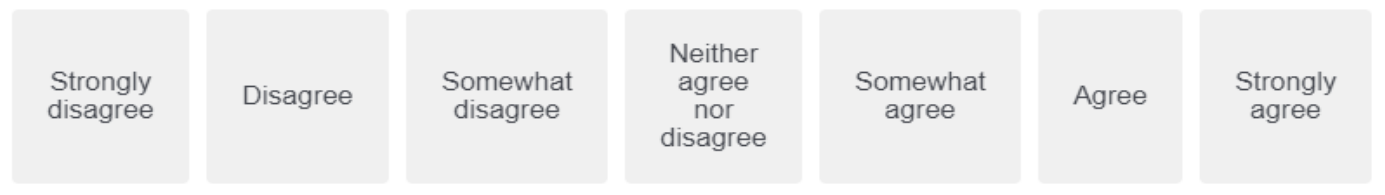

While vacationing, I would prefer to stay in my home country, rather than visit another country.

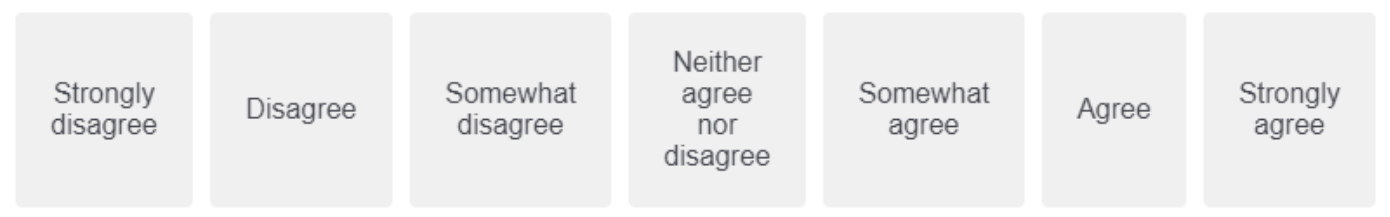

I am proud to be Kenyan.

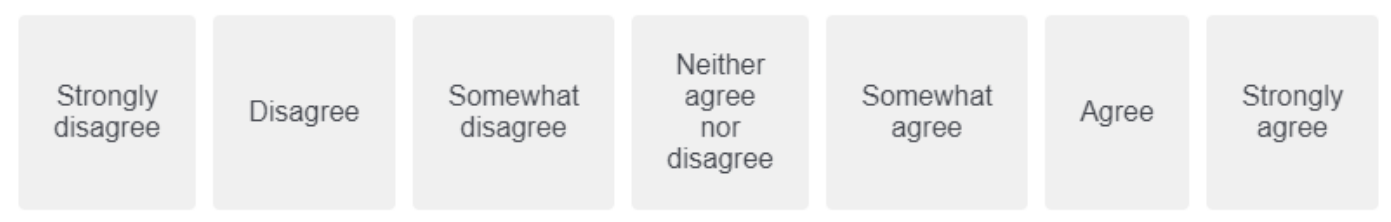

I care about knowing global events.

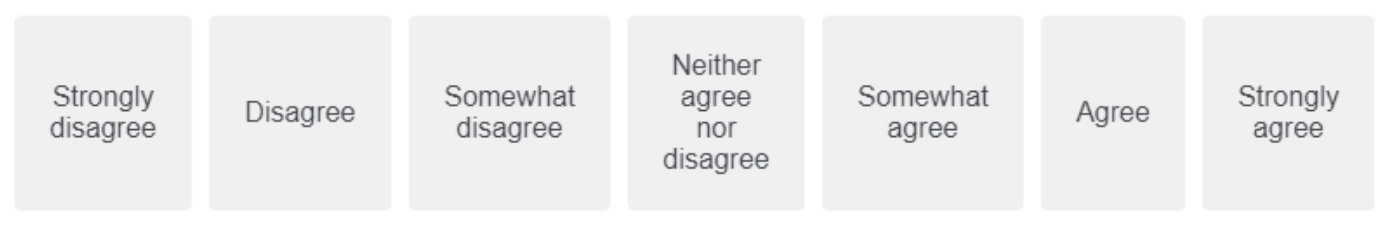


I prefer spending my vacations outside of the country that I live in.

\begin{tabular}{|c|c|c|c|c|c|c|}
\hline $\begin{array}{l}\text { Strongly } \\
\text { disagree }\end{array}$ & Disagree & $\begin{array}{c}\text { Somewhat } \\
\text { disagree }\end{array}$ & $\begin{array}{c}\text { Neither } \\
\text { agree } \\
\text { nor } \\
\text { disagree }\end{array}$ & $\begin{array}{c}\text { Somewhat } \\
\text { agree }\end{array}$ & Agree & $\begin{array}{c}\text { Strongly } \\
\text { agree }\end{array}$ \\
\hline
\end{tabular}

I care about knowing local events.

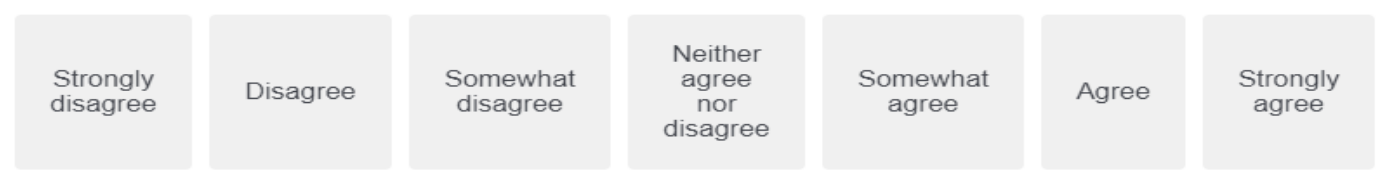

A real Kenyan should always buy Kenyan-made products.

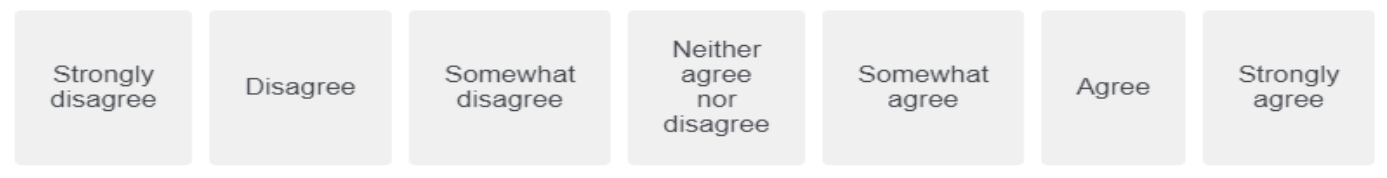

I respect my local traditions.

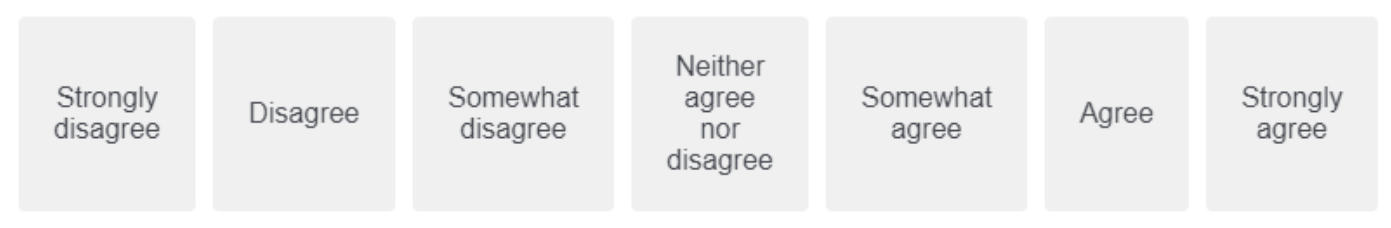

I don't feel any attachment towards Kenya.

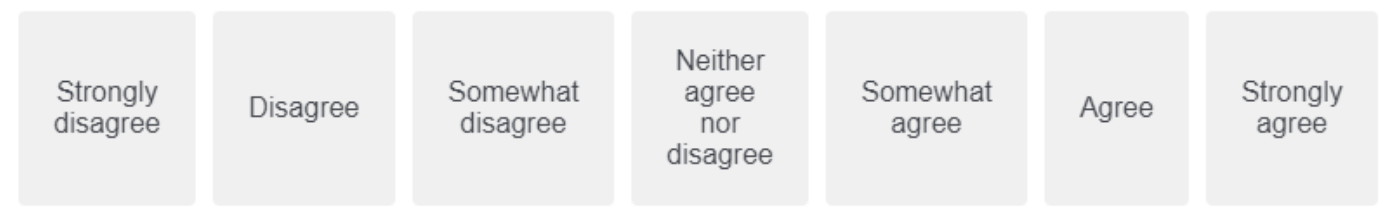

We should purchase products manufactured in Kenya instead of letting other countries get rich off us.

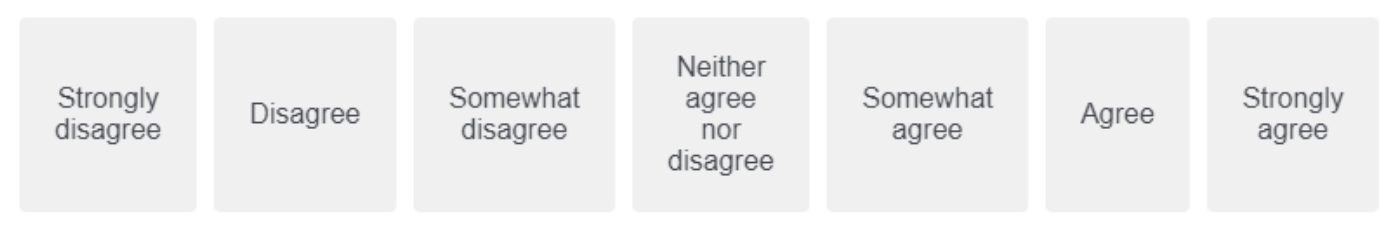


Kenyans should not buy foreign products, because this hurts Kenyan business and causes unemployment.

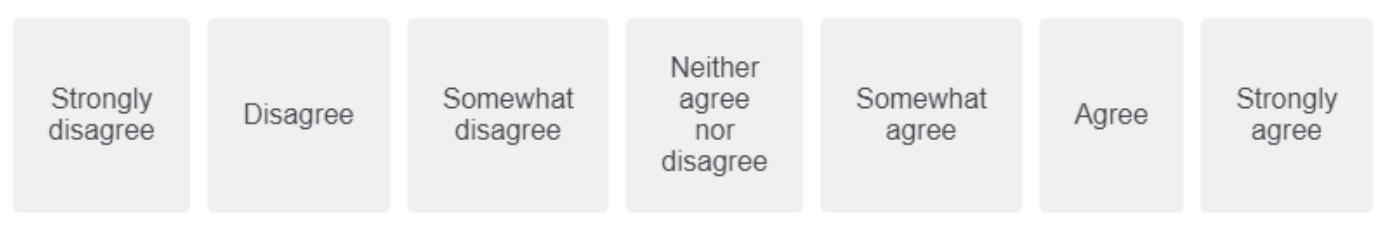

It may cost me in the long-run but I prefer to support Kenyan products.

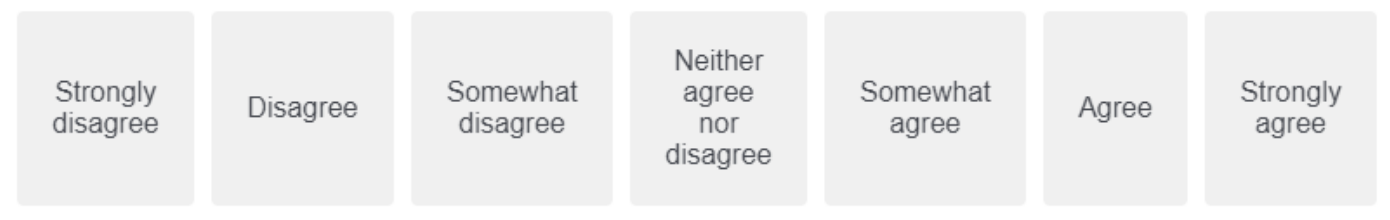

We should buy from foreign countries only those products that we cannot obtain within our own country.

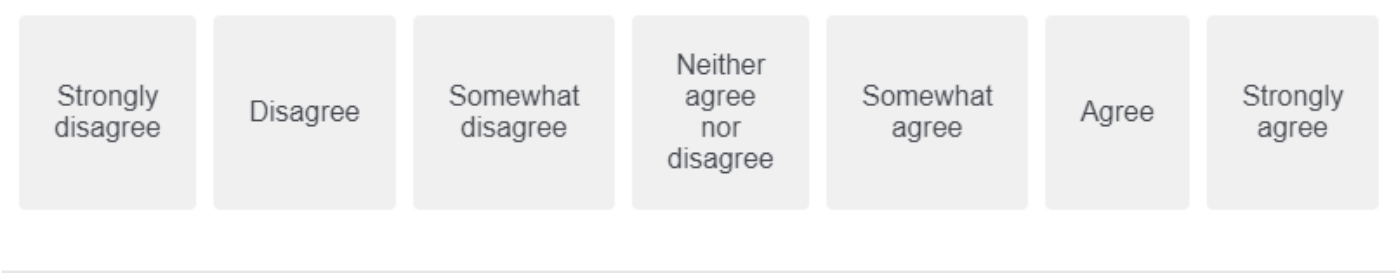

Kenyan consumers who purchase products made in other countries are responsible for putting their fellow Kenyans out of work.

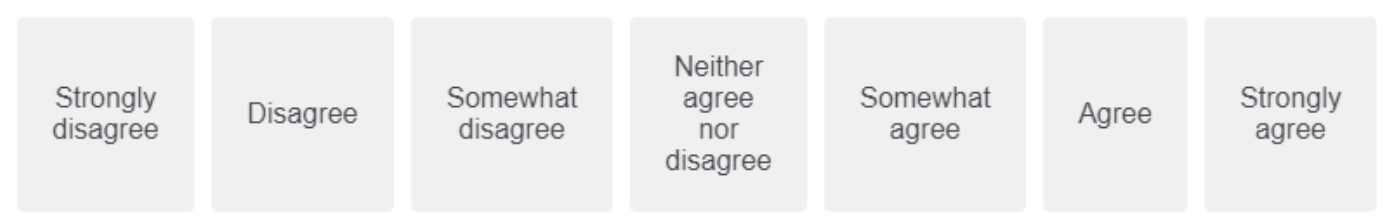




\section{SECTION V - YOUR MEDIA PREFERENCES}

\begin{tabular}{|c|c|c|c|c|}
\hline & $\begin{array}{c}\text { Never } \\
1\end{array}$ & 23 & 4 & 5 \\
\hline $\begin{array}{l}\text { How often do you watch television programs that are about people who live in other } \\
\text { countries of the world? }\end{array}$ & $\mathrm{O}$ & $\mathrm{O}$ & $\mathrm{O}$ & \\
\hline $\begin{array}{l}\text { How often do you read features, reports or stories in magazines that are about people who } \\
\text { live in other countries? }\end{array}$ & $\mathrm{O}$ & $\mathrm{O}$ & 0 & \\
\hline How often do you see movies about people who live in other countries? & $\mathrm{O}$ & $\mathrm{O}$ & $\bigcirc$ & \\
\hline $\begin{array}{l}\text { How often do you watch television programs that are produced in other countries and } \\
\text { shown in your country? }\end{array}$ & 0 & $\mathrm{O}$ & & \\
\hline
\end{tabular}

SECTION VI - DEMOGRAPHIC INFORMATION

This last section includes some demographic questions. Your responses are confidential.

Which category below includes your age?

$18-24$

$25-34$

$35-44$

$45-54$

$55-64$

$64+$ 
What is your gender?

Male

Female

Which category below does your occupation fall under?

Business

Salaried professiona

Laborer/ skilled labor

Student

Retired/others

What is the highest level of education that you have completed?

Secondary/O-Level/high school graduate or less

Trade school/polytechnic

University Degree (Bachelors)

Post graduate degree (Masters, $\mathrm{PhD}$ ) 
Appendix D: Diagram of complete proposed consumer xenocentrism model

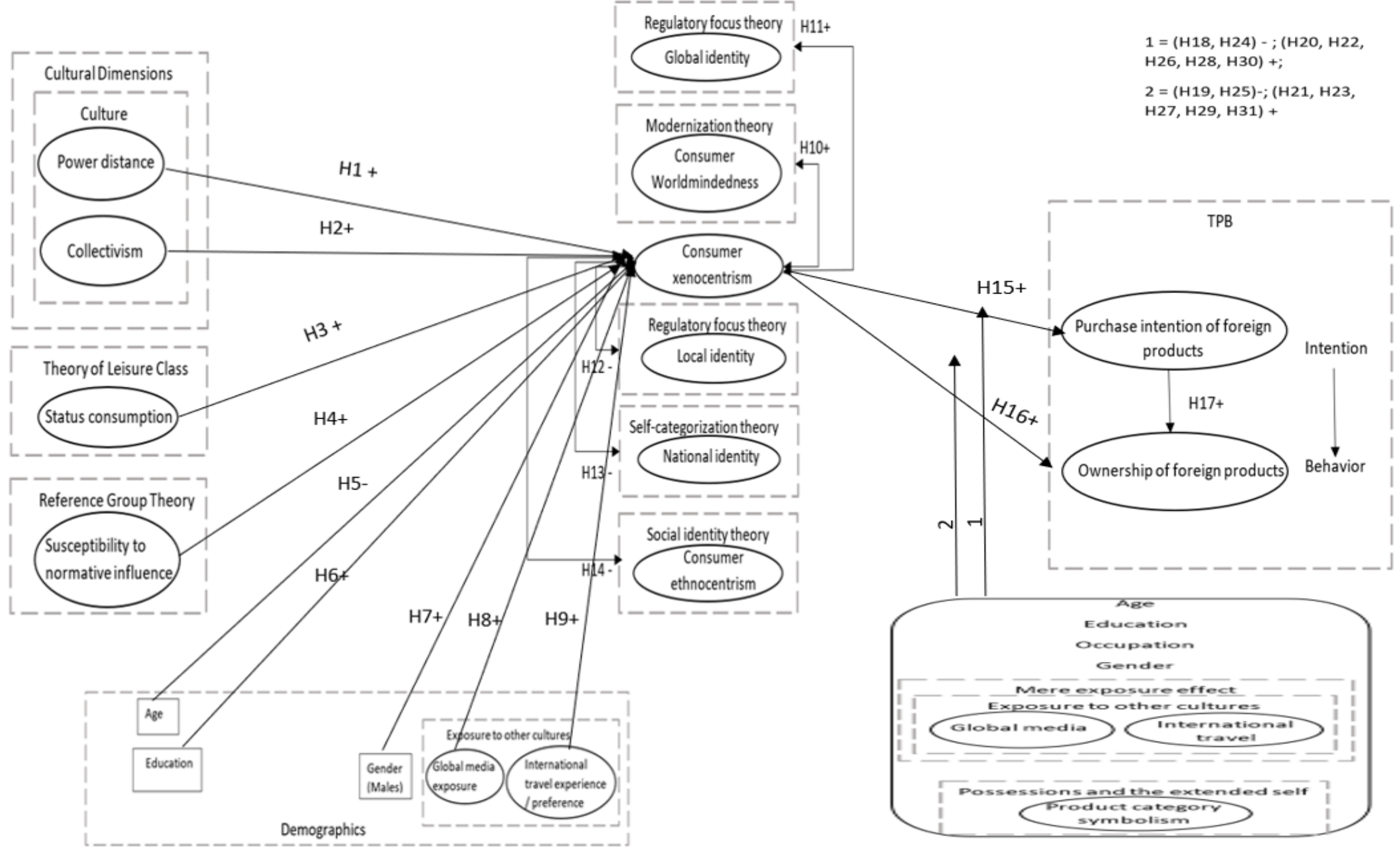

